\title{
3 Papierherstellung im deutschen Südwesten
}

Im deutschsprachigen Südwesten, eingangs definiert als der schwäbisch-alemannische Raum mit der Oberrheinregion, der heutigen deutschsprachigen Schweiz, dem heutigen Baden-Württemberg und dem heutigen bayerischen Regierungsbezirk Schwaben, wurden nach aktuellem Forschungsstand bis 1500 an 17 Orten Papiermühlen eingerichtet (vgl. Tab. 9). Ein Großteil dieser Werke bestand auch noch im 16. Jahrhundert und darüber hinaus, sodass an ihnen die Etablierung der Papiermacherei bis 1550 in ihrer sozial- und wirtschaftsgeschichtlichen Dimension nachvollzogen werden kann.

Einleitend werden im ersten Abschnitt zunächst die Überlieferungslage sowie der Forschungsstand für die Fallstudie Basel dargelegt, darauf folgt ein Überblick über die Studien zu den weiteren südwestdeutschen Papiermühlenstandorten. Im zweiten Abschnitt steht die Papiermühle als Arbeitsplatz sowie als Arbeitsmittel im Fokus. Zur Einführung werden die Papiermühlen mit ihren Besitzern nach Standorten vorgestellt, die in geographische Räume eingeteilt sind. Nach der prominent behandelten Fallstudie Basel macht der oberschwäbische Raum mit Ravensburg, Augsburg, Kempten, Memmingen und Söflingen den Anfang, gefolgt von der heutigen deutschsprachigen Schweiz mit Bern und Zürich. Aus dem württembergischen Raum werden Urach und Reutlingen betrachtet, badische Gebiete sind mit Ettlingen, Lörrach, Gengenbach und Offenburg vertreten. Abschließend werden die elsässischen Papiermühlen in Straßburg sowie Vieux-Thann und Cernay vorgestellt.

Diesem Überblick über die untersuchten Papiermühlenstandorte schließen sich thematische Kapitel an. Zunächst wird nach der Ausstattung einer Papiererwerkstatt gefragt: Welche Gebäude gehörten zu einer Papiermühle? Mit welchem Werkzeug arbeitete ein Papiermacher? Und was lässt sich davon in den Quellen überhaupt greifen? Dann rücken die Eigentums- und Besitzverhältnisse in den Mittelpunkt und damit die Frage, wer in welcher rechtlichen Form Besitzer einer Papiermühle war. Um in den Besitz eines Mühlwerks zu kommen, musste es gepachtet oder gekauft werden. Mit den Kaufpreisen und den auf den Grundstücken lastenden Renten und damit mit dem Wert einer Papiermühle beschäftigt sich daher das vierte Kapitel. Schließlich werden die mit den Mühlen verbundenen Wasserrechte beleuchtet.

Im dritten Abschnitt werden mit dem Blick auf die Papiermacher sozialgeschichtliche Aspekte behandelt. Zunächst wird die Stellung von Meistern, Gesellen und Lohnarbeitern innerhalb ihres Handwerks untersucht. Im zweiten Kapitel werden die Herkunft der Papiermacher und damit die Migrationsbewegungen dieses Gewerbes betrachtet. Wie sich die Papierer in die städtischen Strukturen ihres Arbeitsorts integrierten, wird anhand der Aufnahme ins Bürgerrecht sowie der Zunftzugehörigkeit ermittelt. Anschließend wird der Frage nachgegangen, ob die Papiermacher zu den reichen oder zu den armen Handwerkern zählten. Das letzte Kapitel ist schließlich den geschäftlichen Beziehungen zu Zulieferern und Kunden gewidmet. 
Tab. 9: Erstbelege für Papiermühlen im deutschen Südwesten bis $1500 .^{1048}$

\begin{tabular}{|c|c|c|c|}
\hline & Standort & erster Beleg & \\
\hline 1. & Ravensburg & $\begin{array}{l}1392 \\
1402\end{array}$ & $\begin{array}{l}\text { Wasserzeichen Stadtwappen (Doppeltürme) } \\
\text { Eintrag eines Papierers ins Bürgerbuch }\end{array}$ \\
\hline 2. & Basel & 1440 & Nennung bei Wasserrechtsstreitigkeiten \\
\hline 3. & Straßburg & 1445 & Leihbrief der Stadt Straßburg \\
\hline 4. & Augsburg & $\begin{array}{l}\text { um } 1460 \\
1483\end{array}$ & $\begin{array}{l}\text { Wasserzeichen Stadtwappen (Pyr) } \\
\text { Eintrag der Liegenschaft ins Steuerbuch }\end{array}$ \\
\hline 5. & Ettlingen & 1461 & $\begin{array}{l}\text { Brief des Schultheißen zu Ettlingen an den Straßburger } \\
\text { Rat von } 1462 \text { wegen eines Rechtsstreits im Jahr } 1461\end{array}$ \\
\hline 6. & Vieux-Thann & 1463 & Konzession für den Bau einer Papiermühle \\
\hline 7. & Bern & 1466 & städtischer Spruchbrief in einem Konkursverfahren \\
\hline 8. & Söflingen & 1469 & Nennung bei Wasserrechtsstreitigkeiten \\
\hline 9. & Reutlingen & $\begin{array}{l}\text { vor } 1470 \\
1489\end{array}$ & $\begin{array}{l}\text { Wasserzeichen Minuskel r } \\
\text { Zinsbuch des Reutlinger Spitals }\end{array}$ \\
\hline 10. & Zürich & 1471 & $\begin{array}{l}\text { Rentenverkauf eines Papiermachers von einem frisch } \\
\text { erworbenem Mühlwerk }\end{array}$ \\
\hline 11. & Lörrach & 1472 & Geschäftsbuch des Basler Kaufmanns Ulrich Meltinger \\
\hline 12. & Urach & 1477 & $\begin{array}{l}\text { Revers über Leihbrief, in kopialer Überlieferung in } \\
\text { Repertorien des } 17 . \text { und } 18 \text {. Jahrhunderts }\end{array}$ \\
\hline 13. & Kempten & $\begin{array}{l}\text { um } 1480 \\
1488\end{array}$ & $\begin{array}{l}\text { Gründungsdatum nach der Chronik von Christoph } \\
\text { Schwarz aus dem Jahr } 1606 \\
\text { Wasserzeichen Ochsenkopf } \\
\text { erste zeitgenössische Nennung der Papiermühle in } \\
\text { einer Klage des Fürstabts von Kempten gegen die } \\
\text { Reichsstadt }\end{array}$ \\
\hline 14. & Memmingen & 1478 & $\begin{array}{l}\text { Erwähnung der Einrichtung einer Papiermühle in einer } \\
\text { Liegenschaftsübertragung von } 1485\end{array}$ \\
\hline 15. & Offenburg & 1483 & $\begin{array}{l}\text { Wasserzeichen zwei Türme mit dazwischenstehendem } \\
\text { Halbmond }\end{array}$ \\
\hline 16. & Gengenbach & $\begin{array}{l}\text { um } 1490 \\
1511\end{array}$ & $\begin{array}{l}\text { Wasserzeichen Stadtwappen (heraldisch nach rechts } \\
\text { gekrümmte Gangfisch) } \\
\text { Schuldverschreibung an das Kloster Gengenbach, } \\
\text { Kopialbuch }\end{array}$ \\
\hline 17. & Cernay & 1497 & Geschäftsbriefe des Basler Druckers Johann Amerbach \\
\hline
\end{tabular}

1048 Für die Belege vgl. das Kapitel 3.2.1 zu den einzelnen Standorten. 


\subsection{Fallstudie und Vergleichsbeispiele im Überblick}

\subsubsection{Fallstudie Basel}

Bereits gegen Ende des 15. Jahrhunderts - knapp 60 Jahre nach der ersten Erwähnung einer Papierproduktion vor Ort - arbeiteten in Basel mehrere Papiermühlen, die sich zusammen als kleines Papiermühlenrevier bezeichnen lassen. ${ }^{1049}$ Warum die Papierherstellung gerade in dieser mittelalterlichen Großstadt mit ihren 10.000 Einwohner florierte, ist kaum mit Sicherheit zu beantworten. ${ }^{1050}$ In der Forschung wurden verschiedene politische, kulturelle und ökonomische Faktoren aus der Geschichte der freien Stadt Basel ${ }^{1051}$ ins Feld geführt, denen Einfluss auf die Etablierung der Papierproduktion am Rheinknie zugeschrieben wurde. Erstens erwog die ältere Forschung das Basler Konzil ${ }^{1052}$ mit seinem Bedarf an Beschreibstoff als maßgeblichen Impuls für die Einrichtung der ersten Papiermühle durch den älteren Heinrich Halbysen. ${ }^{1053}$ Gerhard Piccard widerspricht dieser Vermutung. In seinem Aufsatz zur Basler Papierherstellung legt er dar, dass das Konzil zur Zeit der von ihm auf 1440 datierten Gründung der ersten Papiermühle bereits in eine Krise geraten war, sodass geschäftlicher Profit kaum noch zu erwarten gewesen sei. ${ }^{1054}$ Überhaupt sei diese erste Papiermühle vor dem Riehentor nur ein kleiner Betrieb mit geringer Wasserkraft und daher nicht rentabel gewesen. ${ }^{1055}$ Aus diesem Grund habe Heinrich Halbysen d. Ä. seine Papierproduktion im Jahr 1448 in das St. Albantal verlegt. Dies stelle nach Piccard den eigentlichen Beginn der Basler Papierherstellung dar. $\mathrm{Zu}$ dieser Zeit sei jedoch

1049 Vgl. Stromer 1986, 103-108, bes. 103 f.; Zaar-Görgens 2004, 1 f.

1050 In der Oberrheinregion war Basel nach Straßburg mit circa 18.000 bis 19.000 Einwohnern die zweitgrößte Stadt, vgl. H. Ammann 1950, 51 f.; Simon-Muscheid 1988, 4; Isenmann 2014, 58; Hirschmann 2016, $19 \mathrm{f}$.

1051 Zur Geschichte des mittelalterlichen Basels vgl. allgemein Heusler 1860; Heusler 1918; Wackernagel 1907-1924; Gilomen 1980; Berner/Sieber-Lehmann/Wichers 2008. Zu den freien Städten vgl. allgemein Fahlbusch 1989, 895 f. Zu Basel als freier Stadt vgl. Heusler 1860, 310-321. Zur Problematik des Begriffs freie Stadt vgl. Möncke 1971, 230-242.

1052 Das Konzil von Basel, das in einem ersten Anlauf bereits 1431 einberufen, dann jedoch von Papst Eugen IV. im selben Jahr wieder aufgelöst worden war, nahm seine Verhandlungen letztlich im Jahr 1433 auf. Mit dem Ziel, eine Reform der Kirche anzustoßen, tagte es bis 1448. Zum Basler Konzil vgl. Meuthen 1985; Helmrath 1987. Zum Verhältnis der Stadt Basel zum Konzil vgl. Geering 1886, 266-295; Wackernagel 1907, Bd. 1, 476-538; Heusler 1918, 48-53; Sieber-Lehmann 2007; Berner/ Sieber-Lehmann/Wichers 2008, 68-70.

1053 Vgl. Geering 1886, 288, 313; Wattenbach 1896, 146; Wackernagel 1916, Bd. 2.2, 604; Wyler 1927, 8; Koelner 1935, 301.

1054 Vgl. Piccard 1967, 35.

1055 Hier argumentiert Piccard weiter mit der geringen Produktionskraft des Betriebs: Diese bescheidene Papiermühle sei nicht in der Lage gewesen, das Konzil mit ausreichend Beschreibstoff zu versorgen, vgl. Piccard 1967, 36 f. 
das Konzil bereits in Auflösung begriffen gewesen. ${ }^{1056}$ Hans Kälin geht ebenfalls davon aus, dass das Konzil nicht die ausschlaggebende Anregung für die Aufnahme der Papierherstellung lieferte. Zwar ist es tatsächlich unwahrscheinlich, dass allein dieses Großereignis und sein präsupponierter massenhafter Bedarf an Beschreibstoff zur Errichtung der ersten Basler Papiermühlen führten. ${ }^{1057}$ Dennoch ist seine Rolle als einer der möglichen Impulsgeber nicht komplett von der Hand zu weisen. Vielleicht war es nicht der Bedarf an Schreibmaterialien, sondern die durch das Konzil vermittelte Begegnung mit italienischen Kaufleuten, die mit Papier handelten, oder der Kontakt zu mit dem Konzil gekommenen Papiermachern, die den Kaufmann Heinrich Halbysen d. Ä. dazu anregten, die Papierproduktion in Basel einzuführen.

Zweitens könnte man die Eröffnung der Universität 1460 in Folge des Konzils ${ }^{1058}$ sowie der rasche Aufschwung des Basler Buchdrucks ${ }^{1059}$ als Katalysatoren des aufblühenden Papiergewerbes vermuten. Mit dem Argument, dass es zum einen Orte mit Universitäten respektive Druckereien, aber ohne eine eigene Papierproduktion gegeben habe und zum anderen - vice versa - Orte mit einer etablierten Papierherstellung, aber ohne Hochschule beziehungsweise Offizinen, lehnt Piccard auch diese Erklärung ab. ${ }^{1060}$ Seine Begründung ist zwar an sich korrekt, dennoch ist ein Einfluss vor allem des Basler Buchdrucks auf das Papiergewerbe denkbar, wenn man die

1056 Vgl. Piccard 1967, 36.

1057 War der Bedarf der Basler Konzilsteilnehmer höher als der der Teilnehmer am Konzil von Konstanz, das 15 Jahre zuvor endete? Warum entstanden in Konstanz keine Papiermühlen, wo sie doch noch nicht einmal die ersten in deutschsprachigem Gebiet gewesen wären, sondern in Nürnberg und Ravensburg schon Vorbilder gehabt hätten?

1058 Bereits während der Kirchenversammlung war eine Hohe Schule eingerichtet worden, die den Lehrbetrieb nach Pariser und Bologneser Vorbild aufnahm. Nachdem Enea Silvio Piccolomini im Jahr 1458 als Papst Pius II. gewählt wurde, richtete der Basler Rat neben seinen Gratulationen auch den Wunsch nach einer eigenen Universität an das frisch erkorene Kirchenoberhaupt. Pius II. stiftete am 12. November 1459 die Basler Universität, die schließlich im darauffolgenden April - im Jahr 1460 feierlich eröffnet wurde, vgl. Wackernagel 1916, Bd. 2.2, 550-567; Heusler 1918, 66-69; Gilomen 1980, 1513 f.; Berner/Sieber-Lehmann/Wichers 2008, 71-73.

1059 Der Einfluss der Universität auf die Entwicklung Basels zur Buchdruckerstadt wird in der Forschung nicht allzu hoch angesetzt. In inhaltlicher Hinsicht erwiesen sich die vielfältigen Beziehungen der Basler Drucker zu den in Basel weilenden Humanisten wie beispielsweise Erasmus von Rotterdam und Sebastian Brant als besonders fruchtbar. Hatten die Offizinen in den Anfängen des Basler Buchdrucks gegen Ende der 1460er-Jahre vor allem alte scholastische Werke neu aufgelegt, bildete sich durch die Zusammenarbeit von Gelehrten und Buchdruckern ein Repertoire an sorgfältig edierten humanistischen Schriften heraus, die weite Verbreitung fanden und Basels Ruf als Druckerstadt begründeten, vgl. Geering 1886, 322-330; Wackernagel 1916, Bd. 2.2, 603-414; Heusler 1918, 89 f.; Ehrensperger 1972, 359; Geldner 1980, 1514 f.; Teuteberg 1986, 170-178; van der Haegen 2001; Berner/Sieber-Lehmann/Wichers 2008, 81-84.

1060 Vgl. Piccard 1967, 157-161. 
engen Beziehungen der Buchdrucker mit den heimischen Papiermachern betrachtet. $^{1061}$

Drittens wurde Basels Bedeutung als wirtschaftlicher Knotenpunkt in die Diskussion eingebracht. Das neue Gewerbe der Papiermacherei fügte sich in eine breit gefächerte Gewerbelandschaft ein, die allerdings - bis auf die neue Ware Papier und später das ebenfalls neue Produkt des gedruckten Buchs - keine nennenswerten Exportgüter herstellte. ${ }^{1062}$ Ihren Reichtum verdankte die Stadt vor allem dem regen Handel Basler Kaufleute mit Waren aus Italien, Spanien und Frankreich, die entweder zum Verkauf in Basel selbst bestimmt waren oder als Transitgüter vor allem nach Norden gehandelt wurden. ${ }^{1063}$ Neben diversen anderen Handelsgesellschaften agierten im Basel des ausgehenden Mittelalters zwei bedeutende Konsortien, die auch in Hinblick auf die Papiermacherei von Interesse sind. Die erste dieser Gesellschaften, die Halbysen-Gesellschaft, stellte einen Zusammenschluss dreier Kaufmänner dar: Hans Waltenheim, Wernlin von Kilchen und Heinrich Halbysen d. Ä., der als Begründer der Basler Papierherstellung gilt. ${ }^{1064}$ In der zweiten Hälfte des 15. Jahrhunderts überragte die Meltinger-Zscheckapürlin-Gesellschaft, auch Große Gesellschaft genannt, die anderen Handelsvereinigungen. ${ }^{1065}$ Durch die Person Ulrich Meltingers,

1061 Vgl. Kapitel 3.3.6.1, S. 458-465.

1062 Allenfalls Basler Lederwaren wurden überregional exportiert, alle anderen Güter waren nur auf den lokalen und regionalen Märkten vertreten. Die Tuchproduktion, das klassische gewinnversprechende Exportgewerbe, erlangte in Basel aufgrund von zünftischen Reglementierungen und starker, qualitativ hochwertigerer Konkurrenz in der weiteren Nachbarschaft - zum Beispiel der Leinwandherstellung in Oberschwaben - keine herausragende Bedeutung, vgl. Ehrensperger 1972, 338-340.

1063 Befördert wurde der Transitverkehr durch die Messen in Genf und Frankfurt, die nach dem Wegfall der Champagne-Messen für Basel immer bedeutender wurden. Besonders Frankfurt spielte in der zweiten Hälfte des 15. Jahrhunderts auch für den Papier- und Buchhandel eine wichtige Rolle, vgl. Geering 1886, 190 f., 330; Schlieder 1966, 141; Zaar-Görgens 2004, 121, 136, 143. Im Jahr 1471 erhielt Basel das kaiserliche Privileg für zwei jährliche Messen, die in der Zeit vor Pfingsten beziehungsweise vor dem Martinstag stattfinden sollten. Die Pfingstmesse wurde jedoch 1494 wieder eingestellt. Das Einzugsgebiet der Messeteilnehmer beschränkte sich auf den südwestdeutschen Raum. Internationale Besucher kamen nur selten gezielt zu den Basler Messen, viele von ihnen waren ohnehin bereits wegen ihrer alltäglichen Handelsgeschäfte in der Stadt, vgl. Geering 1886, 336-343; Wackernagel 1911, Bd. 2.1, 480-483; Ehrensperger 1972, 333-338; Teuteberg 1986, 168.

1064 Auf welches Jahr die Begründung der Gemeinschaft fiel, ist unklar. Johannes Apelbaum nennt die Jahre zwischen 1415 und 1420, besonders aktiv war das Konsortium von 1425 bis 1430. Die nach einem ihrer Gesellschafter benannte Halbysen-Gesellschaft handelte international und nur en gros, so zum Beispiel mit Safran aus Barcelona. Sie bezog von dort aber auch Indigo, Korallen, Nüsse und Muskatblüten und lieferte im Gegenzug Wolle und Tuch, vgl. Apelbaum 1915, 17-30; Hagemann 1983, 557-561.

1065 Ihre Gesellschafter waren unter anderen Ulrich Meltinger, Ludwig Zscheckapürlin, Bastian Told, Ludwig von Busch, Martin Lepart, Hans Bär sowie Michael und Hans Bernhard Meyer. Diese handelten sowohl im Namen der Gesellschaft als auch auf eigene Rechnung mit einer Vielzahl an Waren, darunter Wolle, Baumwolle, Eisen, Blei, Stockfisch, Leder sowie Safran, vgl. Apelbaum 1915, 43-47; Hagemann 1983, 564 f.; Steinbrink 2007, 184-191. 
einer der namengebenden Gesellschafter, stand die Große Gesellschaft in geschäftlichem Kontakt zu Basler Papiermachern, die von Meltinger Lumpen und Leim bezogen und ihrerseits Papier verkauften. ${ }^{1066}$

Zwar lässt Gerhard Piccard das Argument von Basels günstiger geographischer Lage als wirtschaftlicher Knotenpunkt nicht bestehen, da auch andere Städte an Schifffahrtsstraßen angeschlossen gewesen seien, und nennt daher als einzigen ausschlaggebenden Standortfaktor die Rohstoffversorgung mit Lumpen. ${ }^{1067}$ Allerdings führt er den wirtschaftlichen Erfolg der Basler Papiermacherei auf das unternehmerische Geschick der Papiermühlenbetreiber und damit auf kaufmännische Fähigkeiten zurück, die am besten in einer großen Handelsstadt wie Basel erlernt und umgesetzt werden konnten. ${ }^{1068}$ Auch Hans Kälin nennt als Impuls für die Einrichtung einer Papiermühle in Basel den Unternehmergeist des weit gereisten Kaufmanns Heinrich Halbysen d. Ä., der bereits mit Papier handelte. Als Motiv führt er die Erschließung eines neuen Geschäftsfelds und als Voraussetzung die Begegnung mit Papiermachern auf Halbysens Reisen durch Italien an. ${ }^{1069}$

Monokausale Erklärungsversuche sind angesichts der vielfältigen Einflüsse, die $\mathrm{zu}$ einer Entscheidung führen, meist nicht befriedigend, sodass davon ausgegangen werden kann, dass ein Konglomerat aus den soeben genannten Faktoren die Einführung der Papiermacherei in Basel begünstigte. Solange die wichtigsten Standortfaktoren wie die Versorgung mit Wasser - als Energiequelle und als Rohstoff -, der stetige Nachschub an Lumpen guter Qualität und ein gesicherter Absatzmarkt gegeben waren, mögen vielleicht eher persönliche, uns unbekannte Motive der beteiligten Personen oder spezifische, möglicherweise nur punktuell bestehende Beziehungsgeflechte den Ausschlag für die Aufnahme der Produktion an einem Ort gegeben haben. Dass allein Heinrich Halbysens d. Ä. unternehmerischer Geist die Etablierung der Papierherstellung in Basel ermöglicht hat, wie es Kälin annimmt, kann eine Erklärung für diesen konkreten Fall sein. Als Universalerklärung scheitert sie jedoch, da ein unternehmerischer Geist allein weder die notwendige, noch die hinreichende Bedingung für die Einführung der Papierherstellung an einem bestimmten Ort ist.

1066 Vgl. Kapitel 3.3.6.1, S. 453-457.

1067 Vgl. Piccard 1967, 159-165.

1068 Vgl. Piccard 1967, 165.

1069 Vgl. Kälin 1974, 171. Auch Piccard geht davon aus, dass Halbysen d. Ä. sich die Inspiration zur Einrichtung einer Papiermühle von außerhalb geholt habe, vermutet jedoch, dass die Stromersche Gleismühle als Vorbild gedient habe, da Heinrich Halbysen d. Ä. sich oft in Nürnberg aufgehalten habe, vgl. Piccard 1967, 74. 


\subsubsection{1 Überlieferungslage}

Die hervorragende Überlieferungssituation für die Stadt Basel kommt durch zwei Faktoren zustande. Zum einen wurde das Staatsarchiv Basel-Stadt ${ }^{1070}$ in seiner Geschichte nur einmal zerstört. Rund 80 Jahre vor der ersten Nachricht über eine Papiermühle erschütterte im Jahr 1356 ein Erdbeben die Stadt, ${ }^{1071}$ infolgedessen die Stat Basel verfallen verbrent und umb alle Ir bucher und briefe komen was. ${ }^{1072}$ Zum anderen wurden, zumindest hinsichtlich der mittelalterlichen Urkunden sowie Verwaltungsbücher, nur wenige Quellenbestände kassiert, sodass von vielen Amtsbüchern seit dem 14. Jahrhundert noch vollständige oder nahezu vollständige Serien erhalten sind. ${ }^{1073}$

Die für die vorliegende Studie eingesehenen Quellenbestände zur Erforschung der Papierherstellung im spätmittelalterlichen Basel verteilen sich ungleichmäßig auf die vier Hauptabteilungen des Staatsarchivs. ${ }^{1074}$ Dem nach dem Pertinenzprinzip gegliederten älteren Hauptarchiv (Bestände von 1056 bis circa 1936) zugeordnet sind die städtischen Urkunden. ${ }^{1075}$ Diese sind über Regesten erschlossen, die auch größtenteils über den online-Archivkatalog eingesehen werden können. Weitere Sachgruppen mit relevanten Dokumenten sind die Protokolle des Basler Rats und die Ratsbücher, in denen vor allem Bürgerrechtsaufnahmen und -aufgaben finden, sowie die Steuerbücher, die über Vermögen und Wohnort Auskunft geben. In der Sachgruppe Handel und Gewerbe findet sich ein Bestand Papierer, Papierfabrikation, Kartonfa-brikation, Papierstofffabrikation, der allerdings erst gegen Ende des Untersuchungszeitraums mit dem Jahr 1536 einsetzt. Wie bereits Andreas Staehelin richtig bemerkt, führt diese Etikettierung in die Irre: In der Kategorie Papierherstellung sind bei weitem nicht alle Hinweise auf die Basler Papiermacherei versammelt, sondern nur ein kleiner Teil an die Papierproduktion betreffenden Akten, nämlich die, die problemlos aus ihrem ursprünglichen Zusammenhang herausgelöst werden konnten. ${ }^{1076}$

Als noch reichhaltiger für eine Untersuchung der frühen Basler Papiermacherei erweisen sich die älteren Nebenarchive sowie das Zunftarchiv. Die Basler Papiermacher schlossen sich der Zunft der Krämer an, daher finden sich im Basler Zunftarchiv der Safranzunft Hinweise auf Papierer, zum Beispiel in Eintrittsrodeln, die die Aufnahme in die Zunft dokumentierten, und Heizgeldrodeln, die die Beiträge zum Heizen des Zunfthauses verzeichnen. Für Fragen zu den Papiermühlen, die in Basel haupt-

1070 Zur Geschichte des Archivs vgl. Staehelin 2007.

1071 Zum Erdbeben vgl. Münster 1550a, 494; Wackernagel 1907, Bd. 1, 270-273; Heusler 1918, 30 f.; Fouquet 2003; Berner/Sieber-Lehmann/Wichers 2008, $45 \mathrm{f}$.

1072 StABS, Ratsbücher A 1, 1. Vgl. Staehelin 2007, 14.

1073 Vgl. Barth 1992, 89.

1074 Für einen allgemeinen Überblick über die für die Basler Papiergeschichte relevanten Archivalien vgl. Staehelin 1982. Zu den Hauptabteilungen - Hauptarchiv, Nebenarchive, Privatarchive, Sammlungen - vgl. Staehelin 2007, 127-136, 144-152.

1075 Vgl. Staehelin 2007, $105 \mathrm{f}$.

1076 Vgl. Staehelin 1982, 15. 
sächlich an den zwei Gewerbekanäle im St. Albantal lagen und damit Grundeigentum des Klosters St. Alban waren, sind aus der Reihe der älteren Nebenarchive das Klosterarchiv und die Teichkorporationen, beide mit Beständen zum Kloster St. Alban, relevant.

Eine nahezu unerschöpfliche Quelle sind aber vor allem die Bücher des Großbasler und des Kleinbasler Schultheißengerichts. ${ }^{1077}$ Das Schultheißengericht war für die niedere Gerichtsbarkeit zuständig, folglich vor allem für Angelegenheiten, die wir heute zivilrechtlich nennen würden. ${ }^{1078}$ Für den Historiker ist es ein großes Glück, dass dieser Bestand derart geschlossen erhalten ist, da sich aus ihm alle möglichen Arten von Informationen ziehen lassen: über Personen und ihre Beziehungen zueinander, über Orte, aber auch über Vermögensverhältnisse und die Gerichtspraxis, über immer wiederkehrende Streitigkeiten. $\mathrm{Zu}$ beachten ist, dass es sich oft, außer bei den Liegenschaftsänderungen und den Vollmachten, um ,Problemfälle‘ handelt: Geschäftliche Verträge oder Verabredungen wurden nicht eingehalten oder führten durch äußere Umstände nicht zum Erfolg, sodass eine Partei gegen die andere prozessierte, um ihren Schaden gering zu halten. In ,geglückte' Vereinbarungen und Geschäftsbeziehungen erhält der Historiker kaum Einsicht, da sich die Verträge zumeist in privatem Besitz befanden und daher nicht dauerhaft archiviert wurden. ${ }^{1079}$

Die spätmittelalterlichen Gerichtsprotokolle waren bereits in verschiedene Sachgebiete unterteilt. Unter der heutigen Signatur A finden sich die sogenannten Urteilsbücher. Sie enthalten die Verhandlungen in strittigen Rechtsangelegenheiten und die vor Gericht erteilten Vollmachten. ${ }^{1080}$ Hier sind relativ häufig auch Papiermacher zu finden, die entweder eine Vollmacht gaben oder erhielten oder in einen Rechtsstreit - meist um die Zahlung von Geldschulden - verwickelt waren.

Die Signatur B bezeichnet die Fertigungsbücher oder Fertigungen. Sie halten die vor Gericht erfolgten Übertragungen von Liegenschaften fest, also den Kauf und Verkauf von Grundstücken und Immobilien, aber auch Zins- und Rentgeschäfte. ${ }^{1081}$ In dieser Protokollserie finden sich neben von Papiermachern gekauften Häusern und

1077 Die bis zu ihrem Anschluss an die Eidgenossen freie Stadt Basel verteilte sich auf zwei Stadtteile: die ,mehrern Stadt' oder Großbasel auf der linken Rheinseite und die ,mindere Stadt" oder Kleinbasel auf der rechten Rheinseite. Diese zwei Stadtteile bildeten ursprünglich zwei separate Städte und verschmolzen erst durch den Erwerb Kleinbasels durch die große Stadt im Jahr 1392 weitgehend zu einer Einheit. Erhalten blieb trotz der Zusammenlegung der Ämter das Kleinbasler Schultheißengericht. Es konnte nicht mit dem Großbasler Schultheißengericht zusammengelegt werden, da der Rat dieses nur als Pfand erhalten hatte, vgl. Heusler 1918, 40; Hagemann 1987, 16.

1078 Zum Gerichtswesen im mittelalterlichen Basel vgl. allgemein Heusler 1922; Hagemann 1981. Insbesondere zum Zivilrecht vgl. Hagemann 1987.

1079 Vgl. Esch 1985, 541. Zur Vermehrung des Quellenmaterials durch die Verrechtlichung der Gesellschaft im späten Mittelalter vgl. Keller 1990, 196-199.

$1080 \mathrm{Zu}$ Vollmachten vgl. Hagemann 1987, 61-69. Zu vor dem Großbasler Schultheißengericht ausgetragenen Rechtsstreitigkeiten des 15. Jahrhunderts vgl. ebd., 76-117.

1081 Vgl. Hagemann 1987, 34-48. 
Gärten auch die Handänderungen von Papiermühlen. Da Übertragungen von Liegenschaften im spätmittelalterlichen Basel vor dem Schultheißengericht vorgenommen werden mussten und die Gerichtsschreiber die Käufe und Verkäufe in Fertigungsbüchern protokollierten, kann die Reihe der Papiermühlenbesitzer beinahe lückenlos erschlossen werden. ${ }^{1082}$

Die Vergichtbücher, unter C subsummiert, enthalten die vor Gericht ausgestellten Schuldbekenntnisse, bei denen es sich meist um das Bekennen einer Geldschuld handelt. ${ }^{1083}$ Diesem Bekenntnis ist häufig ein Versprechen beigefügt, die Schuld innerhalb einer bestimmten Frist oder in festgelegten Raten zu begleichen. Oft nicht genannt ist das zugrundeliegende Geschäft, sodass nur selten zu erkennen ist, wie die Schulden zustande kamen.

Unter D finden sich die sogenannten Kundschaften, das heißt Zeugenaussagen zu bestimmten Rechtsstreitigkeiten. Diese naturgemäß meist längeren Einträge geben einen detaillierteren Einblick in die darin verhandelten Rechtsfälle, da sie oft den Hergang der Ereignisse schildern und auch Personen zu Wort kommen lassen, die ansonsten kaum in den Quellen auftauchen würden. ${ }^{1084}$

Die Signatur E, Frönungen und Verbote, und G, Verrechnungen, enthalten Protokolle von Zwangsvollstreckungen. Während die Frönungen und Verbote gerichtliche Pfändungen und Arreste umfassen, belegen die Verrechnungen Vermögensauflösungen. ${ }^{1085}$ Der Gegenstand einer Frönung, das heißt einer Pfändung, war meist ein liegendes Gut, also ein Grundstück, auf dem Zinsen lasteten. Zahlte der Zinsmann den Zins nicht termingerecht - dieser Fall wurde mit dem Begriff versessene Zinsen bezeichnet - oder ließ die Immobilie verkommen, dann konnte sich der Zinsherr für die Beschlagnahmung des Guts an das Gericht wenden. Die Verbote betrafen den Arrest von fahrendem Gut durch den Gläubiger. ${ }^{1086}$ Die Verrechnungen verzeichnen Vermögensliquidationen, meist im Fall eines flüchtigen oder verstorbenen Schuld-

1082 Die Protokolle dienten als Vorlage für die Ausfertigung des Fertigungsbriefs, der dem Erwerber übergeben wurde. Aus diesem Grund sind auch nahezu alle Einträge in den Fertigungsbüchern durchgestrichen - von den durchgestrichenen Rechtsakten wurde nämlich bereits eine Urkunde erstellt. Bei Verlust des Fertigungsbriefs konnte das Gerichtsbuch konsultiert werden, das zu diesem Zweck aufbewahrt wurde. Vgl. Hagemann 1987, 31 f. Dieses gerichtlich geregelte und vor allem verschriftlichte Verfahren der Grundstücksübertragung eröffnet dem Historiker einen Einblick in die privaten Immobiliengeschäfte der spätmittelalterlichen Basler, die andernfalls verloren wären, da Urkunden von Privatpersonen nur eine sehr geringe Überlieferungschance hatten.

1083 Vgl. Hagemann 1987, 48-61.

1084 So erfahren wir beispielsweise von dem Schicksal des Gesellen Melchior, der Knecht bei Anton Gallician war, bevor er in einen Streit verwickelt, durch einen Messerstich lebensgefährlich verletzt und schließlich bis zu seinem Tod von dem Zeugen gepflegt wurde, StABS, Gerichtsarchiv D 13, 51. Anhand der Kundschaften, die häufig die Aussagen in der Sprache der Zeugen protokollierten, konnte Ernst Erhard Müller die Eigenheiten der Basler Mundart bestimmen, vgl. E. E. Müller 1953.

1085 Vgl. Hagemann 1987, 117-139.

1086 Vgl. Hagemann 1987, 124-128. 
ners. ${ }^{1087}$ Die Aufteilung der Konkursmasse auf die Gläubiger zeigt hierbei, mit wem der Schuldner in geschäftlichen Beziehungen stand und in welchen Dimensionen sich seine Schulden bewegten. Um die Konkursmasse bestimmen zu können, wurden Inventare von den Gütern des Schuldners angelegt, wie sie in den Beschreibbüchlein unter der Signatur K zu finden sind. ${ }^{1088}$

Das Kleinbasler Schultheißengericht war gegenüber dem Großbasler Schultheißengericht unabhängig und führte eigene Gerichtsbuchserien. ${ }^{1089}$ Für die vorliegende Arbeit relevant waren die Gerichtsbücher, die heute unter der Signatur P zu finden sind. Sie verzeichnen den Kauf der Allenwindenmühle durch Heinrich Halbysen d. Ä. im Jahr 1433 und enthalten damit den ersten Hinweis auf den Beginn der Papiermacherei in Basel. ${ }^{1090}$

Die Überlieferungsserie der Gerichtsbücher des Kleinbasler Schultheißengerichts beginnt mit dem Jahr 1410, weist jedoch im 15. und beginnenden 16. Jahrhundert einige Unterbrechungen auf. Die Gerichtsbuchserien des Großbasler Schultheißengerichts sind bis auf wenige Jahrgänge vollständig auf uns gekommen und äußerst materialreich. Die Urteilsbücher beispielsweise umfassen für den Untersuchungszeitraum von circa 1435 bis 155047 Bände mit jeweils durchschnittlich 200 Blatt.

Die Masse der Basler Gerichtsbücher, deren Umfang Hans-Rudolf Hagemann treffend mit den Adjektiven „beglückend“ und „erdrückend“ beschreibt, ${ }^{1091}$ sind bisher archivalisch kaum erschlossen. Für einzelne Bücher existieren im Staatsarchiv Basel-Stadt handschriftliche Regesten, die der Rechtshistoriker Karl Stehlin für seinen privaten Gebrauch anfertigte. ${ }^{1092}$ Besonders wertvoll für eine Untersuchung der Papierherstellung im spätmittelalterlichen Basel sind die ebenfalls von Karl Stehlin herausgegebenen Regesten zur Geschichte des Buchdrucks, die er zum großen Teil aus den Gerichtsbüchern extrahiert hat. ${ }^{1093}$ Zum Vorteil des Papiergeschichtsforschers nahm Stehlin hier nicht durch die die Buchdrucker betreffenden Hinweise auf, sondern sammelte ebenso Informationen zu den benachbarten Gewerben der Buchbinder, Schriftgießer und Kartenmaler. ${ }^{1094}$ Da diese Handwerke, einschließlich des Buchdrucks, eine enge Bindung zum Papiergewerbe hatten, führte diese Erweiterung dazu, dass auch Papiermacher relativ häufig in den Regesten auftauchen. Somit lässt sich eine erste Schneise in die Überlieferung schlagen. Eine vollständige Durchsicht der Gerichtsbücher war im Rahmen dieser Studie nicht möglich. Daher stützen sich

1087 Vgl. Hagemann 1987, 128.

1088 Zur Inventarisierung der Güter des Druckers Michel Wenssler vgl. Hagemann 1987, 134.

1089 Zur Genese dieser Gerichtsverfassung mit zwei Schultheißengerichten vgl. Hagemann 1981, 5, 154; Hagemann 1987, 15 f. Vgl. auch Anm. 1077.

1090 StABS, Gerichtsarchiv P 3, 211r (röm. Ziffern) bzw. 200r (arab. Ziffern).

1091 Hagemann 1987, 5.

1092 Vgl. Hagemann 1981, 4 f.; Hagemann 1987, 6.

1093 Vgl. Stehlin 1888; Stehlin 1889; Stehlin 1891.

1094 Vgl. Stehlin 1888, 6. 
die Recherche auf die Stehlinschen Regesten sowie auf Hinweise in der Literatur. Für die Betrachtung der Papiermühlen konnte das Historische Grundbuch der Stadt Basel herangezogen werden. ${ }^{1095}$

\subsubsection{Forschungsstand}

Schon in der gelehrten Literatur des 16. bis 19. Jahrhunderts genoss die Basler Papiermacherei große Prominenz. Während dieser Jahrhunderte kursierte die Geschichte, dass die Herstellung von Leinenpapier 1470 in Basel erfunden worden sei. Einzig in der Beschreibung der Protagonisten kann man zwei unterschiedliche Stränge unterscheiden. Eine erste Erzähltradition besagte, dass im Jahr 1470 ins Exil nach Basel geflüchtete Griechen dort die Papiermacherei eingeführt hätten. Alternativ entstand die Erzählung um die Brüder Anton und Michel, die aus dem spanischen Galicien nach Basel kamen und dort die Papierherstellung, ebenfalls im Jahr 1470, begründeten. Während manche Autoren beide Überlieferungsstränge ansprechen, meist, ohne einem der beiden mehr zugeneigt zu sein,, ${ }^{1096}$ erwähnen andere nur eine der beiden Ausformungen. ${ }^{1097}$ Dritte wiederum verkürzen die Aussage zu der bloßen Feststellung, dass im Jahr 1470 in Basel eben das Leinenpapier erfunden worden sein solle. ${ }^{1098}$ Von diesem Datum abweichend gibt der Jurist Franz Henning Schaden an, dass die Papiermacherei bereits $1420 \mathrm{zu}$ Basel erfunden worden sei. ${ }^{1099}$ Bemerkenswert bei diesen Überlieferungstraditionen sind die zahlreichen wortwörtlichen Übernahmen ganzer Textpassagen von einem Werk in ein anderes.

1095 Dieses durch den Rechtshistoriker Karl Stehlin (1859-1934) angelegte Historische Grundbuch verzeichnet die Liegenschaften der Basler Altstadt, ihre Besitzerwechsel und Zinsbelastungen, indem es für das jeweilige Grundstück Auszüge aus Archivalien auf Karteikarten zusammenstellt.

1096 Vgl. beispielsweise den Artikel Paper, in: Chambers 1741; vgl. auch die drei zum großen Teil gleichlautenden Stellen in Breitkopf 1784, 72, 104 f.; Wehrs 1788, 183-185, 273 f.; Krünitz et al., 1807, Bd. 106, 537 f., 554 f. Zur den sehr häufigen wörtlichen Übernahmen des Texts anderer Werke im Artikel Papier in Krünitz' Encyklopädie vgl. Bayerl 1987, 18, 629-633.

$1097 \mathrm{Zu}$ der Griechen-Legende vgl. Jaucourt 1765/1966, 856; wörtlich übernommen in Desmarest 1788, 480. Zur Galicien-Legende vgl. Weigel 1698/1987, 263; Abraham a Santa Clara 1711, 474 f.; Leu 1754, 200. Christoph Gottlieb von Murr erwähnt in seinem Werk ebenfalls die Legende von Anton und Michel aus Galicien als erste deutsche Papierhersteller, weist sie jedoch als irrig ab, da bereits 1390 in Nürnberg eine Papiermühle bestanden habe, vgl. Murr 1778, 677 f.

1098 Vgl. beispielsweise deutsche, vor allem enzyklopädische Werke der ersten Hälfte des 18. Jahrhunderts, allen voran die gleichlautenden Textabschnitte in: [Marperger] 1712, 927; Beier 1722, 314; Artikel Papier, in: Zedler 1740/1961, 646. Vgl. auch Beyer 1735, 90.

1099 Vgl. Schaden 1740/1962, 4. Auch Johann Samuel Halle nennt nicht 1470, sondern 1420 als Begründungsdatum der Papiermacherei durch Anton und Michel aus Galicien, vgl. Halle 1762, $125 \mathrm{f}$. Sowohl Piccard als auch Kälin vermuten, dass dieses Datum, nicht aber der Ort, aus dem Werk von Johann Matthias Beyer übernommen wurde. Dieser berichtet in seinem Theatrum Machinarum Molarium von der Erfindung des Papiers in Basel um 1470, merkt jedoch zugleich an, dass bereits 50 Jahre zuvor in Konstanz Papier gebraucht wurde, vgl. Beyer 1735, 90. 
Diese Traditionslinien bis an ihren Ausgangspunkt zu verfolgen, haben bereits Gerhard Piccard und Hans Kälin versucht. ${ }^{1100}$ Als Ursprung des ersten Strangs machen beide eine 1610 in Paris gedruckte Streitschrift Contra Guillandinum des klassischen Philologen Joseph Justus Scaliger (1540-1609) aus. Hierin berichte der Autor von der Etablierung der Papierproduktion durch exilierte Griechen im Jahr $1470 .{ }^{1101}$ Diese Textstelle konnte in den Recherchen zur vorliegenden Arbeit leider nicht gefunden werden. Piccard zitiert den Text nach eigenen Angaben aus der dritten Edition der Bibliographia antiquaria von Johann Albert Fabricius aus dem Jahr 1760 und verzichtet daher komplett auf eine eigene Listung des Titels in den Anmerkungen. Kälin hingegen gibt das Werk zwar in seiner Literaturliste unter „Scaliger Josephus Justus, Contra Guillandinum. Paris 1610“ an, allerdings platziert er den Verweis nicht in der entsprechenden Fußnote und gibt auch keine Seitenzahlen an. Daher kann davon ausgegangen werden, dass keiner der beiden Papierforscher die betreffende Passage bei Scaliger eingesehen hat. Bereits die bibliographische Angabe des Werktitels ist nicht vollständig. Die Polemik gegen den Kommentar des Botanikers Melchior Guillandinus, auch Melchior Wieland, zum 13. Kapitel von Plinius' Naturalis historia wurde allem Anschein nach nicht einzeln publiziert, sondern findet sich in einer Sammeledition von posthum veröffentlichter Schriften Scaligers. ${ }^{1102}$ Die Durchsicht des Texts im Rahmen dieser Arbeit konnte leider nicht bestätigen, dass Scaliger den Ausgangspunkt der „Griechen-Legende“ darstellt. Auch die weiteren Literaturhinweise, die Piccard und Kälin liefern, belegen nicht, dass Scaliger von der Erfindung des Leinenpapiers 1470 in Basel schrieb. Johann Albert Fabricius nennt in der dritten Auflage seiner Bibliographia antiquaria zwar die Streitschrift von Joseph Justus Scaliger, allerdings lediglich als bibliographische Notiz. Zudem geht nicht klar hervor, ob er sich auf Papier oder nicht eher auf Papyrus bezieht. ${ }^{1103}$ Auch die Genfer Edition der Encyclopédie von d'Alembert und Diderot, die sowohl Piccard als auch Kälin als Dictionnaire encyclopédique de Genève ${ }^{1104}$ bezeichnen, schreibt die Legende von den exilierten Griechen nicht Scaliger zu. Vielmehr lautet das Zitat:

1100 Vgl. Piccard 1967, 27-32; Kälin 1974, 5-12.

1101 Vgl. Piccard 1967, 27; Kälin 1974, 6.

1102 Vgl. Scaliger 1610.

1103 Vgl. Fabricius 1760, 957. Zur undifferenzierten Verwendung des lateinischen papyrus für Papyrus und Papier vgl. die Studie von Carla Meyer-Schlenkrich zu Fragen des Papiergebrauchs mit den Kapiteln zu Marco Polo und den vielen Worten für Papier und zu Plinius dem Älteren als unverhofftem Vater der Papierforschung (s. Anm. 25).

1104 Dieses Werk zitiert Gerhard Piccard nach Wehrs - und zwar augenscheinlich ohne Kenntnis des Originaltexts, aber immerhin mit deutlicher Kenntlichmachung der Übernahme aus Wehrs. Kälin hingegen scheint sich bei seinen Angaben zum Dictionnaire encyclopédique de Genève nur auf Piccard und Briquet zu stützen, vgl. Breitkopf 1784, 104; Wehrs 1788, 274; Briquet 1955a, 110, Anm. 58; Piccard 1967, 27; Kälin 1974, 6, 216, Anm. 9. Dass weder Piccard noch Kälin das Werk in den Händen hielten, zeigt sich daran, dass sie offenbar nicht wussten, worum es sich tatsächlich handelt. Hinter dem Dic- 
Scaliger en donne sans preuve la gloire aux Allemands, \& le comte Maffei aux Italiens. D'autres en attribuent l'honneur à quelques Grecs refugiés à Basle, à qui la maniere (sic!) de faire le papier de coton dans leur pays en suggéra l'idée. ${ }^{1105}$

Dieser Text wurde von Breitkopf und Wehrs verkürzt und damit verfälscht wiedergegeben. ${ }^{1106}$ Nach der Encyclopédie spricht sich Scaliger für die Deutschen als Erfinder des Leinenpapiers aus, während andere, nicht genannte Autoren diese Ehre geflohenen Griechen zuteilwerden lassen. ${ }^{1107}$ Der Ursprung der „Griechen-Legende“ bleibt somit unklar.

Nachvollziehen lässt sich hingegen der Ausganspunkt des zweiten Strangs. Dieser ist nach Kälin nicht - wie von Piccard angenommen - das 1677 erschienene Lexicon universale von Johann Jacob Hofmann, ${ }^{1108}$ sondern das 1577 in Basel veröffentlichte Werk Epitome Historiae Basiliensis des Basler Chronisten Christian Wurstisen (lat. Christianus Urstisius, 1544-1588). ${ }^{1109}$ Wurstisen beschreibt darin das St. Albantal mit seinen Papiermühlen und erwähnt auch deren ersten Betreiber. So hätten die aus Spanien stammenden Anthonius \& Michael Galliciones anno $1470^{1110}$ als erstes die Papiermacherei in Basel eingerichtet. Ihre spanische Herkunft leitet Wurstisen dabei in guter humanistischer Manier von ihrem Beinamen ab: Gallicion steht bei ihm für die spanische Region Galicien. ${ }^{1111}$

Während Kälins Hinweis auf den Text Wurstisens sehr verdienstvoll ist, kann man sich bei einem Großteil der anderen Belege des Eindrucks nicht erwehren, dass weder Kälin noch Piccard die von ihnen zitierten Werke selbst eingesehen und in den Händen gehalten haben. Dies trifft neben dem Text von Joseph Justus Scaliger und der Passage aus der Encyclopédie auch auf die von ihnen erwähnten, aber nicht näher mit

tionnaire encyclopédique de Genève verbirgt sich die 1778 in Genf gedruckte Edition der Encyclopédie von Diderot und d'Alembert.

1105 Vgl. Jaucourt 1778, $472 \mathrm{f}$.

1106 Er lautet: Scaliger donne sans preuve la gloire de l'invention du papier à quelques Grecs, refugiés à Basle, à qui la manière de faire le papier de coton dans leur Pays en suggéra l'idée. Vgl. Breitkopf 1784, 104; Wehrs 1788, 274. Auf dieses durch Kürzung verfälschte Zitat beziehen sich auch Piccard und Kälin, vgl. Anm. 1104.

1107 Auch Fabricius verweist darauf, dass das Papier von den Deutschen erfunden worden sei und nennt als Beleg die Scaligerana secunda, eine nach Scaligers Tod kompilierte Zitatsammlung, vgl. Fabricius 1760, 958. Zu den Scaligerana secunda vgl. Bernays 1855, 231-237. Tatsächlich steht auf der von Fabricius angegeben Seite 7, dass die Deutschen das Leimen des Papiers, nicht jedoch das Papier selbst erfunden haben: Les Alemands ont commencé à coller le papier, vgl. [Scaliger] 1667, 7.

1108 Vgl. Piccard 1967, 27. Auch Martin Kluge ging noch im Jahr 2008, wohl in Unkenntnis der Entdeckung Kälins, davon aus, dass die ,Galicien-Legende‘ von Hofmann stamme, vgl. Kluge 2008, 10.

1109 Vgl. Kälin 1974, 7 f. Vgl. auch den Originaltext: Wurstisen 1577. Genau 180 Jahre später erschien eine deutsche Übersetzung des Werks: Wurstisen 1757/2011.

1110 Wurstisen 1577, 132; Wurstisen 1757/2011, 208.

1111 Vgl. Wurstisen 1577, 132; Wurstisen 1757/2011, 208. Vgl. auch Kälin 1974, 8. 
Seitenzahlen oder anderen Belegen versehenen Texte von Johann Jacob Hofmann, ${ }^{1112}$ Mylius $^{1113}$ und Joannes Raius (John Ray) ${ }^{1114}$ zu. Die Vermutung liegt nahe, dass sowohl Piccard als auch Kälin diese Textbelege aus Breitkopfs Versuch und Wehrs Vom Papier übernommen haben. ${ }^{1115}$ Andererseits sind Kälin noch weitere Neufunde zu verdanken. So zitiert er zwei Reiseberichte aus dem 18. Jahrhundert, die auch von der Vermutung wissen, dass in Basel das Papier erfunden worden sei. ${ }^{1116}$ Der ungarische Graf Joseph Teleki besuchte im Jahr 1760 eine Basler Papiermühle und notierte - ohne jeden Zweifel an dieser Behauptung -, dass dies die erste Papiermühle Basels und somit, da man Papier erstmals in Basel herstellte, auch die erste Papiermühle der Welt sei. ${ }^{1117}$ Mit Zweifel betrachtet der schwedische Philologe Jacob Jonas Björnståhl die vermeintliche Invention des Papiers in Basel. In seinem Bericht über den Besuch Basels 1773 hält er fest, dass zwar Basel die Erfindung des Leinenpapiers zugeschrieben werde, dass dies allerdings höchstens für Deutschland gelten könne. Er selbst vermutet, dass die Araber oder Mauren die Erfinder des Papiers waren. ${ }^{1118}$

Ein früher Skeptiker der Basel-Legende - bei Piccard und Kälin nicht erwähnt - war der böhmische Jesuit, Literat und Historiker Bohuslav Balbín. In seinem 1679 publizierten Werk Miscellanea historica Regni Bohemiae bezieht er sich auf den Hortus

1112 Hier stellt bereits Kälin - der selbst aus dem Original zitiert - fest, dass Piccard keine Einsicht in den ursprünglichen Text nahm. Piccard selbst nennt als Beleg für das Zitat das Werk von Wehrs, allerdings ohne Seitenzahlen. Vgl. hierzu Wehrs 1788, 183 f.; Piccard 1967, 27; Kälin 1974, 217, Anm. 17, auch Breitkopf 1784, 72. Vgl. Hofmann 1677, 257. Durch einen Druckfehler lautet die Seitenzahl in der ersten Edition des Lexicon universale statt korrekt 257 jedoch 557 und wurde so von Breitkopf und Wehrs übernommen.

1113 An diesem Beispiel wird am besten deutlich, dass Piccard und Kälin die in diesem Fall unvollständigen und fehlerhaften Angaben von Breitkopf und Wehrs übernommen haben. Wie die ältere Literatur nennen sie das Werk von Martin Mylius nämlich irrtümlich Hortus philologicus statt korrekt Hortus philosophicus. Zudem wurde es bereits 1597 verfasst, sodass Mylius nicht in der Tradition von Johann Jacob Hofmann stehen kann, dessen Text erst 1677 gedruckt wurde. Folglich ist es auch nicht Joannes Raius, der das erste Mal explizit davon spricht, dass die Deutschen das Papier vor der Einwanderung von Anton und Michael aus Galicien nicht kannten, wie Kälin angibt, vgl. Kälin 1974, 9. Der Originaltext in Mylius 1597, 601, lautet: quae ars conficiendae chartae circa annum Christi 1470 inventa est: quo tempore ex Gallicia duo viri Antonius \& Michaël in Germaniam \& Basileam venerunt, \& secum artem illam attulerunt antea Germanis ignotam.

1114 Raius 1688, 1302: novo chartarum artificio circa Annum 1470 (quo tempore ex Gallicia duo viri Antonius \& Michael in Germaniam \& Basileam venerunt, \& secum artem illam antea Germanis ignotam attulerunt) invento. Kälin gibt hier ebenfalls die korrekte Seitenzahl, wie sie auch bei Breitkopf und Wehrs zu finden ist, an, während Piccard den Text von John Ray ohne weitere Angaben erwähnt, vgl. Kälin 1974, 219, Anm. 27; Breitkopf 1784, 72; Wehrs 1788, 184; Piccard 1967, 27.

1115 Vgl. hierzu die betreffenden Angaben bei Breitkopf 1784, 72, 104 f., und Wehrs 1788, 183-185, 273 f., wobei Wehrs sich höchstwahrscheinlich auf Breitkopf stützt.

1116 Vgl. Kälin 1974, 10 f. Die betreffenden Reiseberichte finden sich in Spiess 1936; Björnståhl 1782.

1117 Vgl. Spiess 1936, 87.

1118 Vgl. Björnståhl 1782, 53. 
philosophicus des Martin Mylius und tut die Annahme, dass die Papiermacherei 1470 in Basel durch zwei Galicier erfunden worden sei, als irrig ab. Als zweifellos schlagendes Argument führt er an, dass ein Gang in die Bibliotheken genüge: Dort finde man zahlreiche Handschriften, sogar aus der Zeit vor 1340, die auf Papier geschrieben seien. ${ }^{1119}$

Einen erstaunlichen Niederschlag erfuhr das falsche, aber trotz skeptischer Stimmen weit verbreitete Gründungsdatum 1470 auch in der Papiermacherei selbst. Pünktlich zum vermuteten 300-jährigen Jubiläum richteten die Basler Papiermacher im Jahr 1770 die Bitte an den Rat, die Jahrhundertfeier der Papierer öffentlich mit einem Umzug feiern und zudem eine Kasse für hilfsbedürftige Papierergesellen einrichten zu dürfen. Der Rat entsprach bis auf die Erlaubnis für einen Umzug ihrer Bitte, sodass sowohl ein Fest als auch die Hilfskasse zustande kamen. ${ }^{1120}$

Die Legende um Anton und Michel aus Galicien ist zwar nicht ganz richtig, aber auch nicht ganz falsch. Gewiss kommen Anton und Michel Gallician nicht aus der spanischen Region, auf die ihr Name schließen lassen könnte, auch sind sie nicht erst seit 1470 Papiermacher in Basel, sondern bereits seit den 1450er-Jahren, aber dennoch weiß die gelehrte Literatur über Jahrhunderte hindurch immerhin die Namen von zwei frühen Basler Papiermachern, auch wenn sie nicht die ersten Papiermühlenbesitzer waren. Von diesem berichtet uns im Jahr 1819 erstmals der Basler Historiker Peter Ochs, der die Existenz einer ersten Basler Papiermühle auf das Jahr 1440 datiert und als ihren Besitzer einen Halbysen nennt. ${ }^{1121}$

Bis zur Falsifizierung der „Galicien-Legende“ durch Charles-Moïse Briquet und Traugott Geering ${ }^{1122}$ nahmen noch weitere Autoren die Nachricht von den spanischen Papiermachern in Basel auf und vermischten sie zum Teil mit den Angaben von Peter Ochs zum ersten Papiermühlenbesitzer Halbysen. ${ }^{1123}$ Das führt uns in die Anfänge

1119 Vgl. Balbín 1679, 58: Egregrie hallucinatur Mylius, qui artem chartae conficiendae primum circa annum C. 1470. inventam affirmat, cum ex Gallicia duo viri, Antonius \& Michael, Basileam venissent, \& secum artem illam attulissent ante Germanis ignotam. Sed Mylium integrae Manuscriptorum Codicum Bibliothecae refellunt, in quibus plurimos in charta Codices, iam ante Annum 1340. scriptos, quoties lubebit, ostendam. Balbín argumentiert hier erstaunlicherweise - und im Unterschied zu seinen gelehrten Zeitgenossen - mit der Materialität des Papiers. Vgl. auch die aktuell im Entstehen begriffene Studie von Carla Meyer-Schlenkrich zum Papiergebrauch mit einem Kapitel zu Schandhüten als Spur zu einer unerzählten Papiergeschichte (s. Anm. 25).

1120 Vgl. Geering 1886, 540; Wyler 1927, 64; Piccard 1967, 26; Kälin 1974, 11.

1121 Vgl. Ochs 1819, 568. In einer Anmerkung weist Peter Ochs die These von der Einführung der Papiermacherei im Jahr 1470 daher entschieden zurück: Er habe die Urkunde von 1440, die von der Existenz einer Papiermühle in Basel berichtet, mit eigenen Augen gesehen.

1122 Vgl. Briquet 1955a, 92; Geering 1886, 313-319.

1123 Vgl. Stockmeyer/Reber 1840, 1. Stockmeyer und Reber nennen zudem den bei Ochs nicht erwähnten Taufnamen des Papiermühlenbesitzers Halbysen, geben dabei allerdings den falschen Namen Hans, anstelle des korrekten Heinrich an. Dieser Irrtum wird u. a. von Briquet aufgegriffen, obwohl bereits Daniel Albrecht Fechter 1863 den Namen in Heinrich korrigierte, vgl. Briquet 1955a, 
der geschichtswissenschaftlichen Forschung zur frühen Papierherstellung in Basel. Der Genfer Wasserzeichenforscher Charles-Moïse Briquet führt in einem Beitrag aus dem Jahr 1883 in einer knappen Zusammenstellung die neuesten Erkenntnisse zu den frühen Basler Papiermühlen auf, darunter den Quellenbeleg für die piemontesische Herkunft der Gallician, den er von Rudolf Wackernagel erhalten hatte. ${ }^{1124}$ Das erste von Briquet identifizierte Basler Wasserzeichen ist ein Baselstab aus dem Jahr $1535 .{ }^{1125}$

Als erster Historiker, der sich auf Basis eines Quellenstudiums mit der Basler Papiermacherei beschäftigte, kann Traugott Geering angeführt werden. Im Rahmen seines 1886 publizierten Werks Handel und Industrie der Stadt Basel unternimmt Geering den Versuch, die gesamte städtische Wirtschaft einschließlich des Zunftwesens vom 13. bis zum 17. Jahrhundert zu beschreiben. Eingebettet in diesen übergreifenden Kontext ist das neue Gewerbe der Papiermacherei. ${ }^{1126}$ Geering stützt sich dabei auf die Urbare des St. Albanklosters, auf einige wenige Urkunden, auf die Steuerlisten der 1450er-Jahre sowie auf die Eintrittsrodel der Schlüssel- und der Safranzunft. ${ }^{1127}$ Wie bereits erwähnt, falsifiziert Geering die Legende um die spanische Abstammung von Anton und Michel Gallician, indem er bei der Quellenlektüre auf deren Heimatort Caselle in Italien stieß. ${ }^{1128}$ Auch kann er die beiden Papiermacher bereits in den 1450er-Jahren in den Quellen fassen. Interessanterweise lehnt er hingegen die „Griechen-Legende“, die auch er Joseph Justus Scaliger zuschreibt, nicht ab, sondern hält im Gegensatz zu Briquet die Vermittlung der Papiermacherkunst durch griechische Exilanten für plausibel. ${ }^{1129}$

Die zwischen 1921 und 1928 veröffentlichten Arbeiten von Eduard Schweizer legen den Fokus auf die Basler Gewerbe, die auf Wasserkraft angewiesen waren. Darunter fallen - neben Kornmühlen, Gewürzmühlen, Schleifen und Hammerschmieden - eben auch die Papiermühlen, die er für die verschiedenen Basler Gewerbekanäle aufführt. ${ }^{1130}$ Schweizer, dessen Ausführungen über das Papiergewerbe vor allem auf dem Basler Urkundenbuch, dem St. Alban-Archiv sowie auf Wackernagel und Geering

92; Fechter 1863, 27 f. Zur Vermischung der Informationen zu spanischen Papiermachern in Basel seit 1470 und einer ersten Papiermühle im Jahr 1440 vgl. des Weiteren Sotzmann 1846, 103; Wattenbach 1871, 97. In der dritten Auflage nimmt Wattenbach die Ergebnisse von Geering auf und korrigiert seinen Text, vgl. Wattenbach 1896, 146. Beeindruckend ist, dass sogar noch 1966 die Erzählung über die spanischen Gallicianbrüder als historisch verbürgte Tatsache aufgegriffen wurde, vgl. Gayoso Carreira 1966. Vgl. auch Kälin 1974, 231 f. mit Anm. 123.

1124 Vgl. Briquet 1955a, 91-96, bes. 92.

1125 Vgl. Briquet 1955a, $92 \mathrm{f}$.

1126 Vgl. Geering 1886, XIII, 286-289, 313-322, 525-540.

1127 Vgl. Geering 1886, 314-316. Hinweise auf so manche Quellenstelle scheint er von Rudolf Wackernagel erhalten zu haben, wie er auf S. 315, Anm. 2 angibt.

1128 Vgl. Geering 1886, 313, 317-319. Vgl. auch Kälin 1974, 14.

1129 Vgl. Geering 1886, 288. Vgl. auch Briquet 1955a, $91 \mathrm{f}$.

1130 Vgl. Schweizer 1921; Schweizer 1922; Schweizer 1923; Schweizer 1924; Schweizer 1927; Schweizer 1928. Vgl. auch Kälin 1974, 17. 
basieren, bringt erstmals eine tabellarische Übersicht über die Besitzerabfolge der Papiermühlen im St. Albantal. ${ }^{1131}$ An Relevanz gewinnen die Studien Schweizers für die vorliegende Arbeit durch ihre Aufarbeitung aller an den Gewerbekanälen liegenden Mühlwerke. Auf diese Weise ermöglichen sie eine Einordnung des Papiergewerbes in die gesamte Mühlenlandschaft Basels.

Die 1927 publizierte Dissertation von Edwin Wyler, die sich auf Die Geschichte des Basler Papiergewerbes konzentriert, bringt für den hier behandelten Zeitraum bis 1550 keine eigenen Quellenstudien, sondern resümiert die Ergebnisse von Briquet, Geering und Schweizer. ${ }^{1132}$ Der erste Teil der Alten Basler Papiermarken von Walter Friedrich Tschudin, der im Jahr 1954 publiziert wurde, fasst ebenfalls lediglich die Resultate der drei genannten Autoren zusammen. ${ }^{1133}$ Für den ein Jahr später veröffentlichten zweiten Teil gilt dies allerdings nicht. Hier bringt Tschudin weitere Zeugnisse aus dem Basler Stadtarchiv und erweitert somit die Kenntnisse um die ersten Papiermühlen, die Papiermacher und ihre Familien. ${ }^{1134}$ Besonders hervorzuheben ist sein Verdienst, erste Wasserzeichen der Halbysen und der Gallician entdeckt zu haben. Dies gelang ihm durch die Ermittlung der Siegelzeichen und Wappenschilder der beiden Familien. ${ }^{1135}$ Einem breiteren papierwissenschaftlichen Publikum wurden diese Ergebnisse 1958 in der leicht revidierten und ins Englische übersetzten Fassung dieser beiden Aufsätze unter dem Titel The Ancient Paper-Mills of Basle and Their Marks zugänglich gemacht. ${ }^{1136}$ Einen zusammenfassenden Überblick über die bereits von seinem Vater erarbeiteten Daten zur Basler Papiergeschichte gibt Peter Tschudin in mehreren Artikeln. ${ }^{1137}$ Einige seiner jüngeren Publikationen beschäftigen sich dezidiert mit dem oft konfliktreichen - Verhältnis zwischen Papiermachern und Druckern. ${ }^{1138}$

Mit den Beziehungen der Papierer und Buchdrucker zueinander, aber vor allem mit einer getrennten Aufarbeitung zum einen der Frühzeit der Basler Papiermacherei, zum anderen des Buchdruckgewerbes beschäftigt sich Gerhard Piccard 1967 in seiner Studie zu Papiererzeugung und Buchdruck in Basel bis zum Anfang des 16. Jahrhunderts. ${ }^{1139}$ Diese umfangreiche und detaillierte Arbeit führt zahlreiche bis dahin

1131 Vgl. Schweizer 1923, 74.

1132 Vgl. Wyler 1927. Dies gibt Wyler auf S. 8 selbst an. Vgl. auch Kälin 1974, 18.

1133 Vgl. W. Fr. Tschudin 1954.

1134 Auch wenn manche der Interpretationen Tschudins durch die Arbeiten von Piccard und Kälin überholt sind, ist das Urteil Gerhard Piccards, „der liebevollen, aber ganz unkritischen Arbeit eines Papier-Liebhabers“ gegenüberzustehen, nicht rechtfertigt, vgl. Piccard 1967, 33, Anm. 21.

1135 Vgl. W. Fr. Tschudin 1955.

1136 W. Fr. Tschudin 1958. Vgl. auch Kälin 1974, 20.

1137 P. Tschudin 1956; P. Tschudin 1957, 82-92; P. Tschudin 1958; P. Tschudin 1959; P. Tschudin 1984b, 17-27; P. Tschudin 2012b.

1138 Vgl. P. Tschudin 1997; P. Tschudin 2009. Hier greift Tschudin zum einen auf die Regesten zur Geschichte des Buchdrucks von Karl Stehlin und zum anderen auf die Edition der Amerbach-Korrespondenz zurück, vgl. Stehlin 1888; Stehlin 1889; Die Amerbachkorrespondenz 1942.

1139 Vgl. Piccard 1967. 
noch nicht ausgewertete Quellenbelege an und korrigiert auf dieser Grundlage frühere Darstellungen. ${ }^{1140}$ Die erweiterte Quellenbasis betrifft vor allem die Bücher des Gerichtsarchivs, die Piccard in einer breiten Auswahl heranzieht. Inhaltlich legt er den Schwerpunkt auf die Personen der Papiergeschichte, insbesondere auf die Familien der Halbysen und der Gallician, und untersucht deren soziale und wirtschaftliche Stellung innerhalb Basels. Ihm gelingt es unter anderem, erstmals die Verwandtschaftsverhältnisse der Gallician offenzulegen. Zudem interessiert er sich für die Frage der Zunftzugehörigkeit und des Standorts der Papiermühlen. Die Fülle an Quellen, die Piccard oft direkt in den Text einbaut, wirkt allerdings an vielen Stellen schlicht erschlagend, sodass eine Orientierung erschwert wird.

Zeitgleich zur großen Studie Gerhard Piccards veröffentlichte Theodor Gerardy einige kleinere Miszellen zu Fragen der Basler Papiergeschichte, die jedoch über knappe Mitteilungen $\mathrm{zu}$ Basler Wasserzeichen und einigen neu aufgefundenen Quellen nicht hinausgehen. ${ }^{1141}$

Zuletzt hat sich Hans Kälin eingehend mit der Basler Papiermacherei beschäftigt. In seiner 1974 erschienen Dissertation Papier in Basel bis 1500 tritt er in die Fußstapfen Gerhard Piccards und setzt sich gleichzeitig kritisch mit dessen sieben Jahre zuvor publizierter Studie auseinander. Sein Ziel ist es zum einen - und dies ist der innovativere Teil seiner Arbeit - die Basler Papiergeschichte vor der Einrichtung einer eigenen Papierproduktion nachzuzeichnen, ${ }^{1142}$ zum anderen möchte er den bereits geleisteten Arbeiten zur Papierherstellung weitere Details hinzufügen und sie in einer übersichtlichen Gesamtschau darstellen. ${ }^{1143} \mathrm{Zu}$ diesem Zweck hat Kälin weiteres Quellenmaterial erhoben, ausgewertet und teilweise im Anhang transkribiert zur Verfügung gestellt. ${ }^{1144}$ Der gewünschten Übersichtlichkeit geschuldet enthält Kälins Studie zahlreiche Tabellen und Auflistungen von Papiermühlen, Papiermühlenbesitzern und Papiermachern, die auf der eine Seite einen schnellen Überblick gewährleisten, auf der anderen Seite aber oft den Eindruck einer eher additiven Aneinanderreihung von Namen und Fakten erwecken. In dem Bestreben, möglichst viele weitere Daten zur frühen Basler Papiergeschichte zu bieten und damit „der historischen Wahrheit““145 näherzukommen, verzichtet die Arbeit auf einen systematischen Zugriff. Dennoch

1140 Diese Korrekturen sind bisweilen harsch formuliert. Auch Hans Kälin wies bereits darauf hin, dass Piccard über andere Forscher ein hartes Urteil fällt, ohne jedoch selbst vor den Fehlern gefeit zu sein, die er anderen vorwirft, vgl. Kälin 1974, 21 u. 261 f., Anm. 32.

1141 Vgl. Gerardy 1967; Gerardy 1968b; Gerardy 1968c.

1142 Vgl. Kälin 1974, 21.

1143 Vgl. Kälin 1974, 21, 138 f. Vgl. auch die weiteren Veröffentlichungen Kälins zum Thema: Kälin 1972a; Kälin 1972b; Kälin 1973; Kälin 1982; Kälin 1990; Kälin 1993.

1144 Vgl. Kälin 1974, 289-345. In seinem Vorwort zum Anhang stellt Kälin auch eine Quellenedition zur Basler Papiergeschichte in Aussicht, die in den mehr als 40 Jahren seit Erscheinen seiner Dissertation jedoch nicht publiziert wurde.

1145 Vgl. Kälin 1974, 138. 
ermöglicht Kälins Studie einen profunden Einblick in die Basler Papiergeschichte und wird daher in der Papiergeschichtsforschung vielfach zitiert. ${ }^{1146}$

\subsubsection{Forschungsstand zu Papiermühlengründungen im deutschen Südwesten}

Kommen wir nach den Ausführungen über Basel nun zum Forschungsstand zu den weiteren Fallbeispielen aus dem deutschen Südwesten. Ein besonderer Schwerpunkt liegt hierbei auf Ravensburg als frühestem Zentrum der Papiermacherei, da zu diesem Fallbeispiel eigene Archivrecherchen unternommen wurden. Dementsprechend sollen auch Überlegungen zur Ravensburger Überlieferung mit in die Betrachtung einfließen.

Betrachtet man die Chronologie der verschiedenen Publikationen, so lassen sich deutlich zwei zeitliche Schwerpunkte ausmachen. Die ersten Untersuchungen zu südwestdeutschen Papiermühlen wurden Ende des 19. und Anfang des 20. Jahrhunderts veröffentlicht, als die Papiergeschichte als Forschungsdisziplin noch in den Kinderschuhen steckte. ${ }^{1147}$ Für die Papiermühlen in Ravensburg, Augsburg, Kempten, Memmingen, Reutlingen und Urach ist hier Friedrich von Hößle (1856-1935) hervorzuheben. Der technische Leiter der Papierfabrik in Hegge bei Kempten begann seine Recherchen zu alten Papiermühlen im Jahr 1893 an seiner beruflichen Wirkstätte. ${ }^{1148}$ Diesem ersten Werk folgten Untersuchungen zur württembergischen und zur bayerischen Papiergeschichte, die, nach Standorten gegliedert, Informationen zu den Papiermühlen in diesem Raum aufführten. ${ }^{1149}$ Von Hößle selbst sah sein Werk auf der einen Seite im Dienst anderer Papierfabrikanten, denen ein Überblick über die Papiermühlenvergangenheit ihrer Heimat ermöglicht werden sollte. ${ }^{1150}$ Auf der anderen Seite hatte er den Anspruch, mit seiner württembergischen Papiergeschichte einen nicht unerheblichen Beitrag zur württembergischen Landesgeschichte im Allgemeinen zu leisten. ${ }^{1151}$ Das Vorgehen von Hößles, der ungeprüft Angaben von Gewährsmännern übernahm, lässt sich als äußerst unkritisch beschreiben. ${ }^{1152}$ Es war mit den Worten Frieder Schmidts das Vorgehen ,eines im besten Wortsinne dilettierenden Privatmannes, der zugleich Liebhaber und Laie war“. ${ }^{1153}$ Friedrich von Hößle verzichtete beispielsweise weitgehend auf Quellenbelege, sodass eine Überprüfung seiner Ausführungen deutlich erschwert wird. Seine Befunde können daher nicht

1146 Vgl. beispielsweise P. Tschudin 1991, 24-28, 34-40; Irsigler 1999, 258.

1147 Vgl. F. Schmidt 1993, 10.

1148 Hößle 1895.

1149 Hößle 1926a; Hößle 1924-1927.

1150 Vgl. Hößle 1926a, 3.

1151 Vgl. Hößle 1926a, 3; F. Schmidt 1993, 10.

1152 Vgl. Alfred Schulte 1934, 11 f.; Sporhan-Krempel 1972b, 1516; Petz 2006, 240.

1153 F. Schmidt 1993, 10. 
bedenkenlos übernommen werden. Letztendlich besteht sein Verdienst darin, der Papiergeschichtsforschung als Disziplin zur Geburt verholfen zu haben. ${ }^{1154}$

Eine neue Welle der Papiermühlengeschichtsschreibung ist für die 1950er- und 1960er-Jahre festzustellen. ${ }^{1155}$ In diesen Jahrzehnten veröffentlichten mehrere Papierforscher Beiträge zu verschiedenen Standorten, darunter prominent Gerhard Piccard mit Ausführungen zu Ettlingen, Memmingen, Ravensburg und Gengenbach sowie Lore Sporhan-Krempel mit Studien zu Ravensburg, Straßburg und Reutlingen. ${ }^{1156}$ Die Arbeiten dieser beiden Papierforscher wie auch die anderen in diesem Zeitraum entstandenen Untersuchungen zeichnen sich zumeist durch ein solides Quellenstudium aus. Die Ergebnisse wurden häufig in Form einer chronologischen Darstellung präsentiert. Der in vielen Fällen fehlende systematische Zugriff lässt allerdings den Eindruck entstehen, dass die Quellen lediglich nacherzählt werden. Besonders die Texte von Gerhard Piccard erschweren durch eine Überfrachtung mit Quellenzitaten und durch ihre belehrende Kritik an anderen Forschern die Lektüre. ${ }^{1157}$

Seit den 1960er-Jahren wurden nur noch vereinzelt spätmittelalterlichen Papiermühlengründungen im südwestdeutschen Raum grundlegend untersucht. Lediglich für die jeweils erste Papiermühle in Urach und in Söflingen sowie für die Betriebe in und um Kempten sind in den letzten Jahren aktuelle Arbeiten entstanden, die eine neue Interpretation der Quellen anbieten beziehungsweise bisher ungenutztes Archivmaterial heranziehen. ${ }^{1158}$

Als Problem erweist sich zudem, dass die Darstellungen meist einen viel größeren Zeitraum umfassen, als die vorliegende Studie bearbeitet. Häufig beginnen sie bei der Gründung der ersten Papiermühlen am betreffenden Ort und schließen mit dem Dreißigjährigen Krieg, dem Übergang von der Handpapiermacherei zum Maschinenpapier oder dem Verschwinden der örtlichen Papierproduktion im 19. Jahrhundert. Die Ausführungen sind daher für die einzelnen Zeitabschnitte in vielen Fällen relativ kurz und weniger detailliert, als es eine enger zugeschnittene Arbeit ermöglichen würde. Zudem bergen diese großen Schritte durch die Jahrhunderte die Gefahr, zeitund epochenspezifische Besonderheiten aus dem Blick zu verlieren.

Die Papierherstellung in der Reichsstadt Ravensburg weckte bereits Mitte des 19. Jahrhunderts das Interesse der Forschung. Dies lag vornehmlich in der Behauptung begründet, dass in Ravensburg eine der ältesten, wenn nicht gar die älteste Papiermühle auf deutschen Boden gestanden haben soll. Nach dieser inzwischen gegenstandslos gewordenen Vermutung wäre schon im ersten Viertel des 14. Jahr-

1154 Vgl. F. Schmidt 1993, 10-13.

1155 Vgl. F. Schmidt 1993, 19.

1156 Piccard 1951; Piccard 1960; Piccard 1962; Piccard 1963; Sporhan-Krempel 1953; Sporhan-Krempel 1960; Sporhan-Krempel 1972b. Zu Gerhard Piccard und Lore Sporhan-Krempel vgl. Bannasch 2004; Bannasch 2007; F. Schmidt 2011.

1157 Vgl. Bannasch 2004, 305.

1158 Frauenknecht 2014; Frauenknecht 2015; Petz 2006. 
hunderts Papier in Ravensburg produziert worden. ${ }^{1159}$ Auch Friedrich von Hößle, dem es gelingt, einige neue Informationen zu den Ravensburger Papiermachern ans Licht zu bringen, ${ }^{1160}$ schreibt die Gründung der ersten Papiermühle den Brüdern Hans und Fritz Holbain zu Beginn des 14. Jahrhunderts zu. ${ }^{1161}$

Erst in den 1940er- und 1950er-Jahren wurden die Anfänge der Ravensburger Papiergeschichte unter Einbeziehung der im Stadtarchiv Ravensburg vorhandenen Quellen systematisch aufgearbeitet. Neben dem bekannten Werk Ochsenkopf und Doppelturm von Lore Sporhan-Krempel, das im Jahr 1953 veröffentlicht wurde, muss besonders auf einen wenig beachteten Beitrag von Alfred Schulte hingewiesen werden, der im gleichen Jahr in der Zeitschrift Papiergeschichte erschien. ${ }^{1162}$ In diesem Artikel wurden posthum die von Schulte gesammelten und in Regesten zusammengefassten Quellenbelege zur Ravensburger Papiermacherei in Spätmittelalter und Frühneuzeit publiziert. Alfred Schulte, der 1944 im Zweiten Weltkrieg fiel, plante eine Geschichte der Papiermühlen zu Ravensburg, wie aus mit abgedruckten Briefen an Armin Renker und Hans Heinrich Bockwitz hervorgeht. ${ }^{1163}$ Ob Lore Sporhan-Krempel Kenntnis von der Zusammenstellung Schultes hatte, ist nicht sicher zu sagen. Sie selbst nimmt auf die Quellensammlung keinen Bezug. Die von Schulte zusammengetragenen Zeugnisse und die von Sporhan-Krempel in ihrer Darstellung benutzten Archivalien sind für das 15. und beginnende 16. Jahrhundert deckungsgleich. Dies mag zunächst erstaunen und zudem eine Abhängigkeit der Papierforscherin von den Ergebnissen Schultes suggerieren. Die Erklärung für diese Tatsache ist jedoch sehr simpel: Die aufgeführten Quellen stellen einen Großteil der Überlieferung zur mittelalterlichen Papierherstellung in Ravensburg dar, wie später zu zeigen sein wird. Beide Autoren weisen zudem erstmals auf die Möglichkeit hin, dass in dem Kaufmann Conrad Wirt der Begründer der Ravensburger Papiermacherei zu erblicken sei. ${ }^{1164}$

Im Anschluss an Sporhan-Krempel veröffentliche Gerhard Piccard 1962 einen kleinen Aufsatz zu den Anfängen der Ravensburger Papiermacherei. ${ }^{1165}$ Darin setzt er sich zum einen kritisch mit den Autoren des 19. Jahrhunderts auseinander, zum anderen gelingt es ihm mittels seiner Wasserzeichenforschungen, den frühesten Wasserzeichenbeleg für eine Ravensburger Papierproduktion zu ermitteln. Ebenfalls auf Wasserzeichenbelege stützen sich seine Angaben zum Handel mit Ravensburger

1159 K. D. Haßler 1844, 39; Gutermann 1845, 259, 264, 277; Hafner 1900, 8; Hafner 1908, 290 f. Vgl. hierzu den Überblick in Piccard 1962, 88-95.

1160 Vgl. Hößle 1926a, 30-33. Die Interpretationen der Quellen sind heute jedoch in großen Teilen überholt.

1161 Vgl. Hößle 1926a, 25-27. Vgl. auch Piccard 1962, 94 f.

1162 Sporhan-Krempel 1953; Alfred Schulte 1953.

1163 Vgl. Alfred Schulte 1953, $13 \mathrm{f}$.

1164 Vgl. Alfred Schulte 1953, 13 f.; Sporhan-Krempel 1953, 14-17. Diese These wurde unter anderem übernommen von Preger 1979, 3; Preger 1992, 2; Eitel 1990, 47; Siewert 2004, 1183; Rückert 2010, 115. 1165 Piccard 1962. 
Papier. ${ }^{1166}$ Die Monographie von Lore Sporhan-Krempel setzt er dabei als grundlegend voraus, auch wenn er in einigen wenigen Punkten nicht mir ihr übereinstimmt.

Alle in den darauffolgenden Jahrzehnten erschienenen Beiträge zu den ersten 150 Jahren Ravensburger Papierherstellung beziehen sich auf die Arbeiten von Lore Sporhan-Krempel und Gerhard Piccard und interpretieren die Befunden teilweise neu, allerdings ohne eigene Quellenrecherchen anzuführen. ${ }^{1167}$ Auf Archivalien stützt sich hingegen die Untersuchung, die im Vorfeld der vorliegenden Arbeit hinsichtlich der materiellen Beschaffenheit Ravensburger Papiere unternommen wurde. ${ }^{1168}$

Die Überlieferungssituation im Ravensburger Stadtarchiv ist maßgeblich bestimmt durch die Vernichtung zahlreicher Archivbestände im 19. Jahrhundert und die Ordnung des Archivs durch Alfons Dreher im zweiten Viertel des 20. Jahrhunderts. Bis zum Beginn des letzten Jahrhunderts lagen die Bestände des Ravensburger Stadtarchivs größtenteils unsortiert vor. ${ }^{1169}$ Im Jahr 1925 wurde der Lehrer Alfons Dreher von der Stadt beauftragt, dem Archiv eine Ordnung zu geben. Er rekurrierte hierfür auf eine von dem Direktor des Staatsarchivs Stuttgart, Karl Otto Müller, vorgeschlagene Bestandsstruktur, welche die Archivalien nach Pertinenzkriterien gliederte. ${ }^{1170}$ Diese Gliederung ist bis heute erhalten und findet sich in den insgesamt neun handschriftlichen Repertorienbänden. In diesen Repertorien verzeichnete Alfons Dreher zu jedem Dokument ein ausführliches Regest und die dazugehörige Büschelnummer, unter der die Archivalie auch heute noch im Magazin zu finden ist. Gegen Ende seiner Ordnungstätigkeit, im Jahr 1950, beherbergte das Ravensburger Stadtarchiv 280 Regalmeter Akten. Das älteste Dokument stellt eine Urkunde aus dem Jahr 1270 dar, während die jüngsten Bestände aus der württembergischen Zeit Ravensburgs (1810-1871) stammen. Die Bestände des Ravensburger Stadtarchivs sind nicht in ihrem ursprünglichen Umfang erhalten. Viele serielle Dokumente des Mittelalters, wie beispielsweise die Steuer- und Rechnungsbücher der städtischen Kanzlei, sind nur mit großen Lücken überliefert. Die heutzutage fehlenden Jahrgänge wurden im

1166 Ebenfalls zum Papierhandel publizierte Lore Sporhan-Krempel in den Jahren 1972 und 1984, vgl. Sporhan-Krempel 1972a; Sporhan-Krempel 1984.

1167 Vgl. u. a. Schlieder 1966, 92-95; Dreher 1972, Bd. 1, 125-127; Eitel 1990; Siewert 2004; Rückert 2010, 115-117. Ohne Anmerkungsapparat und damit ohne Belege kommen die 1979 und 1992 publizierten Artikel von Max Preger aus. Der Autor gibt zwar an, Archivalien benutzt zu habe, nachvollziehen lässt sich dies jedoch nicht, vgl. Preger 1979; Preger 1992. Eine bunte, aber leider unkritische und ungeordnete Zusammenstellung vor allem von Bildern zur Ravensburger Papiermacherei bieten die teilweise redundanten Kompendien ebenfalls von Max Preger, die im Stadtarchiv Ravensburg einsehbar sind, vgl. Preger 2002; Preger 2003a; Preger 2003b; Preger 2004.

1168 Schultz/Follmer 2015. Hierfür wurden die vier erhaltenen Steuerbücher des 15. Jahrhunderts, die aus Ravensburger Ochsenkopfpapier bestehen, auf Spuren geprüft, die etwas über die Herstellung der Papiere verraten, vgl. Kapitel 2.1.1, S. 27 f.

1169 Für eine allgemeine Übersicht der Archivbestände im Jahr 1950 vgl. Hengstler 1950, 3.

1170 Vgl. Hengstler 1950, 6. Dreher sortierte beispielsweise nach Art der Urkunde (Kaufvertrag, Lehen, Ehevertrag, Testament etc.). 
19. Jahrhundert zusammen mit weiteren Archivalien kassiert. ${ }^{1171}$ Andere Archivalien, vor allem Kaiser- und Papsturkunden, aber auch weitere Diplome, gingen - ebenfalls im 19. Jahrhundert - an das heutige Hauptstaatsarchiv Stuttgart, damals noch Königliches Haus- und Staatsarchiv. ${ }^{1172}$

Für die Geschichte der Ravensburger Papiermacherei von ihren Anfängen bis zur Mitte des 16. Jahrhunderts erwiesen sich die städtischen Urkunden und Urkunden aus dem Spitalarchiv sowie die Bürger-, Steuer- und Rechnungsbücher der betreffenden Zeit als relevant. Leider fehlen in der Ravensburger Überlieferung Gerichtsbücher aus reichsstädtischer Zeit. Auch ausführliche Zunftakten wie beispielsweise Eintrittsbücher ließen sich für den Untersuchungszeitraum nicht ermitteln.

Die erste umfassende Darstellung der Augsburger Papiermühlen bis ins 18. Jahrhundert lieferte Friedrich von Hößle im Jahr $1907 .{ }^{1173}$ Für den hier interessierenden Untersuchungszeitraum nennt er in einem nach Papiermühlen gegliederten Text bereits einen Großteil der heute bekannten Daten zu Papierwerken und Papiermachern. Auf von Hößles Werk fußend stellte Albert Haemmerle in seiner Studie zu den Augsburger Buntpapiermachern von 1937/38 die Besitzer der Augsburger Papiermühlen in einer Tabelle zusammen. ${ }^{1174}$ Zudem führt er in einem alphabetischen Personenverzeichnis der Buntpapierhersteller auch die sonstigen Papiermacher sowie über sie bekannte Fakten auf. Wie er selbst angibt, bezieht Haemmerle die Informationen zu den frühen Papiermachern von von Hößle und bietet daher keine eigenen Archivstudien. ${ }^{1175}$ Die jüngste Darstellung der Augsburger Papiermacherei von Frieder Schmidt aus dem Jahr 1997 verzichtet für den gewählten Untersuchungszeitraum ebenfalls auf eine erneute Durchsicht der Archivalien und übernimmt die Tabelle der Papiermühlenbesitzer von Haemmerle. ${ }^{1176}$ Weitere Details zu Papiermachern können Hans-Jörg Künasts Studie zum frühen Buchdruck in Augsburg und der Rezension dieses Werks durch Peter Amelung entnommen werden. ${ }^{1177}$

Der Papierfabrikant Friedrich von Hößle kann ebenfalls als Pionier der Kemptener Papiermühlengeschichte gelten. In mehreren Studien widmete er sich den Werken in und um Kempten, zu denen er als technischer Direktor eines der Betriebe eine besondere Bindung hatte. ${ }^{1178}$ Die meisten späteren Ausführungen zu den Papiermühlen auf

1171 Vgl. Diemer 1972, 72.

1172 Vgl. Diemer 1972, 72.

1173 Hößle 1907.

1174 Haemmerle 1937/38.

1175 Vgl. Haemmerle 1937/38, 135.

1176 F. Schmidt 1997. Ein 1955 publizierter Beitrag zum Augsburger Textil-, Metall- und Papiergewerbe von Friedrich Haßler fasst die frühe Geschichte lediglich knapp zusammen, vgl. Fr. Haßler 1955, $409 \mathrm{f}$

1177 Künast 1997, 93, 107, 111-113, 115 f.; Amelung 2000/2017.

1178 Vgl. Hößle 1895; Hößle 1900; Hößle 1926b, 209-212; 222 f. u. Fest- und Ausland-Heft, 49-61; Hößle 1935. Vgl. auch Petz 2006, 240. 
reichsstädtischem wie auf stiftischem Gebiet basieren auf seinen Arbeiten. ${ }^{1179}$ Erst in jüngster Zeit wurde die Geschichte der Kemptener Papiermühlen neu bearbeitet. Im Jahr 2006 publizierte Wolfgang Petz seine Untersuchung zum Kemptener Papiergewerbe vor dem Dreißigjährigen Krieg und legte damit eine Abhandlung vor, die von der klassischen, lediglich die Quellen nacherzählenden Papiergeschichtsschreibung abrückt. ${ }^{1180}$ Im Gegensatz zu von Hößle und den ihm nachfolgenden Beiträgen, die die Kemptener Papiermühlengeschichte zumeist chronologisch Mühle für Mühle behandeln, bereitet Petz seine Darstellung thematisch auf. Ohne das Schicksal der einzelnen Papiermühlen zu vernachlässigen, behandelt er die Rohstoffversorgung und den Absatzmarkt der Kemptener Papierwerke, betrachtet die Meister und Gesellen, ihre wirtschaftliche Vernetzung sowie ihre sozialen Aufstiegschancen und untersucht die kommunikative Praxis und die Strategien der Konfliktbewältigung. Hierfür erweitert Wolfgang Petz das durch von Hößle bearbeitete Quellencorpus, das hauptsächlich Urkunden und Chroniken umfasst, beträchtlich, indem er auch die informationsreichen Rats- und Kanzleiprotokolle der Reichsstadt sowie die Lehenbücher des Stifts Kempten einbezieht. ${ }^{1181}$ Da Petz' Studie rund 70 Jahre mehr bearbeitet als die vorliegende Untersuchung, liegen viele instruktive Ergebnisse, die sich für die zweite Hälfte des 16. Jahrhunderts nahezu zu kumulieren scheinen, bedauerlicherweise außerhalb des Untersuchungszeitraums und können daher nicht einbezogen werden.

Zur Geschichte der Memminger Papiermacherei legte Friedrich von Hößle ebenfalls eine Studie in seiner Bayerischen Papiergeschichte vor. ${ }^{1182}$ Seine Ausführungen wurden 1960 von Gerhard Piccard in einem knapp 20-seitigen Artikel korrigiert. ${ }^{1183}$ Während von Hößle keine Quellennachweise für seine Aussagen liefert, belegt Piccard seine Darstellung mit Dokumenten aus dem Stadtarchiv Memmingen. Ob die Überlieferung mit den von Piccard angeführten Belegen erschöpft ist, lässt sich ohne eine Überprüfung am Archivmaterial nicht sagen. Neuere Studien zu den frühen Memminger Papiermühlen fehlen offenbar gänzlich.

Einige knappe Informationen zu den Berner Papiermühlen fasst bereits CharlesMoïse Briquet im Jahr 1883 zusammen. ${ }^{1184}$ Für den Untersuchungszeitraum gehen sie nicht über die Erwähnung der ersten Papiermühlenbesitzer und des Papiermühlen- und Lumpenprivilegs hinaus. Ausführlicher und mit Quellenzitaten belegt stellt Adolf Fluri sen. die Anfänge der Berner Papiermacherei 1896 dar. ${ }^{1185}$ Sein Sohn Adolf Fluri jun. publizierte 1954 einen Artikel zu den Papiermühlen in Bern in der Zeitschrift Papiergeschichte, der sich stark an die Veröffentlichung seines Vaters anlehnt und

1179 Kellenberger 1922, 5-8; Kremser 1923, 11-25; Geldner 1968a, 3-6; Th. Weiss 1986, 17-30.

1180 Petz 2006.

1181 Vgl. Petz 2006, 240.

1182 Hößle 1926b, 223-226.

1183 Piccard 1960, 595-612. Es betreffen jedoch nur Spalte 595 bis 598 den Untersuchungszeitraum.

1184 Briquet 1955a, $87 \mathrm{f}$.

1185 Fluri sen. 1896. 
teilweise sogar Formulierungen übernimmt. ${ }^{1186}$ Eigene Quellenrecherchen hat Adolf Fluri jun. größtenteils nicht unternommen. Gut zwanzig Jahre später veröffentlichte Adolf Fluri jun. seinen bereits gedruckten Text - bis auf die Einfügung eines Nachtrags unverändert - ein weiteres Mal, diesmal als Neujahrsgabe der Schweizer Papierhistoriker. ${ }^{1187}$ Dabei übergeht er inhaltliche Abweichungen, die in Johann Lindts zwischenzeitlich erschienenen Werk The Paper-Mills of Berne von $1964 \mathrm{zu}$ finden sind. ${ }^{1188}$ Auch hinsichtlich der Frühgeschichte der Berner Papiermühlen existieren keine neueren Darstellungen, die auf eine eigenständige Archivarbeit schließen lassen. ${ }^{1189}$

Auch für einen ersten Beitrag zur Geschichte der Züricher Papiermühle auf dem Werd aus dem Jahr 1883 zeichnet Charles-Moïse Briquet verantwortlich. ${ }^{1190} 1927$ erschien die Dissertation Die Papiermühle und Papierfabrik auf dem Werd 1472-1844 von Max Häusler. ${ }^{1191}$ Beide Arbeiten ermöglichen einen Einblick in die wichtigsten Eckdaten der frühen Züricher Papiermacherei, sind jedoch in Teilen durch das Werk Aus der Geschichte der Züricher Papiermühle auf dem Werd 1471-1700, das 1963 zum 125. Jubiläum der SIHL - Zürcher Papierfabrik an der Sihl veröffentlicht wurde, überholt. ${ }^{1192}$ In drei quellenreichen und thematisch zugeschnittenen Studien werden erstens die Herstellung des Papiers in der Papiermühle auf dem Werd, zweitens die Geschichte der Liegenschaft und ihrer Besitzer und drittens ein zentrales Zeugnis für die Papierproduktion im frühen 16. Jahrhundert, die Supplikation Christoph Froschauers, beleuchtet. ${ }^{1193}$ Besonders beeindruckend ist hierbei die Auswertung der Bauamtsakten, die einen für diese Zeit einmaligen Einblick in den Bau und die Ausstattung einer Papiermühle geben. Wiederaufgenommen wurden die Befunde dieser Studie unter anderem in Peter Tschudins Schweizer Papiergeschichte. ${ }^{1194}$

Die Geschichte der Papiermühle auf dem Grund und Boden des Klosters Söflingen bei Ulm hat -dies mag der bescheidenen Dauer ihrer Existenz geschuldet sein - bislang nur zwei Bearbeiter gefunden. Im Jahr 1941 berichtete Alfred Schulte von einer Söflinger Papiermühle und führte dazu bereits die drei Dokumente an, die für ihre Existenz bürgen. ${ }^{1195}$ In jüngster Zeit griff Erwin Frauenknecht das Thema wieder auf und lieferte einige neue Einschätzungen zur Interpretation der bereits bei Schulte zitierten Schriftbelege und zur Identität des ersten Söflinger Papiermachers. ${ }^{1196}$

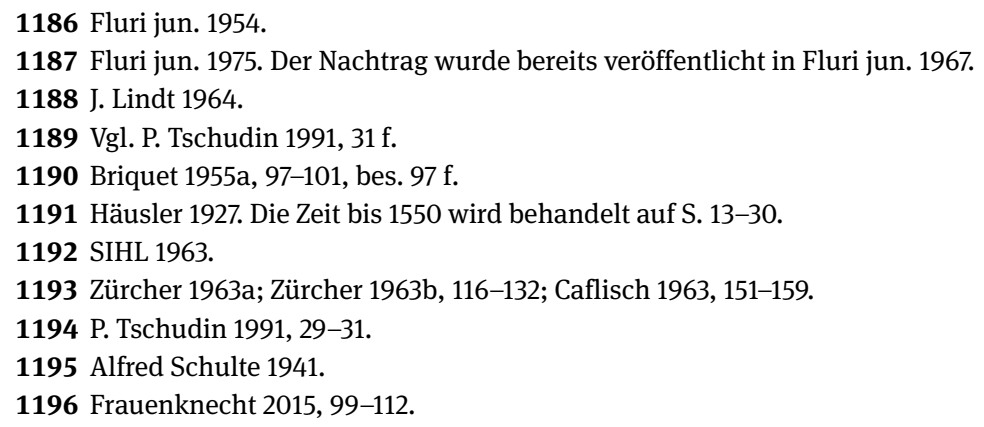


Auch zur ersten Papiermühle in Urach legte Erwin Frauenknecht 2014 und 2015 zwei kleine Studien vor, in denen es ihm gelang, die Herkunft des ersten Uracher Papiermachers zu bestimmen. ${ }^{1197}$ Zudem konnte er neue Erkenntnisse über die ältesten Uracher Wasserzeichen gewinnen. Frauenknechts Beiträge betreffen jedoch nur die Frühzeit der Uracher Papierproduktion, namentlich die Gründung des ersten Werks durch den württembergischen Grafen Eberhard im Bart. Sein Vorgänger Friedrich von Hößle betrachtet in seinen Publikationen die Uracher Papiermacherei über diesen ersten Betrieb hinaus. ${ }^{1198}$ Seine Befunde stellen jedoch vornehmlich eine unkritische Aneinanderreihung von Quellenstellen dar, ohne den Fundort des betreffenden Zeugnisses anzugeben.

Die Anfänge der Reutlinger Papierherstellung wurden ebenfalls zuerst von Friedrich von Hößle beschrieben und schließlich im Jahr 1972 von Lore Sporhan-Krempel auf der Basis der Quellen grundlegend neu bearbeitet. ${ }^{1199}$ Ihr ist der Abdruck der Reutlinger Papiermacherordnung aus dem Jahr $1527 \mathrm{zu}$ verdanken, die als die älteste bekannte Papiermacherordnung des deutschen Raums gilt. ${ }^{1200}$ Die Reutlinger Papiermacherordnung ist zudem - neben anderen Normierungsbestrebungen - Gegenstand der Studie von Christoph Halstrick, der sich mit dem Recht des Papiergewerbes von 1400 bis 1800 auseinandersetzt. ${ }^{1201}$

Eine knappe zusammenhängende Darstellung der Papiermühlengeschichte Ettlingens auf der Grundlage eigener Quellenrecherchen veröffentlichte Gerhard Piccard im Jahr 1951. ${ }^{1202}$ Im Jahr zuvor hatte bereits Lore Sporhan-Krempel auf die Existenz eines Dokuments verwiesen, aus dem hervorgeht, dass die Papiermacherei bereits im Jahr 1461 in Ettlingen etabliert war, und das Gerhard Piccard in seiner Abhandlung wieder aufgreift. ${ }^{1203}$ Gerhard Piccard nimmt auf das Thema der Ettlinger Papiermacherei in seinem Beitrag zu Basler Papierherstellung und Buchdruck erneut Bezug, allerdings mit teilweise anderen Ergebnissen. ${ }^{1204}$ Die Ausführungen von Rüdiger Stenzel zur Ettlinger Papiermühle im Rahmen seiner Stadtgeschichte aus dem Jahr 1985 fußen auf weiteren Quellenrecherchen und bringen teilweise andere, widersprüchliche Befunde im Abgleich mit Piccards Studie. ${ }^{1205}$ Frieder Schmidt hingegen

1197 Frauenknecht 2014; Frauenknecht 2015.

1198 Hößle 1926a, 66-72; Hößle 1939.

1199 Hößle 1926a, 72-75, 78 f.; Sporhan-Krempel 1972b.

1200 Vgl. Sporhan-Krempel 1972b, 1571-1574. Vgl. Halstrick 1990, 29; Zaar-Görgens 2004, 106.

1201 Halstrick 1990.

1202 Piccard 1951.

1203 Sporhan-Krempel 1950, 352.

1204 Piccard 1967, 118-120.

1205 Stenzel 1985, 98-103. 
schließt sich in seinem Überblick über die Papierproduktion in Ettlingen den Ausführungen Piccards an, ohne eigene Archivstudien betrieben zu haben. ${ }^{1206}$

Die Aufnahme einer Papierproduktion in Lörrach Ende des 15. Jahrhunderts wurde bereits von Rudolf Wackernagel vermutet. ${ }^{1207}$ Hans Kälin gelang es schließlich im Rahmen seiner Dissertation zum Basler Papier aus dem Jahr 1974 die Vermutung wahrscheinlich zu machen, dass schon zu Beginn der 1470er-Jahre eine Papiermühle in Lörrach betrieben wurde. ${ }^{1208}$ Kälins Ergebnisse wurden 1983 von Christian Martin Vortisch zusammengefasst und bekräftigt. ${ }^{1209}$ Weitere Publikationen, die summarisch die weitere Entwicklung der Lörracher Papiermacherei behandeln, wurden von Hans Kälin und Peter Tschudin in den 1990er-Jahren vorgelegt. ${ }^{1210}$

Eine Geschichte der Papierherstellung in Gengenbach wurde zuerst von Karl Theodor Weiss geschrieben und in zwei Aufsätzen in den Jahren 1951 und 1952 posthum veröffentlicht. ${ }^{1211}$ Der erste Beitrag betrifft den Untersuchungszeitraum bis 1550 und widmet sich in einer etwas zähen Darstellung den Gengenbacher Wasserzeichen sowie der Frage nach den Besitzern der Papiermühle. Einen zweiten Bearbeiter hat die Papierproduktion zu Gengenbach in Gerhard Piccard gefunden. ${ }^{1212}$ Dieser distanziert sich im Jahr 1963 zunächst von seinem Vorgänger, in dem er unter anderem Weiss' Einschätzung der Quellenlage und seine Wiedergabe von Wasserzeichen kritisierte. ${ }^{1213}$ Trotz des Vorwurfs, Weiss habe einen Großteil der Archivalien übersehen, bietet Gerhard Piccard, zumindest für den Untersuchungszeitraum bis 1550, keine neuen Dokumente. Lediglich die Darbietung des Texts ist konziser, berührt in der chronologischen Darlegung der Mühlengeschichte jedoch dieselben Gesichtspunkte. ${ }^{1214}$ Hinter der Publikation aus dem Jahr 1990 mit dem vielversprechenden Titel Die Papiermühlen in Gengenbach von Edmund Schmitt verbirgt sich ein nicht paginiertes Kompendium aus fotokopierten Quellen zu den Gengenbacher Papierwerken. ${ }^{1215}$ Die beigefügten Transkriptionen sind - nicht nur wortwörtlich, sondern tatsächlich bildlich - durchweg dem Artikel von Gerhard Piccard entnommen und wurden teilweise über den reproduzierten Quellentext fotokopiert. Diese Collage lässt sich vor allem

1206 F. Schmidt 1992. Am Rand sei noch eine halbseitige Notiz zu Ettlinger Papiermachern erwähnt, die weder Neues bringt noch den Erwartungen, die der Titel evoziert, gerecht wird, vgl. Würth 1983, 69.

1207 Wackernagel 1916, Bd. 2.2, 604.

1208 Kälin 1974, 160 f.

1209 Vortisch 1983.

1210 Kälin 1990; P. Tschudin 1996.

1211 K. Th. Weiss 1951; K. Th. Weiss 1952.

1212 Piccard 1963.

1213 Vgl. Piccard 1963, 997-1000.

1214 Eine knappe Zusammenfassung der Kenntnisse zu den Gengenbacher Papiermühlen bietet Junk 1984.

1215 E. Schmitt 1990. 
durch Unübersichtlichkeit charakterisieren, wodurch der Gebrauchswert ziemlich geschmälert wird. Nützlich ist dieses Werk einzig, um einen Eindruck von den Dokumenten zu erhalten, ohne das Gengenbacher Stadtarchiv besuchen zu müssen.

Die Papierproduktion im spätmittelalterlichen Straßburg wurde bereits in der zweiten Hälfte des 19. Jahrhunderts im Rahmen der aufblühenden Straßburger Druckgeschichte thematisiert. Charles Schmidt führt in seinem Werk zu den Bibliotheken und Buchdruckern Straßburgs neben unsicheren Wasserzeichenbelegen für die Jahre 1408 und 1421 bis 1426 schon die erste Straßburger Papiermühle im Rosengarten auf und gibt die auch heute noch gültige Besitzerreihenfolge der städtischen Papiermühlen vor dem Weißturmtor an. ${ }^{1216}$ Ebenfalls für die Geschichte der Buchdrucker interessiert sich Ludwig Schneegans. Er glaubte, in der in einer Urkunde von 1441 erwähnten Mühle von Andreas und Nicolas Heilmann, die in enger geschäftlicher Beziehung mit Johannes Gutenberg standen, die erste Papiermühle der Stadt entdeckt zu haben. ${ }^{1217}$ Hans Heinrich Bockwitz schloss sich gut 80 Jahre später diesem Urteil an. ${ }^{1218}$ Lore Sporhan-Krempel widerlegte diese Annahme im Jahr 1960. ${ }^{1219}$ Neues zu der frühesten Papiermühle im Rosengarten bringt erst François-Joseph Fuchs zwei Jahre später. ${ }^{1220}$ Ihm gelingt es, mehrere Dokumente aus der Zeit zwischen 1445 und 1454 ausfindig zu machen und damit knapp, aber grundlegend und umfassend die Geschichte des ersten Straßburger Werks zu schreiben. Die von Fuchs eingesehenen Urkunden waren Pierre Schmitt, der im Jahr 1960 einen Überblick über die Geschichte der Papiermühlen im Elsass verfasste, offenbar noch völlig unbekannt. ${ }^{1221}$ Er möchte nicht nur die Legende der Heilmannschen Papiermühle aus den Geschichtsbüchern getilgt sehen, sondern negiert auch die Existenz einer Papiermühle im Rosengarten, die von Johann Andreas Silbermann in seiner Stadtgeschichte erwähnt wird. ${ }^{1222}$ Stattdessen listet er die bereits bei Charles Schmidt zu findenden Angaben zu der zweiten Papiermühle vor dem Weißturmtor mit ungenauen Quellenbelegen knapp auf. ${ }^{1223}$

Pierre Schmitt behandelt in seiner Geschichte der elsässischen Papiermühlen in einem kurzen Abschnitt auch die Werke in Cernay und Vieux-Thann. ${ }^{1224}$ Ein weiterer Beitrag zur Papierherstellung in Vieux-Thann stammt ebenfalls aus seiner Feder, während Camille Oberreiner bereits 1926 eine Darstellung der Papiermacherei zu Cernay veröffentlichte, die allerdings erst mit den 1530er-Jahren einsetzt und haupt-

1216 Ch. Schmidt 1882, 38.

1217 Schneegans 1853-1865, 2v. Vgl. auch Schorbach 1932, 70.

1218 Bockwitz 1944.

1219 Sporhan-Krempel 1960.

1220 Fuchs 1962b.

1221 P. Schmitt 1960.

1222 Vgl. P. Schmitt 1960, 41, Anm. 2. Vgl. auch Silbermann 1775, 146.

1223 Vgl. P. Schmitt 1960, 78.

1224 P. Schmitt 1960, 68-70, 79 f. 
sächlich Papiermachernamen auflistet. ${ }^{1225}$ Eine grundlegende Bearbeitung der elsässischen Papiergeschichte im 15. und 16. Jahrhundert steht noch aus.

\subsection{Papiermühlen}

Bei dem notwendigen Rüstzeug des Papiergewerbes handelte es sich - anders als bei einer Vielzahl der Handwerke - um eine Großmaschine, die nicht nur im Erwerb, sondern auch in der Instandhaltung kostenintensiv war. In einem systematischen Zugriff werden im Folgenden daher unterschiedliche Komponenten des Arbeitsorts und Arbeitsmittels Papiermühle beleuchtet. Zunächst werden die Papiermühlen des Untersuchungsraums in ihrer Geschichte bis 1550 kurz vorgestellt. In einem zweiten Schritt wird die Ausstattung einer Papiermühle betrachtet: Wie war eine Werkstatt eingerichtet und was erfahren wir darüber in den Quellen? Drittens rücken die Eigentums- und Besitzverhältnisse in den Blick: Wer hatte das Obereigentum an einer Papiermühle? Wurden die Betriebe in Erbpacht oder nur in Zeitpacht vergeben und $\mathrm{zu}$ welchen Konditionen und Abgaben konnte man das Nutzungsrecht erwerben? Anschließend an dieses Themenfeld stellt sich viertens die Frage nach dem Wert einer Papiermühle, der sich im Kaufpreis, aber auch in den auf der Liegenschaft lastenden Renten ausdrückt. Schließlich werden in einem fünften Kapitel die Rechte und Pflichten behandelt, die mit dem Besitz einer Papiermühle einhergingen. Hier stellen sich Fragen nach den Wasserrechten der Mühlwerke, nach dem Verhältnis, in dem die Papiermacher mit ihren Mühlen zu anderen Mühlenbesitzern standen, und nach Streitigkeiten über die Wassernutzung.

\subsubsection{Zur Geschichte der einzelnen Papiermühlen}

\subsubsection{Basel}

Bereits der Kosmograph Sebastian Münster beschrieb in einer lateinischen Ausgabe der Cosmographia von 1550, dass die Birs die Basler Papiermühlen mit Wasser versorge. ${ }^{1226}$ Der von der Birs abgeleitete Gewerbekanal, der insgesamt zwölf Mühlenlehen antrieb, floss durch das St. Albantal, das zum Grundbesitz des Klosters St. Alban gehörte und innerhalb der Basler Stadtmauern lag. Dort siedelte sich die Papierma-

1225 P. Schmitt 1961-1964; Oberreiner 1926. Vgl. auch Sobek/F. Schmidt 2003, 415 f.

1226 Vgl. Münster 1550b, 404: Et quanquam minor sit opposito fluvio Byrsa, est tamen eo piscosior, pluribusque inseruit officinis, etiamsi Byrsa non modica quoque exhibeat ministeria molitoribus \& papyri confectoribus, qui aliquot insignes habent officinas iuxta hunc fluvium aut potius iuxta rivulum ab eo segregatum \& ad moenia usque maioris Basileae facto alueo deductum. Vgl. Burckhardt-Finsler 1908, 303. 
cherei seit dem Ende der 1440er-Jahre dauerhaft an. Die erste Papiermühle Basels stand jedoch vor den Toren der Stadt am Riehenteich auf der rechten Rheinseite. Ein zweites Mühlwerk, das sich allerdings nur kurz im Besitz eines Papierers befand, lag ebenfalls außerhalb der Stadtmauer am Rümelinbach im Süden Basels. Zu Beginn des 16. Jahrhunderts existierten außerdem noch zwei Papierwerke in Kluben circa 2 Kilometer nördlich vor der Kleinbasler Stadtmauer (vgl. Tab. 10). ${ }^{1227}$

Tab. 10: Basler Papiermühlen bis 1550.

\begin{tabular}{|c|c|c|c|}
\hline & Name der Mühle & spätere Adresse & $\begin{array}{l}\text { als Papiermühle } \\
\text { belegt }\end{array}$ \\
\hline 1. & Allenwindenmühle & heute: Riehenstr. 3 & 1440-vor 1470 \\
\hline 2. & Rümelinbachmühle & --.--- & $1452-1453$ \\
\hline 3. & Rychmühle & heute: St. Albantal 41 & ab 1448 \\
\hline 4. & Zunzigermühle & heute: St. Albantal 39 & ab 1450 \\
\hline 5. & Klingentalmühle & heute: St. Albantal 37 & ab 1453 \\
\hline 6. & Stegreifmühle & heute: St. Albantal 35 & ab 1482 \\
\hline 7. & Hintere Spiegelmühle & $\begin{array}{l}\text { St. Albantal } 31 \\
\text { heute: St. Alban-Rheinweg } 96\end{array}$ & ab $1481 / 84$ \\
\hline 8. & Spisselismühle & $\begin{array}{l}\text { Mühleberg 19/21 } \\
\text { heute: St. Alban-Rheinweg } 52\end{array}$ & $1485-1497$ \\
\hline 9. & neue Papiermühle & $\begin{array}{l}\text { St. Albantal } 23 \\
\text { heute: St. Alban-Rheinweg } 94\end{array}$ & ab 1525 \\
\hline 10. & zwei Papiermühlen zu Kluben & ------ & $1518-1522$ \\
\hline
\end{tabular}

Die erste uns bekannte Basler Papiermühle fand erstmals im Jahr 1440 im Zusammenhang mit einem Wasserrechtsstreit Erwähnung. Die städtische Urkunde vom 22. Mai verkündete den Spruch des Baugerichts der Fünf ${ }^{1228}$ in der Streitsache zwischen dem Ratsherrn und Kaufmann Heinrich Halbysen d. Ä. und den anderen Wassernutzenden und nennt hierbei die Lage und den Namen der Papiermühle. Heinrich Halbysen d. Ä. habe wegen seiner beiden Lehen nemlich der papire mülin genant zu allen winden

1227 Für die Belege vgl. die Anmerkungen in nachfolgendem Text.

1228 Beim Baugericht der Fünf handelte es sich um ein baupolizeiliches Aufsichtsgremium, vgl. Heusler 1860, 185 f.; Wackernagel 1911, Bd. 2.1, 329 f.; Kaufmann 1949, 52-56; Simon-Muscheid 1988, 149-151. 
und der segen do gegen über gelegen vor dem obern tore unser minnren Stat Basel uff dem tiche gegen die anderen Teichanrainer geklagt. ${ }^{1229}$

Die Mühle zu Allenwinden hatte Heinrich Halbysen d. Ä. knapp sieben Jahre zuvor, im Oktober 1433, gekauft, wie sich aus einem Eintrag in die Gerichtsbücher des Kleinbasler Schultheißengerichts ersehen lässt. ${ }^{1230}$ Damals wurde das Gebäude schlicht als muli, Mühle, bezeichnet. Die Geschichte der muli ze Allenwinden, die erstmals 1265 erwähnt wurde, allerdings noch nicht unter ihrem späteren Namen, ${ }^{1231}$ legt den Schluss nahe, dass sie größtenteils als Kornmühle betrieben wurde. Bis circa 1350 wird sie in den Urkunden immer als Mühle zu Allenwinden bezeichnet. ${ }^{1232} \mathrm{Ab}$ der zweiten Hälfte des 14. Jahrhunderts wird zusätzlich zur Allenwindenmühle in mehreren Urkunden ein Hammer erwähnt, der direkt neben der Mühle lag und anscheinend zu der Liegenschaft gehörte. ${ }^{1233}$ Die Existenz eines Hammers in oder bei der Allenwindenmühle belegt auch eine Urkunde vom 21. November 1408, die die Lösung eines Streits zwischen dem Müller Henman Regishein, Betreiber der Mühle zu Allenwinden, und dem Schmied Peter Nüßlin, Besitzer der Schleife auf der anderen Kanalseite,

1229 StABS, St. Urk. 1233 (22.05.1440). Der Inhalt des Streits wird in Kapitel 3.2.5.1, S. 301 behandelt. Vgl. W. Fr. Tschudin 1955, 1; W. Fr. Tschudin 1958, 103; Kälin 1974, 170 f.

1230 StABS, Gerichtsarchiv P 3, 211r (röm. Ziffern) bzw. 200r (arab. Ziffern). Den Kauf der Allenwindenmühle durch Halbysen im Jahr 1433 erwähnen Schweizer 1927, 53; Koelner 1935, 301; W. Fr. Tschudin 1955, 1; W. Fr. Tschudin 1958, 103, und Kälin 1974, 169 f. Gerhard Piccard hingegen schließt sich Traugott Geering und Edwin Wyler an und nennt 1440 als mögliches Jahr der Mühlengründung, um abschließend das Gründungsdatum als irrelevant abzutun, vgl. Piccard 1967, 35 f. Deutlich wird, dass Piccard auf der Basis des schnell gefällten Urteils über den vermeintlichen Dilettantismus Walter Friedrich Tschudins einen wichtigen Beitrag zur Forschung ignorierte, vgl. Piccard 1967, 33 mit Anm. 21; Kälin 1974, 170. Das andere Lehen, die Sägemühle, muss Heinrich Halbysen d. Ä. kurz vor der Beilegung der Wasserrechtsstreitigkeiten erworben haben. Die Fertigungsurkunde ist allerdings erst im August 1440 ausgestellt worden, StABS, St. Urk. 1235 (20.08.1440); Urkundenbuch der Stadt Basel 1902, Bd. 6, 447, Nr. 476. Vgl. Kälin 1974, 170 f., eine Transkription der Urkunde auf 338-340. Die Streichung des Protokolltexts erklärt Kälin damit, dass der Rechtsinhalt nach dem Verkauf der Mühle im Jahr 1470 obsolet geworden sei. Wahrscheinlicher ist jedoch, dass der Eintrag nach Ausstellung des Rechtstitels, also der Fertigungsurkunde, als erledigt gestrichen wurde. Vgl. die Praxis in den Fertigungsbüchern des Großbasler Schultheißengerichts in Hagemann 1987, 31.

1231 Urkundenbuch der Stadt Basel 1890, Bd. 1, 334 f., Nr. 461. Vgl. Schweizer 1927, 6.

1232 StABS, St. Urk. 96 (17.05.1294), Urkundenbuch der Stadt Basel 1896, Bd. 3, 93 f., Nr. 168, auch Kälin 1974, 331 f.; St. Urk. 114 (10.11.1304), Kälin 1974, 333; St. Urk. 119 (13.08.1308); St. Urk. 124 (06.01.1311); St. Urk. 127 (09.02.1311); St. Urk. 130 (31.03.1311); St. Urk. 131 (31.03.1311); St. Urk. 279 (01.04.1350), Urkundenbuch der Stadt Basel 1899, Bd. 4, 174, Nr. 187.

1233 StABS, St. Urk. 287 (20.06.1352); St. Urk. 294 (19.01.1355); St. Urk. 332 (12.12.1360); St. Urk. 333 (16.12.1360); St. Urk. 346 (29.04.1364); St. Urk. 351 (10.07.1365); St. Urk. 392 (04.09.1370). 
verhandelt. ${ }^{1234}$ In diesem Schriftstück berichtet Henman Regishein, dass die Mühle zu Allenwinden seit jeher vier Rädern habe, von denen eines einen Hammer antreibe. ${ }^{1235}$

Im Jahr 1414 und 1417 lesen wir von einer blüwlaten, die in der Allenwindenmühle lag. ${ }^{1236}$ Als blüwlaten, auch Blöwi, Bluwe, Bluwenmühle oder Pleuel, wird meist eine Hanf- oder Flachsstampfe bezeichnet, die mit einem oder mehreren durch Wasserkraft betriebenen Stößeln ${ }^{1237}$ oder Kopfhämmern ${ }^{1238}$ die Hanf- oder Flachsstängel aufbricht - eine Arbeit, die ansonsten manuell mit einem Holzschlegel, einem Bleuel, geschehen musste. ${ }^{1239}$ Die Bedeutung des Worts blüwlaten verweist somit auf das Wort schlagen und ist im heutigen Sprachgebrauch auch noch mit den Begriffen durch-, ver- und einbläuen vertreten. Unter dem Lemma Bleuelmüle führt das Grimmsche Wörterbuch folgenden Beleg an: mola qua linum frangitur, ${ }^{1240}$ das heißt eine Mühle oder ein Mühlstein, die beziehungsweise der Flachs bricht. ${ }^{1241}$ Es ist daher zu vermuten, dass in der Allenwindenmühle eine Stampfe betrieben wurde, mit der Flachs oder Hanf bearbeitet wurde. Löst man das Wort blüwlaten von dem soeben erläuterten

1234 StABS, St. Urk. 877 (21.11.1408). Vgl. Kälin 1974, 174, eine Transkription der Urkunde ebd., 334336.

1235 StABS, St. Urk. 877 (21.11.1408): ...do zů aber Henman Regishein mit sim fúrsprecher antwurtet und sprach, do werent vor alten ziten alwegent fier reder an siner mule gesin und der tribe eis einen hamer... Vgl. Kälin 1974, 334.

1236 StABS, St. Urk. 926 (28.03.1414); St. Urk. 949 (07.06.1417). Vgl. W. Fr. Tschudin 1955, 2; W. Fr. Tschudin 1958, 104.

1237 Vgl. Fr. W. Weber 1981, 219-221; Hellwig 2007, 165.

1238 Vgl. die Stellungnahme Hermann Gleisbergs in Piccard 1969, 15.

1239 Vgl. Piccard 1969, 14 f. Vgl. auch A. J. Lindt 1818, VI. Abtheilung; Fr. W. Weber 1981, $219-221$. Nach Gerhard Piccard liegt der Unterschied zwischen einer Mühle und einer Blöwi in ihrer Größe und in der Anzahl der Wasserräder, wobei es sich bei einer Blöwi immer um einen kleinen, einrädrigen Betrieb handle, vgl. Piccard 1967, 79-81. Theodor Gerardy widerspricht dieser Definition und betont, dass eine Unterscheidung anhand ihrer Funktion, nicht anhand ihrer Größe zu treffen sei. Als Blöwi werde ein Stampfwerk bezeichnet, das Hanf oder Flachs breche, vgl. Gerardy 1969, 9 f. Vgl. auch Kälin 1974, 174. Die Abbildung einer Flachsstampfe mit Stößeln findet sich in W. Fr. Tschudin 1956, 28, Abb. 8, und P. Tschudin 1975, 7. Zum Bleuel vgl. Grimm/Grimm 1860, Bd. 2, 111.

1240 Vgl. Grimm/Grimm 1860, Bd. 2, 111. Vgl. auch Gerardy 1969, 9.

1241 Unter mola wird im Allgemeinen eher der Mühlstein als die Mühle im Sinne des Gebäudes $\mathrm{zu}$ verstehen sein, womit eine weitere begriffliche Unschärfe ins Spiel kommt. Neben Flachs- und Hanfstampfen, die nach dem Prinzip der durch eine Nockenwelle angetriebenen Kopfhämmer oder Stößel funktionierten, existierten auch Flachs- und Hanfreiben, die die Pflanzenstängel in einer Art Kollergang zerrieben und auf diese Weise die verholzten Teile aufbrachen und vom Bast lösten, vgl. A. J. Lindt, 1818, VI. Abtheilung; Fr. W. Weber 1981, 216-225; Hellwig 2007, 165 f. Ob eine Hanfreibe auch als Bleuelmühle bezeichnet werden konnte, ist ungewiss. Bedenkt man indessen die Bedeutung des Worts Bleuel, so wäre die begriffliche Gleichsetzung von Reibe und Hammer äußerst ungenau. Friedrich Wilhelm Weber verweist darauf, dass in den von ihm untersuchten Quellen Hanfstampfen immer von Hanfreiben unterschieden wurden. Er kennt die mittelalterliche Bezeichnung bliuwe nur für Hanfstampfen, vgl. Fr. W. Weber 1981, 219 f. Vgl. auch Anm. 431. 
konkreten Zweck, so ist eventuell auch eine Kornstampfe denkbar, die beispielsweise dem Enthülsen von Getreide diente. ${ }^{1242}$

Rund zehn Jahre später, 1426, wurde die gesamte Allenwindenmühle als Blüweln bezeichnet. ${ }^{1243}$ Hans Kälin geht daher davon aus, dass die Mühle zu Allenwinden eine Bluwenmühle war, die von zwei oder drei Rädern angetrieben wurde und deren viertes Rad einen Hammer bewegte. ${ }^{1244}$ Nach einer erneuten Durchsicht der Zeugnisse spricht jedoch vieles dafür, dass es sich bei der Allenwindenmühle um eine Kornmühle handelte, die Getreide klassisch mit einem Mühlstein zu Mehl verarbeitete und mit einem Hammer - gewissermaßen im ,Nebenbetrieb“ - entweder gewerbefern eine Flachsstampfe oder aber gewerbenah eine Kornstampfe betrieb. 1408 gehört die Mühle zu Allenwinden dem bereits erwähnten Henman Regishein, der in der Urkunde vom 21. November ausdrücklich der muller genannt wird. ${ }^{1245}$ Da in der Urkunde des Weiteren nur für ein Rad explizit die Nutzungsart genannt wird, nämlich der Betrieb eines Hammers, kann man vermuten, dass die anderen Räder der klassischen Funktion einer Mühle dienten: dem Betrieb von Mahlsteinen. Zwar können sich die Funktionen auch mit dem Besitzerwechsel geändert haben, sodass die Allenwindenmühle im Jahr 1426 nur noch als Bluwenmühle diente. Bemerkenswert ist jedoch, dass die Liegenschaft 1433 beim Kauf durch Heinrich Halbysen d. Ä. bereits wieder ausschließlich als Mühle bezeichnet wurde. ${ }^{1246}$

1242 Vgl. den Eintrag unter dem Lemma Gerstenstampfe in Grimm/Grimm 1897, Bd. 4.1.2, 3740.

1243 StABS, St. Urk. 1051 (14.10.1426).

1244 Vgl. Kälin 1974, 174 f. Auch Walter Friedrich Tschudin geht davon aus, dass es sich bei der Allenwindenmühle um eine Hanfstampfe handelte, vgl. W. Fr. Tschudin 1955, 2; W. Fr. Tschudin 1958, 104. Gerhard Piccard ignoriert auch diese Ausführungen Tschudins.

1245 Warum Hans Kälin die eindeutige Berufsbezeichnung Müller in Anführungszeichen setzt, ist nicht nachvollziehbar, vgl. Kälin 1974, 174. Es gibt keinen stichhaltigen Beweis, dass es sich bei Henman Regishein nicht um einen Müller handelte. Ansonsten müsste man in Analogie auch die Berufsbezeichnung smid, mit der der Besitzer der Schleife, Peter Nüßlin, bedacht wird, in Zweifel ziehen.

1246 StABS, Gerichtsarchiv P 3, 211r (röm. Ziffern) bzw. 200r (arab. Ziffern). Die 1969 in der Zeitschrift Papiergeschichte ausgetragene Diskussion zwischen Theodor Gerardy und Gerhard Piccard um den Begriff der Bluwe enthielt als einen der strittigen Aspekte die Frage, ob der Terminus Mühle im Mittelalter immer auf eine Kornmühle schließen lasse. Während Gerardy diese Frage mit einem nicht sehr beweiskräftigen Verweis auf Lore Sporhan-Krempel bejaht, verneint Piccard sie entschieden und führt hierzu Belege für zwei unterschiedliche Fälle an. Im ersten Fall tragen Mühlen trotz eines Nutzungswandels über Jahrzehnte und Jahrhunderte den gleichen Eigennamen, der das Wort Mühle enthält. Als Beispiel nennt Piccard hier die sogenannte Hanrey-Mühle in Augsburg, die zeitweise eine Sägemühle war. Exemplarisch würden sich hier auch die Basler Papiermühlen anführen lassen, die ihre Eigennamen - zum Beispiel Rychmühle, Zunzigermühle - mit der Änderung der Betriebsart ebenfalls nicht ablegen. Diese Argumentation greift jedoch ebenfalls zu kurz. Zwar ist es richtig, dass die Eigennamen von Mühlen trotz häufigen Besitzer- und Nutzungswechsels erstaunlich konstant bleiben. In den meisten Fällen wissen wir jedoch, um welche Art von Betrieb es sich handelte, da die Nennung des Namens mit der Nennung der Mühlenart einhergeht. Der zweite von Piccard ins Feld geführte Beweis ist die Nennung einer „Mühle mit einer Säge“ oder einer „Mühle mit einer Bluwe“. Auch 
In den Jahren zwischen 1433 und 1440, also zwischen dem Erwerb der Allenwindenmühle und dem Wasserrechtsstreit mit den anderen Teichanrainern, ließ Heinrich Halbysen d. Ä. das Mühlwerk in eine Papiermühle umwandeln. Wahrscheinlich ist, dass er sie bereits zu diesem Zweck gekauft hatte und daher unmittelbar nach dem Erwerb mit den Umbaumaßnahmen begann. Wer diese Arbeiten, die einiges an Expertise im Mühlenbau und in der Papierherstellung erforderte, für ihn ausführte, ist nicht bekannt. Über einen Mühlbaumeister oder einen Papiermacher erfahren wir nichts.

Die Lage der Mühle zu Allenwinden an dem wasserreichen Kleinbasler Gewerbeteich, ${ }^{1247}$ ihre mit vier Mühlrädern relativ große Kapazität, ihr Vorrecht auf die Nutzung eines Großteils des Wassers ${ }^{1248}$ sowie die aufgrund des erwähnten Hammers zu vermutende Existenz eines Wellbaums machten das Gebäude zu einem idealen Objekt für die Einrichtung eines Papierbetriebs. Der Hauptarm des Kleinbasler Teichs speiste die Allenwindenmühle auf dem rechten Ufer und die Säge auf der gegenüberliegenden Seite, die Heinrich Halbysen d. Ä. im Jahr 1440 dazukaufte, vermutlich um seinen Papierbetrieb zu vergrößern. ${ }^{1249}$ Außerhalb der Stadtmauern arbeiteten neben diesen beiden Mühlen noch die metallverarbeitenden Hammerwerke des Klosters St. Clara. Alle anderen Mühlwerke lagen innerhalb der Kleinbasler Stadtmauer. Einen Schwerpunkt bildeten zum einen die Kornmühlen mit circa elf Betrieben, zum anderen die dem Metallgewerbe zuzurechnenden Schleifen, die Schweizer zwischen 1400 und 1440 auf 14 beziffert. ${ }^{1250}$ Eine Ölmühle und zwei Sägen ergänzen das Bild der Mühlenlandschaft am Kleinbasler Gewerbeteich zur Zeit der ersten Basler Papiermühle um 1440.

Nach den genannten zwei Urkunden aus dem Jahr 1440 wird es still um die Allenwindenmühle und die darin betriebene Papiermacherei. Die nächste - und auch letzte - bislang bekannte Nachricht von der Papiermühle vor dem Riehentor stammt

dieser Beweis ist nicht stichhaltig, da er nicht aussagt, dass die Mühle eine Säge respektive eine Bluwe ist, sondern nur, dass die Mühle auch eine Säge beziehungsweise Bluwe beherbergt. Vielleicht existierte parallel zu der Säge eine Kornmühle, sodass zwei Funktionen in einem Betrieb vereint waren. Offensichtlich ist, dass jede andere als die klassische Funktion einer Mühle erwähnenswert war. Das ist im Endeffekt auch der Beweis, den Piccard gegen seinen Willen erbringt, da er keine Beweiskette liefern kann, in der ein Mühlwerk, das nicht als Kornmühle genutzt wurde, nur und ausschließlich als Mühle bezeichnet wird. Diese Beweisführung wäre ohnehin nur durch eine reiche Parallelüberlieferung möglich. Vgl. Gerardy 1969, 9; Piccard 1969, $11 \mathrm{f}$.

1247 Zum Kleinbasler Gewerbeteich vgl. Schweizer 1927; Schweizer 1928; Grüninger 1892; Gruner 1978, 35-41; Lutz 2004, 29-56. Zur Kleinbasel vgl. Wackernagel 1892.

1248 Vgl. Kapitel 3.2.5.1, S. 300 f.

1249 StABS, St. Urk. 1235 (20.08.1440). Vgl. Urkundenbuch der Stadt Basel 1902, Bd. 6, 447, Nr. 476. Vgl. Schweizer 1927, 56; Kälin 1974, 173. Eine kartographische Abbildung des Kleinbasler Gewerbeteichs mit seinen Armen und den daran gelegenen Mühlen bietet Schweizer 1928 mit ausfaltbarer Karte im Anhang.

1250 Vgl. Schweizer 1927, 25-56. 
aus dem Jahr 1470. Im November dieses Jahres verkauft Heinrich Halbysen d. J., Sohn des gleichnamigen Vaters, an die Stadt Basel die zwey lehen so gegen einander uber gelegen vorziten eins ein papyr müly und das ander ein Segen gewesen sind. ${ }^{1251}$ Der Zusatz vorziten deuten darauf hin, dass in der Allenwindenmühle schon länger kein Papier mehr gefertigt wurde. Wann die Produktion eingestellt wurde, ist nicht zu eruieren. Gerhard Piccard stellte die These auf, dass der Kleinbasler Betrieb aufgrund seiner geringen Größe und unzureichender Wasserkraft nicht rentabel gewesen sei. Die Verlegung der Werke vom Riehenteich an den St. Albanteich durch Heinrich Halbysen d. Ä. Ende der 1440er-Jahre sei daher die notwendige Maßnahme zur Aufrechterhaltung der Papiermacherei gewesen. ${ }^{1252}$ Dieser mit Nachdruck vorgetragenen Annahme widerspricht Hans Kälin und führt dazu unter anderem die Urkunde vom 21. November 1408 an, die für die Mühle zu Allenwinden vier Räder dokumentiert. Sie war folglich kein kleines einrädriges Werk, wie Piccard annahm. Auch die These der mangelnden Wasserkraft kann Kälin überzeugend entkräften: Bei einer Energiespeisung von mehr als 20 Mühlen, die sich am Kleinbasler Teich befanden, ist davon auszugehen, dass ausreichend Wasserkraft zum Betrieb der Werke vorhanden war. Zudem war der Besitzer der Allenwindenmühle in der besonderen Position, das oberste wasserbetriebene Werk am regulären Flusslauf des Riehenteichs sein Eigen zu nennen, sodass bei Wassermangel der davon abgeleitete Kanal, krummer Teich genannt, geschlossen und alles Wasser zunächst auf die Mühlräder zu Allenwinden geleitet wurde. ${ }^{1253}$ Eine zu geringe Energieversorgung konnte somit nicht der Grund für die Einrichtung weiterer Papiermühlen im St. Albantal sein.

Plausibel erscheint hingegen die von Hans Kälin vorgetragene Vermutung, dass die Papiermühle vor den Toren Kleinbasels während der Fehde mit den vorderösterreichischen Adligen von Verwüstung bedroht war. ${ }^{1254}$ Im Jahr 1446 zerstörten feindliche Truppen das Wehr und den Teichlauf, sodass die Wasserversorgung der zahlreichen Mühlen, darunter auch die Mühle zu Allenwinden, nicht mehr gewährleistet war und die Räder stillstanden. ${ }^{1255}$ Ob die sich außerhalb der schützenden Stadtmauern befindlichen Mühlwerke ebenfalls devastiert oder gar gebrandschatzt wurden, wie Kälin annimmt, ist nicht zu belegen. ${ }^{1256}$ Erfahrung mit marodierenden Söldnern sammelte Heinrich Halbysen d. Ä. jedoch im Jahr 1449, als sein Meierhof bei Schön-

1251 StABS, St. Urk. 1895 (05.11.1470). Vgl. Schweizer 1927, 56; W. Fr. Tschudin 1955, 1; W. Fr. Tschudin 1958, 103; Kälin 1974, 152, 176 mit Tab. 17.

1252 Vgl. Piccard 1967, 36 f., 41, 44.

1253 Vgl. Schweizer 1927, 13, 23; Kälin 1974, 172; Lutz 2004, 52 f. Vgl. auch Kapitel 3.2.5.1, S. 300.

1254 Vgl. Kälin 1974, 173. Zum Großen Adelskrieg, der im Jahr 1449 mit der Breisacher Richtung beendet wurde, vgl. Wackernagel 1907, Bd. 1, 572-605; Heusler 1918, 56-62; Gilomen 1980, 1510; Berner/ Sieber-Lehmann/Wichers 2008, $58 \mathrm{f}$.

1255 Erhard von Appenwiler 1890, 273. Vgl. Schweizer 1927, 65; Kälin 1974, 173.

1256 Vgl. Kälin 1974, 173. 
buch niedergebrannt wurde. ${ }^{1257}$ Für eine Zerstörung der Allenwindenmühle spricht die genannte Verkaufsurkunde von 1470: Das eine Lehen war vor Zeiten eine Papiermühle und wird nun auch nicht mehr als Mühle bezeichnet. Unterstützt wird diese Vermutung durch eine Urkunde aus dem Jahr 1472, in der ein Zins von dem Lehen zu Allenwinden mit Wasserfall und Garten verkauft wurde, ohne dass die Existenz eines Mühlwerks auf diesem Lehen thematisiert wird. ${ }^{1258}$ Anscheinend wurde jedoch spätestens zu Beginn des 16. Jahrhunderts wieder ein Mühlwerk eingerichtet und als Säge betrieben. ${ }^{1259}$ Die Betriebsdauer der Papiermühle zu Allenwinden ist folglich ungewiss. Wahrscheinlich nahm sie kurz nach 1433 die Produktion auf, musste sie jedoch vermutlich bereits Ende der 1440er-Jahre wieder einstellen oder doch zumindest aufgrund des zerstörten Wehrs unterbrechen.

Bevor die Papiermühlen Heinrich Halbysens d. Ä. im St. Albantal behandelt werden, soll noch eine weitere mögliche Papiermühle, die sogenannte Rümelinbachmühle, außerhalb der Stadtmauern betrachtet werden. Der zweite große Gewerbekanal Basels, der sogenannte Rümelinbach, auch oberer Birsig, kleiner Birsig oder Steinenbach genannt, lag im Süden der Stadt. Er wurde in Binningen vom Birsig abgeleitet und floss parallel $\mathrm{zu}$ ihm durch die Steinenvorstadt bis zum Basler Marktplatz. Dort wurde er wieder mit dem Birsig vereint. Die frühste Erwähnung des Rümelinbachs ist auf das Jahr $1280 \mathrm{zu}$ datieren, der Gewerbekanal existierte jedoch schon vor diesem Datum. ${ }^{1260} \mathrm{Zu}$ vermuten ist, dass er bereits im 12. oder frühen 13. Jahrhundert zur gewerblichen Nutzung ausgebaut wurde. Zu Beginn des 15. Jahrhunderts versorgte der Wasserlauf unterschiedliche Mühlwerke mit Energie, darunter Mühlen, Stampfen, Walken, Ölstampfen und metallverarbeitende Betriebe. ${ }^{1261}$ Um die Mitte des 15. Jahrhunderts lagen innerhalb der Stadtmauer die Walke der Grautücher, eine Stampfmühle, zwei Kornmühlen, eine Ölstampfe und eine Schleife. ${ }^{1262}$ Anders als der Kleinbasler Gewerbekanal, der auffällig viele Kornmühlen und metallverarbeitende Betriebe speiste, wies der Rümelinbach keine starke Konzentration eines einzelnen Gewerbezweigs auf. Auch betrieb er deutlich weniger Mühlwerke. Für die Wolltuchproduktion der Stadt dürfte er allerdings aufgrund der Walke der Grautücher von großer Bedeutung gewesen sein. ${ }^{1263}$

Außerhalb der Stadtmauer nutzen ebenfalls Mühlwerke das Wasser des Rümelinbachs. Auf der Au vor dem Steinentor stand unter anderem eine Bluwenmühle,

1257 Vgl. Wackernagel 1907, Bd. 1, 597; Kälin 1974, 146, 173.

1258 StABS, St. Urk. 1924 (01.02.1472). Vgl. Urkundenbuch der Stadt Basel 1901, Bd. 8, 327 f., Nr. 417. Auch Eduard Schweizer interpretiert diese Urkunde dahingehend, dass 1472 die Mühle zu Allenwinden nicht mehr bestand, vgl. Schweizer 1927, 56.

1259 Vgl. Schweizer 1927, 56.

1260 Vgl. Schweizer 1921, 24.

1261 StABS, Ratsbücher A 1, 74. Vgl. Schweizer 1921, 27.

1262 Vgl. Schweizer 1921, 27-35.

1263 Vgl. Schweizer 1921, 27-30. 
die der Papiermacher Anton Gallician mit seiner Ehefrau Adelheid Tschan im März 1452 erwarb. ${ }^{1264}$ Ein Jahr später, im März 1453, verkaufte er das Mühlwerk, hier Blöwi genannt, bereits wieder an Peter Hammerschmid. ${ }^{1265}$ Da das Mühlwerk beide Male als Bluwenmühle bezeichnet wird, ist davon auszugehen, dass es sich in diesem Fall tatsächlich ausschließlich um eine Hanfstampfe handelte. ${ }^{1266}$ Ob Anton Gallician in diesem einen Jahr die Hanfstampfe zu einer Papiermühle umbaute, bleibt in Hinblick auf die durchgängige Bezeichnung als Bluwenmühle fraglich. Wenn die Mühle am Rümelinbach überhaupt zu einer Papierwerkstatt umgewandelt wurde, dann wurde in ihr weniger als ein Jahr lang Papier geschöpft. ${ }^{1267}$ Interessant ist, dass Anton Gallician parallel zum Verkauf der Bluwenmühle vor dem Steinentor den Kauf einer Hammerschmiede im St. Albantal tätigte. Vorbesitzer dieser Hammerschmiede war kein anderer als Peter Hammerschmid, sodass Kauf und Verkauf der beiden Mühlwerke an ein Tauschgeschäft erinnern. ${ }^{1268}$ Die Frage, warum Anton Gallician die Klingentalmühle im St. Albantal vorzog, erklärt Gerhard Piccard mit der mangelnden Größe des Betriebs am Rümelinbach, der durch sein einzelnes Wasserrad nicht genügend Kapazitäten hatte, um rentabel Papier herzustellen. ${ }^{1269}$ Denkbar sind jedoch auch weitere Gründe, so zum Beispiel die durch die Papiermühlen von Heinrich Halbysen d. Ä. bereits vorhandene Infrastruktur im St. Albantal oder der Wunsch, den Betrieb inner-

1264 StABS, Gerichtsarchiv B 6, 123 f. Bereits Traugott Geering und Rudolf Wackernagel erwähnen Anton Gallician als Besitzers des Mühlwerks, vgl. Geering 1886, 314; Wackernagel 1911, Bd. 2.1, 272 f. Den betreffenden Beleg nennt erstmals Kazmeier 1955, 16. Vgl. auch P. Tschudin 1956, 118; P. Tschudin 1957, 83; Piccard 1967, 76 f., 79-82; Kälin 1974, 155 f.; P. Tschudin 1984b, 18. Dass es sich bei Anthonien vilociano de casselis um Anton Gallician handelt, wird durch den ein Jahr darauf erfolgten Verkauf der Liegenschaft deutlich. Hier wird der Familienname Antons angegeben. StABS, Zunftarchive, Gerbern Urk. 14 (21.03.1453): Anthoni Gallitziani de Cassellis der papirmacher ze Basel. Während August Wilhelm Kazmeier den Zusatz vilociano als eine falsche Wiedergabe des Familiennamens auffasst, interpretiert ihn Hans Kälin als Bezeichnung für Dorfbewohner, also aus dem Dorf Caselle, vgl. Kazmeier 1955, 16; Kälin 1974, 155 f., 267 mit Anm. 73.

1265 Vgl. das Fertigungsprotokoll in StABS, Gerichtsarchiv B 6, 171 f., und die ausgefertigte Urkunde in StABS, Zunftarchive, Gerbern Urk. 14 (21.03.1453). Vgl. Schweizer 1921, 36; Kazmeier 1955, 16-18; Piccard 1967, 76 f., 79-82; Kälin 1974, 156.

1266 Schweizer und Kälin nennen das Mühlwerk Hanfreibe, womit wieder die Frage nach der Verwendung des Worts Bluwenmühle zu stellen wäre, vgl. Schweizer 1927, 56; Kälin 1974, 156. Gerhard Piccard schließt aus der Bezeichnung des Werks als Bluwenmühle, dass es sich um einen kleinen, einrädrigen Betrieb handelte, vgl. Piccard 1967, 81. Vgl. auch Anm. 1239, 1241.

1267 Während Walter Friedrich Tschudin und Hans Kälin davon ausgehen, dass die Mühle in eine Papierwerkstatt umgewandelt wurde, hält Peter Tschudin einen Umbau für unwahrscheinlich, vgl. W. Fr. Tschudin 1956, 27; Kälin 1974, 154; P. Tschudin 1957, 84 f. Gerhard Piccard betont, dass bis zur Aufnahme der Produktion vermutlich mindestens drei Monate vergingen, in denen das Werk umgerüstet und die erste Fuhre Lumpen durch Sortieren, Faulen und Stampfen aufbereitet werden musste. Somit verblieben höchstens neun Monate Produktionszeit, vgl. Piccard 1967, 82-85.

1268 Vgl. Kazmeier 1955, 16 f.; Piccard 1967, 77.

1269 Vgl. Piccard 1967, 81. 
halb der schützenden Stadtmauern zu wissen. Das erste Papier produzierte Anton Gallician offenbar noch im selben Jahr 1453, wie ein Eintrag aus dem Pfundzollbuch vermuten lässt ${ }^{1270}$

Die beiden erwähnten Papiermühlenbesitzer, der Kaufmann Heinrich Halbysen d. Ä. und der Papiermacher Anton Gallician, verlegten also ihre Betriebe - nach längerer oder kürzerer Produktionszeit - an den Gewerbekanal des St. Albantals. Das St. Albantal lag im Siedlungsgebiet der St. Albanvorstadt und war damit der östlichste Teil der Großbasler Altstadt. ${ }^{1271}$ Vor dem Erdbeben im Jahr 1356 befanden sich Tal und Vorstadt noch außerhalb der Stadtmauer, wurden danach aber in den Mauerring integriert. Begrenzt wurde das St. Albantal im Norden durch den Rhein und im Osten durch einen Abschnitt des Mauerrings, die sogenannte Letzimauer. Im Süden und Westen wurde das Tal durch Steilhänge abgeschlossen. Das St. Albantal war nicht sehr dicht bebaut: Neben der Klosteranlage St. Alban prägten vor allem die an den beiden Teichen versammelten Mühlwerke sowie eine gegen den Rhein gelegene Häuserreihe das Bild des Dalbelochs, wie das St. Albantal im Volksmund genannt wurde. ${ }^{1272}$ In den Basler Archivdokumenten des 15. Jahrhunderts lautet die Bezeichnung für das St. Albantal häufig in den mülinen. ${ }^{1273}$ Hier tritt die Bedeutung der Mühlen für diesen Ortsteil klar zutage. Eingerichtet wurde dieser Mühlbezirk vom 1083 durch Bischof Burkhard von Fenis gegründete Kloster St. Alban, das innerhalb seiner engeren Grundherrschaft die Möglichkeit zur Versorgung mit Mehl schaffen wollte. Bereits für das Jahr 1154 werden die ersten Kornmühlen im St. Albantal erwähnt. ${ }^{1274}$ Betrieben wurden die Mühlen durch zwei Gewerbekanäle, den hinteren und den vorderen Teich, die durch einen im 12. Jahrhundert von einem nahen Seitenarm der Birs abgeleiteten Kanal gespeist wurden. An jedem Gewerbeteich lagen bereits seit 1284 paarweise angeordnet jeweils sechs Mühlgebäude (vgl. Abb. 14 u. 15). Diese Lehen waren Eigentum des Klosters und wurden entweder in einer Art Nutzungsrecht oder in Erbpacht an Müller oder andere Gewerbetreibende vergeben. ${ }^{1275}$

1270 Vgl. P. Tschudin 2000, 2659 f.; Kluge 2014, 20.

1271 Zum St. Albantal vgl. Fechter 1856, 101-105; Schweizer 1923; Schweizer 1924; Kaufmann 1949, 28 f.; Staehelin 1969, 97 f.; Reinhardt 1975; Baur/Nagel 2009.

1272 Vgl. Reinhardt 1975, 16, 32 f.; Baur/Nagel 2009, 2 f. Die Bezeichnung im loch ist unter anderem für das Jahr 1494 bezeugt, StABS, Klosterarchiv, St. Alban, Urk. 485 (04.11.1494): inn den mülinenn zu Sannt Alban im loch. Auch im Markzahlsteuerbuch von 1453/54 trifft man auf die Ortsbezeichnung im loch, allerdings ist nicht sicher, worauf sich diese Benennung bezieht, vgl. Anm. 1279.

1273 So in den Basler Steuerlisten, den Fertigungsbüchern des Schultheißengerichts sowie den Urbaren des Klosters St. Alban, vgl. beispielsweise StABS, Steuern B 12, 13; B 19, Markzahlsteuer 1475/76, 26r; B 19, Schillingsteuer 1475/76, 21r-22r; Gerichtsarchiv B 6, 171; B 12, 40r; B 22, 327v; Klosterarchiv, St. Alban H, 2.

1274 Vgl. Schweizer 1923, 5-9. Schweizer widerlegt in diesem Textabschnitt die Vermutung früherer Autoren, dass bereits zu Beginn des 12. Jahrhunderts Mühlen am St. Albanteich betrieben wurden.

1275 Vgl. Kapitel 3.2.3.1. Vgl. auch Reinhardt 1975, 15; Baur/Nagel 2009, 4 f. Das Kloster St. Alban übte innerhalb seiner engeren Grundherrschaft eine eigene Gerichtsbarkeit aus, die im Laufe des 15. Jahr- 
Im Zuge der Reformation ging die Grundherrschaft 1538 unverändert an die Stadt Basel über. ${ }^{1276}$

Zur Grundherrschaft des St. Albanklosters gehörteneben dem St. Albantal auch die restliche Vorstadt St. Alban, deren Grenzen sich mit den heutigen Straßen St. Albanberg, St. Albantor, St. Alban-Anlage und Dufourstraße beschreiben lassen. ${ }^{1277}$ In der St. Alban-Registratur H, die den Stand der Jahre zwischen 1502 und 1505 wiedergibt, werden zu den abgabepflichtigen Liegenschaften der Albanvorstadt diejenigen in den mülinen, uff Sant Alben berg und in der maltzgassen gezählt. ${ }^{1278}$ Die 1453/54 begonnene Steuerliste für die Albanvorstadt nennt hingegen als Unterteilung des Bezirks die Abschnitte im loch sowie vor dem tuichen hus und Alban Mülinen. ${ }^{1279}$ Anhand

hunderts jedoch zunehmend an die betreffenden Institutionen der Stadt Basel überging, vgl. Gilomen 1977, 94-111; Hagemann 1987, 10 mit Anm. 53, 16 mit Anm. 97.

1276 Vgl. Schweizer 1924, 87 f.; Reinhardt 1975, 15.

1277 Vgl. Füglister 1981, 58. Zur Vorstadt St. Alban vgl. auch Fechter 1856, 101-106; Kaufmann 1949, 28 f.; Staehelin 1969, 97 f.

1278 StABS, Klosterarchiv, St. Alban H, 2, 14, 29. Kälin bezeichnet diese Registratur des St. Albanklosters als „eine recht unzuverlässige Quelle“, vgl. Kälin 1974, 226 mit Anm. 82, 269 mit Anm. 85, 278 mit Anm. 168. Dieser Eindruck entsteht dadurch, dass die Eigendatierung der Quelle auf das Jahr 1486 nicht mit den anderweitig datierbaren Angaben von Hausbesitzern und Zinsgebern übereinstimmt, wie Kälin richtig bemerkt. Nach Hans-Jörg Gilomen ist der eigentliche Zeitraum der Niederschrift zwischen 1502 und 1505 anzusetzen. Neben dem falschen Datum gibt nämlich das Vorwort der Registratur an, dass Christoph von Utenheim, Bischof von Basel, den Auftrag zur Erneuerung des Zinsbuchs erteilte und dass der Schaffner des Klosters St. Alban, Lienhart Mentel, die Niederschrift besorgte. Diese beiden Personen waren 1486 jedoch noch nicht im Amt. Christoph von Utenheim wurde erst 1502 zum Basler Bischof gewählt, Lienhart Mentel ein Jahr zuvor, 1501, zum Schaffner von St. Alban bestellt. Zudem basiert die Registratur H für die Liegenschaften außerhalb Basels auf dem Urbar des Klosters mit der heutigen Signatur J, das erst 1489 verfasst wurde. Gilomen vermutet, dass für die Aufstellung der zinspflichtigen Liegenschaften in der Albanvorstadt und in Großbasel eine nicht auf uns gekommene Vorlage aus dem Jahr 1486 verwendet wurde, womit sich die Eigendatierung der Registratur erklären ließe. Befragt man also die Registratur H nach der Zeit zwischen 1502 und 1505, so ist sie zuverlässig. Zur Datierungsfrage vgl. Gilomen 1977, 307, 312 f., 384. Zu Christoph von Utenheim vgl. A. Hartmann 1957, 243.

1279 StABS, Steuern B 12, Markzahlsteuer 1453/54-1456/57. Welchen Raum die drei St. Albaner Steuerbezirke im loch, Alban Mülinen und vor dem tuichen hus jeweils abstecken, ist nicht eindeutig zu klären. Mit der Bezeichnung im loch wurde und wird üblicherweise das St. Albantal bezeichnet, weil es in einer Mulde zum Rhein hin liegt, vgl. Anm. 1272. Gustav Schönberg weist jedoch darauf hin, dass die Personen, die 1453/54 im loch steuerten, in der nächsten Steuerperiode von 1457/58 bis 1460/61 unter der Ortsbezeichnung vom spittel biß zu wonlichs turn und uff burg zu finden sind, also zwischen städtischem Spital und Münsterplatz, und damit nicht in der St. Albanvorstadt lebten, vgl. Schönberg 1879, 616. Unter Alban Mülinen oder auch in den mülinen waren die am St. Albanteich liegenden Mühlwerke und die dazwischenliegenden Häuser bekannt, die allerdings auch im St. Albantal lagen. Die Lokalisierung vor dem tuichen hus bezieht sich nach Katharina Simon-Muscheid auf das von der Albanvorstadt gesehen stadteinwärts gelegene Haus der Deutschordensritter, vgl. Simon-Muscheid 1988, 404 mit Anm. 32. Es befand sich beim St. Albanschwibbogen, auch Cunostor genannt, einem früheren Stadttor, das die Innenstadt von der St. Albanvorstadt trennte, vgl. Wackernagel 1907, Bd. 1, 177; Kaufmann 1949, 29. 


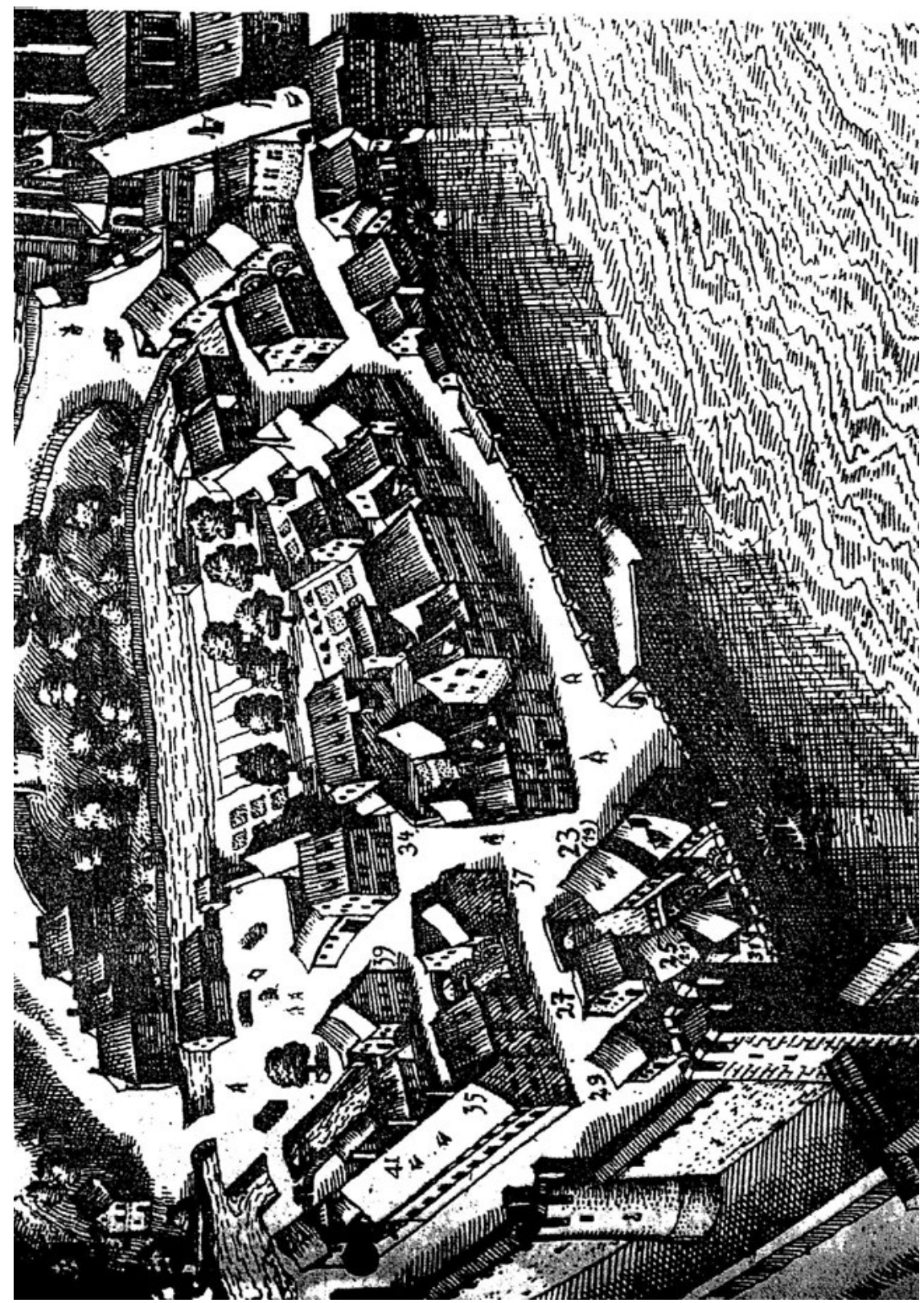

Abb. 14: Das Basler St. Albantal mit den Mühlenlehen, Blick von Norden, Ausschnitt aus Matthäus Merian, Plan der Stadt Basel, 1615, Kupferstich, aus: W. Fr. Tschudin 1954. Mit Nummer bezeichnet sind die Rychmühle (41), die Zunzigermühle (39), die Klingentalmühle (35), die Stegreifmühle (37), die hintere Spiegelmühle (25 u. 31), die hintere Schleife (23). 


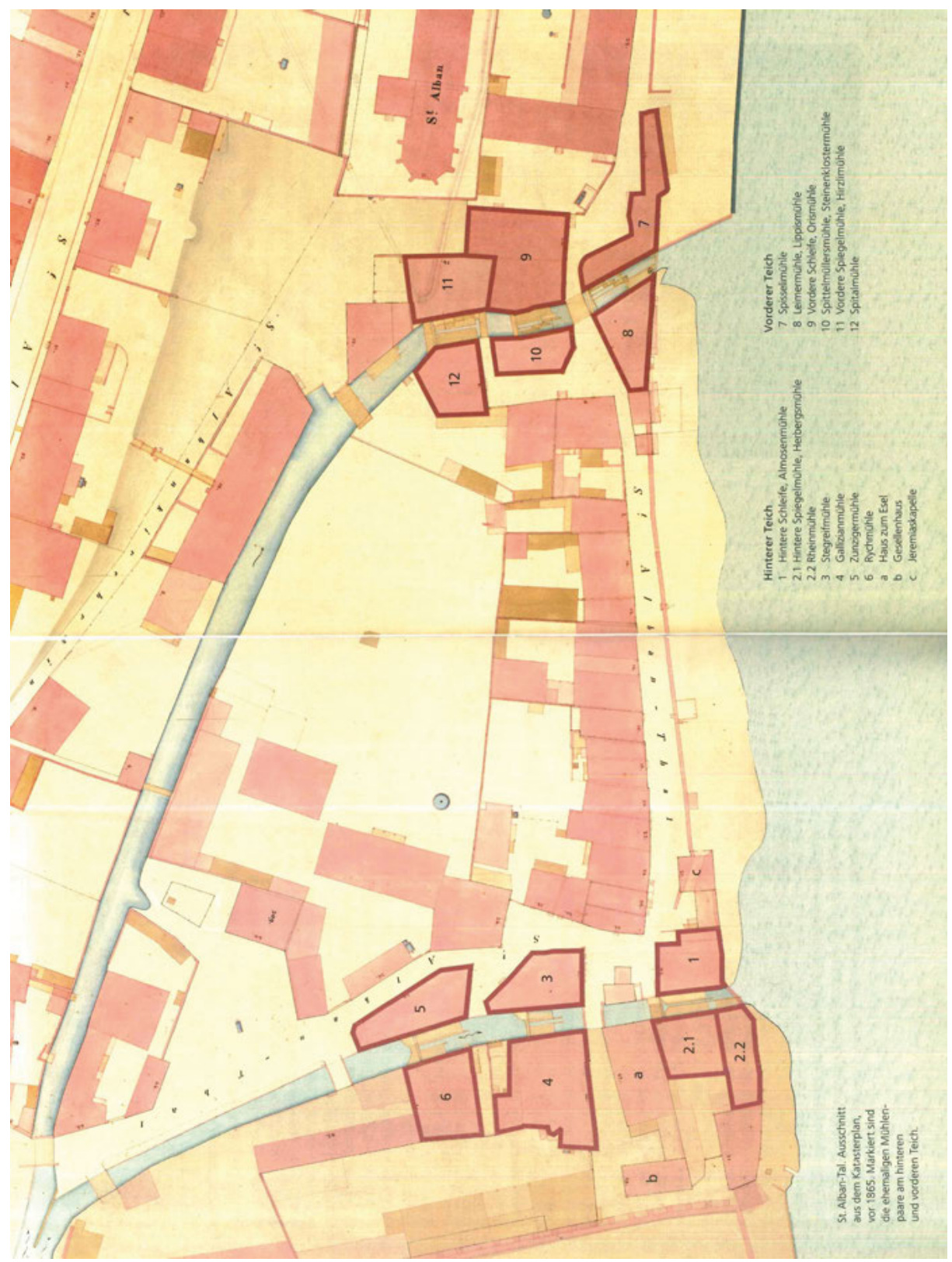

Abb. 15: Die Mühlenlehen im Basler St. Albantal, Ausschnitt aus dem Katasterplan von 1865, gesüdet, aus: Baur/Nagel 2009, $8 \mathrm{f}$. 
dieser Steuerliste hat Katharina Simon-Muscheid für das Jahr 1453/54 schlaglichtartig die Zusammensetzung der Bewohner der Albanvorstadt nach Vermögen, Beruf und Zunftzugehörigkeit ermittelt. ${ }^{1280}$ Das Quartier im loch wies zu dieser Zeit eine durchmischte Bewohnerstruktur auf. Zwar können knapp 40 Prozent der Bewohner zu den Armen ${ }^{1281}$ gerechnet werden, aber immerhin 14 Prozent der Anwohner besaßen ein Vermögen von über 1.000 Gulden. ${ }^{1282}$ Die Zusammensetzung nach Berufsgruppen war ebenfalls sehr heterogen, auf die knapp 20 eruierten Berufe kommen jeweils meist nur ein oder zwei Personen. In den Abschnitten vor dem tuichen hus und Alban Múlinen wohnten dem gegenüber eher unvermögenden Basler: Über 80 Prozent der Anwohner besaßen weniger als 100 Gulden $^{1283}$ und nur ein Prozent kann der Kategorie der Reichen mit über 1.000 Gulden Vermögen zugeschlagen werden. ${ }^{1284}$ Die berufliche Struktur der Bewohner dieser beiden Quartiere war zwar ebenfalls durchmischt, wies aber mit den Rebleuten, den Schindlern und Müllern Spitzengruppen auf, wobei die Rebleute sowohl die größte als auch die ärmste Berufsgruppe darstellten. ${ }^{\mathbf{1 2 8 5}}$ Dieser Befund passt im Ganzen sehr gut zu der Siedlungsstruktur der Albanvorstadt. An den Gewerbekanälen und im St. Albantal siedelten die Mühlenbetreiber und die Schindler, die auf Weisung des Rats bei den städtischen Schindelhöfen wohnten. Die Rebleute bewirtschafteten die weiten ländlichen, kaum bebauten Flächen des Albantals, während sich oberhalb des Tals einige größere Höfe befanden, die von reicheren Basler Bürgern bewohnt wurden. ${ }^{1286}$

Dank der Arbeit von Hans Füglister ist ein weiterer zeitlicher Querschnitt möglich. ${ }^{1287}$ Füglister wertete für seine Studie der politischen und sozialen Struktur Basels in der ersten Hälfte des 16. Jahrhunderts unter anderem den Liegenschaftsmarkt aus und gliederte den städtischen Raum anhand der Grundstückswerte sozialtopographisch. Er ging davon aus, dass der Wert der auf den städtischen Raum verteilten Liegenschaften einen Indikator für die soziale Strukturierung dieses Raums darstellt. ${ }^{1288}$ Für die Albanvorstadt kommt er zu dem Ergebnis, dass ein verhältnismäßig hoher Prozentsatz an Grundstücken in der minderen Wertklasse angesiedelt war, dass nämlich 66,3 Prozent der verkauften Liegenschaften unter 150 Pfund wert waren. 25,3 Prozent wurden für 151 bis 450 Pfund gehandelt, während nur 8,4 Prozent über 450 Pfund

1280 Vgl. Simon-Muscheid 1988, 208-210. Zu sozial- und gewerbetopographischen Studien allgemein vgl. Rublack 1979; Denecke 1980; Röber 1999; Denecke 2005; Schulz 2010, 15, 82-86.

1281 Diese Personen besaßen ein Vermögen von bis zu 10 Gulden, vgl. Simon-Muscheid 1988, 55.

1282 Vgl. Simon-Muscheid 1988, 208.

128341 Prozent zählten zu den Armen, von 44 Prozent war das Hab und Gut immerhin zwischen 10 und 100 Gulden wert, vgl. Simon-Muscheid 1988, 55, 209, 404 mit Anm. 32.

1284 Vgl. Simon-Muscheid 1988, 209, 404 mit Anm. 32.

1285 Vgl. Simon-Muscheid 1988, 210.

1286 Vgl. Simon-Muscheid 1988, 207.

1287 Füglister 1981.

1288 Vgl. Füglister 1981, $57 \mathrm{f}$. 
kosteten. ${ }^{1289}$ Dieses Bild passt erstaunlich gut zu den Befunden aus der Basler Steuerliste von 1453/54. Neben den zahlreichen, ärmeren“ Bewohnern der Albanvorstadt gab es auch einige wenige vermögende Bürger, deren Grundstücke einen entsprechenden Wert hatten. $\mathrm{Zu}$ beachten ist hierbei sicherlich, dass gerade die Mühlgebäude tendenziell einen höheren Wert besaßen als Wohnhäuser und somit den Anteil der höchsten Wertklasse unverhältnismäßig vergrößern. Da ein Mühlwerk nicht unbedingt von demjenigen betrieben werden musste, der es besaß, sagt der Wert dieser Liegenschaft noch nicht viel über die soziale Gliederung der Anwohnerschaft aus. Der sozialtopographischen Untersuchung stellt Füglister eine gewerbetopographische Studie zur Seite. Wenig überraschend besaßen die Papiermacher vorwiegend in der Albanvorstadt Liegenschaften, was darauf hindeutet, dass sie nicht nur dort arbeiteten, sondern auch wohnten. ${ }^{1290}$

Die erste Papiermühle im St. Albantal war die 1448 von Heinrich Halbysen d. Ä. erworbene Rychmühle. Sie war das oberste Lehen auf der rechten Seite des hinteren Teichs und trägt heute die Bezeichnung St. Albantal 41. Erstmals belegt ist das Mühlgebäude als Kornmühle im Jahr 1284. ${ }^{1291}$ Ihren Namen hat die Rychmühle von den Herren Reich von Reichenstein, in deren Besitz sich das Werk von 1366 bis 1447 befand. Betreiber war seit spätestens 1428 der Müller Heinrich Brüygen, der das Lehen in diesem Jahr von den Herren von Reichenstein pachtete. ${ }^{1292}$ Im Jahr 1447 verkaufte Peter Reich die Mühle an den Müller Peter Cuntz. ${ }^{1293}$ Von diesem erwarb Heinrich Halbysen d. Ä. sie im Januar 1448. ${ }^{1294}$ Auch bei dieser Mühle erfahren wir nichts über den Umwandlungsprozess der Kornmühle in eine Papiermühle. Im Jahr 1450 verkaufte Heinrich Halbysen d. Ä. seinem gleichnamigen Sohn vermutlich neben weiteren Gütern eine Papiermühle, sicherte sich aber das lebenslange Nutzungsrecht. ${ }^{1295}$ Um welches Werk es sich dabei handelte, kann nicht ausgemacht werden, da die beiden relevanten Einträge in den Fertigungsbüchern nach dem ersten Satz abbrechen und somit keine weiterführende Beschreibung der Papiermühle bieten. Es ist möglich, dass die Rychmühle und die ihr gegenüberliegende Zunzigermühle zu dieser Zeit als ein Papiermühlenkomplex galten. Sicher ist, dass Heinrich Halbysen d. J. nach seinem Vater - und nach zahlreichen Pfändungen in der Folge des Tods von Heinrich Halbysen d. Ä. im Jahr $1451^{1296}$ - Besitzer der Rychmühle war, denn er

1289 Vgl. Füglister 1981, 58-65.

1290 Vgl. Füglister 1981, 65 f., 75.

1291 StABS, Klosterarchiv, St. Alban Da, 18v. Vgl. Baur/Nagel 2009, 7.

1292 StABS, Klosterarchiv, St. Alban F, 2v; Gerichtsarchiv B 2, 2v. Vgl. Schweizer 1923, 67; Baur/Nagel 2009, 7.

1293 StABS, Gerichtsarchiv B 5, 50v.

1294 StABS, Gerichtsarchiv B 5, 93v-94r. Vgl. Schweizer 1923, 68; W. Fr. Tschudin 1955, 3; W. Fr. Tschudin, 1958, 23; Piccard 1967, 36; Kälin 1974, 146, 184; P. Tschudin 1991, 24.

1295 StABS, Gerichtsarchiv B 5, 186v. Vgl. Piccard 1967, 61 f.; Kälin 1974, 184.

1296 StABS, Gerichtsarchiv E 3, 143v-145v. Vgl. Piccard 1967, 61-64, 172 f. 
verkaufte sie im November oder Dezember 1467 an den Papiermacher Michel Gallician. ${ }^{1297}$ Dieser hatte das Lehen knapp 27 Jahre inne, bis er es 1494 an den Papiermacher Hans Lufft von Ettlingen veräußerte. ${ }^{1298}$ Hans Lufft bewirtschaftete die Papiermühle bis in das Jahr 1519 und verkaufte sie schließlich an den Papierer Fridlin Hüsler d. Ä. ${ }^{1299}$ Der nächste Handwechsel fand 23 Jahre später statt: 1542 erwarb der Papierer Joachim Degenhart die Rychmühle. ${ }^{1300}$

Auch die sogenannte Zunzigermühle wurde bereits 1284 als Kornmühle erwähnt. ${ }^{1301}$ Heute als St. Albantal 39 bezeichnet lag sie der Rychmühle gegenüber, das heißt auf der anderen Seite des hinteren Teichs und war somit das oberste Lehen linker Hand. Ihren Namen erhielt sie von Hans Müller von Zunzikon, der das Werk von 1403 bis 1446 besaß und wohl in eine Säge umwandelte. ${ }^{1302}$ Wann Heinrich Halbysen d. Ä. das Werk in seinen Besitz brachte, ist nicht bekannt. ${ }^{1303}$ Er erwarb es zwi-

1297 Ein Kaufvertrag ist nicht erhalten, allerdings verkaufte Michel Gallician im Dezember 1467 eine Rente an Heinrich Halbysen d. J., vermutlich, um die gerade von Halbysen erworbene Papiermühle, die auch die dingliche Sicherung war, zu finanzieren, vgl. StABS, Hausurkunden 716, N, Urk. (03.12.1467). Vgl. auch Kapitel 3.2.4.1, S. 283 f. Vgl. Schweizer 1923, 68 f.; W. Fr. Tschudin 1955, 3; W. Fr. Tschudin 1958, 23, 40; Kälin 1974, 184. Gerhard Piccard, dem diese Urkunde nicht bekannt ist, nimmt hingegen an, dass der Verkauf an Michel Gallician nicht rechtskräftig geworden ist und er erst nach 1471 die Rychmühle erwarb, vgl. Piccard 1967, 71 f. Diese These basiert auf drei irreführenden Einträgen in den städtischen Jahresrechnungen, die Piccard nach Gustav Schönberg und Traugott Geering zitiert, vgl. Schönberg 1879, 442, 444; Geering 1886, 289, und die sich in der Edition der Rechnungsbücher von Bernhard Harms wiederfinden, vgl. Der Stadthaushalt Basels 1910, 350, 355, 358. Diese Einträge aus dem Rechnungsjahr 1470/71 vermerken zweimal Ausgaben für eine Papiermühle, die an Heinrich Halbysen d. J. zu entrichten seien. In einem Eintrag wird präzisiert, dass es sich um eine Papiermühle zu St. Alban handele. Ein dritter Eintrag vermerkt Ausgaben für eine Papiermühle in St. Alban, ohne jedoch einen Namen zu nennen. Hans Kälin konnte überzeugend nachweisen, dass sich diese Angaben nicht, wie von Piccard vermutet, auf die Rychmühle, sondern auf die Allenwindenmühle beziehen, die Heinrich Halbysen d. J. im Jahr 1470 an die Stadt verkaufte. Die Assoziation der Papiermühle Halbysens vor dem Riehentor mit einer Mühle im St. Albantal war offensichtlich eine Fehleistung des Schreibers, vgl. Kälin 1974, $184 \mathrm{f}$.

1298 StABS, Gerichtsarchiv B 13, 167v. Vgl. auch den Eintrag in die St. Alban-Registratur H, in der Hans Lufft zwischen 1502 und 1505 als Besitzer der Rychmühle aufgeführt wird, StABS, Klosterarchiv, St. Alban H, 5.

1299 StABS, Gerichtsarchiv B 22, 69r-69v. Vgl. auch den Eintrag in das St. Alban-Corpus von 1523/24, in dem die Zinszahlung Fridlin Hüsler d. Ä. von seiner Papiermühle genannt ist, die vorher Hans von Ettlingen leistete, StABS, Klosterarchiv, St. Alban DD 1, Corpus 1523/24, [6v]. Für die beiden Besitzerwechsel seit 1494 vgl. Schweizer 1923, 74; W. Fr. Tschudin 1958, 23, 40; Piccard 1967, 171; Kälin 1974, $180,188$.

1300 StABS, Hausurkunden 716, N, Urk. (12.07.1542); Gerichtsarchiv B 28, 191r-191v. Vgl. W. Fr. Tschu$\operatorname{din} 1958,23,40$.

1301 StABS, Klosterarchiv, St. Alban Da, 18v. Vgl. Schweizer 1923, 67; Baur/Nagel 2009, 7.

1302 StABS, Klosterarchiv, St. Alban G, 1v; Gerichtsarchiv E 3, 100v. Vgl. Schweizer 1923, 67; Baur/ Nagel 2009, 7.

1303 Vgl. hier die unterschiedlichen Angaben bei Schweizer 1923, 68; W. Fr. Tschudin 1955, 3; W. Fr. Tschudin 1958, 23, 40; Piccard 1967, 36; Kälin 1974, 179, 183, 188. 
schen 1446 und 1450, fand doch im Jahr 1450 die bereits erwähnte Übertragung einer Papiermühle, die möglicherweise die Rychmühle und die Zunzigermühle in einem Betrieb vereinte, an seinen Sohn statt. ${ }^{1304}$ Heinrich Halbysen d. J. verkaufte die Zunzigermühle 1470 an den Papiermacher Ulrich Züricher. ${ }^{1305}$ Züricher häufte während der nächsten Jahre offensichtlich beträchtliche Schulden an, denn im Jahr 1486 wurde ein Konkursverfahren gegen ihn eingeleitet und sein Gut verrechnet. ${ }^{1306}$ Seine Papiermühle wurde von Barbara Bischoff, die einen Zinsanspruch auf der Liegenschaft hatte, im Juni 1486 gepfändet und schließlich im August desselben Jahres nach Ablauf des üblichen Verfahrens gekauft. ${ }^{1307}$ Anscheinend veräußerte Barbara Bischoff das Mühlgebäude so schnell wie möglich wieder, denn im Oktober 1486 gehörte die Papiermühle bereits Meister Hans Strub, dem Weinmann, und seiner Frau Anna Plattner. ${ }^{1308}$ Ein halbes Jahr später, im März 1487, befand sich die Papiermühle im Besitz eines zweiten (Peter) Hans Strub, der als Papierer bezeichnet wird und dessen Frau Elsin Wesslin hieß. ${ }^{1309}$ Im Jahr 1489 wurde der Papiermacher Hans Züricher, der Sohn des vormaligen Besitzers Ulrich Züricher, als Inhaber der Zunzigermühle genannt. ${ }^{1310}$ Ihm widerfuhr anscheinend dasselbe Schicksal wie seinem Vater: Er ging bankrott und versuchte, sich seinen Verpflichtungen durch Flucht $\mathrm{zu}$ entziehen. ${ }^{1311} \mathrm{Im}$ Mai 1494 pfändete der Messerschmied Conrat Wesslin daher die Papiermühle und kaufte sie gut drei Monate später. ${ }^{1312}$ Nach zwei Jahren in Conrat Wesslins Besitz ging die Papiermühle im Jahr 1496 an den Papiermacher Hans Kielhammer von Schaffhausen über. ${ }^{1313}$ Als er im Jahr 1523 verstarb, wurde das Mühlwerk als eins erblosen Manns gut

1304 StABS, Gerichtsarchiv B 5, 186v. Vgl. Piccard 1967, 61 f.; Kälin 1974, 183.

1305 StABS, Gerichtsarchiv B 9, 71. Vgl. Schweizer 1923, 69, 74; W. Fr. Tschudin 1955, 3; W. Fr. Tschudin 1958, 40; Piccard 1967, 72, 167, 174 f.; Kälin 1974, 179, 189, 198.

1306 StABS, Gerichtsarchiv G 2, 82v. Vgl. Schweizer 1923, 69; Piccard 1967, 168; Kälin 1974, 199.

1307 StABS, Gerichtsarchiv B 11, 260r. Vgl. Kälin 1974, 183. Zum Prozedere der Pfändung vgl. Kapitel 3.2.4.1, S. $282 \mathrm{f}$.

1308 StABS, Gerichtsarchiv B 11, 263r-264r. Vgl. Kälin 1974, 179, 183.

1309 StABS, Gerichtsarchiv B 12, 13r. Nach Hans Kälin wurde dieser Hans Strub zumeist Peter Hans Strub genannt, vgl. Kälin 1974, 179, 183 f., 197. Gerhard Piccard identifiziert den Namen Hans Strub hingegen mit einem Gerbermeister, vgl. Piccard 1967, 169. Vgl. auch Kapitel 3.3.4.1, S. 405.

1310 StABS, Gerichtsarchiv B 12, 125v. Vgl. Schweizer 1923, 69; Piccard 1967, 168; Kälin 1974, $179,184$. Walter Friedrich Tschudin war nicht bekannt, dass Hans Züricher die Zunzigermühle von 1489 bis 1494 besaß. Er vermutet Hans Strub bis 1494 als Inhaber des Mühlwerks, vgl. W. Fr. Tschudin 1958, 40. 1311 StABS, Gerichtsarchiv E 7, 16r-17r. Vgl. Schweizer 1923, 69; Piccard 1967, 169; Kälin 1974, 184, 198.

1312 StABS, Gerichtsarchiv E 7, 16v-17r; B 13, 165r. Vgl. Schweizer 1923, 74; Piccard 1967, 169; Kälin 1974, 179, 184.

1313 StABS, Gerichtsarchiv B 14, 71v. Vgl. auch die Zinszahlung von Hans von Schaffhausen an das Kloster St. Alban: StABS, Klosterarchiv, St. Alban DD 1, Corpus 1502 und Corpus 1505. Vgl. Schweizer 1923, 69, 74; Piccard 1967, 169; Kälin 1974, 179, 184. 
gepfändet und an Margarethe Wesslin, die Witwe Conrat Wesslins, ausgegeben. ${ }^{1314}$ Wie und wann die Papiermühle an den Papiermacher Gregorius (Gorius) Dürr kam, ist nicht bekannt. Im Juni 1530 besaß er jedenfalls die Nutzungsrechte und verkaufte Zinsen von der Papiermühle. ${ }^{1315}$ Etwas mehr als zwei Jahre später, im Oktober 1532, verkaufte er die Mühle an den Papierer Fridlin Hüsler d. Ä., der zu dieser Zeit bereits die gegenüber gelegene Rychmühle innehatte. ${ }^{1316}$ Die Papiermühle St. Albantal 39 verblieb bis zur Mitte des 19. Jahrhunderts in Besitz der Familie Hüsler, deren Namen sich im Laufe der Jahrhunderte in Heusler wandelte. ${ }^{1317}$

Zur dritten Papiermühle im St. Albantal, Klingentalmühle genannt, wurde die im März 1453 von Anton Gallician gegen seine Bluwenmühle am Rümelinbach ,eingetauschte' Hammerschmiede am hinteren Teich umgebaut. ${ }^{1318}$ Sie gehörte zu dem mittleren Mühlenpaar und lag am rechten Teichufer. ${ }^{1319}$ Von ihrer Ersterwähnung 1284 bis zum Jahr 1433 war die Mühle eine Kornmühle im Besitz des Klosters Klingental zu Basel, das der Mühle ihren Namen gab. ${ }^{1320}$

Im Jahr 1433 ist sie als Hammerschmiede in der Überlieferung fassbar. ${ }^{1321}$ Diese Funktion erfüllte sie bis zu ihrer Umwandlung in eine Papiermühle im Jahr 1453. Die Mühle blieb bis zu Anton Gallicians Tod im Jahr 1497 und damit 44 Jahre in seinem Besitz. ${ }^{1322}$ Danach übernahm sein Sohn Hans Gallician II für 24 Jahre das Werk. Nach dessen Flucht aus Basel 1521 führte Franz Gallician, ein Bruder Hans Gallicians II,

1314 StABS, Gerichtsarchiv E 9, 26r; B 23, 13v-14r. Vgl. Kälin 1974, 179, 184. Zu seinem Tod vgl. StABS, Zunftarchive, Zunft zu Safran 28, 4 f. Warum Hans Kielhammer als ein Mann ohne Erben bezeichnet und seine Vermögen dementsprechend behandelt wird, ist nicht nachvollziehbar, da sein Sohn Anton Kielhammer im Jahr 1523 noch lebte. Dieser trat 1518 in die Safranzunft ein und kämpfte 1529 im ersten Kappeler Krieg, vgl. Kapitel 3.3.4.1, S. 400 f., 409.

1315 StABS, Gerichtsarchiv B 25, 146v-147r. Vgl. W. Fr. Tschudin 1958, 41.

1316 StABS, Gerichtsarchiv B 26, 133v. Vgl. Schweizer 1924, 130; W. Fr. Tschudin 1958, 23, 41; Kälin 1972a, 12.

1317 Vgl. Kälin 1972a, 12; P. Tschudin 1991, 36 f.

1318 StABS, Gerichtsarchiv B 6, 171. Vgl. Schweizer 1923, 70; Kazmeier 1955, 16 f.; Piccard 1967, 77; Kälin 1974, 156, 178.

1319 Ihre heutige Adresse ist St. Albantal 37, vgl. P. Tschudin 1991, 37; Baur/Nagel 2009, 7, 40, 65. Eduard Schweizer, Walter Friedrich Tschudin, Gerhard Piccard, Hans Kälin und Ursula Reinhardt bezeichnen die Klingentalmühle hingegen mit St. Albantal 35 und die gegenüberliegende Stegreifmühle mit St. Albantal 37, vgl. Schweizer 1923, 66; W. Fr. Tschudin 1958, 23, 40; Piccard 1967, 167; Kälin 1974, 178, 183; Reinhardt 1975, $24 \mathrm{f}$.

1320 StABS, Klosterarchiv, St. Alban Da, 18v; St. Alban, Urk. 305 (28.08.1427). Vgl. Schweizer 1923, 66; Baur/Nagel 2009, 7. Heute wird das Gebäude, das das Schweizerische Museum für Papier, Schrift und Druck beherbergt, Gallicianmühle genannt, vgl. Baur/Nagel 2009, 40-44; P. Tschudin 2014, 18 f. 1321 StABS, Gerichtsarchiv E 1, 151r. Vgl. Schweizer 1923, 66; Baur/Nagel 2009, 7.

1322 Im April 1497 wurde Anton Gallician als selig bezeichnet, StABS, Gerichtsarchiv A 41, 206r. Vgl. Piccard 1967, 95 (mit falschem Datum); Kälin 1974, 183. 
den Betrieb weiter. ${ }^{1323}$ Im Jahr 1523 verkaufte er die Papiermühle schließlich an den Papiermacher Conrad Grebel. ${ }^{1324}$ Kein Jahr später, im Januar 1524 pfändete und kaufte das hohe Stift zu Basel die Papiermühle. ${ }^{1325}$ Danach scheint sie wieder an die Erben Conrad Grebels gelangt zu sein, denn diese veräußerten das Werk 1528 an den Papiermacher Peter Sontach. ${ }^{1326}$ Von dessen Witwe Verena Dölin und ihrem neuen Ehemann Niclaus Ruckh von Épinal erwarb der Papierer Hans Düring von Ettingen die Klingentalmühle im Jahr 1550. ${ }^{1327}$

Seit den frühen 1450er-Jahren waren im St. Albantal folglich drei Papierwerke in Betrieb. Im Jahr 1471 verfügte schließlich der Basler Rat, dass im St. Albantal keine Papiermühlen mehr eingerichtet werden durften. ${ }^{1328}$ Ob es einen konkreten Anlass gab, der den Rat veranlasste, einzugreifen und die Papierproduktion zu beschränken, wird aus dem kurzen Eintrag in das Öffnungsbuch nicht deutlich. Möglich ist, dass es sich um eine protektionistische Maßnahme handelt, die vor allem das Bestehen der Kornmühlen und damit auch die Versorgung mit Mehl gegenüber einer expansiven und florierenden Papiermacherei sichern sollte. Anscheinend blieb diese Bestimmung nur ein Jahrzehnt in Kraft, denn in den 1480er-Jahren wurden drei weitere Papierwerke im St. Albantal eingerichtet: vor 1482 die Stegreifmühle, vor 1484 die hintere Spiegelmühle und vor 1489 die halbe Spisselismühle.

Die Stegreifmühle wurde ebenfalls im Jahr 1284 das erste Mal erwähnt. Ein Nachweis aus dem Jahr 1395 belegt sie als Kornmühle. ${ }^{1329}$ Sie lag auf der linken Seite des St. Albanteichs - der Klingentalmühle gegenüber - und war damit die zweite Mühle des mittleren Mühlenpaars am hinteren Teich. ${ }^{1330}$ Bis in die Mitte des 15. Jahrhunderts gehörte die Mühle ihrer Namensgeberin, der Müllerfamilie Stegreif. ${ }^{1331} \mathrm{Im}$ Jahr 1453 verkaufte Wilhelm Stegreif die Mühle, die als Kornmühle betrieben wurde, an

1323 Als Besitzer der Klingentalmühle wird Hans Gallician II beispielsweise in der St. Alban-Registratur von 1502/05 genannt, StABS, Klosterarchiv, St. Alban H, 4. Vgl. Kälin 1974, 178, 183. Zur Flucht Hans Gallicians II vgl. Piccard 1967, 102-117; Kälin 1972a, 7-9.

1324 StABS, Gerichtsarchiv B 22, 333r-333v. Vgl. W. Fr. Tschudin 1958, 23, 40; Piccard 1967, 171; Kälin 1974, 178. Im St. Alban Corpus wird Franz Gallician als Besitzer der Klingentalmühle nicht erwähnt, sondern vielmehr „übersprungen“. Dort heißt es: Conrat Grebel prius Hans Gallicion git alle fronfasten von siner pappirmüli, StABS, Klosterarchiv, St. Alban DD 1, Corpus 1523/24, [6v].

1325 StABS, Gerichtsarchiv B 23, 44v-45r.

1326 StABS, Gerichtsarchiv B 24, 201v-202r. Vgl. Schweizer 1923, 74; W. Fr. Tschudin 1958, $23,40$.

1327 StABS, Gerichtsarchiv B 30, 225v-226r. Vgl. Schweizer 1924, 131; W. Fr. Tschudin 1958, 23, 40; Kälin 1972a, 14; P. Tschudin 1991, 37.

1328 StABS, Protokolle, Öffnungsbuch 5, 71r: Lxxi ${ }^{\circ}$ uff mittwůchen vor sannt keyser Heinrichs taghe ist bekennt daß man hinnfưr nyemand gestatten solle papir müllen zů sant Alban ze machen. Vgl. Kälin $1974,160$.

1329 StABS, Klosterarchiv, St. Alban Da, 18v; St. Alban F, 2v. Vgl. Schweizer 1923, 66.

1330 Die heutige Bezeichnung des Gebäudes lautet St. Albantal 35. Mindestens bis in die 1970erJahre wurde das Gebäude allerdings als St. Albantal 37 bezeichnet, vgl. Anm. 1319.

1331 Vgl. Schweizer 1923, 67; Baur/Nagel 2009, 6. 
den Kaufmann Peter Wolfer. ${ }^{1332} \mathrm{Zu}$ einer Papierwerkstatt baute sie schließlich der Papiermacher Anton Gallician um. Er muss das Werk vor 1482 erworben haben, da er in diesem Jahr eine Rente von seinen beiden Papiermühlen, nämlich der Klingentalmühle und der Stegreifmühle, an die Kartause in Kleinbasel verkaufte. ${ }^{1333}$

Offenbar hatte Anton Gallician auch an Conrad Lützelmann Zinsen aus der Papiermühle verkauft, denn dieser pfändete sie im März 1496, ${ }^{1334}$ jedoch ohne sie einzuziehen, da sie nach dem Tod Anton Gallicians in den Besitz seines Sohns Franz Gallician überging. ${ }^{1335}$ Bis zu der Veräußerung an den Papiermacher Jörg Dürr d. Ä. wurde die Papiermühle zweimal gepfändet, $1519^{1336}$ und 1522, ${ }^{1337}$ jedoch auch in diesen Fällen nicht an die Gläubiger ausgegeben. So konnte Franz Gallician sie im Mai 1523 an Jörg Dürr d. Ä. verkaufen. ${ }^{1338}$ Auch in dessen Besitz wurde die Mühle im Jahr 1524 gepfändet. ${ }^{1339}$ Das Mühlwerk blieb jedoch bis in die 1580er-Jahre Eigentum der Familie Dürr. ${ }^{1340}$

Die hintere Spiegelmühle, nach dem Müller Cunz Tockenburg, Leheninhaber im Jahr 1379, auch Tockenburgsmühle genannt, bildete mit der hinteren Schleife das unterste Mühlenpaar am hinteren St. Albanteich und lag auf der rechten Seite des Teichs an der Stadtmauer zum Rhein hin. Auch sie wurde bereits 1284 als Kornmühle erwähnt und diente diesem Zweck bis in das letzte Drittel des 15. Jahrhunderts. ${ }^{1341}$ Vor dem Jahr 1484 muss die Aufteilung des Lehens auf zwei Besitzer erfolgt sein. In diesem Jahr existierten nämlich zwei halbe Lehen, die Mühle von Hans Cuntz, später St. Albantal 25 genannt, sowie die Mühle des Papiermachers Peter Höfflin, später als St. Albantal 31 bezeichnet. ${ }^{132}$ In der Beschreibung der Mühle von Peter Höfflin wird eine Papiermühle erwähnt, die an seiner Mühle lag. ${ }^{1343}$ Hier wird erstmals ein Teil der

1332 StABS, Gerichtsarchiv B 6, 210. Vgl. Schweizer 1923, 67; W. Fr. Tschudin 1958, 24; Kälin 1974, 111. 1333 StABS, Klosterarchiv, Kartause E, 180r-182r; Hausurkunden 716, C, Urk. (24.06.1482). Vgl. Kälin 1974, 183.

1334 StABS, Gerichtsarchiv E 7, 35v. Vgl. Kälin 1974, 178.

1335 Um 1505 zinste Franz Gallician von der Stegreifmühle an das Kloster St. Alban, StABS, Klosterarchiv, St. Alban H, 4; St. Alban DD 1, Corpus 1505, 14v. Vgl. Kälin 1974, 178, 183. Die falsche Datierung der St. Alban-Registratur ließ Walter Friedrich Tschudin und Gerhard Piccard annehmen, dass die Stegreifmühle bereits seit 1486 im Besitz von Franz Gallician war, vgl. W. Fr. Tschudin 1958, 40; Piccard 1967, 92.

1336 StABS, Gerichtsarchiv E 9, 9v.

1337 StABS, Gerichtsarchiv E 9, 21v.

1338 StABS, Gerichtsarchiv B 22, 327v. Vgl. auch StABS, Klosterarchiv, St. Alban DD 1, Corpus 1523/24, 14v: Jorg Dur [...] Aber von seiner Muli prius Frantz Gallician. Vgl. Schweizer 1923, 73 f.; W. Fr. Tschudin 1958, 24, 40; Piccard 1967, 171; Kälin 1972a, 13 f.; Kälin 1974, 178.

1339 StABS, Gerichtsarchiv E 9, 29r.

1340 Vgl. Schweizer 1924, 130; Baur/Nagel 2009, 6.

1341 Vgl. Schweizer 1923, 65.

1342 StABS, Gerichtsarchiv E 6, 84r. Vgl. Schweizer 1923, 65.

1343 StABS, Gerichtsarchiv E 6, 84r: So dann Peter Höffliß mülin und lehen [...] mit der bappir mulin daran gelegen. 
hinteren Spiegelmühle als Papiermühle bezeichnet. Dass es sich bei diesen beiden Mühlen um nur ein Lehen handelte, wird aus einem Eintrag in die Basler Fertigungsbücher ersichtlich. Im Jahr 1487 verkauften der Papiermacher Peter Höfflin und seine Frau Christina die besagte Papiermühle an ihren Stiefsohn respektive leiblichen Sohn Michel Gernler, behielten sich jedoch das lebenslange Nutzungsrecht vor. ${ }^{1344}$ Im Zuge dieser Transaktion wurden auch die an das St. Albankloster zu zahlenden Zinsen aufgeführt, die zusammen mit der danebengelegenen Mühle entrichtet werden sollten. ${ }^{1345}$ Die Kornmühle des Müllers Veit und die Papiermühle von Peter Höfflin stellten folglich ein Lehen mit zwei Besitzern und zwei Betrieben dar. Wann das Werk geteilt und in der einen Hälfte die Papierproduktion aufgenommen wurde, lässt sich nicht feststellen. Vermutlich gehörte Peter Höfflin bereits 1481 das halbe oder sogar das ganze Lehen, da in einem Eintrag in die Fertigungsbücher des Großbasler Schultheißengerichts von Peter Höffliß mülin die Rede ist. ${ }^{1346}$ Im Jahr 1513 erwarb der Papiermacher Jörg Dürr d. Ä. die Papiermühle von den Erben des verstorbenen Michel Gernlers. ${ }^{1347}$ Nach dem Tod Jörg Dürrs 1526/27 verkaufte seine Witwe Veronica Gallician

1344 StABS, Gerichtsarchiv B 12, 40r. Vgl. Piccard 1967, 170; Kälin 1974, 177, 196.

1345 StABS, Gerichtsarchiv B 12, 40r: Zinset mit des genantten Viten mülin einem bropst zu Sannt Alban [...]. Vgl. Schweizer 1923, 65 f.

1346 StABS, Gerichtsarchiv B 11, 36v. Hans Kälin nimmt an, dass Peter Höfflin zu diesem Zeitpunkt Besitzer des gesamten Lehens war, da er ihn für die Jahre von 1481 bis 1484 auch als Inhaber der Kornmühle, St. Albantal 25, bezeichnet, vgl. Kälin 1974, 181, 182, 278 mit Anm. 167. Wann das halbe Lehen St. Albantal 31 zu einer Papiermühle umgebaut wurde, ist nicht zu eruieren. Das Werk wurde erstmals im Jahr 1484 als Papiermühle bezeichnet. Peter Höfflin war jedoch wahrscheinlich schon zu Beginn der 1470er-Jahre selbstständig, da er zu dieser Zeit Leim und Lumpen vom Kaufmann Ulrich Meltinger bezog und in dessen Rechnungsbuch als Peter Höfly der pappirmuller bezeichnet wird, StABS, Privatarchive 62, 76v. Vgl. Kälin 1974, 318; Steinbrink 2007, 305. Vgl. Kapitel 3.3.6.1, S. 454 f. Zudem wurde er 1472 als Papiermacher in die Safranzunft aufgenommen, vgl. Tab. 23. Hans Kälin vermutet mit einiger Plausibilität, dass Peter Höfflin schon im Jahr seines Zunftbeitritts Pächter des Müllers Heini Cuntz war, der zu dieser Zeit die gesamte hintere Spiegelmühle besaß, vgl. Kälin 1974, 183. Allerdings belegt er seine Vermutung ein paar Seiten später mit einem Eintrag in einem Fertigungsbuch des Schultheißengerichts, das kein eindeutiges Pachtverhältnis, sondern lediglich eine durch eine Bürgschaft ausgedrückte Beziehung nachweist, vgl. Kälin 1974, 187 f. Der Eintrag betrifft einen Zinsverkauf von Peter Höfflin und seiner Frau Margreth als Hauptverkäufer an Herrn Johannes Held, Kaplan zu St. Peter, von ihrem Haus und ihrer Hofstatt. Als Mitverkäufer und damit als Bürge fungierte der Müller Heini Cuntz, der Sicherheiten von seiner Mühle, genannt Spiegels mülin, gab. Haus und Hofstatt von Peter Höfflin lagen allerdings nicht bei dieser Mühle, sondern ze Basel in der vorstatt zu sant Alban [...] zwischen Henßlins von Altkirch ze einer und Weydlingers hüsern zer anderen syten. Die Beifügung in den mülinen wurde gestrichen. StABS, Gerichtsarchiv B 9, 293. Zum Mitverkäufer als Bürgen, vgl. Hagemann 1987, 274.

1347 StABS, Gerichtsarchiv B 19, 182r-182v. Vgl. Schweizer 1923, 71; W. Fr. Tschudin 1958, 24 f., 39 ; Kälin 1972a, 13. Gerhard Piccard zieht den Kauf des Mühlwerks durch Jörg Dürr d. Ä., den er aus Paul Koelners Beitrag zur Geschichte der Safranzunft zitiert, zu Unrecht in Zweifel, vgl. Piccard 1967, 170. Als Michel Gernlers Erben werden seine acht Kinder, vertreten durch ihren Vogt Hans Gernler, und deren Mutter Ursula Segesserin, ebenfalls durch einen Vogt, den Junker Michel Meiger, vertreten 
den Betrieb im Oktober 1530 an den Papierer Bartholome Blum. ${ }^{1348}$ Nur ein Jahr später stieß dieser die Papiermühle wieder ab und gab sie an den Papiermacher Claus Dürr, dessen Familie sie bis ins 17. Jahrhundert besaß. ${ }^{1349}$

Ebenfalls ein geteiltes Lehen war von circa 1485 bis 1497 die sogenannte Spisselismühle. Im Gegensatz zu den bereits beschriebenen Mühlwerken lag sie nicht am hinteren, sondern am vorderen St. Albanteich. Hier bildete sie zusammen mit der Leimermühle, die ihr am rechten Teichufer gegenüberlag, das letzte Mühlenpaar vor dem Rhein. Das Grundstück, heute unter der Adresse St. Alban-Rheinweg $52 \mathrm{zu}$ finden, wurde noch zur Zeit der Erstellung des Historischen Grundbuchs der Stadt Basel Ende des 19. Jahrhunderts als Mühleberg 19/21 bezeichnet. Bis ins 15. Jahrhundert hinein war die Spisselismühle, deren Namen von der Müllerfamilie Spisselin stammt, eine Kornmühle. ${ }^{1350}$ Um die Mitte des Jahrhunderts gehörte sie dem Müller Hermann Helg. Im Jahr 1459 wollte dieser die halbe Mühle an den Papiermacher Hans Gallician I verkaufen. Allerdings scheint diese Handänderung nicht erfolgt zu sein, da der Eintrag im Basler Fertigungsbuch durchgestrichen ist und am linken Rand den Vermerk Non transivit trägt. ${ }^{1351}$ Der Ankauf einer Mühle am vorderen Teich durch einen Papiermacher gelang zu dieser Zeit also nicht. Mit der Übernahme des Lehens durch den Schleifer Hans Krafft im Jahr 1465 diente die Spisselismühle stattdessen fortan als Schleifmühle. ${ }^{1352}$ Eine Teilung des Lehens, die 1459 wohl gescheitert war, wurde schließlich vor 1485 realisiert, als Hans Krafft den an der Stadtmauer gelegenen unteren Teil der Mühle an Hans Strub verkaufte. ${ }^{1353}$ Vier Jahre später, 1489, war bereits der Papierma-

genannt. Zur Vogtei vgl. Hagemann 1987, 140-161; Signori 1999. Vgl. auch die Zinszahlung Jörg Dürrs d. Ä. an das St. Albankloster im Jahr 1523/24, StABS, Klosterarchiv, St. Alban DD 1, Corpus 1523/24, 14v. 1348 StABS, Gerichtsarchiv B 25, 175r-175v. Vgl. Schweizer 1923, 74; W. Fr. Tschudin 1958, 25, 39; Kälin 1972a, 14. Zum Sterbejahr Jörg Dürrs d. Ä. vgl. StABS, Zunftarchive, Zunft zu Safran 28, 10 f.

1349 StABS, Gerichtsarchiv B 26, 25r-25v. Vgl. W. Fr. Tschudin 1958, 25, 39; Kälin 1972a, 14; Baur/ Nagel 2009, 6.

1350 Vgl. Schweizer 1923, 58 f.; Baur/Nagel 2009, 10.

1351 StABS, Gerichtsarchiv B 8, 43r. Vgl. Piccard 1967, 86, 175; Kälin 1974, 157. Zwar wurden auch erfolgte Liegenschaftsänderungen, die in der Ausstellung einer Urkunde mündeten, durchgestrichen, allerdings mit einer Schlangenlinie, während dieser Eintrag mit geraden, miteinander gekreuzten Strichen getilgt wurde. Zudem wurden erfolgreich erledigte Übertragungen mit einem gekreuzten Kreis gekennzeichnet, vgl. hierzu auch Hagemann 1987, 31. Gerhard Piccard geht dennoch davon aus, dass Hans Gallician I die Liegenschaft für kurze Zeit besaß.

1352 Vgl. Schweizer 1923, 58.

1353 Dass Hans Strub 1485 diesen Teil des Lehens besaß, lässt sich an einem Urteil der Fünferherren erkennen, das ihm gestattete, auf seinem Grundstück bei der Schleifmühle neu zu bauen und hierfür das Fundament des vorherigen, abgebrannten Gebäudes sowie Teile der Stadtmauer zu nutzen, vgl. Urkundenbuch der Stadt Basel 1905, Bd. 9, 8 f., Nr. 11. Vgl. Schweizer 1923, 59 mit Anm. 92. Es ist nicht sicher, ob es sich um den Weinmann Hans Strub, um den als Papiermacher bezeichneten (Peter) Hans Strub oder um den von Piccard angeführten Gerbermeister Hans Strub handelt, vgl. hierzu Piccard 1967, 169; Kälin 1974, 197. 
cher Hans Züricher Besitzer des anscheinend neu erbauten Mühlwerks. ${ }^{1354}$ Wie oben angedeutet, geriet Züricher in finanzielle Schwierigkeiten und flüchtete aus Basel. Sein Gut wurde im Mai 1494 gepfändet ${ }^{1355}$ und schließlich im September desselben Jahres an die Gläubiger ausgegeben, darunter neben der Zunzigermühle auch das halbe Lehen der Spisselismühle, ${ }^{1356}$ nämlich die kleine mülin mit aller zu gehord als die zwischen Hanns Krafft des schliffers schliffe unnd dem thurn gelegen. ${ }^{1357}$ Beide Mühlen gingen in den Besitz des Messerschmieds Conrat Wesslin über. Im Jahr 1497 vereinte der Schleifer Hans Krafft die beiden Teile der Spisselismühle wieder in seiner Hand, ${ }^{1358}$ bis schließlich 1501 der Schaffner von St. Alban, Lienhart Mentel, das Lehen um versessenen Zins an sich zog. ${ }^{1359}$ Ab diesem Zeitpunkt diente das ganze Lehen wieder zum Kornmahlen. ${ }^{1360}$ Die halbe Spisselismühle wurde folglich nur in einem Zeitraum von minimal fünf und maximal zwölf Jahren als Papiermühle betrieben. ${ }^{1361}$

Die soeben vorgestellten Papiermühlen wurden alle vor 1500 gegründet. Abzüglich der wahrscheinlich seit 1494 nicht mehr als Papiermühle betriebenen Spisselismühle arbeiteten in den mülinen fünf Papiermühlen, alle am hinteren Teicharm. Als Kornmühlen wurden die vordere Spiegelmühle, die Spitalmühle, die Spittelmüllersmühle und die Leimermühle am vorderen Teich sowie die halbe hintere Spiegelmühle am hinteren Teich betrieben, sodass insgesamt fünf Betriebe Korn mahlten. Zwei Schleifen, eine am vorderen und eine am hinteren Teich, sowie die Gewürzmühle der Safranzunft am vorderen Teich komplettierten das Bild. ${ }^{1362}$ Bedenkt man den ungleich lebensnotwendigeren Nutzen von Mehl im Vergleich zum Papier, so erstaunt die identische Anzahl an Kornmühlen und Papierbetrieben.

In der ersten Hälfte des 16. Jahrhunderts wurde noch eine weitere Papiermühle, die sogenannte neue Papiermühle, in einem der Lehen am St. Albanteich eingerichtet. 1525 erwarb der Papiermacher Jörg Dürr d. Ä., der seit 1513 einen Teil der hinteren Spiegelmühle und seit 1523 die Stegreifmühle sein Eigen nannte, die hintere Schleif-

1354 StABS, Gerichtsarchiv B 12, 125v. Hier werden die zwei Papiermühlen des Hans Züricher genannt, von denen die eine die Zunzigermühle und die andere die halbe Spisselismühle gewesen sein müssen. Deutlich geht dies aus späteren Dokumenten hervor. Vgl. Schweizer 1923, 59; W. Fr. Tschudin 1958, 27; Piccard 1967, 154; Kälin 1974, 177, 189.

1355 StABS, Gerichtsarchiv E 7, 15v-17r. Vgl. Anhang V.

1356 StABS, Gerichtsarchiv B 13, 166r.

1357 StABS, Gerichtsarchiv E 7, 17r.

1358 Vgl. Schweizer 1923, 59.

1359 StABS, Gerichtsarchiv B 15, 89v.

1360 Vgl. Schweizer 1923, 59.

1361 Eine Betriebsdauer von fünf Jahren ergibt sich aus den beiden Jahren der Nennung Hans Zürichers, 1489 und 1494. Sollte Hans Züricher die Mühle sehr bald nach der Erwähnung von Hans Strub, also noch im Jahr 1485 gekauft haben, und erst der Rückkauf von Hans Krafft im Jahr 1497 eine Umwandlung der Papiermühle in eine Schleife veranlasst haben, würde dies eine Betriebsdauer von zwölf Jahren ergeben.

1362 Vgl. Schweizer 1923, 58-66. 
mühle, St. Albantal 23, von dem Stampfer Anton Welz und baute sie zur Papiermühle um. ${ }^{1363}$ In dem betreffenden Fertigungsprotokoll wird das Lehen zů wüssen mülli genannt. ${ }^{1364}$ Nach Einrichtung der Papierwerkstatt wurde es als die nüw Bapyrmüli bezeichnet. ${ }^{1365}$ Die Mühle war seit 1379 in zwei Werke geteilt, die vermutlich beide als Schleife betrieben worden waren. Im Jahr 1440 kaufte die Safranzunft das untere Rad und richtete eine Gewürzmühle ein, die sie 1487 gegen die vordere Schleife, auch Orismühle genannt, tauschte. Tauschpartner war der Schleifer Hans Löwenberg, der seit spätestens 1465 das obere Rad der hinteren Schleifmühle sowie die vordere Schleifmühle besaß und nun das ganze Lehen St. Albantal 23 in seiner Hand vereinte. ${ }^{1366}$ Seine Witwe, die noch in der St. Alban-Registratur von 1502/05 als Inhaberin des Mühlwerks aufgeführt wurde, übergab es um 1505 an ihren Schwiegersohn Anton Welz. ${ }^{1367}$ Ob das Mühlwerk beim Kauf durch Jörg Dürr d. Ä. noch als Schleife betrieben wurde oder ob der Stampfer Anton Welz es in eine Stampfe umgewandelt hatte, ist nicht bekannt.

Damit schließt sich der Kreis der Papiermühlen im St. Albantal. Bei der von Walter Friedrich Tschudin als Papiermühle bezeichneten Liegenschaft St. Albantal 27 handelte es sich vermutlich um das Haus zum Esel, das bis 1488 der Müllergesellschaft als Trinkstube diente. ${ }^{1368}$ Im November 1494 pfändete Conrat Wesslin das Anwesen, das zu diesem Zeitpunkt dem flüchtig gewordenen Hans Züricher gehörte. ${ }^{1369}$ Die Liegenschaft wurde eindeutig als Haus bezeichnet. Im Jahr 1515 kaufte wahrscheinlich Jörg Dürr d. Ä. das Grundstück. ${ }^{1370}$ Auch die Spittelmüllersmühle (St. Albantal 2), die

1363 StABS, Gerichtsarchiv B 23, 155r. Vgl. Schweizer 1923, 65, 71; W. Fr. Tschudin 1958, 25. Die Liegenschaft St. Albantal 23 war nicht, wie Hans Kälin vermutet, ein Papiermacherwohnhaus, sondern ein Mühlwerk, vgl. Kälin 1974, 182. Ihm gegenüber lagen allerdings zwei Häuser, die sich im Besitz von Papiermachern befanden. Vermutlich handelte es sich um die Grundstücke St. Albantal 26 und St. Albantal 28, wobei letzteres nach dem Katasterplan von 1865 ein Eckhaus war. Dieses Haus kaufte der Papiermacher Diebolt Hanman im Jahr 1478 und nannte es auch noch um 1502/05 sein Eigen. Es wurde zum Brestenberg genannt und lag zwischen der hinteren Schleife und der Stadtmauer zum Rhein hin, StABS, Gerichtsarchiv B 10, 266; Klosterarchiv, St. Alban H, 13; St. Alban DD 1, Corpus 1505, 16v. Der Papiermacher Diebolt Junkher hingegen nannte mit St. Albantal 26 eine Liegenschaft neben dem Haus der alten Schleiferin, der Witwe Hans Löwenbergs, vermutlich St. Albantal 22/24, sein Eigen, vgl. St. Alban H, 9. Vgl. Abb. 15. Vgl. auch Reinhardt 1975, 23.

1364 StABS, Gerichtsarchiv B 23, 155r. Vgl. Schweizer 1923, 64.

1365 StABS, Klosterarchiv, St. Alban H, 13. Vgl. Schweizer 1923, 73; W. Fr. Tschudin 1958, 25.

1366 Vgl. Schweizer 1923, 64.

1367 StABS, Klosterarchiv, St. Alban H, 5. Vgl. Schweizer 1923, 64 f.

1368 Vgl. W. Fr. Tschudin 1958, 24, 39; Reinhardt 1975, 24; Baur/Nagel 2009, 7.

1369 StABS, Klosterarchiv, St. Alban, Urk. 485 (04.11.1494): ...sin huss unnd hoffstatt mit aller zugehörd sind etwan zwey gehüss gewest als das inn der statt Basell inn den mülinenn zu Sannt Alban im loch gegen meister Anthony Galizians Bappirmülin uber gelegenn und zum alten Esell genannt ist.

1370 StABS, Gerichtsarchiv B 20, 146v. Inwiefern die Liegenschaft tatsächlich zur hinteren Spiegelmühle gehörte, wie Walter Friedrich Tschudin und Hans Kälin annehmen, lässt sich nicht abschließend beurteilen, vgl. W. Fr. Tschudin 1958, 24, 39; Kälin 1974, 182. In den Beschreibungen 
Anton Gallician 1476 erwarb, war keine Papiermühle, sondern wurde weiterhin als Kornmühle betrieben. ${ }^{1371}$ Um 1550 waren sechs von 13 Betrieben Papierwerkstätten. Sie lagen alle am hinteren Teicharm, sodass die Papiermacherei eine Vorrangstellung gegenüber den anderen Gewerben hatte.

In der näheren Umgebung von Basel existierten zu Beginn des 16. Jahrhunderts noch zwei weitere Papiermühlen. Sie gehörten zu dem Weiherschloss Kluben, dem späteren Klybeck, das bei Kleinhüningen an der Wiese lag, die wenig später in den Rhein mündete. Im Jahr 1512 erwarb der Steinschneider und Weinhändler Hans Sigmund von Aug das Anwesen, das sich von 1462 bis 1484 mit Heinrich Halbysen d. J. bereits einmal im Besitz eines Papiermühleninhabers befunden hatte. ${ }^{1372}$ Wann Hans Sigmund von Aug die Papierproduktion bei Kluben aufnahm, ist ungewiss. Hans Kälin gibt an, dass er bereits seit 1514 als Papierlieferant in den Quellen auftritt; sein erster Beleg stammt allerdings erst aus dem Jahr 1518. ${ }^{1373}$ Beim Verkauf der Liegenschaft zu Kluben im Juni 1522 an die Stadt Basel wurden schließlich die beiden Papiermühlen erwähnt, von der eine oberhalb, die andere unterhalb des Hauses lag. ${ }^{1374}$ Weitere Informationen über diese beiden Papiermühlen fehlen.

\subsubsection{Ravensburg}

Einen scharfen Kontrast zu der beinahe lückenlos zu dokumentierenden Reihe der Basler Papiermühlen und ihrer Besitzer stellt das Fallbeispiel Ravensburg dar. ${ }^{1375}$ Geschuldet ist dieser Unterschied der ungleich schlechteren Quellenlage, mit der sich Papierhistoriker für die Ravensburger Papiermacherei in ihrer Frühzeit arrangieren müssen. Ravensburg muss mit mehreren Papiermühlen in den Vorstädten Ölschwang und Schornreute um das Jahr 1500 ein prosperierender Standort gewesen sein. Dies unterstreicht nicht zuletzt die Beschreibung der Stadt durch den kaiserlichen Historiographen und Geographen Ladislaus Sunthaym, der selbst gebürtiger Ravensburger war. ${ }^{1376}$ In einer um 1511 zusammengestellten Chronik verschiedener süddeutscher Städte stellte Sunthaym auch das Schussental und die dort gelegene Stadt Ravensburg vor. ${ }^{1377}$ Neben der bunten Aufführung von Stadttoren, Kirchen, Brunnen, Hir-

des St. Albantals wird das Grundstück jedoch separat behandelt und ab den 1520er-Jahren zur Stegreifmühle gerechnet, vgl. Reinhardt 1975, 24; Baur/Nagel 2009, 7.

1371 Vgl. W. Fr. Tschudin 1958, 27; Kälin 1974, 165, 182.

1372 Vgl. Kälin 1972a, 10; Kälin 1982, 32.

1373 Vgl. Kälin 1982, 32.

1374 Vgl. Urkundenbuch der Stadt Basel 1905, Bd. 9, 473, Nr. 536. Vgl. Kälin 1982, 37.

1375 Eine erste Annäherung an die Ravensburger Papiergeschichte wurde unternommen in Schultz/ Follmer 2015, 12-15.

1376 Zur Biographie Ladislaus Sunthayms vgl. Uhde 1993, Bd. 1, 18-34.

1377 Ladislaus Sunthaym, Chronik, WLB Stuttgart, Cod. hist. fol. 250, 61r-64r. Vgl. auch die Textstelle in der Edition von Karsten Uhde, Uhde 1993, Bd. 2, 318-324. Eine Übertragung ins Neuhochdeutsche findet sich in Eitel 1977, 23-25. Die einzelnen Beschreibungen von Orten und geographischen 
schen im Stadtgraben, verschiedenen lokalen Obstsorten, der Großen Ravensburger Handelsgesellschaft und weiterem hielt er auch die Ravensburger Papiermühlen für erwähnenswert und lokalisierte sie, ohne Nennung der genauen Anzahl, in der Vorstadt Schornreute: ausserhalb der vorstat genannt Schornrewtte sind papier mul. ${ }^{1378}$ In einem an den Rand notierten Nachtrag fügte der Schreiber hinzu: da macht man papier genannt Ravenspurger papier mit dem ochsen kopff nutzt man gern in den cantzleien. ${ }^{1379}$

Diese Aussage, die zunächst durchaus als Lokalpatriotismus abgetan werden könnte, wird durch Studien zur Verbreitung des Ravensburger Papiers bestätigt. Lore Sporhan-Krempel und Gerhard Piccard konnten anhand von Textbelegen und Wasserzeichenuntersuchungen nachweisen, dass Papier aus Ravensburg bereits im 15. Jahrhundert den Weg in viele süddeutsche Kanzleien fand. ${ }^{1380}$ Trotz dieser - zumindest regionalen - Bedeutung des Ravensburger Papiers ist es aufgrund der schlechten Überlieferung nicht möglich, ein zusammenhängendes Bild der ersten 150 Jahre der Ravensburger Papiermacherei zu skizzieren. ${ }^{1381}$

So liegen die frühesten Hinweise auf die Etablierung dieses neuen Gewerbes auch nicht in Form von Textbelegen vor, sondern wurden mithilfe der Wasserzeichenforschung ermittelt. Ausgehend von Papieren mit dem Doppelturm, der als Ravensburger Wappen- oder auch Schauzeichen verstanden wird und auch noch heute das Stadtwappen ziert, konnte Gerhard Piccard plausibel machen, dass der Brief Johanns von Cronenberg d. J. an die Stadt Köln vom 24. September 1393 das älteste bisher bekannte beschriebene Ravensburger Papier darstellt. ${ }^{1382}$ Die Papierherstellung in Ravensburg muss folglich, so Piccard, spätestens Anfang 1393, vielleicht aber auch schon 1392 aufgenommen worden sein. ${ }^{1383}$

Das erste schriftliche Indiz stammt aus dem Jahr 1402 und ist damit zehn Jahre jünger als Piccards Wasserzeichenbeleg. In diesem Jahr wurde ein Staengly Bapirer in das Bürgerrecht aufgenommen. ${ }^{1384}$ Das erste Mal von einer Papierwerkstatt ist im Jahr

Gegebenheiten wurden zwischen der Mitte der 1480er-Jahre und 1505/06 verfasst und wahrscheinlich um 1511 zusammengetragen, vgl. Uhde 1993, Bd. 2, 200-202. Die Beschreibung Ravensburgs datiert Alfons Dreher auf 1495, vgl. Dreher 1972, Bd. 1, 117 f.

1378 Ladislaus Sunthaym, Chronik, WLB Stuttgart, Cod. hist. fol. 250, 62r. Vgl. Uhde 1993, Bd. 2, 320. 1379 Nach Karsten Uhde handelte es sich hierbei um dieselbe Hand, die auch den Haupttext schrieb, vgl. Uhde 1993, Bd. 2, 197.

1380 Piccard 1962, 96 f.; Sporhan-Krempel 1953, 94; Sporhan-Krempel 1984, 36-38.

1381 Besser gelingt dies ab dem späten 16. Jahrhundert. So konnte Lore Sporhan-Krempel für die Zeit nach 1550 für jede Ravensburger Papiermühle eine Liste mit der Reihe ihrer Besitzer erstellen, vgl. Sporhan-Krempel 1953, 29, 112-119.

1382 Vgl. Piccard 1962, 97.

1383 Vgl. Piccard 1962, 97. Ihm folgend auch Sporhan-Krempel 1972a, 29; Sporhan-Krempel 1984, 33; Eitel 1990, 47; Preger 1992, 2; Rückert 2010, 115.

1384 StR, Bü 26, Bürgerbuch 1 (1324-1436), 205. Vgl. Sporhan-Krempel 1953, 18; Alfred Schulte 1953, 15; Eitel 1990, 47. 
1411 die Rede, folglich liegen zwischen dem ältesten Wasserzeichenbeleg und diesem Hinweis knapp 20 Jahre. Am 31. Oktober 1411 vererbte Anna Holbain, Witwe des Kaufmanns Frick Holbain und Tochter des Händlers und Ravensburger Bürgermeisters Conrad Wirt, ihre Bleiche im Ölschwang, einen Hof zu Tobel sowie den jährlichen Zins von und ab dem margtrecht der pappir hüser da selbn im ölswang zur einen Hälfte an ihre Schwester Christine und deren Kinder, zur anderen Hälfte an Peter, den Sohn ihres Bruders Hans Wirt. ${ }^{1385}$ Mit dieser Urkunde erfahren wir also zum einen, dass die Papiermacherei in der Vorstadt Ölschwang angesiedelt war und zum anderen, dass mehr als ein Papierhaus dort stand. Bemerkenswert ist hierbei die Bezeichnung Papierhaus anstelle von Papiermühle. Zu Beginn der Papierherstellung in Ravensburg taucht in den Zeugnissen nur die Bezeichnung Papierhaus auf, erst gegen Ende des 15. Jahrhundert wird auch der Begriff Papiermühle verwendet. ${ }^{1386}$ Der vermutlich erste Gebrauch des Worts Papiermühle in einem Ravensburger Dokument ist in einer Urkunde vom 27. März 1487 belegt. ${ }^{1387}$ Die parallele Verwendung beider Begriffe, die auch die Bedeutung der Bezeichnung Papierhaus zu klären vermag, findet sich in einer Urkunde aus dem Jahr 1498. Hier heißt es:

Ich Felix Humpis zu Ravenspurg bekenn offennlich und tun kundt allermengcklich für mich und mein erben mit dem brieve das ich...recht und redlich verkaufft und zukouffen gegeben han und tun das in crafft diz brieffs den erbern Hannsenn Wähen und Hannsen Schmidt seinem stieffdochterman, beyd bürger alhie, und ir beider erben, meine drew bappirhüßer oder bappyrmüly. ${ }^{1388}$

Der Gebrauch des Worts bappyrmüly im Singular deutet darauf hin, dass es sich bei den Papierhäusern nicht um mehrere Papiermühlen handelte, sondern um einen einzigen Betrieb, der auf verschiedene Gebäude verteilt war. Diese Vermutung äußerte bereits Alfred Schulte 1941 in einem in der Zeitschrift Papiergeschichte veröffentlichten Brief an Hans Heinrich Bockwitz und Armin Renker. ${ }^{1389}$ Auch Wolfgang Schlieder sprach sich für die Möglichkeit aus, dass die drei Papierhäuser ein Ensemble darstellten. ${ }^{1390}$ Bestärkung finden diese Hypothesen in der Erläuterung, die sich nach der Nennung der drei Papierhäuser anschließt. In der Verkaufsurkunde heißt es:

...meine drew bappirhüßer oder bappyrmüly nemlich das ober schindelhuß das besthüßlin und das unnder groshuß mitsampt der leymküchin und kessel usserhalb der stat Ravenspurg ob des Tollin-

1385 StR, Urk. 613 (31.10.1411). Vgl. Sporhan-Krempel 1953, 21; Alfred Schulte 1953, 17.

1386 Vgl. Sporhan-Krempel 1953, 16.

1387 StR, Urk. 707 (27.03.1487): ain hofstatt zu Schornrutty by der unndern bappirmully an der strasz. Vgl. Alfred Schulte 1953, 22.

1388 StR, Urk. 670 (24.07.1498). Vgl. Sporhan-Krempel 1953, 24, 28; Alfred Schulte 1953, 22.

1389 Vgl. Alfred Schulte 1953, 13.

1390 Vgl. Schlieder 1966, 95. 
gers mülli by ainander gelegen ouch den rädern stampff wasser wasserflus und annder wytin zu und ingehörungen. ${ }^{1391}$

Bei den drei Papierhäusern handelt es sich folglich tatsächlich um Häuser, das obere Schindelhaus, das Besthäuslein und das untere Großhaus, die alle beieinander gelegen waren und anscheinend nur einen Stampf besaßen. Eventuell handelte es sich bei diesem Stampf um das stampfes mülin genannte Mühlwerk, das Jos und Haintz Segelbach 1410 von Anna Holbain erworben hatten. ${ }^{1392}$ Hinter den drei zu diesem Mühlwerk gehörenden Hofstätten könnten sich dementsprechend die drei namentlich genannten Papierhäuser verbergen. Auch in weiteren Quellen findet sich die parallele Verwendung von Papierhaus und Stampf. In einer Urkunde vom 28. August 1413, in der die Papierhäuser von Segelbachs Kindern erwähnt werden, wird in derselben Zeile festgehalten, dass das Wasser weiterhin auf den Stampf des Besitzers der Papierhäuser fließen soll. ${ }^{1393}$

Auch bei dem nächsten Besitzer der Papierhäuser, Heinrich Gelderich, lesen wir in Zusammenhang mit den Papierhäusern von einem Stampf. In einem Wasserrechtsstreit mit Anna Holbain beklagte Heinrich Gelderich im Jahr 1424, dass die Wasserumleitung, die Anna Holbain oberhalb der Papierhäuser baue, nicht rechtens sei, da alle Wasserrechte zu seinem Stampf und zu seinen Rädern gehören würden. ${ }^{1394}$ Zwar wird Gelderich hier nicht explizit als Besitzer der Papierhäuser genannt. Die Erwähnung der Papierhäuser, die von dieser Umleitung betroffen waren, sowie die Aussage, dass alles Wasser auf seinen Stampf fließen müsse, legen die Vermutung dennoch nahe, dass Heinrich Gelderich neben dem Stampf auch über die Papierhäuser verfügte. Im Jahr 1432 wurde er in einer Urkunde schließlich ausdrücklich als Inhaber eines Papierhauses bezeichnet, in einer anderen Urkunde aus demselben Jahr beklagte Gelderich wiederum, dass der Umbau am Bachbett seinen Stampf schädigen werde. ${ }^{1395}$ Explizit von sinem papirhus ist auch im Jahr 1435 die Rede. ${ }^{1396}$ Warum hier der Singular anstelle des Plurals verwendet wird, ist nicht festzustellen. Im Jahr 1442 wurde Gelderich nochmals als Besitzer der Papierhäuser im Ölschwang erwähnt. ${ }^{1397}$

Aus der häufig parallelen Nennung von Stampf und Papierhäusern könnte man folglich die Hypothese ableiten, dass zwei oder mehr Papierhäuser von nur einem

1391 StR, Urk. 670 (24.07.1498). Vgl. Sporhan-Krempel 1953, 28; Alfred Schulte 1953, 22.

1392 StR, Urk. 756 (20.05.1410); Urk. 757 (26.05.1410). Vgl. Alfred Schulte 1953, 15-17, der die Urk. 756 jedoch versehentlich falsch auf Dienstag nach Fronleichnam, anstatt auf Dienstag vor Fronleichnam datiert; Sporhan-Krempel 1953, $19 \mathrm{f}$.

1393 StR, Urk. 759 (28.08.1413). Vgl. Alfred Schulte 1953, 17 f.

1394 StR, Urk. 1214 (19.05.1424). Vgl. Alfred Schulte 1953, 19.

1395 SpR, Urk. 4220 (01.09.1432). Vgl. Alfred Schulte 1953, 20.

1396 StR, Urk. 1218 (08.07.1435). Vgl. Alfred Schulte 1953, 20.

1397 StR, Urk. 788 (30.01.1442): nemlich die nunzehen pfund pfenning järlichs vorzins so mir ab des erbern Hainrich Gäldrichs bappir hüsern und der mülin darunder die Ruch Haintz innhaut alles sampt ob dem Öllschwang gelegen. Vgl. Alfred Schulte 1953, 21. 
Stampfwerk versorgt wurden. Dies würde auch eine Erklärungsmöglichkeit für die Frage bieten, warum die Papiermühlen in Ravensburg zunächst Papierhäuser genannt wurden: In ihnen wurden keine Lumpen im Stampfgeschirr zerkleinert, da sie keine Mühlgebäude mit Wasserrad waren. Die Aufbereitung der Pulpe besorgte vielmehr eine sogenannte Stampfe oder Stampfmühle, die in einem separaten Gebäude untergebracht war. Die Papierhäuser wurden erst ab der Weiterverarbeitung des Ganzzeugs, das heißt ab der Arbeit an der Bütte, benötigt. Für das Ende des 16. Jahrhunderts ist zudem in einer Urkunde eine sprachliche Parallelisierung von Papiermühle und Stampf fassbar. Im Januar 1598 ersuchte Katharina Metzgerin, die Witwe des Ravensburger Bürgermeister Georg Möckh, den Rat um die Erlaubnis, an statt gemeltt hammers ain bappeir oder stampfmülin, wie man es nennen möchte, zubauwen. ${ }^{1398}$

Diese Beispiele machen die von Lore Sporhan-Krempel vermutete Gleichsetzung von Stampf und Papiermühle plausibel, über die sie den Begründer der Ravensburger Papiermacherei zu fassen versuchte. Nachdem lange Zeit die Familie Holbain als Begründerin der Ravensburger Papierproduktion um die Mitte des 14. Jahrhunderts galt, wird seit den Forschungen Sporhan-Krempels der Kaufmann Conrad Wirt als Initiator angesehen. ${ }^{1399}$ In ihrer Argumentation stützt sich die Autorin hauptsächlich auf zwei Urkunden. In dem einen Dokument aus dem Jahr 1406 wurde zum ersten Mal ein Papiermacher in einem konkreten Kontext erwähnt. ${ }^{1400}$ Im Juli dieses Jahres klagten nämlich Frik Luprecht und Meister Dietrich der Papierer gegen die Müller Bentz Rusch und Cuntz Rottacher wegen einer Wasserrechtsstreitigkeit, die ihre Mühlen im Ölschwang betraf. Daher ist davon auszugehen, dass der Papierermeister Dietrich zumindest Betreiber eines Wasserwerks im Ölschwang war.

Die zweite Urkunde wurde 1435 ausgestellt und betraf ebenfalls einen Wasserrechtsstreit, auf den im entsprechenden Kapitel näher eingegangen wird. ${ }^{1401}$ An dieser Stelle ist vor allem die als Rechtsbekräftigung eingesetzte Erwähnung einer früheren Urkunde von Interesse. In dieser laut Aussage des Klägers Heinrich Gelderich vom Bürgermeister und vom Rat gesiegelten Urkunde, deren Ausstellungsdatum bedauerlicherweise nicht genannt wird und die zudem nicht auf uns gekommen ist, war verzeichnet, dass Conrad Wirt Mühlenbesitzer in der Ravensburger Vorstadt

1398 StR, Urk. 2006 (30.01.1598). Vgl. Alfred Schulte 1953, 25. Diese Hypothese findet sich noch nicht in Schultz/Follmer 2015, 13.

1399 Sporhan-Krempel 1953, 17. Interessanterweise beruhte auch Friedrich von Hößles Vermutung, dass bereits in der ersten Hälfte des 14. Jahrhunderts durch die Brüder Holbain Papier in Ravensburg hergestellt wurde, auf einer Gleichsetzung von Stampfmühle mit einem Stampfwerk zur Lumpenaufbereitung, vgl. Hößle 1926a, 26 f. Diese Herleitung mag zwar nicht korrekt sein, da ansonsten keinerlei Anhaltspunkte für die Papiermacherei auszumachen sind, dennoch ist die Gleichsetzung generell nicht von der Hand zu weisen, wie die obigen Ausführungen belegen. Gänzlich ablehnend äußert sich Piccard 1962, 95.

1400 StR, Urk. 1208 (30.07.1406). Vgl. Alfred Schulte 1953, 15; Sporhan-Krempel 1953, 17.

1401 Vgl. Kapitel 3.2.5.2, S. 311. 
Ölschwang war und dass er seine Mühle, die man stampfes mülin nannte, an einen Meister Dietrich Wolfartshofer verpachtet hatte. ${ }^{1402}$ In diesem Meister Dietrich Wolfartshofer, Pächter von Conrad Wirt, erkennt Sporhan-Krempel den 1406 genannten Papiermacher Meister Dietrich und schlussfolgert daraus, dass der Besitzer der an diesen Papiermacher verliehenen Mühle als Begründer der Ravensburger Papiermacherei anzusprechen sei. ${ }^{1403}$

Zur Bekräftigung ihrer These führt Sporhan-Krempel eine Urkunde aus dem Jahr 1390 an, in der Conrad Wirt als Besitzer eines Hauses - allerdings nicht als Inhaber einer Mühle - im Ölschwang bezeichnet wird. ${ }^{1404}$ Ob es sich bei dieser Liegenschaft um das in der Urkunde von 1435 als stampfes mülin bezeichnete Mühlengebäude handelte, ist nicht mit Sicherheit zu sagen. Die Gleichsetzung von Meister Dietrich Papierer und Meister Dietrich Wolfartshofer erscheint hingegen plausibel, da ab 1410 weitere Papiermacher mit dem Namen Wolfartshofer in den Quellen fassbar sind. ${ }^{1405}$ Auf der aktuellen Quellenbasis ergibt sich jedoch lediglich, dass Conrad Wirt vor seinem Tod 1402 dem Papiermacher Dietrich Wolfartshofer eine Mühle verpachtete, die dieser wahrscheinlich als Papiermühle betrieb. Ob diese Mühle bereits zuvor von dem Kaufmann zur Papierwerkstatt ausgebaut wurde oder ob dies erst durch den Pächter geschah, lässt sich anhand der vorliegenden Quellen nicht beurteilen. Damit kann die Rolle, die Conrad Wirt bei der Einführung der Papierherstellung in Ravensburg spielte, nicht klar definiert werden. ${ }^{1406}$ Ebenfalls ist unklar, welche Funktion die Stampfmühle vor der Einführung der Papierproduktion erfüllte. Lore Sporhan-Krempel weist darauf hin, dass in Oberdeutschland Walkmühlen als Stampfen bezeichnet wurden. ${ }^{1407}$ Denkbar wäre aber auch eine Vielzahl anderer Funktionen, beispiels-

1402 StR, Urk. 1218 (08.07.1435): Und zögt uf das einen brief für mich in gericht und batt und begert den ouch zůverhören der nach gemainer fraug verhört und verlesen ward, und staut und wyset under andern wortten das vorziten Conrat Wirt sälig Maister Dietrichen Wolffortzhofern sin mülin obnan im Ölschwang die man nempt stampfes mülin mit sampt allen rechten und sunder darin das brünnli das obnan $u \beta$ dem berg herab flusset, gelihen und verlihen haut. Vgl. Alfred Schulte 1953, 21 f.; SporhanKrempel 1953, 17.

1403 Vgl. Sporhan-Krempel 1953, 17.

1404 StR, Urk. 1205 (23.02.1390). Vgl. Sporhan-Krempel 1953, 16 f.; Alfred Schulte 1953, 14.

1405 Vgl. beispielsweise StR, Bü 26, Bürgerbuch 1 (1324-1436), 221; Urk. 1216 (11.01.1432). Vgl. Alfred Schulte 1953, 15; Sporhan-Krempel 1953, 18.

1406 Auf diesen Umstand hat bereits Gerhard Piccard aufmerksam gemacht, der die Einrichtung der ersten Ravensburger Papiermühle durch den Kaufmann in Zweifel zieht, vgl. Piccard 1962, 98 f. Auch die von Piccard erhoffte „Neubearbeitung des Quellenmaterials“, die im Rahmen der vorliegenden Arbeit unternommen wurde, konnte keine neuen Befunde zutage fördern. Vgl. Schlieder 1966, 92-94, der Conrad Wirt eine aktive Rolle an der Einführung der Papierproduktion, wie sie Ulman Stromer in Nürnberg innehatte, abspricht. In einigen späteren Darstellungen zur Ravensburger Papiermacherei wird der Kaufmann Conrad Wirt in Anlehnung an Lore Sporhan-Krempel dennoch als ihr Begründer angegeben, vgl. Preger 1979, 3; Eitel 1990, 47; Preger 1992, 2; Siewert 2004, 1183; Rückert 2010, 115. 1407 Vgl. Sporhan-Krempel 1953, 16. 
weise die einer Getreidestampfe, einer Gewürz- oder Pulverstampfe, einer Loh- oder Waidstampfe oder einer Flachs- oder Hanfstampfe. ${ }^{1408}$

Die stampfes mülin des Conrad Wirt ging nach seinem Tod an seine Tochter Anna Holbain. Diese übergab die Mühle ebenso wie ihre Walke in Erbleihe an die Kinder von Johannes Segelbach, Jos und Haintz Segelbach. ${ }^{1409}$ Ein gutes Jahr später, im Oktober 1411, wurden das erste Mal die Papierhäuser genannt, von denen Anna Holbain jährlich Zinsen bezog. ${ }^{1410}$ Wer sie zu diesem Zeitpunkt innehatte, ist leider nicht erwähnt. Im Jahr 1413 wurden jedoch die Kinder von Johannes Segelbach als Besitzer der Papierhäuser genannt. ${ }^{1411}$ Ob es sich bei den Papierhäusern um Gebäude handelte, die zu der stampfes mülin gehörten, die Jos und Haintz Segelbach 1410 erworben hatten, ist nicht mit letzter Sicherheit zu sagen. Während Gerhard Piccard dies bezweifelt, spricht sich Lore Sporhan-Krempel für ihre Gleichsetzung aus. ${ }^{1412}$

Legitimieren diese Ergebnisse auf der einen Seite die Gleichsetzung von den Papierhäusern und der Stampfmühle, wie sie Sporhan-Krempels vornimmt, so rütteln sie auf der anderen Seite an der bislang tradierten Anzahl der Papiermühlen im mittelalterlichen Ravensburg, die ebenfalls auf Angaben von Sporhan-Krempel fußt. Die Papierforscherin geht bereits für den Beginn des 15. Jahrhunderts von insgesamt drei Papiermühlen im Ölschwang aus: Zu der als Papiermühle identifizierten Stampfmühle zählt sie zwei weitere Papierhäuser, die sie in den drei Hofstätten oberhalb der Stampfmühle vermutet. Bestärkt sieht Sporhan-Krempel ihre Vermutung durch die Nennung der drei Papierhäuser im Jahr 1498. ${ }^{1413}$ Mit den zwei Papiermühlen in Schornreute, die im Folgenden noch näher behandelt werden, sollen um die Mitte des 15. Jahrhunderts fünf Papiermühlen in Ravensburg bestanden haben. ${ }^{1414}$ Verfolgt man die oben entwickelte Hypothese jedoch konsequent, so existierte im 15. Jahrhundert im Ölschwang lediglich eine Papiermühle, das heißt ein Stampfwerk mit drei Papierhäusern.

Im Jahr 1498 verkaufte Felix Humpis dieses Papiermühlenensemble - wie wir bereits gesehen haben - an die Papiermacher Hans Wäch und Hans Schmid. Wann es zu seinen Händen gekommen war, ist nicht festzustellen. Lore Sporhan-Krempel

1408 Vgl. Elmshäuser et al. 1993, 890.

1409 StR, Urk. 756 (20.05.1410); Urk. 757 (26.05.1410). Vgl. Alfred Schulte 1953, 15-17.

1410 StR, Urk. 613 (31.10.1411). Vgl. Alfred Schulte 1953, 17.

1411 StR, Urk. 759 (28.08.1413): Ouch ist geredt $d z$ wir und unß nachkomen Segelbachs kinden oder wer denn die bappir hüser inn hat. In einer Urkunde von 1415 erscheint hingegen Johannes Segelbach selbst als Inhaber der Papierhäuser, vgl. SpR, Urk. 3624 (05.12.1415). Vgl. Alfred Schulte 1953, 17 f.; Sporhan-Krempel 1953, 20-22; Piccard 1962, 98.

1412 Vgl. Sporhan-Krempel 1953, 20 f.; Piccard 1962, 98.

1413 Vgl. Sporhan-Krempel 1953, 20.

1414 Vgl. Sporhan-Krempel 1953, 24; Preger 1979, 4; Eitel 1990, 48; Preger 1992, 3; Siewert 2004, 1183; Rückert 2010, 116. Auch noch in Schultz/Follmer 2015, 13 f. 
vermutet, dass es sich bereits im Besitz seines Vaters Wilhelm Humpis befand. ${ }^{1415}$ Von Hans Wäch und Hans Schmid erwarben im Jahr 1513 die Papierer Hans Härb und Jörg Wolfartshofer die Liegenschaft. Sie wurde zu diesem Zeitpunkt beschrieben als die under Bappirmüli zu Ravenspurg vorm oberthor allernächst ob Tollingers müli gelegen, genant auff vederburg. ${ }^{1416}$ Hiermit ist wohl zum ersten Mal der später gängige Name Federburg belegt. ${ }^{1417}$ Bis in die 1570er-Jahre lassen sich keine weiteren Papiermühlenbesitzer namentlich fassen. ${ }^{1418}$

In der Vorstadt Schornreute, dort, wo nach dem Zeugnis Ladislaus Sunthayms das Ravensburger Papier mit dem Ochsenkopf hergestellt wurde, entstand die erste Papiermühle zu Beginn der 1430er-Jahre durch die Initiative der drei Papiermacher Peter Bappirer, Cuntz Wolfartshofer und Hans Stengeli. Als diese im Jahr 1432 bauliche Veränderungen am Bachbett vornehmen wollten, klagte Heinrich Gelderich dagegen. Zwar könne er gegen das Papierhaus nichts sagen, der Bau am Flappach solle jedoch unterbunden werden. ${ }^{1419}$ Gelderich hatte mit seiner Klage keinen Erfolg. Erfolg hatten aber anscheinend die drei Papiermacher, denn sie errichteten im Jahr 1436 ein zweites Papierhaus, das unterhalb des ersten Betriebs, das heißt flussabwärts lag. ${ }^{1420}$ Aus einer Urkunde aus dem Jahr 1437 geht hervor, dass eines dieser Papierhäuser zuvor eine Kornmühle war. ${ }^{1421}$ Die beiden Betriebe verblieben nach Ausweis der Steuerbücher bis zur Mitte des 16. Jahrhunderts im Besitz der Familie Wolfartshofer. ${ }^{1422}$ Vermutlich um 1545 erwarb der Säckler und Händler Jörg Sauter d. Ä., der auch als Vormund der Kinder von Hans Wolfartshofer fungierte, die äußere Papiermühle in Schornreute. ${ }^{1423}$

1415 Vgl. Sporhan-Krempel 1953, 20.

1416 StR, Urk. 690 (13.05.1513). Vgl. Alfred Schulte 1953, 23.

1417 Alfons Dreher gibt an, dass der Name Federburg bereits im 15. Jahrhundert gebräuchlich war, vgl. Dreher 1972, Bd. 1, 126. Dies konnte anhand der eingesehenen Quellen nicht bestätigt werden.

1418 Erst ab dieser Zeit verbessert sich die Quellenlage, sodass die Reihe der Papiermühlenbesitzer nachgezeichnet werden kann, vgl. Sporhan-Krempel 1953, 112-114.

1419 StR, Urk. 1216 (11.01.1432): [...] und clegt sich da Hainrich Gäldrich mit sinem fürsprechen Josen Huntpiß zu den yetzgenanten bapyrern also wie das sich die understanden hetten ain bappirhus ze machen da ze Schornrüti dar in er in nütz redte aber doch so hetten si in fürgenomen einen buw ze tun underhalb der müli [...] Vgl. Alfred Schulte 1953, 20; Sporhan-Krempel 1953, 23.

1420 StR, Urk. 723 (03.02.1436). Vgl. Alfred Schulte 1953, 21; Sporhan-Krempel 1953, 23.

1421 Vgl. Alfred Schulte 1953, 21. Friedrich Gutermann datierte 1845 dieses Zeugnis auf das Jahr 1407 und verlegte somit die Anfänge der Papiermacherei in Schornreute mehr als zwanzig Jahre vor, Gutermann 1845, 278. Diesen Irrtum übernahmen einige spätere Papierforscher, vgl. Sotzmann 1846, 107; V. Thiel 1932, 113; V. Thiel 1941, 49 mit Anm. 1.

1422 StR, Bü 42, Steuerbuch 1473-1476, 1r-1v; Bü 43, Steuerbuch 1482-1485, 1r-1v; Bü 45, Steuerbuch 1497-1499, 1r-1v; Bü 46, Steuerbuch 1504-1506, 1r-1v; Bü 47, Steuerbuch 1506-1508, 1r-1v; Bü 48, Steuerbuch 1512-1514, 3r-3v; Bü 49, Steuerbuch 1521-1524, 3r-3v; Bü 50, Steuerbuch 1545, 3r, 4v.

1423 Vgl. Sporhan-Krempel 1953, 30. Zur Vormundschaft Sauters, vgl. StR, Bü 50, Steuerbuch 1545, 5r. 
Es ist ungewiss, wie viele Papiermühlen zwischen den Anfängen der Ravensburger Papiermacherei und 1550 tatsächlich betrieben wurden. In der Vorstadt Schornreute waren es vermutlich zwei Betriebe, im Ölschwang arbeiteten je nach Interpretation der Quellen eine bis drei Papiermühlen. Alle diese Werke wurden vom Flappach betrieben, der noch heute wenige Kilometer südlich von Ravensburg bei Kemmerlang entspringt und im Osten der Stadt in die Schussen mündet. ${ }^{1424}$ Die wasserbetriebenen Mühlwerke vor und in der Stadt lagen alle an diesem Wasserlauf, der vermutlich zu Beginn des 14. Jahrhunderts kanalisiert worden war, um ein für das Antreiben von Mühlrädern ausreichendes Gefälle zu schaffen. ${ }^{1425}$ Innerhalb der Stadtmauern und in ihrer Umgebung standen vor allem Kornmühlen, während flussaufwärts in Richtung Schornreute vornehmlich Schleifmühlen arbeiteten. ${ }^{1426}$

\subsubsection{Augsburg}

In der Reichsstadt Augsburg wurde die erste Papiermühle möglicherweise um 1460 von dem Drucker Johann Schüßler eingerichtet. ${ }^{1427}$ Diese Annahme stützt sich ausschließlich auf Wasserzeichenbelege: So erscheint zu Beginn der 1460er-Jahre ein Element des Augsburger Stadtwappens - der Pinienzapfen, auch Zirbelnuss oder Pyr genannt - als Wasserzeichen. ${ }^{1428}$ Es wird zudem vermutet, dass die Gründung der ersten Papiermühle an der Sinkel mit der Anlage dieses Kanals, dem heutigen Senkelbach im Norden Augsburgs, und neuer von ihm angetriebener Mühlwerke gegen Ende der 1440er-Jahre zusammenfiel. So stand die obere Papiermühle an der Sinkel zwischen zwei Kornmühlen, die 1456 beziehungsweise 1458 vollendet waren. ${ }^{1429}$ Ob dieses Mühlgebäude allerdings bereits zu dieser Zeit als Papiermühle angelegt worden war oder ob es sich um einen anderen Mühlentyp handelte, kann nicht gesagt werden. Einen eindeutigen Beweis für die Existenz einer Papiermühle in Augsburg in den 1460er-Jahren liefert der Kanalneubau daher nicht.

Erste Textzeugnisse, die eine Papierproduktion in Augsburg belegen, sind erst für die Mitte der 1480er-Jahre überliefert. Die obere Papiermühle an der Sinkel befand sich von circa 1485 bis 1494 im Besitz des Buchdruckers Anton Sorg. Von diesem übernahm der Papiermacher Hans Oesterreicher im Jahr 1495 die Mühle. Er betrieb sie bis zu seinem Tod 1527/28 mehr als dreißig Jahre lang. Danach führte seine Witwe Anna

1424 Vgl. Dreher 1972, Bd. 1, $120 \mathrm{f}$.

1425 Vgl. Dreher 1972, Bd. 1, 121.

1426 Vgl. Dreher 1972, Bd. 1, 122-125. Über die mittelalterlichen Mühlwerke in und um Ravensburg herrscht keine vollkommene Klarheit, sodass für den Untersuchungszeitraum keine Verortung der Papiermühlen innerhalb des Ravensburger Mühlenreviers vorgenommen werden kann.

1427 Vgl. Hößle 1907, 7; Haemmerle 1937/38, 136, 172 f., 176; F. Schmidt 1997, 75, 91.

1428 Vgl. Hößle 1907, 5 u. Tafel 1; Hößle 1926a, 118, Abb. 213-218; F. Schmidt 1997, 75 f.

1429 Vgl. Hößle 1907, 5; F. Schmidt 1997, 75. 
Oesterreicher die Werkstatt bis 1540/41 weiter. Der nächste Besitzer, Georg Lang, war ebenfalls ein Papiermacher und wirkte bis 1581 in der oberen Papiermühle. ${ }^{1430}$

Die zweite Papierwerkstatt Augsburgs war die untere Papiermühle an der Sinkel, die seit 1483 durch einen Eintrag im Steuerbuch nachweisbar ist. Von 1485 bis 1487 gehörte sie dem Drucker Johann Bämler. Anschließend befand sie sich bis $1521 \mathrm{im}$ Besitz des Papiermachers Hans Widmann d. Ä., dessen gleichnamiger Sohn den Betrieb bis 1543 weiterführte. In diesem Jahr erwarb der Papierer Antoni Fietz, auch Fieg genannt, die untere Papiermühle. ${ }^{1431}$

Ein drittes Werk, die kleine Papiermühle an der Sinkel, die der oberen Papiermühle gegenüberlag, wurde 1503/4 von Gladius Buchmair errichtet. Bis sie 1530 an den Ölmüller Conrad Greiner kam, durchlebte sie vier Handwechsel. In den Jahren zwischen 1505 bis 1507 war sie im Besitz des Papiermachers Gallus Oberdorfer. Von 1509 bis 1516 ist ein Oswald Mayr als Inhaber belegt, sein Nachfolger war von 1517 bis 1520 ein Papierer mit Namen Alhailig. Von diesem kam die Papiermühle um 1520 an Hans Oesterreicher, der somit zwei Papiermühlen sein Eigen nannte. Im Jahr 1530 verkaufte seine Witwe Anna das Mühlwerk an Conrad Greiner, der darin vermutlich eine Ölmühle betreiben wollte. Auf die Produktion von Papier auf diesem Grundstück musste er jedenfalls vertraglich auf alle Zeit verzichten. ${ }^{1432}$ Der vierten Papiermühle vor dem Schwibbogen beim Roten Tor war nur eine kurze Lebensdauer bescheiden. Sie gehörte von 1491 bis 1493 dem Buchdrucker Johann Schönsperger d. Ä. und ist bereits 1494 in den Quellen nicht mehr nachweisbar. ${ }^{1433}$

\subsubsection{Kempten}

Im 18. Jahrhundert gab es nicht nur Stimmen, die die Ursprünge der deutschen Papierproduktion in Basel vermuteten. Auch Kempten stand im Ruf, Standort der ersten Papiermühle im deutschsprachigen Raum zu sein. Johann Gottlob Immanuel Breitkopf und Georg Friedrich Wehrs geben - allerdings hier ohne Beleg - an, dass der Philologe Johann Albert Fabricius diese erste Papierwerkstatt für das Jahr 1477 in Kempten vermutet. ${ }^{1434}$ Übernommen wurde diese Angabe von Gerhard Piccard unter Hinzufügung einer Quellenstelle. ${ }^{1435}$ Die Überprüfung dieses Belegs führte jedoch ins Leere: In der dritten Auflage der Bibliographia antiquaria von Johann Albert Fabricius von 1760 wird auf den betreffenden Seiten zum Thema Papier weder auf Kempten

1430 Vgl. Hößle 1907, 7; Haemmerle 1937/38, 136, 138, 155, 161; F. Schmidt 1997, 76 f., 91 f.

1431 Vgl. Hößle 1907, 11 f.; Haemmerle 1937/38, 136, 146, 155, 177; F. Schmidt 1997, 76, 91 f.

1432 Vgl. Hößle 1907, 11; Hößle 1926a, 128; Haemmerle 1937/38, 136, 138, 145, 148, 165, 170; F. Schmidt 1997, $76 \mathrm{f}$.

1433 Vgl. Hößle 1907, 13; Haemmerle 1937/38, 136, 172; F. Schmidt 1997, 76, 91.

1434 Vgl. Breitkopf 1784, 105; Wehrs 1788, 274.

1435 Vgl. Piccard 1962, 88 f. Piccard gibt als Beleg an: Fabricius 1760, 957. Übernommen in Petz 2006, 241. 
noch auf das Jahr 1477 verwiesen. ${ }^{1436}$ Vermutlich übernahm Gerhard Piccard, ohne sie zu verifizieren, die bibliographische Angabe, die Breitkopf und Wehrs an anderer Stelle zu Fabricius' Werk und der darin enthaltenen Passage zum Papier machten. ${ }^{1437}$ Rätselhaft bleibt, woher diese beiden Autoren ihre Informationen über die erste Kemptener Papiermühle von 1477 bezogen.

Wie im Beispiel zur Basler Überlieferung steckt aber auch in dieser Legende mehr als ein Körnchen Wahrheit. Denn das Jahr 1477 als Beginn der Kemptener Papiermacherei wird auch durch ein anderes Zeugnis bestätigt. In seiner ab 1606 verfassten Chronik präzisiert der Prediger Christoph Schwarz, dass im Jahr 1477 die erste Kemptener Papiermühle an der Iller eingerichtet wurde und zwar in einem ehemaligen Hammerwerk. ${ }^{1438}$ Es habe sich hierbei um eine Hammerschmiede gehandelt, die beim Dorf Kottern südlich von Kempten lag. Die Angabe Christoph Schwarz' wird - auch in diesem Fall - durch Wasserzeichenbelege gestützt. ${ }^{1439}$ Das erste zeitgenössische Textzeugnis stammt aus dem Jahr 1488 und datiert damit rund zehn Jahre später als das vermutliche Gründungsdatum. Es handelt sich um eine Klage des Fürstabts Johann von Riedheim gegen den Neubau und die Erweiterung von Mühlen durch die Reichsstadt Kempten, die er im Rahmen von Auseinandersetzungen zwischen Fürststift und Reichsstadt führte und die in kopialer Überlieferung aus dem Jahr 1715 erhalten ist. ${ }^{1440}$

Die erste Papiermühle Kemptens lag also bei Kottern in der Pfarrei St. Mang an der Iller und diente zuvor als Hammerwerk. Sie wurde offenbar auf Initiative der Stadt eingerichtet. ${ }^{1441}$ Wer der erste Pächter war, ist nicht zweifelsfrei festzustellen. Der erste bekannte Betreiber war Bernhard Baschgott aus dem piemontesischen Caselle, der 1501 erstmals erwähnt wurde. Seine Witwe Margareth besaß das Werk noch bis 1519. ${ }^{1442}$ Für die Jahre zwischen 1519 und 1528, als die Papiermühle noch städtisches Eigentum war, sind keine weiteren Namen von Werksleitern überliefert. Im Jahr 1528 kaufte der Papiermacher Peter Stähelin die Mühle und verpflichtete sich vertraglich dazu, sie nur zur Papierherstellung einzusetzen, das Werk nicht umzubauen und es nur an einen Bürger der Stadt zu veräußern. Er bewirtschaftete es circa 20 Jahre, bis er es Ende der 1540er-Jahre an seinen Berufsgenossen Martin Mayr verkaufte. ${ }^{1443}$ Die zweite Kemptener Papiermühle lag ebenfalls bei Kottern an der Iller und wurde vermutlich vor 1502 eingerichtet. Seit diesem Jahr betrieb sie der Papiermacher Wolf Berchtricht, dessen Nachfolger 1519 Bernhard Walch wurde. Dieser hatte zuvor offensichtlich in der Papiermühle von Johann Schönsperger d. Ä. in Augsburg gearbei-

1436 Vgl. Fabricius 1760, 957-959.

1437 Vgl. Breitkopf 1784, 45 mit Anm. c; Wehrs 1788, 174 mit Anm. a.

1438 Vgl. Petz 2006, 242.

1439 Vgl. Piccard 1966, Bd. 1, 34, 233, Abteilung XV, Typ 421. Vgl. Petz 2006, 243.

1440 Vgl. Petz 2006, $242 \mathrm{f}$.

1441 Vgl. Geldner 1968a, 3.

1442 Vgl. Petz 2006, 260, 295.

1443 Vgl. Petz 2006, 296. 
tet. ${ }^{1444}$ Im Jahr 1528 ging auch diese zweite Papiermühle aus dem Besitz der Stadt Kempten in den Besitz eines Papiermachers über. Moritz Staiger, dem ebenfalls zur Auflage gemacht wurde, die Mühle nur zur Papierherstellung zu verwenden, baulich nicht zu verändern und nur an einen Kemptener Bürger zu verkaufen, besaß das Mühlwerk bis zu seinem Tod 1560. ${ }^{1445}$

Weiter südlich am Westufer der Iller in Hegge wurde wahrscheinlich vor 1506 die Produktion in einer dritten Papiermühle aufgenommen. ${ }^{1446}$ Diese lag im Gegensatz zu den beiden ersten Papiermühlen nicht auf reichsstädtischem Territorium, sondern auf dem Gebiet des Fürststifts Kempten. Als Besitzer des Werks wurde 1506 der Papiermacher Marx Baruttel genannt, dessen Witwe Ursula Ostner den Betrieb nach seinem Tod zusammen mit dem gemeinsamen Sohn Anton Baruttel weiterführte. Wann die Papiermühle an den Papierer Caspar Hitzlenberger kam, ist ungewiss. Sie verblieb jedoch bis 1543 in seinem Besitz. Danach erwarb Jörg Hensler das Papierwerk zu Hegge. ${ }^{1447}$

Ebenfalls auf stiftischem Territorium lag die vierte vor 1550 in Betrieb genommene Papiermühle. Bei Weidach, das zur Pfarrei Durach zählte, erbaute der Papiermacher Wolff Morga mit Erlaubnis des Fürstabts im Jahr 1519 eine Papierwerkstatt an der Iller. ${ }^{1448}$ Für die darauffolgenden Jahrzehnte sind keine Betreiber dieser Mühle bekannt, da nicht festzustellen ist, ob der 1536 und 1541 genannte Papierer Bastian Reibel sowie der 1549 erwähnte Martin Marxenn Werksleiter oder lediglich Gesellen waren. ${ }^{1449}$

\subsubsection{Memmingen}

Die erste Papiermühle Memmingens wurde auf die Initiative eines Memminger Bürgers am Heuenbach errichtet, der in einer Süd-Nord-Achse östlich der Stadt verläuft. Im Jahr 1478 baute Ulrich Frey d. Ä. ein schleiffmülin genanntes Mühlwerk zu einer Papiermühle um und verpachtete sie an einen unbekannten Papiermacher. $\mathrm{Ob}$ dieses Werk zuvor tatsächlich als Schleifmühle betrieben wurde, ist nur zu vermuten. Ulrich Frey veräußerte die Papiermühle im April 1485 an das Spital zu Memmingen. ${ }^{1450}$ Im Dezember 1493 verkaufte Anna Karthenmalerin, die Witwe des Papierma-

1444 Vgl. Künast 1997, 112; Petz 2006, 295.

1445 Vgl. Petz 2006, 297. Hier nennt Petz die Jahreszahl 1526, auf S. 246 schreibt er jedoch, dass beide Kotterner Papiermühlen im Jahr 1528 in Privatbesitz übergingen.

1446 Vgl. Petz 2006, 290 f. Zur Anfangszeit dieser Papiermühle vermeldet Friedrich von Hößle lediglich nicht sehr präzise, dass sie zwischen 1477 und 1584 in Betrieb genommen wurde, vgl. Hößle 1895, 74. Auch Ferdinand Geldner wusste noch keine konkreten Jahreszahlen zu nennen, vgl. Geldner 1968a, 5.

1447 Vgl. Petz 2006, 290-292.

1448 Vgl. Petz 2006, 299.

1449 Vgl. Petz 2006, 299.

1450 Vgl. Piccard 1960, 595 f. 
chers Peter Fort, der die zweite Memminger Papiermühle pachtete, ihre Rechte an der Einrichtung der Papiermühle am Heuenbach ebenfalls an das Spital. Gerhard Piccard schließt daraus, dass Peter Fort beim Umbau der Schleifmühle in eine Papiermühle beteiligt war und im Zuge dessen Rechte auf die Einrichtung der Papiermühle erworben hatte. Diese Rechte wurden ihm nach dem Kauf der Papiermühle durch das Spital 1485 im Jahr 1487 bestätigt. Mit dem Verkauf der Rechte verzichtete Anna Karthenmalerin auf jeglichen Anspruch an der Papiermühle am Heuenbach. ${ }^{1451}$ Über das weitere Schicksal dieser Mühle ist nichts bekannt. ${ }^{1452}$

Im Jahr 1482 wurde auf Betreiben der Stadt eine zweite Papiermühle von Grund auf neu gebaut. Sie lag nach Ausweis einer Urkunde im Ried an der Ach und wurde dem Papiermacher Peter Fort, der auch an der Einrichtung der ersten Papiermühle beteiligt war, auf 20 Jahre verliehen. ${ }^{1453}$ Peter Fort starb jedoch schon vor Ende des Jahres 1493. Von den weiteren Pächtern dieser Mühle sind lediglich Gregory Schütz und Dominikus Meyr bekannt. Schütz pachtete das Werk im Jahr 1502 auf zehn Jahre, zwei Jahre später wurde es jedoch bereits an Dominikus Meyr vergeben. Weitere Nachrichten über diese Memminger Papiermühle fehlen. Gerhard Piccard nimmt an, dass sie 1525 im Bauernkrieg zerstört wurde. Erst 1560 wurde erneut eine Papiermühle am Heuenbach erwähnt. ${ }^{1454}$

\subsubsection{Söflingen}

In den 1460er-Jahren wurde wahrscheinlich nur für kurze Zeit auf den Besitzungen des Klarissenklosters Söflingen bei Ulm eine Papiermühle betrieben. ${ }^{1455}$ Für die Existenz dieses Werks können lediglich drei Belege herangezogen werden, von denen wiederum nur einer datiert ist. Das Jahr der Werksgründung ist daher nicht bekannt, allerdings sprechen mehrere Hinweise für die Mitte der 1460er-Jahre. ${ }^{1456} \mathrm{Zu}$ dieser Zeit erhielt der Papiermacher Anton Dasell von Elisabeth Züllenhart, Äbtissin des Klosters zu Söflingen, eine Liegenschaft, auf der ein Schleifstein und eine blaw, also vermutlich eine Bluwenmühle, standen. Diese durfte der Papiermacher abreißen und auf eigene Kosten eine Papiermühle errichten. ${ }^{1457}$

Anton Dasell ging nach Ausweis eines weiteren Dokuments einen Gesellschaftervertrag mit einem anderen Papiermacher, Anton Wyß, ein. In diesem Vertrag, der

1451 Vgl. Piccard 1960, 597 f. Friedrich von Hößle interpretiert dieses Dokument fälschlicherweise als Vertrag über den Verkauf der zweiten Memminger Papiermühle, vgl. Hößle 1926b, 223.

1452 Vgl. Piccard 1960, 598.

1453 Vgl. Hößle 1926b, 223; Piccard 1960, 596 f.

1454 Vgl. Piccard 1960, 598.

1455 Vgl. Alfred Schulte 1941; Frauenknecht 2015, 99.

1456 Vgl. Alfred Schulte 1941, 98 f.; Frauenknecht 2015, 102 f.

1457 Dieser Beleg ist nur in Kopialüberlieferung aus dem 17. Jahrhundert auf uns gekommen, vgl. Alfred Schulte 1941, 95 f.; Frauenknecht 2015, 102, dort auch ein Abdruck der Belegstelle auf S. 100. 
lediglich als zeitgenössischer Entwurf ohne Datumsangabe erhalten ist, wurde er Anton Turwel sowie in den Varianten Tirwel und Truwel genannt. Dass es sich bei Anton Dasell und Anton Turwel um dieselbe Person handelt, erhellt die Tatsache, dass Anton Turwel als Erbauer der Papiermühle angesprochen wurde. ${ }^{1458}$ Plausibel interpretiert Erwin Frauenknecht den Namen Dasell als Bezeichnung des Herkunftsorts Antons. Gestehe man dem frühneuzeitlichen Kopisten nämlich eine Verschreibung zu, so könne Dasell auf das piemontesische Caselle bei Turin verweisen. ${ }^{1459}$ Während Schulte die Entstehung dieses Dokuments für die Zeit nach 1469 ansetzt, vermutet Frauenknecht, dass der Gesellschaftervertrag kurze Zeit nach dem Bau der Papiermühle, also bereits drei bis vier Jahre zuvor, zustande kam. Ein Endpunkt sowohl für den Vertrag als auch für die Papiermühle ist vermutlich im Rechtsstreit zwischen dem Kloster Söflingen als Eigentümer der Mühle und Krafft Schuchmacher von Söflingen vom Juni 1469 zu fassen. Krafft Schuchmacher klagte, dass der Bau der Papiermühle, neben der sich sein Haus und Hof befinde, und die damit einhergehende Veränderung des Wasserzuflusses seinem Grundstück durch Überschwemmung großen Schaden zugefügt hätten. ${ }^{1460}$ Obgleich dem Kloster die Erlaubnis zum Betreiben der Papiermühle seitens der Schiedsleute zugesagt wurde, finden sich nach diesem Datum keine weiteren Hinweise auf eine Weiterführung des Betriebs. ${ }^{1461}$ Die Söflinger Papiermühle bestand somit vermutlich nur wenige Jahre.

\subsubsection{Bern}

Das neue Gewerbe der Papiermacherei muss sich in Bern bereits vor 1466 etabliert haben, denn in diesem Jahr wurden erstmals zwei Papiermühlen an der Worblen erwähnt. Das eine Werk lag etwa 5 Kilometer nördlich von Bern bei Worblaufen am rechten Ufer der Worblen vor ihrer Einmündung in die Aare. ${ }^{1462}$ Als Besitzer wurden zu diesem Zeitpunkt der als Weinhändler und Papiermacher bezeichnete Tschan Jacki und sein Sohn Anton genannt. ${ }^{1463}$ Papier wurde in diesem Werk jedoch nur bis 1470 hergestellt. In diesem Jahr erwarb der Berner Rat die Papiermühle und baute sie zu einer Walke um. ${ }^{1464}$ Bis 1654 wurde in Worblaufen keine Papiermühle mehr betrieben, sodass diese mittelalterliche Gründung lediglich fünf bis höchstens zehn Jahre in Betrieb war. ${ }^{1465}$

1458 Vgl. Frauenknecht 2015, 103.

1459 Vgl. Frauenknecht 2015, 103.

1460 Vgl. Alfred Schulte 1941, 96-98; Frauenknecht 2015, 103.

1461 Vgl. Frauenknecht 2015, 103.

1462 Vgl. Fluri jun. 1954, 79; Fluri jun. 1975, 27.

1463 Der Familienname Jacki findet sich auch in den Versionen Jaggi, Jecki, Jaque. Der Taufname Tschan ist die Berner Verschriftlichung des Namens Jehan - Johann, vgl. Fluri sen. 1896, 193; Fluri jun. 1954, 47; J. Lindt 1964, 77; Fluri jun. 1975, 7.

1464 Vgl. Fluri sen. 1896, 195; Fluri jun. 1954, 79; J. Lindt 1964, 78; Fluri jun. 1975, 27.

1465 Vgl. Fluri jun. 1954, 79; Fluri jun. 1975, 27. 
Ebenfalls im Jahr 1466 ist erstmals die zweite Papiermühle auf Berner Gebiet belegt. Sie lag weiter flussaufwärts in Ittingen in der heutigen Gemeinde Bollingen am linken Ufer der Worblen und wurde Papiermühle zu Thal genannt. Auch dieses Werk muss zu diesem Zeitpunkt bereits einige Jahre in Betrieb gewesen sein. Das Datum der Gründung konnte jedoch bislang nicht festgestellt werden. Der vermutliche Gründer, der Geldwechsler Antonio von Novara, verkaufte die Papiermühle jedenfalls im Jahr 1466 wegen Schulden an Tschan Jacki und dessen Sohn Anton, die wie oben beschrieben schon die Papiermühle zu Worblaufen besaßen. ${ }^{1466} \mathrm{Im}$ Jahr 1467 erhielt Anton Jacki die 1470 erneuerte Zusicherung des Rats, dass keine andere Papiermühle auf Berner Territorium erbaut werden dürfe. ${ }^{1467}$

Seit 1469 betrieben die Jacki ihre Papiermühle nicht selbst, denn in diesem Jahr verpachteten sie ihre Mühle auf zehn Jahre an den Papiermacher Jehan Pastor von Caselle. ${ }^{1468}$ Offenbar trugen sie sich bereits mit dem Gedanken, den Betrieb zu veräußern, da sie ihrem Pächter ein Vorkaufsrecht versprachen, das zudem eine Preisreduzierung von 4 Gulden auf den anderweitig gebotenen Kaufpreis enthielt. ${ }^{1469}$ Die Papiermühle blieb jedoch noch weitere fünf Jahre im Besitz der Jacki. Zu Beginn des Jahres 1474 kaufte dann der Basler Papiermacher Anton Gallician zusammen mit seinen beiden Schwiegersöhnen Michel Warmund und Jacob Meyer das Werk und übertrug Michel Warmund die Leitung. ${ }^{1470}$ Jacob Meyer fungierte vor allem als Kreditgeber und lieh seinem Schwiegervater und seinem Schwippschwager mit 450 Gulden einen Großteil der Kaufsumme von 600 Gulden. Michel Warmund ist bis zum Jahr 1483 in Bern fassbar. ${ }^{1471}$ Die nächste Nachricht über die Papiermühle zu Thal betrifft eine Enneli Burkart. Sie verkaufte das Mühlwerk im Jahr 1491 an die piemontesischen Papiermacher Michel Pol und Constanz zu Worwe. ${ }^{1472}$

1466 Vgl. P. Tschudin 1991, 31.

1467 Vgl. J. Lindt 1964, 77; Fluri sen. 1896, 193, 195; Fluri jun. 1954, 47, 79; Fluri jun. 1975, 7, 27.

1468 Vgl. J. Lindt 1964, 77. Adolf Fluri sen. und Adolf Fluri jun. beziehen den Pachtvertrag mit Jehan Pastor auf die Mühle zu Worblaufen, vgl. Fluri sen. 1896, 195; Fluri jun. 1954, 79; Fluri jun. $1975,27$. Johann Lindt widerlegt dies jedoch überzeugend, indem er darauf verweist, dass im Pachtvertrag von der oberen Papiermühle die Rede ist und es sich bei dieser um die weiter flussaufwärts gelegene Papiermühle zu Thal gehandelt haben muss, vgl. J. Lindt 1964, 102 mit Anm. 6.

1469 Vgl. Fluri sen. 1896, 195; Fluri jun. 1954, 79; Fluri jun. 1975, 27.

1470 Vgl. Fluri sen. 1896, 197 f.; Fluri jun. 1954, 47; Fluri jun. 1975, 8 f.; Kälin 1974, 204.

1471 Vgl. Kälin 1974, 204. Mit welcher Tochter Anton Gallicians er verheiratet war, ist nicht abschließend geklärt, vgl. hierzu Kälin 1974, 285 mit Anm. 242.

1472 Über die Beantwortung der Frage, wie die Papiermühle in den Besitz von Enneli Burkart kam, herrscht in der Papierforschung keine einheitliche Meinung. Adolf Fluri sen. und in seiner Nachfolge Adolf Fluri jun. vermuten, dass Ennelis Mann Peter Seltzach Eigentümer der Mühle war und Enneli nach seinem Tod als seine Witwe die Papiermühle veräußerte. Der Tod Peter Seltzachs müsste nach dieser These vor oder in das Jahr $1491 \mathrm{zu}$ datieren sein, vgl. Fluri sen. 1896, 200; Fluri jun. 1954, 48; Fluri jun. 1975, 9. Johann Lindt hingegen gibt an, dass Enneli Burkart die Witwe Michel Warmunds war und nach dessen Tod um 1485 die Papiermühle in ihre zweite Ehe mit Peter Seltzach brachte. 
Für die erste Hälfte des 16. Jahrhunderts sind nur vereinzelt Informationen zu den Inhabern der Papiermühle zu Thal überliefert, sodass keine lückenlose Besitzerreihenfolge erschlossen werden kann. Häufig wurde der Betreiber der Papiermühle in den Berner Quellen schlicht und einfach als der Papierer bezeichnet. ${ }^{1473}$ Die bei Fluri jun. für das Jahr 1508 erwähnten Papiermühlenbesitzer Lienhard Schüfferlin und Hans Linder führt Lindt nicht auf. ${ }^{1474}$ Für das Jahr 1529 ist der Papierermeister Franz Bergier belegt, der vermutlich die Papiermühle besaß. ${ }^{1475}$ Lindt vermutet, dass das Werk zu Beginn der 1540er-Jahre im Besitz eines seiner Söhne, Hans Bergier, war. ${ }^{1476}$ Von 1544 bis 1550 ist der Papiermacher Anton Bergier, ebenfalls ein Sohn von Franz Bergier, als Eigentümer der Papiermühle greifbar. ${ }^{1477}$

\subsubsection{Zürich}

Die Anfänge der Züricher Papiermühle auf dem Werd reichen in das Jahr 1471 zurück. Im August dieses Jahres verkaufte Otto im Werd seine Pulverstampfe, die Sägemühle und das Wohnhaus an den Papiermacher Heinrich Walchwiler. ${ }^{1478}$ Die Gebäude lagen auf einer kleinen Insel in der Limmat, Werd genannt, die durch den unteren Mühlensteg mit der rechten Uferseite verbunden war. ${ }^{1479}$ An diesem Steg lagen, wie der Name bereits verrät, bis zu fünf Mühlen, die durch das Limmatwasser betrieben wurden. Seit dem 14. Jahrhundert und bis zu seinem Umbau in eine Pulverstampfe und eine Sägemühle durch Otto im Werd in den 1450er-Jahren hatte das Mühlwerk auf dem Werd als Walkmühle gedient. ${ }^{1480}$ Welches Mühlwerk der Papiermacher Heinrich Walchwiler in eine Papiermühle umbaute, die Sägemühle oder die Pulverstampfe, ist nicht sicher zu sagen. ${ }^{1481}$ Bis um 1480 war Walchwiler vermutlich Eigentümer der Liegenschaft auf dem Werd, zwischen 1480 und 1484/85 bewirtschaftete er die Mühle gemeinsam mit dem Papiermacher Hans Conrad Grebel. Für diese Zeit ist nicht belegt, ob die beiden Papiermacher Eigentümer des Grundstücks waren. ${ }^{1482}$ Vermutlich wurde die Papiermühle im Jahr 1484 durch einen Gläubiger Walchwilers um versessene Zinsen gepfändet und eingezogen. ${ }^{1483}$

Noch zu Lebzeiten ihres zweiten Manns, der im Jahr 1503 noch als lebend erwähnt werde, habe sie die Papiermühle verkauft, vgl. J. Lindt 1964, 78.

1473 Vgl. Fluri sen. 1896, 205 f.; Fluri jun. 1954, 48; Fluri jun. 1975, $10 \mathrm{f}$.

1474 Vgl. Fluri jun. 1954, 48; Fluri jun. 1975, 10; J. Lindt 1964, 78-80.

1475 Vgl. J. Lindt 1964, 79.

1476 Vgl. J. Lindt 1964, 79.

1477 Vgl. Fluri sen. 1896, 206; Fluri jun. 1954, 48; J. Lindt 1964, 80; Fluri jun. 1975, 10 f.

1478 Vgl. Schnyder 1937, 729, Nr. 1248; Zürcher 1963, 120.

1479 Vgl. Zürcher 1963b, 114-116; P. Tschudin 1991, 29.

1480 Vgl. Zürcher 1963b, 116-119; P. Tschudin 1991, 29.

1481 Vgl. Zürcher 1963a, 61; Zürcher 1963b, 121.

1482 Vgl. Zürcher 1963b, 121.

1483 Vgl. Zürcher 1963b, 121. 
Von 1484/85 bis 1513 besaß und leitete Hans Conrad Grebel das Werk alleine. Aber auch er hatte offenbar finanzielle Schwierigkeiten, denn 1491 wurde die Mühle gepfändet und den Gläubigern zugeschlagen. Sie befand sich daraufhin im Besitz von Grebels Gläubiger Ulrich Studer, der Grebel weiterhin auf der Papiermühle arbeiteten ließ. Vor 1513 scheint der Papiermacher die Liegenschaft aber wieder in seinen Besitz gebracht zu haben. ${ }^{1484}$ Interessant ist die Doppelnutzung des Mühlwerks zwischen 1471 und 1513, das neben der Zerkleinerung der Lumpen auch zum Kornstampfen eingesetzt wurde. ${ }^{1485}$ Hiermit verdienten sich die Papiermacher Heinrich Walchwiler und Hans Conrad Grebel anscheinend ein Zubrot. Über den Besitzer der Papiermühle auf dem Werd sind für die Jahre von 1513 bis 1521 keine sicheren Nachrichten erhalten. ${ }^{1486} 1521$ befand sich das Grundstück wohl schon längere Zeit in Besitz der Stadt Zürich, denn aus diesem Jahr verzeichnet ein Bericht des Rats, dass der Wiederaufbau der Papiermühle erst einmal eingestellt werden solle. Der Rat trug sich also bereits vor diesem Jahr mit dem Gedanken, die verlassene Papiermühle wieder instand zu setzen. ${ }^{1487}$ Nach einem weiteren gescheiterten Anlauf in den Jahren 1527 bis 1529, in denen der Rat erste Baumaßnahmen zur Wiedererrichtung ergriff,, ${ }^{1488}$ wurde 1532 endlich mit einem kompletten Neubau der Papiermühle begonnen. ${ }^{1489}$ Dieser war im Herbst 1535 so weit fertiggestellt, dass es zu ersten Verhandlungen mit einem Pächter kam. Die Stadt verlieh die Papiermühle auf dem Werd schließlich dem Drucker Christoph Froschauer, dessen Bruder Eustach, ein Papiermacher, den Betrieb als Werkmeister leitete. ${ }^{1490}$ Die Mitglieder der Familie Froschauer blieben bis 1729 Leheninhaber der Papiermühle auf dem Werd. ${ }^{1491}$ Vor unliebsamer Konkurrenz schützte der Züricher Rat seinen Betrieb, indem er 1552 den Bau einer weiteren Papiermühle auf Züricher Territorium ohne seine Erlaubnis verbot. ${ }^{1492}$

\subsubsection{Urach}

Die älteste Uracher Papiermühle wurde im Jahr 1477 vermutlich auf Initiative des württembergischen Grafen Eberhard im Bart eingerichtet. In diesem Jahr verlieh Eberhard das Mühlwerk als Erblehen an den Papiermacher Anton Terriere. Dieser Vorgang wird durch das lediglich in verschiedenen Repertorien des 17. und 18. Jahrhunderts

1484 Vgl. Zürcher 1963b, $121 \mathrm{f}$.

1485 Vgl. Zürcher 1963a, 92; Zaar-Görgens 2004, 83. Eine solche parallele Nutzung einer Mühle ist auch für Papiermühlen im Troyes des 14. Jahrhunderts belegt, vgl. Rouillard 2010, 155-158.

1486 Vgl. Zürcher 1963b, 123.

1487 Vgl. Zürcher 1963b, 123.

1488 Vgl. Zürcher 1963b, $124 \mathrm{f}$.

1489 Vgl. Zürcher 1963b, 127.

1490 Vgl. Zürcher 1963a, 82; Caflisch 1963, 159, 168; P. Tschudin 1991, 30.

1491 Vgl. Caflisch 1963, 169; P. Tschudin 1991, 30.

1492 Vgl. Caflisch 1963, 165. 
überlieferte Revers des Papiermachers belegt. ${ }^{1493}$ Die Papiermühle lag an der Erms südlich von Urach am Oberen See, der im 18. Jahrhundert - als insgesamt drei Papiermühlen dort arbeiteten - auch als Papiersee bekannt war. ${ }^{1494}$ Wie lange die Papiermühle durch Anton Terriere betrieben wurde, ist nicht bekannt. Während Erwin Frauenknecht das Wasserzeichen dieses ersten Werks nur bis ins Jahr 1487 belegen konnte, geht Friedrich von Hößle davon aus, dass der Betrieb ohne Unterbrechung fortgeführt wurde. ${ }^{1495}$ Das Uracher Wasserzeichen ist zusammengesetzt aus der heraldisch dem Grafen von Württemberg zuzuordnenden Hirschstange und dem Jagdhorn als Stadtwappen Urachs und deutet damit auf die aktive Förderung der Papierherstellung durch Eberhard im Bart hin. ${ }^{1496}$ Da diese Papiermarken hauptsächlich in Inkunabeln entdeckt wurden, die in Urach selbst oder in Ulm gedruckt wurden, liegt die Vermutung nahe, dass Eberhard im Bart, der 1479 den Drucker Conrad Fyner in die Residenzstadt holte, eine gemeinsame Förderung von Papiermacherei und Buchdruck anstrebte. ${ }^{1497}$

Informationen zu der Uracher Papiermacherei gegen Ende des 15. und zu Beginn des 16. Jahrhunderts lassen sich bislang anhand der Forschungsliteratur nur vereinzelt fassen. Zwar werden nach Friedrich von Hößle in den Jahren 1490, 1516, 1523, 1525 und 1542 Namen von Papiermachern in verschiedenen Dokumenten wie beispielsweise einer Wehrliste und einer Türkensteuerliste erwähnt, dies geschah aber ohne Bezug auf die Papiermühle. ${ }^{1498}$ Als Besitzer des Werks wurden seit 1540 die Brüder Hans und Ulrich Heinzelmann genannt. ${ }^{1499}$ Zudem soll bereits am Anfang des 16. Jahrhunderts eine zweite Papiermühle bei Urach eingerichtet worden sein, die 1516 vermutlich von dem Papiermacher Hans Dietz bewirtschaftet wurde. ${ }^{1500}$

\subsubsection{Reutlingen}

Auch für die Anfänge der Reutlinger Papiermacherei gilt, was für andere Papiermühlenstandorte festgestellt werden konnte: Die ersten schriftlichen Zeugnisse, die die örtliche Produktion von Papier belegen, sind mehr als ein Jahrzehnt jünger als die ersten Wasserzeichenbelege. Gerhard Piccard konnte die frühesten Reutlingen zugeschriebenen Wasserzeichen bereits für die Zeit vor 1470 nachweisen. ${ }^{1501}$ Die ersten Textbelege stammen hingegen aus den Jahren 1489 und 1491 und finden sich

1493 Vgl. Frauenknecht 2014, 86, 88; Frauenknecht 2015, 97 f.

1494 Vgl. Frauenknecht 2014, 86 f.

1495 Vgl. Frauenknecht 2015, 104-106; Hößle 1926a, 67; Hößle 1939, 560.

1496 Vgl. Frauenknecht 2014, 90; Frauenknecht 2015, 104.

1497 Vgl. Frauenknecht 2014, 85, 90-95; Frauenknecht 2015, 105 f.

1498 Vgl. Hößle 1926a, 67; Hößle 1939, 560.

1499 Vgl. Hößle 1926a, 67; Hößle 1939, 560.

1500 Vgl. Hößle 1926a, 70; Hößle 1939, 560.

1501 Es handelt sich hierbei um die Minuskel r, vgl. Sporhan-Krempel 1972b, 1518. 
im Spitalzinsbuch der Stadt Reutlingen. ${ }^{1502}$ Aus diesem Zeugnis geht leider nicht hervor, wie viele Papiermühlen zu dieser Zeit betrieben wurden. Fassbar ist nur eine einzige Papiermühle, die vermutlich an der Echaz vor dem Mühltörlein westlich der Stadt lag und Jacob Gallician, dem Sohn des Basler Papiermachers Michel Gallician, gehörte. ${ }^{1503} 1509$ kaufte der Papiermacher und Reutlinger Bürger Jacob Hirten einen Teil einer Messerschmiede, die zu dem bei Reutlingen gelegenen Klosters Zwiefalten gehörte, um daraus eine Papiermühle zu machen. ${ }^{1504}$

Für die darauffolgenden zehn Jahre konnte Lore Sporhan-Krempel keine weiteren Hinweise auf Reutlinger Papiermühlen ermitteln. Erst für das Jahr 1519 kann ein Eindruck von der Anzahl der Werke gewonnen werden. Nach der Belagerung der Stadt durch Herzog Ulrich von Württemberg gaben die Papiermacher ebenso wie die anderen Bürger der Stadt an, welche Schäden ihnen durch den Krieg entstanden waren. In dieser Quelle lassen sich mindestens vier Papiermühlen fassen, die aber leider bis auf eine Ausnahme nicht lokalisiert, sondern nur durch ihren Inhaber bezeichnet werden. Darunter befanden sich auch der Besitzer der Papiermühle zu Zwiefalten, Jacob Hirten, sowie ein Paul Ruep und ein Jacob Ziser. Als viertes Werk ist eine städtische Papiermühle aufgeführt, die bei der St. Leonhard-Kapelle lag. ${ }^{1505}$ Bei zwei weiteren Papiermachern, Conrad Gretzinger und Peter Ziser, ist es ungewiss, ob sie eine Papiermühle besaßen oder ob die Schadenssumme, die sie nannten, andere Besitzungen betraf. ${ }^{1506}$ Mit diesem Dokument erschöpfen sich die Nachrichten über die Reutlinger Papiermühlen bis zur Mitte des 16. Jahrhunderts. Eine lückenlose Besitzerreihe, ja selbst eine genaue Anzahl und Lokalisierung der Papiermühlen, ist auch im Fall Reutlingen nicht zu ermitteln. ${ }^{1507}$

\subsubsection{Ettlingen}

Die Papiermühle zu Ettlingen muss vor 1461 gegründet worden sein, da für den August dieses Jahres bereits ein Rechtsstreit zwischen dem Papierermeister Wilhelm von Paris und dem Straßburger Lumpensammler Dietrich von Dielsperg überliefert ist. Von diesem vor dem Ettlinger Gericht entschiedenen Streitfall erfahren wir durch einem Brief des Schultheißen zu Ettlingen an den Straßburger Rat, der das Datum des 28. Juni 1462 trägt. ${ }^{1508}$ Die Papiermühle war ein markgräfliches Lehen und wurde

1502 Vgl. Sporhan-Krempel 1972b, 1518.

1503 Vgl. Sporhan-Krempel 1972b, 1515 mit Anm. 3, 1518.

1504 Vgl. Hößle 1926a, 78; Sporhan-Krempel 1972b, $1519 \mathrm{f}$.

1505 Vgl. Sporhan-Krempel 1972b, 1521.

1506 Vgl. Sporhan-Krempel 1972b, 1521.

1507 Vgl. Sporhan-Krempel 1972b, 1516, 1535.

1508 Vgl. Sporhan-Krempel 1950, 352; Piccard 1951, 59; Piccard 1967, 118; Stenzel 1985, 99; F. Schmidt 1992, 116. 
Wilhelm von Paris im Jahr 1482 erneut auf zehn Jahre verpachtet. ${ }^{1509}$ Geht man von einer gleichbleibenden Pachtdauer von zehn Jahren aus, so ergibt sich in Anbetracht der Tatsache, dass das Werk bereits vor 1461 existierte, als Gründungsdatum dieser Papiermühle das Jahr 1452. Diese These wird in der Forschung zwar erwähnt, aber auch als spekulativ charakterisiert. ${ }^{1510}$ Für das Jahr 1495 ist ein neuer Leheninhaber in den Quellen zu fassen. Es handelte sich um Claus Gallician, Sohn des Basler Papiermachers Michel Gallician. ${ }^{1511}$ Dieser pachtete die Papiermühle ebenfalls auf zehn Jahre, verließ Ettlingen jedoch bereits nach fünf Jahren wieder und kehrte nach Basel zurück. Da sein Pachtvertrag noch nicht ausgelaufen war, stellte er mit dem Papiermacher Gallus Beck einen Ersatzmann, der an seiner Stelle das Werk bis 1505 betreiben sollte. Claus Gallician bürgte zudem vollumfänglich für ihn. ${ }^{1512}$

$\mathrm{Ab}$ diesem Zeitpunkt gehen die Hypothesen der Forschung über die Betreiber der Papiermühle und den zeitlichen Ablauf auseinander. In seinem Aufsatz aus dem Jahr 1951 schreibt Gerhard Piccard, dass der Pachtvertrag mit Gallus Beck nicht zustande gekommen und an seiner statt im Jahr 1502 Wendel Spengler als neuer Pächter eingesetzt worden sei. Dieser habe die Mühle bis 1515 bewirtschaftet. Sein Nachfolger sei ab 1515 Andreas Beck, der Bruder des erst kürzlich verstorbenen Gallus Beck, geworden. ${ }^{1513}$ Diese Darstellung übernahm Frieder Schmidt in einem Beitrag aus dem Jahr 1992. ${ }^{1514}$ In seinem Aufsatz über die Basler Papierherstellung von 1967 scheint Gerhard Piccard zu neuen Erkenntnissen gekommen zu sein, allerdings ohne Bezug auf seinen vorhergehenden Beitrag zu nehmen. Er gibt an, dass Gallus Beck noch vor Ablauf der Vertragslaufzeit verstorben sei, sodass mit Wendel Spengler im Jahr 1502 ein neuer Pächter eingesetzt worden sei. Dieser sei bis 1515 auf der Mühle verblieben. Sein Nachfolger sei ab 1515 der Bruder des vor mehr als 13 Jahren verstorbenen Gallus Beck, Andreas Beck, geworden. ${ }^{1515}$

Nach Rüdiger Stenzel sei Gallus Beck zwar auch bereits vor Ablauf des Vertrags verstorben, und zwar kurz nach Abschluss desselbigen im Jahr 1500, allerdings soll anschließend sein Bruder Andreas den Betrieb für zwei Jahre geführt haben, bis in Wendel Spengler ein neuer Pächter gefunden worden sei. Dieser habe den Betrieb bis 1515 geleitet. Als nächster Leheninhaber sei dann erst wieder 1522 Jerg Moser aus Reutlingen genannt. ${ }^{1516}$ Unklarheit herrscht folglich zum einen über das Todesjahr von Gallus Beck, zum anderen über den Pachtzeitraum der Mühle durch seinen Bruder Andreas. Ab den 1520er-Jahren fließen die Stränge wieder ineinander. Im Jahr

1509 Vgl. Piccard 1951, 59; Piccard 1967, 118; Stenzel 1985, 99 f.; F. Schmidt 1992, 116.

1510 Vgl. Piccard 1951, 59; Stenzel 1985, 99.

1511 Vgl. Piccard 1951, 59; Piccard 1967, 118 f.; Kälin 1974, 166; Stenzel 1985, 100; F. Schmidt 1992, 116. 1512 Vgl. Piccard 1967, 119; Kälin 1974, 166; Stenzel 1985, 100; F. Schmidt 1992, 116.

1513 Vgl. Piccard 1951, 60.

1514 Vgl. F. Schmidt 1992, 118.

1515 Vgl. Piccard 1967, 119.

1516 Vgl. Stenzel 1985, $100 \mathrm{f}$. 
1521 wurde die wohl baufällige Papiermühle an einen Eisenschmied verliehen, der sie für seine Zwecke umrüsten wollte. Zu der geplanten Umwandlung kam es jedoch nicht, da der Pachtvertrag zwischen dem Eisenschmied und dem Markgrafen noch im selben Jahr in beidseitigem Einverständnis aufgelöst wurde. ${ }^{1517}$ Die Papiermühle wurde daraufhin 1522 an den Papiermacher Jerg Moser aus Reutlingen ausgegeben, der gleichzeitig auf Kreditbasis 100 Gulden zur Sanierung der Mühle erhielt. Im Jahr 1526 folgte ihm Jörg Schöpper aus Augsburg. ${ }^{1518}$ Weitere Nachrichten über die Papiermühle und ihre Pächter fehlen bis in die 1570er-Jahre. ${ }^{1519}$

\subsubsection{Lörrach}

Das Papiergewerbe in Lörrach hing seit Beginn eng mit der Basler Papiermacherei zusammen. Im Jahr 1472 schickte der Basler Papiermacher Michel Gallician, Besitzer der Rychmühle im St. Albantal, 44 Zentner und 54 Pfund Lumpen, die er von dem Kaufmann Ulrich Meltinger erworben hatte, nach Lörrach. Im selben Jahr nahm der Papiermacher zu Lörrach weitere 31 Zentner und 30 Pfund aus Basel in Empfang. ${ }^{1520}$ Diese Lumpensendungen nach Lörrach veranlassten Hans Kälin dazu, die Existenz einer Lörracher Papiermühle für die frühen 1470er-Jahre und zudem ihre Gründung durch Michel Gallician anzunehmen. ${ }^{1521}$ In Anbetracht der Tatsache, dass der Basler Rat im Jahr 1471 festgelegt hatte, dass im St. Albantal keine Papiermühlen mehr eingerichtet werden durften, erscheint diese Hypothese von einer Lörracher Papiermühle im Besitz Michel Gallicians plausibel. ${ }^{1522}$ Da er in Basel keine neue Papiermühle errichten durfte, wich er auf einen anderen Ort aus und fand anscheinend in Lörrach die passenden Voraussetzungen für die Einrichtung eines neuen Betriebs. Wer sich jedoch hinter der von Meltinger verwendeten Beschreibung der von Lörach verbarg und damit Pächter der Papiermühle war, kann nur vermutet werden. Kälin hält es für wahrscheinlich, dass bereits der erste Pächter der Lörracher Mühle ein Mitglied der Papiermacherfamilie Pastor gewesen sei. Möglich sei ebenfalls, dass ein Papiermacher aus der vormals jüdischen Basler Familie Mennli den Betrieb leitete. ${ }^{1523}$

1517 Vgl. Piccard 1951, 60; F. Schmidt 1992, 118.

1518 Vgl. Piccard 1951, 60; Stenzel 1985, 101; F. Schmidt 1992, 118.

1519 Vgl. Piccard 1951, 63; Stenzel 1985, 101; F. Schmidt 1992, 118. Vgl. hier auch die widersprüchlichen Angaben bezüglich des Papiermachers Georg Rupp/Rapp. Während Stenzel einen Papiermacher namens Georg Rapp bereits für das Jahr 1549 nennt, erwähnen Gerhard Piccard und Frieder Schmidt einen Georg Rupp erst für das Jahr 1579.

1520 StABS, Privatarchive 62, 51r. Vgl. Kälin 1974, 161, 317; Steinbrink 2007, 282. Vgl. auch Kapitel 3.3.6.1, S. $454 \mathrm{f}$.

1521 Vgl. Kälin 1974, 160.

1522 Vgl. Anm. 1328. Vgl. auch Vortisch 1983, 124; Kälin 1990, 172.

1523 Vgl. Kälin 1974, 160 f.; Vortisch 1983, 124. 
Belegt ist ein Bartholome Pastor allerdings erst im Jahr 1497. ${ }^{1524}$ Auch ein Mitglied der Familie Mennli lässt sich erst für die Jahre von 1508 bis 1518 fassen. Zu dieser Zeit arbeitete offenbar ein Fridlin Mennli als Papiermacher in der Lörracher Papiermühle. ${ }^{1525}$ Auch weitere Nachrichten über den Betrieb sind für die erste Hälfte des 16. Jahrhunderts eher sporadischer Natur. Im Jahr 1537 wurde der Papierer Bartholome Blum als Betreiber der Mühle genannt. ${ }^{1526}$ Für den Zeitpunkt, zu dem er das Werk kaufte, sind bislang keine Zeugnisse gefunden worden. Sicher ist, dass er zuvor als Papiermacher in Basel tätig war und dort für ein Jahr, von 1530 bis 1531, die hintere Spiegelmühle im St. Albantal besaß. ${ }^{1527}$ Ob die Familie Blum bis zum Erwerb der Papiermühle durch den Basler Hans Ecklin im Jahr 1573 im Besitz der Lörracher Papiermühle verblieb, kann aus den Beiträgen zum Papiergewerbe in Lörrach nicht erschlossen werden. ${ }^{1528}$

\subsubsection{Gengenbach}

Auch für die Papiermühle in Gengenbach fehlt aus ihrer Anfangszeit jeglicher schriftliche Beleg ihrer Existenz. ${ }^{1529}$ Das erste Indiz für eine Papierproduktion ist auch in diesem Fall das zu einem Wasserzeichen verarbeitete Wappen der Stadt Gengenbach: der heraldisch nach rechts gekrümmte Gangfisch, der in Straßburger Inkunabeln um $1490 \mathrm{zu}$ finden ist. ${ }^{1530}$ Damit ist ein terminus ante quem gefunden, ein exaktes Gründungsjahr ergibt sich daraus jedoch nicht. Lore Sporhan-Krempel gibt für die Aufnahme der Papierproduktion das Jahr 1488 an, Gerhard Piccard vermutet, dass die Einrichtung der Papiermühle nicht vor 1485 erfolgt sein konnte, legt sich aber auf kein Jahr fest. ${ }^{1531}$ Der erste schriftliche Beleg - eine Schuldverschreibung an das Kloster Gengenbach - ist auch in diesem Fall zwei Jahrzehnte jünger als der durch Wasserzeichen gegebene Hinweis. Er stammt aus dem Jahr 1511 und erwähnt lediglich den Namen eines Papiermachers Anastasius, der zu diesem Zeitpunkt bereits verstorben war. ${ }^{1532}$ Sieben Jahre später wurde ein weiterer Papiermacher zu Gengenbach, Wolff, ebenfalls als verstorben genannt. ${ }^{1533}$

1524 Vgl. Wackernagel 1916, Bd. 2.2, 604; Kälin 1974, 203; Vortisch 1983, 124; Kälin 1990, 172.

1525 StABS, Gerichtsarchiv C 20, 34v; C 22, 244v, 256v. Vgl. Stehlin 1891, 35, Nr. 1820; 71, Nr. 2030, 2032; Kälin 1990, 173.

1526 Vgl. Kälin 1990, 173.

1527 StABS, Gerichtsarchiv B 25, 175r-175v; B 26, 25r-25v. Vgl. P. Tschudin 1996b, 79.

1528 Vgl. Kälin 1990, 173; P. Tschudin 1996b, 79, 82.

1529 Auch scheint Gengenbach als früher Papiermühlenstandort noch im Jahr 1950 der Papierforschung kaum bekannt gewesen zu sein, vgl. Sporhan-Krempel 1950, 353.

1530 Vgl. Piccard 1963, 1000.

1531 Vgl. Sporhan-Krempel 1950, 353; Piccard 1963, 1001.

1532 Vgl. Piccard 1963, 1001; Junk 1984, 762.

1533 Vgl. Piccard 1963, 1001. 
Erste Angaben zu einer Gengenbacher Papiermühle und ihrem Besitzer lassen sich erst für das Jahr 1523 fassen. In diesem Jahr forderte der Straßburger Kaufmann Hans Wild wegen einer Schuldverschreibung die Übergabe der Papiermühle, die der Papiermacher Hans Grapp innehatte. ${ }^{1534}$ Das Werk wurde in den Dokumenten als alte Papiermühle bezeichnet und befand sich uff dem grien uff der almendt an der Kinzig. ${ }^{1535}$ Die Papiermühle wurde Hans Wild unter gerichtlichem Protest des vormaligen Besitzers Hans Grapp zugesprochen. Neben der alten Papiermühle existierte wahrscheinlich seit circa 1520 bereits die neue Papiermühle, als deren Besitzer im Jahr 1529 ebenfalls der Straßburger Hans Wild auftritt. Zuvor scheint sie auch von dem Papiermacher Hans Grapp bewirtschaftet worden zu sein. ${ }^{1536}$ Sie lag nach Ausweis des Zinsbuchs des Klosters Gengenbach bei den guten leuth ebenfalls an der Kinzig. ${ }^{1537}$ Gerhard Piccard nimmt an, dass die alte Papiermühle bereits 1523 , also in dem Jahr, als sie in den Besitz von Hans Wild überging, nicht mehr betrieben wurde. ${ }^{1538}$ Diese These kann nicht in allen Punkten nachvollzogen werden, da unklar ist, aus welchen der von ihm angegebenen Quellenbelegen Piccard seine Schlussfolgerung zieht. Plausibler erscheint die Vermutung von Karl Theodor Weiss, dass die alte Papiermühle zwischen 1523 und 1529 stillgelegt wurde. ${ }^{1539}$ Im Jahr 1529 sollte Hans Wild angeben, ob er das Grundstück, auf dem die alte Papiermühle gestanden hatte, veräußert habe. ${ }^{1540}$ Dieser Beleg spricht dafür, dass im Jahr 1529 die alte Papiermühle nicht mehr existierte.

Um 1525 war vermutlich der Papiermacher und Bürger von Gengenbach Hans Reiter Betreiber einer der Mühlen. ${ }^{1541}$ Weitere Pächter waren der Papiermacher Hans Volpis, der bis 1525 die Papiermühle in Straßburg innehatte, sowie der Papierer Wolf Müller. ${ }^{1542}$ Gegen letzteren erhoben die Söhne Hans Wilds, Joachim ${ }^{1543}$ und Jacob, im Jahr 1533 Klage, da er den ihnen zustehenden Zins nicht zahlte. Offenbar hatten sie das Erbe ihres verstorbenen Vaters angetreten. Ob der Papiermacher Anastasius, der 1536 Zinsen von der Papiermühle zahlte, Pächter oder Eigentümer war, lässt sich nicht eruieren. Als Besitzer ist hingegen der Papiermacher Georg Dietz im Jahr $1540 \mathrm{zu}$ bezeichnen. Er starb unter Hinterlassung einiger Schulden im Jahr 1544. Als Hauptgläubiger trat das Benediktinerkloster Gengenbach auf, dem schließlich die Papier-

1534 Vgl. K. Th. Weiss 1951, 19; Piccard 1963, 1002, 1041; E. Schmitt 1990, [25-28].

1535 Vgl. Piccard 1963, 1003; E. Schmitt 1990, [5]

1536 Vgl. Piccard 1963, $1002 \mathrm{f}$.

1537 Vgl. Piccard 1963, 1002 f., 1041.

1538 Vgl. Piccard 1963, 1002.

1539 Vgl. K. Th. Weiss 1951, 20.

1540 Vgl. K. Th. Weiss 1951, 20; Piccard 1963, 1002, 1041; E. Schmitt 1990, [29].

1541 Vgl. Piccard 1963, 1004.

1542 Vgl. K. Th. Weiss 1951, 20 f.; Piccard 1963, 1004.

1543 In einem Dokument wurde er als Johann, in den weiteren Belegen jedoch als Joachim bezeichnet, vgl. Piccard 1963, 1042; E. Schmitt 1990, [31-33]. 
mühle zugesprochen wurde. ${ }^{1544}$ An wen der Abt als Klostervorstand das Mühlwerk anschließend veräußerte, ist nicht zu festzustellen. Für die Jahre 1548 bis 1555 ist der Frankfurter Drucker Christian Egenolff als Eigentümer der Papiermühle zu Gengenbach nachweisbar. ${ }^{1545}$

\subsubsection{Offenburg}

Des Weiteren gilt in der Papiergeschichtsforschung eine Papiermühle in Offenburg als spätmittelalterliche Gründung. ${ }^{1546}$ Allerdings basiert diese Annahme lediglich auf einem durch Charles-Moïse Briquet entdeckten und Offenburg zugeschriebenen Wasserzeichen. Dieses Wasserzeichen stammt aus dem Jahr 1483/84 und stellt zwei Türme mit einem dazwischenstehenden Halbmond dar, die als Stadtwappen Offenburgs interpretiert wurden. ${ }^{1547}$ Weitere Forschungen zu Offenburger Papiermühlen fehlen bislang. Lore Sporhan-Krempel gibt zudem - leider ohne Beleg - an, dass auch Giengen an der Brenz bereits vor 1500 eine Papiermühle besaß. ${ }^{1548}$ Nach den Forschungen von Alfred Schulte zu schließen, ist dies zwar durchaus möglich, aber bislang weder durch einen Wasserzeichenbeleg noch durch ein Textzeugnis bestätigt. Die älteste Quelle, die auf Giengen als Standort der Papiermacherei verweist, datiert vom April 1502 und nennt den Papiermacher Claus Härtli zu Giengen. ${ }^{1549}$ Bereits Friedrich von Hößle vermutete, dass die erste Papiermühle in Giengen zu Beginn des 16. Jahrhunderts errichtet wurde, die frühesten Wasserzeichen mit dem Giengener Einhorn konnte er jedoch erst für das Jahr 1523 nachweisen. ${ }^{1550}$

1544 Vgl. K. Th. Weiss 1951, 25-27, 43-45; Piccard 1963, 1006 f., 1042 f.; E. Schmitt 1990, [34-49]. 1545 Vgl. Piccard 1963, 1011 f.; E. Schmitt 1990, [55-59].

1546 Lore Sporhan-Krempel nimmt eine Papiermühle in Offenburg in die Reihe der vor 1500 gegründeten Werke auf, allerdings ohne einen entsprechenden Beleg zu bieten, vgl. Sporhan-Krempel 1956, 58. Ebenso Bockwitz 1935, 95. Vgl. auch V. Thiel 1932, 115; V. Thiel 1941, 38; Piccard 1963, 1009; F. Schmidt 1992, 116; Zaar-Görgens 2004, 262.

1547 Vgl. Heitz 1903, 9 u. Tafel 3f., Nr. 69-74; Briquet 1968, Bd. 2, 802; Kirchner 1912, 4; Kähni 1972, 88.

1548 Vgl. Sporhan-Krempel 1956, 58.

1549 Vgl. Alfred Schulte 1940, 106. Übernommen in V. Thiel 1941, 39.

1550 Vgl. Hößle 1926a, 102. Albert Dangel gab 1958 zu bedenken, dass das Wasserzeichen Einhorn zwar bislang immer der Papiermühle in Giengen zugeschrieben wurde, dass aber auch die Möglichkeit bestehe, dass es aus der Papiermühle in Gmünd stammt. Das Werk in Gmünd wurde 1512 erstmals erwähnt und im Jahr 1550 in eine Schleifmühle umgewandelt, vgl. Dangel 1958, 61 f. Vgl. auch die von Piccard getroffenen Ortszuschreibungen hinsichtlich des Wasserzeichens Einhorn, Piccard 1980, 13. 


\subsubsection{Straßburg}

Neben Nürnberg und Ravensburg galt Straßburg lange Zeit als eine der ältesten Papiermühlengründungen auf deutschsprachigem Gebiet. Als Gründungsdatum kursierte in der Literatur, teilweise bis heute, das Jahr 1408. ${ }^{1551}$ Dieses Datum ermittelte Charles Schmidt 1882 anhand eines Wasserzeichens, in welchem er das Straßburger Wappen zu erkennen glaubte. ${ }^{1552}$ Ein ähnliches Zeichen, das er ebenfalls als Straßburger Wappen, diesmal ergänzt durch einen Bischofstab, interpretierte, fand er auch für die Jahre 1421 bis 1426 in Papieren, die in Straßburg beschrieben wurden. ${ }^{1553}$ Als das erste schriftliche Indiz für die Existenz einer Straßburger Papiermühle benennt Schmidt allerdings eine Urkunde aus dem Jahr 1452. Ob es sich bei dem Wasserzeichen, das ein Wappen mit einem Schrägbalken darstellt, tatsächlich um das Straßburger Wappen handelt, wurde seitdem in der Wasserzeichenforschung nicht mehr bestätigt. Gerhard Piccard konnte für die fragliche Zeit kein Wasserzeichen ausmachen, das auf die Existenz einer Straßburger Papierproduktion hinweist. Erst gegen Ende des 15. und zu Beginn des 16. Jahrhunderts fand er Papiermarken, die auf einen Straßburger Ursprung hindeuten. ${ }^{1554}$ Eine Straßburger Papiermühlengründung um 1408 kann folglich mit einiger Plausibilität in Zweifel gezogen werden. ${ }^{155}$

Auch die Mitte des 19. Jahrhunderts aufgekommene Annahme, dass die Straßburger Brüder Andreas und Nicolas Heilmann im Jahr 1441 eine Papiermühle an der Bruche besaßen, wurde inzwischen überzeugend entkräftet. ${ }^{1556}$ Die von Ludwig Schneegans 1858 zitierte Urkunde vom 13. November 1441, ${ }^{1557}$ die - zwischenzeitlich verschollen - im Jahr 1944 erneut von Hans Heinrich Bockwitz zum Ausgangspunkt einer Geschichte über eine Heilmannsche Papiermühle gemacht wurde, besagt lediglich, dass Andreas und Nicolas Heilmann Inhaber einer Mühle waren. ${ }^{1558}$ Eine Papiermühle findet in dem Dokument keine Erwähnung, auch gibt der Kontext keinen Hinweis darauf, dass in dieser Mühle Papier hergestellt wurde. ${ }^{1559}$ Die Vermutung, dass der mit dem Drucker Johannes Gutenberg in geschäftlichen Beziehungen stehende Andreas Heilmann diesem aus seiner eigenen, bereits seit 1441 bestehenden Papierwerkstatt Bedruckstoff lieferte, ${ }^{1560}$ ist somit nicht belegt.

1551 Vgl. Ch. Schmidt 1882, 38; Briquet 1968, Bd. 1, 77; Kirchner 1912, 1; Hößle 1925, 232; Schorbach 1932, 70; V. Thiel 1932, 115; V. Thiel 1941, 36; Bockwitz 1935, 94; Bockwitz 1941a, 24; Santifaller 1953, 151; Stahlberg 2004, 173.

1552 Vgl. Ch. Schmidt 1882, 38.

1553 Vgl. Ch. Schmidt 1882, 38.

1554 Vgl. Sporhan-Krempel 1960, 73.

1555 Vgl. Schlieder 1966, 100.

1556 Vgl. Sporhan-Krempel 1960; P. Schmitt 1960, 41; Fuchs 1962b, 102 f.

1557 Vgl. Schneegans 1853-1865, 2v; wieder aufgenommen in Schorbach 1932, 70.

1558 Vgl. Bockwitz 1944; Sporhan-Krempel 1960.

1559 AVES, CH 231, Nr. 4764 (13.11.1441). Vgl. Sporhan-Krempel 1960, 72 f.

1560 Vgl. P. Tschudin 2002, 1. 
Eine Papiermühle nannte jedoch sein Bruder Nicolas Heilmann seit dem Jahr 1451 sein Eigen. ${ }^{1561}$ Diese Papiermühle lag nicht an der Bruche, sondern an einem kleinen Kanal, der von der kleinen Aar, einem Nebenfluss der Ill, eigens zum Betrieb der Papiermühle abgezweigt wurde. Eingerichtet wurden Kanal und Papiermühle 1445. In diesem Jahr erhielt nämlich Wilhelm de Altomonte - auch Wilhelm de Montealto, Wilhelm vom Hohenberg und Wilhelm Medicis vom Hohenberge genannt - von der Stadt Straßburg ein Grundstück verliehen, das er ausschließlich zum Bau einer Papiermühle nutzen durfte. Die Allmende lag außerhalb der Stadt am Rosengarten und an einer Viehweg genannten Straße, die nach Schiltigheim führte. ${ }^{1562}$ FrançoisJoseph Fuchs lokalisiert das Grundstück an der heutigen Place de Haguenau nördlich der Straßburger Altstadt.

Bereits zwei Jahre später verkaufte Wilhelm de Altomonte eine Rente von 100 Gulden an Agnes, Nicolas Heilmanns Ehefrau. ${ }^{1563}$ Als Wilhelm mit den Zinszahlungen im Rückstand war, zog Nicolas Heilmann die Papiermühle im Jahr 1451 schließlich gerichtlich an sich und ließ sich im darauffolgenden Jahr vom Rat als rechtmäßiger Besitzer bestätigen. ${ }^{1564}$ Dafür verpflichtete sich Heilmann, die Mühle nur zur Papierherstellung zu nutzen und für keinen anderen Zweck zu gebrauchen. ${ }^{1565}$ Ansonsten falle die Papiermühle wieder an die Stadt zurück. Ab diesem Zeitpunkt existierte die Papiermühle am Rosengarten noch ungefähr zwei Jahre. Da die seit 1445 bestehende Umleitung der kleinen Aar offenbar die städtischen Mühlen am Weißturmtor sowie die Stadtmauer beschädigt hatte, fand sich Nicolas Heilmann im August 1454 dazu bereit, die Papiermühle auf eigene Kosten abzubrechen und das Wasser wieder in sein natürliches Bett zu leiten. ${ }^{1566}$ Als Entschädigung erhielt er lediglich 20 Gulden. Warum er diesem für ihn ungünstigen Abkommen zustimmte, kann nicht eindeutig beantwortet werden. François-Joseph Fuchs nimmt überzeugend an, dass die Papierproduktion keine Gewinne abwarf, sondern - im Gegenteil - eventuell weitere Kosten

1561 AVES, CH 251, Nr. 5164 (26.08.1451). Vgl. Fuchs 1962b, 104 f.

1562 AVES, CH 239, Nr. 4918 (02.08.1445): [...] sita in superiori parte vie sive transitus animalium vulgariter oben am vyhewege ex opposito orti rosarum [...] Vgl. Fuchs 1962b, 103.

1563 Vgl. Fuchs 1962b, 104.

1564 AVES, CH 251, Nr. 5164 (26.08.1451); CH 254, Nr. 5228 (22.11.1452). Vgl. Fuchs 1962b, 104 f.

1565 AVES, CH 254, Nr. 5228 (22.11.1452): [...] mit sollicher gedinge das es nit anders dann ein bappirin müle sin sol. Darumb so sollent die egenanten personen noch ir erben wer dann die müle yezüziiten under inen innehat niemer keyn ander müle weder malemüle walckmüle sliffmüle bluwelmüle noch kain ander müle doselbs machen noch tün machen ouch keyn ander werck do würcken noch tün würcken dann was bappiren wercks daruff zu würcken und zu machen ist [...]. Vgl. Fuchs 1962b, 105.

1566 AVES, CH 257, Nr. 5292 (07.08.1454): Und als nu durch sollich bappiren müle das wasser ettlich zyt verswellet worden ist das es durch sollich swall der statt mülen an dem wissenturn und ouch der statt ringmuren schaden broht hat. So sint die obgenannten min herren meister und rat der statt Strasburg mit mir und ich mit inen gütlich uberkommen also und in die wise das ich die bappiren müle mit allem irem gebüwe abebrechen und ganz dannan tun sol in myme costen und die obgemelt hovestatt der selben müle aller dinge rumen und wider der statt Strasburg almende sin und bliben lossen sol. 
verursachte. ${ }^{1567}$ In diesem Fall waren die einmaligen Ausgaben für den Abriss sicherlich leichter zu verschmerzen als die andauernde Investition in einen wenig rentablen Betrieb. Die erste Papiermühle Straßburgs bestand also nur neun Jahre.

Die Einrichtung einer neuen Papiermühle wurde offensichtlich erst zu Beginn des 16. Jahrhunderts in Angriff genommen. Dieses im Besitz der Stadt befindliche Mühlwerk lag vor dem Weißturmtor an einem von der Bruche abgeleiteten Kanal und war seit 1503 an den Kartenmaler Gabriel Schwartz verpachtet, der allerdings auch als Papiermacher bezeichnet wurde. ${ }^{1568}$ Wann die Papiermühle an den Papierer Hans Volpis überging, ist nicht auszumachen. Sicher ist, dass er sie bis 1525 betrieb. Danach vergab die Stadt das Werk an den Buchdrucker Wolf Koepfel. ${ }^{1569}$ Ab 1550 waren der Drucker Wendelin Rihel und seine Erben Betreiber der Papiermühle. ${ }^{1570}$ Weitere Papiermühlen sind für die erste Hälfte des 16. Jahrhunderts nicht zu fassen, sodass davon ausgegangen werden muss, dass die Stadt Straßburg, die sowohl als Druckerstadt als auch als Umschlagplatz für Papier bekannt war, selbst nicht über eine namhafte Papierproduktion verfügte.

\subsubsection{Vieux-Thann und Cernay}

Im Elsass bestanden im 15. Jahrhundert noch zwei weitere Papiermühlen, die von Pierre Schmitt in seinem Essai d'une histoire du papier en Alsace kurz benannt werden. In Vieux-Thann richtete der Papiermacher Peter von Genf bereits im Jahr 1463 ein Werk ein. ${ }^{1571}$ Für Cernay (Sennheim) ist im Jahr 1497 der Papiermacher Lorentz Jörg, der die untere Mühle bis mindestens 1519 betrieb, in einem Briefwechsel mit dem Basler Drucker Johann Amerbach fassbar. ${ }^{1572}$ Als spätere Besitzer der Papiermühle werden 1527 Hans Zub und von 1543 bis 1550 Bernhard Mörstatt genannt. ${ }^{1573}$

\subsubsection{Ausstattung}

Über die Ausstattung einer Papierwerkstatt mit Wasserrädern, Wellbaum, Stampfwerk und anderem Werkzeug, über ihre Größe und die Aufteilung der Arbeitsräume erfahren wir aus den mittelalterlichen Quellen nur wenig. ${ }^{1574}$ Oftmals kann daher kein

1567 Vgl. Fuchs 1962b, 105.

1568 Vgl. Ch. Schmidt 1882, 38; P. Schmitt 1960, 78.

1569 Vgl. Amelung 1995, 275.

1570 Vgl. Ch. Schmidt 1882, 38; P. Schmitt 1960, 78.

1571 Vgl. P. Schmitt 1960, 79.

1572 Die Amerbachkorrespondenz 1942, 63, Nr. 54. Vgl. P. Schmitt 1960, 68 f.; P. Tschudin 1997, 6 f. Dieser Papiermacher ist Camille Oberreiner noch unbekannt, vgl. Oberreiner 1926.

1573 Vgl. P. Schmitt 1960, 69.

1574 Vgl. Bayerl 1984, 10 f.; Zaar-Görgens 2004, 87. Vgl. allgemein für die kaum fassbare Ausstattung von Werkstätten Brandt 2008, 298 f. 
umfassendes Bild der Produktionseinheit Papiermühle gezeichnet werden. Dass eine mittelalterliche Mühle für die Herstellung von Papier ähnlich ausgerüstet gewesen sein muss wie spätere Werke, von denen detaillierte Beschreibungen vorhanden sind, liegt zwar nahe, kann jedoch nicht bedingungslos vorausgesetzt werden. Aus diesem Grund soll es in diesem Kapitel nicht um die zu vermutende Ausstattung der frühen Papiermühlen im südwestdeutschen Raum gehen, sondern um die tatsächlich in den Zeugnissen fassbaren Hinweise auf die Einrichtung einer Papierwerkstatt. Zu der Ausstattung zählen dabei nicht nur die unmittelbar auf die Papiermacherei bezogenen Werkzeuge und Einrichtungsgegenstände, sondern auch die zu einem Mühlwerk gehörenden Grundstücke und Gebäude, da sie ebenso wie diese zur Arbeitsund Lebenswelt eines Papiermachers gehörten. Die Papiermühle soll folglich als Ensemble aus - um mit mittelalterlichem Vokabular zu sprechen - liegendem und fahrendem Gut, aus Immobilien und Mobilien betrachtet werden. Den Anfang macht auch hier das Fallbeispiel Basel. Anschließend werden die Informationen, die sich für andere Papiermühlenstandorte im deutschen Südwesten gewinnen ließen, unter drei Aspekte zusammengefasst: erstens die Mühle und weitere zur Liegenschaft gehörende Gebäude, zweitens die Wasseranlagen und Räder und drittens die Innenausstattung einer Papiermühle mit Geräten, Werkzeugen und weiteren Utensilien.

\subsubsection{Basel}

Mit einem Lamento über die spärliche Informationslage ist man - zumindest für Basel - nicht allein. Auch Hans Kälin bedauert, dass aus den Quellen nur wenig Wissen beispielsweise über die Ausstattung der Allenwindenmühle geschöpft werden könne. ${ }^{1575}$ Allgemein kann gesagt werden, dass zu den meisten Basler Papiermühlen weitere Grundstücke gehörten. Diese werden in den Fertigungsprotokollen oder Fertigungsbriefen direkt nach dem Mühlgebäude genannt, manchmal auch in Relation zur Mühle lokalisiert. Eine Erwähnung von zur Papierherstellung benötigten Werkzeugen und Gegenständen kommt nur in manchen Fällen vor. Abgeschlossen wird die Beschreibung der Liegenschaft meist mit dem umfassenden Zusatz mit allen iren rechten und zu gehörungen. ${ }^{1576}$ Schaut man sich die Liegenschaftsauflistungen der einzelnen Mühle über den Untersuchungszeitraum hinweg an, dann ist eine erstaun-

1575 So extrahiert er beispielsweise aus Dokumenten, die deutlich älter als die Basler Papierherstellung sind, zumindest die Anzahl der Wasserräder, vgl. Kälin 1974, $171 \mathrm{f}$.

1576 StABS, Gerichtarchiv B 9, 71. Dieses Zitat betrifft die Zunzigermühle, die formelhafte Wendung ist aber in diesem oder einem ähnlichen Wortlaut bei nahezu allen Fertigungen über Papiermühlen zu finden. Vgl. StABS, Gerichtarchiv B 11, 260r: und allen zugehörd. Sie stellt den Historiker vor das Problem, dass höchstwahrscheinlich viele zu einem Lehen gehörige Liegenschaften unter dem Begriff zugehörungen subsummiert wurden und damit seinem Zugriff entzogen sind. 
liche Konstanz in den aufgezählten Gebäuden und Flächen erkennbar. ${ }^{1577}$ Diese Kontinuität erlaubt es, ein relativ statisches Bild der einzelnen Papiermühle zu zeichnen, auch wenn bewusst bleiben muss, dass sich das Aussehen dieser Grundstücke und Gebäude über die Jahrzehnte komplett verändert haben kann.

Beginnen wir mit der Allenwindenmühle. Im Jahr 1433 kaufte Heinrich Halbysen d. Ä. sie mit einem dahintergelegenen Rebengarten, einem weiteren kleinen Garten sowie dem Wasser und dem Wasserfluss. ${ }^{1578}$ Die Anzahl ihrer Räder konnte Hans Kälin auf vier bestimmen. ${ }^{1579}$ Das lässt darauf schließen, dass das Gebäude relativ groß war, da die dem Teich zugewandte Seite Platz für vier Wasserräder aufweisen musste. Ein Wohngebäude scheint die Mühle zu Allenwinden nicht besessen zu haben, zumindest wird es nicht erwähnt. Beim Verkauf der Mühle durch Heinrich Halbysen d. J. 1470 gehörten zu den beiden Lehen, die zuvor eine Säge und eine Papiermühle gewesen waren, ein Wasserfall, Weg und Steg sowie ein Garten. ${ }^{1580}$ Auch zu diesem Zeitpunkt wurde kein Wohnhaus erwähnt.

Im Gegensatz dazu wies die von Anton Gallician 1452 erworbene Bluwenmühle am Rümelinbach neben dem Wasser und einem Wehr auch Haus und Hof auf. ${ }^{1581}$ Ein Jahr später, als Anton Gallician das Werk wieder veräußerte, wurde zudem noch ein dazugehörender Garten aufgeführt. ${ }^{1582}$ Zusammen mit dieser Liegenschaft wurde beide Male eine Halde mit Reben von der Größe eines halben Jucharts verkauft, ${ }^{1583}$ die nicht im eigentlichen Sinne zur Liegenschaft gehörte, da auf ihr ein separater Grundzins lastete. ${ }^{1584}$

Die Papiermühlen im St. Albantal wiesen alle ein Haus sowie einen Hof auf und waren damit nicht nur Gewerbe-, sondern auch Wohngebäude. ${ }^{1585}$ Zudem besaßen die Papiermühlenbesitzer, gemeinsam mit den anderen Inhabern der zwölf Mühlenlehen am St. Albanteich, jeweils einen Anteil an weiteren Grundstücken, die an die Gemeinschaft der Leheninhaber ausgegeben worden waren. Darunter fielen zum einen die Matten, das heißt Wiesen, zwischen der Birs und dem Gewerbeteich, Her-

1577 Die oft wortgleiche Formulierung lässt darauf schließen, dass die Beschreibung aus dem vorangegangenen Fertigungsbrief oder Fertigungsprotokoll übernommen wurde.

1578 StABS, Gerichtsarchiv P 3, 211r (röm. Ziffern) bzw. 200r (arab. Ziffern).

1579 Vgl. Kälin 1974, 172.

1580 StABS, St. Urk. 1895 (05.11.1470).

1581 StABS, Gerichtsarchiv B 6, 123: die Bluvlen mit huß und mit hoff, mit wasser und mit wur und allen Rechten und zugehörungen.

1582 StABS, Gerichtsarchiv B 6, $171 \mathrm{f} .:$ die Bluwelen mit hus und hoff, wasser und wur und mit allen rechten und zugehorungen mit den garten so darzu gehörend.

1583 Bei einem Juchart handelt es sich um ein Flächenmaß für Ackerland, das dem Tagewerk eines Pflügers entspricht, vgl. Dubler 2007, $826 \mathrm{f}$.

1584 StABS, Gerichtsarchiv B 6, 123 f., 172.

1585 Zur Einheit von Arbeiten und Wohnen im Mittelter vgl. Brunner 1968, 108 f.; Reininghaus 1983, 55. 
renmatten genannt, sowie die Matten zwischen dem Teich und dem Rhein. ${ }^{1586} \mathrm{Zu}$ den Herrenmatten gehörten nach der St. Alban-Registratur aus dem Jahr 1502/05 auch Grünholz und Weiden, die von den Leheninhabern verwendet werden durften. ${ }^{1587} \mathrm{Im}$ Lehensbrief aus dem Jahr 1336, in dem den Mühlenbesitzern die Matten verliehen wurden, wurde zudem bestimmt, dass die Weiden zur Instandhaltung des Wehrs eingesetzt werden sollen. ${ }^{1588}$ Ein weiteres in der Registratur erwähntes Gemeinschaftslehen der zwölf Mühlenbesitzer war eine hanffbüni am St. Albanteich, das heißt ein umgrenztes Stück Land, das dem Hanfanbau diente. ${ }^{1589}$ Traugott Geering setzt diese Hanfbünde mit der Papierherstellung in Beziehung. ${ }^{1590}$ Diese Relation ist aus mindestens zwei Gründen unwahrscheinlich. Zum einen besaßen auch die korn- oder metallverarbeitenden Mühlen einen Anteil an der Hanfbünde. Zum anderen erscheint ein Zusammenhang zwischen Hanfanbau und Papierproduktion nicht zwingend. Weder wurden in der europäischen Papiermacherei frische Hanffasern als Rohstoff verwendet noch ist es plausibel, dass der von den Papiermachern selbst angebaute Hanf zu Tuch weiterverarbeitet wurde und dann beträchtliche Zeit später als Lumpen wieder in das St. Albantal kam. Wahrscheinlicher ist, dass der Hanfanbau schlicht und ergreifend als Nebentätigkeit zu dem eigentlichen Gewerbe der jeweiligen Mühleninhaber betrieben wurde, wie dies auch für die Nutzung der Matten gelten kann. ${ }^{1591}$ Neben den Matten und der Hanfbünde wurden bei manchen Papiermühlen des Weiteren auch Acker, Feld, Holz oder Weiden aufgeführt. ${ }^{1592}$

Für den Betrieb der Mühlen besonders wichtig war die stete Zufuhr von Wasser. Es ist daher nicht verwunderlich, dass neben dem Landbesitz auch Wasser und Was-

1586 Diese beiden Matten wurden den zwölf Mühlenbesitzern im Jahr 1336 verliehen, vgl. Schweizer 1923, $44 \mathrm{f}$.

1587 Auch der Propst von St. Alban durfte Holz und Weiden zur Umzäunung seines Gartens verwenden. StABS, Klosterarchiv, St. Alban H, 5: Item ein matt zwischen dem tich und dem birse, die man nempt der herren matt. Die selbe mit grien holtz und widen under ander zugehörung, so obwendig und darumb lyt ist verlihen den meisteren und iren nachkomen der nechsten vorgeschribnen xii lehen der Mülen. [...] Ouch mag ein brobst widen und holtz nehmen und (sic!) disem obgemelten lehen, das er sin gart damit verzüne.

1588 StABS, Teichkorporationen, St. Alban A1, 46v. Vgl. Schweizer 1923, 45.

1589 StABS, Klosterarchiv, St. Alban H, 13: Item die meister der xii lehen gebent alle jar iiii $\beta$ von einer hanffbüni lyt uff dem tich. Vgl. Schweizer 1923, 45. Zum Begriff Bünde vgl. Mone 1854, 259 f. Franz Joseph Mone unterscheidet zudem die Hanfbünden in ihrer Bebauungsform von den späteren Hanfländern. In den vorliegenden Quellen werden die Begriffe hanffbüni und hanfflender jedoch synonym verwendet, vgl. die Verwendung beider Begriffe in einem Eintrag der Fertigungsbücher, StABS, Gerichtsarchiv B 9, 71.

1590 Vgl. Geering 1886, 288. Auch erwähnt bei Schweizer 1923, 45.

1591 Der relativ kleinflächige Anbau von Hanf als Nebentätigkeit, auch bei landwirtschaftlichen Betrieben, war weit verbreitet, vgl. Reinicke/Dilg 1989, 1918 f.

1592 So beispielsweise bei der Rychmühle im Jahr 1519 und 1542, StABS, Gerichtsarchiv B 22, 69r; B 28, 191r, sowie bei der Zunzigermühle im Jahr 1486, vgl. Gerichtsarchiv B 11, 260r, und bei der Klingentalmühle im Jahr 1523, vgl. Gerichtsarchiv B 22, 333r. 
serleitungen zu den Mühlenlehen gehörten und bei der Beschreibung des Lehens explizit angeführt werden. So lesen wir von wasser, wasserrunsen ${ }^{1593}$ beim Verkauf der Rychmühle und von wasser, wasserleitinen ${ }^{1594}$ in Bezug auf die Zunzigermühle. Die Klingentalmühle wurde 1453 mit wasser, mit wur ${ }^{1595}$ an Anton Gallician übergeben, während die hintere Spiegelmühle mit dem wasserfal ${ }^{1596}$ verliehen wurde. Bei der hinteren Spiegelmühle sowie der Rychmühle wurden auch die Zugänge zum Lehen mit in die Aufzählung aufgenommen, sodass auch Weg und Steg sowie die Einund Ausgänge Erwähnung fanden. ${ }^{1597}$

Ein Blick auf die einzelnen Papiermühlen im St. Albantal zeigt die Unterschiede in den Auflistungen der zugehörigen Grundstücke. Die Beschreibung der von Anton Gallician gekauften Klingentalmühle umfasst im Jahr 1453 nur das Mühlengebäude mit Haus, Hofstatt, Wasser, Wehr und Gitter. ${ }^{1598}$ Als Antons Sohn Franz Gallician die Papiermühle im Jahr 1523 an Conrad Grebel veräußerte, hatte sich die Auflistung um einige Punkte erweitert. Nun wurde die Papiermühle mit dem dahinterliegenden Garten, einer großen Scheune, einer kleinen Hofstatt und einer weiteren Scheune sowie Haus, Hof, Wasser, Wehr, Holz, Matten und Hanfbünde verkauft. ${ }^{1599}$ Zumindest der Garten gehörte dabei nicht zum eigentlichen Lehen, da der Käufer für ihn einen Grundzins an den Fürsten zu Neuenburg zu zahlen hatte. ${ }^{1600}$

Die Stegreifmühle wird in den Quellen zumeist mit Haus, Hof, Wasser, Wehr, Holz, Matten und all ir zugehört beschrieben. ${ }^{1601}$ In den 1520er-Jahren finden sich Erwähnungen einer Papierhenke, für die der Besitzer der Stegreifmühle, Jörg Dürr d. Ä., und später seine Witwe Veronica Gallician Zinsen an das Kloster St. Alban zahlten. ${ }^{1602}$ Bemerkenswert ist die räumliche Trennung von Papiermühle und Trockenraum, die dem klassischen Bild einer Papiermühle mit Henkboden unter dem Dach

1593 StABS, Gerichtsarchiv B 13, 167v; B 22, 69r; B 28, 191v; B 29, 10v.

1594 StABS, Gerichtsarchiv B 9, 71; B 13, 165r.

1595 StABS, Gerichtsarchiv B 6, 171. Vgl. auch die Fertigungsprotokolle aus den Jahren 1523 und 1528, StABS, Gerichtsarchiv B 22, 333, 334v; B 24, 202.

1596 StABS, Gerichtsarchiv B 19, 182r; B 26, 25 r.

1597 Vgl. zur hinteren Spiegelmühle StABS, Gerichtsarchiv B 19, 182r; B 22, 60v; B 25, 175r; B 26, 25r, und zur Rychmühle StABS, Gerichtsarchiv B 22, 69r; B 28, 191r; B 29, 10v.

1598 StABS, Gerichtsarchiv B 6, 171.

1599 StABS, Gerichtsarchiv B 22, 333r: Die bapir mülin mit sampt dem garrten darhinder, der großen schuren, dem hoffstetlin und der anderen schuren und das alles mit hus, hoff, wasser, wur, holz, matten, hanfbundi mit aller eehaft, gerechtigkeit.

1600 StABS, Gerichtsarchiv B 22, 333r.

1601 StABS, Gerichtsarchiv E 7, 35v; E 9, 21v; B 22, 327v.

1602 StABS, Klosterarchiv, St. Alban DD 1, Corpus 1523/24, 14v: Jorg Dur [...] von den zweyen husern unnd pappir henki prius Frantz Gallician. St. Alban DD 1, Corpus 1526/27, 13v: Jörg Thürr [...] von den zweyenn heusern und papir henky prius Franntz Gallician. St. Alban DD 1, Corpus 1527/28, 13v: Jörg Thürren des papirers seligen erbenn [...] von den zweyen hüsern und papyr hennckenen prius Frantz Gallician. Vgl. des Weiteren St. Alban DD 1, Corpus 1528/29, 21v; Corpus 1529/30, 13v; Corpus 1530/31, 18v. 
nicht entspricht. ${ }^{1603}$ Ob Jörg Dürr d. Ä. die Trocknung komplett ausgelagert hatte oder aus Platzmangel einen zweiten Trockenraum einrichtete, ist leider nicht zu beantworten.

Unter den wenigen Zeugnissen bezüglich der in eine Papiermühle umgewandelten halben Spisselismühle am vorderen Teich hingegen findet sich lediglich bei der nicht zustande gekommenen Fertigung aus dem Jahr 1459 eine knappe Angabe zu den inbegriffenen Grundstücken, nämlich zu Haus und Hofstatt. ${ }^{1604}$

Ausführlicher werden die Rychmühle und ihre Ausstattung dargestellt. Als Heinrich Halbysen d. Ä. sie im Jahr 1448 kaufte, wurden außer der Mühle auch nur Häuser, Hof und ein dahinter gelegener Garten erwähnt. ${ }^{1605}$ Gegen Ende des Jahrhunderts wächst die Aufzählung jedoch an. Hans Lufft von Ettlingen erwarb im Jahr 1494 von Michel Gallician die Papiermühle und das ganze Lehen bereits mit Haus, Hof, Hofstatt, Weide, Äckern, Matten, Wasser und Wasserrunsen. ${ }^{1606}$ Auch bei den darauffolgenden Handänderungen 1519 und 1542 wurden diese zugehörungen genannt, ergänzt wurden die dazugehörigen infrastrukturellen Gegebenheiten, nämlich Weg, Steg, Ein- und Ausgänge. ${ }^{1607}$ Insgesamt ist die Beschreibung des ganzen Lehens sehr detailliert und erlaubt einen profunden Einblick in das Ensemble Papiermühle, auch wenn ein Verweis auf den Anteil an der Hanfbünde fehlt.

Aufgeführt wird die Hanfbünde hingegen bei der Zunzigermühle. Außerdem wurden diesem Lehen Wasser, Wasserleitungen, ein Garten und der Anteil an den Matten zugeordnet. ${ }^{1608}$ Seit Ulrich Züricher die Mühle im Jahr 1470 erwarb, gehörte ebenfalls ein Haus mit Hofstatt und Scheune, genannt Losers huß, zu der Liegenschaft. ${ }^{1609}$ Dass es nicht zum eigentlichen Lehen gehörte, ist an dem separaten Grundzins zu erkennen, der von dem Haus an das Kloster St. Alban abgeführt werden musste. Ein eigener Grundzins lastete ebenfalls auf einem Stock, in dem der Leimkessel stand. ${ }^{\mathbf{1 6 1 0}}$

Die Hälfte der hinteren Spiegelmühle, in der spätestens seit 1484 eine Papiermühle untergebracht war, wurde bei den Handänderungen in den Jahren 1513 und

1603 Vgl. Kapitel 2.3.6, S. 137 f.

1604 StABS, Gerichtsarchiv B 8, 43r.

1605 StABS, Gerichtsarchiv B 5, 93v.

1606 StABS, Gerichtsarchiv B 13, 167v.

1607 StABS, Gerichtsarchiv B 22, 69r; B 28, 191v.

1608 StABS, Gerichtsarchiv B 9, 71; B 11, 260r, 263v; B 13, 165r; B 26, 133v.

1609 StABS, Gerichtsarchiv B 9, 71. Seinen Namen hat dieses Anwesen (St. Albantal 34/36) von dem Schindler Ulli Loser, in dessen Besitz es von 1447 bis 1451 war. Im Jahr 1451 kaufte Heinrich Halbysen d. Ä. die Liegenschaft. Sein gleichnamiger Sohn verband das Haus mit Hofstatt und Scheune und die Zunzigermühle durch den gemeinsamen Verkauf zu einer Liegenschaft. Dieser Verbund blieb bis in das 20. Jahrhundert bestehen. Vgl. hierzu Reinhardt 1975, 27 f.; Baur/Nagel 2009, 45-47.

1610 StABS, Gerichtsarchiv B 9, 71, 78; B 11, 260r, 263v; B 12, 13r; B 14, 71v. 
1530 mit Haus, Hofstatt und Wohnsitz mit schiff und geschirr darinn ${ }^{1611}$ sowie mit Wasserfall, Wegen, Stegen, Ein- und Ausgängen genannt. ${ }^{1612} 1531$ gehörte auch noch einiges an Bauholz zu dem Lehen. ${ }^{1613}$

Der unbestimmte Ausdruck mit Schiff und Geschirr verweist zwar auf die Geräte und Werkzeuge des Papiermachers, benennt sie jedoch nicht. Bei der Übertragung der hinteren Spiegelmühle an Michel Gernler im Jahr 1487 finden wir diesen unbestimmten Verweis in einer anderen Formulierung. Hier wurde nämlich die pappir mülin mit dem limkessin und allem andrem werkzug zu dem werkzug (sic!) ${ }^{1614}$ dienende und geherende ${ }^{1615}$ übertragen. Explizit erwähnt wurde bei dieser Handänderung der Leimkessel, der - wie die anderen, nicht benannten Werkzeuge - zum Handwerk der Papiermacher gehört. Pauschal auf das zur Mühle gehörende und zum Papierhandwerk nötige Werkzeug wird auch bei einigen Handänderungen der Rychmühle ${ }^{1616}$ und der Zunzigermühle ${ }^{1617}$ hingewiesen.

Um welche Werkzeuge es sich dabei im Einzelnen handeln könnte, verraten uns zwei mehr oder minder wortgleiche, die Zunzigermühle betreffende Fertigungsprotokolle. Das erste dieser Protokolle ist auf den 27. Januar 1470 datiert und nennt die Papiermühle mit dem lim kessel, büken, liksteinen, marmelsteinen och mit den mödeln formen. ${ }^{1618}$ Das zweite Protokoll vom 6. September 1494 weicht in der Beschreibung der Werkzeuge nur unwesentlich von diesem ab. ${ }^{1619}$ Es führt die Papiermühle mit dem lymkessel, buckin, licksteinen, marmelstein, ouch mit den mödeln formen ${ }^{1620}$ an. Expli-

1611 StABS, Gerichtsarchiv B 19, 182. Der Ausdruck Schiff und Geschirr bezeichnet nach dem Grimmschen Wörterbuch im oberdeutschen Sprachraum all das Gerät, das zum Betreiben einer Sache oder eines Gewerbes notwendig ist, vgl. Grimm/Grimm 1899, Bd. 9, 60. Es handelt sich bei dem Wort geschirr daher vermutlich nicht um eine konkrete Bezeichnung des Stampfgeschirrs, sondern um eine allgemeine Benennung aller Geräte, die der Papierherstellung dienen und mit der Mühle verkauft werden. Höchstwahrscheinlich befand sich darunter auch ein Stampfgeschirr.

1612 StABS, Gerichtsarchiv B 19, 182; B 25, 175r.

1613 StABS, Gerichtsarchiv B 26, 25r: die bapyr müly mit hus, hoff und gesähs mit schiff und geschyr und ettlichem Buwholtz darzü gehörig mit dem wasserfal, wegen, stegen, in und ußgengen.

1614 Es ist zu vermuten, dass sich der Schreiber hier verschrieb und es statt Werkzeug Handwerk lauten muss. Weiter unten in demselben Eintrag ist als Ergänzung zu solich mülin am Rand notiert: mit ir zugehord und allen werkzug so dem handtwerk zugehört, StABS, Gerichtsarchiv B 12, 40r.

1615 StABS, Gerichtsarchiv B 12, 40r.

1616 Im Jahr 1494 vgl. StABS, Gerichtsarchiv B 13, 167v: unnd allen unnd yegklichen stucken unnd werckzug so zu dem bappirhandtwerck gehört unnd uff hutt in der bappirmülin ist. Im Jahr 1519 vgl. StABS, Gerichtsarchiv B 22, 69r: mit sampt allem werkzeug, schiff und geschirr so zu dem bapirer handtwerg gehört.

1617 Im Jahr 1532 vgl. StABS, Gerichtsarchiv B 26, 133v: sampt dem werchzüg so zu dem bapyrer handtwerch gehört.

1618 StABS, Gerichtsarchiv B 9, 71.

1619 Hieran lässt sich erkennen, dass für die Ausfertigung des neuen Fertigungsbriefs ein älterer als Vorlage genutzt wurde.

1620 StABS, Gerichtsarchiv B 13, 165r. 
zit aufgelistet wird also erstens der Leimkessel, welcher der Zubereitung von Leim aus frischen Schlachtabfällen oder dem Erwärmen von bereits fertigem Leim diente. Dass er einen prominenten Platz in der Beschreibung des Werkzeugs einnimmt, lässt sich zum einen mit seinem separaten Standort außerhalb des Gebäudes im dem bereits erwähnten Stock und zum anderen mit der Wichtigkeit des Leimens für die Herstellung von Schreibpapier erklären. ${ }^{1621}$

Zweitens wird das Wort buken beziehungsweise buckin genannt. Nach Hans Kälin handelt es sich hierbei um die Bütte, aus welcher der Faserbrei geschöpft wurde. ${ }^{1622}$ Drittens werden zwei Steinarten, nämlich ein likstein und ein marmorner Stein genannt. Bei dem likstein handelt es sich vermutlich um einen Glättstein, ${ }^{1623}$ der Stein aus Marmor könnte, so vermutet auch Kälin, als Unterlage beim Glätten eingesetzt worden sein. ${ }^{1624}$ Viertens werden mödeln formen aufgeführt, die wohl mit den unentbehrlichen Schöpfsieben gleichgesetzt werden können. ${ }^{1625}$

Einige Werkzeuge und Einrichtungen die eigentlich ebenfalls zur Papierherstellung benötigt werden, kommen in dieser Quelle allerdings nicht zur Sprache, so beispielsweise das zur Aufbereitung des Rohstoffs unersetzliche Stampfgeschirr, die Pressen sowie der Trockenraum, in dem die Papiere nach dem Schöpfen und nach dem Leimen zum Trocknen aufgehängt wurden. ${ }^{1626}$ Es ist zu vermuten, dass diese doch eher großen Geräte deshalb nicht aufgeführt wurden, weil sie nur schwer aus dem Gebäude zu entfernen waren und daher unter allen zugehörungen gefasst werden konnten. Warum lediglich bei einer Mühle einige Werkzeuge genannt wurden, ist leider nicht nachzuvollziehen. Ob bei den anderen Mühlen unter die zugehörungen auch Werkzeuge fielen oder ob der verkaufende Papiermacher in manchen Fällen die tragbaren Arbeitsinstrumente mitnahm, muss an dieser Stelle offenbleiben.

\subsubsection{Bern, Memmingen, Ravensburg, Reutlingen, Söflingen und Zürich}

Auch für andere Papiermühlenstandorte im deutschen Südwesten bleibt unser Wissen um die Ausstattung der Werkstätten unvollständig. Von vielen Papiermühlen wissen wir nichts, von manchen haben wir lediglich vereinzelte Nachrichten über ihre Einrichtung, über ihre Wasseranlagen oder über die zur Papiermacherei notwendigen Werkzeuge, da die Kaufverträge - wie auch in Basel - häufig generalisierende

1621 Vgl. Kapitel 2.3.7, S. 144 f.

1622 Vgl. Kälin 1974, 281 f. mit Anm. 206.

1623 Vgl. Kälin 1974, 281 f. mit Anm. 206. Peter Tschudin hingegen identifiziert die Bezeichnung likstein mit einem Faultrog für die Lumpenfäule, vgl. P. Tschudin 1984b, 20.

1624 Vgl. Kälin 1974, 281 f. mit Anm. 206. Vgl. auch die Beschreibungen des Glättraums in neuzeitlichen Quellen, in denen auch eine Unterlage aus Marmor erwähnt wird: Peri 1651, 69, engl. Übers. in Fahy 2003/2004, 254; Schaden 1740/1962, 10; Becker 1740/1962, 6. Vgl. Kapitel 2.3.8, S. 163.

1625 Vgl. Kälin 1974, 281 f. mit Anm. 206.

1626 Daher ist der Begriff Mühleninventar, wie ihn Hans Kälin vorschlägt, nicht ganz passend, vgl. Kälin 1974, 198. 
Bezeichnungen verwenden oder nur auf bestimmte Aspekte der Ausstattung eingehen.

Vergleichsweise detailliert sind die Kauf- und Pachtverträge aus Bern und aus Memmingen. Sie verzeichnen - ähnlich wie die 1470 abgeschlossene Fertigung zur Basler Zunzigermühle - eine Auflistung der Geräte und Werkzeuge, die zusammen mit dem Mühlengebäude veräußert wurden. In Zürich führte der Neubau der Papiermühle durch die Stadt in den Jahren 1532 bis 1535 dazu, dass die Ausstattung und die daraus entstehenden Kosten in den städtischen Bauamtsrechnungen protokolliert wurden. Dieser Umstand macht deutlich, dass die Überlieferungschance von amtlichen Dokumenten deutlich höher war als die von privaten Aufzeichnungen. ${ }^{1627}$ In Reutlingen war eine kriegerische Auseinandersetzung mit Herzog Ulrich von Württemberg im Jahr 1519 Anlass dafür, dass Informationen zur Einrichtung der Papiermühlen Eingang in die amtliche Überlieferung fanden: Der Rat hatte alle Bürger aufgefordert, die Schäden zu taxieren, die ihnen während der Belagerung der Stadt durch die württembergischen Truppen entstanden waren. Unter ihnen befanden sich auch die Reutlinger Papiermacher, die die Verluste an ihren Papiermühlen und deren Einrichtung benannten und somit einen Einblick in ihre Werkstätten gaben.

Wie das Fallbeispiel Basel zeigte, gehörte zu der Liegenschaft häufig nicht nur das Mühlengebäude, sondern noch ein Wohnhaus sowie weitere Grundstücke und Bauten. Der Kaufvertrag die Papiermühle zu Thal bei Bern betreffend umfasste 1474 einen Speicher sowie ein Wiesengrundstück. ${ }^{1628}$ Bei einem darauffolgenden Verkauf im Jahr 1491 wurden neben dem Mühlengebäude ein Fasshaus, ein Leimhaus, ein Trockenhaus sowie wiederum ein Wiesengrundstück aufgeführt. ${ }^{1629}$ Die Einheit von Wohn- und Arbeitsort, wie sie auch in Basel nachweisbar ist, lässt sich in Zürich besonders eindrücklich fassen, da der Neubau der Papiermühle auf dem Werd nicht nur die Werkräume, sondern auch die Wohnräume des künftigen Papiermeisters umfasste. Anhand der Bauamtsrechnungen lässt sich der Ablauf der Bauarbeiten erkennen. Die Arbeitsräume der Papiermühle wurden im Rechnungsjahr 1534/35 fertiggestellt. In den Jahren 1535 bis 1537 folgte dann die Ausgestaltung der Wohnräume im oberen Stockwerk des Gebäudes. Neben Kachelöfen, einem Kästchen und einem Tisch wurden die beiden Stuben mit Bildwerk ausgestattet, nämlich mit einer

1627 Auch unser Wissen über die Einrichtung der Papiermühle zu Mömpelgard um 1600 verdanken wir dem Umstand, dass die Papiermühle auf Wunsch des württembergischen Herzogs Friedrich I. durch seinen Hofbaumeister Heinrich Schickhardt konzipiert und erbaut wurde. Die Bauzeichnungen und Notizen Schickhardts liegen heute im Hauptstaatsarchiv Stuttgart im Bestand N 220: Nachlass Heinrich Schickhardt mit den Signaturen N 220 T 185 und N 220 T 186. Vgl. Piccard 1953a; Piccard 1953b.

1628 Vgl. Fluri jun. 1954, 47; Fluri jun. 1975, 27

1629 Vgl. J. Lindt 1964, 78. 
geschnitzten Supraporte und einem Wappenschild, die beide oberhalb der Stubentür platziert wurden. Das Haus erhielt zudem insgesamt mehr als dreißig Glasfenster. ${ }^{1630}$

Das bereits erwähnte Ravensburger Ensemble aus drei Papierhäusern und einem anscheinend separaten Stampfhaus, die zusammen einen Betrieb bildeten, stellt vermutlich einen Sonderfall dar. ${ }^{1631}$ Als Sonderfall kann auch die Söflinger Papiermühle gewertet werden. Beim Neubau eines Papierwerks auf dem Grundstück einer Schleife und einer Bluwenmühle erhielt der Papiermacher Anton Turwel die Auflage, dass er in dem Gebäude weder wohnen noch eine Feuerstelle unterhalten dürfe, es sei denn zum Erwärmen des Leims. ${ }^{1632}$ Die in Basel, Zürich und anderen Papiermühlenorten übliche Verbindung von Wohnhaus und Papiermühle wurde hier von der Söflinger Äbtissin explizit unterbunden, sodass die Papiermühle lediglich als Arbeitsplatz genutzt werden durfte. ${ }^{1633}$

Auch die Wasseranlagen zum Antrieb der Räder fanden Erwähnung. Wasserlauf, Wehr und Kanal sowie die dazugehörigen Wasserrechte waren Teil der Liegenschaft und wurden dementsprechend zusammen mit der Papiermühle verkauft. Ersichtlich wird dies beispielsweise bei dem Verkauf der Papierhäuser 1498 in Ravensburg. Zu ihnen gehörten auch wasser und wasserflus. ${ }^{1634}$ Auch der Kauf der Berner Papiermühle zu Thal durch Anton Gallician und seine Schwiegersöhne im Jahr 1474 umfasste Wasser, Wasserrunsen und Mühlwehr. ${ }^{1635}$ Für die neue Papiermühle in Zürich wurde auch die Kettanlage, das heißt hölzerne Wasserrinnen, die das Wasser von dem Kanal oder dem Wehr auf das Mühlrad leiteten, ${ }^{1636}$ eigens neu gebaut. Hierbei half im Jahr 1532/33 der Müller einer benachbarten Mühle, der sich offenbar darauf verstand. ${ }^{1637}$

Informationen zu den Mühlrädern und den von ihnen angetriebenen Wellbäumen können Aufschluss über die Größe des Betriebs geben. Günter Bayerl unternahm in den 1980er-Jahren den Versuch, die Betriebsgröße vorindustrieller Papiermühlen zu typisieren und wählte als Parameter zum einen die Anzahl der Bütten und zum anderen die Anzahl der Wasserräder. Nach Bayerl war ein Großteil der Betriebe bis 1800 mit nur einer Bütte ausgestattet, sodass dies den Normalfall darstellte. Bayerl unterscheidet jedoch zwischen Werken mit einer Bütte und einem Wasserrad, die er als Kleinbetriebe bezeichnet, und Werken mit einer Bütte und zwei Rädern, die er als Normalbetriebe charakterisiert. Papiermühlen mit zwei Bütten und zwei Rädern

1630 Vgl. Zürcher 1963b, $128 \mathrm{f}$.

1631 Vgl. Kapitel 3.2.1.2, S. 225-227.

1632 Vgl. Alfred Schulte 1941, 96, 101. Vgl. auch den Abdruck des Belegs in Frauenknecht 2015, 100.

$1633 \mathrm{Vgl}$. Alfred Schulte 1941, 101.

1634 StR, Urk. 670 (24.07.1498). Vgl. Alfred Schulte 1953, 22.

1635 Vgl. Fluri jun. 1954, 47; Fluri jun. 1975, 27.

1636 Zur Kettanlage, vgl. Grimm/Grimm 1873, Bd. 5, 630.

1637 Vgl. Zürcher 1963a, 59; Zürcher 1963b, 128. 
klassifiziert er als Mittelbetriebe, während als Großbetrieb ein Werk mit mehr als zwei Bütten sowie zwei oder mehr Wasserrädern gelten könne. ${ }^{1638}$

Der Papiermühlenneubau in Memmingen wurde 1482 beispielsweise mit zwei Rädern versehen, die 36 Stampfhämmer antrieben. ${ }^{1639}$ Wie die Hämmer auf die Stampflöcher verteilt waren, gibt das Memminger Dokument nicht preis. Denkbar wäre jedoch bei jeweils vier Hämmern pro Stampfloch die Existenz eines kleineren Löcherbaums mit vier Löchern und eines größeren Löcherbaums mit fünf Löchern. Auch die erste Züricher Papiermühle von Heinrich Walchwiler auf dem Werd besaß vermutlich zwei Räder, die eine große und eine kleine Nockenwelle antrieben. ${ }^{\mathbf{1 6 4 0}}$ Ebenfalls mit zwei Rädern ausgestattet war der städtische Neubau der Züricher Papiermühle. Ursprünglich sah der Bauplan zwar nur ein Rad vor, der neue Pächter Christoph Froschauer konnte sich jedoch 1536 ein zweites Rad ausbedingen. ${ }^{1641}$ Ebenso wurden von Seiten der Stadt zu Beginn nur zehn Stampflöcher eingebaut. Auch hier forderte Froschauer eine Aufstockung um vier weitere Stampftröge, damit er ausreichend Rohstoff zur Befüllung seiner zwei Bütten aufbereiten konnte. In der Züricher Mühle auf dem Werd versorgten folglich zwei Wendelbäume insgesamt vierzehn Stampflöcher, wobei vermutlich der erste, ältere Wendelbaum zehn, der zweite, nachträglich eingebaute nur vier Löcher bediente. Über die Anzahl der Stampfhämmer liegen keine Hinweise vor. Rechnet man mit den üblichen drei bis vier Hämmern pro Loch, so ergibt sich eine Gesamtanzahl von 42 beziehungsweise 56 Hämmern. ${ }^{1642}$

$\mathrm{Zu}$ den Stampftrögen der neuen Papiermühle geben die Züricher Bauamtsakten noch weitere interessante Informationen. Mit der Ausstattung des Stampfgeschirrs war nämlich der Basler Papiermacher Joachim Degenhart ${ }^{1643}$ betraut worden. Im Auftrag der Stadt Zürich reiste er zweimal nach Kandern, um dort die Bodenplatten für die Stampflöcher zu besorgen. ${ }^{1644}$ Zudem brachte er für das Stampfgeschirr Nägel und Kase mit. Die Nägel könnten zur Bestückung der Stampfhämmer verwendet worden sein. Hinter dem Begriff Kase wiederum könnte sich der Kas, auch Scheibenkasten genannt, verbergen, der bei der Ableitung des verbrauchten Wassers aus dem Stampftrog als Sieb fungierte. Er bestand zumeist aus einer Holzscheibe oder -platte, die mit Löchern versehen waren. Durch diese Löcher floss das Schmutzwasser ab. Damit mit dem Wasser nicht auch die bereits fein zerkleinerten Lumpenfasern abgin-

1638 Vgl. Bayerl 1984, 11-14.

1639 Vgl. Piccard 1960, 596. Zum Stampfgeschirr vgl. Kapitel 2.3.2.3.

1640 Schnyder 1937, 717, Nr. 1233. Vgl. Zürcher 1963a, 63.

1641 Vgl. Zürcher 1963a, 61.

1642 Zur durchschnittlichen Anzahl der Hämmer vgl. Kapitel 2.3.2.3, S. 85.

1643 Joachim Degenhart ist ab 1520 als Papiermacher in Basel belegt, wo er 1542 die Rychmühle kaufte, vgl. S. 214, 377, 409.

1644 Vgl. Zürcher 1963a, 64. Nach Hans Kälin ist eine Papiermühle zu Kandern erst ab dem Jahr 1564 belegt, vgl. Kälin 1990, 175 f. Eventuell existierte sie jedoch schon vor 1535, wie der Bezug der Bodenplatten für die Züricher Papiermühle nahelegt. 
gen, bespannte man den Scheibenkasten mit einem Sieb aus Rosshaaren. ${ }^{1645}$ Zur Herstellung der Wellbäume sowie der Löcherbäume wurden in den Jahren 1532 und 1536 insgesamt drei große Eichenstämme in den Züricher Neubau geliefert. ${ }^{1646}$ Aber auch andere Hölzer waren offenbar geeignet: Der Berner Papiermacher Anton Bergier erhielt 1549 von der Stadt eine Tanne zur Fertigung einer neuen Nockenwelle. ${ }^{1647}$

Mit drei Wellbäumen kann die Papiermühle des Paul Ruep in Reutlingen als vergleichsweise großes Werk beschrieben werden. Die Beschädigung eben dieser drei Wellbäume sowie einen Schaden an fünfzehn Stampflöchern beklagte der Papiermacher im Jahr 1519 nach der Belagerung der Stadt durch den württembergischen Herzog. Er bezifferte den Schaden je Loch und je Wellbaum auf 5 Gulden, insgesamt war ihm an seinem Stampfgeschirr also ein Schaden von 90 Gulden entstanden. ${ }^{1648}$ Ob dies dem Neuwert des Stampfwerks entsprach, kann leider nicht nachvollzogen werden. Weitere Ersatzleistungen forderte Paul Ruep für zwei Bütten à 4 Gulden, zwei Pressen à 2 Gulden sowie für 45 Pfund Seil. ${ }^{1649}$ Auch die Nennung der zwei Bütten und der zwei Pressen unterstreichen, dass es sich um einen ansehnlichen Betrieb gehandelt haben muss, der nach Bayerl als Mittelbetrieb charakterisiert werden kann. ${ }^{1650}$

Die vierzehn Stampflöcher der neuen Papiermühle in Zürich bereiteten ebenfalls Lumpen für zwei Bütten auf. Im Jahr 1536 wurden zwei große eichene Standen in das Werk geliefert, die offensichtlich - wie dies für spätere Papiermühlen bekannt ist beheizbar waren. Zeitgleich fertigte nämlich ein Schmied zwei Häfen und baute sie in die Bütten ein. ${ }^{1651}$ Dies ist einer der frühesten Belege für diese Heizvorrichtung, die Johann Michael Becker 1740 als Blase bezeichnet und Joseph Jérôme de Lalande 1761 pistolet nennt. ${ }^{1652}$

Das Gesuch Christoph Froschauers vertieft die durch die Bauamtsrechnungen ermöglichten Einsichten in die Ausstattung der Züricher Papiermühle. Um den Pachtzins von 100 Gulden auf 30 bis 40 Gulden zu drücken, legte der Drucker Froschauer dem Züricher Rat im Jahr 1535 eine Kostenkalkulation vor, die neben einer Berechnung der Personalkosten auch eine Aufstellung der jährlichen Auslagen für Rohstoffe und Werkzeug enthielt. ${ }^{1653}$ In dieser Auflistung finden sich zwei Pauscht Filze, für die Froschauer 24 Gulden veranschlagte, sowie vier Paar Formen, deren Anschaf-

1645 Vgl. Becker 1740/1962, 16; Lalande 1820, 35; Goussier 1765/1966, 835 f.; Labarre 1937, 227, Sp. 265, Nr. 1; Grimm/Grimm 1873, Bd. 5, 246 f.; J. Lindt 1964, 124.

1646 Vgl. Zürcher 1963a, 63.

1647 Vgl. Fluri jun. 1954, 48; Fluri jun. 1975, 11.

1648 Vgl. Sporhan-Krempel 1972b, 1521.

1649 Vgl. Sporhan-Krempel 1972b, 1521.

1650 Vgl. Bayerl 1984, 14.

1651 Vgl. Zürcher 1963a, 68.

1652 Vgl. Becker 1740/1962, 3; Lalande 1820, 68 f. Vgl. Kapitel 2.3.3.2, S. 114 f.

1653 Vgl. Caflisch 1963, 152-158. 
fungspreis er mit 12 Gulden angab. ${ }^{1654}$ Zudem berechnete Christoph Froschauer den Bedarf an Schnüren auf 3.000 Klafter. Karl Zürcher geht davon aus, dass die Schnüre zum Verpacken des Papiers eingesetzt wurden. Für die Verschnürung von 300 Ballen Papier kalkulierte Froschauer demnach einen Bedarf von 3.000 Klafter Schnur. Ein Ries wurde dementsprechend mit einem Klafter Schnur, das heißt 1,80 Meter, umwickelt, was eine kreuzweise Schnürung ermöglichte, wie sie im 18. Jahrhundert als üblich beschrieben wurde. ${ }^{1655}$ Eine Leimküche wird für die Züricher Papiermühle in der ersten Hälfte des 16. Jahrhunderts zwar nicht erwähnt, allerdings führt Froschauer den geschätzten jährlichen Verbrauch von 16 Klafter Holz zum Leimsieden auf. ${ }^{1656}$ Weiteres, nicht näher benanntes Werkzeug brachte Christoph Froschauer aus Basel in die Züricher Papiermühle. ${ }^{1657}$

Beim Verkauf der Papiermühle zu Worblaufen bei Bern 1470 an den städtischen Rat durften die vormaligen Besitzer Tschan und Anton Jacki einen Großteil der Ausstattung behalten. Darunter befanden sich Stampfhämmer, Pressen, Kessel, Seile und Räder. ${ }^{1658}$ Da die Stadt das Mühlwerk in der Absicht gekauft hatte, es in eine Walke umzuwandeln, bedurfte sie der für das Papiererhandwerk benötigten Arbeitsgeräte nicht. Die Jacki hingegen besaßen mit der Papiermühle zu Thal einen Einsatzort für das übriggebliebene Werkzeug. Erstaunlich ist, dass sie auch die Räder, die zweifelsohne auch für den Betrieb einer Walke benötigt wurden, mitnehmen durften. Die erwähnten Pressen wurden zur Entwässerung des Papiers durch Druck eingesetzt, der Kessel wurde wahrscheinlich zur Bereitung des Leims verwendet. Die Seile dienten vermutlich zum Aufhängen des Papiers in einem Trockenraum. Als Anton Gallician und seine Schwiegersöhne 1474 das zweite Werk der Jacki, die Papiermühle zu Thal, kauften, erwarben sie mit dem Gebäude und seiner fest installierten Ausstattung auch die Schöpfformen und die Glättsteine. ${ }^{1659}$ Das Überlassen dieser leicht transportablen Werkzeuge war offensichtlich eine Absprache, die die beiden Vertragsparteien getroffen hatten und die darin begründet lag, dass Tschan und Anton Jacki sich aus dem Papiergewerbe zurückziehen wollten und daher keine Verwendung mehr für die Arbeitsgeräte hatten.

Klare Eigentumsverhältnisse hinsichtlich der Ausstattung herrschten bei der städtischen Papiermühle in Memmingen, die 1482 erbaut wurde. Die gesamte Einrichtung, darunter Tröge, Rinnen, Stampfblöcke und Pressen, waren Eigentum der Stadt und mussten in der Papiermühle verbleiben. Nur die Seile, vermutlich auch hier zur Aufhängung der feuchten Papiere eingesetzt, die Schöpfformen und die Filze

1654 Vgl. Caflisch 1963, $156 \mathrm{f}$.

1655 Vgl. Zürcher 1963a, 103. Zur kreuzweisen Bindung vgl. Kapitel 2.3.9, S. 169.

1656 Vgl. Zürcher 1963a, 80; Caflisch 1963, 156 f.

1657 Vgl. Zürcher 1963a, 69.

1658 Vgl. Fluri sen. 1896, 195; Fluri jun. 1954, 47; Fluri jun. 1975, 7; J. Lindt 1964, 78, 102 mit Anm. 9.

1659 Vgl. Fluri sen. 1896, 198; Fluri jun. 1954, 47 f.; Fluri jun. 1975, 9. 
gehörten dem Pächter und Papiermacher Peter Fort und durften vom ihm vererbt werden. ${ }^{1660}$ Das Memminger Beispiel zeigt, dass auch der Besitz von Anteilen an der Ausstattung einer Papiermühle vorkam. So besaß Peter Fort Rechte sowohl an der Papiermühle am Heuenbach, die er 1478 wohl mit aufgebaut hatte, als auch an dem dazugehörigen Werkzeug, das man zum Papiermachen benötigte. ${ }^{1661}$

In Basel sowie in Bern, Zürich und Ravensburg gehörte folglich zu dem Ensemble Papiermühle eine Vielzahl an unterschiedlichen Gebäuden und Grundstücken.

Diese waren nicht genuin mit der Papiermacherei verbunden, sondern gehörten zu dem Mühlgebäude, das in vielen Fällen, so im Basler St. Albantal, ursprünglich als Kornmühle gebaut worden war. Die Einbindung der Basler Papiermühleninhaber in den Lehenverband beispielsweise durch den anteiligen Besitz der Herrenmatten und der Hanfbünde stellte sie auf eine Stufe mit den anderen Gewerben und zeigt, dass das relativ neue Papierhandwerk in Basel keine Sonderstellung innehatte, sondern sich in bestehende Besitzstrukturen integrierte. Die exklusiv zum Papiergewerbe gehörenden Werkzeuge und Geräte wurden in den untersuchten Fällen, so unter anderem in Basel, Bern und Memmingen, teilweise mit der Mühle verkauft oder verpachtet. Dies war jedoch nur sinnvoll, wenn der Käufer ebenfalls Papiermacher war oder zumindest beabsichtigte, das Mühlwerk als Papiermühle zu betreiben.

\subsubsection{Eigentums- und Besitzverhältnisse}

Die Eigentums- und Besitzverhältnisse einer Papiermühle waren vielschichtig und sowohl von klassischen mittelalterlichen Leiheformen als auch von wirtschaftlichen Pachtbeziehungen geprägt. Aufgrund des Mühlregals waren Mühlen jedweder Art häufig Eigentum eines Grundherrn, zum Beispiel eines adligen Landesherrn, einer Stadt oder einer kirchlichen Institution. ${ }^{1662}$ Dieser Grundherr konnte das Werk auf Zeit verpachten oder in Erbleihe dauerhaft vergeben, wobei ihm nur mehr das Obereigentum mit festgelegten Rechten und einem Grundzins verblieb und der sogenannte Untereigentümer ein umfassendes Nutzungs- und Verfügungsrecht erlangte, das auch den Verkauf und die Vererbung mit einschloss. ${ }^{1663}$ Der Pächter, häufig eine Privatperson, betrieb die Werkstatt nicht immer selbst, sondern konnte sie an einen Unterpächter ausgeben. Bei Papiermühlen war dies der Fall, wenn der Pächter selbst das

1660 Vgl. Piccard 1960, 597.

1661 Vgl. Piccard 1960, 597.

1662 Vgl. Werkmüller 1984, 716-722.

$1663 \mathrm{Zu}$ Leiheformen vgl. Illichmann 1975; Reinicke 1993. 
Handwerk nicht beherrschte und daher seine Mühle an einen Papiermacher vergab. Ein dreistufiges Pachtsystem war daher keine Seltenheit. ${ }^{1664}$

Bereits früh greifbar sind zudem Verlagsverträge, die den eigentlichen Betreiber einer Papiermühle nicht nur durch eine jährliche Zinszahlung dem Besitzer des Werks verpflichteten, sondern ihn wirtschaftlich und finanziell an diesen banden. Das Verlagssystem zeichnete sich dadurch aus, dass ein Auftraggeber einen rechtlich selbstständigen Gewerbetreibenden finanzierte oder mit Rohstoffen und Arbeitsmitteln ausstattete und dafür ein Vorkaufs- und Vertriebsrecht auf die produzierten Waren beanspruchte. ${ }^{1665}$ Für die Papierherstellung im deutschsprachigen Raum ist das bekannteste und früheste Beispiel der Verlagsvertrag zwischen dem Kaufmann Ulman Stromer, Besitzer der ersten Papiermühle im deutschen Raum vor den Toren Nürnbergs, und dem Papiermacher Jörg Tirmann. Im Jahr 1394 verpflichtete sich Stromer, die Versorgung mit Lumpen und die Instandhaltung der Wasserräder zu übernehmen und für jedes Ries Papier einen Viertel Gulden zu zahlen. Im Gegenzug musste Tirmann das Papier auf eigene Kosten produzieren und Stromer jedes Jahr 30 Ries großformatiges Papier kostenlos liefern. ${ }^{1666}$

\subsubsection{Basel}

Die Eigentums- und Besitzverhältnisse der Basler Papiermühlen können für den Untersuchungszeitraum gut nachvollzogen werden. Bis auf die Allenwindenmühle, die wohl ein freies Lehen und damit keinem Grundherrn zu eigen war, ${ }^{1667}$ gehörten alle Mühlwerke zu klösterlichem Grundbesitz. So zinste die Bluwenmühle am Rümelinbach beim Kauf sowie Verkauf durch Anton Gallician 1452 beziehungsweise 1453 von Eigenschaft wegen an das Klarissenkloster Gnadental ${ }^{1668}$ jährlich am Michaelstag, dem 29. September, 17 Schilling neuer Pfennige. Hinzu kamen weitere 4 Schilling für einen Weg sowie 2 Schilling für die einen halben Juchart große Halde mit Reben. ${ }^{1669}$

Alle Mühlwerke im St. Albantal waren Eigentum des Klosters St. Alban, das die zwölf Mühlenlehen im 12. Jahrhundert eingerichtet hatte. Die gesamte Grundherr-

1664 Vgl. allgemein Zaar-Görgens 2004, 78 f.

1665 Zum Verlagswesen vgl. die grundlegende und umfassende Habilitationsschrift von Rudolf Holbach: Holbach 1994. Vgl. auch Reininghaus 1986, 18 f. Zum Verlag in der lothringischen Papiermacherei, vgl. Zaar-Görgens 2004, 111-122.

1666 Vgl. Ulman Stromer 1990a, 95v-96r; Ulman Stromer 1990b, 70-73; Sporhan-Krempel 1954a, 92, 102; Sporhan-Krempel/Stromer 1960, 95; Sporhan-Krempel/Stromer 1963, 201 f.; Stromer 1992, 300.

1667 Auch die anderen Mühlwerke am Kleinbasler Teich besaßen keinen Grundherrn, vgl. Schweizer 1927, 58.

1668 Das Kloster Gnadental lag vor dem inneren Spalentor, auch Spalenschwibbogen genannt, auf dem Areal des heutigen Gewerbemuseums an der Ecke, an der sich die Straßen Petersgraben und Spalenvorstadt begegnen, vgl. zum Kloster Degler-Sprengler 1969.

1669 StABS, Gerichtsarchiv B 6, 123 f., 171 f. Vgl. Kazmeier 1955, 16-18; Piccard 1967, 76 f. 
schaft - so auch die Mühlwerke - ging nach der Reformation 1538 unverändert an die Stadt über. ${ }^{1670}$ Das St. Albankloster, später die Stadt Basel, waren somit Obereigentümer und verfügten über das dominium directum. Zum Betrieb gab das Kloster die Mühlwerke entweder in einer Art Nutzungsrecht oder in Erbleihe an Müller oder andere Gewerbetreibende aus, die folglich das dominium utile besaßen und als Untereigentümer bezeichnet werden können. ${ }^{1671}$ Dieses Untereigentum zeichnete sich dadurch aus, dass die Inhaber einen unablösbaren Grundzins an das St. Albankloster zu zahlen hatten. ${ }^{1672}$ Die Ausgestaltung dieses Grundzinses unterschied sich von Mühle zu Mühle und wandelte sich über die Jahrhunderte von Naturalabgaben hin zu Geldzahlungen. ${ }^{1673}$ Für die Zeit von 1450 bis 1550 blieben die Grundzinsen auf den Papiermühlen relativ stabil.

Informationen $\mathrm{zu}$ dem auf dem jeweiligen Mühlenlehen lastenden Grundzins sind zum einen aus den erhaltenen Urbaren und Zinsbüchern des St. Albanklosters zu gewinnen. ${ }^{1674}$ Während die Urbare vor allem auf eine Dokumentation des weit verstreuten klösterlichen Besitzes und damit auf eine ausführliche Beschreibung der Güter zielten, konzentrierten sich die Zinsbücher hauptsächlich auf die zu entrichtenden Abgaben, wobei zu beachten ist, dass manche Codices Mischformen darstellen. Das erste auf uns gekommene Zinsbuch des St. Albanklosters ist eine auf 1284 datierte Handschrift mit der Signatur Da. Hierin werden zum ersten Mal alle zwölf Mühlenlehen mit ihrer Abgabepflicht aufgeführt. Weitere Zinsbücher folgten im 14. und 15. Jahrhundert, teilweise jedoch ohne Aufführung der Liegenschaften in Basel. ${ }^{1675}$ Für eine Betrachtung der Grundzinsen im Untersuchungszeitraum bietet sich daher vor allem die St. Alban-Registratur $\mathrm{H}$ an, deren Entstehungszeit zwischen 1502 und 1505 anzusetzen ist. ${ }^{1676}$ Die Registratur führt, nach Wohngebieten geordnet und beginnend in den mülinen, die aktuellen Liegenschaftsbesitzer, die Lage der Liegenschaft sowie die zu entrichtenden Zinsen auf.

Zum anderen geben die sogenannten St. Alban-Corpora Aufschluss über den jährlich zu entrichtenden Zins und den tatsächlichen Zahlungseingang. ${ }^{1677}$ Sie wurden im 15. Jahrhundert mit dem Ziel angelegt, die Erfüllung der Abgabepflicht zu kontrollieren. ${ }^{1678}$ Das erste erhaltene Corpus datiert von 1476/77. Innerhalb des Untersuchungs-

1670 Vgl. Schweizer 1924, 87 f.; Reinhardt 1975, 15.

1671 Zur Erbleihe vgl. Illichmann 1975, 7-26; Dannhorn 2003, 11-40. Vgl. auch Schweizer 1923, 49; Reinhardt 1975, 15.

1672 Vgl. Schweizer 1923, 42.

1673 Vgl. Schweizer 1923, 58-67.

1674 Für eine detaillierte Beschreibung der Urbare und Zinsbücher des St. Albanklosters vom Ende des 13. bis zum Beginn des 16. Jahrhunderts vgl. Gilomen 1977, 294-312.

1675 Vgl. Gilomen 1977, 294-312.

1676 StABS, Klosterarchiv, St. Alban H. Zur Datierung vgl. Gilomen 1977, 307, 312 f., 384. Vgl. Anm. 1278.

1677 StABS, Klosterarchiv, St. Alban DD 1, Corpora.

1678 Zur Anlage und Strukturierung der Corpora vgl. Gilomen 1977, $314 \mathrm{f}$. 
zeitraums sind außerdem folgende Jahrgänge im Basler Archiv vorhanden, die auch die Zinszahlungen in Basel und damit im St. Albantal enthalten: 1487/88, 1502, 1505, 1523/24, 1526/27, 1528-1531. Drittens finden sich auch in den Fertigungsprotokollen des Großbasler Schultheißengerichts Angaben zu dem auf den verkauften Liegenschaften lastenden Grundzins. Neben der Ausstattung der Mühle wurde nämlich bei den bereits beschriebenen Handänderungen auch die Zinsbelastung angegeben, meist beginnend mit den Worten ,zinst von Eigenschaft wegen einem Propst zu St. Alban/ dem Gotteshaus zu St. Alban“. Danach folgte der Zinsbetrag.

Aus diesen unterschiedlichen Quellen lässt sich der jeweilige Grundzins ermitteln. Erstaunlich ist, dass jedes der sechs Mühlenlehen, die vor 1500 als Papiermühle betrieben wurden, einen anderen Zins zu entrichten hatte. Gemein war allen Lehen zum einen die Zinszahlung für ihren Anteil an den Matten und dem Holz sowie an der Hanfbünde. Laut der St. Alban-Registratur von 1502/05 wurde von den Herrenmatten ein jährlicher Zins von 6 Pfund neuer Pfennige entrichtet, die die zwei Wassermeister von den einzelnen Lehennehmern einsammeln sollten. ${ }^{1679}$ Jeder Mühlenbesitzer zahlte folglich ein Zwölftel von diesen 6 Pfund, also 10 Schilling. In den eingesehenen Fertigungsprotokollen wird nur bei den Handänderungen der Zunzigermühle und der Stegreifmühle dieser anteilige Zins an den Matten aufgeführt. Während jedoch bei der Stegreifmühle im Jahr 1523 die erwähnten 10 Schilling angegeben werden,, ${ }^{160}$ dokumentieren die Einträge zur Zunzigermühle von 1470, 1486, 1487 und 1496 wiederholt einen Gesamtzins von 7 Pfund statt von 6 Pfund. ${ }^{1681}$ Offenbar wurde der Zins zwischen 1496 und 1502/05 um einen Schilling gesenkt. ${ }^{1682}$ Die Zunzigermühle ist auch die einzige Papiermühle, bei der der Anteil an dem Grundzins für die Hanfbünde explizit angeführt wird. Dieser Zins betrug für alle zwölf Mühlenlehen 4 Schilling, folglich für jede Mühle 4 Pfennig. ${ }^{1683} \mathrm{Im}$ Jahr 1523 zinste die Stegreifmühle für einen geteilten Acker ebenfalls 4 Pfennig, sodass anzunehmen ist, dass es sich bei diesem Acker um das Areal der Hanfbünde handelte. ${ }^{1684}$ Jede Mühle hatte des Weiteren jährlich ein Fastnachtshuhn sowie einen Heuer, das heißt einen Knecht, der bei der Heuernte half, zu stellen. ${ }^{1685}$ In der St. Alban-Registratur wird zudem eine beson-

1679 StABS, Klosterarchiv, St. Alban H, 6; St. Alban DD 1, Corpus 1487/88, 8.

1680 StABS, Gerichtsarchiv B 22, 328r.

1681 StABS, Gerichtsarchiv B 9, 71, 77; B 11, 260r; B 12, 13r; B 14, 71v.

1682 Eduard Schweizer vermutet, dass sich der Zins für die Matten unter dem Propst Claudius de Alingio verringert hatte, der von 1517 bis 1526 Vorsteher des St. Albanklosters war, vgl. Schweizer 1923, 45. Zu Claudius de Alingio vgl. Gilomen 1977, 375.

1683 StABS, Klosterarchiv, St. Alban H, 13. Vgl. Schweizer 1923, 45.

1684 StABS, Gerichtsarchiv B 22, 328r.

1685 StABS, Klosterarchiv, St. Alban H, 2-5. Das Fastnachtshuhn war, wie der Name sagt, meist zur Fastnacht zu geben, der Heuer sollte zum Johannistag gestellt werden. Vgl. Schweizer 1923, 41. Zum Fastnachtshuhn vgl. Andermann 2014, $126 \mathrm{f}$. 
dere Abgabe bei Handänderungen, der sogenannte Ehrschatz, ${ }^{1686}$ genannt, die dem Betrag des jährlichen Bodenzinses entsprechen sollte, wenn nichts anderes vereinbart wurde. ${ }^{1687}$ Bei den Fertigungsprotokollen die Rychmühle betreffend findet sich ein Kapaun als Ehrschatz. ${ }^{1688}$ Der neue Besitzer durfte das Lehen erst nutzen, wenn er diese einmalige Abgabe entrichtet hatte. ${ }^{1689}$

Auf den Papiermühlen im St. Albantal lasteten im 15. und beginnenden 16. Jahrhundert neben dem Fastnachtshuhn und dem Heuer Korn- und vor allem Geldzinsen. Diese Zinsen waren meist zu den vier Fronfasten fällig. ${ }^{1690}$ Bei manchen Papiermühlen musste auch ein Jahreszins oder andere $\mathrm{zu}$ verschiedenen Fälligkeitsterminen zahlbare Abgaben entrichtet werden. Die Zinszahlungen der einzelnen Papiermühlen unterschieden sich relativ stark.

Im Jahr 1448 zinste die Rychmühle noch 36 Schilling jährlich, wie sich aus dem Fertigungsprotokoll den Kauf durch Heinrich Halbysen d. Ä. betreffend ersehen lässt. ${ }^{1691}$ Seit den 1470er-Jahren zahlte der Besitzer der Rychmühle - zunächst Michel Gallician, dann Hans Lufft von Ettlingen, später Fridlin Hüsler d. Ä. - nach den St. Alban-Corpora einen Fronfastenzins von 4 Schilling und 6 Pfennig, im Jahr folglich insgesamt 18 Schilling. ${ }^{1692}$ Die Fertigungsprotokolle erwähnen hingegen einen Zins von nur 16 Schilling Zinspfennige, die an Propst und Konvent von St. Alban entrichtet werden sollten. ${ }^{1693}$ Die St. Alban-Registratur von 1502/05 bezifferte die Jahressumme des Fronfastenzinses auf 8 Schilling neuer Pfennige, was ebenfalls einem

1686 Der Ehrschatz wurde bei Liegenschaftsübertragungen von einem Erbpächter auf eine andere Person, die nicht sein Erbe war, als Gegenleistung zur Zustimmung des Obereigentümers geleistet, vgl. Deutsches Rechtswörterbuch 1932-1935, Bd. 2, 1294 f.; B. Roth 2005, 106.

1687 StABS, Klosterarchiv, St. Alban H, 1: so dick sich die handt verwandelt, sol man so vil zů erschatz geben, als sich jerlich bodenzins trift. Es sye dann, das von ettlichen sunderlichen miner oder me gewonheit syg, zů geben als denn clärlich in disem bůch gezeichnet ist oder man mit dem Schaffner überkomen mag. Vgl. zum Ehrschatz in der Grundherrschaft des St. Albanklosters auch Gilomen 1977, $267 \mathrm{f}$.

1688 StABS, Gerichtsarchiv B 5, 93v; B 13, 167v; B 22, 69; B 28, 191; B 29, 11r. In der St. Alban-Registratur findet sich bei der Rychmühle ebenfalls der - in diesem Falle von einer späteren Hand hinzugefügte - Hinweis, dass als Ehrschatz ein Kapaun zu zahlen war, StABS, Klosterarchiv, St. Alban H, 5. Vgl. Schweizer 1923, 41. Kapaune, das heißt kastrierte und gemästete Hähne, die wegen ihres besonders milden und fetten Fleischs geschätzt wurden, waren über das Mittelalter hinaus ein üblicher Zins, wurden aber auch öffentlichen Amtsträgern als Lohn ausgezahlt, vgl. die Lemmata Kapaun und Kapaunzins in Deutsches Rechtswörterbuch 1974-1983, Bd. 7, 296 f.

1689 StABS, Teichkorporationen A 1, 42r.

1690 Vgl. beispielsweise StABS, Klosterarchiv, St. Alban H, 2-5. Die Fronfasten, lat. angaria, oder auch Quatember unterteilten das Jahr in vier Zeitabschnitte. Die jeweils drei Fastentage fielen auf den Mittwoch, Freitag und Samstag nach Aschermittwoch (cineres), Pfingsten (pentecoste), Kreuzerhöhung (exaltatio crucis, 19. September) und den Tag der heiligen Lucia (Lucie, 13. Dezember), vgl. Deutsches Rechtswörterbuch 1935-1938, Bd. 3, 988; Franz 1995, 357.

1691 StABS, Gerichtsarchiv B 5, 94r. Vgl. Schweizer 1923, 67.

1692 StABS, Klosterarchiv, St. Alban DD 1, Corpus 1477/78, 33-36; Corpus 1487/88, 4-7; Corpus 1502, 5v; Corpus 1523/24, [6]; Corpus 1526/27, 5v; Corpus 1527/28, 4v.

1693 StABS, Gerichtsarchiv B 13, 167v; B 22, 69r; B 28, 191r; B 29, 11r. 
Betrag von 16 Schilling Zinspfennigen entsprach. ${ }^{1694}$ Wie es zu dieser Differenz kam, ist nicht sicher festzustellen. 18 Schilling Zins pro Jahr ergeben sich jedoch, wenn man die in den Fertigungsbüchern separat aufgeführten 2 Schilling, die für den zur Mühle gehörenden Garten zu entrichten waren, dazurechnet. ${ }^{1695}$ Nach den Corpora sowie der St. Alban-Registratur lastete zudem noch ein Jahrzins von 2 Schilling auf dem Mühlenlehen. ${ }^{1696}$ Im Zuge der Reformation wurde der Zins 1532 abgelöst. ${ }^{1697}$

Der Erbpächter der Zunzigermühle gab bis zur Reformation sowohl einen Kornals auch einen Geldzins, nämlich nach der St. Alban-Registratur und dem Corpus von 1487/88 jede Fronfasten 3 Sester Kerne, das heißt ausgehülstes Getreide, und 3 Sester Mühlenkorn, das heißt noch mit Hülsen vermischtes Korn $^{1698}$ sowie 3 Schilling und 3 Pfennig. ${ }^{1699}$ Dies summiert sich jährlich auf jeweils 12 Sester Kerne und Mühlenkorn sowie 13 Schilling neuer Pfennige Geldzins. Die Fertigungsprotokolle nennen mit einem Zinssatz von einem Pfund und 6 Schilling Zinspfennige jährlich, also 26 Schilling Zinspfennige, ${ }^{1700}$ den gleichen Wert, da ein Zinspfennig halb so viel wert war wie ein neuer Pfennig. Der Kornzins allerdings beträgt in den Einträgen der Fertigungsprotokolle die Hälfte weniger, nämlich jeweils 3 kleine Sester zu je 17 Litern Kerne und Mühlenkorn. ${ }^{1701} \mathrm{Ob}$ es sich bei dieser Angabe um einen immer weiter fortgeschriebenen Fehler des Gerichtsschreibers handelte oder ob der Kornzins variierte, konnte nicht festgestellt werden. Das spätestens seit 1470 zur Mühle gehörende Haus, Losers Haus genannt, zinste separat, und zwar nach der St. Alban-Registratur 13 Schilling jede Fronfasten, dazu jährlich 7 Schilling, zwei Fastnachtshühner und zwei Heuer. ${ }^{1702}$ Eine Trennung von Mühlenzins und den Abgaben für das Haus ist jedoch nicht immer möglich, da gerade bei den frühen Corpora eine allgemeine Summierung der Abgaben unter dem jeweiligen Zinszahler festzustellen ist. So zinste Ulrich Züricher im Jahr 1477/78 einen Fronfastenzins von 3 Schilling und 3 Pfennig, drei Hühner und

1694 StABS, Klosterarchiv, St. Alban H, 5. Der Wert eines neuen Pfennigs entsprach zwei Zinspfennigen, vgl. Gilomen 1977, 120-122.

1695 StABS, Gerichtsarchiv B 13, 167v; B 22, 69; B 28, 191; B 29, 11r.

1696 StABS, Klosterarchiv, St. Alban DD 1, Corpus 1526/27, 28v: Fridlin Heußler von siner papirmüly prius Hanns von Ettlingenn - ii $\beta$. Vgl. auch Corpus 1527/28, 28v; Corpus 1528/29, 36v; Corpus 1529/30, 27v; Corpus 1530/31, 31v; St. Alban H, 5.

1697 Vgl. Schweizer 1923, 67.

1698 Vgl. Schweizer 1923, 40 mit Anm. 67.

1699 StABS, Klosterarchiv, St. Alban H, 5; St. Alban DD 1, Corpus 1487/88, 4-7, 9.

1700 StABS, Gerichtsarchiv B 9, 71; B 11, 260; B 12, 13; B 14, 71v.

1701 StABS, Gerichtsarchiv B 9, 71; B 11, 260r; B 12, 13r; B 14, 71v. Ein Sester war ein Hohlmaß für Getreide, wobei der kleine Sester im Basler Raum ungefähr 17 Liter fasste. In einem großen Sester waren 2 kleine Sester enthalten. 16 kleine oder 8 große Sester wiederum entsprachen einem Sack. 2 Säcke wurden als Vierzel bezeichnet, vgl. Dubler 2011, 604; Dubler 2012, 457; Dubler 2013, 877.

1702 StABS, Klosterarchiv, St. Alban H, 5. Die 7 Schilling pro Jahr, die Jörg Dürr d. Ä. für eine Liegenschaft zahlte, die vorher Hans Kielhammer von Schaffhausen gehörte, sind daher eher dem Haus als der Mühle zuzurechnen, vgl. St. Alban DD 1, Corpus 1526/27, 13v; Corpus 1527/28, 13v; Corpus 1529/30, 13v; Corpus 1530/31, 18v. 
drei Heuer, sowie einen Jahrzins von 6 Schilling, allerdings geht aus den Einträgen nicht hervor, wofür er welchen Zins entrichtete. ${ }^{1703}$ Unter Propst Claudius de Alingio wurde der Kornzins und vermutlich auch der auf der Papiermühle lastende Geldzins abgelöst, sodass das Fertigungsprotokoll beim Kauf der Zunzigermühle durch Fridlin Hüsler d. Ä. im Jahr 1532 nur noch den Grundzins für Losers Haus verzeichnet. ${ }^{1704}$

Der Besitzer der Klingentalmühle hatte im Untersuchungszeitraum einen Geldzins von 5 Pfund jährlich zu entrichten, das heißt jede Fronfasten ein Pfund und 5 Schilling neuer Pfennige. ${ }^{1705}$ Ob von der Klingentalmühle neben dem Fastnachtshuhn und dem Heuer eine weitere jährliche Abgabe zu entrichten war, ist nicht klar zu ersehen. In den St. Alban-Corpora der Jahre 1477/78 sowie 1487/88 zahlte der Besitzer des Lehens, Anton Gallician, mehrere Jahrzinsen, die jedoch nicht zu bestimmten Liegenschaften zugeordnet werden können. ${ }^{1706}$ Sein Sohn Hans Gallician II, der die Mühle nach seinem Tod übernahm, entrichtete im Jahr 1502 zusätzlich zu den Fronfastenzinsen 6 Schilling jährlich für die Papiermühle und den Garten. ${ }^{1707}$ Die nachfolgenden Besitzer Conrad Grebel und Peter Sontach zinsten ebenfalls 6 Schilling Jahrzins, allerdings ausschließlich für den hinter der Mühle gelegenen Garten. ${ }^{1708}$

Von dem Lehen der Stegreifmühle waren jede Fronfasten 30 Schilling neuer Pfennige fällig, folglich zahlte der Inhaber dieses Mühlwerks insgesamt 6 Pfund pro Jahr. ${ }^{1709}$ Dieser Fronfastenzins galt bereits im St. Alban-Corpus von 1523/24 als abgelöst, während der jährliche Zins von einem Huhn und einem Heuer bestehen blieb. ${ }^{1710}$

Das gesamte Lehen der hinteren Spiegelmühle zinste dem Kloster St. Alban 6 Säcke Kerne und 6 Säcke Mühlenkorn, die der Müller von St. Albantal 25 an das Kloster abführte. ${ }^{1711}$ Der Papiermacher, der die andere Hälfte des Lehens, St. Albantal 31, betrieb, zahlte diesem seinen Anteil. ${ }^{1712}$ In der nicht gefertigten Übertragung

1703 StABS, Klosterarchiv, St. Alban DD 1, Corpus 1477/78, 33-36, 39.

1704 StABS, Gerichtsarchiv B 26, 133v. Zur Ablösung des Kornzinses vgl. StABS, Klosterarchiv, St. Alban H, 5. Vgl. Schweizer 1923, 67.

1705 StABS, Klosterarchiv, St. Alban H, 4; St. Alban DD 1, Corpus 1477/78, 33-36; Corpus 1487/88, 4-7; Corpus 1502, 5v; Corpus 1523/24, [6v]; Corpus 1526/27, 4v; Corpus 1527/28, 3v; Corpus 1528/29, 3v; Gerichtsarchiv B 6, 171; B 22, 333r; B 22, 334v; B 24, 202r; B 30, 226r.

1706 StABS, Klosterarchiv, St. Alban DD 1, Corpus 1477/78, 37 f.; Corpus 1487/88, 11, $20,22$.

1707 StABS, Klosterarchiv, St. Alban DD 1, Corpus 1502, 5v: Item aber git er vi $\beta$ i hun $i$ hower tag von der obgemelten bappir mule und vom garten.

1708 StABS, Klosterarchiv, St. Alban DD 1, Corpus 1523/24, 24v; Corpus 1526/27, 32v; Corpus 1528/29, 39v; Corpus 1529/30, 29v.

1709 StABS, Klosterarchiv, St. Alban H, 4; St. Alban DD 1, Corpus 1505, 14v; Gerichtsarchiv B 22, 327v. 1710 StABS, Klosterarchiv, St. Alban DD 1, Corpus 1523/24, [7v]: Jorg Dir prius Frantz Galliciann ist abgelöst doch widerkouffig alle fronfasten drißig schilling. Ebd., 14v; Corpus 1526/27, 13v; Corpus 1527/28, 13v; Corpus 1528/29, 21v; Corpus 1529/30, 13v; Corpus 1530/31, 18v.

1711 StABS, Klosterarchiv, St. Alban H, 4; St. Alban DD 1, Corpus 1487/88, 9; Gerichtsarchiv B 12, 40. 1712 Schweizer 1923, 65 f. In welcher Höhe sich dieser anteilige Zins bewegte, konnte nicht eruiert werden. 
der halben Spisselismühle an Hans Gallician I wurden im Jahr 1459 als Grundzinsen 3 Vierzel Kerne und 3 Vierzel Mühlenkorn angegeben. Peter Zunziger, der anscheinend die andere Hälfte des Lehens besaß, musste jährlich 1,5 Vierzel Kerne und 1,5 Vierzel Mühlenkorn entrichten. ${ }^{1713}$ Nach der St. Alban-Registratur lastete um 1502/05 ein Fronfastenzins von 2 Pfund und 4 Schilling neuer Pfennige auf der Spisselismühle, folglich im Jahr 8 Pfund und 16 Schilling. ${ }^{1714}$ Die 1525 von Jörg Dürr d. Ä. gekaufte und in eine Papiermühle umgewandelte hintere Schleife im St. Albantal 23 zinste nach den St. Alban-Corpora jährlich 5 Schilling und 6 Pfennig sowie des Weiteren ein Pfund und 5 Schilling am Johannistag und ein Pfund, 5 Schilling und 6 Pfennig an Weihnachten. ${ }^{1715}$

Diese Zusammenstellung verdeutlicht, dass jedes als Papiermühle betriebene Mühlenlehen unterschiedliche Abgaben zu leisten hatte. Die meisten Papiermühlenbesitzer entrichteten einen Geldzins, der zumeist viermal im Jahr fällig war. Die Klingentalmühle und die Stegreifmühle, die das mittlere Mühlenpaar am hinteren Teich bildeten, zinsten die höchste Geldsumme, nämlich 5 Pfund beziehungsweise 6 Pfund jährlich. Deutlich weniger und zwar 18 Schilling hatte der Inhaber der Rychmühle zu leisten. Der niedrigste Zinssatz, 13 Schilling im Jahr, wurde von der gegenüberliegenden Zunzigermühle gezahlt. Allerdings gab dieses Mühlenlehen als einzige Papiermühle auch noch einen Kornzins von insgesamt 24 Sestern Getreide im Jahr. Die hintere Spiegelmühle zinste zwar ausschließlich in Getreide, allerdings beherbergte nur eine Hälfte des Lehens eine Papierwerkstatt, während in der anderen eine Kornmühle untergebracht war. Die erst im Jahr 1525 zur Papiermühle umgebaute hintere Schleife, die der hinteren Spiegelmühle gegenüberlag, siedelt sich hinsichtlich der Höhe der Abgaben in der Mitte an: Ihr Besitzer hatte im Jahr 2 Pfund und 16 Schilling zu entrichten. Die termingerechte Zahlung der Grundzinsen war für die Mühlenbesitzer von Interesse, da der Propst bei Säumigkeit das Recht hatte, die Räder - und damit den gesamten Betrieb - stillzulegen. ${ }^{1716}$

Zusammengefasst befand sich also die Mehrzahl der Basler Papiermühlen im Obereigentum des Klosters St. Alban. Das Untereigentum, als Erblehen konzipiert, war jedoch privater Natur und in den meisten Fällen in der Hand von Papiermachern. Lediglich die erste Papierwerkstatt Basels, die Allenwindenmühle, gehörte von ihrer Gründung bis zu ihrer Stilllegung dem Kaufmann Heinrich Halbysen d. Ä. und nach seinem Tod seinem gleichnamigen Sohn, der auch Handel trieb. ${ }^{1717}$ Ebenfalls über einen langen Zeitraum im Besitz der Halbysen befanden sich die beiden ersten

1713 StABS, Gerichtsarchiv B 8, 43r.

1714 StABS, Klosterarchiv, St. Alban H, 2. Vgl. Schweizer 1923, 59.

1715 StABS, Klosterarchiv, St. Alban DD 1, Corpus 1526/27, 13v; Corpus 1527/28, 13v, 14v; Corpus 1529/30, 13v; Corpus 1530/31, 18v.

1716 StABS, Teichkorporationen, St. Alban A 1, 38v-39r.

1717 Zu Heinrich Halbysen d. Ä. und seinem Sohn vgl. Piccard 1967, 50-76; Kälin 1974, 140-154. 
Papiermühlen im St. Albantal, die Rychmühle und die Zunzigermühle, nämlich beide um die zwanzig Jahre. ${ }^{1718}$ Während die Rychmühle nach der Übernahme durch Michel Gallician im Jahr 1467 dauerhaft in den Händen von Papiermachern verblieb (1494-1519 Hans Lufft von Ettlingen, 1519-1542 Fridlin Hüsler d. Ä., ab 1542 Joachim Degenhart), kam die Zunzigermühle durch Pfändungen zwei Mal in den Besitz von handwerksfremden Personen. So gehörte sie im Jahr 1486 der Witwe des Kaufmanns Andres Bischoff, Barbara Bischoff, anschließend bis in das Jahr 1487 dem Weinmann Hans Strub. Im Jahr 1494 pfändete der Messerschmied Conrat Wesslin nicht nur die Zunzigermühle, sondern ebenfalls die halbe Spisselismühle von Hans Züricher. Beide Werke verblieben jedoch nur zwei bis drei Jahre in seinem Besitz: Die Zunzigermühle kam wieder an Papiermacher (1496-1523 Hans Kielhammer von Schaffhausen, 1530-1532 Gregorius Dürr, ab 1532 Fridlin Hüsler d. Ä.), in der halben Spisselismühle wurde fortan kein Papier mehr produziert. Die Klingentalmühle sowie die Stegreifmühle waren seit dem Kauf durch Anton Gallician in der Hand von Fachleuten. Einzige Ausnahme bildete sein Sohn, Hans Gallician II, der zwar aus einer Papiererfamilie stammte, selbst aber ausschließlich als Kaufmann tätig war. ${ }^{1719} \mathrm{Er}$ besaß die Klingentalmühle von 1497 bis 1521. Danach übernahm sein Bruder Franz Gallician, der seit 1497 bereits die gegenüberliegende Stegreifmühle innehatte, den Betrieb bis ins Jahr 1523. Er übte offenbar den Beruf seines Vaters aus oder hatte ihn zumindest erlernt. ${ }^{1720}$ Die nachfolgenden Inhaber beider Werke können ebenfalls als Papiermacher angesprochen werden (Klingentalmühle: 1523-1528 Conrad Grebel, 1528-1550 Peter Sontach, ab 1550 Hans Düring/Stegreifmühle: ab 1523 Jörg Dürr d. Ä.). Die hintere Spiegelmühle befand sich durchgängig im Besitz von Papierern (bis 1487 Peter Höfflin, 1487-1513 Michel Gernler, 1513-1530 Jörg Dürr d. Ä., 1530-1531 Bartholome Blum, ab 1531 Claus Dürr).

Für das St. Albantal lässt sich folglich festhalten, dass außer den Halbysens und Hans Gallician II, die um die 20 Jahre im Besitz einer Papierwerkstatt waren, fachfremde Personen nur wenige Jahre Inhaber von Papiermühlen blieben. Sie kamen immer durch ein Rentengeschäft und eine daraus resultierende Pfändung an die Mühlwerke und hatten vermutlich nicht die Intention, Papier produzieren zu lassen, sondern wollte sich lediglich schadlos halten und veräußerten die Liegenschaft daher relativ rasch wieder. ${ }^{1721}$ Anders war der Fall der Papiermühlen zu Kluben gelagert.

1718 Für die Belege zu den folgenden Angaben vgl. Kapitel 3.2.1.1.

1719 Hans Gallician II wurde nicht als Papiermacher, sondern als Krämer oder Kaufmann bezeichnet, StABS, Gerichtsarchiv B 12, 75r; A 40, 94r. Zu Hans Gallician II vgl. Piccard 1967, 96, 102-117, 178; Kälin 1972a, 7-9; Kälin 1974, 162.

1720 Im Gegensatz zu seinem Bruder Hans wurde Franz Gallician als Papiermacher bezeichnet, zum Beispiel bei seiner Aufnahme in die Safranzunft im Jahr 1485, vgl. Kapitel 3.3.4.1, S. 408. Im Jahr 1514 wurde er allerdings auch Krämer genannt, StABS, Gerichtsarchiv C 21, 134r.

$1721 \mathrm{Zu}$ den Papiermachern, die den Betrieb für die handwerksfernen Besitzer leiteten, vgl. Kapitel 3.3.1.1, S. 324, 329, 331, 333, 336. Ob die Werke in Pacht vergeben oder ob die betriebsführenden Papiermacher nur angestellt waren, lässt sich aus den Basler Quellen nur in Einzelfällen ersehen. 
Hier war es dem Besitzer des Anwesens, Hans Sigmund von Aug, der wohl gelernter Steinschneider und im Weinhandel tätig war, offensichtlich ein Anliegen, Papier herzustellen und zu verkaufen, auch wenn er kein Fachmann war. ${ }^{1722}$

\subsubsection{Augsburg, Bern, Ettlingen, Gengenbach, Kempten, Memmingen, Ravensburg, Reutlingen, Söflingen, Straßburg, Urach und Zürich}

Die Papiermühlen in Ravensburg befanden sich in Privatbesitz, wobei auch hier in manchen Fällen der eigentliche Betreiber nur ein Untereigentum innehatte und einen Grundzins an einen Obereigentümer entrichtete. Interessant ist, dass das Obereigentum im Falle der ersten in den Quellen fassbaren Ravensburger Papierhäuser anscheinend ebenfalls in Privathand war. Im Jahr 1410 gab Anna Holbain, wie wir bereits gesehen haben, ihre Mühle und weitere Liegenschaften an Jos und Haintz Segelbach für einen jährlichen Grundzins von 18 Pfund zur Erbleihe. ${ }^{1723}$ Zudem verlieh sie den beiden Brüdern eine Walke im Ölschwang, für die sie einen jährlichen Bodenzins von einem Pfund verlangte. ${ }^{1724}$ Für beide Grundstücke werden in der jeweiligen Urkunde keine weiteren Zinsbelastungen erwähnt.

Dass es sich bei der Stampfmühle und den dazugehörigen Gebäuden mit hoher Wahrscheinlichkeit um die Papierhäuser im Ölschwang handelte, kann anhand der Grundzinsen erschlossen werden. Als erster Ansatzpunkt bietet sich eine Urkunde von 1442 an. In diesem Jahr verkaufte Hans Züricher, ein Neffe Anna Holbains, die Zinsen, die er von den Papierhäusern Heinrich Gelderichs sowie weiteren Liegenschaften bezog und die er von seiner Tante geerbt hatte, für 449 Pfund und 8 Schilling an die Stadt Ravensburg. ${ }^{1725}$ Die Höhe der Zinsen betrug 19 Pfund und war damit deckungsgleich mit dem Zinsbetrag, den die Brüder Segelbach ab 1410 für die Stampfmühle und die Walke bezahlten. Somit könnten die betreffenden Liegenschaften identisch sein.

Die Vererbung der Grundzinsen an Hans Züricher hatte eine für Anna Holbain wohl eher unerfreuliche Vorgeschichte. Anderthalb Jahre nach der Verleihung der Stampfmühle an die Brüder Segelbach wurde Anna von ihren Geschwistern gezwungen, bereits zu Lebzeiten die Verteilung ihres Erbes vorzunehmen. ${ }^{1726}$ Dies geschah mit der Urkunde vom 31. Oktober 1411, in der zum ersten Mal die Papierhäuser

\footnotetext{
1722 Vgl. Kälin 1972a, 10-12; Kälin 1982, 30-32, 38. Ob Hans Sigmund tatsächlich selbst Papiermacher war, ist ungewiss, auch wenn Kälin ihn in seinem pathetischen letzten Satz als solchen bezeichnet. 1723 StR, Urk. 756 (20.05.1410). Vgl. Alfred Schulte 1953, 15-17; Sporhan-Krempel 1953, 19-21. 1724 StR, Urk. 757 (26.05.1410). Vgl. Alfred Schulte 1953, 17. 1725 StR, Urk. 788 (30.01.1442): [...] nemlich die nunzehen pfund pfenning järlichs vorzins, so mir ab des erbern Hainrich Gäldrichs bappir hüsern und der mülin darunder die Ruch Haintz innhaut alles sampt ob dem öllschwang gelegen järlich gänd [...] als die von der ersamen Anna Holbainin miner lieben basen an mich in erbschafft wyse gevallen sind [...] Vgl. Alfred Schulte 1953, 21; Sporhan-Krempel 1953, 22.
}

1726 Vgl. Sporhan-Krempel 1953, $21 \mathrm{f}$. 
erwähnt wurden. ${ }^{1727}$ Eine zugunsten von Anna Holbain eingefügte Klausel besagte jedoch, dass die Rechte und Liegenschaften beim Todesfall der Beschenkten wieder an sie zurückfallen. Dieser Fall trat im Jahr 1433 tatsächlich ein: Anna Holbains Schwester Christine Wirt sowie ihr Mann Hans Züricher waren verstorben. Sie hinterließen einen Sohn, Hans Züricher, den Anna Holbain noch im selben Jahr in ihr Erbe einsetzte. ${ }^{1728}$ Auf diese Weise kamen die Rechte auf die Grundzinsen aus den Papierhäusern, deren Höhe in der Übertragungsurkunde leider nicht genannt wurde, zum Teil an Hans Züricher. Den anderen Teil übertrug Anna Holbain noch im selben Jahr ihrem Sohn Hans Blarer, der als Geistlicher in Konstanz lebte. ${ }^{1729}$ Zudem musste Hans Züricher seinem Vetter ein jährliches Leibgedinge von 9 Pfund zusagen. ${ }^{1730}$ Offenbar war in den nächsten Jahren Streit um diese Güter aufgekommen, denn 1441 kamen Hans Züricher und Hans Blarer zu einem Vergleich: Durch die Zahlung von 380 Pfund erwarb Hans Züricher auch den Anteil Hans Blarers. ${ }^{1731}$ Somit konnte er im darauffolgenden Jahr den Gesamtbetrag der Zinsen an die Stadt Ravensburg verkaufen. Als Felix Humpis im Jahr 1498 die drei Papierhäuser verkaufte, besaß die Stadt Ravensburg immer noch das dominium directum an den Papierhäusern - in Form eines jährlichen Zinses von 19 Pfund. ${ }^{1732}$ Das Obereigentum an den Papierhäusern im Ölschwang wechselte im 15. Jahrhundert folglich mehrmals den Inhaber: von Anna Holbain über ihre Geschwister zu ihrem Neffen, der seine Rechte an den Papierhäusern wiederum der Stadt Ravensburg verkaufte.

Die Eigentumsverhältnisse des ersten Papierhauses in Schornreute treten nicht klar zutage. Sicher ist, dass der Stadt der Flappach und damit die Wasserrechte an diesem Kanal gehörten. ${ }^{1733}$ So vergaben Bürgermeister und Rat den drei Papiermachern Peter Bappirer, Cuntz Wolfartshofer und Hans Stengeli im Jahr 1436 den Wasserfall unterhalb des rechten Papierhauses zu Schornreute als Erbleihe. Auf einer Hofstatt, die anscheinend zu diesem Wasserfall gehörte, bauten die Papierer ein weiteres Papierhaus. Von der gesamten Liegenschaft zahlten sie der Stadt Ravensburg jährlich 4 Pfund Pfennig Zinsen. ${ }^{1734}$ Zwei Klauseln schränkten die Verfügungsgewalt über das Untereigentum ein: Zum einen durften die drei Papiermacher den Wasser-

1727 StR, Urk. 613 (31.10.1411). Vgl. Alfred Schulte 1953, 17; Sporhan-Krempel 1953, 21.

1728 StR, Urk. 624 (06.07.1433). Vgl. Alfred Schulte 1953, 20; Sporhan-Krempel 1953, 21.

1729 Vgl. Sporhan-Krempel 1953, $21 \mathrm{f}$.

1730 StR, Urk. 625 (24.07.1433). Vgl. Alfred Schulte 1953, 20; Sporhan-Krempel 1953, 21.

1731 StR, Urk. 1439 (04.09.1441). Vgl. Alfred Schulte 1953, 21.

1732 StR, Urk. 670 (24.07.1498): [...] zinst järlich gemeiner stat alhie newnzehen pfundt pfennig [...] Vgl. Alfred Schulte 1953, 22.

1733 StR, Urk. 1218 (08.07.1435). Vgl. Alfred Schulte 1953, 20 f.

1734 StR, Urk. 723 (03.02.1436). Vgl. Alfred Schulte 1953, 21; Sporhan-Krempel 1953, 23. 
fall, Haus und Hofstatt nur zur Papierherstellung nutzen, zum anderen durften sie ihre Rechte nur an Ravensburger Bürger veräußern. ${ }^{1735}$

Die Besitzer der Papierhäuser im Ölschwang waren im 15. Jahrhundert keine gelernten Papiermacher, sondern - mit der Familie Segelbach, Heinrich Gelderich sowie der Familie Humpis - Kaufleute. Erst gegen Ende des Jahrhunderts, 1498, erwarben zwei Papiermacher, Hans Wäch und Hans Schmid, die Liegenschaft. Auch die nächsten Inhaber, Hans Härb und Jörg Wolfartshofer waren vom Fach. ${ }^{1736}$ Die Papiermühlen zu Schornreute waren von ihrer Gründung bis in die 1540er-Jahre im Besitz von Papiermachern aus der Familie der Wolfartshofer. Um das Jahr 1545 erwarb der Säckler und Kaufmann Jörg Sauter das Mühlwerk. Da zum Betrieb des Werks ein erfahrener Papiermacher nötig war, schlossen er und sein gleichnamiger Sohn zwei Jahre später einen Pacht- und Verlagsvertrag mit Heinrich Im Thurn, in welchem der jährliche Pachtzins auf 50 rheinische Gulden und die Pachtdauer auf sechs Jahre festgelegt wurde. Zudem sollte Im Thurn seine gesamte Produktion, sei es Schreibpapier, Druckpapier, Kartenpapier, dünnes Papier oder Einbindepapier, für einen festgelegten Preis an die Sauter verkaufen. Im Gegenzug wollten diese dem Papiermacher die benötigte Menge Lumpen sowie Holz und Eisen für Reparaturen stellen und ihm einen Vorschuss für anfallende Kosten gewähren. ${ }^{1737}$ Die geschäftliche Beziehung zwischen Verlagsherr und Papiermacher verlief jedoch nicht reibungslos, denn bereits zwei Jahre später standen sich beide Parteien vor Gericht gegenüber. Während Jörg Sauter und sein Sohn klagten, dass Heinrich Im Thurn das festgelegte Gewicht für ein Ries Schreibpapier nicht einhalte, beschwerte sich dieser, dass die zugesagte finanzielle Unterstützung ausbliebe und dass er daher bereits Kleider seiner Frau verkaufen müsse, um zu etwas Geld zu kommen. Zudem warf Heinrich Im Thurn Jörg Sauter vor, von einer Finte Gebrauch gemacht zu haben. Sauter habe einen Mann heimlich beauftragt, Papier von ihm zu kaufen, damit der Papiermacher vertragsbrüchig werde und ein Rechtsgrund für die Aufhebung des Verlagsvertrags geschaffen sei. ${ }^{1738}$ Wie der Rechtsstreit geschlichtet wurde, ist nicht bekannt, ebenso wenig, ob Heinrich Im Thurn danach noch Pächter der Sauter war.

1735 StR, Urk. 723 (03.02.1436): Doch hand si mit merklich worten hierinne bedingt daz wir den vorgeschriben val mit sampt den redern daran nicht anders bruchen innehaben noch niessen süllen denn zů unserm handtwerch bappiren und nu hinanthin in ewigzitt weder malmulin segmulin schliffin noch nutz anders an den selben val buwen noch machen süllen. Vgl. Alfred Schulte 1953, 21; Sporhan-Krempel 1953, 23.

1736 Vgl. Schlieder 1966, 95. Schlieder lässt die Phase der Papiermacher als Eigentümer von Papiermühlen erst mit Hans Härb und Jörg Wolfartshofer 1513 beginnen, da er in Hans Wäch fälschlicherweise keinen Papierer vermutet. Hans Wäch wurde jedoch im Steuerbuch der Jahre 1483 bis 1485 als Papierer bezeichnet, wenn auch nur in der Ausführung des Steuermeisters, StR, Bü 44, Steuerbuch 1482-1485, 7r.

1737 Vgl. Sporhan-Krempel 1953, $30 \mathrm{f}$.

1738 Vgl. Sporhan-Krempel 1953, 31 f. 
Die beiden Papiermühlen zu Bern befanden sich im Untersuchungszeitraum ebenfalls im Besitz von Privatpersonen. Ob das nur wenige Jahre betriebene Mühlwerk zu Worblaufen gänzlich das Eigentum von Tschan und Anton Jacki war oder ob eine andere Person oder eine Institution das Obereigentum innehatte, lässt sich nicht feststellen. Die Stadt Bern scheint jedenfalls keine Rechte an der Liegenschaft besessen zu haben, da sie das Grundstück im Jahr 1470 von den Jacki kaufte. ${ }^{1739}$ In Bezug auf die Papiermühle zu Thal lässt sich hingegen festhalten, dass das Obereigentum beim Niederen Spital der Stadt Bern lag und dass Tschan und Anton Jacki Untereigentümer mit allen Nutzungs- und Verfügungsrechten waren. Eines dieser Rechte, welches Vater und Sohn auch in Anspruch nahmen, war die Verpachtung der Papiermühle. Im Jahr 1469 überließen sie dem Papiermacher Jehan Pastor das Werk auf zehn Jahre und verlangten dafür einen Jahreszins von 29 Gulden. ${ }^{1740}$ Fünf Jahre später verkauften die Jacki die Papiermühle an Anton Gallician und seine beiden Schwiegersöhne und machten damit von ihrem Veräußerungsrecht Gebrauch. Anlässlich dieses Verkaufs wurden auch die Bodenzinsen in Höhe von einem Gulden erwähnt, die zugunsten des Niederen Spitals auf dem Grundstück lasteten. ${ }^{1741}$ In den Jahren 1545 bis 1548 lag das Obereigentum an der Papiermühle offenbar nicht mehr beim Niederen, sondern beim Oberen Spital und wurde 1548 an das Große Spital übertragen. ${ }^{1742}$ Zudem hatte sich der Grundzins erhöht: Anstatt eines Guldens musste der Besitzer der Papiermühle nun jährlich 2 Gulden und fünf Buch Papier entrichten. ${ }^{1743}$

Die Zahlung des Grundzinses in Naturalien ist auch für eine Papiermühle bei Reutlingen zu beobachten, die auf dem Territorium des Klosters Zwiefalten lag. Im Jahr 1509 wandelte der Papiermacher Jacob Hirten einen Teil einer Messerschmiede auf eigene Kosten in eine Papiermühle um. Den auf der Liegenschaft lastenden Bodenzins musste er anteilig mittragen. Zusätzlich musste er von der Papiermühle jedoch jährlich ein Ries gutes Schreibpapier zahlen. ${ }^{174}$ Ebenfalls in privatem Untereigentum befand sich die erste in Reutlingen fassbare Papiermühle. Sie wird $1491 \mathrm{im}$ Spitalzinsbuch erwähnt, stand folglich auf dem Grund und Boden des Spitals. Claus Gallician entrichtete von diesem Erblehen 2,5 Pfund und 5 Schilling Grundzins. ${ }^{1745}$

1739 Vgl. Fluri sen. 1896, 195; Fluri jun. 1954, 79; J. Lindt 1964, 78; Fluri jun. 1975, 27.

1740 Vgl. Fluri sen. 1896, 195; Fluri jun. 1954, 47; J. Lindt 1964, 77; Fluri jun. 1975, 8.

1741 Vgl. Fluri sen. 1896, 195; Fluri jun. 1954, 79; J. Lindt 1964, 102 mit Anm. 10; Fluri jun. 1975, 27.

1742 Vgl. J. Lindt 1964, 80. Zu den Spitälern im mittelalterlichen Bern vgl. die kurzen Notizen in Durheim 1859, 136 mit Anm. 1; Bloesch 1898, Bd. 1, 119; P. Hofer 1952, 348-350.

1743 Vgl. J. Lindt 1964, 103 f. mit Anm. 22.

1744 Vgl. Sporhan-Krempel 1972b, 1520. Auch in Troyes war die Zahlung der Pacht in Papier bekannt. Der Pächter der Mühle Le Roi entrichtete zweieinhalb Ries Papier pro Woche an das Domkapitel, vgl. Rouillard 2010, 142 f. Für die Papiermühlen in Essonnes im 16. Jahrhundert vgl. Berthier 2010, 122. Vgl. auch Zaar-Görgens 2004, 79.

1745 Vgl. Sporhan-Krempel 1972b, 1518 f. Eventuell besaß auch die Stadt das Obereigentum an der Papiermühle, da der städtische Rechenmeister mit dem Spital über den Bodenzins aus der Papiermühle abrechnete. 
Die ersten sieben Jahre ihres Bestehens war auch die ältere Papiermühle zu Memmingen in privater Hand. Der Memminger Bürger Ulrich Frey d. Ä. hatte 1478 sein Haus am Heuenbach in eine Papiermühle umgewandelt und an Papiermacher verliehen. Im Jahr 1485 verkaufte er das Mühlwerk an das städtische Spital, das sich acht Jahre später durch die Ablösung der Rechte, die der Papiermacher Peter Fort an der Papiermühle besaß, die alleinigen Eigentumsrechte sicherte. ${ }^{1746} \mathrm{Ob}$ auf dem Grundstück ein Bodenzins lastete, ist aus der Forschungsliteratur nicht zu ersehen. Das Gleiche gilt leider für die vier Augsburger Papiermühlen, die offenbar auch Eigentum von Privatpersonen waren. ${ }^{1747}$ Ebenfalls nicht eindeutig feststellbar sind die Verhältnisse in Gengenbach. Vermutlich waren auch die dortigen Papiermühlen in der ersten Hälfte des 16. Jahrhunderts in privater Hand. Dies lässt sich daran erkennen, dass der Papiermacher Hans Grapp seine Papiermühle als dingliche Sicherheit für einen Kredit eingesetzt hatte und sein Gläubiger Hans Wild im Jahr 1523 die Übergabe der Liegenschaft wegen säumiger Zinszahlungen forderte. ${ }^{1748}$ Dieses Vorgehen, die Versetzung eines Grundstücks gegen Geld, war jedoch nur möglich, wenn der Schuldner wenigstens das Untereigentum an der Liegenschaft besaß und nicht bloß Pächter war. An Grundzinsen zahlte der Besitzer des Werks lediglich einen jährlichen Wasserzins von 4 Schilling für die Nutzung der Wasserkraft an das Kloster Gengenbach. ${ }^{179}$ Ob dem Kloster darüber hinaus auch die Liegenschaft gehörte, wird nicht deutlich. ${ }^{1750}$

Die zwei Kemptener Papiermühlen bei Hegge und bei Weidach waren stiftische Lehen und damit der Fürstabt des Stifts Kempten Obereigentümer der beiden Werke. Sie wurden jedoch in Erbpacht an Privatpersonen vergeben, sodass die Eigentumsund Verfügungsrechte in privater Hand lagen. ${ }^{1751}$ Wolff Morga zahlte von der Weidacher Mühle einen Bodenzins von einem Pfund Heller jährlich. ${ }^{1752}$

Weitere in Privatbesitz befindliche Papiermühlen waren die anderen Werke in Kempten, die auf reichsstädtischem Gebiet lagen, und die Mühle in Zürich, wobei die beiden Standorte allerdings eine entgegengesetzte Entwicklung durchliefen. Die Züricher Papiermühle auf dem Werd war seit ihrer Gründung 1471 bis in das Jahr 1513 Eigentum von Privatpersonen. So gehörte das Mühlwerk bis circa 1480 dem Papiermacher Heinrich Walchwiler, der es von 1480 bis 1484/85 gemeinsam mit Hans Conrad

1746 Vgl. Piccard 1960, 595 f.

1747 Die Augsburger Papiermühlen befanden sich im Untersuchungszeitraum im Privatbesitz von Druckern und Papiermachern. Sie veräußerten die Werke nach ihrem Belieben. In wessen Obereigentum sich die Papiermühlen befanden und ob die Besitzer einen Grundzins entrichteten, ist nicht erforscht, vgl. Hößle 1907, 7 f., 11-13; Haemmerle 1937/38, 136, 138; F. Schmidt 1997, 76 f., 91 f.

1748 Vgl. Piccard 1963, 1002.

1749 Vgl. Piccard 1963, $1002 \mathrm{f}$.

1750 Karl Theodor Weiss geht hingegen davon aus, dass die gesamte Liegenschaft im Obereigentum des Klosters Gengenbach war, vgl. K. Th. Weiss 1951, 43 f.

1751 Für die Papiermühle in Hegge lässt sich dies daran erkennen, dass der Erbpächter eine Hypothek auf die Papiermühle aufnahm. Vgl. Petz 2006, 246, 290 f., 299.

1752 Vgl. Petz 2006, 299. 
Grebel betrieb. Für diese Zeit ist nicht belegt, ob die beiden Papierer auch Eigentümer der Papiermühle waren. Mit einigen auf Pfändungen der Mühle zurückzuführenden Unterbrechungen hatte Hans Conrad Grebel das Werk jedoch von 1484/85 bis 1513 inne. ${ }^{1753}$ Danach erwarb die Stadt die Liegenschaft und trug sich seit 1521 mit dem Gedanken, die Papiermühle wieder aufbauen zu lassen. ${ }^{1754}$ In Zürich änderten sich die Eigentumsverhältnisse zu Beginn des 16. Jahrhunderts demnach von privatem zu städtischem Eigentum. Den umgekehrten Weg ging man in der Reichsstadt Kempten. Die beiden Papiermühlen in Kottern, die auf reichsstädtischen Gebiet lagen, gehörten von ihren Anfängen bis 1528 der Stadt Kempten. Allerdings besaß die Stadt offenbar nur das Untereigentum an den Papiermühlen, da die Liegenschaften vom Stift Kempten als Lehen ausgegeben wurden. ${ }^{1755} \mathrm{Im}$ Jahr 1528 erwarben die Papiermacher Peter Stähelin und Moritz Staiger jeweils ein Mühlwerk und somit wechselten die Papiermühlen in das (Unter-)Eigentum von Privatpersonen. ${ }^{1756}$ Jeder musste dem Rat zusichern, die Mühle nur zur Papierherstellung zu verwenden, nicht umzubauen und nur an einen Kemptener Bürger zu verkaufen. ${ }^{1757}$ Wer die Mühlen vorher bewirtschaftete, ist nicht bekannt. Sie wurden vermutlich entweder mithilfe eines angestellten Papiermachers direkt durch die Stadt betrieben oder an einen Papierermeister verpachtet. ${ }^{1758}$

Für die neu gebaute städtische Papiermühle in Zürich sind Informationen zu Verpachtung und Betrieb vorhanden. Diese Informationen verdanken wir den Verhandlungen, die der Drucker und potentielle Pächter Christoph Froschauer mit dem Züricher Rat direkt nach der Fertigstellung des Werks im Jahr 1535 über die Höhe des Pachtzinses führte. In einem ersten Vorstoß ersuchte Froschauer den Rat, ihm die Papiermühle zu verkaufen. Dieses Gesuch lehnte der Rat mit der Begründung ab, dass er die Mühle nur als Handlehen auf eine vertraglich festgelegte Anzahl an Jahren vergab. ${ }^{1759}$ Daraufhin unterbreitete der Buchdrucker dem Rat das Angebot, die Papiermühle für einen Jahreszins von 30 Gulden für eine Bütte beziehungsweise 40 Gulden für zwei Bütten auf sechs Jahre zu pachten. Die Züricher Stadtherren beharrten jedoch auf dem von ihnen veranschlagten Pachtzins von 100 Gulden. Auch Froschauers Erhöhung auf 50 Gulden konnte die Ratsherren nicht überzeugen, da sie nach eigener Aussage für den Neubau der Papiermühle, der seitens des Druckers forciert worden sei, sehr viel Geld aufgewendet hätten. Christoph Froschauer versuchte daraufhin, die unterschwelligen Anschuldigungen zu entkräften und beteuerte, er habe zwar

1753 Vgl. Zürcher 1963b, $121 \mathrm{f}$.

1754 Vgl. Zürcher 1963b, 123.

1755 Vgl. Petz 2006, 245, 295.

1756 Vgl. Petz 2006, 295-297.

1757 Vgl. Petz 2006, $296 \mathrm{f}$.

1758 Vgl. Petz 2006, $245 \mathrm{f}$.

1759 Tatsächlich wurde die Papiermühle über 220 Jahre von der Stadt an Lehennehmer verpachtet und erst im Jahr 1755 in ein Erblehen umgewandelt, vgl. Caflisch 1963, 151-153. 
zum Bau des Mühlwerks geraten, aber weder gewusst, dass die Stadt so teuer bauen lassen wollte, noch, dass er der zukünftige Pächter sein sollte. Froschauer konnte zwar auch den Standpunkt der Stadt nachvollziehen, die ihre Investition so schnell wie möglich amortisiert sehen wollte, hätte aber, wenn der Rat ihn vor dem Bau um eine realistische Einschätzung hinsichtlich eines angemessenen Pachtzinses gefragt hätte, dargelegt, dass ein Zins von 100 Gulden für den Mühlenbetreiber nicht rentabel sei. ${ }^{1760}$

Um seiner Forderung nach einem niedrigeren Zins Nachdruck $\mathrm{zu}$ verleihen, verwies der Drucker zum einen auf die Pachtgebühren, die in anderen Städten zu entrichten waren. So gebe man in Basel ${ }^{1761}$ und anderen Orten nicht mehr als 40 Gulden für zwei Bütten, in Straßburg hingegen sei der Zins zwar mit 60 Gulden der höchste im deutschen Sprachgebiet, aber zu der Papiermühle würden noch Weingärten, Wiesen und Äcker gehören. ${ }^{1762}$ Zum anderen erstellte Froschauer je eine Kalkulation für Personal- und für Materialkosten, anhand derer er nachweisen wollte, wie kostspielig der Betrieb einer Papiermühle sei. ${ }^{1763}$ Diese Strategie führte letztlich zu einem Teilerfolg: Christoph Froschauer und der Züricher Rat einigten sich auf einen Pachtpreis von 65 Gulden, womit der Buchdrucker immerhin eine Reduktion von 35 Gulden herausgehandelt hatte. ${ }^{1764}$

Der Verweis auf den Pachtzins, den der Betreiber der Straßburger Papiermühle zu entrichten hatte, und der mit 60 Gulden als besonders hoch angesehen wurde, lässt sich am Straßburger Material leider nicht verifizieren. Die erste Papiermühle am Rosengarten errichtete Wilhelm de Altomonte auf einer städtischen Allmende. Hierfür hatte der Straßburger Rat ihm ein Grundstück zur Erbpacht verliehen und gleichzeitig zur Bedingung gemacht, dass die Mühle nur zur Papierherstellung dienen dürfe. Wilhelm durfte die Mühle zwar veräußern, allerdings behielt sich der Rat das Recht vor, die Liegenschaft wieder an sich zu ziehen, falls der Nachbesitzer ein anderes Gewerbe als die Papiermacherei betreiben wollte. Auch im Fall, dass die Papiermühle durch Schäden nicht mehr zur Produktion von Papier eingesetzt werden konnte, fiel sie an die Stadt Straßburg zurück. ${ }^{1765}$ Dieses Verfügungsrecht der Stadt wurde anlässlich der Übertragung der Papiermühle an Nicolas Heilmann im Jahr 1452 nochmals bestätigt. ${ }^{1766}$ Schließlich ordnete der Rat 1454 an, dass das Mühlwerk abgerissen werden sollte. ${ }^{1767}$ Die Einflussnahme seitens der Stadt auf die Geschicke der ersten Papiermühle Straßburgs war demnach sehr hoch, auch wenn es sich offenbar

1760 Vgl. Caflisch 1963, 153.

1761 Vgl. Caflisch 1963, 153.

1762 Vgl. Caflisch 1963, 158.

1763 Vgl. Caflisch 1963, 154-158.

1764 Vgl. Caflisch 1963, 158.

1765 AVES, CH 239, Nr. 4918 (02.08.1445). Vgl. Fuchs 1962b, 103 f.

1766 AVES, CH 254, Nr. 5228 (22.11.1452). Vgl. Fuchs 1962b, 105.

1767 AVES, CH 257, Nr. 5292 (07.08.1454). Vgl. Fuchs 1962b, 105. 
nicht um einen städtischen Betrieb handelte, der lediglich von einem Pächter auf Zeit bewirtschaftet wurde. Angaben zu einem an die Stadt zahlbaren Bodenzins finden sich in den Urkunden nicht. Bemerkenswert ist zudem, dass dem ersten Betreiber, Wilhelm de Altomonte, für die Zeit, in der er sein Handwerk ausübte, eine Steuererleichterung gewährt wurde, denn er war vom Stallgeld befreit. ${ }^{1768}$

Die zweite, erstmals im Jahr 1503 fassbare Straßburger Papiermühle vor dem Weißturmtor war Eigentum der Stadt und wurde vermutlich als Zeitlehen ausgegeben. Angaben zu den Pächtern und dem fälligen Zins bietet ein städtisches Almendbuch, das von 1503 bis 1564 geführt wurde. ${ }^{1769}$ Als erster Pächter ist der Kartenmaler Gabriel Schwartz genannt. Er entrichtete zu allen Fronfasten 3 Pfund 5 Schilling Zinsen, also jährlich insgesamt 13 Pfund. ${ }^{170}$ Sein Nachfolger Hans Volpis, der die Papiermühle bis 1525 innehatte, zahlte mit 15 Pfund jährlich beziehungsweise 3 Pfund 15 Schilling vierteljährlich bereits einen höheren Betrag. ${ }^{1771}$ Bei der Übernahme des Werks durch Wolf Koepfel waren anscheinend neue Leihebedingungen eingeführt worden, denn der Buchdrucker zahlte nun einen deutlich erhöhten Jahreszins von 30 Pfund. ${ }^{1772}$ Dem vom Züricher Buchdrucker Christoph Froschauer erwähnten 60 Gulden Pachtzins entspricht leider keine dieser Angaben.

Neben einer städtischen Papiermühle um 1519 in Reutlingen, über die keine detaillierten Informationen vorliegen, ${ }^{173}$ existierte ein weiteres städtisches Werk in Memmingen. 1482 hatte der Rat eine zweite Papiermühle zu Memmingen komplett neu erbauen lassen. Der erste Betreiber, Peter Fort, pachtete die Mühle auf 20 Jahre für einen jährlichen Zins von 20 Gulden. ${ }^{1774}$ Im Pachtvertrag wurde deutlich hervor-

1768 AVES, CH 239, Nr. 4918 (02.08.1445). Vgl. Fuchs 1962b, 104. Das Stallgeld war eine Vermögenssteuer und die einzige direkte Steuer Straßburgs. Sie entstand aus der Unterhaltspflicht der städtischen Pferde vor allem für den Kriegsfall und wandelte sich im 16. Jahrhundert in eine reine Geldsteuer, vgl. Dollinger 1981, 114 f.; Sauerbrey 2012, 195.

1769 AVES, VII 1436. Vgl. Mariotte 2000, 109. Die Begriffe Almendbuch und Zinsbuch scheinen im Falle Straßburgs in eins zu fallen. Während das Heft selbst den Titel Der Statt Straßburgs Zinsbuch trägt, ist es dem Bestand der Almendbücher zugeordnet. Interessanterweise gibt Pierre Schmitt in seinem Beitrag zu den Straßburger Papiermühlen sowohl ein Zinsbuch als auch ein Almendbuch als Quellen an und scheint damit zwei unterschiedliche Dokumente zu meinen, die jedoch im Straßburger Archiv nicht ausgemacht werden konnten, vgl. P. Schmitt 1960, 78.

1770 AVES, VII 1436, 24: Item xiii lib git Gabriel der karttenmoler von der bapirmülen by sant Gallen alle fronvast iii lib $v \beta$.

1771 AVES, VII 1436, 24: Item xv lb git Cleinhans Volpis der bapirmacher von der bapirmülen und bluwlmülen by sant Gallen alle fronvast iii $l b x v \beta$. Anscheinend war das Werk zu diesem Zeitpunkt doppelt genutzt: Als Papiermühle und als Hanf- oder Flachsstampfe. Zur Bluwenmühle vgl. S. $202 \mathrm{f}$.

1772 AVES, VII 1436, 24: gibt jetz Wolff Kopffel der trucker xxx lb zins jerlich dovon lut einer nuwen lihenung.

1773 Vgl. Sporhan-Krempel 1972b, 1521. Neben den Mühlen in Privatbesitz war auch der städtischen Papiermühle während der Belagerung der Stadt durch den württembergischen Herzog Schaden entstanden, der sich auf 100 Gulden bezifferte.

1774 Vgl. Piccard 1960, 596 f. 
gehoben, dass der Papiermacher nur ein Nutzungsrecht hatte und sich verpflichtete, alles in gutem Zustand zu halten. In seinem Eigentum befanden sich lediglich Schöpfformen, Filze und Seile, die restliche Ausstattung gehörte der Stadt. ${ }^{1775}$ Nach Ablauf der 20 Jahre wurde die städtische Mühle 1502 für zehn Jahre gegen 40 Pfund Jahreszins an Gregory Schütz verliehen. ${ }^{1776}$

Neben Städten traten auch Klöster und Landesherren als Begründer und Eigentümer von Papiermühlen auf. So war das Mühlwerk in Söflingen Eigentum des dortigen Klarissenklosters, wie sich anhand eines die Papiermühle betreffenden Wasserrechtsstreits erkennen lässt, der zwischen Krafft Schuchmacher und den Frauen zu Söflingen entschieden wurde. ${ }^{1777}$ Der eigentliche Betreiber des Werks, Anton Turwel, wurde in dieser Urkunde nicht genannt, sodass zu vermuten ist, dass er die Liegenschaft auf Zeit gepachtet hatte und keine Eigentumsrechte besaß. Die jährlichen Zinsleistungen beliefen sich auf 13 Gulden. ${ }^{1778}$ Ebenfalls als Zeitlehen wurde die markgräfliche Papiermühle in Ettlingen vergeben. Der erste Pachtvertrag ist für das Jahr 1482 überliefert und lautet auf zehn Jahre, wobei die ersten drei Jahre eine Pachtgebühr von 10 Gulden und die restlichen sieben Jahre ein jährlicher Pachtzins von 20 Gulden entrichtet werden musste. ${ }^{1779} 1495$ verlieh der Markgraf von Baden die Liegenschaft auf weitere zehn Jahre an Claus Gallician und erhob dafür einen Pachtzins von 20 Gulden. ${ }^{1780}$ Seit 1521/22 wurde die Papiermühle jedoch als Erblehen ausgegeben, sodass der Markgraf nur noch das Obereigentum innehatte. Der Jahreszins von 20 Gulden blieb ihm jedoch erhalten. ${ }^{1781}$ Das Obereigentum an der ersten Uracher Papiermühle besaß der Graf von Württemberg. Er verlieh das Werk 1477 dem Papiermacher Anton Terriere als Erblehen für 15 Gulden Jahreszins. ${ }^{1782}$

Dieser Überblick macht deutlich, dass die Eigentums- und Besitzverhältnisse von Papiermühlen vielschichtig waren. Es gab zum einen Werke, die sich in privater Hand befanden, wobei es sich bei der Liegenschaft meistens um ein Erblehen handelte, das für einen oft vergleichsweise geringen Grundzins vergeben wurde, wie dies in Basel der Fall war. Der Besitzer eines solchen Lehens, der Untereigentümer, hatte an dem Grundstück nicht nur Nutzungsrechte, sondern weitgehend alle Eigentumsrechte, sodass er die Liegenschaft verpachten, verkaufen oder verpfänden konnte. Als Inhaber des dominium utile konnten zum einen Papiermacher selbst in Erscheinung

1775 Vgl. Piccard 1960, 596 f.

1776 Vgl. Piccard 1960, 598.

1777 Vgl. Alfred Schulte 1941, 96-98; Frauenknecht 2015, 103.

1778 Vgl. Alfred Schulte 1941, 96. Frauenknecht gibt hingegen an, dass die Papiermühle zu Söflingen ebenfalls ein Erblehen war, vgl. Frauenknecht 2015, 112.

1779 Vgl. Stenzel 1985, 100; F. Schmidt 1992, 116.

1780 Vgl. Piccard 1951, 59; Stenzel 1985, 100.

1781 Vgl. Piccard 1951, 60.

1782 Vgl. Hößle 1926a, 67; Hößle 1939, 560; Frauenknecht 2014, 88. 
treten, wie es beispielsweise für einen Großteil der Basler Papiermühlen und für Reutlingen der Fall war. Zum anderen befanden sich Papiermühlen aber auch im Besitz von Buchdruckern (Augsburg, Gengenbach, Straßburg) oder von Kaufleuten (Basel, Ravensburg, Gengenbach). Diese mussten für den Betrieb der Papierwerkstatt einen Papierer anstellen oder die Mühle verpachten.

Als Obereigentümer konnten für die südwestdeutschen Papiermühlen die Stadt (Ravensburg), Klöster (Basel, Reutlingen/Zwiefalten), städtische Einrichtungen wie das Spital (Bern, Memmingen) oder ein Landesherr (Fürststift Kempten, Graf von Württemberg für Urach, Markgraf von Baden für Ettlingen) festgestellt werden. Im Falle einer Ravensburger Papiermühle scheint eine Privatperson Obereigentümer gewesen zu sein. Das dominium directum berechtigte häufig lediglich zum Empfang eines Bodenzinses. Weitere Rechte - wie zum Beispiel die Festlegung, dass die Mühle nur an Bürger der betreffenden Stadt verkauft werden dürfe (Kempten, Ravensburg), oder ein Zurückfallen des Werks an den Obereigentümer bei Stillstand (Straßburg) - mussten vertraglich vereinbart werden. In den untersuchten Beispielen geht das Spektrum der zu entrichtenden jährlichen Grundzinsen von 2,5 Pfund und 5 Schilling in Reutlingen über 2 Gulden und fünf Buch Papier in Bern und 6 Pfund für die Basler Stegreifmühle hin zu 15 Gulden in Urach und 19 Pfund im Ravensburger Ölschwang.

Zum anderen gab es Werke, die sich im Besitz von Städten, Klöster oder Landesherren befanden und die lediglich zur Pacht auf Zeit ausgegeben wurden. Beispiele für diese Form der Bewirtschaftung finden sich in den Städten Straßburg, Zürich, Memmingen, Reutlingen und Kempten, für das Kloster Söflingen sowie im markgräflichen Ettlingen. Über den Nutzen, den sich diese Institutionen von der Einrichtung und Protektion der Papiermühle versprachen, kann nur spekuliert werden. Vermutlich war die jeweilige Verwaltung vorrangig daran interessiert, die kostengünstige Versorgung mit Papier zu sichern und jederzeit Zugriff auf die Papierproduktion zu haben. Die Rechte des Pächters beschränkten sich auf Nutzungsrechte, wobei die Mühle und ihre Einrichtung jedoch häufig vom Beständer instandgehalten werden musste. Als Pachtdauer konnten für die Papiermühlen im Südwesten des Reichs sechs, zehn und zwanzig Jahre ermittelt werden (Ravensburg, Ettlingen, Memmingen). Sicherlich gab es aber auch andere Pachtzeiträume. Wie bei den in Privatbesitz befindlichen Papiermühlen bestand auch bei der Pacht die Möglichkeit, dass entweder ein Papiermacher selbst Pächter wurde (Memmingen, Söflingen, Kempten) oder dass ein Drucker (Straßburg, Zürich) die Mühle pachtete und an einen Fachmann weitervermietete oder ihn anstellte. Den höchsten Pachtzins entrichtete in den Fallbeispielen der Züricher Drucker Christoph Froschauer mit 65 Gulden jährlich. Jörg Sauter d. Ä. veranschlagte 50 Gulden für die Pacht einer Papiermühle in Ravensburg. In Bern wurden 29 Gulden verlangt, in Memmingen und Ettlingen 20, in Söflingen 13 Gulden. Im Allgemeinen kann gesagt werden, dass der Pachtzins deutlich höher war als der Bodenzins, auch wenn die höchsten Beträge des ersten und die niedrigsten des letzten für die untersuchten Fälle mit 13 Gulden (Söflingen) beziehungsweise 15 Gulden (Urach) derselben Größenordnung angehörten. 
Bemerkenswert ist zudem, dass bei vielen Mühlen die Eigentumsverhältnisse wechselten. Manche wurden gewissermaßen privatisiert, indem sie in Erblehen verwandelt wurden (Kempten ab 1528, Ettlingen ab 1521/22), andere wurden durch den Verkauf an die Stadt zu kommunalem Gut (Zürich ab 1521).

\subsubsection{Kaufpreis und Renten}

Nach der Betrachtung von Ausstattung und Eigentumsverhältnissen der Papiermühlen im südwestdeutschen Raum soll nun der Wert einer solchen Liegenschaft in den Fokus rücken. Während die Ausstattung eines Werks seinen Wert mitbestimmte, spiegelt sich in den Besitzverhältnissen zum Teil wider, dass der Erwerb, der Betrieb und die Instandhaltung eines Mühlgebäudes äußerst kapitalintensiv waren. Daher ist es nicht verwunderlich, dass häufig entweder finanzkräftige Kaufleute eine Papiermühle erwarben und bewirtschaften ließen oder Papiermacher Hypotheken auf ihre Werke aufnahmen. Dies wird auch in der Forschung oft als Allgemeinplatz angeführt, allerdings meist ohne den Vermögenswert einer solchen Immobilie und der auf ihr lastenden Renten zu beziffern. ${ }^{1783}$ Insbesondere anhand des Basler Quellenmaterials soll daher der Versuch unternommen werden, diese Prämisse zu überprüfen und mit Zahlen zu belegen. Um den Wert einer Papiermühle annähernd bestimmen zu können, wird zum einen der Verkaufspreis in den Blick genommen. Zum anderen soll das Wertspektrum einer Papiermühle durch die auf ihr lastenden Renten ermittelt werden. Da die Rentenbelastung eines Grundstücks nicht höher sein durfte, als sein Wert geschätzt wurde, ergibt sich daraus ein Mindestwert. Ein Vergleich mit den anderen südwestdeutschen Papiermühlenstandorten ergänzt die Befunde.

Der Rentenkauf war im Spätmittelalter für den hier betrachteten Raum die übliche Form der Kreditgewährung. ${ }^{1784}$ Das Wort Rente stand hierbei für einen jährlich zu einem festen Termin zahlbaren Zins, den der Rentenkäufer durch die einmalige Zahlung eines Geldbetrags erwarb. Der auf diese Weise kreditierte Kapitalbetrag, Hauptgut genannt, lastete ähnlich wie die heutige Hypothek auf einer im Rentenvertrag definierten Liegenschaft, die als dingliche Sicherung diente. Kreditnehmer durch Rentenverkauf konnte folglich nur eine Person sein, die eine Immobilie besaß. War auf der Seite des Rentenverkäufers die Gewinnung von Kapital die Motivation, so waren die Rentenkäufer entweder an einer kurz- oder langfristigen Anlagemöglichkeit von überschüssigem Vermögen oder an einer (Alters-)Vorsorge interessiert.

1783 Vgl. beispielsweise Schlieder 1966, 110 f.; Kälin 1974, 182; Zaar-Görgens 2004, 81-84.

1784 Vgl. die Überblicksdarstellung zur Rente in Füglister 1981, 92-102, und Gilomen 1995, 735-738. Vgl. auch Trusen 1972; Gilomen 1984/2017; Gilomen 1994. Zu den Anfängen des Rentenkaufs in Basel vgl. Hagemann 1986. Nicht nur Privatpersonen, auch Städte wie Basel nutzen den Rentenverkauf, um an benötigte Geldmittel zu gelangen, vgl. hierzu Gilomen 1982; Gilomen 2003. 
Das Rentengeschäft war im Spätmittelalter in den meisten Fällen nur durch den Rentenschuldner kündbar. Hierfür musste dieser sich die Zinsen „wiederkaufen“, das heißt, er hatte das zu Beginn der Kreditbeziehung eingelegte Hauptgut in derselben Höhe an den Rentenkäufer zurückzuerstatten. Die einzige Möglichkeit für den Rentengläubiger, die Rente zu rekapitalisieren, bestand in ihrem Weiterverkauf an eine dritte Person. Neben dem vollständigen Verkauf der Renten konnten auch eine Teilsumme veräußert werden. Zu unterscheiden ist zwischen den Rentenverkäufen, die die Kapitalgrundlage für den Kauf eines Hauses bildeten, und den Zinsgeschäften, die nicht in unmittelbarem Zusammenhang mit einem Immobilienkauf standen, sondern zu Investitions- oder Konsumzwecken getätigt wurden. Als Hauskaufrenten können diejenigen Rentengeschäfte bezeichnet werden, bei denen unmittelbar nach dem Liegenschaftskauf - innerhalb desselben Jahres - der Käufer dem Verkäufer eine jährliche Rente verkaufte und als Sicherheit die zuvor erworbene Immobilie gab. ${ }^{1785}$

\subsubsection{Basel}

In den Studien zur Basler Papiergeschichte wurde mehrfach angemerkt, dass auf vielen Papiermühlen eine - modern ausgedrückt - Hypothek lastete, allerdings blieb es bei vereinzelten Hinweisen. ${ }^{1786}$ Auch Kaufsummen wurden lediglich sporadisch genannt. Dabei bietet das Quellenmaterial die Möglichkeit, bei nahezu jeder erfassten Handänderung nicht nur den Kaufpreis, sondern auch auf dem Grundstück lastende Renten zu erfassen. Als Quellenbasis dienen daher zum einen die Fertigungsbücher des Großbasler Schultheißengerichts. Zum anderen lassen sich Zinsverpflichtungen besonders eindrücklich in den Frönungs- und Verbotsbüchern des Schultheißengerichts fassen. Im Falle einer Zahlungssäumigkeit seitens des Rentenverkäufers hatte der Rentenbezieher die Möglichkeit, das belastete Gut an sich zu ziehen. Hierfür musste er seine Forderung dem Gericht melden und die Beschlagnahmung und Einsetzung in die Liegenschaft beantragen. ${ }^{1787}$ Dieses Gesuch wurde in die Gerichtsprotokolle eingetragen und dem Schuldner die Frönung, das heißt Pfändung, des betreffenden Guts verkündet. Hieraufhin hatte dieser 14 Tage Zeit, entweder den versessenen Zins zu zahlen oder den Anspruch des Frönenden erfolgreich zu entkräften. Geschah dies nicht, so konnte der Gläubiger sein Anrecht gegen den geringen „Kaufpreis“ von einem Pfund und einem Schilling geltend machen. Bevor der Gläubiger die Liegenschaft an sich ziehen konnte, musste er allerdings noch zweimal eine Frist von 14 Tagen verstreichen lassen, in der der Schuldner die Möglichkeit hatte, den Verlust des Grundstücks abzuwehren. Nach diesem dritten Gerichtstag wurde der Frönende unter Vorbehalt in das Gut eingesetzt. ${ }^{1788}$ Hatten mehrere Gläubiger Kapital

1785 Vgl. Füglister 1981, 99; Hagemann 1987, 267.

1786 Vgl. Piccard 1967, 72, 76 f., 167, 170; Kälin 1974, 165, 176-180, 182-184.

1787 Vgl. Hagemann 1987, $117 \mathrm{f}$.

1788 Vgl. Hagemann 1987, 121. 
auf einer Liegenschaft, so wurde sie nicht an den Frönenden vergeben, sondern versteigert. Mit dem Erlös wurden die Forderungen der Gläubiger befriedigt. ${ }^{1789}$

Im Jahr 1433 kaufte Heinrich Halbysen d. Ä. für 126 Gulden die Mühle zu Allenwinden, die $\mathrm{zu}$ dieser Zeit mit insgesamt 80 Gulden Zinsen belastet war. ${ }^{1790}$ Für diese 80 Gulden Hauptgut wurden verschiedene jährliche Zinsen gezahlt, nämlich 30 Schilling Zinspfennige wegen eines Seelgeräts, 4 Schilling Zinspfennige von einem Garten, weitere 7 Schilling neuer Pfennige von demselben Garten sowie 3 Gulden für ein Almosenamt. ${ }^{1791}$ Obwohl die Zinssätze sehr unterschiedlich sind, gibt der Eintrag in das Kleinbasler Gerichtsbuch an, dass entweder alle vier Renten zusammen mit 80 Gulden oder jede einzelne mit 20 Gulden abzulösen seien. ${ }^{1792}$ Dies ist, wie wir sehen werden, der einzige Fall, in dem der Zinssatz nicht die üblichen 5 Prozent des Hauptguts betrug. ${ }^{1793}$

Auf der nur ein Jahr - von März 1452 bis März 1453 - im Besitz eines Papiermachers befindlichen Bluwenmühle am Rümelinbach lasteten zu dieser Zeit ein jährlicher Zins von 2 Gulden für 38 Gulden Hauptgut, die jeweils zur Hälfte an das Kloster Klingental und an St. Martin zu zahlen waren. Anton Gallician kaufte und verkaufte das Grundstück für jeweils 90 Gulden. ${ }^{1794}$ Beim Kauf der Liegenschaft konnte Anton Gallician eine Stundung in Anspruch nehmen. Er erlegte lediglich 12 Gulden in bar und wollte die Restsumme in Raten abbezahlen. Zudem wurde die Übernahme der Rentenbelastung auf den Kaufpreis angerechnet, sodass Anton Gallician zusätzlich zu den 12 Gulden nur zweimal 10 Gulden und einmal 20 Gulden entrichten musste. Ihm blieb es überlassen, ob er die Rente ablösen oder verzinsen wollte. ${ }^{1795}$

Wie viel Michel Gallician im Jahr 1467 für die Rychmühle im St. Albantal 41 zahlte, ist in den Quellen nicht fassbar. Der Mindestwert der Liegenschaft lässt sich jedoch durch die mit 15 Gulden verzinsbare Hauskaufrente von 300 Gulden bestimmen, die der Vorbesitzer Heinrich Halbysen d. J. von Michel Gallician im gleichen Jahr kaufte. ${ }^{1796}$ Der Kaufpreis lag dementsprechend bei mindestens 300 Gulden. Mit

1789 Vgl. Hagemann 1987, $122 \mathrm{f}$.

1790 StABS, Gerichtsarchiv P 3, 211r (röm. Ziffern) bzw. 200r (arab. Ziffern). Vgl. Kälin 1974, 169.

1791 Unter einem Seelgerät wurde zumeist eine Güterübertragung an eine kirchliche Institution verstanden, welche dem Gebenden die permanente Fürbitte im Gebet vor allem in einer Seelenmesse am Sterbetag sichern sollte, vgl. Kroeschell 1995, 1680. Vermutlich handelte es sich um eine Stiftung, die ein vorhergehender Besitzer der Liegenschaft tätigte. Unter dem Almosen ist die Armenspeisung der St. Nikolaus-Kapelle in Kleinbasel zu verstehen, vgl. Kälin 1974, 276 mit Anm. 144.

1792 StABS, Gerichtsarchiv P 3, 211r (röm. Ziffern) bzw. 200r (arab. Ziffern): widerköiffig mit lxxx Gulden oder je einen mit xx Gulden.

1793 Zur Verzinsung des Hauptguts mit fünf Prozent vgl. Füglister 1981, 93.

1794 StABS, Gerichtsarchiv B 6, 123 f., 171 f. Vgl. Piccard 1967, 76 f.; Kälin 1974, 156.

1795 StABS, Gerichtsarchiv B 6, 124: [...] doch also dz si die acht und dryssig gulden hoptgut da von man jerlich zwen gulden geltz git einen gen Clingental den andern gen sant Martin ablösen oder verzinsen sollen welhes inen lieber ist. Vgl. Piccard 1967, 76.

1796 StABS, Hausurkunden 716, N, Urk. (03.12.1467). Vgl. Kälin 1974, 184. 
270 Gulden erzielte Michel Gallician eine ähnlich hohe Summe, als er die Mühle 1494 an Hans Lufft von Ettlingen veräußerte. ${ }^{1797} \mathrm{Zu}$ diesem Zeitpunkt lastete auf der Immobilie ebenfalls eine Hypothek von 300 Gulden, die mit einer jährlichen Zahlung von 15 Gulden an das Kloster Gnadental verzinst wurde. ${ }^{1798}$

Erscheinen diese beiden Summen durch ihre ähnliche Höhe plausibel, so verwundert der mit 50 Gulden sehr niedrig angesetzte Kaufpreis, den 1519 Hans Lufft von Ettlingen für das Lehen forderte. ${ }^{1799}$ Hatte sich der Kaufpreis deutlich verringert, so war die Belastung mit Renten signifikant gestiegen: Die Rychmühle war zu diesem Zeitpunkt mit einem Hauptgut von insgesamt 550 Gulden belastet, nämlich die 300 Gulden von dem Kloster Gnadental und weitere 250 Gulden, die das Chorherrenstift St. Peter für einen jährlichen Zins von 12,5 Gulden gegeben hatte. ${ }^{1800} \mathrm{Im}$ Jahr 1542 wechselte das Mühlwerk erneut für die höhere Summe von 250 Gulden den Besitzer. $\mathrm{Zu}$ dieser Zeit war die Liegenschaft ebenfalls mit 300 Gulden vom Kloster Gnadental und 250 Gulden von den Stiftsherren zu St. Peter belastet. ${ }^{1801}$

Wodurch die Schwankungen des Kaufpreises bedingt waren, lässt sich nicht feststellen. Für den Handwechsel im Jahr 1519 ließe sich vermuten, dass die Verringerung der Kaufsumme durch die im Vergleich mit dem Verkauf von 1494 erhöhte Rentenbelastung zustande kam. Wenn man bedenkt, dass der Käufer die Verpflichtung zur Zinszahlung mit der Liegenschaft kaufte, jedoch den Gegenwert nicht nutzen konnte, da das Hauptgut beim Verkäufer der Papiermühle, der gleichzeitig auch Verkäufer der Zinsen war, verblieb oder bereits in die Immobilie oder anderweitig investiert worden war, dann erscheint ein verringerter Kaufpreis plausibel und sogar gerechtfertigt. ${ }^{1802}$ Diese Hypothese trifft jedoch beim nächsten Verkauf nicht mehr zu: Im Jahr 1542 war der Kaufpreis bei gleichbleibender Rentenbelastung um 200 Gulden gestiegen. Als mögliche Ursachen für die Kaufpreisschwankungen kommen daher auch der bauliche Zustand der Liegenschaft in Frage sowie die persönliche Situation des Verkäufers, der sich zum Beispiel aus finanziellen Gründen gezwungen sah, die Mühle schnell abzustoßen.

Als Ulrich Züricher im Jahr 1470 die Zunzigermühle von Heinrich Halbysen d. J. kaufte, zahlte er einen Preis von 700 Gulden für die mit 70 Gulden Hauptgut belastete Liegenschaft. ${ }^{1803}$ Anscheinend konnte er diese Summe nicht direkt bezahlen, denn

1797 StABS, Gerichtsarchiv B 13, 167v.

1798 StABS, Gerichtsarchiv B 13, 167v.

1799 StABS, Gerichtsarchiv B 22, 69r-69v.

1800 StABS, Gerichtsarchiv B 22, 69r-69v.

1801 StABS, Gerichtsarchiv B 28, 191r-191v.

1802 Vgl. hier auch die Verrechnung der 38 Gulden Hauptgut, die auf der Rümelinbachmühle lasteten, mit dem Kaufpreis von 90 Gulden, vgl. S. 283. Diese These würde zudem erklären, warum die Rentenbelastung und damit der Mindestwert der Rychmühle im Jahr 1494 mit 300 Gulden 30 Gulden höher lag als der Kaufpreis von 270 Gulden.

1803 StABS, Gerichtsarchiv B 9, 71. Vgl. Piccard 1967, 167, 174 f. 
einen Monat nach dem Kauf, am 26. Februar 1470, nahm er bei dem Verkäufer Heinrich Halbysen d. J. einen Hauskaufrente von 600 Gulden für eine jährliche Zinszahlung von 30 Gulden auf. ${ }^{1804}$ Anderthalb Jahrzehnte später, im Jahr 1486, so ist aus den Frönungen und Verboten sowie den Fertigungsprotokollen zu entnehmen, besaß Barbara Bischoff ein Hauptgut von 500 Gulden auf der Zunzigermühle, für die sie jedes Jahr 25 Gulden Zinsen von Ulrich Züricher erhalten sollte. Dieser scheint jedoch säumig gewesen zu sein, da die Rentenherrin die Papiermühle im Juni 1486 um versessenen - das heißt nicht gezahlten - Zins pfändete ${ }^{1805}$ und schließlich im dritten Gericht zugesprochen bekam. ${ }^{1806}$ Hans Strub, der das Mühlenlehen kurz danach von Barbara Bischoff erworben haben muss, verschaffte sich im selben Jahr einen Kredit von 625 Pfund, den ihm die Töchter der Vorbesitzerin, Margret und Katrinlin Bischoff, für eine Zinszahlung von 31 Pfund und 5 Schilling gewährten. ${ }^{1807}$ Der gleichnamige Nachfolger (Peter) Hans Strub, Papiermacher, verkaufte im Jahr 1487 eine Rente von 15 Gulden für 300 Gulden von der Zunzigermühle und einem in der Freien Straße gelegenen Haus. ${ }^{1808} \mathrm{Zu}$ dieser Zeit lastete laut den Einträgen im Fertigungsbuch außerdem nur die alte Zinsverpflichtung gegenüber Hans Hohensteg von 3,5 Gulden für einen Kaufpreis von 70 Gulden auf dem Mühlwerk.

Während die Zunzigermühle im Besitz von Hans Züricher war, erwarb der Messerschmied Conrat Wesslin für eine Zahlung von 100 Gulden eine Rente von 5 Gulden von der Papiermühle. Von dieser Rente, seiner 5-Gulden-Rente auf die ebenfalls in Zürichers Besitz befindliche halbe Spisselismühle sowie von einem Haus mit Hofstatt in der Eisengasse verkaufte er im Jahr 1489 wiederum 15 Gulden an den Brotbäcker Berchtold Weibel. ${ }^{1809}$ Die Praxis, auf Grundstücken lastende Renten ganz oder teilweise weiterzuverkaufen, betrieb Conrat Wesslin ebenfalls 1493, als er von seiner inzwischen anscheinend auf 15 Gulden angewachsenen Rente von den beiden Papiermühlen Hans Zürichers 7,5 Pfund an das Chorherrenstift St. Peter verkaufte. ${ }^{1810}$ Einem Eintrag aus den Frönungsprotokollen des Großbasler Schultheißengerichts nach zu urteilen, betrug das von Conrat Wesslin in die beiden Papiermühlen investierte Haupt-

1804 StABS, Gerichtsarchiv B 9, 77. Aus diesem Eintrag in den Fertigungsprotokollen geht hervor, dass die Rente von 70 Gulden, die der Basler Bürger Hans Hohensteg auf der Mühle liegen hatte, weiterhin bestand.

1805 StABS, Gerichtsarchiv E 6, 112r.

1806 StABS, Gerichtsarchiv B 11, 260r.

1807 StABS, Gerichtsarchiv B 11, 263r.

1808 StABS, Gerichtsarchiv B 12, 13r. Bei einem Wechselkurs von einem Gulden zu 1,28 Pfund betrug das Hauptgut umgerechnet circa 488 Gulden. Zusammen mit dem Hauptgut von 70 Gulden, das Hans Hohensteg eingelegt hatte, war die Liegenschaft mit 558 Gulden belastet. Zum Wechselkurs vgl. Rosen 1989, 145.

1809 StABS, Gerichtsarchiv B 12, 125v.

1810 StABS, Gerichtsarchiv B 13, 133r. 
gut im Jahr 1494 nur noch 200 Gulden. ${ }^{1811}$ In diesem Jahr pfändete er beide Mühlwerke. Die Zunzigermühle, die mit weiteren Hypotheken von insgesamt 370 Gulden belastet war, ${ }^{1812}$ bekam er schließlich für 300 Gulden zugesprochen. ${ }^{1813}$ Als Conrat Wesslin das Mühlenlehen zwei Jahre später, im Jahr 1496, wieder veräußerte, lasteten auf der Liegenschaft mehrere neue Renten im Gesamtwert von 470 Gulden. ${ }^{1814}$ Diese Renten wurden zum Teil abgelöst, denn der neue Besitzer Hans Kielhammer von Schaffhausen nahm $1515 \mathrm{zu}$ den weiterhin bestehenden Renten von jeweils 5 Gulden, die Peter Ringisen und das Kloster Klingental innehatten, einen Kredit von 200 Gulden für 10 Gulden jährliche Zinszahlung auf, sodass die Zunzigermühle zu dieser Zeit mit 400 Gulden belastet war. ${ }^{1815}$

Im Juli 1523 wurde die Papiermühle als Gut eines erblosen Manns gefrönt und im September desselben Jahres an Margarethe, die Witwe des Messerschmieds Conrat Wesslin, für 200 Gulden ausgegeben. ${ }^{1816}$ In den diese Pfändung betreffenden Einträgen in den Gerichtsbüchern werden keine Rentenbelastungen des Grundstücks erwähnt. Offenbar war Margarethe Wesslin zu diesem Zeitpunkt die einzige Gläubigerin, die Rechte an der Papiermühle besaß. Im Jahr 1532 erzielte Gregorius Dürr für die Liegenschaft einen Verkaufspreis von 450 Gulden. $\mathrm{Zu}$ diesem Zeitpunkt war die Papiermühle laut Aussage des Fertigungsprotokolls mit keiner Rente belastet. ${ }^{1817}$ Anscheinend hatte Gregorius Dürr die Rente von 100 Gulden, die er zwei Jahre zuvor, im Juni 1530, an das Basler Spital verkauft hatte, bereits wieder abgelöst. ${ }^{1818}$

Die Klingentalmühle ging im Jahr 1453 für 280 Gulden in den Besitz von Anton Gallician über und war zu diesem Zeitpunkt mit keiner Zinsverpflichtung belastet. ${ }^{1819}$ In den 1470er-Jahren verkaufte Anton Gallician jedoch dem Kaufmann Peter Wolfer eine jährliche Rente von 15 Gulden für ein Kapital von 300 Gulden, von denen Wolfer im Jahr 1478 eine Rente von 6 Pfund an das Basler Kartäuserkloster verkaufte. ${ }^{1820}$ Im Jahr 1482 wurde Anton Gallician direkter Rentenmann der Kartäuser zu Kleinbasel, als er seine beiden Papiermühlen, die Klingentalmühle und die Stegreifmühle, zusammen mit einer Hypothek von 300 Gulden belastete und dafür 15 Gulden jähr-

1811 StABS, Gerichtsarchiv E 7, 16v-17r.

1812 Für 300 Gulden Hauptgut gingen jährlich 15 Gulden an den Messerschmied Hans Roggenburg. 3,5 Gulden jährlichen Zins für einen Kredit von 70 Gulden erhielt der Scherer Hans Hohensteg, StABS, Gerichtsarchiv E 7, 17r.

1813 StABS, Gerichtsarchiv B 13, 165r.

1814 StABS, Gerichtsarchiv B 14, 71v.

1815 StABS, Gerichtsarchiv B 20, 191v.

1816 StABS, Gerichtsarchiv E 9, 26r; B 23, 13v-14r. Vgl. Kälin 1974, 179, 184.

1817 StABS, Gerichtsarchiv B 26, 133v: und ist wyter nit beladen, zinshafft noch verbunden.

1818 StABS, Gerichtsarchiv B 25, 146v-147r.

1819 StABS, Gerichtsarchiv B 6, 171. Vgl. Kazmeier 1955, 17; Piccard 1967, 77; Kälin 1974, 156.

1820 StABS, Klosterarchiv, Kartause E, 135r-135v. 
lich an das Kartäuserkloster zu entrichten versprach. ${ }^{1821}$ Der nächste Verkauf der Liegenschaft fand im Jahr 1523 für 400 Gulden statt. Mit der Papiermühle übernahm der Käufer Conrad Grebel auch die Verpflichtung, jährlich zum einen 15 Gulden an die Kartäuser zu Kleinbasel und zum anderen 2,5 Gulden an den Bau auf Burg zu Basel, also dem Basler Münster, zu entrichten. ${ }^{1822}$ Es lag folglich zu dieser Zeit eine Rentenlast von mindestens 350 Gulden auf dem Mühlwerk. Auch Conrad Grebel konnte anscheinend den kompletten Kaufpreis nicht aus eigenen Mitteln aufbringen. Kurz nach der Fertigung des Kaufs nahm er bei dem Verkäufer Franz Gallician einen Kredit von 200 Gulden gegen eine jährliche Zinszahlung von 10 Gulden auf. ${ }^{1823}$ Im darauffolgenden Jahr, 1524, wurde die Klingentalmühle vom Hohen Stift zu Basel wegen versessener Zinsen gepfändet und im dritten Gericht eingezogen. ${ }^{1824}$ Außer den 3 Gulden jährlichen Zinses, die das Hohe Stift von der Papiermühle bezog, werden keine weiteren Belastungen genannt. ${ }^{1825}$

Wie die Papiermühle wieder an die Erben Conrad Grebels gelangte, ist nicht nachweisbar. Im Jahr 1528 verkauften sie jedoch die Liegenschaft für die mehr als geringe Kaufsumme von 25 Gulden an den Papierer Peter Sontach. ${ }^{1826}$ Wieder lasteten die Zinsen von 15 Gulden an die Kartäuser zu Kleinbasel sowie der 2,5-Gulden-Zins an das Basler Münster auf der Klingentalmühle. Zudem bezog ein Jacob Meyer jährlich 12 Gulden von der Papiermühle. Das Gesamtvolumen der hier dargestellten Hypotheken belief sich somit auf 590 Gulden. Setzt man den geringen Kaufpreis mit der hohen Rentenbelastung in Verbindung, so könnte auch bei diesem Beispiel gelten, dass eine hohe Zinslast durch eine niedrige Kaufsumme ausgeglichen wurde, vorausgesetzt, es handelt sich nicht um einen Schreibfehler.

Aber auch hier spricht der nächste Handwechsel gegen die Hypothese, dass eine hohe Zinsbelastung durch einen niedrigen Kaufpreis ausgeglichen wurde. Im Jahr 1550 verkaufte die Witwe Peter Sontachs die Klingentalmühle für 390 Gulden an Hans Düring. Die Belastung mit Renten war jedoch nicht nur gleich hoch geblieben, sondern hatte sich sogar auf 630 Gulden erhöht. Zu den immer noch bestehenden Zinsverpflichtungen gegenüber den Kartäusern und dem Basler Münster kamen ein Zins von 10 Gulden, zahlbar an das Basler Spital, sowie ein Zins von 3 Gulden,

1821 StABS, Klosterarchiv, Kartause E, 180r-182r; Hausurkunden 716, C, Urk. (24.06.1482). Vgl. Kälin 1974, 183. Kälin erwähnt nicht, dass dieser Rentenverkauf beide Papiermühlen Anton Gallicians betraf.

1822 StABS, Gerichtsarchiv B 22, 333r-333v. Ob es sich bei der Rente der Kartäuser um den 1482 ursprünglich auf die zwei Papiermühlen aufgenommen Kredit handelte oder ob dieser abgelöst und eine neue Zinsverpflichtung bei gleichbleibendem Hauptgut eingegangen worden war, ist nicht $\mathrm{zu}$ entscheiden.

1823 StABS, Gerichtsarchiv B 22, 334v.

1824 StABS, Gerichtsarchiv B 23, 44v.

1825 StABS, Gerichtsarchiv B 23, 44v.

1826 StABS, Gerichtsarchiv B 24, 201v. 
zahlbar an Herrn Niclaus Irmy. ${ }^{1827}$ Somit sind die Ursachen für die Schwankungen des Kaufpreises auch bei der Klingentalmühle nicht fassbar.

Von der Stegreifmühle liegen vergleichsweise viele Einträge aus den Frönungsbüchern des Großbasler Schultheißengerichts vor. Da es sich meist um Pfändungen wegen versessener Zinsen handelt, werden in diesen Protokollen häufig zumindest die Zinsverpflichtungen genannt, denen der säumige Schuldner nicht nachkam. So wurde die Papiermühle, die sich zu dieser Zeit im Besitz von Anton Gallician befand, im März 1496 von Conrad Lützelmann gefrönt, der eine Rente von 13 Gulden jährlich von der Papiermühle bezog. ${ }^{1828}$ Da der Zinssatz in der Regel ein Zwanzigstel der Kreditsumme betrug, lastete auf dem Grundstück somit vermutlich eine Hypothek von 260 Gulden. Im Jahr 1519 pfändete der Schreiber Johann Erhardt Reinhardi als Schaffner der Erben des Jacob von Eptingen die Stegreifmühle, weil Franz Gallician den jährlichen Zins von 20 Gulden nicht gezahlt hatte. ${ }^{1829}$ Eine weitere Pfändung $u m b$ versessen zins und ersatzung eins abgangnen Mitschuldners datieren die Frönungsprotokolle auf den 11. Dezember 1522, allerdings wird hier keine Zinssumme genannt. ${ }^{1830}$ Diese soeben genannten drei Frönungen endeten nicht mit einer Zwangsvollstreckung, sodass die Papiermühle in der Hand von Anton beziehungsweise Franz Gallician blieb. Dies änderte sich erst mit dem Verkauf der Mühle an Jörg Dürr d. Ä. im Jahr 1523. Der Kaufpreis für die Liegenschaft, die mit einer jährlichen Rente von 3 Gulden belastet war, betrug 600 Gulden. ${ }^{1831} 1524$ kam es zu einer weiteren Pfändung der Liegenschaft. Als Zinslast wurden 2 Gulden und ein halber dicker Plappart angegeben. ${ }^{1832}$ Der Kaufpreis von 600 Gulden aus dem Jahr 1523, aber auch die Rentenbelastungen von 260 und 400 Gulden zeigen das Wertspektrum auf, in dem sich die Stegreifmühle bewegte.

Die eine Hälfte der hinteren Spiegelmühle, St. Albantal 31, war im Jahr 1484 mit 2 Pfund 7 Schilling jährlichen Zinses belastet. In der Entrichtung dieser Zinsen war der Leheninhaber Peter Höfflin anscheinend nachlässig, da der Schaffner von St. Theodor seine Mühle in diesem Jahr pfändete. ${ }^{1833}$ Er zog sie jedoch nicht an sich, sodass Peter Höfflin im Jahr 1487 das halbe Lehen für 300 Gulden an seinen Stiefsohn Michel Gernler verkaufen konnte. ${ }^{1834}$ In dem Fertigungsprotokoll werden keine auf dem Grundstück lastenden Renten aufgeführt. Die nächste Handänderung erfolgte im Jahr 1513 für 208 Gulden. ${ }^{1835}$ Mit der Papiermühle erwarb der Käufer Jörg Dürr

1827 StABS, Gerichtsarchiv B 30, 226r.

1828 StABS, Gerichtsarchiv E 7, 35v.

1829 StABS, Gerichtsarchiv E 9, 9v.

1830 StABS, Gerichtsarchiv E 9, 21v.

1831 StABS, Gerichtsarchiv B 22, 327v.

1832 StABS, Gerichtsarchiv E 9, 29r.

1833 StABS, Gerichtsarchiv E 6, 84r.

1834 StABS, Gerichtsarchiv B 12, 40r.

1835 StABS, Gerichtsarchiv B 19, 182r. 
d. Ä. auch die Verpflichtung zur Zahlung von 5 Gulden jährlich an das Dorf Mußbach sowie von 3 Gulden jährlich an Ursula Segesserin, die Witwe Michel Gernlers. Völlig frei von Zinslast war die Liegenschaft laut Fertigungsbuch, als Bartholome Blum sie im Jahr 1530 für circa 153 Gulden von Veronica Gallician kaufte. ${ }^{1836}$ Allerdings blieb der Käufer 75 Gulden der Kaufsumme schuldig. Diese Schulden verkaufte er ein Jahr später zusammen mit der Papiermühle bereits wieder, und zwar an Claus Dürr. Der Kaufpreis lag bei 125 Gulden. ${ }^{1837}$ Dieser um 35 Gulden niedrigere Betrag ist sicherlich auf die gleichzeitige Übertragung der Schulden zurückzuführen, derer der Verkäufer somit ledig wurde.

Auch die halbe Spisselismühle war in der recht kurzen Zeit ihrer Existenz als Papiermühle mit Zinsen behaftet. Spätestens seit 1489 bezog der Messerschmied Conrat Wesslin für einmal gezahlte 100 Gulden 5 Gulden jährlich von der Liegenschaft. ${ }^{1838}$ Es war die Fälligkeit dieser Zinsen, die ihn im Jahr 1494 dazu veranlassten, die Papiermühle des inzwischen flüchtigen Hans Züricher zu pfänden. ${ }^{1839}$ Neben seinen 100 Gulden war das Grundstück noch mit weiteren 80 Gulden belastet, für die der Schleifer Hans Krafft, Besitzer der anderen Hälfte der Spisselismühle, eine jährliche Rente von 4 Gulden bezog. ${ }^{1840}$ Conrat Wesslin bot bei der Zwangsversteigerung der Liegenschaft 100 Gulden und bekam den Zuschlag.

Die hintere Schleife, in dem Fertigungsprotokoll auch zur wüssen mülli genannt, erwarb Jörg Dürr d. Ä. im Jahr 1525 für einen Preis von 100 Gulden. Diese Liegenschaft war zu diesem Zeitpunkt mit keiner Rente belastet. ${ }^{1841}$

Versucht man diese Befunde systematisch darzustellen, so kommt man zu dem Ergebnis, dass sowohl der Kaufpreis als auch die Rentenbelastung der Papiermühlen sehr stark variierten und das nicht nur beim synchronen Vergleich der verschiedenen Mühlwerke, sondern bereits bei der diachronen Betrachtung einer einzelnen Mühle. Worin diese Unterschiede begründet sind, lässt nicht nachvollziehen. Generell waren beispielsweise der bauliche Zustand sowie die Rentenbelastung der Liegenschaft

1836 StABS, Gerichtsarchiv B 25, 175r-175v. Der Eintrag gibt die Kaufsumme nicht in Gulden, sondern in Pfund Stebler an: Und ist diser kouf zugangen und beschehen umb iic lb guter stebler basler werung. Im Rechnungsjahr 1530/31 war in Basel ein Gulden 1,31 Pfund wert, daher ergibt sich bei 200 Pfund Stebler ein Betrag von ungefähr 153 Gulden, vgl. Rosen 1989, 146.

1837 StABS, Gerichtsarchiv B 26, 25r-25v.

1838 Die auf der Spisselismühle lastenden Zinsen werden immer zusammen mit den auf der Zunzigermühle liegenden Zinsen genannt. StABS, Gerichtsarchiv B 12, 125v: So denn von ab den iic gulden, so die verkouffere haben uff den zweyen Bappirmülinen... [Am Rand] Alsdann Hanns Züricher der Bappirmacher Innhaber der Bappirmülinen obgemelt offennlich in gericht bekannt. Offenbar hatte der Inhaber der beiden Mühlwerke, Hans Züricher, eine Gesamtrente von 200 Gulden auf die beiden Papiermühlen verkauft.

1839 StABS, Gerichtsarchiv E 7, 16v-17r. Vgl. Kälin 1974, 177.

1840 StABS, Gerichtsarchiv E 7, 16v-17r.

1841 StABS, Gerichtsarchiv B 24, 155r. 
Faktoren, die den Kaufpreis beeinflussen konnten. ${ }^{1842}$ Der Wert einer Papiermühle lässt sich meist nur in einer Momentaufnahme bestimmen. Der anhand der aus den Gerichtsprotokollen gewonnenen Daten ermittelte Durchschnittswert einer Papiermühle in Basel beträgt für das 15. Jahrhundert circa 331 Gulden, wobei der niedrigste Wert bei 90 Gulden und der höchste Wert bei 700 Gulden liegt. Die Daten für die erste Hälfte des 16. Jahrhunderts ergeben einen etwas höheren Wert von 386 Gulden. Für diesen Zeitraum liegt der niedrigste Wert bei 100 Gulden, der höchste bei 630 Gulden (vgl. Tab. 11).

Tab. 11: Kaufpreis, Rentenbelastung und Mindestwert der Basler Papiermühlen im 15. Jahrhundert und in der ersten Hälfte des 16. Jahrhunderts. ${ }^{1843}$

\begin{tabular}{|c|c|c|c|c|}
\hline Mühle & Jahr & Kaufpreis & Hauptgut & Mindestwert \\
\hline \multicolumn{5}{|c|}{ 15. Jahrhundert } \\
\hline Allenwindenmühle & 1433 & 126 Gulden & 80 Gulden & 126 Gulden \\
\hline Rümelinbachmühle & $1452 / 3$ & 90 Gulden & 38 Gulden & 90 Gulden \\
\hline \multirow[t]{2}{*}{ Rychmühle } & 1467 & -..---.-- & 300 Gulden & 300 Gulden \\
\hline & 1494 & 270 Gulden & 300 Gulden & 300 Gulden \\
\hline \multirow[t]{4}{*}{ Zunzigermühle } & 1470 & 700 Gulden & 670 Gulden & 700 Gulden \\
\hline & 1486 & --------. & 558 Gulden & 558 Gulden \\
\hline & 1494 & 300 Gulden & 470 Gulden & 470 Gulden \\
\hline & 1496 & --.---..-- & 470 Gulden & 470 Gulden \\
\hline \multirow[t]{2}{*}{ Klingentalmühle } & 1453 & 280 Gulden & --.---.-. & 280 Gulden \\
\hline & 1478 & & 300 Gulden & 300 Gulden \\
\hline Stegreifmühle & 1496 & --.--.--- & 260 Gulden & 260 Gulden \\
\hline hintere Spiegelmühle & 1487 & 300 Gulden & -..--..-. & 300 Gulden \\
\hline halbe Spisselismühle & 1494 & 100 Gulden & 180 Gulden & 180 Gulden \\
\hline
\end{tabular}

1842 Vgl. Füglister 1981, 33, 93.

1843 Für die Belege vgl. den Text. 


\begin{tabular}{|c|c|c|c|c|}
\hline Mühle & Jahr & Kaufpreis & Hauptgut & Mindestwert \\
\hline \multicolumn{5}{|c|}{ erste Hälfte des 16. Jahrhunderts } \\
\hline \multirow[t]{2}{*}{ Rychmühle } & 1519 & 50 Gulden & 550 Gulden & 550 Gulden \\
\hline & 1542 & 250 Gulden & 550 Gulden & 550 Gulden \\
\hline \multirow[t]{3}{*}{ Zunzigermühle } & 1515 & --.--.--- & 400 Gulden & 400 Gulden \\
\hline & 1530 & --.---.- & 100 Gulden & 100 Gulden \\
\hline & 1532 & 450 Gulden & -------. & 450 Gulden \\
\hline \multirow[t]{3}{*}{ Klingentalmühle } & 1523 & 400 Gulden & 550 Gulden & 550 Gulden \\
\hline & 1528 & 25 Gulden & 590 Gulden & 590 Gulden \\
\hline & 1550 & 390 Gulden & 630 Gulden & 630 Gulden \\
\hline \multirow[t]{2}{*}{ Stegreifmühle } & 1519 & --.--.-- & 400 Gulden & 400 Gulden \\
\hline & 1523 & 600 Gulden & 60 Gulden & 600 Gulden \\
\hline \multirow[t]{3}{*}{ hintere Spiegelmühle } & 1513 & 208 Gulden & 160 Gulden & 208 Gulden \\
\hline & 1530 & 153 Gulden & -------- & 153 Gulden \\
\hline & 1531 & 125 Gulden & (75 Gulden Schulden) & 125 Gulden \\
\hline neue Papiermühle & 1525 & 100 Gulden & -..--..- & 100 Gulden \\
\hline
\end{tabular}

Die Daten für die erste Hälfte des 16. Jahrhunderts können durch die Studie Hans Füglisters zu den politischen und sozialen Strukturen Basels in diesem Zeitraum in Relation zum allgemeinen Basler Liegenschaftsmarkt gesetzt werden. Zu beachten ist hierbei, dass Füglister in seiner Untersuchung alle von Papiermachern getätigten Liegenschaftsgeschäfte verzeichnet, gleich ob es sich dabei um eine Papiermühle oder ein Haus, um einen Kauf oder einen Verkauf handelte. ${ }^{1844}$ Er zählt auf diese Weise 26 Liegenschaftskäufe und -verkäufe mit einem Durchschnittswert von 552,2 Pfund (circa 431 Gulden). ${ }^{1845}$ Damit führten die Papierer mit dem höchsten durchschnittlichen Liegenschaftswert noch vor den Krämern und Apothekern mit durchschnittlich 518,1 Pfund (circa 405 Gulden), den Kaufleuten und Wechslern mit durchschnittlich 474,8 Pfund (circa 371 Gulden) sowie den Druckern mit durchschnittlich 414,4 Pfund (circa 324 Gulden). ${ }^{1846}$ Als Vergleich kann zudem der von Füglister errechnete Mittel-

1844 Vgl. Füglister 1981, 15, 33-39.

1845 Vgl. Füglister 1981, 36. In der ersten Hälfte des 16. Jahrhunderts bewegte sich der Wert eines Guldens zwischen 1,25 und 1,42 Pfund. Die Umrechnung des Pfundwerts in den Guldenwert konnte aufgrund des schwankenden Kurswerts daher nur annäherungsweise erfolgen. Zur Umrechnung wurde anhand der Daten von Josef Rosen ein durchschnittlicher Kurswert von 128 Pfund zu 100 Gulden ermittelt, vgl. Rosen 1989, 146.

1846 Vgl. Füglister 1981, 36. 
wert der Preise aller in Basel in diesem Zeitraum verkauften Liegenschaften gelten, den er auf 248,8 Pfund (circa 194 Gulden) beziffert. Des Weiteren ist der Durchschnittswert der elf wertvollsten von Papiermachern gehandelten Grundstücke von Interesse. Füglister gibt ihn mit stolzen 835,5 Pfund (circa 653 Gulden) an. ${ }^{1847}$

Die von Papiermachern gekauften oder verkauften Liegenschaften gehörten auf dem städtischen Grundstücksmarkt folglich zu den teuersten Gebäuden. Dass diese vergleichsweise teuren Liegenschaften häufig durch Kreditaufnahme unterhalten wurden, wurde bei der Untersuchung der Rentenkäufe der einzelnen Papiermühlen deutlich. Somit gewinnt auch die von Kälin getroffene Aussage, dass „kaum je eine Mühle ohne Fremdgelder gearbeitet hat“, ${ }^{1848}$ an Kontur. Nimmt man die nur ein Jahr im Besitz eines Papiermachers befindliche Bluwenmühle am Rümelinbach heraus, so nahmen tatsächlich alle Papiermühlenbesitzer im betrachteten Zeitraum eine Hypothek auf oder führten eine bereits existierende Zinsbelastung fort.

Ein kleiner Anteil der Renten wurde dabei zur Finanzierung des Mühlenkaufs abgeschlossen. ${ }^{1849}$ Der Großteil der Rentenabschlüsse stand jedoch nicht in Zusammenhang mit dem Immobilienkauf, sondern bestanden in reinen Geld-gegen-GeldGeschäften. Wofür das auf diese Weise gewonnene Kapital eingesetzt wurde, ist leider nicht nachzuvollziehen. Bei der Aufnahme von Hypotheken auf Papiermühlen kann jedoch mit einiger Plausibilität davon ausgegangen werde, dass das Geld unter anderem in die Ausrüstung und Instandhaltung des Betriebs gesteckt wurde. ${ }^{1850}$

Die Arbeit von Füglister zeigt die relativ hohe Beteiligung der Papierer an Rentenverkäufen im Vergleich zu anderen Gewerbegruppen. ${ }^{1851}$ Das bedeutet, dass ein großer Anteil der Papierer in der ersten Hälfte des 16. Jahrhunderts eine oder mehrere Renten verkaufte. Dieses Resultat korreliert mit der Tatsache, dass das Papiergewerbe verhältnismäßig investitionsintensiv war. Neben den Papierern beteiligten sich auch vergleichsweise viele Personen aus der Gruppe der Wirte, der Buchdrucker und der Müller an Rentenverkäufen. ${ }^{1852}$ Auch für diese Berufsgruppen kann gelten, dass sie ein kapitalintensives Gewerbe betrieben. Innerhalb der Safranzunft partizipierten die Papiermacher an ebenso vielen Rentenverkäufen wie die Handeltreibenden (Krämer

1847 Vgl. Füglister 1981, 39.

1848 Kälin 1974, 182.

1849 Dies gilt nicht nur für die Papiermacher: Füglister beziffert den Anteil der Hauskaufrenten an allen von ihm aus den Fertigungsbüchern extrahierten Rentenabschlüssen auf rund 17 Prozent. Das bei den Hauskaufrenten eingebrachte Hauptgut war dabei durchschnittlich beinahe doppelt so hoch wie das Hauptgut der anderen Rentengeschäfte. Erklärbar ist dies sicherlich mit dem erhöhten Kapitalbedarf, der sich durch einen Hauskauf ergab, vgl. Füglister 1981, 99 f.

1850 Vgl. Füglister 1981, 35, 104.

1851 Vgl. Füglister 1981, 104. Die der Rechnung zugrunde gelegten Rentenverkäufe betreffen nicht nur Zinsen aus Papiermühlen, sondern alle im Besitz von Papiermachern befindlichen Liegenschaften.

1852 Vgl. Füglister 1981, 104. 
und Apotheker) und die Gürtler: Diese drei Berufssparten bildeten mit jeweils elf Verkäufen die Spitzengruppe. ${ }^{1853}$ Außer den schmale Lederriemen herstellenden Nestlern, die insgesamt neun Renten verkauften, waren die anderen Gewerbegruppen der Safranzunft nur vereinzelt am Rentenmarkt vertreten.

Neben dem Anteil an den Rentenverkäufen ist auch das dabei umgesetzte Kapital interessant. Wie bereits gezeigt wurde, beliefen sich die Hypotheken, die Papiermacher auf ihre Papiermühlen aufnahmen, häufig auf mehrere hundert Gulden. Damit nahm diese Berufsgruppe überdurchschnittlich hohe Kredite auf, denn mehr als die Hälfte aller von Basler Bürgern verkauften Renten waren unter 50 Pfund (circa 39 Gulden) angesiedelt, insgesamt drei Viertel unter 100 Pfund (circa 78 Gulden). ${ }^{1854}$ Füglister konnte zeigen, dass die Papierer hinter den Kaufleuten und den Krämern/ Apothekern die Renten mit dem im Durchschnitt höchsten Hauptgut verkauften. ${ }^{1855}$ In Anbetracht des sehr hohen durchschnittlichen Liegenschaftswerts der von Papiermachern in der ersten Hälfte des 16. Jahrhunderts gekauften Liegenschaften - Papiermühlen und Häuser - von 552,2 Pfund (circa 431 Gulden) ${ }^{1856}$ nimmt diese rege Nutzung der Kapitalgewinnung durch Rentenverkauf nicht wunder, da sich wahrscheinlich kaum ein Papierer den Kauf oder die Instandhaltung einer Mühle aus eigenen Kräften leisten konnte. So entstand nicht nur absolut, sondern auch relational eine hohe Rentenbelastung: Der Anteil des durchschnittlichen Rentenwerts am durchschnittlichen Liegenschaftswert betrug zwischen 41 und 50 Prozent. In der Gruppe der Berufe, die Liegenschaften mit einem Wert von durchschnittlich über 400 Pfund (circa 313 Gulden) kauften - hierzu gehörten Drucker, Kaufleute, Krämer und Apotheker, Wirte sowie eben die Papiermacher - nahmen letztere die anteilsmäßig höchste Rentenlast auf. ${ }^{1857}$

\subsubsection{Bern, Ettlingen, Gengenbach, Kempten, Ravensburg, Straßburg und Zürich} Auch wenn für die weiteren südwestdeutschen Papiermühlenstandorte keine solche detaillierte Untersuchung möglich ist, lassen sich wie im Fallbeispiel Basel große Unterschiede im Kaufpreis und eine häufige Belastung der Liegenschaft mit einer Rente, die oft auch die Gestalt einer Hauskaufrente annahm, konstatieren. Hinsichtlich des Kaufpreises bieten die herangezogenen Studien nur für wenige Papiermüh-

1853 Vgl. Füglister 1981, $104 \mathrm{f}$.

1854 Vgl. Füglister 1981, 113.

1855 Das durchschnittlich eingesetzte Hauptgut betrug nach Füglister 216,9 Pfund Stebler, vgl. Füglister 1981, 116. Mit dem für die erste Hälfte des 16. Jahrhunderts ermittelten Durchschnittwert des Gulden-zu-Pfund-Kurses umgerechnet sind dies circa 169 Gulden, vgl. Anm. 1845.

1856 Vgl. Füglister 1981, 36.

1857 Im Vergleich dazu lag die Rentenbelastung der von Druckern erworbenen Liegenschaften, deren durchschnittlicher Wert mit 414,4 Pfund ebenfalls sehr hoch war, unter 20 Prozent dieses Durchschnittswerts, vgl. Füglister 1981, 36, 42. 
len Informationen, sei es aufgrund der Überlieferungslage, sei es aufgrund des Forschungsstands. Drei Angaben zum Kaufpreis lassen sich für Bern finden. Sie betreffen sowohl das Werk zu Worblaufen als auch die Papiermühle zu Thal. Beim Verkauf der Mühle zu Worblaufen 1470 an die Stadt Bern erzielten Tschan Jacki und sein Sohn Anton einen Preis von 150 Gulden. ${ }^{1858}$ Dieser Betrag galt offensichtlich für das Grundstück sowie das Mühlengebäude, allerdings ohne die Einrichtung, denn die für die Papiermacherei notwendige Ausstattung durften die Jacki behalten.

Vier Jahre später, im Januar 1474, veräußerten sie die Papiermühle zu Thal für den vierfachen Preis, 600 Gulden, an den Basler Anton Gallician und seine beiden Schwiegersöhne. Bei diesem Kauf erwarben die drei Basler die komplette Papiermühle samt Einrichtung. Lediglich der Hausrat verblieb im Besitz von Tschan und Anton Jacki. ${ }^{1859}$ Der relativ große Preisunterschied lässt sich sicherlich zum Teil mit der Überlassung der gesamten Ausstattung erklären. Vielleicht war auch die Mühle zu Thal größer und mit mehr Rädern ausgestattet als das Werk zu Worblaufen. Im Jahr 1491 bezahlten die Papiermacher Michel Pol und Constanz zu Worwe für die Papiermühle zu Thal die für diese Zeit sehr hohe Summe von 2.350 Pfund Stebler, was ungefähr einem Wert von 1.175 Gulden entsprach. ${ }^{1860}$ Der Betrag hatte sich innerhalb von 17 Jahren folglich fast verdoppelt - und das bei einem bereits relativ hohen Ausgangswert von 600 Gulden. Für Basel konnte überhaupt nur zweimal ein Kaufpreis ermittelt werden, der mit dem Berner Betrag von 1474 vergleichbar ist: 1470 zahlte Ulrich Züricher 700 Gulden für die Zunzigermühle, 1523 wechselten beim Verkauf der Stegreifmühle 600 Gulden den Besitzer.

Welche Besonderheiten in Einrichtung und Ausstattung eine Kaufsumme von mehr als 1.000 Gulden rechtfertigten, kann leider anhand der Quellen nicht eruiert werden. Adolf Fluri sen. vermutet, dass der Betrag aus einer Vergrößerung des Betriebs resultierte. ${ }^{1861}$ Rentabel war diese Vergrößerung anscheinend nicht, da der hohe Kaufpreis durch den Ausstoß der Papiermühle nicht amortisiert werden konnte. Fünf Jahre später, 1496, brachte Constanz zu Worwe nämlich die Klage vor dem Berner Rat, dass die Mühle die Kaufsumme nicht tragen könne und er deshalb erwäge, den Kauf rückgängig zu machen. ${ }^{1862}$ Auch im Vergleich mit anderen Preisen von Papiermühlen dieser Zeit nimmt sich die 1491 in Bern erzielte Summe ausgesprochen hoch aus.

Für die 1498 veräußerten drei Papierhäuser im Ravensburger Ölschwang erhielt Felix Humpis lediglich 40 Gulden, obwohl auch hier das Leimhaus, die Räder, der

1858 Vgl. Fluri sen. 1896, 195; Fluri jun. 1954, 47, 79; J. Lindt 1964, 78; Fluri jun. 1975, 7, 27. 1859 Vgl. Fluri sen. 1896, 197 f.; Fluri jun. 1954, 47; J. Lindt 1964, 78; Fluri jun. 1975, 8 f.

1860 Diese Umrechnung gilt bei einem Wechselkurs von einem Gulden zu zwei Pfund, wie er Ende des 15. Jahrhunderts für Bern anzunehmen ist, vgl. Schmutz/Zäch 2006, 810; Schmutz 2010, 697.

1861 Vgl. Fluri sen. 1896, 200.

1862 Vgl. Fluri sen. 1896, 200; Fluri jun. 1954, 48; J. Lindt 1964, 78 f.; Fluri jun. 1975, 10. 
Stampf, die Wasseranlage und weitere Zugehörungen im Kaufpreis inbegriffen waren. ${ }^{1863}$ Die Liegenschaft war bis auf den an die Stadt Ravensburg zu entrichtenden jährlichen Grundzins von 19 Pfund zudem mit keiner Rente belastet. ${ }^{1864}$ Daher fällt es schwer, eine Erklärung für diese vergleichsweise geringe Kaufsumme zu finden. Es bleibt nur der Hinweis, dass auch in Basel Papiermühlen für 50 oder sogar für nur 25 Gulden verkauft wurden. ${ }^{1865}$ Ob diese Beträge auf Schreiberfehler zurückzuführen sind, ist zwar denkbar, da es sich jedoch offenbar nicht um Einzelfälle handelt, kann diese Erklärung nicht uneingeschränkt herangezogen werden.

Gerhard Piccard erachtet bereits einen Kaufpreis von 330 Gulden als zu gering für eine vollausgestattete, betriebsbereite Papiermühle. ${ }^{1866}$ Soviel hatte vermutlich der Frankfurter Drucker Christian Egenolff im Jahr 1550 für die Gengenbacher Papiermühle bezahlt. Auf Grund dieser Annahme geht Piccard davon aus, dass Egenolff bereits zuvor, zwischen 1544 und 1550, Anteile an dem Mühlwerk erworben hatte und die restlichen Anteile 1550 für 330 Gulden kaufte. ${ }^{1867}$ Dass Egenolff bereits vor 1550 Miteigentümer der Papiermühle war, geht auch aus anderen Hinweisen hervor, wie Piccard selbst darlegt. ${ }^{1868}$ Ob gerade der „geringe“ Kaufpreis ein Indiz für einen Mitbesitz ist, kann allerdings bezweifelt werden. Denn im Vergleich mit zur selben Zeit getätigten Papiermühlenverkäufen in Basel erscheint der Betrag von 330 Gulden nicht zu gering, sondern bewegt sich im Durchschnitt. 1542 wurden für die Rychmühle 250 Gulden erzielt, 1550 wurde die Klingentalmühle für 390 Gulden verkauft. Piccard hält hingegen einen Kaufpreis von 800 Gulden für realistisch, jedoch ohne für diese Schätzung Belege und vergleichbare Papiermühlenkäufe anzugeben. ${ }^{1869}$

Vor dem Hintergrund, dass bei einem Großteil der Papiermühlenverkäufe im südwestdeutschen Raum des Untersuchungszeitraums überhaupt kein Kaufpreis überliefert ist, wäre der Ursprung von Piccards Vermutung von besonderem Interesse. Neben der Kaufsumme kann der Mindestwert einer Liegenschaft auch über ihre Rentenbelastung ermittelt werden, wie es in diesem Kapitel bereits für das Basler Beispiel versucht wurde. Als der Züricher Papiermacher Heinrich Walchwiler im Jahr 1471 die

1863 StR, Urk. 670 (24.07.1498): Unnd ist der kouff beschehenn umb viertzig gulden rinisch. Vgl. Alfred Schulte 1953, 22.

1864 StR, Urk. 670 (24.07.1498): Zinst järlich gemeiner stat alhie newntzehen pfundt pfennig sunst frey ledig aigenn und gegen nyemands annderswo versetzt verschriben noch verkümert.

1865 Im Jahr 1519 wechselte die Rychmühle für 50 Gulden den Besitzer, 1528 wurde die Klingentalmühle für 25 Gulden verkauft, vgl. Kapitel 3.2.4.1, S. 284, 287, 291.

1866 Vgl. Piccard 1963, $1011 \mathrm{f}$.

1867 Vgl. Piccard 1963, $1011 \mathrm{f}$.

1868 So wurde Egenolff bereits 1548 in einem Streit zwischen den Papiermachern Dietrich Lucas und Hans Bauman über die strittige Angelegenheit in Kenntnis gesetzt und um ein Eingreifen gebeten. Im Jahr 1549 wurde er zudem als Prinzipal der Papiermühle bezeichnet, vgl. Piccard 1963, 1008, 1011, 1043 f.; E. Schmitt 1990, [55, 57].

1869 Vgl. Piccard 1963, 1011. Zu Basel vgl. Tab. 11. 
Mühlwerke auf der Werdinsel von Otto im Werd erwarb, verkaufte er diesem zeitgleich eine Rente von 400 Gulden für eine jährliche Zinsleistung von 20 Gulden. ${ }^{1870}$ Es handelte sich dabei offenbar um eine Hauskaufrente, mit der Walchwiler den Erwerb der Papiermühle finanzierte und die ihn und seinen Nachfolger Hans Conrad Grebel noch mehrere Jahrzehnte belasten sollte.

Otto im Werd verkaufte sein Recht auf die jährlichen Zinsen an dritte Personen weiter, sodass es zu einer Splittung der Rentenberechtigten kam. Neben seiner Frau Anastasia Pleth und seinem Schwiegersohn Ulrich Studer, die 9 Gulden beziehungsweise einen Gulden Zinsanrecht hatten, übertrug er Hans Fritag 5 Gulden und Rudolf Rubli sowie dem Kloster Selnau einen Rentenanteil von jeweils 2,5 Gulden. ${ }^{1871} 1488$ verlieh Anastasia Pleth ihrem Schwiegersohn ihre 9 Gulden, sodass Ulrich Studer nunmehr eine jährliche Rente von 10 Gulden von der Papiermühle bezog, die sich inzwischen im Besitz von Hans Conrad Grebel befand. Dieser hatte anscheinend Schwierigkeiten, die Zinsen zu bezahlen, denn im Jahr 1491 pfändete Ulrich Studer die Papiermühle um versessenen Zins und zog sie schließlich an sich. ${ }^{1872}$ Offenbar gelang es Grebel, die Mühle wieder in seinem Besitz zu bringen, allerdings nur unter erheblicher finanzieller Belastung. Im Jahr 1513 wurde eine weitere Klage gegen ihn angestrebt, deren Wortführer der Apotheker Hans Schneeberger war. ${ }^{1873}$ Über den Ausgang dieser Streitsache ist nichts bekannt. Bekannt ist durch diesen Rentenverkauf allerdings, dass die Papiermühle auf dem Werd oder vielmehr die Liegenschaften mit der Sägemühle und der Pulverstampfe mindestens 400 Gulden wert war. Auf den Anteil der Kaufsumme, den Walchwiler durch einen Zinsverkauf finanzierte, das heißt auf die tatsächliche Höhe des Kaufpreises, gibt es keinen Hinweis.

Eine besondere Form des Darlehens erhielt Jerg Moser, dem 1521 die Ettlinger Papiermühle vom Markgrafen von Baden als Erblehen verliehen wurde. Für den Wiederaufbau des heruntergekommenen Betriebs gab der Markgraf ihm einen Kredit von 100 Gulden, den er in Raten zu 5 Gulden tilgen sollte. ${ }^{1874}$ Das Geld stand ihm offenbar jedoch nicht zur freien Verfügung, denn es wurde im Namen des Markgrafen vom

1870 Vgl. Schnyder 1937, 729, Nr. 1248; Zürcher 1963b, 119, 126.

1871 Vgl. Schnyder 1937, 729, Nr. 1248; Zürcher 1963b, 119, 126. Karl Zürcher erwähnt zudem das Kloster Ötenbach als Rentenempfänger von 5 Pfund Jahreszins von der Papiermühle, die es von Eberhard Ottikon und seiner Frau übernommen hatte. Werner Schnyder führt in seiner Quellensammlung denselben Beleg an, nennt jedoch als Quelle das Urbar des Klosters Selnau, während Karl Züricher mit derselben Signatur das Urbar des Klosters Ötenbach bezeichnet, vgl. Schnyder 1937, 1022, Nr. 1288a. Die Recherche im Archivkatalog ergab, dass es sich bei der Signatur StA Zürich, H I 156 um ein Dokument des Zisterzienserinnenklosters Selnau handelt.

1872 Vgl. Zürcher 1963b, $121 \mathrm{f}$.

1873 Der Apotheker Caspar Schneeberger, vermutlich verwandt mit Hans Schneeberger, hatte im Jahr 1486 von Rudolf Rubli die Rente im Wert von 2,5 Gulden übernommen, vgl. Zürcher 1963b, 122, 126.

1874 Vgl. Piccard 1951, 60; Stenzel 1985, 101. 
Ettlinger Schultheiß verwahrt, damit es gänzlich dem Aufbau der Mühle zugutekam. Bereits zu der Zeit, als die Papiermühle zu Ettlingen nur als Zeitlehen ausgegeben wurde, hatte Claus Gallician ein Darlehen in der Höhe von 30 Gulden beim Markgrafen aufgenommen und als dingliche Sicherheit all sein fahrendes Gut verpfändet. ${ }^{1875}$ Eventuell benötigte auch Claus Gallician Startkapital, um die Ausstattung der Papiermühle zu erneuern oder um die Rohstoffe für die erste Produktion zu kaufen.

Der Rentenverkauf war aber nicht nur im direkten Kontext eines Mühlenerwerbs ein beliebtes Mittel zur Kapitalbeschaffung. Auch für die Deckung laufender Kosten - darunter fielen vermutlich die Instandhaltung des Werks, der Rohstoffeinkauf, der Ersatz verbrauchter Werkzeuge - verkauften Papiermühlenbesitzer Renten von ihren Liegenschaften, wie bereits für das Fallbeispiel Basel gezeigt wurde. So nahm der Erbauer der Straßburger Papiermühle im Rosengarten, Wilhelm de Altomonte, 1447 - zwei Jahre nach Verleihung des Grundstücks - ein Darlehen von 100 Gulden bei Agnes, der Frau von Nicolas Heilmann, auf und verpflichtete sich, jährlich einen Zins von 8 Gulden zu entrichten. ${ }^{1876}$ Mit der Zinszahlung befand sich Wilhelm de Altomonte jedoch bereits 1451 im Rückstand, denn Nicolas Heilmann pfändete in diesem Jahr im Namen seiner Frau die Papiermühle im Rosengarten und wandte sich hierfür an den Offizial des Straßburger Bischofs. ${ }^{1877}$ Neben seiner Forderung um versessenen Zins an Wilhelm de Altomonte benannte Nicolas Heilmann noch einen Anspruch auf 253 Gulden, die er dem inzwischen verstorbenen Georg de Altomonte kreditiert hatte und für die Johannes de Altomonte und Johannes Hettag gebürgt hatten, die nunmehr Betreiber der Papiermühle waren. Im darauffolgenden Jahr 1452 ließ sich Nicolas Heilmann seine Einsetzung als Inhaber der Liegenschaft vom Straßburger Rat bestätigen. ${ }^{1878}$ Dieser erkannte jedoch zugleich das Vorrecht Wilhelms de Altomonte - über dessen Verbleib zu diesem Zeitpunkt Ungewissheit herrschte - an, die Papiermühle wieder an sich zu ziehen, wenn er zurückkomme und seinem Gläubiger das Hauptgut und die versessenen Zinsen - insgesamt eine Summe von 172 Gulden - erstatte. ${ }^{1879}$ Wilhelm kehrte offenbar nicht wieder, zumindest machte er seine Ansprüche auf die Papiermühle nicht geltend, bevor sie 1454 abgerissen wurde. ${ }^{1880}$

1875 Vgl. Piccard 1951, 59 f.; Piccard 1967, 118 f.; Stenzel 1985, 100.

1876 Vgl. Fuchs 1962b, 104.

1877 AVES, CH 251, Nr. 5164 (26.08.1451). Vgl. Fuchs 1962b, 104 f.

1878 AVES, CH 254, Nr. 5228 (22.11.1452). Vgl. Fuchs 1962b, 104 f.

1879 AVES, CH 254, Nr. 5228 (22.11.1452): [...] das der obgenante Wilhelm in dem jubel jore gon Rome gangen und nit widerkommen sii ouch keyn bottschaft har geton habe das man nit wisse obe er lebendig oder dot sii. Nu siient siner husfröwen ir acht guldin gelts nie me dann ein zinß worden und standet ir noch vier versessen zinse $u \beta$ und ettlich schulde noch besage siner reces $\beta$. Als habe er die müle mit geistlichem gericht gezogen noch innhalt des versigelten zugbriefes und begert an uns ine doby und by der mülen lossen zu bliben [...].

1880 AVES, CH 257, Nr. 5292 (07.08.1454). Vgl. Fuchs 1962b, 105. 
Die Pfändung seiner Papiermühle erlebte auch der Papiermacher Hans Grapp in Gengenbach. Er hatte offenbar dem Straßburger Kaufmann Hans Wild eine Rente von seinem Werk verkauft und war mit der Zinszahlung in Verzug geraten. Wie hoch das eingelegte Kapital war, ist leider nicht bekannt, gewiss ist jedoch, dass Hans Wild die Papiermühle im Jahr 1523 an sich zog. ${ }^{1881}$ Dem vor Gericht vorgebrachten Protest des Papiermachers wurde wiederholt kein Gehör geschenkt, sodass das Werk endgültig in den Besitz des Straßburger Kaufmanns überging. ${ }^{1882}$ Die nächste Pfändung der Papiermühle ereignete sich anlässlich des Konkursverfahrens nach dem Tod des Besitzers Georg Dietz. Als Hauptgläubiger trat hier offenbar der Abt des Klosters Gengenbach auf, der die Mühle 1544 an sich zog. Vermutlich hatte Georg Dietz, der auch bei weiteren Personen Schulden hatte, dem Abt eine Rente von seiner Papiermühle verkauft. Die Höhe der Forderung ist leider ebenfalls unbekannt. ${ }^{1883}$ Auch über eine auf der Kemptener Papiermühle zu Hegge lastende Hypothek wissen wir lediglich, dass der Besitzer des Werks, Marx Baruttel, dem Hutmacher Balthasar Sparer 1506 eine Rente verkaufte. ${ }^{1884}$

Ein üblicher Marktwert von Papiermühlen im südwestdeutschen Raum bis 1550 ist, wie die vorangegangenen Ausführungen gezeigt haben, nur schwer zu bestimmen, da die Kaufpreise stark variierten. Offenbar spielten bei der Taxierung viele, zum großen Teil unbekannte Faktoren eine Rolle. Darunter konnten der bauliche Zustand der Mühle, ihre Lage und die dazugehörigen Gebäude ebenso fallen wie die Belastung mit Renten oder die allgemeine Situation von Angebot und Nachfrage auf dem Immobilienmarkt. Trotz dieser Schwierigkeiten, einen generalisierten Wert zu ermitteln, wurde deutlich, dass Papiermühlen vergleichsweise teure Liegenschaften waren, deren Erwerb der Käufer häufig nur mit einem Rentenverkauf finanzieren konnte. Auch die Einrichtung der Werkstatt, der Ankauf von Rohstoffen sowie der Unterhalt des Wasserlaufs durch Reinigung und Befestigung des Bachbetts machten einen erheblichen Teil des Kapitalbedarfs aus, der durch Rentenverkäufe zumindest teilweise gedeckt werden konnte.

\subsubsection{Wasserrechte und Wasserordnungen}

Ein steter Zufluss an Wasser war sowohl für die Papiermacher als auch für andere Mühlenbetreiber eine notwendige Voraussetzung für die Ausübung ihres Gewerbes. Das Recht auf Wassernutzung war an das Mühlregal gebunden und war damit herr-

1881 Vgl. K. Th. Weiss 1951, 19; Piccard 1963, 1002; E. Schmitt 1990, [25].

1882 Vgl. Piccard 1963, 1002; E. Schmitt 1990, [26-28].

1883 Vgl. K. Th. Weiss 1951, 25-27, 43-46; Piccard 1963, 1006 f., 1042 f.; E. Schmitt 1990, [34, 39 f.].

1884 Vgl. Petz 2006, 290 f. 
schaftliches Recht, das von einem Landes- oder Grundherrn verliehen wurde. ${ }^{1885} \mathrm{Um}$ die Wassernutzung zu regeln, entstanden zum Teil detaillierte Wasserordnungen, die Rechte und Pflichten definierten und schriftlich fixierten. Dass solche Regulierungsbestrebungen erforderlich waren, zeigen die zahlreichen Wasserrechtsstreitigkeiten, in die Papiermacher verwickelt waren. Zwistigkeiten entbrannten beispielsweise, weil ein Kanalanrainer sich der Instand- und Sauberhaltung des Kanalbetts zu entziehen versuchte. Auch die befürchtete oder tatsächliche Übervorteilung, die der Anschluss eines neuen Mühlwerks an den Wasserzufluss oder das Abzweigen von Wasser verursachten, führte immer wieder zu Streitigkeiten. Mögen diese Auseinandersetzungen für die Streitparteien unangenehm gewesen sein und sie bisweilen existenziell betroffen haben, so stellen sie für den Historiker einen Glücksfall dar: Wichtige Informationen zu einigen Papiermühlen sind lediglich durch Wasserrechtsstreitigkeiten auf uns gekommen.

\subsubsection{Basel}

Die Rechte und Pflichten bezüglich der Wassernutzung, aber auch die darüber immer wieder aufkommenden Streitigkeiten können für Basel nicht einheitlich gefasst werden, da zwischen den drei Gewerbekanälen geographisch, herrschaftlich und historisch bedingte Unterschiede existierten. Alle drei Kanalsysteme - der Riehenteich in Kleinbasel, der Rümelinbach und der St. Albanteich - standen jedoch seit der zweiten Hälfte des 15. Jahrhunderts unter der Aufsicht der sogenannten Wasserfünf, einem von der Schmiedezunft eingesetzten Kollegium aus vier ehrbaren Männer und einem Zunftmeister. ${ }^{1886}$ Die Zusammensetzung der Wasserfünf berücksichtigte alle drei Gewerbeteiche. Zwei der Gewählten sollten Leheninhaber am St. Albanteich sein, zwei oder drei ein Mühlwerk am Kleinbasler Riehenteich betreiben, wenn möglich, sollte außerdem ein Vertreter der Mühlenbesitzer am Rümelinbach unter ihnen sein. $\mathrm{Zu}$ den Aufgaben des Wasserkollegiums gehörte vor allem die regelmäßige Kontrolle der Gewerbekanäle. Außerdem wurde die Wasserfünf häufig als Fachausschuss bei Streitfällen hinzugezogen, die die Wassernutzung betrafen und vor dem für baupolizeiliche Aufgaben zuständigen Fünfergericht verhandelt wurden. ${ }^{1887}$ Eine eigene

1885 Vgl. hierzu die Einleitung in Kapitel 3.2.3 sowie die Ausstattung einer Mühle mit Wasserkraft in Kapitel 3.2.2.

1886 Die Schmiedezunft vereinte traditionell die meisten mit Wasserkraft arbeitenden Handwerke, nämlich neben den Messerschmieden, Schleifern und Harnischmachern auch die Müller, vgl. SimonMuscheid 1988, 78. Die Ursprünge dieses Wasserkollegiums sieht Eduard Schweizer in der okkasionellen Hinzuziehung von Mühlenexperten bei Wasserrechtsstreitigkeiten, die vor dem Fünferbaugericht verhandelt wurden, so beispielsweise im Jahr 1431 bei einem Entscheid über den Kleinbasler Teich, vgl. Schweizer 1927, 24, bes. Anm. 32. Vgl. auch Schweizer 1922, 255.

1887 Vgl. Anm. 1228. 
Jurisdiktionsgewalt besaß das Gremium im Gegensatz zum Baugericht der Fünf allerdings nicht. ${ }^{1888}$

Die Besitzer der Mühlwerke am Kleinbasler Teich waren genossenschaftlich organisiert und wählten halbjährlich vier Meister aus ihrer Mitte in das Amt des Wassermeisters. Die Wassermeister hatten die Aufgabe, den Teich und seinen baulichen Zustand zu überwachen und die Leheninhaber bei Bedarf zur Mitarbeit bei Reparaturen anzuhalten. War das Wassermeisteramt bis in die Mitte des 14. Jahrhunderts ausschließlich den Müllern vorbehalten, so konnten ab den 1360er-Jahren auch Vertreter der metallverarbeitenden Gewerbe das Amt ausfüllen. ${ }^{1889}$ Die Genossenschaft der Mühlenbesitzer vertrat die Rechte der wasserbetriebenen Werkstätten gegen andere Teichnutzer, die das Wasser widerrechtlich für ihre Zwecke ableiteten. Die meisten dieser nicht erlaubten Wasserentnahmen fanden innerhalb der Stadtmauern von Kleinbasel statt, sodass die Papiermühle zu Allenwinden nicht tangiert war. Einzig von der Ableitung des Wassers zur Bewässerung der außerhalb von Kleinbasel liegenden Wiesen, die häufig Streitpunkt zwischen den Mühleninhabern und den Mattenbesitzern war, war sie betroffen. ${ }^{1890}$

Die Lage der Mühle zu Allenwinden direkt vor dem Kleinbasler Stadttor war, was die Wasserversorgung betraf, überhaupt äußert günstig, da flussaufwärts keine weiteren Mühlwerke lagen. Zudem hatten die Besitzer der Mühle vor Heinrich Halbysen d. Ä. einige Privilegien hinsichtlich der Wassernutzung erwirken können. Im Jahr 1294 hatte der Inhaber der Allenwindenmühle die Ableitung eines 12 Fuß breiten Kanals oberhalb seiner Mühle aus dem bis dahin ungeteilten Riehenteich gestattet. Allerdings hatte er die Bedingung gestellt, dass er den neuen Kanal - später als der krumme Teich bekannt - abschlagen dürfe, wenn auf seine Mühlräder nicht genügend Wasser komme. ${ }^{1891}$ Die Regelung eines konkreten Wasseranteils erfolgte 1304 durch den Basler Rat. In der Urkunde vom 10. November wurde verfügt, dass der krumme Teich nur eine Breite von 12 Fuß aufweisen dürfe, während der Hauptarm des Riehenteichs, an dem die Allenwindenmühle lag, eine Breite von 24 Fuß habe dürfe. Folglich sollen auch zwei Drittel des Wassers durch diesen Hauptkanal fließen, nur ein Drittel des Wassers stand den am neuen Kanal gelegenen Mühlwerken des Klosters St. Clara zu. ${ }^{1892}$ Spätere Briefe bestätigen zum einen diese Regelung, zeigen zum anderen aber auch, dass das vom Besitzer der Allenwindenmühle beanspruchte Recht, den krummen Teich bei Wassermangel zu schließen, häufig zu Auseinander-

1888 Vgl. Simon-Muscheid 1988, 78.

1889 Vgl. Schweizer 1927, 62; Simon-Muscheid 1988, 83.

1890 Vgl. Schweizer 1927, 70; Simon-Muscheid 1988, 84.

1891 StABS, St. Urk. 96 (17.05.1294). Vgl. Urkundenbuch der Stadt Basel 1896, Bd. 3, 93 f., Nr. 168. Vgl. Schweizer 1927, 13; Kälin 1974, 172.

1892 StABS, St. Urk. 114 (10.11.1304). Vgl. Schweizer 1927, 23; Kälin 1974, 172, und die Transkription der Urkunde ebd., 333. 
setzungen mit den dortigen Teichanrainern führte. ${ }^{1893}$ Auch im Jahr 1408 wurde das Vorrecht des Allenwindenmüllers auf den ununterbrochenen Betrieb seines Mühlwerks ein weiteres Mal anerkannt. Allerdings musste er den Wasserzulauf mit der gegenüberliegenden Sägemühle teilen, der ein Recht auf das halbe Wasser zugesprochen wurde. ${ }^{1894}$

Handelt es sich hierbei um Rechte an der Wassernutzung, so betrifft die erste erhaltene Urkunde, welche die Allenwindenmühle als Papiermühle bezeichnet, einen Zwist um die Pflichten, die die Teichnutzung mit sich brachte. Der Besitzer der Papiermühle und der gegenüberliegenden Säge, Heinrich Halbysen d. Ä., klagte im Jahr 1440 gegen das Kloster St. Clara, den Schultheißen Dietrich von Sennheim und weitere Teichanrainer. ${ }^{1895}$ Streitpunkt war die Räumung des Teichs, an der sich die anderen Teichanlieger nicht beteiligen wollten, obwohl ein Großteil des Schutts, unter anderem Steine, von ihren Grundstücken stammte. Zudem beschwerte sich Heinrich Halbysen darüber, dass man das ausgeräumte Material nicht, wie es eigentlich verabredet war, auf der Teichböschung bei den Liegenschaften der anderen Teichanlieger ablegen konnte. Diese waren nämlich mit der Umzäunung ihrer Grundstücke bis zum Teichufer vorgerückt, sodass kein Platz für die Ablagerung des Schutts blieb, dieser wieder in den Teich zurückfiel und were also kosten und erbeit verloren. ${ }^{1896}$ Die Fünf vom Baugericht urteilten in dieser Streitsache differenziert. Heinrich Halbysen musste den Teich bei seinen Lehen auf eigene Kosten räumen, wobei er den Schutt zur einen Hälfte bei den Gütern der Gegenpartei und zur anderen Hälfte auf der Allmende abladen durfte. Die anderen Teichanrainer waren dazu angehalten, ihre Zäune in mindestens 5 Fuß Entfernung zum Teichufer zu setzen. Auch mussten sie den Teichabschnitt räumen, an den ihre Liegenschaften grenzten. Des Weiteren wurde bei Strafe verboten, Steine und anderes in den Teich zu werfen.

Auch die Leheninhaber am Rümelinbach waren zu einer Korporation zusammengeschlossen und auch sie versuchten, ihre Rechte auf Wassernutzung gegen andere Nutzungsberechtigte zu verteidigen. ${ }^{1897}$ Im Jahr 1459, als Anton Gallician die Bluwenmühle am Rümelinbach bereits längst wieder verkauft hatte, erhielten sie eine vom Baugericht der Fünf statuierte Wasserordnung. Diese Ordnung sah die Wahl von zwei Wassermeistern vor, deren Aufgaben und Kompetenzen - ähnlich wie die der Wassermeister am Kleinbasler Teich - die Kontrolle von Teich und Wehr, das Heranziehen der Lehengenossen zu Reparaturarbeiten sowie die Aufsicht über das alljährlich zu Pfingsten stattfindende Ablassen des Teichs umfassten. ${ }^{1898}$

1893 Vgl. Schweizer 1927, 24.

1894 StABS, St. Urk. 877 (21.11.1408). Vgl. Kälin 1974, 172; für eine Transkription der Urkunde vgl. ebd., 334-336.

1895 StABS, St. Urk. 1233 (22.05.1440). Vgl. Kälin 1974, 146, 170 f.

1896 StABS, St. Urk. 1233 (22.05.1440).

1897 Vgl. Schweizer 1921, 49-57; Simon-Muscheid 1988, 79-82.

1898 Vgl. Schweizer 1922, 254; Simon-Muscheid 1988, 80. 
Ausführlicher als der Kleinbasler Gewerbekanal und der Rümelinbach soll aufgrund seiner Bedeutung für das Basler Papiergewerbe der St. Albanteich betrachtet werden. Als Quellengrundlage dient herfür vor allem ein zwischen 1505 und 1509 angefertigtes Kopialbuch, in dem die als am wichtigsten erachteten Urkunden zusammengestellt wurden. ${ }^{1899}$ Manche dieser Dokumente sind im Original erhalten. Neben einzelnen Streitfällen wurde für die folgende Darstellung hauptsächlich die sogenannte Teichordnung aus dem Jahr 1477 herangezogen. ${ }^{1900}$ Sie gibt durch ihren normativen Charakter nicht nur einen Einblick in die „ideale“ Lehengemeinschaft, sondern zeigt auch die Situationen auf, die Konfliktpotential bargen und damit überhaupt der Regulierung bedurften.

Das Recht, das Wasser aus der Birs in einen Gewerbekanal abzuleiten, wurde dem Kloster St. Alban bereits im 12. Jahrhundert verbrieft und im 15. Jahrhundert im Urteilspruch zur Auseinandersetzung mit dem Grafen von Thierstein um das Wehr bestätigt. ${ }^{1901}$ Die Situation innerhalb des St. Albantals war geprägt durch die Gemeinschaft der zwölf Mühlenlehen, die einen Sonderstatus innerhalb der St. Albanvorstadt einnahm. Die zwölf Lehen, in deren gemeinsamen Besitz sich die Herrenmatten und die Hanfbünde befanden, ${ }^{1902}$ bildeten auf der Grundlage der gemeinsamen Wassernutzung eine Korporation mit gemeinsamen Rechten und Pflichten, wie es auch bei den beiden anderen Gewerbekanälen der Fall war. ${ }^{1903}$ So waren die Leheninhaber dazu angehalten, sich gegenseitig zu helfen, damit die Lehen in gutem Zustand blieben, gleich ob der Teich und seine Instandhaltung oder die anderen gemeinsamen Güter wie Acker und Matten betroffen waren. ${ }^{1904}$ Dem Propst und dem Kloster St. Alban gegenüber waren die Mühlenbesitzer verpflichtet, den nutz noch aller vermüglichkeit zu fürdern unnd schaden zu wenden. ${ }^{1905}$ Im Gegenzug konnten sie auf die Hilfe und den Beistand des Propsts zählen. ${ }^{1906}$ Bei der Übernahme eines Lehens musste der neue Meister gegenüber dem Kloster, dem Prior und der Lehengemeinschaft einen Eid schwören. Dieser enthielt unter anderem die Zusicherung von Gehorsam und die unbedingte Wahrnehmung aller in den Teichordnungen festgelegten Pflichten. ${ }^{1907}$

1899 StABS, Teichkorporationen, St. Alban A1.

1900 StABS, Teichkorporationen, St. Alban A1, 33v-44r.

1901 Vgl. Schweizer 1923, 13-16.

1902 Vgl. Kapitel 3.2.2.1, S. 251 f.

1903 Die Rechte der Leheninhaber auf Nutzung des Wassers betraf nicht nur die Energiegewinnung, sondern erstreckte sich auch auf den Fischfang, StABS, Teichkorporationen, St. Alban A1, 37r-37v, 40v-41r.

1904 StABS, Teichkorporationen, St. Alban A1, 37r.

1905 StABS, Teichkorporationen, St. Alban A1, 41v.

1906 StABS, Teichkorporationen, St. Alban A1, 41r-41v.

1907 StABS, Teichkorporationen, St. Alban A1, 41v: schwerenn eynen eyde, mit gelertten wortten und uff gehepten fingern, dem gotzhuse, eynem probste, den gemeynen lehenen das beste ze thün, gehörig 
$\mathrm{Zu}$ diesen Pflichten gehörte die Teilnahme am Lehengericht, das der Propst in Streitfällen zwischen den Leheninhabern einberief. ${ }^{1908}$ Die Mühlenbesitzer waren verpflichtet, jedweden Streit zwischen den Lehen ausschließlich vor dem Propst zu St. Alban zu verhandeln und sich nicht an den Offizial des Basler Bistums, das Baugericht oder das Schultheißengericht der Stadt Basel zu wenden. ${ }^{1909}$ Dieses Recht wurde dem Propst im Jahr 1473 erneut zugesichert ${ }^{1910}$ und in der Teichordnung von 1477 bekräftigt. ${ }^{1911}$ Bei Zuwiderhandlung gegen diese alleinige gerichtliche Zuständigkeit sowie bei Vernachlässigung der Teilnahmepflicht am Gericht konnte der Propst eine Strafe nach seinem Ermessen erheben. ${ }^{1912}$ Zwistigkeiten der Lehenmeister mit anderen Streitparteien wurden hingegen meist vor Bürgermeister und Rat der Stadt Basel oder vor dem Baugericht ausgetragen, da das Kloster St. Alban im Jahr 1383 die niedere Gerichtsbarkeit der Stadt Basel übergeben hatte und seither nur noch den Vorsitz über das Lehengericht für sich beanspruchen konnte. ${ }^{1913}$ Vertrat anfangs noch der Propst von St. Alban die Interessen der Leheninhaber vor den städtischen Ämtern, so entwickelte die Lehengemeinschaft im Laufe des 15. Jahrhunderts Eigenständigkeit und verhandelten ohne Unterstützung des Propsts über ihre Rechte. ${ }^{1914}$

Die Lehenkorporation verfügte über zwei Ämter, die ihren genossenschaftlichen Charakter unterstrichen: das Amt der Büchsenmeister und das Amt der Wassermeister. Für das Amt der Büchsenmeister wählten die Leheninhaber mit Wissen und Willen des Propsts aus ihrer Mitte jährlich zwei Meister, einer von den vorderen und einer von den hinteren Lehen. ${ }^{1915}$ Die gewählten Meister mussten die Wahl annehmen. Die Aufgabe der Büchsenmeister war es, alle Abgaben, aber auch Bußen und Strafgelder, die von den Lehen stammten, einzuziehen und in der Büchse zu verwahren. Diese gemeinsame Kasse diente zur Erhaltung des Kanals und des Wehrs. So konnten aus ihr Baumaterialien, aber auch Arbeitskräfte bezahlt werden. ${ }^{1916}$ Am Johannistag legten die alten Büchsenmeister vor dem Propst und der Lehengemeinschaft Rechnung ab und führten an, wofür das eingenommene Geld verwendet wurde. Zudem wurden die neuen Büchsenmeister gewählt. ${ }^{1917}$ In der Teichordnung von 1477 wurde

unnd gehorsam ze sin, die botte so denn beschehenn von eynem propst, den wassermeistern und sust von den anderen meystern von nottwegen der lehenn oder sust nit verschmahen noch verachten.

1908 StABS, Teichkorporationen, St. Alban A1, 38r. Vgl. Schweizer 1923, 37; Gilomen 1977, 107 f.

1909 StABS, Teichkorporationen, St. Alban A1, 37v.

1910 StABS, Teichkorporationen, St. Alban, Urk. 12 (16.07.1473). Vgl. auch Urkundenbuch der Stadt Basel 1901, Bd. 8, 344-346, Nr. 439, allerdings mit einem Tippfehler bei der Jahreszahl: Statt 1473 steht beim Regest 1475 .

1911 StABS, Teichkorporationen, St. Alban A1, 37v.

1912 StABS, Teichkorporationen, St. Alban A1, 37v.

1913 Vgl. Schweizer 1923, 37 f.; Gilomen 1977, 103-108.

1914 Vgl. Schweizer 1923, 37.

1915 Zur Ordnung des Büchsenmeisteramts vgl. StABS, Teichkorporationen, St. Alban A1, 34r-35r.

1916 Vgl. Schweizer 1923, 47.

1917 StABS, Teichkorporationen, St. Alban A1, 34v. 
zudem festgelegt, dass arckwones halben der eine Büchsenmeister die Kasse, der andere jedoch den Schlüssel dazu verwahren solle. ${ }^{1918}$

Waren die Büchsenmeister gewissermaßen die Kassenwarte der Korporation, so fiel es wie beim Kleinbasler Teich und beim Rümelinbach in den Zuständigkeitsbereich der beiden Wassermeister, über den Zustand der Lehen und des Teichs zu wachen. ${ }^{1919}$ Sie wurden vierteljährlich an allen Fronfasten ${ }^{1920}$ durch die meysterschafft, ${ }^{1921}$ das heißt die Gemeinschaft aller Leheninhaber, gewählt. Zu ihren Aufgaben gehörte die regelmäßige Kontrolle des Teichs und des Wehrs. Diesen Wartungsaufgaben hatten die Wassermeister mit großer Sorgfältigkeit nachzukommen. Wenn die Lehen Schaden erlitten, konnte der Propst die Säumigen strafen, allerdings lagen Art und Maß der Strafe im Ermessen der anderen Leheninhaber. ${ }^{1922}$ Entdeckten die Wassermeister einen Schaden, riefen sie die anderen Meister herbei, die dazu angehalten waren, bei der Reparatur entweder in eigener Person oder vertreten durch einen arbeitstüchtigen Knecht zu helfen. ${ }^{1923}$ Kamen die Lehenbesitzer dieser Pflicht nicht nach, mussten sie eine Strafe zahlen. ${ }^{1924}$ Damit kein Mühlenbesitzer Unwissen vorschützen konnte, sollte der sogenannte gemeine Knecht, der die Wassermeister unterstützte, von Haus zu Haus gehen und die Einberufung seitens der Wassermeister verkünden. ${ }^{1925} \mathrm{Ihm}$ oblag es auch, jeden Tag den Teich und das Wehr zu kontrollieren und etwaige Schäden sofort den Wassermeistern zu melden. Wenn er eine Person entdeckte, die den Teich oder die gemeinsamen Lehen beschädigte, so musste diese Person 5 Schilling Strafe zahlen. ${ }^{1926}$ Die Befugnisse der Wassermeister wurden durch den Anspruch des Propsts auf die Grundherrschaft und durch den genossenschaftlichen Charakter der Lehengemeinschaft jedoch deutlich beschnitten. So durften sie den Teich nicht ohne Wissen und Einwilligung des Priors sowie einen gemeinsamen Beschluss aller Leheninhaber ablassen. ${ }^{1927}$

Vermutlich für die 1470er-Jahre existiert eine konkrete Aufstellung der Wassermeisterpaare. ${ }^{1928}$ Sie zeigt, dass die ein Mühlenlehen innehabenden Papiermacher

1918 StABS, Teichkorporationen, St. Alban A1, 35r. Vgl. Schweizer 1923, 47.

1919 StABS, Teichkorporationen, St. Alban A1, 35r: Item so denn darnoch ordnen wir unnser ernstliche meynung desshalb das die lehen in gütten eren gehalten werden das die meysterschafft gemeynlichen uff den lehenen sollen zu allen und yeglichen fronfasten zwen under inen erwelen setzen und ordnen zu dem wasser die do geheissen sint die wassermeister.

1920 Vgl. Anm. 1690.

1921 StABS, Teichkorporationen, St. Alban A1, 35r.

1922 StABS, Teichkorporationen, St. Alban A1, 36v.

1923 StABS, Teichkorporationen, St. Alban A1, 36r.

1924 StABS, Teichkorporationen, St. Alban A1, 36r.

1925 StABS, Teichkorporationen, St. Alban A1, 36v-37r.

1926 StABS, Teichkorporationen, St. Alban A1, 43v-44r.

1927 StABS, Teichkorporationen, St. Alban A1, 39v.

1928 Das Original dieser Abschrift wird in dem Ordnungenbuch A 1 auf circa 1460 datiert. Wie bereits Eduard Schweizer richtig anmerkt, kann diese Datierung nicht stimmen, da Ulrich Züricher die Zun- 
ebenso in die Gemeinschaft eingebunden waren wie die Müller und die Metallhandwerker. $\mathrm{Zu}$ dieser Zeit befanden sich vier der zwölf Lehen in der Hand von insgesamt drei Papierern: Anton Gallician besaß mit der Klingentalmühle und der Stegreifmühle zwei Wasserwerke, sein Bruder Michel Gallician war Inhaber der Rychmühle und Ulrich Züricher betrieb die gegenüberliegende Zunzigermühle. Durch das Rotationsprinzip, bei dem zu jeden Fronfasten das vorhergehende Wassermeisterpaar durch das nächste bereits festgelegte abgelöst wurde, ${ }^{1929}$ besetzten Papiermacher zwei Drittel der Zeit das Amt eines Wassermeisters. Anton Gallician amtierte sogar zweimal hintereinander, da er zwei Lehen innehatte (vgl. Tab. 12).

Tab. 12: Wassermeisterpaare im St. Albantal, vermutlich in den 1470er-Jahren (Quelle: StABS, Teichkorporationen, St. Alban A 1, 59v).

\begin{tabular}{|c|c|c|}
\hline & Vorderer Teich & Hinterer Teich \\
\hline 1. & $\begin{array}{l}\text { Müller } \\
\text { Spitalmühle, St. Albantal } 4\end{array}$ & Hintere Schleife, St. Albantal 23 \\
\hline 2. & $\begin{array}{l}\text { Drahtzieher } \\
\text { Vordere Schleife, Mühlenberg } 24\end{array}$ & $\begin{array}{l}\text { Anton Gallician, Papiermacher } \\
\text { Klingentalmühle, St. Albantal } 37\end{array}$ \\
\hline 3. & $\begin{array}{l}\text { Ullin Oberdorff, Müller } \\
\text { Vordere Spiegelmühle, St. Albainkirchrain } 14\end{array}$ & $\begin{array}{l}\text { Anton Gallician, Papiermacher } \\
\text { Stegreifmühle, St. Albantal } 35\end{array}$ \\
\hline 4. & $\begin{array}{l}\text { Hans Krafft, Schleifer } \\
\text { Spisselismühle, Mühlenberg 19/21 }\end{array}$ & $\begin{array}{l}\text { Michel Gallician, Papiermacher } \\
\text { Rychmühle, St. Albantal } 41\end{array}$ \\
\hline 5. & $\begin{array}{l}\text { Erben v. Peter Cuntz, Müller } \\
\text { Spittelmüllersmühle, St. Albantal } 2\end{array}$ & $\begin{array}{l}\text { Ulrich Züricher, Papiermacher } \\
\text { Zunzigermühle, St. Albantal } 39\end{array}$ \\
\hline 6. & $\begin{array}{l}\text { Alban Leimer, Müller } \\
\text { Leimermühle, St. Albantal } 1\end{array}$ & $\begin{array}{l}\text { Heini Cuntz, Müller } \\
\text { hintere Spiegelmühle, St. Albantal 25/31 }\end{array}$ \\
\hline
\end{tabular}

Die bisher beschriebenen Artikel der Teichordnung von 1477 bilden die Rechtsverhältnisse innerhalb der Lehengemeinschaft ab. Weitere Regelungen betreffen die oft spannungsreiche Beziehung zu anderen Teichnutzern. Beim St. Albanteich handelte

\footnotetext{
zigermühle erst 1470 erwarb. Michel Gallician kaufte die Rychmühle ebenfalls erst 1467 von Heinrich Halbysen d. J. Unsicher scheint eine Datierung in die 1470er-Jahre hinsichtlich Anton Gallician. Er ist eigentlich erst ab 1482 als Besitzer seiner zweiten Papiermühle, der Stegreifmühle, fassbar. Da aber wiederum der Müller Ullin Oberdorff sein Lehen nur bis zum Jahr 1476 innehatte, könnte der Kauf der Stegreifmühle durch Anton Gallician bereits einige Jahre vor 1482 erfolgt sein. Vgl. Schweizer 1923, 47 mit Anm. 78.

1929 StABS, Teichkorporationen, St. Alban A1, 59v: Also sollen zu yeder fronfasten ye die zwen so zu sammen geordnet sint eyner uff den hinderen der ander uf den fordern lechen wassermeister sin nach und nach.
} 
es sich vor allem um die Flößer, die Holz aus dem Jura die Birs flussabwärts und durch den Gewerbekanal zu den im St. Albantal gelegenen Schindelhöfen flößten. ${ }^{1930}$ Die städtischen Schindelhöfe dienten nicht nur als Arbeitsstätte der Schindler, die die für den Hausbau benötigten Dachschindeln herstellten, sondern gleichfalls als Annahme- und Lagerplatz für das gesamte in Basel benötigte Holz. ${ }^{1931}$ Die Flößer sowie die Schindler stellten folglich neben den Mühlwerken die wichtigste Nutzergruppe des St. Albanteichs dar. Konflikte zwischen Leheninhabern und Flößern entstanden hauptsächlich wegen der Beschädigung der Teichwände durch die daran stoßenden Hölzer oder wegen des zu langen Verbleibs der Hölzer im Wasser, die den Teich oberhalb der Mühlen stauten und somit die Wasserzufuhr auf die Mühlräder behinderten. Um den Schaden für die Mühlwerke durch das geflößte Holz so gering wie möglich zu halten, durften die Flößer ihr Gewerbe im St. Albanteich nur während einer Stunde wöchentlich ausüben, nämlich samstags zur Vesperzeit. ${ }^{1932}$

Zudem mussten die Flößer als Beitrag zu den Instandhaltungskosten an Teich und Wehr Abgaben an die Leheninhaber entrichten, die sich nach der Größe und Art des Holzes richteten. ${ }^{1933}$ Diese Abgaben sammelten die Büchsenmeister zum Gemeinnutz der Mühlenlehen. ${ }^{1934}$ Beschädigten ungebundene Hölzer den Teich, so mussten die Flößer eine Strafe zahlen. ${ }^{1935}$ Auch der Verbleib des Holzes im Wasser wurde geregelt. Ein Urteilsspruch von Bürgermeister und Rat der Stadt Basel aus dem Jahr 1442 in Bezug auf eine Klage des Propsts zu St. Alban besagte, dass das Holz innerhalb von vier Tagen aus dem Wasser entfernt werden müsse. ${ }^{1936}$ Erstaunlicherweise wurde diese Zeitspanne in einem weiteren Entscheid der Stadt Basel aus dem Jahr 1449 beachtlich ausgedehnt: Bauholz durfte nun einen Monat, Brennholz vierzehn Tage und kleine Flöße acht Tage im Wasser verbleiben, bevor eine Strafe erhoben wurde. ${ }^{1937}$ In der Teichordnung von 1477 finden sich diese verlängerten Fristen wieder. Zudem enthielt die neue Ordnung einen Artikel, der dem Prior und den Leheninhabern das Vorkaufsrecht auf Brennholz zubilligte. ${ }^{1938}$

1930 Vgl. Schweizer 1923, 16; Simon-Muscheid 1988, 82.

1931 Vgl. Baur/Nagel 2009, 14.

1932 Dies wurde in einer Urkunde vom 14.07 .1301 festgelegt, deren Inhalt jedoch nur noch in einem Vidimus aus dem Jahr 1432 erhalten ist, StABS, St. Urk. 1113 (08.05.1432). Eine weitere Urkunde, die auf das Jahr 1221 datiert, jedoch eine Fälschung aus dem 15. Jahrhundert ist, seit dieser Zeit aber als rechtskräftig gilt, enthält dieselben Bestimmungen hinsichtlich der Flößerei, vgl. Urkundenbuch der Stadt Basel 1890, Bd. 1, 67-72, Nr. 100. Vgl. Schweizer 1923, 14-16, 18.

1933 Vgl. Schweizer 1923, $17 \mathrm{f}$.

1934 StABS, Teichkorporationen, St. Alban A1, 42r.

1935 StABS, Teichkorporationen, St. Alban A1, 42v.

1936 StABS, Teichkorporationen, St. Alban A1, 50v-54r, bes. 53r. Vgl. Schweizer 1923, 17.

1937 StABS, Teichkorporationen, St. Alban A1, 54v-55v. Vgl. Schweizer 1923, 18.

1938 StABS, Teichkorporationen, St. Alban A1, 43r. Ein weiterer Rechtsstreit mit den Schindlern - in der Zeit vor der Aufnahme der Papierproduktion - betraf die Pfähle an der Floßlandungsstelle, StABS, Teichkorporationen, St. Alban, Urk. 7 (07.10.1434); A 1, 48r-50r. Vgl. Schweizer 1923, 51. 
In den erhaltenen Zeugnissen, die einen Wasserrechtsstreit verhandeln oder die Teichbenutzung im St. Albantal regeln, treten die Mühlenbesitzer gemeinsam als Lehenkorporation auf. Daher können an dieser Stelle keine Quellen angeführt werden, die den Streit eines Papiermachers mit einer anderen Partei betreffen. Spezifische Probleme, die durch die einzelnen Handwerke auf den Mühlenlehen hervorgerufen werden konnten, wurden bislang in keiner Quelle angetroffen. Dennoch wurden in den Dokumenten der Teichgenossenschaft Papierer genannt. Diese Erwähnungen, die zumeist bei der Aufführung der Streitparteien geschehen, sind entweder allgemeiner, entpersonalisierter Natur oder beziehen sich auf namentlich genannte Papiermacher. ${ }^{1939}$

In der Teichordnung von 1477 werden die Meister auf den Lehen sowohl in einer generalisierten als auch in einer personalisierten Aufzählung angeführt. Der Propst von St. Alban erließ die Ordnung für die Müller, Papiermacher, Drahtmacher und Schleifer auf den zwölf Lehen. ${ }^{1940}$ Die Auflistung der Berufe ist vermutlich nach der numerischen Stärke der Betriebe erfolgt, denn zu diesem Zeitpunkt arbeiteten am St. Albanteich tatsächlich mehr Papiermühlen als Schleifen. Interessanterweise wurden bei der namentlichen Aufzählung der Lehenmeister die drei Papiermacher als erstes genannt, danach folgten die beiden Schleifer und anschließend der Drahtmacher und die Müller. ${ }^{1941}$

Beim Urteil über die richterliche Gewalt des Propsts gegenüber den Leheninhabern aus dem Jahr 1473 fungierten nicht alle zwölf Lehennehmer als Zeugen. Vielmehr wurden nur fünf Mühlenbesitzer vorgeladen. Neben einem Müller und einem Schleifer waren darunter auch die drei Papiermacher, die zu dieser Zeit ein Mühlwerk am St. Albanteich besaßen, namentlich Anton und Michel Gallician sowie Ulrich Züricher. ${ }^{1942}$ Damit stellten die Papiermacher über die Hälfte der Zeugen, obwohl sie sich den Platz der stärkste Berufsgruppe mit den Müller teilte. Ob die Besetzung der Zeugenschaft auf eine besondere Wertschätzung des Propsts für die betreffenden Papiermacher zurückzuführen ist, muss eine Hypothese bleiben. In der allgemeinen Aufzählung der Handwerke, die auf den Lehen sitzen, erscheinen die Papiermacher

1939 Auf die vielleicht etwas zu intensive Lektüre dieser Quellen durch früherer Papiergeschichtsforscher lassen spezifische Benutzungsspuren schließen: In manchen Dokumenten sind die Namen der Papiermacher mit Kugelschreiber unterstrichen und somit von den anderen Leheninhabern abgehoben, StABS, Teichkorporationen, St. Alban A 1, 22v, 33v; Urk. 12 (16.07.1473).

1940 StABS, Teichkorporationen, St. Alban A 1, 33v: den ersamen erberen meistern den mulleren, bappier macheren, trottmachern und schliffern uff den zwölff lehenen.

1941 StABS, Teichkorporationen, St. Alban, A 1, 34r: und sint disse die meister die by dieser ernuwerung der genanten ordenung sint gewesen Meister Anthonii Galicion, Meister Michel Galicion, Meister Ulrich Züricher, Meister Hanns Krafft, Meyster Hans Löwenberg, der allt Grünenstein, Meister Berchtold der trottmacher, Hans Cuntz, Hanns Brotbeck, Alban Leymer unnd andere.

1942 StABS, Teichkorporationen, St. Alban, Urk. 12 (16.07.1473). Vgl. Urkundenbuch der Stadt Basel 1901, Bd. 8, 345 f., Nr. 439. 
in der Urkunde von 1473 wieder direkt hinter den Müllern und vor den Schleifern. ${ }^{1943}$ Auch in einem weiteren Brief vom August desselben Jahres, der die Rechte der Vorstadtämter in St. Alban betrifft, erscheinen die drei Papiermacher Anton und Michel Gallician sowie Ulrich Züricher als Zeugen. ${ }^{1944}$ In der Bestätigung dieser Urkunde vom November 1473 werden allerdings nur Michel Gallician und Ulrich Züricher als Zeugen aufgeführt. ${ }^{1945}$ Dieses selbstverständliche Einbeziehen der Papierermeister und ihres Handwerks zeigt, dass die Papiermacherei in den 1470er-Jahren vollständig und in Bezug zu den anderen Handwerken gleichberechtigt etabliert war.

\subsubsection{Ravensburg, Söflingen und Straßburg}

Eine umfassende Wasserordnung, wie sie für den St. Albanteich existierte, konnte für die anderen südwestdeutschen Papiermühlenstandorte nicht ausgemacht werden. Hingegen ist es gerade für die Ravensburger Überlieferung erstaunlich, dass viele Quellen, aus denen wir überhaupt Informationen zu den Papiermühlen gewinnen können, Wasserrechte und Wasserrechtstreitigkeiten behandeln. ${ }^{1946}$ So wurden beim Verkauf oder bei der Verleihung einer Liegenschaft im Ölschwang oder in Schornreute häufig die dazugehörigen Rechte an der Wassernutzung, aber auch die Pflichten zur Erhaltung des Wasserlaufs beschrieben. Gerade die Nutzungsrechte zeigen dabei, dass die Wassernutzung mehreren Anliegern zustand und daher immer Rücksicht auf ältere Rechte genommen werden musste. Als Anna Holbain die stampfes mülin genannte Mühle im Jahr 1410 an Jos und Haintz Segelbach verlieh, durften diese zum Betrieb des Mühlwerks das Wasser des Flappachs nach Bedarf nutzen, allerdings mit der Bestimmung, dass eine unterhalb gelegene Mühle sowie eine Walke nicht beeinträchtigt werden. ${ }^{1947}$ Zudem hatte eine ebenfalls vom Flappach betriebene Schleifmühle das Recht, das Wasser an einem Tag in der Woche auf ihre Räder zu leiten und zu schleifen. ${ }^{1948}$

Dieses Recht mag für den Besitzer der Papierhäuser bereits ein Zugeständnis gewesen sein, für den Betreiber der Schleifmühle stellte es eine starke Einschränkung seiner Arbeit dar. Gegen die Beschränkung der Wassernutzung auf nur einen Tag in der Woche klagte daher rund 22 Jahre später - im Jahr 1432 - der Spitalmeister im Namen des Spitals, dem die Schleifmühle zu dieser Zeit gehörte. Der Besit-

1943 StABS, Teichkorporationen, St. Alban, Urk. 12. Vgl. Urkundenbuch der Stadt Basel 1901, Bd. 8, 345 f., Nr. 439.

1944 StABS, Teichkorporationen, St. Alban A 1, 16v. Vgl. Urkundenbuch der Stadt Basel 1901, Bd. 8, 348, Nr. 441.

1945 StABS, Teichkorporationen, St. Alban A 1, 22v. Vgl. Urkundenbuch der Stadt Basel 1901, Bd. 8, 357, Nr. 448.

1946 Vgl. Schultz/Follmer 2015, $14 \mathrm{f}$.

1947 StR, Urk. 756 (20.05.1410). Vgl. Alfred Schulte 1953, 15-17.

1948 StR, Urk. 756 (20.05.1410): [...] daz die schlifymülin all wochen einen tag sel schliffen und daz wasser darzů bruchen als von alter her ist komen ungevarlich [...]. 
zer der Papierhäuser, Heinrich Gelderich, lasse den vom Spital eingesetzten Pächter, einen Messerschmied, nur an einem Tag in der Woche, nämlich am Freitag, schleifen, obwohl es früher üblich gewesen sei, dass die Schleifmühle das Wasser nach Bedarf nutzen konnte. Auf diesen Vorwurf entgegnete Gelderich, dass die Schleifmühle bislang immer nur das Anrecht auf einen Tag Wassernutzung gehabt habe und dass jede darüberhinausgehende Benutzung der Zustimmung des Inhabers der Papierhäuser bedürfe. ${ }^{1949}$ In diesem Streitfall sprachen die eingeholten Beweise - Dokumente und Zeugenaussagen - für die Version von Heinrich Gelderich, sodass das Ravensburger Gericht das bloß eintägige Nutzungsrecht der Schleifmühle bestätigte. ${ }^{1950}$

Die Einschränkung der eigenen Nutzungsrechte zugunsten der Anrechte anderen Bachanrainer ist ebenfalls Gegenstand weiterer Verkaufs- oder Verleihungsurkunden. Im Jahr 1413 verpachtete Anna Holbain einen Acker und einen Bifang - wohl ein eingefriedetes Feld ${ }^{1951}$ - beide oberhalb der Papierhäuser im Ölschwang gelegen, an die Weber Hans Fuchs und Cuntz Schlegel unter der Auflage, dass das Wasser weiterhin ungehindert zum Stampf der Papierhäuser fließen solle. ${ }^{1952}$ Im selben Jahr verlieh die Holbainin, die anscheinend über einen ausgedehnten Besitz im Ölschwang verfügte, einen Bifang bei ihrem Haus an eine Gemeinschaft von sechs Personen. Diese hatten das Recht, Wasser und Wasserlauf für ihre Bedürfnisse zu nutzen. Während der Zugriff auf das Wasser uneingeschränkt blieb, galt für die Nutzung des Wasserlaufs als Antriebskraft, dass dieser nur genutzt werden durfte, wenn die Mühlen und Papierhäuser das Wasser nicht bräuchten, das hieß in den vier Nächten, in denen nicht gemahlen und nicht gestampft wurde. ${ }^{1953}$ Bereits im darauffolgenden Jahr verlieh Anna Holbain den Bifang unter denselben Bedingungen an die Stadt Ravensburg. ${ }^{1954}$ Ob sich die Zeitangabe von vier Nächten, in denen diese Werke nicht arbeiteten, auf die Woche oder auf den Monat bezieht, geht leider aus den beiden Quellen

1949 SpR, Urk. 4220 (01.09.1432): Dawider redt Hainrich Gäldrich mit sinem fürsprechen Clausen Stouß er hett nit me rechts da ze schlifen denn ainen tag in der wochen uff den frytag er tätt denn das mit sinem willen.

1950 SpR, Urk. 4220 (01.09.1432): Also wurden nu darumb brief und lut verhört. Nach ir sag so ist ertailt also das der messerschmid oder wer die schliffi inn haut nit me denn ain tag in der wochen da schliffen sol mit namen uff den frittag.

1951 Vgl. Grimm/Grimm 1860, Bd. 2, 8.

1952 StR, Urk. 759 (28.08.1413): Ouch ist geredt $d z$ wir und unß nachkomen Segelbachs kinden oder wer denn die bappir hüser inn hat $d z$ wasser durch ir wis aben sond gan lassen uff sin stempf als dz hut des tags da hin ab gat nach ir brief lut und sag ungevarlich. Vgl. Alfred Schulte 1953, $17 \mathrm{f}$.

1953 StR, Urk. 758 (04.07.1413): [...] das si all das wasser ußer dem bach nacht und tag haben sond so vil als die blaichi von alter her gehebt hat dar zů mügen si niessen den bach über al ze den ziten so das den müllinen und den pappir hüssern nit schaden bringet das ist an den für nächten so man nit stampfet noch meldt [...] Vgl. Alfred Schulte 1953, 17.

1954 StR, Urk. 716 (06.12.1414); Urk. 717 (14.12.1414). Vgl. Alfred Schulte 1953, 18. 
nicht hervor. Generell war es üblich, dass das Stampfgeschirr Tag und Nacht in Betrieb war, da die Lumpenaufbereitung insgesamt ein bis zwei Tage in Anspruch nahm. ${ }^{1955}$

Streit entstand zumeist, weil eine oder gar beide der Streitparteien sich in ihren Nutzungsrechten beschnitten oder zumindest benachteiligt sahen. Im Jahr 1406 verhandelte die Stadt Ravensburg eine Streitsache zwischen Frik Luprecht und Meister Dietrich dem Papierer auf der einen und den Müllern Bentz Rusch und Cuntz Rottacher auf der anderen Seite. Gegenstand der Auseinandersetzung war die Erhaltung des Bachrains, für die laut Frik Luprecht und seinem Mitkläger die beiden Müller verantwortlich waren, da es seit jeher zu den Pflichten der Besitzer der Rottacher Mühle gehört habe, den Rain in gutem Zustand zu erhalten. Nun habe der Bach das Ufer teilweise weggespült, sodass der Weg zu Luprechts Mühle nicht mehr nutzbar sei. ${ }^{1956}$ Die Instandsetzung liege bei Bentz Rusch und Cuntz Rottacher. Die Müller erwiderten jedoch, dass sie in den 16 Jahren, in denen sie Besitzer der Mühle waren, noch nie etwas von dieser Pflicht vernommen hätten. Das Urteil wurde zu Gunsten von Frik Luprecht und Meister Dietrich gesprochen und verpflichtete die Müller, den Rain zu befestigen, sodass man den Weg zur Mühle der Kläger gefahrlos benutzen könne. ${ }^{1957}$

Ebenfalls Streitigkeiten um die Bachbefestigung standen 1424 im Mittelpunkt der Auseinandersetzung zwischen Heinrich Gelderich als Besitzer der Papierhäuser und Anna Holbain. Letztere hatte anscheinend eine Dole - wohl ein Abzugsgraben oder eine Wasserrinne - anlegen lassen, die den Bachrain bei Gelderichs Haus unpassierbar machte. ${ }^{1958}$ Zudem - und hieran wird ein weiterer gängiger Streitpunkt zwischen Bachanrainern deutlich - hatte die Holbainin oberhalb der Papierhäuser einen Brunnen graben lassen und das Wasser zu ihrem Haus umgeleitet. Gelderich sah sich hierbei in seinen Rechten beschnitten, da er als Inhaber der Papierhäuser einen exklusiven Anspruch auf die Wassernutzung für seine Räder und seinen Stampf habe. ${ }^{1959}$ Die Klage Gelderichs wurde abgewiesen.

Auch in weiteren Wasserrechtstreitigkeiten war Heinrich Gelderich kein Glück beschieden. Im Jahr 1432 klagte er gegen die Papiermacher Peter Bappirer, Cuntz Wolfartshofer und Hans Stengeli wegen der Einrichtung des neuen Papierhauses zu Schornreute. ${ }^{1960}$ Er befürchtete, dass ihm dadurch - im wahrsten Sinne des Worts

1955 Vgl. Kapitel 2.3.2.3, S. 87, 89 f. Vgl. auch Regensburger Mühlenordnung, in: Blanchet 1900, 92; Piccard 1967, 166.

1956 StR, Urk. 1208 (30.07.1406): [...] daz der bach im ölschwang der obnan von Luprechtz müli herab louft den rain gebrochen und geschlaipft hett daz man den weg nit wol gefaren noch buwen möchte. Vgl. Alfred Schulte 1953, 15.

1957 StR, Urk. 1208 (30.07.1406): [...] do wart ertailt daz die vorgenanten Bentz Rusch und Cuntz Rottacher oder wer denn des Rottachers müli jetz oder hernach innhat den rain versorgen sond daz man den weg zů Luprechtz müli hinuff wol und ane sorg gewandlen und gefaren mug. Vgl. Alfred Schulte 1953, 15. 1958 StR, Urk. 1214 (19.05.1424). Vgl. Alfred Schulte 1953, 19. 1959 StR, Urk. 1214 (19.05.1424). Vgl. Alfred Schulte 1953, 19. 1960 StR, Urk. 1216 (11.01.1432). Vgl. Alfred Schulte 1953, 20. 
- das Wasser zum Betreiben seines Stampfs abgegraben werde. Gelderich forderte daher, dass der Bau eingestellt werde. Allein ihm und den Müllern stehe das Nutzungsrecht $\mathrm{zu}$, da sie auch die Unterhaltspflicht hatten. ${ }^{1961}$ Die Stadt entschied hingegen, dass die drei Papierer das Recht hatten, das Papierhaus und die dazu notwendigen Wasseranlagen $\mathrm{zu}$ bauen, da ihnen das Grundstück und der dortige Wasserfall gehörten. Drei Jahre später wandte sich Heinrich Gelderich abermals an den Ravensburger Rat. In einer Urkunde vom 8. Juli 1435 beanstandete er erneut die baulichen Veränderungen, welche die drei Papiermacher am Bachbett vorgenommen hatten und die sich nachteilig auf die Wasserversorgung seines Papierhauses auswirkten. ${ }^{1962}$ Der Hauptstreitpunkt, der sich an einer von der Stadt gebauten Brücke entzündet hatte, die das Bachufer beschädigte, behandelte jedoch die Frage, ob die Stadt Ravensburg verpflichtet sei, das Bachbett des Flappachs zu unterhalten und bei Bedarf zu verstärken. Das Urteil sah prinzipiell vor, dass jeder, der den Wasserlauf für seine Zwecke nutzte, auch für die Instandhaltung desselbigen zuständig war. In diesem besonderen Fall allerdings sollte die Stadt einen Abschnitt des Bachs auf ihre Kosten sichern lassen. Das Recht, Änderungen am Bachbett vorzunehmen, fand 1436 in einem Revers der drei Papiermacher an die Stadt Ravensburg erneut Erwähnung. ${ }^{1963}$

Die Genehmigung, den Flappach zu begradigen und dazu auch städtischen Boden aufzugraben, erhielten im Jahr 1513 Hans Härb und Jörg Wolfartshofer. ${ }^{1964}$ Die beiden Papiermacher hatten die Papierhäuser im Ölschwang zuvor von Hans Wäch und Hans Schmid erworben und waren nun im Begriff, die an manchen Stellen baufällige Papiermühle wieder instand zu setzen. Gleichzeitig baten sie den Rat um Erlaubnis, dem Bach, der krumm und gebogen verlief, ein neues Bett zu graben und ihn darin schnurgerade zu führen. ${ }^{1965}$ Zudem verpflichteten sie sich, den Bachrain durch Pfähle zu verstärken und auch zukünftig für die Versorgung des Bachs aufzukommen.

1961 StR, Urk. 1216 (11.01.1432): [...] si sölten den buw underwegen laussen und nit vollbringen wan vormals von ainem raute wär gesprochen und erkennt worden das er und die andern müller die den bach bruchen wölten den bach da versorgen und machen sölten [...].

1962 StR, Urk. 1218 (08.07.1435): [...] ain ändrung getaun und den pappirern zů Schornrutin ettwz daran ze buwen verlihen und sunder inen gegunnen den bach usser dem alten ahruns ze füren und ze laitten das alles im merklichen bärlichen und verderblichen schaden brächte und gebraucht hette und mit namen das wasser durch sölichs erkelttet wurde, das uf diß jaur gemaine statt wol empfunden hette und darumb getruwete er got und dem rechten sy sölten nach herkomen gelegenhait und gestalt der sach und sunder nach der vorbegriffen geschrift ußwysung daran sin und sölichen buw abtün und widerrüfen damit der bach in sinem alten ahruns und in mauß als von altter herkomen wär flusse und gienge. Vgl. Alfred Schulte 1953, $20 \mathrm{f}$.

1963 StR, Urk. 723 (03.02.1436). Vgl. Alfred Schulte 1953, 21.

1964 StR, Urk. 690 (13.05.1513). Vgl. Alfred Schulte 1953, 23.

1965 StR, Urk. 690 (13.05.1513): [...] und den bach, der an ettlichen enden durch die hüser und entzwüschen krom und bogenwyß yetz lofft außwendig un nachst by und an den hůser der grede nach zůrichten füren und laiten unnd aber ain teil der statt Ravenspurg boden darzůnemen und abgraben müssen das 
Bauliche Eingriffe in den Wasserlauf, die das Betreiben einer Papiermühle ermöglichen oder verbessern sollten, wurden auch bei der Einrichtung der Straßburger Papiermühle im Rosengarten 1445 vorgenommen. Da hier anscheinend kein geeigneter Wasserfluss für die Räder des Werks vorhanden war, gestattete der Straßburger Rat Wilhelm de Altomonte, auf eigene Kosten einen neuen Kanal zu bauen. ${ }^{1966}$ Diesen künstlichen Wasserzufluss sollte er von der kleinen Aar, einem Nebenfluss der Aar, abzweigen. Da auf diese Weise der Viehweg durchschnitten wurde, sollte Wilhelm zugleich ebenfalls auf seine Kosten eine Brücke von zwei Karren Breite über den neu angelegten Kanal bauen. ${ }^{1967}$ Zudem war er dazu verpflichtet, den Weg vor Überschwemmung zu schützen. Die Stadt versprach im Gegenzug, für die Erhaltung der Brücke aufzukommen.

Gerade am Straßburger Beispiel wird deutlich, dass Bedenken hinsichtlich der Zerstörung des Bachbetts oder einer Schädigung der Mühlwerke durch die bauliche Veränderung des Flusslaufs, wie sie unter anderem Heinrich Gelderich in Ravensburg hegte, nicht von der Hand zu weisen waren. Im Jahr 1454, neun Jahre nach dem Bau des Kanals, verlangte der Straßburger Rat, dass der jetzige Besitzer Nicolas Heilmann die Mühle auf seine Kosten abbrechen und den Kanal beseitigen sollte, da dieser die städtischen Mühlen am Weißturmtor sowie die Stadtmauer durch sein Wasser beschädigt hatte. ${ }^{1968}$

Einen Wasserschaden hatte ebenfalls Krafft Schuchmacher zu beklagen, der Nachbar der Papiermühle zu Söflingen war. Laut seiner Aussage vor dem eingesetzten Schiedsgericht hatte der Neubau der Papiermühle die Überschwemmung seines Hauses und seines Gartens verursacht. Die Vertreter des Söflinger Klosters versuchten diesen Vorwurf zu entkräften und behaupteten, der Wasserlauf würde sein Haus überhaupt nicht fluten, sondern habe vor langer Zeit, noch vor dem Bau der Papier-

... burgermaister und rate der statt Ravenspurg ... zůgelassen haben, das wir den bach ob unnsern bappir hüsern nächst by dem unndern blaich brůggli darüber man in und auß der statt blaich feld ferdt anfahen und durch das obere stampf hüs loffen unnd darnach furab schnurrichts der grede nach den bach nächst ausserhalb der andern unnsern hüser hinab biß under und fưr das alt bappirhůs [...] Alfred Schulte überträgt die Begriffe krom und bogenwy $\beta$ falsch als „Krone und Bogenwiese“ ins Neuhochdeutsche und vermutet dahinter eine Ortsbeschreibung, vgl. Alfred Schulte 1953, 23.

1966 AVES, CH 239, Nr. 4918 (02.08.1445). Vgl. Fuchs 1962b, 103.

1967 AVES, CH 239, Nr. 4918 (02.08.1445): Primo quod predictus magister Wilhelmus fossam tendentem ad ripam sive fluvium dictum die klein aher prope predictam viam descendentem sive fluentem similiter et pontem unam per eandem aquam actu suis sumptibus et expensis facere, dictamque viam in tali latitudine sive amplitudine permittere debeat quod duo currus quibuscumque rebus bene ponderati sive gravidati contigui et cum bona commodositate per eandem viam a superiori parte usque ad finem eiusdem vie duci valeant. Vgl. Fuchs 1962b, $103 \mathrm{f}$.

1968 AVES, CH 257, Nr. 5292 (07.08.1454): Und als nu durch sollich bappiren müle das wasser ettlich zyt verswellet worden ist das es durch sollich swall der statt mülen an dem wissenturn und ouch der statt ringmuren schaden broht hat. 
mühle, lediglich seine Dunggrube unterspült. ${ }^{1969}$ Das Urteil der Schiedsleute sprach sich grundsätzlich für die Version Schuchmachers aus, denn es befand, dass das Kloster zu Söflingen Krafft Schuchmacher 15 Gulden Schadensersatz zahlen sowie ihm die Pachtzinsen für das vergangene Jahr erlassen sollte. Dennoch durfte das Kloster die Papiermühle - ungehindert von etwaigen Einsprüchen Schuchmachers weiterhin betreiben, unter der Bedingung, dass es zum Schutz des Geschädigten ein Wehr bauen und dieses in Zukunft unterhalten sollte. ${ }^{1970}$

Die vorgestellten Reglungen und Gerichtsurteilen zeigen, dass die Wassernutzung eine großes Konfliktpotential barg, das nicht selten zu langwierigen Streitigkeiten zwischen Mühlenbetreibern und anderen Anrainern führte. Hauptstreitpunkt waren dabei zum einen die Versorgung mit Wasser, die durch einen Umbau des Wasserlaufs oder durch neue Mühlwerke eventuell nicht mehr in gewohnter Weise gewährleisten war. Besonders diejenigen Mühlenbesitzer, die vermeintliche oder tatsächliche ältere Rechte oder Vorrechte auf die Nutzung des Wassers hatten, stemmten sich gegen jegliche Änderung am Wasserlauf. Häufig problematisch war zum anderen der Erhalt und die Befestigung des Bachbetts. Während die Mühlenbesitzer ihre Rechte gerne wahrnahmen, war bei den Pflichten die Frage der Zuständigkeit umstritten, sodass sie wie in Basel in einer Teichordnung geregelt oder - wie im Fall der Basler Allenwindenmühle oder den Papiermühlen in Ravensburg - vor Gericht geklärt wurde. Einen dritten Streitpunkt stellte die Zerstörung von Bauten durch den Wasserlauf dar, wie sie für die erste Straßburger und die Söflinger Papiermühle fassbar ist.

\subsection{Papiermacher}

Nach der Betrachtung der Papiermühle fragt das vorliegende Kapitel nach den Papiermachern und ihrem sozialen Status. Wie viele Papiermacher lassen sich in einer Stadt greifen, wie war das Handwerk organisiert und wie gestalteten sich die Beziehungen zwischen Meister und Gesellen? Woher kamen die Papiermacher und wie mobil waren sie? Wurden die Papierer Bürger der Stadt, in der sie lebten und arbeiteten? Wie waren sie in das örtliche Zunftsystem integriert? In welchen finanziellen Verhältnissen lebten sie? Und schließlich: Wer waren ihre Zulieferer, wer ihre Kunden?

Das generelle Problem einer sozialgeschichtlichen Untersuchung von Handwerkern im Spätmittelalter und in der Frühen Neuzeit, die in Teilen auch auf quantitative Verhältnisse Bezug nehmen will, liegt im Informationsgehalt der Quellen begründet. Fassbar sind selbstverständlich nur die Personen, in diesem Fall Papiermacher, deren Name in ein schriftliches Dokument gelangt ist. Notiert wurde ein Name aber

1969 Vgl. Alfred Schulte 1941, 97.

1970 Vgl. Alfred Schulte 1941, 97 f. 
nur dann, wenn er für die schriftführende Verwaltung von Bedeutung war. Dies war beispielsweise bei Bürgeraufnahmen und Zunftbeitritten der Fall. So lassen sich die Papierer greifen, die Bürger einer Stadt oder Mitglied einer Zunft wurden. Wie viele Handwerksgenossen auf diesen Status verzichteten oder verzichten mussten, erschließt sich dadurch jedoch nicht. Daher sind quantitative Aussagen beispielsweise darüber, welcher Anteil der Papiermacher das Bürgerrecht erwarb oder einer Zunft angehörte, nur sehr beschränkt und dann vermutlich verzerrt zu treffen. Für das Basler Beispiel lassen sich vor allem über Gerichtsprotokolle, aber auch vereinzelt über andere Zeugnisse die Papiermacher fassen, die nicht anlässlich eines Liegenschaftskaufs, des Bürgerrechtserwerbs oder des Zunftbeitritts in den städtischen Akten registriert wurden. Dennoch ist davon auszugehen, dass ein großer Teil der Personen, die im Papiergewerbe tätig war, unbekannt bleibt.

\subsubsection{Meister, Gesellen und Lohnarbeiter}

Über die Organisation des Papiererhandwerks im südwestdeutschen Raum ist für den Untersuchungszeitraum aufgrund von mangelnden Textzeugnissen nur wenig bekannt. Fragen zum Tagesablauf in einer Papiermühle, zur Ausbildung der Lehrlinge, zur Anzahl von Gesellen und Lohnarbeitern sowie zum sozialen Stand der Gesellen und Lehrlinge können daher nur selten und dann lediglich räumlich sowie zeitlich punktuell beantwortet werden. ${ }^{1971}$ Auch bleibt die allgemeine Darstellung der sogenannten Handwerksbräuche in den Überblickswerken und Einzelstudien zur Papiergeschichte meist holzschnittartig und nur schwer nachprüfbar, da entweder Quellenbefunde aus 400 Jahren zu einer Tatsachenbeschreibung amalgamiert oder die Gegebenheiten des 18. und 19. Jahrhunderts als die Gebräuche des Papiererhandwerks auf frühere Jahrhunderte übertragen werden. ${ }^{1972}$

Ebenso schwer zu eruieren ist die Anzahl der in einer Papiermühle beschäftigten Personen. Zwar kann man anhand von Angaben allgemeiner Natur eine Mindestbelegschaft berechnen. Ob dies im Einzelnen auf die konkreten Betriebe zutraf, ist auf Grundlage von Quellenbelegen jedoch kaum zu überprüfen, da derartige Angaben selten schriftlich festgehalten wurden oder nicht auf uns gekommen sind. ${ }^{1973}$ Gerhard Piccard geht bei einer Papiermühle mit einer Bütte von wenigstens drei, bei zwei

1971 Zum Gesellenstand allgemein vgl. Dirlmeier 1978; Reininghaus 1981a; Reininghaus 1982; Schulz 1985b; Wesoly 1985; Simon-Muscheid 1991; Simon-Muscheid 2004, 123-207.

1972 Vgl. beispielsweise Renker 1950, 124-134; Sporhan-Krempel 1953, 70-81; Bockwitz 1956; Schlieder 1966, 131-138; Schlieder 1985, 38-55; Halstrick 1990; P. Tschudin 1991, 42-48; P. Tschudin 2012a, 129-142. Als maßgebliche Referenz wird häufig ein Gerichtsprotokoll aus dem Jahr 1798 herangezogen, dass die Stellungnahme des Papiermachers Stahl aus Weende bei Göttingen zu den Gebräuchen der Papiermacher verzeichnet, vgl. Die Gebräuche der Papiermacher 1934.

1973 Vgl. Schlieder 1966, 108. 
Bütten von der doppelten Anzahl an Papiermachern aus. ${ }^{1974}$ Peter Tschudin berechnet in seiner Aufstellung neben den Papierergesellen, die an der Bütte arbeiteten, auch die Hilfsarbeiter mit ein. So nimmt er an, dass das minimal notwendige Personal einer Papiermühle mit einer Bütte acht bis neun Personen umfasste. Als Durchschnittsbelegschaft bei einer Bütte gibt er 13 bis 15 Beschäftigte an, zwei Bütten erforderten die Arbeitskraft von bis zu 23 Angestellten. ${ }^{1975}$ Wolfgang Schlieder beziffert die minimale Beschäftigtenzahl für eine Papiermühle mit einer Bütte mit ähnlichen Zahlen: mindestens sieben Personen, höchstens jedoch 15 Personen. ${ }^{1976}$ Das Verhältnis von gelernten zu ungelernten Arbeitern liege dabei ungefähr bei $50 \mathrm{zu} 50$.

Über den Anteil der Frauenarbeit in der Papiermacherei ist der Papierhistoriker erst für das 17. und 18. Jahrhundert gut unterrichtet. Für diese Zeit ist belegt, dass weibliche Arbeitskräfte für das Sortieren und Reißen der Lumpen sowie für das Aufhängen, Glätten und Sortieren der Papiere eingesetzt wurden. ${ }^{1977}$ Auf der Basis dieses Wissens wird in der Papiergeschichtsforschung pauschal angenommen, dass diese Arbeitsschritte in der gesamten Handpapierzeit von Frauen ausgeführt wurden. ${ }^{1978}$ Explizite Belege für spezifisch weibliche Tätigkeiten in der Papierherstellung des 15. und 16. Jahrhunderts werden jedoch nur selten genannt. So führt der Beitrag von Hans Heinrichs Bockwitz aus dem Jahr 1947 als Hinweise auf die Mitarbeit von Frauen in der Papierherstellung lediglich an, dass in den Zeugnissen zur Stromerschen Mühle in Nürnberg sowie zu den frühen Basler Betrieben auch Frauen genannt werden. ${ }^{1979}$ Über ihre tatsächlichen Aufgaben innerhalb der Papiermühle kann er nur spekulieren.

Als herausragende Quellen für die Zeit bis zur Mitte des 16. Jahrhunderts können drei Dokumente gelten, die im süddeutschen Raum entstanden. Es sind dies zum einen das Püchel von mein geslecht und von abentewr des Ulman Stromer aus Nürnberg vom Beginn des 15. Jahrhunderts, die Supplikation des Druckers Christoph Froschauer an den Züricher Rat aus dem Jahr 1535 sowie die sogenannte Reutlinger Papiermacherordnung von 1527. Sie ermöglichen eine punktuelle Überprüfung der Vermutungen, die zur Organisation der mittelalterlichen Papiermacherei angestellt wurden. Für Basel lassen sich zudem aus vielen einzelnen Hinweise vergleichsweise viele Papiermacher und damit ihr numerisches Verhältnis in den Quellen, aber auch teilweise ihre Beziehungen zueinander fassen.

1974 Vgl. Piccard 1967, 155.

1975 Vgl. P. Tschudin 2012a, 128.

1976 Vgl. Schlieder 1966, 107 f., 123.

1977 Vgl. S. 73, 139, 154, 163, 167.

1978 Vgl. Bockwitz 1947, 72 f.; Renker 1950, 133; Schlieder 1966, 107; Bayerl/Pichol 1986, 54 f., 90, 97; Bayerl 2008, $177 \mathrm{f}$.

1979 Vgl. Bockwitz 1947, 72. 


\subsubsection{Basel}

Für das Fallbeispiel Basel konnte keine Handwerksordnung entdeckt werden, die die Beziehungen und Aufgaben von Meistern, Gesellen und Lehrlingen in der Papiermacherei zu regeln versuchte. Daher fehlt für das Basler Papiererhandwerk in der Untersuchungsperiode eine Vorstellung davon, wie das ideale Verhältnis von Arbeitgeber und Beschäftigten aussah. Auch die tatsächlichen Relationen dieser Arbeits- und teilweise auch Wohngemeinschaft werden nur von wenigen Quellen beleuchtet.

Für zwei Zeitfenster ist es jedoch dank der Schillingsteuerbücher von 1454 und von 1475/76 bis 1480/81 möglich, die Anzahl der in der Basler Papiermacherei beschäftigten Personen annähernd zu bestimmen und zwar über die Mitglieder der Papiermacherhaushalte. Das Schillingsteuerverzeichnis von 1454 führt im St. Albantal drei Haushalte auf, denen ein Papiermacher vorstand. ${ }^{1980}$ Neben dem Papiermacher Peter, der zusammen mit seiner Frau einen Haushalt bildete, ${ }^{1981}$ arbeiteten im St. Albantal des Jahres 1454 zwei weitere Papiermacher mit einer deutlich größeren Haushaltung. Anton Gallician, der seit 1453 die Klingentalmühle besaß, lebte zusammen mit seiner Frau, seinen zwei namentlich nicht genannten Brüdern, fünf Knechten und zwei Mägden. ${ }^{1982}$ Wahrscheinlich ist, dass ein Großteil dieser Personen in der Klingentalmühle und damit in der Papierherstellung tätig war. Anton Gallician als Meister beschäftigte zum einen fünf Knechte, von denen mit großer Wahrscheinlichkeit angenommen werden kann, dass sie sich im Papiergewerbe verdingten. ${ }^{1983}$ Zum anderen

1980 StABS, Steuern B 15. Das Schillingsteuerverzeichnis entstand im Rahmen einer 1454/55 festgesetzten Personalsteuer. Die Schillingsteuer wurde im Rechnungsjahr 1457/58 von der Rappensteuer abgelöst. Sowohl von der Schillingsteuer als auch von der ihr folgenden Rappensteuer sind - bis auf eine Ausnahme - weder die Steuergesetze noch die Steuerbücher erhalten. Lediglich aus den Fronfastenrechnungen der Stadt ergibt sich für die Schillingsteuer ein Steuerbetrag von einem Schilling, der alle Fronfasten gezahlt werden musste. Bei der Rappensteuer, die mit dem Finanzjahr 1461/62 auslief, handelte es sich nach Schönberg vermutlich um eine wöchentliche Steuer in der Höhe von einem Rappen, id est 2 Pfennig. Steuerpflichtig war jede weltliche Person ab 14 Jahre. Das Schillingsteuerverzeichnis diente offenbar als Grundlage für die Erstellung der nicht auf uns gekommenen Schillingsteuerbücher und führt daher zumeist den Namen des Haushaltvorstands an und ergänzt ihn um die Anzahl der im Haushalt lebenden Personen, die ebenfalls schillingsteuerpflichtig waren. Teilweise ist nicht nur die Anzahl der steuerpflichtigen Personen genannt, sondern auch ihre Beziehung zum Hausherrn oder ihr Stand in der Haushaltung, vgl. Schönberg 1879, 340-348.

1981 StABS, Steuern B 15, 6v: Item Peter papir macher und sin wipp. Vgl. auch Schönberg 1879, 728. Gerhard Piccard und Hans Kälin vermuten, dass dieser Papiermacher namens Peter mit dem Papiermacher Peter Höfflin identisch ist, sie werden in der vorliegenden Arbeit jedoch als zwei Personen behandelt, da es bis auf den Taufnamen keinen Hinweis darauf gibt, dass sie identisch sind, vgl. Piccard 1967, 152; Kälin 1974, 196.

1982 StABS, Steuern B 15, 6v: Item meyster Anthonig und sin wipp und sin zwen bruder und funff knecht und zwo junckfraw. Vgl. Schönberg 1879, 728; Geering 1886, 315, 317; Piccard 1967, 152; Kälin 1974, 156 f.

1983 Welchen Ausbildungsgrad diese Personen aufzuweisen hatten, das heißt, ob sie ausgebildete Gesellen oder ungelernte Lohnarbeiter waren, ist aus dem Steuerbuch nicht zu ersehen. 
arbeiteten vermutlich auch seine zwei Brüder, Michel und Hans Gallician I, die zu diesem Zeitpunkt keine eigenen Mühlwerke besaßen, in Anton Gallicians Betrieb. Rechnet man noch die Unterstützung einer der Mägde hinzu, so umfasste das Personal der Klingentalmühle im Jahr 1454 einschließlich Meister neun Arbeitskräfte. ${ }^{1984}$ Der dritte Papiermacher und Haushaltsvorstand war Meister Andres. Er besaß kein eigenes Werk, sondern wohnte und arbeitete zusammen mit seiner Frau und sechs Knechten in der Papiermühle Heinrich Halbysens d. J., die wahrscheinlich aus der Rychmühle und der ihr gegenüberliegenden Zunzigermühle bestand. ${ }^{1985}$ Die Beschäftigtenzahl von sieben Männern in diesem großen Betrieb erscheint im Vergleich mit der neunköpfigen Belegschaft der Klingentalmühle eher gering. Wahrscheinlich ist dem Betrieb von Halbysen noch der Papiermacher Peter zuzurechnen, der zwar in einem eigenen Haushalt lebte, aber dennoch in dem zeitgleich geführten Markzahlsteuerbuch als famulus, als Knecht, bezeichnet wurde. ${ }^{1986}$ Denkbar wäre auch, dass einer der beiden Brüder Anton Gallicians nicht in der Mühle des Bruders arbeitete, sondern sich im Betrieb Halbysens verdingte. Für drei Papiermühlen lässt sich insgesamt eine Beschäftigtenzahl von 16 bis 17 Personen festhalten, wovon zwölf Personen als Knechte bezeichnet werden. Bis auf den verheirateten Peter lebten alle diese Knechte im Haushalt ihres Arbeitsgebers.

Aufschlussreich bezüglich der Größe der Papiermacherhaushalte sind auch die Schillingsteuerbücher der sechsjährigen Steuererhebung von 1475/76 bis 1480/81. ${ }^{1987}$ Anton Gallician zahlte für sich und die zu seinem Haushalt gehörenden Personen im Jahr 1475/76 einmal 13 und einmal 12 Schilling. Hinter seinem Namen steht die Zahl 10. ${ }^{1988}$ Es ist daher davon auszugehen, dass zu seinem Haushalt noch weitere neun Personen zählten. Bei einer Steuersumme von 13 Schilling müssen daher in seinem Haushalt drei Personen gelebt haben, die die volle Summe von 2 Schilling zahlen mussten, und sieben Personen, die entweder Kinder über 14 Jahre oder Dienstleute waren. ${ }^{1989}$ Bei dem Steuerbetrag von 12 Schilling fiele dementsprechend eine dieser

1984 Die andere Magd versorgte nach dieser Rechnung zusammen mit Anton Gallicians Frau die acht im Haushalt lebenden Männer.

1985 StABS, Steuern B 15, 7r: Item in juncker Heinrich Halbysens papir mulin meyster Andres und sin fraw und vi knecht. Vgl. Schönberg 1879, 728; Piccard 1967, 152; Kälin 1974, 190, 200.

1986 StABS, Steuern B 12, Markzahlsteuerbuch 1453/54-1456/57, ohne Blattzählung, unter der Ortsbezeichnung mülinen.

1987 StABS, Steuern B 19. Schillingsteuerpflichtig waren alle weltlichen Personen ab 14 Jahren. Während die haushäblichen, selbstständigen Personen vierteljährlich zu allen Fronfasten 2 Schilling zu entrichten hatten, musste bei ihren Eltern im Haushalt lebende Kinder ab 14 Jahren sowie im Haus ihres Herrn wohnende Dienstleute nur einen Schilling zahlen. Diese Steuersumme verringerte sich für die letzten beiden Jahre dieser außerordentlichen Steuer um die Hälfte, auf einen Schilling beziehungsweise 6 Pfennig, StABS, Steuern B 19, Markzahlsteuer 1475/76-1476/77, 2r. Vgl. Schönberg 1879, 454.

1988 StABS, Steuern B 19, Schillingsteuer 1475/76, 24 r.

1989 Die Rechnung hierfür lautet: 3 mal 2 Schilling plus 7 mal einen Schilling gleich 13 Schilling. 
letzten Personen, die einen Schilling entrichten mussten, weg. Im darauffolgenden Rechnungsjahr, für das keine Personenanzahl mehr genannt ist, stieg der Betrag der Fronfastenabgabe von 11 auf 16 Schilling und deutet damit auf die Einstellung von Personal und/oder auf den 14. Geburtstag eines seiner Kinder hin. ${ }^{1990}$ Ab 1477/78 stabilisieren sich die Ausgaben für die Schillingsteuer bei 14 Schilling beziehungsweise bei 7 Schilling für die letzten zwei Steuerjahre. ${ }^{1991}$ Geht man davon aus, dass eigentlich nur Hausherr und Hausherrin 2 Schilling zu zahlen hatten, dann müssen in den Jahren von 1477 bis 1481 zehn weitere Personen im Haushalt von Anton Gallician gelebt haben. Von den fünf bekannten Kindern Antons können zu diesem Zeitpunkt nur die drei jüngsten - Hans, Franz und eine Tochter - noch bei ihren Eltern gewohnt haben, wobei die Tochter bereits vor 1480 Adam Kridwyß heiratete. ${ }^{1992}$ Daher ist zu vermuten, dass Anton Gallician die Schillingsteuer für sieben oder acht Angestellte bezahlte, die zu seiner Haushaltung gehörten. Diese Zahl scheint nicht zu hoch, wenn man sie mit den in dem Schillingsteuerverzeichnis von 1454 erwähnten fünf Knechten und zwei Mägden vergleicht. Ein Großteil dieser Dienstleute war wahrscheinlich in der Papierherstellung tätig.

Auch Michel Gallician zahlte für mehrere Personen die Schillingsteuer. Im ersten Steuerjahr 1475/76 ist hinter seinem Namen die Zahl 7, der Steuerbetrag einmal mit 9 Schilling und einmal mit 10 Schilling angegeben. ${ }^{1993}$ Gesetzt den Fall, dass es sich bei der Zahl 7 um die zum Haushalt gehörenden steuerpflichtigen Personen handelte und Michel Gallician für sich und seine Frau zusammen 4 Schilling gab, befanden sich zum ersten Zahlungstermin noch weitere fünf Personen im Haus, die nicht selbstständig waren. Beim zweiten Termin scheint eine weitere Person hinzugekommen zu sein, da Michel Gallician nun 10 Schilling steuerte. Da vermutlich keines seiner Kinder zu diesem Zeitpunkt das 14. Lebensjahr vollendet hatte, ${ }^{1994}$ ist es wahrscheinlich, dass es sich bei den fünf beziehungsweise sechs Personen um Dienstpersonal handelte, das zum Teil in seiner Papiermühle, der Rychmühle, zum Teil im Haus arbeitete. In den folgenden Steuerjahren schwankte der Betrag zwischen 10 und 13 Gulden. ${ }^{1995}$ Dies lässt auf eine Personalfluktuation schließen. Beim Spitzenwert von 13 Gulden zu Beginn des Rechnungsjahres 1478/79 bestand der Haushalt von Michel Gallician

1990 StABS, Steuern B 19, Schillingsteuer 1476/77, 21 r.

1991 StABS, Steuern B 19, Schillingsteuer 1477/78, 21v; Schillingsteuer 1478/79, 21r; Schillingsteuer 1479/80, 20r; Schillingsteuer 1480/81, 20v. Da der Steuersatz für die beiden letzten Jahre um die Hälfte gesenkt wurde, entspricht die Anzahl an steuernden Personen bei einer Steuersumme von 7 Schilling der Anzahl an Personen bei einer Steuersumme von 14 Schilling in den vorangegangenen Jahren, vgl. Schönberg 1879, 454.

1992 Vgl. Kälin 1974, Tafel 6.

1993 StABS, Steuern B 19, Schillingsteuer 1475/76, 25 r.

1994 Vgl. Kälin 1974, Tafel 7.

1995 StABS, Steuern B 19, Schillingsteuer 1476/77, 22v; Schillingsteuer 1477/78, 20v; Schillingsteuer $1478 / 79,19 v$. 
neben ihm, seiner Frau und seiner Schwiegermutter Anna ${ }^{1996}$ vermutlich aus sieben Dienstpersonen. ${ }^{1997}$ In den letzten beiden Steuerjahren zahlte Michel Gallician jede Fronfasten 5,5 Schilling, dies allerdings wieder zusammen mit seiner Schwiegermutter. ${ }^{1998}$ Es ist also davon auszugehen, dass neben den drei vollzahlenden Personen fünf Knechte und Mägde in dem Haushalt zu finden waren.

Der Besitzer der Zunzigermühle, Ulrich Züricher, steuerte in den ersten Fronfasten ebenfalls für sieben Personen. ${ }^{1999}$ Abzüglich der 4 Schilling für sich und seine Frau Agata verbleiben 5 Schilling, die für die fünf weiteren im Haushalt lebenden Personen gegeben wurden. Wahrscheinlich entrichtete er einen Schilling für seinen Sohn Hans Züricher und die restlichen 4 Schilling - wenn man mögliche weitere Kinder außer Acht lässt - für vier Dienstleute. Bei Ulrich Züricher arbeiteten während der sechsjährigen Steuerperiode vermutlich zwischen zwei und fünf Knechte und Mägde: Für die Jahre 1476/77 und 1477/78 ist von fünf, für das Jahr 1478/79 von nur zwei und für die Jahre 1479/80 und 1480/81 von vier Dienstpersonen auszugehen. ${ }^{2000}$

Ob der Papiermacher Peter Höfflin zu Beginn der Steuerperiode bereits Besitzer der halben hinteren Spiegelmühle war, ist ungewiss. Vermutlich war er jedoch ihr Pächter und somit selbstständiger Meister. ${ }^{2001} \mathrm{Zu}$ seinem Haushalt gehörten im Jahr 1475/76 sechs Personen. ${ }^{2002}$ Auch er zahlte zu den ersten Fronfasten für sich und seine Ehefrau zusammen 4 Schilling und für die anderen vier Personen jeweils einen Schilling, folglich insgesamt 8 Schilling. Die Höhe der Steuersumme und damit wahrscheinlich auch die Anzahl der im Haushalt lebenden Personen schwankten in den folgenden Jahren. ${ }^{2003}$ Einen Höchstbetrag von 10 Schilling erreichten die Zahlungen im Jahr 1477/78. ${ }^{2004}$ Für dieses Jahr, eventuell auch für die Jahre davor und danach, ist zu vermuten, dass Peter Höfflin die Steuern ebenfalls für seine bei ihm lebenden Ziehsöhne Hans und Hug Pastor bezahlte. ${ }^{2005}$ Mit seinem Zunftkauf im Jahr 1480 hatte

1996 Der Name von Michel Gallicians swiger ist im Markzahlsteuerbuch zu finden, StABS, Steuern B 19, Markzahlsteuer 1476/77, 49r. Zur Deutung von swiger als Schwiegermutter, vgl. E. E. Müller 1953, 188.

1997 StABS, Steuern B 19, Schillingsteuer 1478/79, 19v.

1998 StABS, Steuern B 19, Schillingsteuer 1479/80, 18v; Schillingsteuer 1480/81, 19r.

1999 StABS, Steuern B 19, Schillingsteuer 1475/76, 23v.

2000 StABS, Steuern B 19, Schillingsteuer 1476/77, 21r; Schillingsteuer 1477/78, 21v; Schillingsteuer 1478/79, 21r; Schillingsteuer 1479/80, 20v; Schillingsteuer 1480/81, 20v. Dies gilt, wenn man davon ausgeht, dass seine Frau über den gesamten Zeitraum mitsteuerte. Sein Sohn Hans Züricher entrichtete ab dem Steuerjahr 1477/78 selbstständig die Steuern.

2001 Vgl. Kapitel 3.2.1.1, S. 218 f.

2002 StABS, Steuern B 19, Schillingsteuer 1475/76, 23v.

2003 StABS, Steuern B 19, Schillingsteuer 1476/77, 21v; Schillingsteuer 1477/78, 21v; Schillingsteuer 1478/79, 21r; Schillingsteuer 1479/80, 20r; Schillingsteuer 1480/81, $20 \mathrm{v}$.

2004 StABS, Steuern B 19, Schillingsteuer 1477/78, 21v.

2005 Peter Höfflin nahm vor dem Jahr 1477 offenbar die beiden Söhne Anton Pastors I als Kinder an. In diesem Jahr übergab er ihnen als seinen Stiefsöhnen nämlich ihr väterliches und mütterliches Erbe 
sich vermutlich zumindest Hug Pastor selbstständig gemacht. ${ }^{2006}$ Das Absinken der Steuerleistungen im Jahr 1480/81 deutet zudem eventuell auf den Tod der ersten Frau Peter Höfflins, Margreth, hin. ${ }^{2007}$ Bezieht man diese beiden Thesen mit ein, so waren für Peter Höfflin über den Zeitraum der Steuererhebung mindestens zwei und höchstens fünf Dienstleute tätig.

Mit Anton Gallician, Michel Gallician, Ulrich Züricher und Peter Höfflin sind diejenigen vier Papiermacher erfasst, die zum Zeitpunkt der Steuererhebung selbstständige Papierermeister waren. Über den Zeitraum der sechs Steuerjahre waren pro Jahr zwischen minimal 17 und maximal 23 Dienstleute, die in ihrem Haushalt lebten, für sie tätig, also durchschnittlich 18 bis 20 Personen. Der Großteil dieser Personen arbeitete wahrscheinlich in der Papierherstellung. Auch hier sind die Ausbildung und der Einsatzort innerhalb der Werkstatt nicht zu eruieren. Neben diesen Personen gab es jedoch noch mindestens neun weitere Papiermacher, die weder einen eigenen Betrieb führten noch im Haushalt ihres Arbeitgebers lebten. Diese Papierer waren zwar bei einem der Papiermühlenbesitzer angestellt, führten jedoch einen eigenständigen Haushalt.

So steuerte Ulrich Zürichers Sohn Hans Züricher seit dem Rechnungsjahr 1477/78, dem Jahr seines Zunftkaufs, selbstständig und zwar konstant entweder für sich und eine Ehefrau oder für sich und zwei Dienstpersonen. ${ }^{2008}$ Der Papiermacher Hans Kielhammer von Schaffhausen, der später - ab 1496 - mit der Zunzigermühle einen eigenen Betrieb besaß, steuerte laut der hinter seinem Namen angegebenen Zahl für drei Personen und musste dafür 4 Schilling geben. Allerdings scheint er zu den ersten Fronfasten nur 3 Schilling gegeben zu haben. ${ }^{2009}$ Auch im Steuerjahr 1476/77 gab er nur 3 Schilling. ${ }^{2010}$ Vermutlich lebten daher in seinem Haushalt nur zwei statt der angegebenen drei Personen: Er selbst und ein Knecht oder eine Magd. In den darauffolgenden vier Steuerjahren bildete Hans von Schaffhausen offenbar einen EinMann-Haushalt, da er nur noch für sich selbst zahlte. ${ }^{2011}$

von 28 Pfund, das er bis dato offensichtlich für die beiden verwaltet hatte, StABS, Gerichtsarchiv C 12, 222 f. Vgl. Kälin 1974, 196.

2006 Vgl. Kapitel 3.3.4.1, Tab. 23.

2007 Im Jahr 1472 ist eine Margreth als Peter Höfflins Frau bezeugt, StABS, Gerichtsarchiv B 9, 293. Wann sie verstarb, ist ungewiss. In zweiter Ehe war Peter Höfflin spätestens seit 1487 mit einer Christina verheiratet, die ihren Sohn Michel Gernler mit in die Ehe brachte, StABS, Gerichtsarchiv B 12, 40r. Vgl. Kälin 1974, 196.

2008 StABS, Steuern B 19, Schillingsteuer 1477/78, 21v; Schillingsteuer 1478/79, 21r; Schillingsteuer 1479/80, 20v; Schillingsteuer 1480/81, 20v. Zum Zunftkauf vgl. Kapitel 3.3.4.1, Tab. 23.

2009 StABS, Steuern B 19, Schillingsteuer 1475/76, 21r.

2010 StABS, Steuern B 19, Schillingsteuer 1476/77, 18v.

2011 StABS, Steuern B 19, Schillingsteuer 1477/78, 18r; Schillingsteuer 1478/79, 19r; Schillingsteuer 1479/80, 18r; Schillingsteuer 1480/81, 18v. Anscheinend war er zu diesem Zeitpunkt noch nicht mit seiner späteren Frau Brigida verheiratet, vgl. Tab. 13. 
Der Papiermacher Bastian, der wahrscheinlich identisch mit dem Papierer Sebastian Franz war, ${ }^{2012}$ steuerte im Jahr 1475/76 für drei Personen 4 Schilling. Daher ist davon auszugehen, dass er entweder mit zwei Kindern, mit zwei Dienstleuten oder mit einem Kind und einer Dienstperson in seinem Haus wohnte. ${ }^{2013}$ Im nächsten Steuerjahr hatte er jedoch Basel verlassen, da sein Schwager, der Weber Friedrich Lemli, die 4 Schilling für ihn entrichtete. ${ }^{2014}$ Für wen der Papiermacher Bastian arbeitete, ist ungewiss. Auch die Papiermacher Peter Fester und Jacob Parella wohnten nicht im Haushalt ihres Arbeitgebers, welcher im Falle Jacob Parellas offenbar Anton Gallician hieß. ${ }^{2015}$ Beide zahlten eine Steuersumme von 3 Schilling. Dies deutet darauf hin, dass die beiden Papiermacher nicht verheiratet waren, sondern mit einer nichtselbstständigen Person über 14 Jahre zusammenlebten. ${ }^{2016}$ So steuerte Jacob Parella für sich und einen Gesellen. ${ }^{2017}$ Eine enge Beziehung zwischen Peter Fester und Jacob Parella lässt sich daran erkennen, dass Peter Fester in den dritten Fronfasten des Steuerjahres 1476/77 die Steuerzahlung für Jacob Parella übernahm. ${ }^{2018}$

Je nach Gleichsetzung der Michel genannten Papierer wohnten in der gesamten Steuerperiode entweder zwei oder drei angestellte Papiermacher dieses Namens nicht unter dem Dach ihres Arbeitgebers. Vermutlich bei Michel Gallician angestellt, ${ }^{2019}$ aber in einem eigenen Haushalt wohnend, steuerte der Papiermacher Michel Gallician II, ein Vetter Anton Gallicians und auch Langmichel Gallician genannt, in den ersten drei Steuerjahren $1475 / 76$ bis $1477 / 78$ zwischen 2 und 4 Schilling. ${ }^{2020}$ Im dritten

2012 Der Papiermacher Sebastian Franz wird im Jahr 1472 anlässlich einer Schuldverschreibung erwähnt, vgl. StABS, Gerichtsarchiv C 12, 31. Hans Kälin setzt den Papiermacher Bastian und Sebastian Franz plausibel in eins, vgl. Kälin 1974, 201, 284 mit Anm. 228.

2013 Zum Haus vgl. StABS, Gerichtsarchiv C 12, 31r; B 10, 92. Vgl. auch Anm. 2680.

2014 StABS, Steuern B 19, Schillingsteuer 1475/76, 24r, und 1476/77, 21v: Git lemly der weber. Vgl. Kapitel 3.3.5.1.

2015 StABS, Steuern B 19, Schillingsteuer 1475/76, 24v: Jacob Parella Anthoni knecht; Schillingsteuer 1476/77, 22r: Jocob Parela Anthons knecht.

2016 Bei dem Eintrag zu Peter Fester steht hinter seinem Namen die Zahl 3, sodass eigentlich davon auszugehen ist, dass drei Personen in seinem Haushalt lebten. Da er selbst als Haushaltsvorstand jedoch 2 Schilling zu entrichten hatte, hätten für zwei zusätzliche Personen zusammen mindestens 2 weitere Schilling, folglich also 4 Schilling insgesamt gezahlt werden müssen.

2017 StABS, Steuern B 19, Schillingsteuer 1477/78, 22r: Jocob Parelya dat $x \beta$ stur fur sich und sin gesellen donstag post valentini anno 79.

2018 StABS, Steuern B 19, Schillingsteuer 1476/77, 22r: Peter Fester bapirmacher, er het fer sprochen fur Jocob Parelya [...] Jocob Parela Anthons knecht, Peter Fester ferspricht für in. Auch an den entrichteten Beträgen wird deutlich, dass Peter Fester für Jacob Parella zahlte. In die Tabelle wurden nämlich in die Spalte der entsprechenden Fronfasten bei Peter Fester 6 Schilling, bei Jacob Parella nichts eingetragen.

2019 StABS, Steuern B 19, Markzahlsteuer 1477/78, 21v: der Langmichel Galician Michel Galician papirknecht.

2020 StABS, Steuern B 19, Schillingsteuer 1475/76, 23v; Schillingsteuer 1476/77, 21r; Schillingsteuer 1477/78, 21v. Zur Bezeichnung als Anton Gallicians Vetter vgl. Tab. 23, Anm. iii. 
Jahr erscheint in der Steuerliste zudem parallel ein Michel Rere. ${ }^{2021}$ Er ist wahrscheinlich mit dem Papiermacher Michel Reri identisch, der 1479 sein Haus im St. Albantal an Michel Gallician verkaufte. ${ }^{2022}$ Auch im vierten Steuerjahr wird er in den Steuerbüchern geführt. ${ }^{2023}$ In den letzten beiden Steuerjahren 1479/80 und 1480/81 wird nur noch ein Michel bappirer aufgeführt, ein zweiter Michel, der Papiermacher war, wird - außer der an anderer Stelle gelistete Michel Gallician, Bruder von Anton Gallician nicht mehr genannt. ${ }^{2024} \mathrm{Ob}$ es sich bei dieser Person um einen der beiden genannten Michel oder um einen dritten Papiermacher handelte, ist nicht zu klären. ${ }^{2025}$

Ebenfalls eine eigene Haushaltung führten im Steuerjahr 1480/81 die Papierergesellen Anton und Diebolt, wobei Diebolt, der mit dem später belegten Diebolt Hanman zu identifizieren ist, seit 1478 sogar ein eigenes Haus besaß. ${ }^{2026}$ Während Anton, der nur einen Schilling Personensteuer zahlte, offensichtlich alleine wohnte, lebte Diebolt Hanman, der 1,5 Schilling steuerte, mit einer weiteren Person zusammen. ${ }^{2027}$ Zwei Gründe sprechen dagegen, dass es sich um seine Frau Agnes von Biel handelte. ${ }^{2028}$ Zum einen hätte sie als Hausherrin wie ihr Mann auch einen Schilling anstatt 6 Pfennig entrichten müssen. ${ }^{2029}$ Zum anderen - und dies ist bemerkenswert - steuerte sie fünf Jahre, von 1475/76 bis 1479/80, eigenständig in St. Alban. In den

2021 StABS, Steuern B 19, Schillingsteuer 1477/78, 21r. Zunächst wurde lediglich Michel bappirer verzeichnet. Eine spätere Hand hat den Zusatz bappirer durchgestrichen und mit Rere überschrieben. 2022 StABS, Gerichtsarchiv B 10, 273; A 33, 160. Vgl. Kälin 1974, 203. Vgl. auch S. 433, 435.

2023 Er taucht hier als Michel pappirer knecht genant Rere auf. Allerdings wurde im Schillingsteuerbuch der Zusatz genant Rere wieder gestrichen, während er im Markzahlsteuerbuch erhalten ist, StABS, Steuern B 19, Schillingsteuer 1478/79, 21r; Markzahlsteuer 1478/79, 21 r.

2024 StABS, Steuern B 19, Schillingsteuer 1479/80, 20r; Schillingsteuer 1480/81, 20 .

2025 Die Sachlage verkompliziert sich ein weiteres Mal, wenn man in Betracht zieht, dass ein weiterer Papiermacher namens Michel zu dieser Zeit in die Safranzunft aufgenommen wurde. Im Jahr 1479 kaufte Michel Gerbera mit Anton Gallician als Bürgen die Zunft. Auch er könnte mit Michel Bappirer gemeint sein, vgl. Kapitel 3.3.4.1, Tab. 23.

2026 Zum Hausbesitz Diebolts vgl. StABS, Gerichtarchiv B 10, 266: [...] dem erbern Diepolt von tann dem bappirer knecht och hindersess der im selbs Agnes von Biel siner efrowen und ir beider erben recht und redlich kofft hat...dz huß und hoffstatt mit allen rechten und zügehörungen, gelegen in der statt Basel in der vorstatt zü sannt alban in den mülinen zwischen dem bulverstampff ze einer und Hans Löwenbergs schliffin [...] Dass es sich bei Diebolt von Thann um den später erwähnten Diebolt Hanman und nicht um den ebenfalls zu einem späteren Zeitpunkt genannten Papierer Diebolt Junkher handelt, lässt sich anhand des Hauses feststellen, das Diebolt Hanman urkundlich belegt zwischen 1502 und 1505 besaß. Es handelte sich hierbei um das Haus Brestenberg, das zwischen der hinteren Schleife und der Stadtmauer zum Rhein hin lag und das identisch mit dem 1478 gekauften Haus zwischen der nun nicht mehr existenten Pulverstampfe und der Schleife Hans Löwenbergs war. Vgl. hierzu StABS, Klosterarchiv, St. Alban H, 13; St. Alban DD 1, Corpus 1502, 17v; Corpus 1505, 16v.

2027 StABS, Steuern B 19, Schillingsteuer 1480/81, 20r-20v.

2028 Agnes von Biel wurde 1478 als Diebolts Frau erwähnt, vgl. StABS, Gerichtsarchiv B 10, 266. Vgl. Anm. 2026.

2029 Vgl. Schönberg 1879, 454. 
Schillingsteuerbüchern ist sie immer als die von Biel aufgeführt. ${ }^{2030}$ In den Jahren 1478/79 und 1479/80, also seit dem Hauskauf Diebolt Hanmans im November 1478, wurde dieser Bezeichnung der Zusatz Dieboltz wib beigefügt. ${ }^{2031}$ Diebolt Hanman selbst erscheint in diesen Jahren hingegen nicht als eigenständiger Steuerzahler. Erst im letzten Steuerjahr ist er in der Steuerliste fassbar, während die von Biel nicht mehr aufgeführt wird. ${ }^{2032}$ Dies legt die Vermutung nahe, dass Agnes von Biel zu diesem Zeitpunkt verstorben war. Daher wohnte Diebolt Hanman möglicherweise mit einem Knecht oder einer Magd zusammen. Festzuhalten bleibt, dass der Papierergeselle einen eigenen Hausstand besaß und verheiratet war, auch wenn er in den Steuerbüchern offensichtlich zunächst unter dem Namen seiner Frau geführt wurde.

Für den Zeitraum zwischen 1475 und 1481 lassen sich neben den durchschnittlich 18 bis 20 im Haushalt eines der vier Papiermühlenbesitzer lebenden Personen je nach Identifizierung der Michel genannten Personen neun bis zehn weitere Papierergesellen greifen, die ein eigenes Haus oder eine eigene Wohnung besaßen, also haushäblich waren. ${ }^{2033}$ Ungefähr ein Drittel der fassbaren Papiermachergesellen lebte folglich nicht im Haus des Arbeitgebers. Die Anzahl der Angestellten je Papiermühle betrug im Durchschnitt zwischen sieben und acht Personen. Dieser Befund bestätigt die Beschäftigtenzahlen, die die Papiergeschichtsforschung für eine Papiermühle mit einer Bütte annimmt.

Da die Auswertung der Schillingsteuerbücher nur ein kleines Zeitfenster abdeckt, soll die Betrachtung von Meistern und Gesellen nun auf den gesamten Untersuchungszeitraum erweitert werden. Die Aufnahme möglichst vieler Namen ${ }^{2034}$ von Papiermachern aus den unterschiedlichsten Quellen weist sowohl ein quantitatives als auch ein qualitatives Element auf. Zum einen macht das numerische Verhältnis zwischen den genannten Papierermeistern und den genannten Gesellen deutlich, wer Eingang in die Überlieferung fand, und zum anderen bieten die aufeinander bezogenen Nennungen von Papiermachern die Möglichkeit, Beziehungen der Personen zueinander auszuloten. Eine Schwierigkeit ergibt sich hierbei allerdings dadurch, dass längst

2030 StABS, Steuern B 19, Schillingsteuer 1475/76, 24r; Schillingsteuer 1476/77, 21v; Schillingsteuer 1477/78, 21v; Schillingsteuer 1478/79, 21r; Schillingsteuer 1479/80, 20r.

2031 StABS, Steuern B 19, Schillingsteuer 1478/79, 21r; Schillingsteuer 1479/80, 20 r.

2032 StABS, Steuern B 19, Schillingsteuer 1480/81, 20v.

2033 Der Begriff haushäblich muss nicht unbedingt auf den Besitz eines Hauses hindeuten, sondern konnte in einer abgeschwächten Form auch schlicht meinen, dass die betroffene Person einen eigenen Haushalt mit eigener Feuerstelle führte, vgl. Isenmann 2002, 217-219.

2034 Die Namen sind im Folgenden, sofern sie in mehreren Quellen vorkommen und miteinander identifiziert werden konnten, „normalisiert“ worden. Ich folge dabei in den meisten Fällen der Schreibweise, die durch vorangegangene Untersuchungen etabliert wurde. Dies gilt für ebenfalls für die folgenden Kapitel. 
nicht alle Personen, die vermutlich die entsprechende Stellung innehatten, mit der expliziten sprachlichen Kennzeichnung Meister oder Knecht versehen wurden. ${ }^{2035}$

Zunächst sollen die Papiermacher in den Blick rücken, die die Stellung eines Meisters einnahmen. In der Papierherstellung wurde, so der Stand der Forschung, kein Meisterstück angefertigt, sodass eine formelle Meisterprüfung entfiel. Als Meister wurden daher meist jene Papiermacher bezeichnet, die einen eigenen Betrieb führten und Angestellte anleiteten. Beim Verlust dieser Position konnte ein Papierer in den Gesellenstand zurückfallen. Für die Selbstständigkeit war folglich der Kauf oder die Pacht einer Papiermühle grundlegend, aber nicht jeder Papiermacher war dazu finanziell in der Lage. ${ }^{2036}$ Anders als bei anderen Handwerken war es in der Papierherstellung aufgrund des Produktionsprozesses nicht möglich, eine kleine Werkstatt aufzumachen, in der nur der Meister arbeitete.

In Basel konnten zwischen 1450 und 1550 insgesamt sieben Papiermacher gezählt werden, die explizit als Meister bezeichnet wurden. Hierzu gehörten in chronologischer Reihenfolge Meister Andres, Meister Anton Gallician, Meister Michel Gallician, Meister (Peter) Hans Strub, Meister Hans Lufft von Ettlingen, Meister Jörg Dürr d. Ä. sowie Meister Fridlin Hüsler d. Ä. Bis auf Meister Andres, der wohl nur Pächter oder Werkmeister der Papiermühle Heinrich Halbysens d. J. war, besaßen alle Papierermeister einen eigenen Betrieb. Zudem waren sie alle verheiratet. Für weitere 13 Papiermühlenbesitzer konnte die Bezeichnung als Meister nicht nachgewiesen werden, obwohl sie sicherlich die Position eines Meisters einnahmen. Auch von ihnen waren alle verheiratet (vgl. Tab. 13).

Von den Meistern kommen wir nun zu den Gesellen: 17 dezidiert als Papiererknecht oder als Knecht eines namentlich genannten Papiermachers bezeichnete Personen konnten gefunden werden. Bei vier weiteren Handwerksgenossen wird explizit das Dienstverhältnis zu einem anderen Papiermacher erwähnt, sodass insgesamt 21 Papiermacher deutlich als Gesellen gekennzeichnet wurden (vgl. Tab. 14 mit Belegen). Bei einem Großteil dieser Personen ist es daher möglich, nicht nur ihren Status als Geselle zu definieren, sondern auch zu ermitteln, bei welchem Papiermacher sie arbeiteten.

2035 Zur Bedeutung des Worts Knecht, das im Spätmittelalter neben ungelernten Dienstleuten auch die Personen bezeichnete, die im heutigen Sprachgebrauch mit Geselle benannt werden, vgl. Wesoly 1985, 99-102; Schulz 1985b, 47-54.

2036 Vgl. Sporhan-Krempel 1972b, 1527; Petz 2006, 272. 
Tab. 13: Papiermühlenbesitzer und Papierermeister in Basel 1450 bis 1550, alphabetisch nach Taufnamen geordnet. ${ }^{2037}$

\begin{tabular}{|c|c|c|c|}
\hline & Personen & $\begin{array}{l}\text { Bezeichnung als } \\
\text { Meister }\end{array}$ & Ehefrau \\
\hline 1. & Andres & $\begin{array}{l}\text { Meister } \\
\text { 1454: Steuern B 15, 7r }\end{array}$ & $\begin{array}{l}\text { verheiratet, Name unbekannt } \\
\text { 1454: Steuern B 15, } 7 \mathrm{r}\end{array}$ \\
\hline 2. & $\begin{array}{l}\text { Anton Gallician } \\
\text { Stegreifmühle (1478/81-1497) } \\
\text { Klingentalmühle (1453-1497) }\end{array}$ & $\begin{array}{l}\text { Meister } \\
\text { 1476: GA A 32, 7r } \\
\text { 1480: GA A 33, 366r } \\
\text { 1495: GA A 40, 245v }\end{array}$ & $\begin{array}{l}\text { 1. Adelheid Tschan } \\
\text { 1453: GA B 6, } 171 \\
\text { 2. Anna Schaffner } \\
\text { 1482: Kartause E, 180r }\end{array}$ \\
\hline 3. & $\begin{array}{l}\text { Bartholome Blum } \\
\text { Hintere Spiegelmühle (1530-1531) }\end{array}$ & & $\begin{array}{l}\text { Clara } \\
\text { 1530: GA B } 25,175 r\end{array}$ \\
\hline 4. & $\begin{array}{l}\text { Claus Dürr } \\
\text { Hintere Spiegelmühle (ab 1531) }\end{array}$ & & $\begin{array}{l}\text { Anna } \\
\text { 1531: GA B 26, 25r }\end{array}$ \\
\hline 5. & $\begin{array}{l}\text { Conrad Grebel } \\
\text { Klingentalmühle (1523-1528) }\end{array}$ & & $\begin{array}{l}\text { Agta } \\
\text { 1523: GA B 22, 333r }\end{array}$ \\
\hline 6. & $\begin{array}{l}\text { Franz Gallician } \\
\text { Stegreifmühle (1497-1523) } \\
\text { Klingentalmühle (1521-1523) }\end{array}$ & & $\begin{array}{l}\text { Barbara Breitschwert } \\
\text { 1512: GA A 51, 5r }\end{array}$ \\
\hline 7. & $\begin{array}{l}\text { Fridlin Hüsler d. Ä. } \\
\text { Rychmühle (1519-1542) } \\
\text { Zunzigermühle (ab 1532) }\end{array}$ & $\begin{array}{l}\text { Meister } \\
\text { 1545: Sfz 25, } 166\end{array}$ & $\begin{array}{l}\text { Agnes } \\
\text { 1532: GA B 26, 133v }\end{array}$ \\
\hline 8. & $\begin{array}{l}\text { Gregorius Dürr } \\
\text { Zunzigermühle (1530-1532) }\end{array}$ & & $\begin{array}{l}\text { Küngoldt } \\
\text { 1530: GA B 25, 146v }\end{array}$ \\
\hline 9. & $\begin{array}{l}\text { Hans Düring } \\
\text { Klingentalmühle (ab 1550) }\end{array}$ & & $\begin{array}{l}\text { Katharina } \\
\text { 1550: GA B 30, 226r }\end{array}$ \\
\hline 10. & $\begin{array}{l}\text { Hans Kielhammer } \\
\text { Zunzigermühle (1496-1523) }\end{array}$ & & $\begin{array}{l}\text { Brigida } \\
\text { 1496: GA B 14, 71v }\end{array}$ \\
\hline 11. & $\begin{array}{l}\text { Hans Lufft } \\
\text { Rychmühle (1494-1519) }\end{array}$ & $\begin{array}{l}\text { Meister } \\
\text { 1521: GA A 54, 306r }\end{array}$ & $\begin{array}{l}\text { Gysella } \\
\text { 1522: GA B 22, 69r }\end{array}$ \\
\hline 12. & $\begin{array}{l}\text { Hans Züricher } \\
\text { Zunzigermühle (1489-1494) } \\
\text { halbe Spisselismühle (1489-1494) }\end{array}$ & & $\begin{array}{l}\text { verheiratet, Name unbekannt } \\
\text { 1492: GA A 39, 181v }\end{array}$ \\
\hline
\end{tabular}

2037 Die Tabelle bietet in einem Überblick die Belege zu den Papiermachern, die als Papiermühlenbesitzer einen Meisterstatus innehatten und/oder Meister genannt wurden, und ihren Ehefrauen. Dabei führt sie nicht alle Belege an, sondern beschränkt sich in den meisten Fällen auf einen Nachweis. Lediglich bei Anton und Michel Gallician führt sie mehrere Nachweise an, da die beiden Brüder vergleichsweise häufig als Meister bezeichnet wurden. Die Quellen befinden sich alle im Staatsarchiv des Kantons Basel-Stadt. 


\begin{tabular}{|c|c|c|c|}
\hline & Personen & $\begin{array}{l}\text { Bezeichnung als } \\
\text { Meister }\end{array}$ & Ehefrau \\
\hline 13. & $\begin{array}{l}\text { Joachim Degenhart } \\
\text { Rychmühle (ab 1542) }\end{array}$ & & $\begin{array}{l}\text { Barbara Mennlin } \\
\text { 1543: Hausurkunden } 716 \mathrm{~N}\end{array}$ \\
\hline 14. & $\begin{array}{l}\text { Jörg Dürr d. Ä. } \\
\text { Hintere Spiegelmühle (1513-1530) } \\
\text { Stegreifmühle (ab 1523) } \\
\text { Hintere Schleife (ab 1525) }\end{array}$ & $\begin{array}{l}\text { Meister } \\
\text { 1518: Sfz 25, } 61\end{array}$ & $\begin{array}{l}\text { Veronica Gallician } \\
\text { 1530: GA B 25, 175r }\end{array}$ \\
\hline 15. & $\begin{array}{l}\text { Michel Gallician } \\
\text { Rychmühle (1467-1494) }\end{array}$ & $\begin{array}{l}\text { Meister } \\
\text { 1479: GA A33, } 142 \\
\text { 1482: GA C 13, 42v } \\
\text { 1495: GA A 40, 247v }\end{array}$ & $\begin{array}{l}\text { Adelheid Phunser } \\
\text { 1464: Lehenarchiv 0, Urk. } 23\end{array}$ \\
\hline 16. & $\begin{array}{l}\text { Michel Gernler } \\
\text { Hintere Spiegelmühle (1487-1513) }\end{array}$ & & $\begin{array}{l}\text { Ursula Segesserin } \\
\text { 1513: GA B 19, 182r }\end{array}$ \\
\hline 17. & $\begin{array}{l}\text { Peter Höfflin } \\
\text { Hintere Spiegelmühle (1481-1487) }\end{array}$ & & $\begin{array}{l}\text { 1. Margreth } \\
\text { 1472: GA B 9, } 293 \\
\text { 2. Christina } \\
\text { 1487: GA B 12, 40r }\end{array}$ \\
\hline 18. & $\begin{array}{l}\text { Peter Sontach } \\
\text { Klingentalmühle (1528-1550) }\end{array}$ & & $\begin{array}{l}\text { Verena Dölin } \\
\text { 1550: GA B 30, 225v }\end{array}$ \\
\hline 19. & $\begin{array}{l}\text { (Peter) Hans Strub } \\
\text { Zunzigermühle (1487) }\end{array}$ & $\begin{array}{l}\text { Meister } \\
\text { 1487: GA B 12, 13r }\end{array}$ & $\begin{array}{l}\text { Elsin Wesslin } \\
\text { 1487: GA B 12, 13r }\end{array}$ \\
\hline 20. & $\begin{array}{l}\text { Ulrich Züricher } \\
\text { Zunzigermühle (1470-1486) }\end{array}$ & & $\begin{array}{l}\text { Agata } \\
\text { 1470: GA B 9, } 71\end{array}$ \\
\hline
\end{tabular}

Tab. 14: In den Quellen explizit als Gesellen gekennzeichnete Papiermacher in Basel bis 1550 (alle Belege im StABS).

\begin{tabular}{|c|c|c|c|c|}
\hline & Jahr & Person & Quellentext & Beleg \\
\hline 1. & 1454 & Peter & Peter der bappirmacher famulus & Steuern B 12 \\
\hline 2. & 1473 & Ulrich & Ulrich ein bappirmacher knecht & GAC 12,75 \\
\hline 3. & $\begin{array}{l}1475 / \\
1476\end{array}$ & Jacob Parella & $\begin{array}{l}\text { Jacob Parella Anthoni knecht } \\
\text { Meister Anthoni Gallician und Ulrich } \\
\text { Zuricher den bappirmacher an eim, so } \\
\text { dann Peter Festerern und Jacoben iren } \\
\text { knechten am anderen teilen }\end{array}$ & $\begin{array}{l}\text { Steuern B 19, Schil- } \\
\text { lingsteuer } 1475 / 76 \text {, } \\
24 \mathrm{v} \\
\text { GA A 32, 7r }\end{array}$ \\
\hline 4. & 1476 & Peter Fester & $\begin{array}{l}\text { Meister Anthoni Gallician und Ulrich } \\
\text { Zuricher den bappirmacher an eim, so } \\
\text { dann Peter Festerern und Jacoben iren } \\
\text { knechten am anderen teilen }\end{array}$ & GA A $32,7 r$ \\
\hline
\end{tabular}




\begin{tabular}{|c|c|c|c|c|}
\hline & Jahr & Person & Quellentext & Beleg \\
\hline 5. & 1477 & Michel & $\begin{array}{l}\text { Michel bappirmacher Meister Antoniß } \\
\text { knecht }\end{array}$ & GA D 11, 42r \\
\hline 6. & 1477 & Michel Gallician II & $\begin{array}{l}\text { der Langmichel Galician Michel Galician } \\
\text { papirknecht }\end{array}$ & $\begin{array}{l}\text { Steuern B 19, Mark- } \\
\text { zahlsteuer 1477/78, } \\
21 \text { v }\end{array}$ \\
\hline 7. & 1478 & Michel Reri & Michel pappirer knecht genant Rere & $\begin{array}{l}\text { Steuern B 19, Mark- } \\
\text { zahlsteuer 1478/79, } \\
21 \mathrm{r}\end{array}$ \\
\hline 8. & 1478 & Diebolt Hanman & Diepolt von Tann dem bappirer knecht & GA B 10, 266 \\
\hline 9. & 1479 & Anton & Anthony bappirer knecht & $\begin{array}{l}\text { Steuern B 19, Schil- } \\
\text { lingsteuer 1479/80, } \\
20 \mathrm{r}\end{array}$ \\
\hline 10. & 1486 & $\begin{array}{l}\text { Frydlin von } \\
\text { Lornnach }\end{array}$ & Frydlin von Lornnach Zurichers knecht & GA G 2, 82v \\
\hline 11. & 1486 & Melchior & $\begin{array}{l}\text { ein gesell genant Melchior Anthoni Bap- } \\
\text { pirers knecht }\end{array}$ & GAD $13,51 \mathrm{r}$ \\
\hline 12. & 1491 & Oswald Sutter & $\begin{array}{l}\text { Oswald Sutters von Zurchsee des Bappir- } \\
\text { machers [Hans Züricher] knecht }\end{array}$ & GA G 2, 106v \\
\hline 13. & 1494 & Stefan & Steffann Hanns Zürichers knecht & GAE 7, 15v \\
\hline 14. & 1494 & Jacob von Reinach & $\begin{array}{l}\text { Da verbüit Jacob von Rinach dasselb } \\
\text { [Hans Zürichers] gut für vii lb v } \beta \text { lidlonn }\end{array}$ & GA E 7, 15v \\
\hline 15. & 1494 & Adam & $\begin{array}{l}\text { Dessglich Adam sin Leger verbüit dasselb } \\
\text { [Hans Zürichers] gut für xxxv } \beta \text { ouch } \\
\text { lidlonn }\end{array}$ & GAE $7,15 \mathrm{v}$ \\
\hline 16. & 1494 & Caspar Helg & Caspar Helg des Zürichers knecht & GA E 7, 16v \\
\hline 17. & 1500 & Anton Loub & $\begin{array}{l}\text { Zwischen Anthoni Loub und ettlichen } \\
\text { bappyrer gesellen eins, unnd meister } \\
\text { Michel Gallicion dem bappyrmacher } \\
\text { andersteils, alßdann dieselbn gesellen } \\
\text { offneten wie vormals inen erkannt were } \\
\text { das sy meister Michel und iren lidlon } \\
\text { als ouch im vom richter gepotten were, } \\
\text { ußzerichten }\end{array}$ & GA A 43, 70r \\
\hline 18. & 1518 & Oswald Banwart & $\begin{array}{l}\text { Oswald Banwart der Bapirer hatt gesworn } \\
\text { unnd sagt das er vor einem Jar by Meister } \\
\text { Sigmund zu Klůben gedient unnd Bapir } \\
\text { gemacht }\end{array}$ & GA D 23, 26 \\
\hline
\end{tabular}




\begin{tabular}{lllll}
\hline Jahr & Person & Quellentext & Beleg \\
\hline 19.1521 & $\begin{array}{l}\text { Thirion von } \\
\text { Lothringen }\end{array}$ & $\begin{array}{l}\text { Zwischen Thirion von Luthringen dem } \\
\text { Bapirer eins und Joachim Degenhart dem } \\
\text { Bapirer andersteils ist erkannt wordenn } \\
\text { das Tirion der Bapirer Joachimen das zil } \\
\text { bis pfingsten ußdienenn [...] solli }\end{array}$ & GA A 54, 318v \\
& & $\begin{array}{l}\text { Hans Helg der papirer knecht } \\
20.1528\end{array}$ & Hans Helg & Ratsbücher 0 3, 185 \\
21.1539 & Niclaus Bonan & $\begin{array}{l}\text { Niclaus Bonan von Troy ab der Tschan- } \\
\text { panien der papirer [...] demnach er dis } \\
\text { winters alhie by Fridlin Hüslern dem } \\
\text { Bapirer unser Burger gedienndt }\end{array}$ & Ratsbücher D 1, \\
\hline
\end{tabular}

Über die Bürgschaften, die Papiermacher für Berufsgenossen anlässlich des Zunftoder Bürgerrechtserwerbs leisteten, lässt sich der Kreis von Arbeitgebern und Angestellten erweitern. ${ }^{2038}$ Zwar war ein Bürge nicht zwingend auch der Arbeitgeber, dennoch liegt diese Vermutung nahe. So konnten weitere elf Papiermacher, die nicht Mühlenbesitzer waren, mit großer Wahrscheinlichkeit einem Dienstherrn zugeordnet werden. Für Heinrich Halbysen d. J. arbeitete in den 1450er-Jahren der Papiermacher Anton Pastor I. ${ }^{2039}$ In einer von Anton Gallicians Papiermühlen beschäftigt waren die drei Papiermacher Michel Gerbera, ${ }^{2040}$ Bartholome Pass und Marx Trappo. ${ }^{2041}$ Auch Antons Sohn Franz Gallician bürgte für drei Papierer: Peter von Lothringen, Roland von Caselle und Bartholome Pastor. ${ }^{2042}$ Da Franz Gallician zur Zeit der Gewährsübernahmen - 1486 bis 1492 - noch nicht Inhaber einer Papiermühle war, sondern wahrscheinlich in einem der Werke seines Vaters mitarbeitete, war der Arbeitsort der drei Papiermacher vermutlich die Werkstatt von Anton Gallician. Eine mögliche Mitarbeit von Hug Pastor und Wilhelm Frone in Hans Zürichers Papiermühle erschließt sich aus der Bürgschaft Zürichers beim Zunftbeitritt im Jahr 1480 beziehungsweise 1489. ${ }^{2043}$

2038 Vgl. Kapitel 3.3.3.1, S. 375-377, und 3.3.4.1, S. 410-412.

2039 Vgl. StABS, Zunftarchive, Zunft zu Safran 24, 81.

2040 Hans Kälin vermutet, dass Michel Gerbera identisch mit dem 1477 erwähnten Papiermacher Michel ist, einem Knecht Anton Gallicians, vgl. Tab. 14; Kälin 1974, 190. Diese Vermutung liegt aufgrund der Verbindung zu Anton Gallician zwar nahe, ist jedoch nicht gesichert, da noch weitere Papierergesellen mit dem Taufnamen Michel in Basel arbeiteten, vgl. hierzu Anm. 2025.

2041 StABS, Zunftarchive, Zunft zu Safran 24, 164, 180 f. Vgl. Tab. 23. Bartholome Pass und Marx Trappo werden im Eintrittsrodel der Safranzunft zwar nicht explizit als Papiermacher bezeichnet, ihr Herkunftsort, das piemontesische Caselle, sowie ihr Bürge lassen jedoch vermuten, dass sie in der Papierherstellung tätig waren. Zu Caselle vgl. Kapitel 3.3.2.1, S. 349-352.

2042 StABS, Zunftarchive, Zunft zu Safran 24, 189, 208, 223. Vgl. Tab. 23.

2043 StABS, Zunftarchive, Zunft zu Safran 24, 168, 204. Vgl. Tab. 23. Im Jahr 1489 bürgte Hans Züricher zudem für den Papiermacher Wilhelm Varner anlässlich des Bürgerrechtserwerbs. Dies legt die Vermutung nahe, dass es sich bei Wilhelm Frone und Wilhelm Varner um dieselbe Person handelt, vgl. Koelner 1935, 532; Kälin 1974, 195, 204. 
Hans Wetzel von Blaubeuren war vermutlich um 1518 bei Jörg Dürr d. Ä. angestellt. ${ }^{2044}$ Möglicherweise in der Werkstatt seines Schwiegervaters Peter Sontach war der Papiermacher Hans Bussi beschäftigt. ${ }^{2045}$

$\mathrm{Zu}$ diesen elf Papiermachern lassen sich weitere Personen addieren, für die sich eine Verbindung zu einem anderen Papiermacher nachweisen lässt. Wer sich hinter Růll dem Papiermacher verbirgt, der 1491 für Anton Pastor II bei dessen Bürgerrechtsaufnahme bürgte, ist nicht sicher zu sagen. ${ }^{2046}$ Da es sich eigentlich um eine Person handeln musste, die bereits Basler Bürger war, kommt eventuell der Papiermacher Roland von Caselle in Frage, der zwei Jahre zuvor das Bürgerrecht erworben hatte und laut Kälin auch Růll genannt wurde. ${ }^{2047}$ Roland von Caselle besaß selbst allerdings keine Papiermühle, sondern war, wie gerade aufgeführt, wahrscheinlich in Anton Gallicians Werkstätten tätig und bürgte somit vielleicht für einen direkten Kollegen.

Als Pächter von Papiermühlen, die sich im Besitz einer handwerksfremden Person befanden, sind zwei Papierer zu greifen. In den 1460er- und 1470er-Jahren pachtete Bartholome de Conmola ein Werk Heinrich Halbysens d. J. ${ }^{2048}$ Der Papiermacher Joachim Degenhart wurde 1521 als Pächter der Papiermühle von Hans Gallician II beschrieben, der seit dem Tod seines Vaters Anton Gallicians um 1497 Inhaber der Klingentalmühle war. ${ }^{2049}$

Der 1528 erwähnte Papiererknecht Hans Helg, wahrscheinlich ein Sohn Caspar Helgs, arbeitete vermutlich für seinen Schwager Fridlin Hüsler d. Ä., zu dieser Zeit Besitzer der Rychmühle. Meister und Geselle hatten in diesem Jahr eine gewalttätige Auseinandersetzung mit dem Stiftskaplan Jacob Loderer, für die alle drei Beteiligten im September Urfehde schwören mussten. ${ }^{2050}$

Ebenfalls zu einem „Dienstherrn“ zuzurechnen sind die Brüder und Söhne von Papiermühlenbesitzern, die als Papiermacher bezeichnet werden, da davon auszugehen ist, dass sie im Betrieb ihrer Väter arbeiteten, so lange dieser bestand. ${ }^{2051}$ Für weitere 15 Papiermacher konnte weder die Bezeichnung Knecht oder Geselle noch eine direkte Verbindung zu einem Papiermühlenbesitzer nachgewiesen werden (vgl.

2044 StABS, Zunftarchive, Zunft zu Safran 25, 61. Vgl. Tab. 23.

2045 StABS, Zunftarchive, Zunft zu Safran 25, 182. Vgl. Tab. 23.

2046 StABS, Ratsbücher P 1, 311v. Ebenfalls nicht belegt ist, dass Anton Pastor, der zweite dieses Namens, tatsächlich Papiermacher war. Aufgrund der Bürgschaft eines Papiermachers und seiner Herkunft aus dem Papiermacherort Caselle im Piemont ist jedoch davon auszugehen, vgl. Tab. 17; Tab. 19; Tab. 23.

2047 Vgl. Kälin 1974, 200. Leider gibt Kälin nicht an, wie er zu dieser Vermutung kommt.

2048 StABS, Gerichtsarchiv A 28, 118r, 119v. Auch Bartholome (von) Camola, Bartolme Conmorra, StABS, Protokolle, Öffnungsbuch 4, 10v; Zunftarchive, Zunft zu Safran, 24, 116. Vgl. Kälin 1974, 200.

2049 StABS, Gerichtsarchiv A 54, 322v. Vgl. Piccard 1967, 171, 178.

2050 StABS, Ratsbücher O 3, 184-186. Vgl. Kälin 1972a, 12.

2051 Dies betrifft beispielsweise Hans Gallician I, Bruder von Anton und Michel Gallician; Jacob und Claus Gallician, Söhne von Michel Gallician; Jörg Dürr d. J., Sohn von Jörg Dürr d. Ä.; Hieronymus Dürr, Sohn von Claus Dürr; Anton Kielhammer, Sohn von Hans Kielhammer. 
Tab. 15). ${ }^{2052}$ Dennoch ist es wahrscheinlich, dass sie entweder als Geselle oder als Lohnarbeiter in einer der Basler Papiermühlen beschäftigt waren. All diesen männlichen Personen sind drei Frauen hinzuzufügen, die laut den Basler Quellen in der Papierherstellung tätig waren. ${ }^{2053}$

Tab. 15: Nicht als Gesellen bezeichnete und keinem Dienstherrn zuzuordnende Basler Papierer.

\begin{tabular}{|c|c|c|c|}
\hline & Person & Jahr & Beleg (alle StABS) \\
\hline 1. & Odere Nicolau & 1453 & Sfz 24, 67 \\
\hline 2. & Sebastian Franz & $1472-1477$ & $\begin{array}{l}\text { 1472/76: GA C 12, 31; B 10, } 92 \\
\text { Steuern B 19, Markzahlsteuer 1475/76, 26r } \\
\text { Steuern B 19, Markzahlsteuer 1476/77, 48 }\end{array}$ \\
\hline 3. & Marx Reri & 1478 & GA A 33,160 \\
\hline 4. & Werly & 1487 & St. Alban DD 1, 1487/88, 15 \\
\hline 5. & Heinrich in Eda & 1489 & Ratsbücher P 1, 240v \\
\hline 6. & Peter Schlegel & 1489 & St. Peter Urk. 1159 (20.07.1489) \\
\hline 7. & Melchior & 1501 & GAC $17,5 r$ \\
\hline 8. & Diebolt Junkher & $1502-1505$ & $\begin{array}{l}\text { 1502/1505: St. Alban H, } 9 \\
\text { 1502: St. Alban DD 1, 1502, 10v } \\
\text { 1505: St. Alban DD 1, 1505, 15v }\end{array}$ \\
\hline 9. & $\begin{array}{l}\text { Mundyn von } \\
\text { Caselle }\end{array}$ & 1515 & Protokolle, ÖB 7, 160v \\
\hline 10. & $\begin{array}{l}\text { Bartholome von } \\
\text { Caselle }\end{array}$ & 1522 & Sfz 25, 76 \\
\hline 11. & Andres Tröly & 1525 & Sfz 25, 97 \\
\hline 12. & Joseph Velek & 1539 & Protokolle, ÖB 8, 61r \\
\hline 13. & Heinrich Rytz & $1539-1540$ & Protokolle, ÖB 8, 65r; Sfz 25, 146 \\
\hline 14. & Christian Schmidt & 1547 & Sfz 25, 176 \\
\hline 15. & Niclaus Ruckh & 1550 & Ratsbücher D 2, 137v; GA B 30, 225v \\
\hline
\end{tabular}

Die Auswertung nach Meistern oder Papiermühleninhabern sowie Gesellen und anderen Angestellten ergibt ein Verhältnis von 20 Mühlenbesitzern zu 53 Angestellten

2052 Eine Ausnahme bildet eventuell Odere Nicolau, der nach Theodor Gerardy mit dem in der Papiermühle von Heinrich Halbysen d. J. arbeitenden Meister Andres identifiziert werden kann, vgl. Anm. 2227.

2053 Vgl. S. 334 f. 
für den gesamten Untersuchungszeitraum (Tab. 16). ${ }^{2054}$ Hierbei ist zu beachten, dass es sich vermutlich nicht bei allen unselbstständigen Papiermachern um Gesellen im eigentlichen Sinne handelt, das heißt um Angestellte, die mit dem Meister zusammen in der Werkstatt arbeiteten. Vielmehr ist für einige Papiermacher zu vermuten, dass sie den Betrieb als Werkmeister oder Meisterknecht leiteten. Zutreffen mag der Status eines Werkstattleiters vor allem auf Anton Pastor I und Bartholome de Conmola, die beide im Betrieb Heinrich Halbysens d. J. beschäftigt waren. Da Halbysen selbst kein Papiermacher war, benötigte er erfahrene Handwerker, die das Papier produzierten und das Personal anleiteten. Ähnliches trifft auch für Anton Gallician zu, der zwar selbst Papiermacher war, aber vermutlich seit den 1470er-Jahren nicht mehr regelmäßig selbst an der Bütte stand, wie seine zahlreichen geschäftlichen Aktivitäten anzeigen. ${ }^{2055}$ Er und sein Sohn Franz führten zwischen 1479 und 1492 sieben Papiermacher in die Safranzunft ein. Michel Gallician II, auch Langmichel Gallician genannt, war vermutlich aber für Michel Gallician tätig, ${ }^{2056}$ sodass immerhin sechs safranzünftige Papiermacher in diesem Zeitraum in der Klingental- und der Stegreifmühle beschäftigt waren. Einige von ihnen waren sicherlich Meisterknechte oder Werkmeister. Wer diese Position tatsächlich ausfüllte, ist nicht zu ermitteln.

Vergleicht man das auf den gesamten Untersuchungszeitraum ausgedehnte Verhältnis von Meistern/Papiermühlenbesitzern und Gesellen mit dem Zahlenverhältnis dieser beiden Parteien, das die Analyse der Schillingsteuerbücher der Jahre 1475 bis 1481 ergeben hat, so wird deutlich, dass nur ein Bruchteil aller Namen von Papiermachergesellen bekannt ist. Konnten für die 1470er-Jahre sieben oder acht Angestellte für einen Mühlenbesitzer ermittelt werden, so lässt sich für den gesamten Untersuchungszeitraum bis 1550 ein Verhältnis von lediglich zwei bis drei Knechte zu einem Meister fassen. Das sind für das personenintensive Gewerbe der Papierherstellung deutlich zu wenige Knechte je Werkstatt. Wie bereits eingangs erörtert, benötigte man für die Herstellung von Papier mindestens drei gelernte Papiermacher - Schöpfer, Gautscher, Leger - und mindestens ein bis zwei Lohnarbeiter, die für das Zerreißen der Lumpen, das Aufhängen der Bogen und andere Arbeiten zuständig waren. So bleibt der Schluss, dass ein Großteil, ungefähr zwei Drittel, der in der Basler Papiermacherei

2054 Tab. 16 stellt alle in diesem Kapitel erörterten Beziehungen komprimiert dar. Für die jeweiligen Belege vgl. Tab. 13, Tab. 14 und Tab. 15 sowie die Angaben im Text. Die Söhne von Papiermühlenbesitzern, die innerhalb des Untersuchungszeitraums noch nicht selbstständig waren, sind aus diesen Zahlen ausgeklammert. Da die Identifizierung mancher Personen schwierig ist, sind Doppelnennungen nicht ausgeschlossen. Die angegebenen Zahlen sind daher nicht absolut, sondern als Näherungswert zu verstehen. Eine weitere Unschärfe ergibt sich aus der Tatsache, dass z. B. Joachim Degenhart für die betrachtete Zeitspanne zweimal aufgeführt wird: einmal 1521 als Pächter auf der Klingentalmühle von Hans Gallician II und einmal 1542 als Besitzer der Rychmühle.

2055 Vgl. Kapitel 3.3.6.1, S. 458-462. Vgl. auch Piccard 1967, 89 f.; Kälin 1974, 158.

2056 StABS, Steuern B 19, Markzahlsteuer 1477/78, 21v. Vgl. Tab. 14. 
Beschäftigten für den Forschenden nicht greifbar ist. ${ }^{2057}$ Und dies gilt sicherlich nicht nur für die Papierherstellung.

Tab. 16: Dienst- und Pachtverhältnisse zwischen Basler Papiermühlenbesitzern und Papiermachern bis $1550 .{ }^{2058}$

\begin{tabular}{|c|c|c|}
\hline Papiermühlenbesitzer & safranzünftige Angestellte/Pächter & nicht-safranzünftige Angestellte \\
\hline Heinrich Halbysen d. J. & $\begin{array}{l}\text { Anton Pastor I (1455) B } \\
\text { Bartholome de Conmola (1465) }\end{array}$ & \\
\hline Anton Gallician & $\begin{array}{l}\text { Michel Gerbera (1479) B } \\
\text { Bartholome Pass (1483) B } \\
\text { Marx Trappo (1483) B }\end{array}$ & $\begin{array}{l}\text { Jacob Parella }(1475 / 76) \\
\text { Michel }(1477)^{\star} \\
\text { Melchior }(1486)\end{array}$ \\
\hline Franz Gallician & $\begin{array}{l}\text { Peter von Lothringen (1486) B } \\
\text { Roland von Caselle (1490) B } \\
\text { Anton Pastor II (1491) B } \\
\text { Bartholome Pastor (1492) B }\end{array}$ & \\
\hline Michel Gallician & Michel Gallician II (1477) & Anton Loub $(1495,1500)$ \\
\hline Ulrich Züricher & & $\begin{array}{l}\text { Peter Fester (1476) } \\
\text { Frydlin von Lornnach (1486) }\end{array}$ \\
\hline Hans Züricher & $\begin{array}{l}\text { Hug Pastor (1488) B } \\
\text { Wilhelm Frone (W. Varner) (1489) B } \\
\text { Caspar Helg (1494) }\end{array}$ & $\begin{array}{l}\text { Oswald Sutter (1491) } \\
\text { Stefan (1494) } \\
\text { Jacob von Reinach (1494) } \\
\text { Adam (1494) } \\
\text { Agnes Tschan (1494) } \\
\text { Ennelin (1494) }\end{array}$ \\
\hline Hans Sigmund von Aug & & Oswald Banwart (1518) \\
\hline Jörg Dürr d. Ä. & Hans Wetzel (1518) B & \\
\hline Hans Gallician II & Joachim Degenhart (1521) & Thirion von Lothringen (1521) \\
\hline Fridlin Hüsler d. Ä. & & $\begin{array}{l}\text { Hans Helg (1528) } \\
\text { Niclaus Bonan (1539) }\end{array}$ \\
\hline Peter Sontach & Hans Bussi (1548) B & \\
\hline
\end{tabular}

2057 Vgl. hierzu auch Piccard 1967, 155.

2058 Die Kennzeichnung B steht für ein Bürgschaftsverhältnis. Vgl. auch die Zuordnung von Geselle zu einem Meister und einer Mühle, die Hans Kälin für die Zeit bis 1500 vornimmt, Kälin 1974, 176-180. Für die Zugehörigkeit zur Safranzunft vgl. Tab. 23. Der Asteriskus macht darauf aufmerksam, dass es sich bei der gekennzeichneten Person eventuell um eine Doppelnennung handelt, da sie mit einer anderen Person identifiziert werden könnte. 


\begin{tabular}{lll}
\hline Papiermühlenbesitzer & safranzünftige Angestellte/Pächter & nicht-safranzünftige Angestellte \\
\hline unbekannt & Odere Nicolau (1453) & Peter (1454) \\
& Bartholome von Caselle (1522) & Elsin Spelter (1470, [1484, \\
& Andres Tröly (1525) & 1488]) \\
Heinrich Rytz (1539-1540) & Sebastian Franz (1472-1477) \\
Christian Schmidt (1547) & Ulrich (1473) \\
& Diebolt Hanman (1478) \\
& Michel Reri (1478-1479) \\
& Marx Reri (1478) \\
& Anton (1479) \\
& Werly (1487) \\
& Heinrich in Eda (1489) \\
& Peter Schlegel (1489) \\
& Melchior (1501) \\
& Diebolt Junkher (1502-1505) \\
& Mundyn von Caselle (1515) \\
& Joseph Velek (1539) \\
& Niclaus Ruckh (1550) \\
\hline
\end{tabular}

Die finanzielle, soziale und berufliche Lage der Papiermachermeister und -gesellen war vielfältig. Neben den Papiermühlenbesitzern, die vermutlich in eigener Person an der Bütte standen, gab es Mühleninhaber, die zwar selbst das Handwerk beherrschten, deren Hauptbetätigung sich jedoch auf Handels- und Kreditgeschäfte verlegt hatte und die daher einen Betriebsleiter einstellten. Einige Papiermacher, darunter eine als Meister bezeichnete Person, arbeiteten als Pächter in Papiermühlen, deren Besitzer kein Papiermacher war. Damit waren sie zu hundert Prozent für das Funktionieren des Betriebs verantwortlich. Welche Form der Vertrag mit dem Papiermühlenbesitzer annahm, ob es sich um einen Pachtvertrag, einen Verlagsvertrag oder einen Anstellungsvertrag handelte, ist für Basel nur in zwei Fällen fassbar: In einem Pachtvertrag lag wohl das Geschäftsverhältnis zum einen von Heinrich Halbysen d. J. und Bartholome de Conmola und zum anderen von Joachim Degenhart und Hans Gallician II begründet. So klagte Hans Gallician II im Jahr 1521, weil sein Pächter mit den zu zahlenden Zinsen im Rückstand war. ${ }^{2059}$

Auch die Situation der Papiermachergesellen ist als heterogen $\mathrm{zu}$ bezeichnen. Wie anhand der Schillingsteuerbücher deutlich wurde, lebte ein Teil der Gesellen als Dienstperson im Haushalt des Meisters und war somit theoretisch seiner Autorität als Haus- und Dienstherr in allen Bereichen unterworfen. Ein anderer Teil der Gesellen - zwischen 1475 und 1481 ungefähr ein Drittel - wohnte nicht unter dem Dach des Arbeitgebers, sondern führte einen eigenen Haushalt. Von einigen ist bekannt,

$2059 \mathrm{Zu}$ Bartholome de Conmola vgl. StABS, Gerichtsarchiv A 28, 118r, und Anm. 2076-2078. Zu Joachim Degenhart vgl. StABS, Gerichtsarchiv A 54, 322v. 
dass sie verheiratet waren. ${ }^{2060}$ Zudem waren unter den Gesellen auch Hausbesitzer anzutreffen. ${ }^{2061}$ Vermutlich war auch die Stellung der als Papierergesellen definierten Personen innerhalb der Werkstatt sehr unterschiedlich.

Lediglich für einen Papiermacher konnte seine Funktion festgemacht werden. Im Rahmen des Konkursverfahrens gegen den Papiermacher und Papiermühlenbesitzer Hans Züricher, der im Jahr 1494 vor seinen Schulden geflohen war, erfasste das Schultheißengericht im Mai dieses Jahres alle Gläubiger, die auf der Grundlage ihrer jeweiligen Forderungen Besitz von Hans Züricher mit Arrest belegt hatten. ${ }^{2062}$ Darunter war auch eine Person namens Adam, die als Leger von Hans Züricher bezeichnet wurde. ${ }^{2063}$ Dies ist eine für diese Zeit seltene Spezifizierung der Tätigkeit innerhalb der Papiermühle und verweist zudem darauf, dass zwischen den drei Gesellen an der Bütte differenziert wurde.

Noch nicht näher beleuchtet wurde der Themenkomplex der Frauenarbeit. Für das mittelalterliche Basel sind Textzeugnisse, die die Mitarbeit von weiblichem Personal in einer Papierwerkstatt belegen, rar gesät. Geerings Berechnung, nach der ein Fünftel bis ein Drittel der in der Basler Papiermacherei beschäftigten Personen Frauen gewesen seien, ${ }^{2064}$ stützt sich unter anderem auf die fehlerhafte Quellenangabe von Gustav Schönberg, der für den Haushalt von Heinrich Halbysen d. Ä. im Jahr 1446 neun Knechte und drei Mägde anführt, und auf die äußerst unwahrscheinliche Annahme Geerings selbst, dass es sich bei diesen neun Knechten und drei Mägden um die Belegschaft der Allenwindenmühle handelte. ${ }^{2065}$ Tatsächlich führt das betreffende Steuerbuch aus dem Jahr 1446 lediglich einen Knecht und drei Mägde auf, die aller Wahrscheinlichkeit nach im Haushalt Halbysens gearbeitet haben. ${ }^{2066}$

2060 Anton Pastor I war mit Margret Tschan verheiratet, vgl. StABS, Urk. Spital 566 (06.03.1459); Anton Kielhammers Ehefrau hieß Agnes Bernstat, vgl. Gerichtsarchiv A 54, 27v; Diebolt Hanman hatte Agnes von Biel geehelicht, vgl. Gerichtsarchiv B 10, 266; Heinrich Rytz war mit Barbara Grawenstein die Ehe eingegangen, vgl. Ratsbücher D 2, 43r; Michel Reri war mit einer Jonatha verheiratet, vgl. Gerichtsarchiv B 10, 273, und Peter Schlegel hatte mit Agnes Mennli den Bund der Ehe geschlossen, vgl. St. Peter Urk. 1159 (20.07.1489).

2061 Vgl. Kapitel 3.3.5.1, S. 433 f.

2062 StABS, Gerichtsarchiv E 7, 15v-17r.

2063 StABS, Gerichtsarchiv E 7, 15v: Dessglich Adam sin Leger verbüit dasselb gut für xxxvi $\beta$ ouch lidlonn.

2064 Vgl. Geering 1886, 336.

2065 Vgl. Schönberg 1879, 584; Geering 1886, 228, 336; auch Wyler 1927, 8, 114. Gerhard Piccard lehnt die Annahme Geerings zwar ab und identifiziert die Knechte und Mägde als Halbysens Hausgesinde, aber auch er benutzt für seine Erklärung die falschen Zahlen Schönbergs, vgl. Piccard 1967, 41 f. Vgl. auch Kälin 1974, 261 f. mit Anm. 32.

2066 StABS, Steuern B 3, [9 von hinten]: Item Henrich Halbisen der altt/ Item Henrich sin sun und sin wip/Item Jokop und sin wip Halbisen/Item Jerg und Adolf sin knechtt/Item iii jungfrow. Ursprünglich waren zwei Knechte namentlich genannt, der Name Jerg ist jedoch durchgestrichen worden. Die korrekte Wiedergabe des Quellentexts findet sich bei Walter Friedrich Tschudin sowie bei Hans Kälin, vgl. W. Fr. Tschudin 1955, 1; W. Fr. Tschudin 1958, 104; Kälin 1974, 147. 
Der ebenfalls von Geering angeführte Text aus dem Schillingsteuerverzeichnis von 1454 gibt an, dass im Haushalt von Anton Gallician fünf Knechte und zwei Mägde lebten. ${ }^{2067}$ Keine Angaben macht dieser Text über die Art ihrer Beschäftigung. Es ist durchaus möglich, dass eine oder sogar alle zwei Frauen zumindest zeitweise als Hilfsarbeiterinnen in der Papiermühle eingesetzt wurden, wie Geering vermutet. ${ }^{2068}$ Allerdings könnte ebenfalls mit einiger Plausibilität vermutet werden, dass die zwei Mägde ausschließlich Anton Gallicians Frau bei der Versorgung der acht im Haushalt lebenden und bis auf den Hausherrn vermutlich unverheirateten Männer - Anton Gallician, seine zwei Brüder und die fünf Knechte - halfen. Anhand dieser Daten ist es jedenfalls nicht möglich, den Frauenanteil in der Basler Papierproduktion zu eruieren.

So bleiben fünf Belege, die einen Hinweis auf die Mitarbeit von Frauen geben. ${ }^{2069}$ Drei dieser Indizien wurden erstmals von Hans Kälin veröffentlicht. ${ }^{2070}$ Im Jahr 1470 wurde in das Vergichtbuch das Bekenntnis einer Margret Sigristin von Zürich eingetragen, die einer Elsin Spelter in der bappir mulin 1,5 Gulden schuldete. ${ }^{2071}$ Offenbar wohnte - und arbeitete - Elsin Spelter in einer Papiermühle und war damit zum weiblichen Personal der Werkstatt zu zählen. Ein weiterer Beleg aus dem Jahr 1483 nennt eine Elsi papirerin von Zurich, die vor dem Kleinbasler Schultheißengericht eine Aussage über die Schulden machte, die eine Ennelin Webelin bei ihr hatte. ${ }^{2072}$ Vermutlich um dieselbe Person handelte es sich bei Elsin bappirerin, deren Aussage in dem Entführungsfall um ein Kind 1488 in das Kundschaftenbuch des Großbasler Schultheißengerichts aufgenommen wurde. ${ }^{2073}$ Ob nicht sogar alle drei Belege auf dieselbe Person hindeuten, kann leider nicht beantwortet werden. Auch wissen wir nicht, ob Elsi Papiererin tatsächlich im Papiergewerbe arbeitete oder ob sie ihren Beinamen eventuell durch einen Ehemann erhalten hatte, der Papiermacher war.

Zwei weitere, bislang nicht publizierte Hinweise auf in der Papierproduktion beschäftigte Frauen finden sich - wie der Hinweis auf den Leger Adam - im Rahmen

2067 StABS, Steuern B 15, 6v. Vgl. Geering 1886, 315, 336.

2068 Vgl. Geering 1886, 317. Vgl. dagegen Piccard 1967, 152.

2069 Die in der Basler Papiermacherei arbeitenden Frauen wurden bereits in Tab. 16 aufgenommen. 2070 Vgl. Kälin 1974, 199, 201, 203 f.

2071 StABS, Gerichtsarchiv C 11, 360r.

2072 StABS, Gerichtsarchiv P 5, 310v.

2073 StABS, Gerichtsarchiv D 14, 16r: Elsin bappirerin seit das Hans Knol ir swager iren geseit das einer denselben knaben uff ein karren gesetzt und in hinweg gefiert habe. Und diese zugin seit sy wysse wol das der selbig knab Diettrich Stahels sun gewesen und ungeverlich by zweyen Joren sy das ir swager solichs ir geseit habe. Kälin liest hier Hans Kuol und vermutet, dass es sich um Hans Kielhammer handelt, vgl. Kälin 1974, 201. In der Tat ist der Name des Schwagers von Elsin bappirerin nicht eindeutig zu entziffern. Dass der zweite Buchstabe im Beinamen des Schwagers eher als ein „n“ zu lesen ist, lässt das „n“ im Wort knaben vermuten, dass sich im letzten Absatz auf fol. 16r am Ende der letzten Zeile befindet. Liest man allerdings Knol, so fällt eine Gleichsetzung mit Hans Kielhammer von Schaffhausen weg. 
des Konkursverfahrens gegen Hans Züricher im Jahr 1494. Unter den Personen, die eine Geldforderung an Züricher haben, finden sich auch Ennelin lumpenzerrerin und Agnes Zschany die lumpenzerrerin. ${ }^{2074}$ Glücklicherweise ist bei diesen Personen nicht nur erkennbar, dass sie in der Papiermühle Zürichers gearbeitet hatten, sondern auch in welchem Bereich sie tätig waren. Offensichtlich waren sie zum Zerreißen der Lumpen angestellt worden, übten folglich eine Tätigkeit aus, die auch in späteren Jahrhunderten in den Bereich weiblicher Arbeit fiel. Agnes Tschan war vermutlich ein Mitglied der Schindlerfamilie Tschan, die im 15. Jahrhundert im St. Albantal ansässig war und deren männliche Mitglieder im städtischen Schindelhof arbeiteten. ${ }^{2075}$

Ebenso wie die Hinweise auf Frauen in der Papierherstellung sind auch detailliertere Nachrichten über das Papiergewerbe und das Verhältnis zwischen Meister und Gesellen nur vereinzelt anzutreffen. Die vorliegenden Belege betreffen vorwiegend das Einhalten des zu Beginn geschlossenen Pacht- oder Arbeitsvertrags. So verließ der Papiermacher Bartholome de Conmola im Jahr 1465 die Papiermühle Heinrich Halbysens d. J., die er wohl in Pacht hatte, ohne Rücksprache mit dem Besitzer und ließ die für ihn arbeitenden Gesellen zurück. ${ }^{2076}$ Heinrich Halbysen, der die Mühle an sich nahm, versprach vor Gericht, die Gesellen weiter zu beschäftigten und ihnen ihren Lohn zu zahlen. Keinen Monat später kehrte Bartholome de Conmola offensichtlich wieder und das Schultheißengericht entschied, dass Heinrich Halbysen Bartholome die Papiermühle wieder verpachten solle. ${ }^{2077}$ Nach gut zehn Jahren floh Bartholome jedoch erneut - und diesmal endgültig - aus Basel. ${ }^{2078}$

Um handwerkliches Geschick und den Schritt in die Selbstständigkeit geht es in dem nächsten Beispiel. Im Oktober 1476 wurde vor dem Basler Schultheißengericht ein Streitfall zwischen den Papiermühlenbesitzern Anton Gallician und Ulrich Züricher auf der einen Seite und ihren Gesellen Peter Fester und Jacob ${ }^{2079}$ auf der anderen Seite verhandelt. ${ }^{2080}$ Die beiden Gesellen hatten beschlossen, sich selbst-

2074 StABS, Gerichtsarchiv E 7, 15v-16r. Vgl. Anhang V.

2075 Auch Anton Gallicians Frau Adelheid sowie Anton Pastors I Frau Margret entstammten der Familie Tschan, vgl. StABS, Gerichtsarchiv B 6, 123; Urk. Spital 566 (06.03.1459). Vgl. W. Fr. Tschudin 1955, 7; Piccard 1967, 127; Kälin 1974, 155, 202.

2076 StABS, Gerichtsarchiv A 28, 118r. Vgl. W. Fr. Tschudin 1955, 3; Kälin 1974, 200.

2077 StABS, Gerichtsarchiv A 28, 119v. Vgl. Kälin 1974, 200.

2078 StABS, Gerichtsarchiv B 10, 92; E 6, 11v. Vgl. Kälin 1974, 200.

2079 Im Gegensatz zu Peter Fester wurde bei Jacob kein Bei- oder Familienname angegeben. Es ist allerdings zu vermuten, dass es sich bei dieser Person um Jacob Parella handelte, der in den Jahren 1475/76 und 1476/77 im St. Albantal steuerte. Die Steuerbücher belegen zudem, dass, wie bereits beschrieben, zwischen Peter Fester und Jacob Parella eine Verbindung bestand, die immerhin so eng war, dass Peter für Jacob eintrat und in den dritten Fronfasten des Steuerjahres 1476/77 seine Schillingsteuer bezahlte, vgl. StABS, Steuern B 19, Schillingsteuer 1476/77, 22r. Vgl. auch Tab. 14. Hans Kälin vermutete, dass Jacob bei Ulrich Züricher und Peter Fester bei Anton Gallician angestellt war, da er die Einträge aus den Steuerbüchern nicht mit einbezog, vgl. Kälin 1974, $201 \mathrm{f}$.

2080 StABS, Gerichtsarchiv A 32, 7r. 
ständig zu machen und eigen gewerbe an zufahen. Allerdings hatten sie zu Beginn ihres Dienstverhältnisses mit ihren Arbeitgebern eine Vertragslaufzeit vereinbart, die zu erfüllen sie eigentlich gebunden waren. Dennoch schlugen sie anscheinend ihren Meistern vor, sie bereits vor Beendigung des Arbeitsvertrags zu entlassen und für die bisher geleistete Arbeit auszubezahlen. Anton Gallician und Ulrich Züricher wollten die Knechte jedoch nicht freigeben. Sie sagten aus, dass sie keine anderen Gesellen finden könnten, die dieselben handwerklichen Fähigkeiten wie ihre jetzigen Knechte besäßen. ${ }^{2081}$ Damit die beiden Meister keine Einbußen davontrügen, sollten die beiden die vereinbarte Vertragslaufzeit einhalten. Das Gericht entschied zu Gunsten der Meister. Die Gesellen Peter und Jacob mussten noch bis zur Erfüllung des Vertrags bei Anton Gallician und Ulrich Züricher arbeiten oder aber zwei andere, gleich gut qualifizierte Gesellen an ihrer statt stellen.

Der Fortgang dieses Falls lässt sich nur erahnen, da die Vertragslaufzeit leider nicht präzisiert wurde. Allerdings lassen sich Peter Fester und Jacob Parella, wie wir bereits gesehen haben, in den Schilling- und Markzahlsteuerbüchern der Jahre 1475/76 und 1476/77 fassen. ${ }^{2082}$ Im nächsten Steuerjahr 1477/78 wurde nur noch Jacob Parella aufgeführt. ${ }^{2083}$ Das spricht dafür, dass zumindest Peter Fester den Plan, sich selbstständig zu machen, in die Tat umsetzte und dafür aus Basel fortzog. Ob er tatsächlich das notwendige Startkapital für den Kauf oder die Pacht einer Papiermühle besaß, ist unwahrscheinlich, da beide Papiermacher laut der Steuerbücher unvermögend waren. ${ }^{2084}$ Die Bezugnahme auf ihr handwerkliches Geschick ist mehrdeutig zu lesen. War es für die Papierermeister schwierig, geeignete Fachkräfte für die alltägliche Arbeit in einer Papiermühle zu finden? Beherrschten Peter und Jacob die Herstellung besonderer Papiere, etwa großformatiger Bogen? ${ }^{2085}$ Oder nutzten die Meister den Verweis auf das handwerkliche Können ihrer Knechte lediglich als schlagendes Argument? Das Schultheißengericht hielt dieses Argument offenbar für plausibel. Zwischen den Papiermachergesellen bestanden demnach nicht nur Unterschiede in ihrem sozialen Stand, sondern auch in ihren fachlichen Kompetenzen.

2081 StABS, Gerichtsarchiv A 32, 7r: da wider die meister antwurten die knecht kunten besunder arbeit zu irem hantwerk.

2082 StABS, Steuern B 19, Markzahlsteuer 1475/76, 26v; Markzahlsteuer 1476/77, 48v, 49r; Schillingsteuer 1475/76, 22v, 24v; Schillingsteuer 1476/77, 22r.

2083 StABS, Steuern B 19, Schillingsteuer 1477/78, 22r.

2084 Vgl. Kapitel 3.3.5.1, S. 430.

2085 Von den Gallicianbrüdern ist bekannt, dass sie zu den wenigen Papiermachern nördlich der Alpen gehörten, die großformatige Bogen herstellten. Erste Papiere im Regalformat mit dem Gallicianzeichen als Wasserzeichen wurden ab 1467/68 in Inkunabeln verwendet. Zu dieser Zeit hatte Michel Gallician die Rychmühle erworben, sodass ein Zusammenhang zwischen diesen Papieren und der Aufnahme einer eigenen Produktion durch den jüngeren Galicianbruder bestehen könnte. Vgl. Piccard 1967, 90, 165, 307 f.; Ziesche/Schnitger 1980, 1315. 
Der Wunsch nach vorzeitigem Ausscheiden aus dem Dienstverhältnis war ebenfalls Ursache eines weiteren Streifalls zwischen Arbeitgeber und Angestelltem. Im Jahr 1521 standen sich Joachim Degenhart, Pächter der Klingentalmühle, ${ }^{2086}$ und Thirion von Lothringen, beide Papiermacher, vor Gericht gegenüber. Das Gericht erkannte, dass der bei Joachim Degenhart arbeitende Thirion noch bis Pfingsten seinen Verpflichtungen gegenüber seinem Dienstherrn nachzukommen habe. Im Gegenzug dürfe Joachim Degenhart seinen Knecht jedoch nur zu dem Bapirerhanndtwerk bruchenn und ihn ohne seine Einwilligung an niemanden ausleihen. ${ }^{2087}$ Da lediglich das Urteil, nicht aber eine Schilderung der Streitsache vorliegt, kann nur vermutet werden, welche Ereignisse dem Gerichtsverfahren vorausgingen.

Ein vierter Beleg betrifft die eigenmächtige Beendigung des Dienstverhältnisses durch einen Knecht. Der Papierergeselle Niclaus Bonan hatte im Winter 1538/39 bei Fridlin Hüsler d. Ä. gearbeitet und quittierte vor Ablauf der festgelegten Frist den Dienst, indem er Basel einfach verließ. Zwar habe er nach eigener Aussage eigentlich länger in Hüslers Diensten bleiben wollen, sei aber aus Angst vor der Pest, ${ }^{2088}$ an der einige seiner Mitgesellen gestorben seien, geflohen. Dabei habe er, unwissend etwas Falsches zu tun, die Kleider dieser verstorbenen Gesellen, die im Verbot lagen, mitgenommen. ${ }^{2089}$ Der Gedanke, dass ihm diese überstürzte Flucht von seinen Handwerksgenossen, den Papiermachern, negativ ausgelegt und er deshalb aus dem Handwerk ausgeschlossen werden könnte, veranlasste Niclaus Bonan, mit samt der entwendeten Kleidung nach Basel zurückzukehren. ${ }^{2090}$ Hier erwirkte er im April 1539 die briefliche Bestätigung des Bürgermeisters Jacob Meyer und des Basler Rats, dass er nicht mit bösem fürsatz, sondern aus Angst vor dem Tod seine Stelle verlassen

2086 StABS, Gerichtsarchiv A 54, 322v.

2087 StABS, Gerichtsarchiv A 54, 318v: Zwischen Thirion von Luthringen dem bapirer eins und Joachim Degenhart dem bapirer andersteils ist erkannt wordenn das Tirion der bapirer Joachimen das zil bis pfingsten ußdienenn doch das inn Joachim nit wyther dann zu dem bapirerhanndtwerk bruchenn unnd inn niemans onn Tirions willenn lihenn solli.

2088 In den Jahren 1538/1539 und 1541 wurde Basel von der Pest heimgesucht, vgl. Fridolin Ryff 1872, 156, 162; Kraatz 1929, 8; Rosen 1971, 108.

2089 StABS, Ratsbücher D 1, 147r-147v, hier 147r: Wir Jacob Meyger Bürgermeister unnd der Rath der Statt Basel bekennend hiemit, das an dato vor unns erschinen ist Niclaus Bonan von Troy ab der Zschanpanien der papirer unnd hat unns zu erkennen geben, dannach er dis winters alhie by Fridlin Hüslern dem bapirer unnser bürger gedienndt ouch wie er saigt lennger by im zeverharen willens gewesen aber von weg das ettliche siner gesellen an der schüchlichen kranckheit der pestilentz mit tod abganngen vor schrecken und vorcht uffgebrochen, hingezogenn unnd ouch ettliche siner abgestorbnen gesellenn kleydung $u ß$ dem verbott hingetragen. Woher Niclaus Bonan die Kleider genommen hatte und worum es sich bei dem Verbot genau handelte, ist nicht ganz klar. Eventuell lagerten sie nach dem Ableben der pestkranken Gesellen in einer Art „Quarantäne“, das heißt, sie wurden als Maßnahme gegen weitere Erkrankungen isoliert aufbewahrt. Vgl. hierzu Hatje 1992, 69; Kinzelbach 1995, 254 f.

2090 StABS, Ratsbücher D 1, 147r. 
habe und dass ihn deswegen niemand belangen dürfe. ${ }^{2091}$ Diese Episode aus dem Leben des Papiermachergesellen Niclaus Bonan ermöglicht einen kleinen Einblick in die Handwerksorganisation der Papiermacher. Offenbar musste ein Knecht, der vor Ende seines Arbeitsvertrags eigenmächtig und ohne Einwilligung seines Dienstherrn seine Stellung aufgab, damit rechnen, dass er unter seinen Handwerksgenossen verrufen war und in keiner Werkstatt mehr eingestellt wurde. Um diesem Schicksal zu entgehen, musste ein triftiger Grund für das vorzeitige Verlassen des Arbeitsplatzes erbracht werden. Todesfurcht scheint dabei zu den überzeugenden Gründen gehört zu haben. ${ }^{2092}$

Aber nicht nur Gesellen ließen ihre Meister im Stich, auch umgekehrt konnte es zu Klagen kommen, wenn der Arbeitgeber den verabredeten Lohn, den Lidlohn, nicht zahlen konnte oder wollte. ${ }^{2093}$ Im Rahmen der Konkursverhandlungen von Hans Züricher im Jahr 1494 meldeten sechs Angestellte - vier Knechte und zwei Lumpenzerrerinnen - ihre Forderungen für nicht gezahlten Lohn dem Basler Schultheißengericht (vgl. Anhang V). ${ }^{2094}$ Dies macht deutlich, dass Züricher nicht nur die Schulden bei seinen Geschäftspartner nicht begleichen konnte, sondern dass auch seine Angestellten ihren letzten Lohn nicht erhalten halten und nun um ihr Auskommen kämpften.

In eine ähnliche Situation gerieten die Papiermachergesellen, die für den Papiermühlenbesitzer Michel Gallician gearbeitet hatten. Auch er war mehreren Angestellten, die vor Gericht namentlich durch den Papiermacher Anton Loub vertreten wurden, ihren Lidlohn schuldig, offenbar, weil er sich selbst in ernsten finanziellen Schwierigkeiten befand. Bereits 1495, im Jahr nach dem Verkauf der Rychmühle, verlangte Loub die Auszahlung einer Summe, die ihm Michel Gallician schuldig war und bei der es sich möglicherweise um ausstehenden Lohn handelte. ${ }^{2095}$ Ende Juli 1500 klagte der Papiermacher Anton Loub zusammen mit weiteren Papierergesellen wiederholt gegen Michel Gallician. Die Gesellen verlangten die Herausgabe von Pfändern, die sie zur Befriedigung ihres Anspruchs verkaufen konnten. Doch Michel Gallician war nach eigener Aussage nicht in der Lage, dieser Forderung nachzukommen,

2091 StABS, Ratsbücher D 1, 147r-147v.

2092 Vgl. Hatje 1992, 48-53.

2093 Hierbei handelte es sich um einen zu Beginn des Arbeitsverhältnisses dem Arbeitnehmer zugesicherten (Jahres-)Lohn, vgl. Schmidt-Wiegand 1978.

2094 StABS, Gerichtsarchiv E 7, 15v, 16v. So lautet der Eintrag zu Caspar Helg auf fol. 16v: Caspar Helg des Zürichers knecht verbüit desselben gütt fur i lb iiii $\beta$ hürigs lidlonn. Im Konkursverfahren hatte die Forderungen, die sich auf den Lidlohn bezogen, eine privilegierte Stellung: Sie mussten vor allen anderen Ansprüchen erfüllt werden. Vorrangig waren lediglich Grund- und Hauszinsen sowie Begräbniskosten, vgl. Hagemann 1987, 136; Simon-Muscheid 2004, 127-129.

2095 StABS, Gerichtarchiv A 40, 247v-248r. 
da seine Söhne sein gesamtes Gut an sich genommen hatten. ${ }^{2096}$ Ob die Gesellen zu ihrem Recht und damit zu ihrem Lohn kamen, ist nicht bekannt.

\subsubsection{Nürnberg, Reutlingen und Zürich}

Müssen für Basel die Befunde aus den unterschiedlichsten Quellen zusammengetragen werden, so erhellen drei prominente Zeugnisse aus dem süddeutschen Raum schlaglichtartig einige Fragen zur Organisation des Papiererhandwerks im 15. und frühen 16. Jahrhundert. Neben der Reutlinger Papiermacherordnung aus dem Jahr 1527 und der Supplikation des Züricher Druckers Christoph Froschauer von 1535 soll auch die älteste Papiermühle auf deutschem Boden in den Fokus rücken.

Über die erste Nürnberger Papiermühle, die Gleismühle vor den Toren der Stadt, liegt mit dem Püchel von mein geslecht und von abentewr des Kaufmanns Ulman Stromer ein beredtes Zeugnis über die Anfangsjahre des jungen Unternehmens vor. So führte Ulman Stromer alle Personen auf, die von 1390 bis 1398 die Arbeit in der Gleismühle aufnahmen und zu diesem Zwecke einen Treue- und Geheimhaltungseid leisteten. ${ }^{2097}$ Anhand dieser Auflistung lässt sich die Anzahl der in der Papiermühle tätigen Personen gut umreißen. Leider hielt Stromer nicht fest, für welche Tätigkeit die jeweilige Person angestellt worden war und nur manchmal notierte er den Beruf, dies allerdings nur bei Personen, die keine Papiermacher waren. So wurde in den Jahren 1396 und 1398 jeweils ein Zimmermann für Arbeiten in und an der Papiermühle eingestellt. Zudem verpflichtete Ulman Stromer neben seinem Handelsknecht Ulrich Koler auch seinen Schreiber Johannes zur Geheimhaltung. ${ }^{2098}$ Offenbar hatte dieser Einblick in den Arbeitsablauf der Papierwerkstatt, möglicherweise führte er sogar Buch über Rohstoffe und Produkte. ${ }^{2099}$

\footnotetext{
2096 StABS, Gerichtarchiv A 43, 70r: Zwischen Anthoni Loub und ettlichen bappyrer gesellen eins, unnd meister Michel Gallicion dem bappyrmacher andersteils, alßdann dieselbn gesellen offneten wie vormals inen erkannt were das sy meister Michel und iren lidlon als ouch im vom richter gepotten were, ußzerichten, das er nit getan, darumb sy hofften witer erkannt zewerden das inen pfender fur ir schuld geben und verkoufft werden sollten etc. Unnd aber meister Michel under anderen dargetan, er wölt die urtel gern erstattet, aber sine kind haben ime alles das uß dem huß getragen so er gehept deßhalb er weder pfender noch anders zegeben gehept und inn sinem vermögen die urteil witer ze erstatten nit gewesen, id also ward erkannt, das die amptlut mit den gesellen gan unnd wo sy meister Michel gut wissen es syg inn der sunen husern oder sust finden mögen, fur ir schuld geben doch soll meister Michel mit den amptluten inn siner sunen huser gan unnd sin eigen und mit der kinden gut anzeigen.

2097 Vgl. Sporhan-Krempel 1954a, 102 f.; Sporhan-Krempel/Stromer 1960, 85 f., 95 f.

2098 Vgl. Sporhan-Krempel/Stromer 1960, 95 f.

2099 Penibel notiert wurden beispielsweise nach der Regensburger Mühlenordnung aus der zweiten Hälfte des 16. Jahrhunderts die Lumpensorten und ihr Gewicht, vgl. Regensburger Mühlenordnung, in: Blanchet 1900, 86. Vgl. auch Schlieder 1966, 88.
} 
Insgesamt legten in einem Zeitraum von acht Jahren 19 Personen den Eid ab. ${ }^{2100}$ Abzüglich der vier Männer, die nicht direkt mit dem Handwerk der Papiermacherei in Verbindung standen, engagierte Ulman Stromer also 15 Personen, die vermutlich an der Papierherstellung beteiligt waren. Darunter befanden sich mit den Ehefrauen von Erhard, Arnold und Clos Obsser auch drei Frauen, die vermutlich die Hilfsarbeiten wie das Reißen der Lumpen, das Aufhängen der Papiere oder das Sortieren der fertigen Bogen übernahmen. ${ }^{2101}$ Wolfgang Schlieder vermutet hinter dem kleinen Heinzel ein Kind, das ebenfalls zu Hilfsarbeiten herangezogen wurde. ${ }^{2102}$

Wie viele Fachkräfte sich unter den elf Männern befanden, die den Eid leisteten, ist nicht festzustellen. Sicher ist, dass Clos Obsser und Jörg Tirmann vom Fach waren. Clos Obsser nahm als erster die Arbeit in der Gleismühle auf und leistete hierfür Anfang August 1390 den Treueeid. Lore Sporhan-Krempel vermutet in ihm den Mühlenerbauer und damit wohl eher einen Zimmermann, es ist aber auch möglich, dass es sich um einen gelernten Papierer handelte. ${ }^{2103}$ Sicher als erfahrener Papiermacher zu bezeichnen ist Jörg Tirmann, der nur wenige Tage nach Clos Obsser auf zehn Jahre vereidigt wurde. ${ }^{2104}$ Im Januar 1394 schloss er mit Ulman Stromer einen Verlagsvertrag ab, der ihm deutlich mehr Verantwortung, aber kaum mehr Freiheiten verschaffte, da er auf eigenes Risiko produzierte, der Absatz der Ware jedoch in den Händen Stromers lag. ${ }^{2105}$ Bis zu diesem Vertragsabschluss wurden außer Clos Obsser und Jörg Tirmann noch fünf oder sechs Männer sowie die drei erwähnten Frauen angestellt, die die Belegschaft komplettierten. ${ }^{2106}$ Auch die vier danach eingestellten Papiermacher und Gehilfen wurden von Ulman Stromer vereidigt. Wie viele Personen parallel in der Papiermühle arbeiteten, ist nicht festzustellen, ebenso wenig, ob vielleicht einer der Angestellten den Dienst innerhalb des achtjährigen Zeitraums quittierte und seine Arbeitskraft daher durch einen neuen Mitarbeiter ersetzt wurde. Sollten alle 15 Fachkräfte und Hilfsarbeiter zeitgleich in der Werkstatt tätig gewesen sein, dann würde dies der von Peter Tschudin beschriebenen Durchschnittsbelegschaft einer Papiermühle mit einer Bütte entsprechen, während diese Anzahl nach Wolfgang Schlieder die Obergrenze für eine solche Betriebsgröße darstellt. ${ }^{2107}$

Genaue Informationen zur Belegschaft einer Papiermühle bietet die Supplikation des Züricher Druckers Christoph Froschauer. Wie bereits in Hinblick auf die Ausstattung einer Papiermühle erwähnt, präsentierte Froschauer dem Züricher Rat im Jahr

2100 Ulman Stromer 1990a, 96v-99r; Ulman Stromer 1990b, 74-85.

2101 Ulman Stromer 1990a, 97r-97v; Ulman Stromer 1990b, 76-79. Vgl. Schlieder 1966, 90.

2102 Vgl. Schlieder 1966, 88, 90.

2103 Vgl. Sporhan-Krempel 1990b, 178, 180.

2104 Vgl. Sporhan-Krempel/Stromer 1960, 85; Sporhan-Krempel 1990b, 180.

2105 Ulman Stromer 1990a, 96r; Ulman Stromer 1990b, 72 f. Vgl. Kapitel 3.2.3, S. 263.

2106 Wenn der kleine Heinzel tatsächlich ein Kind war, dann beläuft sich die Zahl der männlichen Beschäftigten auf fünf.

2107 Vgl. P. Tschudin 2012a, 128; Schlieder 1966, 107 f., 123. 
1535 eine Kostenkalkulation für den Betrieb der Papiermühle, um eine Reduzierung des Pachtzinses zu erlangen. ${ }^{2108}$ Neben den voraussichtlichen Ausgaben für die benötigten Materialien berechnete der Drucker auch die Personalkosten. Hierfür listete er die verschiedenen Arbeitskräfte, ihre Anzahl sowie ihren jährlichen Lohn auf. ${ }^{2109}$ Für eine Mühle mit zwei Bütten veranschlagte Froschauer zwei Büttenknechte, zwei Gautscher und zwei Leger, folglich pro Bütte das klassische Trio. Den Jahreslohn eines Büttenknechts bezifferte er auf 20 Gulden, ein Gautscher sollte 18 Gulden erhalten und die Arbeit eines Legers wurde mit 12 Gulden entlohnt.

Froschauer machte also bei der Bezahlung einen deutlichen Unterschied zwischen den drei Positionen an der Bütte. Am meisten war die Arbeit des Schöpfgesellen wert. Der Gautscher verdiente bereits ein Zehntel weniger, während der Leger nur 60 Prozent des Lohns eines Büttenknechts erhielt. Wenn die Arbeit von Büttengesellen, Gautscher und Leger unterschiedlich viel wert war und sie dementsprechend entlohnt wurde, dann spricht das für eine konsequente Arbeitsteilung und gegen einen dem Rotationsprinzip unterworfenen Wechsel der Arbeitspositionen. ${ }^{2110}$ Neben diesen drei Papiermachern führte er zudem einen Meisterknecht und einen Mühlenbereiter an, deren Jahreslohn sich auf 34 respektive 25 Gulden belief und damit die herausgehobene Stellung innerhalb des Betriebs verdeutlicht. Der Meisterknecht war der Vorarbeiter der Werkstatt, ihm oblag die Aufsicht über die Gesellen und er sprang dort ein, wo gerade eine Arbeitskraft benötigt wurde. ${ }^{2111}$ Im Verantwortungsbereich des Mühlenbereiters lagen die Aufbereitung der Lumpen zu Faserbrei sowie die Instandhaltung des Stampfwerks. ${ }^{2112}$ Eine weitere Person war für das Glätten vorgesehen. Diesem Glätter wollte Froschauer 20 Gulden jährlich zahlen, also so viel wie einem Büttenknecht. Dies deutet darauf hin, dass dieser Position eine große Bedeutung zugemessen wurde und dass sie nicht zu den Hilfsarbeiten zählte. Für das Zerreißen der Lumpen waren zwei Frauen vorgesehen. Sie sollten anders als die anderen Angestellten keinen Jahreslohn erhalten, sondern mit 2 Batzen pro Tag bezahlt werden. ${ }^{2113}$ Dies spricht dafür, dass die Lumpenzerrerinnen, anders als das übrige Personal, nicht fest angestellt waren. Weitere 6 Gulden kalkulierte Froschauer für zwei Lehrjungen, die vermutlich den Gesellen zuarbeiten und Aufgaben wie das Aufhängen und das Sortieren der Bogen übernehmen sollten. Schließlich führt der Drucker eine Magd auf, die er mit 5 Gulden jährlich entlohnen wollte.

2108 Vgl. Caflisch 1963, 152-158. Vgl. dort auch den Abdruck der Kostenberechnung. Vgl. Kapitel 3.2.2.2, S. 260 f., und Kapitel 3.2.3.2, S. 276 f.

2109 Vgl. Caflisch 1963, 154 f.; Zürcher 1963a, 86. Vgl. auch Briquet 1955a, 98; Häusler 1927, 22; ZaarGörgens 2004, 82; P. Tschudin 2012a, $122 \mathrm{f}$.

2110 Zum sogenannten Rundarbeiten an der Bütte vgl. T. Schulte 1957, 70; Schlieder 1966, 112; Bayerl 1987, $278 \mathrm{f}$.

2111 Vgl. Regensburger Mühlenordnung, in: Blanchet 1900, 78, 80.

2112 Vgl. Regensburger Mühlenordnung, in: Blanchet 1900, 80, 86, 92, 94.

2113 Ein Batzen entsprach dem 15. Teil eines Guldens. 
Froschauers Auflistung wurde von dem Papierermeister und seiner Frau angeführt, für die er keinen Lohn angab, möglicherweise, weil dieser noch verhandelt werden musste. ${ }^{2114}$ Insgesamt bestand die ideale Belegschaft der Züricher Papiermühle im Jahr 1535 aus 16 Personen. Dies war vermutlich die Mindestanzahl für eine Papiermühle mit zwei Bütten. ${ }^{2115}$

Zum Personal einer Papiermühle gehörten in gewisser Weise auch die Mühlenbauer, da sie nicht nur bei der Einrichtung, sondern auch bei der Reparatur der Mühlwerke benötigt wurden. Maria Zaar-Görgens konnte nachweisen, dass lothringische im Mühlenbau spezialisierte Zimmermänner im späten 16. und im 17. Jahrhundert häufig Besitzer von Papiermühlen waren. ${ }^{2116}$ Für Zürich ist bemerkenswert, dass Christoph Froschauer den Papiermühlenmacher Heinrich Schöpfer aus Basel holen ließ, um die städtische Papiermühle neu zu errichten. ${ }^{2117}$ In der Basler Überlieferung konnte dieser Mühlenbauer leider nicht gefunden werden. Überhaupt treten diese Spezialisten in Basler Zeugnissen nicht erkennbar in Erscheinung, obwohl sie für den Betrieb einer Papiermühle eine nicht zu unterschätzende Rolle spielten, wie das Beispiel der Mühle in Frouard bei Nancy zeigt. Sie musste 1477 die Produktion bis auf weiteres einstellen, da die Expertise fehlte, um das beschädigte Werk zu auszubessern. ${ }^{2118}$

Einen Einblick in die Organisation des Handwerks bietet die sogenannte Reutlinger Papiermacherordnung aus dem Jahr 1527, die nicht nur die älteste erhaltene Papiermacherordnung im deutschsprachigen Raum ist, sondern zudem auch noch aus einem südwestdeutschen Papiermühlenstandort stammt. ${ }^{2119}$ Die in einem Druck vorliegende Ordnung wurde von den Reutlinger Papiermachern aufgesetzt und vom Rat bestätigt und umfasst 15 Artikel, wovon einer nachträglich handschriftlich hinzugefügt wurde. ${ }^{2120}$ Arbeitstechnische Aspekte werden in zwei Artikeln verhandelt. Zum einen wurden in Artikel 13 die Pauschtgröße auf sieben Buch und sieben Filze sowie die Tagesleistung einer Papiermühle auf 18 bis 20 Pauscht festgelegt. ${ }^{2121}$ Zum anderen legte der zusätzliche Artikel 15 die Höchstpreise für Lumpen auf 12 Batzen für

2114 Vgl. Zaar-Görgens 2004, 82.

2115 Vgl. P. Tschudin 2012a, 128.

2116 Vgl. Zaar-Görgens 2004, 70, 74 f.

2117 Vgl. Leemann-van Elck 1940, 99.

2118 Vgl. Zaar-Görgens 2004, 61, 70.

2119 Vgl. Sporhan-Krempel 1972b, 1524; Halstrick 1990, 29; Zaar-Görgens 2004, 106. Peter Tschudin führt hingegen die Krakauer Papiermacherordnung von 1546 als älteste an, vgl. P. Tschudin 2012a, 129 mit Anm. 87.

2120 Für den Text der Ordnung vgl. Sporhan-Krempel 1972b, 1571-1574; Halstrick 1990, 142-145.

2121 Vgl. Sporhan-Krempel 1972b, 1574. Vgl. auch Kapitel 2.3.1.2, S. 65. 
einen Zentner weiße Lumpen fest. ${ }^{2122}$ Eine Übertretung dieser Festsetzung wurde mit 4 Gulden geahndet. ${ }^{2123}$

Der Großteil der Artikel betrifft gewerbliche und soziale Fragen. So setzt der erste Artikel die Wahl von drei Gesellen fest, die eine Art Vorstand für die Reutlinger Papiermachergesellschaft bildeten. In ihren Aufgabenbereich fielen unter anderem die Verwaltung der Gesellschaftskasse und die Einholung von Strafgeldern, die Vermittlung von Arbeit an wandernde Gesellen sowie die Rechtsprechung bei Vergehen gegen die Statuten. ${ }^{2124}$ Die weiteren Artikel beziehen sich immer wieder auf das Spannungsverhältnis zwischen gelernten Papiermachern und ungelernten Personen, die sich in der Papierherstellung versuchten oder eine Papiermühle besaßen. Dies spiegelt sich bereits in den zwei Artikeln zur Lehrzeit wieder, in denen festgelegt wurde, wann ein Papiermacher ausgelernt hatte. Die Lehrzeit sollte bei älteren und körperlich kräftigen Jungen, die in der Lage waren am Gautschstuhl zu arbeiten, vier Jahre dauern. Bei jüngeren und körperlich noch nicht reifen Lehrlingen, die lediglich den Legestuhl bedienen konnten, verlängerte sich die Ausbildung auf fünf Jahre. ${ }^{2125}$ Wer die Ausbildung abbrach, durfte weder als Geselle für einen Meister arbeiten noch andere Gesellen für sich arbeiten lassen (Artikel 2 und 3). Dasselbe galt für Lehrjungen oder Gesellen, die ihrem Meister nicht treu und redlich dienten. Verdingte sich eine nicht ausgelernte oder unredliche Person bei einem Meister, so durfte nach Artikel 3 kein gelernter Geselle für denselben Meister arbeiteten. Artikel 4 bestätigt nochmals, dass kein Papiermacher einem Ungelernten dienen dürfe. Wer dennoch für einen Ungelernten oder bei einem Meister, der ungelernte Arbeiter beschäftige, arbeitete, der sollte in Reutlingen keine Arbeit finden, es sei denn, er unterwarf sich der Jurisdiktion der drei Gesellen (Artikel 5).

Der Vorstand der Papiermachergesellschaft war auch für die Vermittlung von Arbeitsstellen zuständig. Kam ein Papiererknecht neu in die Stadt, suchten die drei Gesellen einen Arbeitsplatz für ihn. Nach 14 Tagen sollte er das Gesellengeschenk erhalten, bei dem alle Mitglieder der Papiermachergesellschaft sowie mindestens ein Vorstandsmitglied anwesend sein mussten (Artikel 6). Nahm der Geselle das Geschenk an und wollte weiterhin in Reutlingen arbeiten, so sollte sich nach Artikel

2122 Dies entspricht auch dem Zentnerpreis, den Christoph Froschauer in seiner Kostenaufstellung angibt, vgl. Caflisch 1963, $156 \mathrm{f}$.

2123 Vgl. Sporhan-Krempel 1972b, 1574.

2124 Vgl. Artikel 3, 5, 6, 7, 11 in Sporhan-Krempel 1972b, 1572 f. Vgl. Halstrick 1990, 32 f.

2125 Vgl. Artikel 2 in Sporhan-Krempel 1972b, 1525, 1572. Während Lore Sporhan-Krempel und Gerhard Piccard diese Passage plausibel so deuten, dass das Bedienen der Positionen an Gautsch- und Legestuhl von der körperlichen Kraft der Lehrlinge abhängig war, vermutet Toni Schulte weniger überzeugend in Hinblick auf einen ähnlichen Artikel in der Krakauer Papiermacherordnung von 1546, dass die Ausbildung zum Leger anspruchsvoller sei und daher länger dauerte. Auch Halstrick interpretiert den Paragraphen auf diese Weise. Vgl. Piccard 1960, 608 mit Anm. 30; T. Schulte 1952, 40 mit Anm. 6.; Halstrick 1990, 122. 
7 einer der drei Gesellen erkundigen, ob gegen ihn etwas vorlag. Wenn das nicht der Fall war, dann konnte der fremde Geselle in Reutlingen dienen, jedoch nur unter der Voraussetzung, dass er 8 Pfennig in die Gemeinschaftskasse gab und zudem schwor, die Artikel der Ordnung einzuhalten (Artikel 10). Arme und kranke Gesellen, die neu in die Stadt kamen, sollten - so Artikel 9 - von der Gesellschaft durch eine Spende unterstützt werden.

Bemerkenswert ist, dass nach Artikel 14 jedes Mitglied der Reutlinger Papierergesellschaft diese Ordnung einhalten musste, gleich, wo es sich befand. ${ }^{2126}$ Wer den Statuten zuwiderhandelte, der durfte das Handwerk in Reutlingen nicht mehr ausüben (Artikel 12). Dass die Reutlinger Papiermacher diese Regelungen rigoros umsetzten, zeigt sich am Beispiel ihres Handwerksgenossen Jacob Sichelschmidt d. J., Bürger zu Reutlingen. Im Jahr 1538 schloss er einen Vertrag mit zwei Bürgern in Rothenburg ob der Tauber, in dem er sich verpflichtete, für die beiden eine Papiermühle einzurichten und zehn Jahre lang für sie zu arbeiten. Da die beiden Rothenburger Bürger keine Papiermacher waren, lag ein Verstoß gegen die Reutlinger Ordnung vor. Kaum in seine Heimatstadt zurückgekehrt, wurde Sichelschmidt gefangen genommen. Auf die Intervention des Rothenburger Rats zugunsten des Gefangenen erwiderte die Stadt Reutlingen, dass Sichelschmidt geschworen hatte, der Ordnung nachzukommen, und diesen Schwur gebrochen habe. Daher möge der Rothenburger Rat seine Bürger dazu anhalten, den Vertrag mit Sichelschmidt zu lösen. Dieser wurde schließlich unter der Bedingung, dass er von nun an die Statuten einhalten werde, wieder freigelassen. ${ }^{2127}$

Die Reutlinger Papiermacherordnung regelte zusammenfasst also die Tagesleistung einer Papiermühle, den Lumpenpreis, die Lehrzeit, die Vermittlung von Arbeit, die Unterstützung für arme oder kranke fremde Gesellen sowie das Verhältnis von gelernten zu ungelernten Personen. Nach Sporhan-Krempel entsprang die Bestrebung, ungelernte Arbeiter vom Handwerk auszuschließen, dem Wunsch der gelernten Gesellen, ihre Existenz zu sichern und Konkurrenz durch „Pfuscher“ zu vermeiden. ${ }^{2128}$ Besonders bei durch Kaufleute geführten Papiermühlen sahen sie - so Sporhan-Krempel - die Gefahr, dass ungelernte, eventuell auch billigere Arbeitskräfte eingestellt wurden. ${ }^{2129}$ Insgesamt ist die Reutlinger Papiermacherordnung stark an den Bedürfnissen der Gesellen ausgerichtet. Den Meistern teilte sie keine besonderen Befugnisse zu. Selbst eine Änderung der Tagesleistung konnte ein Meister nur mit Einwilligung der Gesellen durchführen. ${ }^{2130}$ Dass die Reutlinger Papiermacherordnung

2126 Für das ausgehende 16. Jahrhundert konnte Lore Sporhan-Krempel nachweisen, dass auch die Papiermacher von Urach, Esslingen und Rottenburg am Neckar Mitglieder der Reutlinger Papiermachergesellschaft waren, vgl. Sporhan-Krempel 1972b, 1531. Vgl. Halstrick 1990, 46; Zaar-Görgens 2004, 106.

2127 Vgl. Sporhan-Krempel 1972b, $1530 \mathrm{f}$.

2128 Vgl. Sporhan-Krempel 1972b, 1524, 1526.

2129 Vgl. Sporhan-Krempel 1972b, 1527.

2130 Vgl. Sporhan-Krempel 1972b, 1526, 1574. 
offenbar Anklang bei den Gesellen fand, deren Stand sie so umfassend schützte, zeigt der Versuch der Augsburger Papierergesellen, die Ordnung im Jahr 1527 auch in ihrer Stadt einzuführen. Sie scheiterten jedoch am Widerstand ihrer Meister, die vom Rat unterstützt wurden. ${ }^{2131}$

Dieses Beispiel macht deutlich, wie unterschiedlich die Situation der Papiermacher - ob Meister oder Geselle - im deutschen Südwesten des ausgehenden Mittelalters von Standort zu Standort war. Die Reutlinger Verhältnisse konnten und können daher - damals von den Papierergesellen, heute vom Historiker - nicht auf die Lebensund Arbeitssituation in anderen Städten übertragen werden. Wer im Papiergewerbe arbeitete und wie diese Arbeit organisiert war, ist daher nur punktuell zu beantworten. Interessanterweise bestätigen die Beschäftigenzahlen aus Basel, Nürnberg und Zürich die Annahmen der Papierforschung, dass für eine Papiermühle mit ein bis zwei Bütten zwischen sieben und 16 Personen arbeiteten. Wie das Basler Beispiel vor Augen führte, umfassten die Arbeitsbeziehungen zwischen Meister und Geselle häufig das gemeinsame Wohnen im Haushalt des Meisters, der für diese erweiterte Familie unter anderem bei Steuerzahlung verantwortlich war. Neben diesem für das alte Handwerk traditionellen Bild vom ganzen Haus lassen sich jedoch auch Gesellen fassen, die in einem eigenen Haushalt lebten und verheiratet waren. Dass das Verhältnis zwischen Meister und Geselle nicht immer spannungsfrei verlief, zeigen die Fälle, in denen sich Arbeitgeber und Arbeitnehmer vor Gericht gegenüberstanden, zumeist, weil der Geselle seinen Dienst vor Ablauf der vereinbarten Laufzeit quittieren wollte. Aber auch ausstehende Lohnzahlungen, die in den Basler Beispielen durch den Konkurs des Arbeitsgebers bedingt wurden, führten zu gerichtlichen Auseinandersetzungen.

\subsubsection{Herkunft und Migration}

Die geographische Herkunft der Papiermacher ist in doppelter Perspektive eine Untersuchung wert. Zum einen wurde diesem Thema in der Papiergeschichtsforschung bereits einige Beachtung geschenkt. Hervorzuheben ist hier vor allem die Fokussierung auf aus Italien eingewanderte Fachkräfte, die ihr Know-how über die Alpen in die ersten Papiermühlen im deutschsprachigen Raum brachten. ${ }^{2132}$ Dieser Techniktransfer von Süd nach Nord durch italienische Papierer wird für eine Vielzahl von Papiermühlenstandorten geltend gemacht. Für welche Orte im südwestdeutschen Raum diese Vermutungen zutreffen, soll in diesem Kapitel untersucht werden. Zum

2131 Vgl. Hößle 1907, 12.

2132 Vgl. beispielsweise V. Thiel 1932, 113-115; Bockwitz 1935, 51, 54, 56; V. Thiel 1941, 60; Piccard 1967, 75; P. Tschudin 1999, 15; Irsigler 1999, 257, 262-266; Irsigler 2006, 315-317; Zaar-Görgens 2004, 70; Mariani/Pellegrini 2009, 16; P. Tschudin 2012a, $109 \mathrm{f}$. 
anderen ist die Herkunft von Papiermachern im Rahmen sowohl einer historischen Migrationsforschung als auch der Handwerksforschung interessant. ${ }^{2133}$ Unter dem Schlagwort Migration von Handwerkern sollen hierbei alle mittel- bis längerfristigen räumlichen Veränderungen von Personen gefasst werden. Dies betrifft wandernde Gesellen, die sich nur wenige Monate bis Jahre an einem Ort aufhielten, ebenso wie dauerhaft immigrierte Handwerker. ${ }^{2134}$

Für eine statistische Erhebung von Herkunftsdaten und die Ermittlung von Migrationsräumen bietet sich ein möglichst geschlossen überliefertes Quellencorpus gleichartiger Dokumente an. ${ }^{2135}$ So legte das von Rainer Christoph Schwinges geleitete Projekt Neubürger im späten Mittelalter: Migration und Austausch in der Städtelandschaft des Alten Reichs 1250-1550 zur Bestimmung des Migrationsverhaltens von Neubürgern die Neubürgerverzeichnisse verschiedener Städte zugrunde. ${ }^{2136}$ Bei einer Untersuchung der Herkunft einer spezifischen Berufsgruppe kann und darf jedoch auf kein geschlossenes Quellencorpus zurückgegriffen werden, da der Blick je nach Wahl des Corpus auf die Berufsangehörigen verengt werden würde, die beispielsweise Bürger wurden oder einer Zunft beitraten. Da dies aber bei Weitem nicht für alle Handwerker gilt, würden vielen Personen, die sich in anderen Zeugnissen fassen lassen, unter das Radar fallen. Allerdings birgt die Suche nach Angehörigen einer bestimmten Berufsgruppe in den städtischen Dokumenten den Nachteil, dass die so gewonnenen Zahlen nur sehr begrenzt statistisch ausgewertet werden können. Dies resultiert aus der arbeitspraktischen Unmöglichkeit, alle in den Zeugnissen erwähnten Personen dieses Berufs zu erfassen. Des Weiteren muss immer bedacht werden, dass ein großer Anteil an Leuten, die in einem Gewerbe tätig waren, überhaupt keine Erwähnung in den Quellen finden und somit für den Historiker unsichtbar bleiben.

Auch bei den namentlich fassbaren Personen ergeben sich hinsichtlich der Herkunftsbestimmung verschiedene Probleme. ${ }^{2137}$ Zum einen wurde - so auch in den Neubürgerbüchern - nur einem Teil der Personen eine Ortsbezeichnung - teilweise als Bestandteil des Namens - beigefügt. ${ }^{2138}$ Sie ist außerdem kein Garant dafür, dass die betreffende Person tatsächlich gebürtig aus diesem Ort stammte. ${ }^{2139}$ Vielmehr ist es möglich, dass beispielsweise der vorherige Aufenthaltsort, also der Ort, von dem

2133 Vgl. allgemein und einführend S. Hahn 2012. Für das Mittelalter vgl. die bibliographischen Angaben in Schwinges 2002b, 372 mit Anm. 4.

2134 Vgl. den konzisen Überblick in Reininghaus 1999.

$2135 \mathrm{Zu}$ den Problemen der statistischen Erhebung auf der Basis mittelalterlicher Quellen vgl. die Überlegungen in Schwinges 2002b, $371 \mathrm{f}$.

2136 Vgl. den gleichnamigen Sammelband Schwinges 2002, sowie die darin enthaltenen Beiträge Schwinges 2002b und Schulz 2002. Für eine kurze Projektbeschreibung vgl. Gerber/Koch 1994.

2137 Vgl. hierzu Portmann 1979, 25-31; Reininghaus 1982, 26-29.

2138 Das gleiche gilt für Berufsangaben, vgl. Schwinges 2002a, 49 f.; Schwinges 2002b, 372; Koch 2002, 411.

2139 Vgl. Portmann 1979, 79. 
aus die Person in die aktuelle Stadt kam, angegeben wurde. Eventuell trug sie die Ortzuschreibung aber auch schon seit mehreren Stationen mit sich, sodass der Ort nur einer von vielen von der betreffenden Person bewohnten Orten war. Möglich ist auch die Vererbung des Ortsbeinamens an Kinder, die bereits am Zielort geboren waren. Auch die willkürliche Zuschreibung eines Ortsnamens ist denkbar. ${ }^{2140}$ Bei der Analyse der Herkunftsorte von Papiermachern - wie von anderen Handwerksgruppen - ist folglich mit der Ungewissheit zu leben, ob die Personen in dem Ort, der ihnen beigefügt wurde, geboren und aufgewachsen waren, ob sie dort ihre Lehre absolviert oder ob sie dort gearbeitet hatten.

Die Migration von Handwerkern, die das Ziel verfolgten, sich am Bestimmungsort dauerhaft niederzulassen, muss von der zeitlich begrenzten Wanderung der Handwerksgesellen unterschieden werden. ${ }^{2141}$ Während die einen meist nach einer größtmöglichen Integration in die städtische Gesellschaft suchten, hielten sich die anderen nur für einen befristeten Zeitraum von mehreren Monaten oder Jahren in einer Stadt auf, bevor sie weiterzogen. ${ }^{2142}$ Eine numerisch kritische Masse hatten die wandernden Gesellen bereits im 14. und 15. Jahrhundert erreicht, sodass für diese Zeit nicht mehr von einem Einzel-, sondern von einem Massenphänomen auszugehen ist. ${ }^{2143}$ Als Gründe für das Wandern von Handwerksgesellen werden in der Forschungsliteratur unter anderem die Suche nach einer Arbeitsstelle, die berufliche Weiterbildung sowie signifikante Lohnunterschiede zwischen unterschiedlichen Orten genannt. ${ }^{2144}$ Eine tatsächliche Wanderpflicht als Voraussetzung, um Meister werden zu können, wurde für die meisten Handwerke erst gegen Ende des 16. Jahrhunderts oder Anfang des 17. Jahrhunderts eingeführt. ${ }^{2145}$

Auch für die Papiermacherei lässt sich im Untersuchungszeitraum kein Wanderzwang für Gesellen feststellen, oftmals fällt es bereits schwer, die Migration von Gesellen überhaupt zu fassen. Viele Beiträge zur Mobilität von Papiermachern unterscheiden zudem nicht zwischen der Handwerkermigration mit dem Ziel einer langfristigen Ansiedlung in einer Stadt und der Gesellenwanderung als Teil der Ausbildung. ${ }^{2146}$

2140 So macht Wilfried Reininghaus für sein Basler Beispiel darauf aufmerksam, dass Jacob Schvedenland aus Mainz kam, und zieht zudem in Zweifel, dass ein Heynrich von Constantinopel tatsächlich einmal in der Stadt am Bosporus war, vgl. Reininghaus 1982, 28.

2141 Vgl. Reininghaus 1999, 201.

2142 Vgl. Reininghaus 1982, 19-31, hier bes. 21. Allgemein zur Gesellenmigration vgl. H. Ammann 1966; Reininghaus 1981b; Schulz 1985a; Elkar 1999.

2143 Vgl. Reininghaus 1981b.

2144 Vgl. Reininghaus 1982, 23 f.; Schulz 1985a, 74-79; Reininghaus 1999, 201-203.

2145 Vgl. Schulz 1985b, 268. Vgl. auch Reininghaus 1981b, 1 f.; Reininghaus 1982, 22.

2146 So behandelt Maria Zaar-Görgens in ihrer Studie zu den Papiermühlen in der Champagne, in der Grafschaft Bar und in Lothringen unter dem Aspekt eines Technologietransfers ausschließlich längerfristig angelegte Migrationsbewegungen von Papiermachern, vgl. Zaar-Görgens 2004, 69-76; ebenso Irsigler 1999. 
Oftmals treten in der Papiergeschichtsliteratur auch bei diesem Thema anachronistische Vermutungen und die Vermengung oder Aneinanderreihung von Informationen aus über vier Jahrhunderten Handpapiermacherei auf. ${ }^{2147}$ So geht beispielsweise Gerhard Piccard von „unsteten, immer umherwandernden Papiermachergesellen“2148 aus, ohne diese These zu belegen. Im Folgenden sollen anhand des Fallbeispiels Basel die Herkunftsorte von Papiermachern kartiert werden. Zudem werden nicht nur die Papierer betrachtet, die nach Basel kamen, sondern auch diejenigen, die gebürtige Basler waren, sowie diejenigen, die die Stadt am Rheinknie verließen. Ergänzt wird diese Untersuchung durch weitere Beispiele von Papiermachermigration im südwestdeutschen Raum. Ein Exkurs behandelt außerdem die erste Nürnberger Papiermühle. Sie gilt der Forschung immer noch, allerdings zu Unrecht, als ältestes Beispiel dafür, dass italienische Facharbeiter über die Alpen migrierten, um sich in neugegründeten Papierwerken $\mathrm{zu}$ verdingen.

\subsubsection{Basel}

Die Herkunft der Basler Papiermacher war in Hinblick auf einen bestimmten Herkunftsort schon häufig Gegenstand der Papiergeschichtsforschung. Es handelt sich hierbei um den Ort Caselle Torinese im Piemont, aus dem verhältnismäßig viele der in Basel tätigen Papierer stammten. ${ }^{2149}$ Für den Untersuchungszeitraum konnten zwölf Papiermacher ausgemacht werden, die aus dem piemontesischen Ort nach Basel kamen. Hierunter fallen unter anderem die Brüder Anton, Michel und Hans Gallician, die Ende der 1440er-Jahre nach Basel einwanderten. 1451 ist der älteste von ihnen, Anton Gallician, zum ersten Mal in Basler Quellen fassbar. ${ }^{2150}$ Bereits im darauffolgenden Jahr kaufte er die am Rümelinbach gelegene Bluwenmühle. ${ }^{2151}$ Seine beiden Brüder wurden das erste Mal im Jahr 1453 erwähnt, hier allerdings noch ohne Namen. ${ }^{2152}$ Michel Gallician trat namentlich zuerst bei seinem Zunftkauf 1455 in Erscheinung, während Hans Gallician I erst 1459 beim Kauf der halben Spisselismühle mit Namen genannt wurde. ${ }^{2153}$

Einem glücklichen Zufall ist es zu verdanken, dass sowohl für Anton als auch für Michel Gallician das Geburtsjahr ermittelt werden kann. In einer Urkunde vom 24. August 1473 wurde festgehalten, dass Anton Gallician 45 Jahre, sein Bruder Michel

2147 Vgl. beispielsweise Schlieder 1966, 131, 134 f.; Halstrick 1990, 129-131; P. Tschudin 2012a, 130.

2148 Piccard 1967, 155.

2149 Vgl. Geering 1886, 317; Piccard 1967, 75 f.; Kälin 1974, 155, 202 mit Anm. 235, 205; Irsigler 1999, 262 f.; Zaar-Görgens 2004, 71.

2150 StABS, Klosterarchiv, St. Alban A, 119. Vgl. auch Kälin 1974, 155.

2151 StABS, Gerichtsarchiv B 6, 123r. Vgl. Kapitel 3.2.1.1, S. 206 f.

2152 StABS, Gerichtsarchiv E 3, 184r. Vgl. Piccard 1967, 78 f.; Kälin 1974, 156, 344.

2153 StABS, Zunftarchive, Zunft zu Safran 24, 80; Gerichtsarchiv B 8, 43r. Vgl. Kapitel 3.3.4.1 mit Tab. 23 und Kapitel 3.2.1.1, S. 220. 
hingegen 40 Jahre alt sei. ${ }^{2154}$ Der Ältere muss demnach um 1428, der jüngere um 1433 geboren worden sein. Aus diesen Informationen lässt sich ersehen, in welchem Alter die Brüder aus ihrer Heimat aufbrachen, um in einer fremden Stadt zu leben und zu arbeiten: Anton war um die 20 Jahre alt, sein fünf Jahre jüngerer Bruder Michel um die 15 Jahre alt und der jüngste Bruder Hans dementsprechend noch jünger. ${ }^{2155}$ Dass Anton - und damit auch seine Brüder - aus Caselle stammten, belegt der Eintrag in die Fertigungsbücher des Großbasler Schultheißengerichts, in dem 1452 die Übertragung der Bluwenmühle festgehalten wurde. Hier wird Anton Gallician als Anthonien vilociano de Casselis bezeichnet. ${ }^{2156}$ Ebenfalls mit der Herkunftsbezeichnung de Casselis versehen wurde Anton Gallician ein Jahr später im Rahmen des Verkaufs der Bluwenmühle. ${ }^{2157}$ Die Wurzeln des als Langmichel Gallician bekannten Papiermachers, der ein Vetter Anton Gallician war und 1480 in die Safranzunft aufgenommen wurde, lagen vermutlich ebenfalls in Caselle. ${ }^{2158}$

In den 1460er-, 1480er- und 1490er-Jahren kamen sechs weitere Papiermacher aus diesem piemontesischen Ort: Bartholome de Conmola, Bartholome Pass, Marx Trappo, Roland von Caselle, Anton Pastor II und Bartholome Pastor. ${ }^{2159}$ Für den Beginn des 16. Jahrhunderts konnten noch zwei Berufsgenossen entdeckt werden, die denselben Heimatort hatten: Im Jahr 1515 wurde der Papiermacher Mundyn von Caselle Bürger der Stadt Basel, 1522 erwarb Bartholome von Caselle die Safranzunft. ${ }^{2160}$ Im Gegensatz zu diesen sieben Personen, bei denen sich eine konkrete Ortsbezeichnung findet, wissen wir von Odere Nicolau ${ }^{2161}$ und Wilhelm Frone (W. Varner)

2154 StABS, Teichkorporationen, St. Alban A1, 16v; Urkundenbuch der Stadt Basel 1901, Bd. 8, 348, Nr. 441: Ulrich Züricher by drissig und siben jar alt, Michel Gallician der bapirmacher by vierzig jaren alt, Anthonie Gallician ouch der bapirmacher by vierzig und funff jaren alt.

2155 Vgl. Kälin 1974, 155, 157.

2156 StABS, Gerichtsarchiv B 6, 123 r.

2157 StABS, Zunftarchive, Gerbern Urk. 14 (21.03.1453): Anthoni Gallitziani de Casselis der papirmacher ze Basel. Der Herkunftsort von Michel und Hans Gallician wurde in den eingesehenen Dokumenten nicht explizit genannt.

2158 StABS, Steuern B 19, Markzahlsteuer 1477/78, 21v; Zunftarchive, Zunft zu Safran 24, 166. Vgl. Tab. 23, Anm. iii.

2159 StABS, Gerichtsarchiv A 28, 119v; Zunftarchive, Zunft zu Safran 24, 180 f., 208, 215, 223. Vgl. Kapitel 3.3.4.1 mit Tab. 23.

2160 StABS, Protokolle, Öffnungsbücher 7, 160v; Zunftarchive, Zunft zu Safran 25, 76. Vgl. Tab. 19 und Tab. 23.

2161 Aufgrund der großen Ähnlichkeit von „n“ und „u“ ist leider nicht endgültig zu entscheiden, ob es Nicolau oder Nicolan heißen muss. Zudem ist nicht klar, warum Kälin behauptet, dass Nicolau/ Nicolan der „Vorname“ sei. Die anderen Einträge im betreffenden Eintrittsrodel nennen immer zuerst den Taufnamen, dann den Bei- oder Familiennamen. Vgl. StABS, Zunftarchive, Zunft zu Safran 24, 67; Kälin 1974, 202. Vgl. auch weiter unten in diesem Kapitel (S. 359 f.) Theodor Gerardys Vermutung, dass Odere eine Form des Namen Andres sein könnte. 
lediglich, dass sie aus dem Piemont stammten. ${ }^{2162}$ Es ist durchaus möglich, dass auch sie von Caselle nach Basel kamen.

Für einen weiteren Papiermacher - Anton Pastor I - führt Hans Kälin ohne nähere Belege ebenfalls Caselle als Herkunftsort an. ${ }^{2163}$ Für eine Herkunft Anton Pastors I aus Caselle könnte unter Umständen sprechen, dass zwei Basler Papiermacher mit demselben Familiennamen, die jedoch nicht in direkter Verwandtschaft zu Anton Pastor I standen, aus Caselle einwanderten. Es waren dies die bereits erwähnten Anton Pastor II und Bartholome Pastor. Zudem ist 1469 mit Jehan Pastor für die Papiermühle zu Worblaufen bei Bern ein weiterer Papiermacher mit dem Familiennamen Pastor und dem Herkunftsort Caselle belegt. ${ }^{2164}$ Dass der Name Pastor zumindest aber auf die Herkunft aus einem italienischsprachigen Gebiet hinweist, wird dadurch deutlich, dass der Schreiber einer Urkunde vom 6. März 1459 den Namen mit seiner deutschen Übersetzung angibt: Anthonig Pastor zů tutsch genant Hirt der Bapirmacher. ${ }^{2165}$

Der in den Basler Schilling- und Markzahlsteuerbüchern der Jahre 1475/76 und 1476/77 erwähnte Jacob Parella, auch Jacob Parelya genannt, ${ }^{2166}$ stammte möglicherweise aus dem piemontesischen Ort Parella, der ebenfalls bei Turin lag. Auch dort war die Papiermacherei, importiert aus dem nahen Caselle, heimisch: Im Jahr 1471 bauten Meister Franceschino und Meister Giovanni Vach de Casellis ein batitorio papiri in finibus Parellae. ${ }^{2167}$

Ebenfalls von jenseits der Alpen kam der Papiermacher Hans Bussi. Bei der Aufnahme ins Bürgerrecht im Jahr 1548 wurden seinem Namen hinzugefügt: von Hierie $u ß S a v o y e .{ }^{2168}$ Um welchen Ort es sich dabei handelt, ist nicht klar zu entscheiden. ${ }^{2169}$ Festzuhalten ist jedoch, dass Hans Bussi ein Welscher war. ${ }^{2170}$ Der Papiermacher Heinrich in Eda, der nur durch einen Eintrag in das Protokoll über die Bürgerrechtsgebühren in Basel nachweisbar ist, wurde sogar explizit als ein walch bezeichnet. ${ }^{2171}$ Allerdings fehlt für ihn eine genauere Angabe zum Herkunftsort. Da die Bezeichnung

2162 StABS, Zunftarchive, Zunft zu Safran 24, 67: Odere Nicolau der bappir macher von bemund. Vgl. Tab. 23. StABS, Ratsbücher P 1, 300r: Wilhelm Varner van Pemund. Vgl. Tab. 17. Vgl. auch Anm. 2043.

2163 Vgl. Kälin 1974, 202.

2164 Vgl. Fluri jun. 1954, 79; J. Lindt 1964, 77; Fluri jun. 1975, 27. Vgl. Kapitel 3.3.2.2, S. 366.

2165 StABS, Urk. Spital 566 (06.03.1459). Vgl. auch Kälin 1974, 202.

2166 StABS, Steuern B 19, Markzahlsteuer 1475/76, 26v; Markzahlsteuer 1476/77, 49r; Schillingsteuer 1475/76, 24v; Schillingsteuer 1476/77, 22r.

2167 Vgl. Donna d’Oldenico 1962, 9.

2168 StABS, Protokolle, Öffnungsbücher 8, 127v.

2169 Mögliche sind beispielsweise Héry-sur-Alby, Héry-sur-Ugine, das seit 1971 zu Ugine gehört, sowie Les Héris bei Mercury-Gémilly, vgl. http://henrysuter.ch/glossaires/toponymes.html (22.10.2017). Sie alle liegen circa 40 bis 70 Kilometer nördlich bis nordöstlich von Chambéry, sodass zu vermuten ist, dass dort im 16. Jahrhundert ein französischer Dialekt gesprochen wurde.

2170 Zur Bezeichnung Welscher, vor allem während der Burgunderkriege in den 1470er-Jahren, vgl. Sieber-Lehmann 1995, 281-300.

2171 StABS, Ratsbücher P 1, 240v: Item Heinrich in Eda ist ein papirmacher ein walch. 
Welscher sowohl eine Person aus italienisch- als auch aus französischsprachigem Gebiet meinen kann, ist eine konkrete Zuordnung unsicher. ${ }^{2172}$

Ohne diese beiden letzten Personen zählt man zwischen 1450 und 1550 insgesamt 16 Papiermacher italienischer Herkunft, wovon mindestens zwölf Personen aus Caselle Torinese kamen. ${ }^{2173}$

Der Herkunftsort lässt sich noch für 20 weitere Papiermacher ermitteln, die nicht gebürtige Basler waren. Drei Papiermacher kamen wahrscheinlich aus der direkten Umgebung von Basel. Jacob von Reinach, der vor 1494 bei Hans Züricher arbeitete und 1499 das Bürgerrecht erwarb, wanderte aus dem ungefähr 11 Kilometer südlich von Basel gelegenen Dorf Reinach ein. ${ }^{2174}$ Die gleiche Entfernung legte der Papiermacher Hans Düring vor 1550 zurück, der vermutlich aus dem nur wenige Kilometer westlich von Reinach gelegenen Ort Ettingen stammte. ${ }^{2175}$ Frydlin von Lornnach, ein Knecht Ulrich Zürichers, zog, wenn man seinem Namen den Herkunftsort entnehmen kann, vom etwa 12 Kilometer entfernten Lörrach nach Basel. ${ }^{2176}$ Von diesen drei Orten - Reinach, Ettingen und Lörrach - besaß lediglich Lörrach eine eigene Papierproduktion. Sie wurde vermutlich zu Beginn der 1470er-Jahre durch Michel Gallician initiiert. ${ }^{2177}$ Daher ist es denkbar, dass Frydlin, bevor er in Ulrich Zürichers Dienste trat, in der Lörracher Papiermühle gearbeitet hatte.

Aus heutigen schweizerischen Orten, die in einer Entfernung zwischen 90 und 150 Kilometer östlich von Basel lagen, kamen fünf Papiermacher in das St. Albantal. Aus Zürich, das seit 1471 eine eigene Papierproduktion besaß, wanderte vermutlich der Papiermacher Conrad Grebel ein, der 1523 die Klingentalmühle im St. Albantal kaufte. ${ }^{2178}$ Zwar findet sich in Basler Dokumenten keine Herkunftsangabe zu seiner Person, aber ein Conrad Grebel ist 1504 in Züricher Quellen belegt. ${ }^{2179}$ Er arbeitete bei Hans Conrad Grebel in der Papiermühle im Werd und verließ möglicherweise

2172 Vgl. Grimm/Grimm 1922, Bd. 13, 1327-1353.

2173 Vgl. auch Ehrensperger 1972, 286. Hans Kälin bezifferte die von ihm für das 15. Jahrhundert ermittelten Papiermacher auf 49, darunter 19 Papierer italienischer Herkunft. Allerdings zählte er hierbei die in Basel geborenen Nachkommen der italienischen Einwanderer mit, vgl. Kälin 1974, 205. In der vorliegenden Untersuchung werden diese Papiermacher zu den Personen gerechnet, die gebürtige Basler waren, vgl. S. 355 f. Franz Irsigler zählt auch den 1479 in die Safranzunft aufgenommenen Michel Gerbera zu den piemontesischen Papiermachern, vgl. Irsigler 1999, 262. Zur Papiermacherei in Caselle vgl. Donna d'Oldenico 1962, 9-12.

2174 StABS, Gerichtsarchiv E 7, 15v; Protokolle, Öffnungsbuch 7, 67r.

2175 StABS, Gerichtsarchiv B 30, 225v.

2176 Er wurde 1486 im Zuge der Liquidation des Vermögens von Ulrich Züricher genannt, vgl. StABS, Gerichtsarchiv G 2, 82v.

2177 Zur Papierproduktion in Lörrach vgl. Kapitel 3.2.1.12.

2178 Vgl. Kapitel 3.2.1.1, S. 217.

2179 Vgl. Zürcher 1963a, 84 f. 
Zürich gen Basel, nachdem das Werk stillgelegt worden war. ${ }^{2180}$ Hans Kielhammer, oft einfach nur Hans von Schaffhausen genannt, wanderte vor 1475 vermutlich eben aus der hochrheinischen Stadt Schaffhausen ein. ${ }^{2181}$ Aus dem circa 110 Kilometer entfernten Diessenhofen kam vor dem Jahr 1469 der Papiermacher Ulrich Züricher, der zu diesem Zeitpunkt etwa 30 Jahre alt war. ${ }^{2182}$ Da sein Sohn Hans Züricher zum einen bereits 1477 in die Safranzunft aufgenommen wurde und zum anderen die Zunft bei dieser Gelegenheit nicht erneuerte, sondern zur regulären Gebühr erwarb, ist es wahrscheinlich, dass er vor dem Zunfteintritt seines Vaters 1469 geboren worden war und mit ihm aus Diessenhofen nach Basel kam. Der 1491 verstorbene Oswald Sutter, der Geselle bei Hans Züricher war, stammte vom Zürichsee. ${ }^{2183}$ Weder in Schaffhausen noch in Diessenhofen ist für den Untersuchungszeitraum eine Papiermühle belegt. ${ }^{2184}$

Drei weitere Papiermacher stammten vermutlich aus zwei schwäbischen Orten, die ungefähr 230 Kilometer von Basel entfernt lagen. Der 1508 erstmals in Basel belegte Jörg Dürr d. Ä. lebte vorher in Reutlingen, ebenso wie sein vor 1527 nach Basel eingewanderter Verwandter Claus Dürr. ${ }^{2185}$ Der Papiermacher Hans Wetzel hatte vor 1515 den über 200 Kilometer langen Weg von Blaubeuren aus zurückgelegt. ${ }^{2186}$ In Reutlingen war die Papiermacherei vermutlich bereits seit den 1470er-Jahren heimisch, um 1519 arbeiteten dort nachweislich mehrere Papiermühlen. ${ }^{2187}$

Aus dem rund 210 Kilometer entfernten Ettlingen, das bereits vor 1462 ein Papiermühlenstandort war, kam der spätere Papiermühlenbesitzer Hans Lufft vor 1494 in die Stadt am Rheinknie. ${ }^{2188}$ Vermutlich war er seinem Beruf bereits in der badischen Stadt nachgegangen. Unsicher ist die Zuordnung des 1525 erwähnten Papierers Bartholome Blum von Rottenburg. ${ }^{2189}$ Hans Kälin bezweifelt seine Herkunft aus dem mittelfränkischen Rothenburg ob der Tauber, ohne jedoch einen anderen Vorschlag

2180 Vgl. Kälin 1972a, 9. Max Häusler und Gerhard Piccard vermuten hingegen, dass es sich beim Basler Conrad Grebel um den Besitzer der Züricher Papiermühle auf dem Werd, Hans Conrad Grebel, selbst handelte, vgl. Häusler 1927, 15 f.; Piccard 1967, 171. Da Hans Conrad Grebel bereits 1484/85 als Besitzer der Züricher Mühle belegt ist und zudem immer mit dem doppelten Taufnamen genannt wird, ist diese Vermutung unwahrscheinlich.

2181 StABS, Steuern B 19, Markzahlsteuer 1475/76, 22v: Hanß von Schaffhusen. Gerichtsarchiv E 9, 26r: Hansen Schaffhusers genannt Kulhamers bapirmuli. Vgl. auch Kälin 1974, 197.

2182 StABS, Ratsbücher A 1, 226; Protokolle, Öffnungsbücher 5, 29r. Zum Alter Ulrich Zürichers vgl. Anm. 2154.

2183 StABS, Gerichtsarchiv G 2, 106v. Vgl. Kapitel 3.3.1.1, Tab. 14.

2184 Für Schaffhausen vgl. P. Tschudin 1991, $62 \mathrm{f}$.

2185 Zu Jörg Dürr d. Ä. vgl. StABS, Zunftarchive, Zunft zu Safran 25, 27; Protokolle, Öffnungsbücher 7, 139v: Jerg Durr von Ruttlingen. Zu Claus Dürr vgl. StABS, Protokolle, Öffnungsbuch 7, 221r; Zunftarchive, Zunft zu Safran 25, 105: Niclauß Dur der bapirer von Rutlingen.

2186 StABS, Protokolle, Öffnungsbuch 7, 173v: Hans Hetzel von Blowburen der bappirmacher.

2187 Vgl. Sporhan-Krempel 1972b, 1518. Vgl. Kapitel 3.2.1.10.

2188 StABS, Gerichtsarchiv B 13, 167v. Vgl. Kälin 1974, 197. Zu Ettlingen vgl. Kapitel 3.2.1.11.

2189 StABS, Protokolle, Öffnungsbuch 7, 205v. 
zu unterbreiten. ${ }^{2190}$ Peter Tschudin plädiert für den elsässischen Ort Rougemont-leChâteau bei Cernay, früher Rotenburg genannt. ${ }^{2191}$ Denkbar wäre aber auch Rottenburg am Neckar. Für das elsässische Rotenburg spricht, dass das circa 30 Kilometer entfernte Cernay zu den frühen Papiermühlenstandorten im Elsass zählte. ${ }^{2192}$ Aber auch in Rottenburg am Neckar wurde spätestens seit dem Ausgang des 16. Jahrhunderts Papier hergestellt. ${ }^{2193}$

Der elsässisch-lothringische Raum nordwestlich von Basel war Herkunftsregion von fünf Papiermachern. Diebolt Hanman, 1478 erstmals in Basel erwähnt, stammte aus dem elsässischen Ort Thann, der ungefähr 55 Kilometer von Basel entfernt liegt. ${ }^{2194}$ Für den heute direkt neben Thann gelegen Ort Vieux-Thann ist bereits 1463 eine Papiermühle erwähnt. ${ }^{2195}$ Aus Lothringen kamen vier Papiermacher, wobei nur für den 1524 in die Safranzunft aufgenommenen Peter Sontach sowie für Niclaus Ruckh, der Sontachs Witwe heiratete, ein konkreter Ort genannt wird. ${ }^{2196}$ Peter Sontach kam von Bad uß Lutringen nach Basel. ${ }^{2197}$ Vermutlich handelte es sich hierbei um Bains-les-Bains, das 30 Kilometer südlich von Épinal liegt. Eben aus dem circa 150 Kilometer von Basel entfernten Épinal, zeitgenössisch Spinal genannt, stammte der Papierer Niclaus Ruckh. ${ }^{2198}$ Aus welchen Orten die vor 1486 respektive vor 1521 nach Basel gekommenen Papiermacher Peter von Lothringen und Thirion von Lothringen stammten, lässt sich nicht eruieren. ${ }^{2199}$ Es ist jedoch nicht verwunderlich, dass gerade aus dem lothringischen Raum Papierer nach Basel wanderten, da dieser im betreffenden Zeitraum als ein bedeutendes Papiermühlenrevier mit einer großen Ausstrahlung auf die benachbarten Papierproduktionszentren gelten kann. ${ }^{2200}$ Im vogesischen Bains-les-Bains bestand beispielsweise von 1477 bis zur Mitte des 16. Jahrhunderts eine Papiermühle, in der Peter Sontach vor seiner Nieder-

2190 Vgl. Kälin 1990, 173.

2191 Vgl. auch P. Tschudin 1996b, 79, 82.

2192 Vgl. Kapitel 3.2.1.16.

2193 Vgl. Anm. 2126.

2194 StABS, Gerichtsarchiv B 10, 266.

2195 Vgl. P. Schmitt 1960, 79. Vgl. auch Kapitel 3.2.1.16.

2196 Niclaus Ruckh heiratete Verena Dölin, die Witwe Peter Sontachs, vgl. StABS, Gerichtsarchiv B 30, 225v. Vgl. auch Kapitel 3.3.3.1, S. 382.

2197 StABS, Gerichtsarchiv B 24, 201v.

2198 StABS, Ratsbücher D 2, 137v: Niclous Ruckh von Spynall der Bapirer.

$2199 \mathrm{Zu}$ Peter von Lothringen vgl. StABS, Zunftarchive, Zunft zu Safran 24, 189. Zu Thirion von Lothringen vgl. StABS, Gerichtsarchiv A 54, 318v.

2200 Vgl. hierzu die Untersuchung von Maria Zaar-Görgens zu den lothringischen Papiermühlen und der Migration lothringischer Papiermacher, Zaar-Görgens 2004, 24-65, 73-76. Vgl. auch Irsigler 1999, 266-270. Irsigler gibt versehentlich an, dass Thirion von Lothringen in einer Papiermühle der Familie Züricher arbeitete. Die Geschäftsaufgabe Hans Zürichers und sein Konkurs erfolgten jedoch schon 1494, vgl. Kapitel 3.3.5.1, S. 437 f. 
lassung in Basel gearbeitet haben könnte. ${ }^{2201}$ Épinal kann im Untersuchungszeitraum als Mittelpunkt des lothringischen Papiermühlenreviers gelten. ${ }^{2202}$ Bis in die Mitte des 16. Jahrhunderts nahmen dort vier Papiermühlen die Arbeit auf.

Aus einem anderen großen Papiermühlenrevier stammte der Papiermachergeselle Niclaus Bonan. Er wanderte vor dem Jahr 1539 von Troy ab der Tschanpanien nach Basel und kam folglich von einer der zahlreichen Papiermühlen in der ungefähr 350 Kilometern entfernten Stadt Troyes in der Champagne. ${ }^{2203}$ Rund 400 Kilometer legte der Papiermacher Heinrich Rytz zurück, der vor 1539 von Montabaur bei Koblenz in die oberrheinische Bischofstadt kam und damit die nördliche Grenze des bekannten Migrationsraums setzte. ${ }^{2204}$

Damit hatte das Einzugsgebiet der Basler Papiermacher einen Radius zwischen 10 und 400 Kilometern und erstreckte sich in nördliche Richtung bis zum Westerwald, nach Osten bis Blaubeuren, nach Süden bis Caselle im Piemont und nach Westen bis Troyes in der Champagne.

$\mathrm{Zu}$ den soeben aufgeführten 38 Papiermachern, denen in den Quellen ein auswärtiger Herkunftsort zugeschrieben wurde, gesellen sich 14 weitere Personen, bei denen es als erwiesen gilt, dass sie in Basel geboren wurden. Dies gilt zum einen für die Söhne von eingewanderten Papiermachern wie beispielsweise Anton Kielhammer, genannt Schaffhuser. ${ }^{2205}$ Hier wird deutlich, dass der Ortsbeiname vom Vater auf den Sohn übertragen werden konnte, ohne dass der Sohn tatsächlich aus dem betreffenden Ort stammte. Auch die Papierer Franz sowie Jacob und Claus Gallician sind als Kinder von migrierten Papiermachern, nämlich Anton beziehungsweise Michel Gallician, gebürtige Basler. ${ }^{2206}$ Das Gleiche gilt für Gregorius, Jacob und Jörg Dürr d. J., die Söhne von Jörg Dürr d. Ä. ${ }^{2207}$ Auch Hug Pastor, dessen Vater Anton Pastor I in den späten 1440er- oder den frühen 1450-Jahren aus Italien in die Stadt am Rheinknie kam, wurde in Basel geboren. ${ }^{2208}$ Des Weiteren waren zudem Fridlin Hüsler d. Ä. sowie sein gleichnamiger Sohn gebürtige Basler, wobei der Vater von Fridlin Hüsler d. Ä. kein Papiermacher war, sondern einem anderen Beruf nachging: Er war bei der Stadtwache tätig. ${ }^{2209}$ Die Vorfahren der Papiermacher Caspar Helg, Hans Helg, Michel

2201 Vgl. Janot 1952, Bd. 1, 151; Zaar-Görgens 2004, 72.

2202 Vgl. Zaar-Görgens 2004, 40-59.

2203 Zur Champagne als einem der frühesten und größten Papiermühlenreviere in Frankreich vgl. Le Clert 1926; Zaar-Görgens 2004, 17-23.

2204 StABS, Protokolle, Öffnungsbuch 8, 65r; Zunftarchive, Zunft zu Safran 25, 146.

2205 StABS, Gerichtarchiv A 54, 27v: Anthoni Külhamer genannt Schafhuser.

2206 Vgl. Piccard 1967, 126, 135, 145 f.; Kälin 1974, 162 f., Tafel 6 u. 7.

2207 StABS, Lehenarchiv O, Urk. 93 (07.06.1535): Jacobenn und Jörgen Dürren gebrüderenn wylennt Jörg Dürren des bapirers seligenn gelassenen eelichen kinden unnd Gregorius Dürr.

2208 StABS, Gerichtsarchiv C 12, 222: Hans und Huglin Bastor gebrüder wilent Anthonien Bastor des Bappirmachers seligen eliche sune.

2209 Vgl. Kälin 1972a, 12. 
Gernler und Christian Schmidt, die ebenfalls in Basel geboren waren, arbeiteten auch in anderen Berufen. So stammten Caspar Helg und Hans Helg, vermutlich ein Sohn Caspars, ursprünglich aus einer Müllerfamilie, Michel Gernlers Vater Heinrich Gernler war Seiler und der Vater von Christian Schmidt, Jerg Schmidt, war Pulverkrämer. ${ }^{2210}$

Da in der Geschichtsforschung bislang vor allem Bürgerbücher in Hinblick auf Migrationsräume ausgewertet und damit nur Neubürger nach ihrem Migrationsverhalten befragt wurden, ${ }^{2211}$ bietet es sich an, auch bei den Basler Papiermachern diejenigen in den Fokus zu rücken, die als Bürger aufgenommen wurden und im Bürgerbuch verzeichnet sind. Hier finden sich für den Untersuchungszeitraum 16 Papiermacher, denen eine Ortsbezeichnung beigefügt wurde (vgl. Tab. 17). ${ }^{212}$ Vier Papiermacher kommen mit den Ortsnennungen Reinach, Ettingen, Schaffhausen und Diessenhofen aus dem Gebiet der heutigen Schweiz, drei Papiermacher stammten mit der Nennung der Städte Reutlingen und Blaubeuren aus dem schwäbischen Raum. Der Westerwald war das Herkunftsgebiet eines weiteren Berufsgenossen. Ein Papiermacher, Peter Sontach, wanderte, wie wir bereits gesehen haben, vom vogesischen Bains-les-Bains nach Basel ein. ${ }^{2213}$ Nicht eindeutig identifizierbar bleiben immer noch die Bezeichnung Rottenburg sowie die Bezeichnung als Welscher. Vier Papiermacher stammten aus dem Piemont, bei zwei von ihnen wird explizit Caselle als Herkunftsort angegeben, ein weiterer kam aus Savoyen nach Basel.

Vergleicht man diesen Befund mit der Einbürgerungsstatistik von Rolf Portmann, so fallen die letzten drei Papiermacher aus der Betrachtung heraus, da Portmann die Daten zu den Herkunftsangaben nur bis 1527 ermittelt hat. Im Zeitraum von 1358 bis 1527 wurden 71 Prozent der Neubürger mit einer Herkunftsbezeichnung versehen. Bei den bis 1527 im Bürgerbuch fassbaren Papiermachern wurde die Herkunft bei knapp 60 Prozent - 13 von 22 Personen - angegeben. ${ }^{2214}$

Beim Vergleich mit Portmanns Daten fällt zunächst auf, dass er für die Herkunftsregion Piemont im Untersuchungszeitraum keine einzige Person angibt. ${ }^{2215}$ Dieses Fehlen entstand wahrscheinlich durch die Einschränkung der Auswertung auf

2210 Vgl. Kälin 1974, 196, 201; Koelner 1935, 533.

2211 Vgl. Portmann 1979, 71-85; Schwinges 2002b.

$2212 \mathrm{Zu}$ den Bürgerbüchern vgl. Kapitel 3.3.3.1.

2213 Im Öffnungsbuch lautet die Herkunftsbezeichnung für Peter Sontach von Badenn, vgl. StABS, Protokolle, Öffnungsbuch 7, 221r. Wäre dieser Eintrag der einzige Beleg, der Peter Sontach einen Ort beifügt, so fiele die Identifizierung des Orts schwer. Mit Baden könnte sowohl das heutige BadenBaden, Baden im Aargau als auch eben Bains in Lothringen gemeint sein. Vgl. hierzu Reininghaus 1982, 27. Erst durch die Präzisierung des Orts Bad in einem Eintrag in den Fertigungsbüchern des Schultheißengerichts wird deutlich, dass es sich um das lothringische Bains-les-Bains handeln muss, vgl. Anm. 2197.

2214 Vgl. hierfür Kapitel 3.3.2.1, Tab. 17, und Kapitel 3.3.3.1, Tab. 19.

2215 Vgl. Portmann 1979, 129. 
die Orte, die viermal oder mehr genannt wurden. Portmann erfasste somit nur für 58 Prozent der Neubürger von 1358 bis 1527 den Herkunftsort. ${ }^{2216}$

Tab. 17: Ins Basler Bürgerbuch aufgenommene Papierer mit Herkunftsangaben bis $1550 .{ }^{2217}$

\begin{tabular}{|c|c|c|c|c|}
\hline & Jahr & Person & Herkunftsort & Signatur \\
\hline 1. & 1469 & Ulrich Zurcher von Diessenhofen & Diessenhofen & A 1,226 \\
\hline 2. & 1488 & Hanns Külhamer von Schaffhusen & Schaffhausen & ÖB $6,112 r$ \\
\hline 3. & 1489 & Roland van Pemund & Piemont & P 1, 240r \\
\hline 4. & 1489 & $\begin{array}{l}\text { Heinrich in Eda ist ein papirmacher } \\
\text { ein walch }\end{array}$ & $\begin{array}{l}\text { französisch-oder italienisch- } \\
\text { sprachige Region }\end{array}$ & P 1, 240r \\
\hline 5. & 1489 & Wilhelm Varner van Pemund & Piemont & P 1, 300r \\
\hline 6. & 1492 & $\begin{array}{l}\text { Bartholome Pastor von Casselln uß } \\
\text { Piemont }\end{array}$ & Caselle/Piemont & ÖB $7,17 \mathrm{r}$ \\
\hline 7. & 1499 & Jacob von Reinach & Reinach & ÖB $7,67 r$ \\
\hline 8. & 1511 & Jerg Durr von Ruttlingen & Reutlingen & ÖB $7,139 v$ \\
\hline 9. & 1515 & Mundyn von Casel & Caselle & ÖB $7,160 v$ \\
\hline 10. & 1515 & Hans Hetzel von Blowburen & Blaubeuren & ÖB $7,173 v$ \\
\hline 11. & 1525 & Bartholome Blum von Rottenburg & $\begin{array}{l}\text { Rottenburg a. N., Rotenburg im } \\
\text { Elsass oder Rothenburg o. d. T. }\end{array}$ & ÖB $7,205 v$ \\
\hline 12. & 1527 & Claus Dürr von Rutlingen & Reutlingen & ÖB $7,221 \mathrm{r}$ \\
\hline 13. & 1527 & Peter Sonnentag von Badenn & Bains-les-Bains & ÖB $7,221 r$ \\
\hline 14. & 1539 & Heinrich Rytz von Montapaur & Montabaur & ÖB $8,65 r$ \\
\hline 15. & 1548 & $\begin{array}{l}\text { Johann von Bussy von Hierie uß } \\
\text { Savoye }\end{array}$ & Savoyen & ÖB $8,127 v$ \\
\hline 16. & 1550 & Hanns Thuring von Ettingenn & Ettingen & ÖB $8,135 r$ \\
\hline
\end{tabular}

Um eine Vorstellung von den Entfernungen zu erhalten, die die zwischen 1451 und 1527 in das Basler Bürgerrecht aufgenommen Personen zurücklegten, seien an dieser Stelle die von Portmann ermittelten Zahlen angeführt. Der größte Anteil, 37 Prozent, kam aus Orten, die zwischen 16 und 75 Kilometer entfernt lagen. Darauf folgten mit 27 Prozent die Neubürger, deren Migrationsradius zwischen 151 und 300 Kilometern

2216 Vgl. Portmann 1979, 78. Zwar stammten vier Papiermacher aus dem Piemont, aber nur bei dreien wurde dies explizit angegeben. Bei dem Papiermacher Mundyn findet sich lediglich die Bezeichnung Caselle.

2217 Die Belege stammen aus: StABS, Ratsbücher A 1; Ratsbücher P 1; Protokolle, Öffnungsbücher. 
betrug. Die mittlere Distanz von 76 bis 150 Kilometern bewältigten 20 Prozent der zugezogenen Neubürger. Relativ gering fallen hingegen die Anteile der Personen aus, die bis zu 15 Kilometer und über 300 Kilometer wanderten: Sie machten nur knapp 9 beziehungsweise gut 7 Prozent aus. ${ }^{2218}$ Setzt man die Anzahl der in das Bürgerbuch eingetragenen Papiermacher in Prozentzahlen um, muss man sich darüber im Klaren sein, dass sich bei nur elf klar identifizierbaren Herkunftsangaben lediglich eine Tendenz ablesen lässt (vgl. Tab. 17).

Für die geringe Distanz von bis zu 15 Kilometern sowie für den Entfernungsbereich von 76 bis 150 Kilometern ähnelt der Anteil der Papiermacher dem Anteil aller Neubürger. Eine leichte Verschiebung macht sich im Distanzspektrum von 151 bis 300 Kilometern bemerkbar. Hier lag der Anteil der Papiermacher höher als derjenige aller Neubürger. Ein deutlicher Unterschied bestand jedoch in dem Anteil der Personen, deren Herkunftsorte zwischen 16 und 75 Kilometer und über 300 Kilometer entfernt lagen. Für den mittleren Entfernungsradius, aus dem 37 Prozent aller Neubürger einwanderten, konnte kein Papiermacher ausfindig gemacht werden, während der große Entfernungsbereich von über 300 Kilometern von mehr als einem Drittel der Papierer, nämlich gut 36 Prozent, zurückgelegt wurde (vgl. Tab. 18).

Tab. 18: Vergleich der Migrationsdistanz aller Basler Neubürger und der Neubürger mit Beruf Papierer in Kilometern 1451 bis $1527 . .^{2219}$

\begin{tabular}{llllll}
\hline 1451-1527 & $\mathbf{1 5}$ & $\mathbf{1 6 - 7 5}$ & $\mathbf{7 6 - 1 5 0}$ & $\mathbf{1 5 1 - 3 0 0}$ & $\mathbf{3 0 0}$ \\
\hline Alle Neubürger & $8,7 \%$ & $37 \%$ & $20 \%$ & $27 \%$ & $7,3 \%$ \\
Neubürger mit Beruf Papierer & $9 \%$ & $-\cdots$ & $18,2 \%$ & $36,4 \%$ & $36,4 \%$ \\
Alle Papierer mit Ortsangabe & $6,4 \%$ & $3,2 \%$ & $19,4 \%$ & $19,4 \%$ & $51,6 \%$ \\
\hline
\end{tabular}

Noch markanter wird dieser Befund, wenn man nicht nur die Papiermacher betrachtet, die ins Bürgerbuch eingeschrieben wurden, sondern alle 31 Basler Berufsgenossen bis 1527, für die sich eine eindeutige Herkunftsangabe ermitteln ließ. ${ }^{2220}$ Davon stammten mehr als die Hälfte (16 Personen) aus Orten, die über 300 Kilometer entfernt waren. Knapp ein Fünftel (sechs Personen) kam aus einem Entfernungsbereich

2218 Vgl. Portmann 1979, 83.

2219 Angaben zu allen Neubürgern nach Portmann 1979, 83.

2220 Die Papiermacher Niclaus Bonan, Heinrich Rytz, Hans Bussi, Niclaus Ruckh und Hans Düring fallen aus der Betrachtung heraus, da sie erstmals nach 1527 erwähnt wurden. Ebenfalls nicht mit einbezogen wurden die nicht eindeutigen Herkunftsangaben von Heinrich in Eda und Bartholome Blum. Zu beachten ist außerdem, dass dieser Vergleich gewiss methodisch schwierig ist, da man nicht weiß, woher die anderen Basler Einwohner stammten, die keine Bürger wurden. Dennoch soll eine Tendenz aufgezeigt werden. 
zwischen 151 und 300 Kilometern. Die übrigen 28 Prozent (neun Personen) wanderten aus einem Radius von bis zu 150 Kilometern ein. Im Vergleich dazu legten gut 65 Prozent aller Basler Neubürger eine Entfernung von lediglich bis zu 150 Kilometern zurück und nur gut 7 Prozent bewältigten eine Reise von mehr als 300 Kilometern.

Der relativ hohe Anteil an weitgereisten Personen innerhalb der Berufsgruppe der Papierer verweist darauf, dass es sich bei der Papiermacherei um ein spezialisiertes Handwerk handelte, für dessen Ausübung häufig die Expertise von gut ausgebildeten Fachkräften benötigt oder gewünscht wurde. ${ }^{2221}$ Ähnliches konnte Bruno Koch anhand der Bürgerbücher verschiedener Städte für andere spezialisierte Gewerbe wie beispielsweise Apotheker, Bildhauer, Büchsenmeister, Buchdrucker und Schlosser beobachten. ${ }^{2222}$ Diese Personen wurden durch ihr Know-how häufig zu Innovationsträgern, die neue Arbeitstechniken oder sogar neue Handwerkszweige einführten. Allerdings muss hier eine Unterscheidung zwischen dauerhaft umsiedelnden Handwerkern und wandernden Gesellen getroffen werden. Rainer Elkar macht darauf aufmerksam, dass es entgegen der Forschungsmeinung nur selten Handwerksgesellen auf Wanderschaft waren, die zur Verbreitung neuer Ideen und Techniken beitrugen. ${ }^{2223}$ Den bedeutenderen Anteil an der Diffusion technischen Know-hows hatten spezialisierte Fachkräfte, die entweder aus eigenem Antrieb abwanderten oder durch Unternehmer abgeworben wurden. ${ }^{2224}$ Diese Spezialistenmigration konnte von den Fachkräften auf eigene Faust unternommen werden, es gab aber auch von Kaufleuten oder Landesherren initiierte Anwerbungsbestrebungen, um ein bestimmtes Gewerbe vor Ort zu etablieren. ${ }^{2225}$

Dieses Vorgehen ist auch für die Basler Papiermacherei zu vermuten. Namentlich fassbar wird in den ersten Jahren lediglich der Name des Kaufmanns Heinrich Halbysen d. Ä., der durch den Kauf und die Einrichtung einer Papiermühle die nötige Infrastruktur schuf, aber für die Ausübung des Gewerbes auf Experten angewiesen war, die er vermutlich aus Italien anwarb. ${ }^{2226}$ Theodor Gerardy vermutet, dass der seit 1453 safranzünftige Odere Nicolau identisch mit dem in der Papiermühle von Heinrich Halbysen d. J. beschäftigten Meister Andres sei. ${ }^{2227}$ Er leitet die personelle Verschmelzung dieser beiden Namen von einer Gleichsetzung des Namens Odere, der

2221 Vgl. Koch 2002, 414-416.

2222 Vgl. Koch 2002, 416.

2223 Vgl. Elkar 1999, bes. 222.

2224 Vgl. Elkar 1999, bes. 222.

2225 Vgl. Holbach 1999.

2226 Vgl. Piccard 1967, 75; Irsigler 1999, 262; Zaar-Görgens 2004, 71.

2227 Vgl. Gerardy 1968c, 57. Zudem setzt Gerardy Odere und Andres mit dem einmalig erwähnten Papiermacher Udrett gleich, mit dem Anton Gallician und seine Brüder 1453 in geschäftlicher Beziehung standen, vgl. Gerardy 1986, 15 f. Vgl. auch die Quellenstelle in: StABS, Gerichtsarchiv E 3, 184r. Hans Kälin lehnt die Gleichsetzung von Meister Andres und Odere Nicolau ohne Begründung ab, vgl. Kälin 1974, 283 mit Anm. 223. 
auf der letzten Silbe zu betonen sei und in der Aussprache dann dem französischen André ähneln würde, mit dem Namen Andreas oder - in der mittelalterlichen oberdeutschen Form - Andres ab. Diese Hypothese erscheint vor dem Hintergrund seiner weiteren Argumentation durchaus plausibel. Verwunderlich sei es nämlich, dass Odere Nicolau nur ein einziges Mal, anlässlich seiner Aufnahme in die Zunft, belegt ist. ${ }^{2228}$ Bringe man nun allerdings diese beiden Namen zusammen, so löse sich, wie Gerardy darlegt, das Rätsel um die fehlende Zunftzugehörigkeit von Meister Andres, der den Betrieb von Heinrich Halbysen d. J. leitete, aber nicht, wie die anderen Werkmeister, im Eintrittsrodel der Safranzunft verzeichnet wurde.

Für die vorliegende Untersuchung ist die Hypothese noch aus einem anderen Grund von Bedeutung. Wenn Meister Andres mit Odere Nicolau identisch war, dann kam der erste namentlich bekannte Betriebsleiter der Papiermühle Halbysens ebenfalls aus dem Piemont. Somit ist für einen Großteil der ersten in Basel belegten Papiermacher eine Herkunft aus Oberitalien zu verzeichnen. Die ersten namentlichen Nennungen von Papiermachern fallen in die 1450er-Jahre. Hier ist zunächst für das Jahr 1451 Anton Gallician zu nennen. ${ }^{2229}$ In den Jahren 1453 bis 1455 folgen Michel Gallician, Anton Pastor I und Peter Papiermacher sowie Odere Nicolau und Meister Andres. Im Rechnungsjahr 1457/58 wurde diese Gruppe durch Hans Gallician I und den Papiermacher Passion ergänzt. ${ }^{2230}$ Nun ist lediglich für die Papiermacher Peter und Passion (Bastian) nicht bekannt, woher sie stammten. Die anderen fünf Personen waren italienischer Herkunft. ${ }^{2231}$ Da Heinrich Halbysen d. Ä. sowohl Italien bereist hatte als auch vermutlich der italienischen Sprache mächtig war, erscheint die Annahme, dass er für die Einführung der Papiermacherei in Basel Fachkräfte aus dem Piemont anwarb, überzeugend. ${ }^{2232}$ In ähnlicher Weise war im Jahr 1514 der Ulmer Kaufmann Martin Scheller vorgegangen. Er holte italienische Wollweber, die ein spezielles Produkt, sogenannte stammeti, herzustellen wussten, nach Ulm und ließ sie dort nicht nur

2228 Vgl. Kälin 1974, 202. Zur Zunftzugehörigkeit vgl. Kapitel 3.3.4.1, S. 407.

2229 StABS, Klosterarchiv, St. Alban A, 119. Vgl. Kälin 1974, 155.

2230 Vermutlich verbirgt sich hinter dieser Schreibweise der Name Bastian, vgl. auch Anm. 2012, 2664.

2231 Dies gilt, wenn man davon ausgeht, dass Meister Andres und Odere Nicolau identisch sind.

2232 In den Jahren 1432 und 1433, also unmittelbar vor dem Kauf der Allenwindenmühle, begleitete Heinrich Halbysen d. Ä. als Basels Gesandter König Sigismund zur Kaiserkrönung nach Rom. Basel war wie alle anderen freien und Reichsstädte verpflichtet, eine Begleitung zum Romzug zu stellen und traf mit dem Achtburger Heinrich Halbysen d. Ä. eine gute Wahl, denn er sprach offenbar Italienisch. Dies lässt sich aus seiner Vermittlerrolle zwischen der Schlüsselzunft und italienischen Wechslern zur Zeit des Konzils schließen. Auf dieser Reise wurde er vermutlich auf die florierende italienische Papierherstellung aufmerksam. Ob Heinrich Halbysen d. Ä. durch das Piemont gen Basel zog und ob er dort unverzüglich Papiermacher für sein neues Gewerbe anwarb, ist durch Textzeugnisse nicht zu belegen. Vgl. Kälin 1974, 143. 
Tuche herstellen, sondern nutzte ihr Know-how, um einheimische Weber auszubilden. ${ }^{2233}$

Es ist für den Untersuchungszeitraum schwierig, anhand der erhobenen Daten zu unterscheiden, welcher Papiermacher längerfristig nach Basel gekommen und für wen die Stadt lediglich eine Station auf der Wanderschaft war. Für die Papiermühlenund Hausbesitzer sowie für die Bürger und Zunftmitglieder kann gelten: Sie waren definitiv und für unbefristete Zeit nach Basel umgesiedelt und hatten sich dort ein Leben aufgebaut. Für alle anderen, häufig auch nur einmal erwähnten Papiermacher, die zu den Knechten zu rechnen sind, ist nicht bekannt, ob sie längerfristig in Basel sesshaft oder nur auf der Durchreise waren. Lediglich in wenigen Fällen lässt sich vermuten, dass es sich um einen Papierer auf Wanderschaft handelte. Der 1539 aus Furcht vor der Pest aus Basel geflohenen Papiermacher Niclaus Bonan aus Troyes scheint ein wandernder Geselle gewesen zu sein. ${ }^{2234}$ Ebenfalls in einem befristeten Dienstverhältnis stand der Papierergeselle Thirion von Lothringen. Obwohl der Arbeitsvertrag offensichtlich erst zu Pfingsten 1521 endete, wollte Thirion ihn bereits im März kündigen. ${ }^{2235} \mathrm{Ob}$ dahinter der Wunsch stand, weiterzuziehen, ist nicht bekannt.

Bislang wurden lediglich die Papiermacher betrachtet, die nach Basel einwanderten, um dort ihr Gewerbe auszuüben. Es gab jedoch auch Papiermacher, die von Basel aus in die Fremde zogen. Zwischen 1450 und 1550 sind sieben Papierer fassbar, die Basel verließen. Hierzu gehörten unter anderen Jacob und Claus Gallician, die Söhne Michel Gallicians. Jacob Gallician war vermutlich Ende der 1480er-Jahre nach Reutlingen gegangen. Nach Ausweis des dortigen Spitalzinsbuchs besaß er vielleicht schon 1489, sicher aber 1491 eine Papiermühle an der Echaz. ${ }^{2236}$ Auch eine Basler Quelle bezeugt seinen Aufenthalt in Reutlingen. Im Juli 1495 wurde er in einem Eintrag im Urteilsbuch des Großbasler Schultheißengerichts als Bürger von Reutlingen bezeichnet. Sein Vater Michel Gallician bevollmächtigte ihn, die Schulden, die der Drucker Erhard Oeglin, der ebenfalls Bürger von Reutlingen genannt wird, bei ihm hatte, einzuziehen. ${ }^{2237}$ Im Jahr 1499 hielt sich Jacob Gallician anscheinend in Basel auf, denn

2233 Vgl. Holbach 1999, 233-236.

2234 StABS, Ratsbücher D 1, 147r-147v. Vgl. Kapitel 3.3.1.1, S. 338 f.

2235 StABS, Gerichtsarchiv A 54, 318v. Vgl. Kapitel 3.3.1.1, S. 338.

2236 Vgl. Sporhan-Krempel 1972b, 1518. Vgl. auch Kälin 1974, 166.

2237 StABS, Gerichtsarchiv A 41, 5v: Da gibt Michel Galician der bappirmacher burger ze Basel Jacoben Galician sinem bruderßsun burger zu Rittlingen die schuld so im Erhart Ouglin der buchtrucker ouch burger zu Rittlingen schuldig unnd zetund ist die guttlich oder rechtlich ze heyschen unnd inzebringen ze gwin ze verlust unnd allem rechte. Jacob Gallician wird hier als Brudersohn von Michel Gallician bezeichnet. Es ist zu vermuten, dass es sich um eine Verschreibung - entweder des Namens vom Vollmachtgebenden oder der Verwandtschaftsbezeichnung - handelt, da der Gerichtsschreiber Jacob Gallician in einem früheren Eintrag, der ebenfalls Erhard Oeglin betrifft, den ehelichen Sohn Michel Gallicians nennt, vgl. StABS, Gerichtsarchiv A 40, 247r: Da gitt gwalt meister Michel Galitzian Jacoben Galitzian sinem eelichen sun, die schuld so im Erhart Öglin der Trucker schuldig ist. Warum Erhard 
er erneuerte in diesem Jahr die Safranzunft als Sohn Michel Gallicians. ${ }^{2238}$ Bereits im Jahr darauf hatte er seine Geburtsstadt jedoch wieder verlassen und wurde, wiederum in den Gerichtsbüchern des Großbasler Schultheißengerichts, als Bürger von Lauf bei Nürnberg bezeichnet. ${ }^{2239}$ Dieser Hinweis ließ die Forschung eine Papiermühle in Lauf vermuten. ${ }^{2240}$

Wann Jacob Gallician wieder nach Basel zurückkehrte, wo er im Jahr 1518 als Basler Bürger starb, ist nicht sicher zu sagen. ${ }^{2241}$ Gerhard Piccard und Hans Kälin geben an, dass er nach dem Tod seiner Mutter um das Jahr 1509 wieder in seine Heimatstadt zog. ${ }^{2242}$ In dem Reisbüchlein der Safranzunft wurde Jacob Gallician sogar bereits im Jahr 1503 als Teilnehmer am Bellenzer Zug aufgeführt. ${ }^{2243}$ Dass er Bürger einer anderen Stadt war und dennoch aufgrund einer bestehenden Zugehörigkeit zur Safranzunft für Basel in den Krieg zog, erscheint wenig plausibel. Vielleicht stellte folglich auch der Aufenthalt in Lauf an der Pegnitz nur ein kurzes Intermezzo dar. Zudem muss hinterfragt werden, ob Jacob Gallician tatsächlich Bürger von Reutlingen und von Lauf war oder ob der jeweilige Schreiber ihn fälschlicherweise einfach zum Bürger seines aktuellen Aufenthaltsorts deklarierte. Schließlich besteht auch die Möglichkeit, dass sich hinter dem Namen Jacob Gallician mehrere Personen verbergen.

Sein Bruder Claus Gallician verließ Basel um das Jahr 1495. Zu diesem Zeitpunkt verlieh ihm der Markgraf von Baden die Papiermühle zu Ettlingen. ${ }^{244}$ Möglicherweise hatte Hans Lufft von Ettlingen, der 1494 die Basler Papiermühle Michel Gallicians kaufte, Claus nach Ettlingen empfohlen. ${ }^{245}$ Claus kehrte bereits fünf Jahre später wieder nach Basel zurück. ${ }^{2246}$ Die Aufenthalte der beiden Brüder in der Fremde waren somit nur von vergleichsweise kurzer Dauer. Das Motiv für ihren einstweiligen Weggang aus Basel mag der Wunsch gewesen sein, mit dem Erwerb oder zumindest der Pacht einer Papiermühle eine eigene Existenz als Meister aufzubauen. In die Entscheidung Claus Gallicians spielte vielleicht außerdem noch ein durch den Verkauf der Rychmühle getrübtes Verhältnis zu seinem Vater hinein. ${ }^{2247}$

Oeglin, der vermutlich bereits 1491 das Basler Bürgerrecht erworben hatte, noch 1495 als Bürger zu Reutlingen bezeichnet wurde, ist ebenfalls unklar. Zur Einbürgerung Oeglins vgl. Reske 2015, 32.

2238 StABS, Zunftarchive, Zunft zu Safran 24, 250.

2239 StABS, Gerichtsarchiv A 43, 70r: Da hatt gwalt geben Martin Flach burger zu Basel Jacoben Gallician burger zu Louff by Nürnberg gelegen. Vgl. auch StABS, Gerichtsarchiv C 16, 172v.

2240 Vgl. Sporhan-Krempel 1979, $825 \mathrm{f}$.

2241 StABS, Gerichtsarchiv A 53, 217v: Da ist rechtlich vervogtet wordenn Lucia wylend Jacoben Galliceon des Bappirers seligen Burgers zu Basel verlaßne eeliche witwe mit Gerge Durren dem bappirer.

2242 Vgl. Piccard 1967, 138; Kälin 1974, 163, 166.

2243 StABS, Zunftarchive, Zunft zu Safran 55a, 2r.

2244 Vgl. Kapitel 3.2.1.11.

2245 Vgl. Stenzel 1985, 100.

2246 Vgl. Piccard 1967, 97, 118 f.; Kälin 1974, 166.

2247 Vgl. Kapitel 3.3.1.1, S. 339 f., und Kapitel 3.3.5.1, S. 435 f. 
Ein weiterer aus Basel stammender Papiermacher, den es in die Ferne zog, war Hans Ytelheinrich. Das einzige, was wir von ihm aus Basler Quellen wissen, ist, dass er vor 1517 in Preußen verstarb. ${ }^{2248}$ Die Nachricht von seinem Tod findet sich in einer Urkunde vom August 1517, die die eheliche Abstammung seines Bruders, Bernhart Ytelheinrich, bestätigen soll. Als Zeugen für die rechtmäßige Ehe der Eltern Heinrich Ytelheinrich und Verena Möschlin fungierten hier Bewohner der St. Albanvorstadt, sodass davon auszugehen ist, dass auch die beiden Eheleute sowie ihre Kinder dort wohnten. ${ }^{2249}$ Vermutlich erlernte Hans Ytelheinrich dort in einer der Papiermühlen das Handwerk. Wann Hans Ytelheinrich nach Preußen zog, was er dort tat und wann er starb, ist nur in Ansätzen zu vermuten. Hans Kälin hat auf die Möglichkeit hingewiesen, dass er identisch mit dem 1496 in Neisse erwähnten Papiermacher Eytelheinrich sein könnte. ${ }^{2250}$

Der bereits erwähnte Heinrich Rytz, der vermutlich aus Montabaur nach Basel kam, dort 1539 das Bürgerrecht und im Jahr darauf die Safranzunft erwarb, bat den Rat bereits 1543, ihm und seiner Frau einen ehrlichen Abschied zu erteilen. ${ }^{2251}$ Wohin die beiden zogen, ist unbekannt. Auch die Gründe für seinen Aufbruch liegen im Dunkeln. Die Tatsachen, dass Heinrich Rytz sowohl Bürger als auch safranzünftig war, ein Haus besaß und mit seiner Frau Barbara Grawenstein eine gebürtige Baslerin geheiratet hatte, sprechen für eine vorhandene Integration in die Stadt. Unklar bleibt, warum er dies alles aufgab, um woanders sein Glück zu suchen.

Aus welchen Motiven heraus der Papiermacher Niclaus Ruckh Basel verließ, liegt hingegen klar vor uns. Er war aus Épinal in die Stadt am Rheinknie gekommen und hatte dort die Witwe von Peter Sontach geheiratet, der ursprünglich aus dem nur 30 Kilometer von Épinal entfernt gelegen lothringischen Bains-les-Bains stammte. Im Gegensatz zu Niclaus Ruckh hatte Peter Sontach 1527, obgleich ebenfalls ein Welscher, das Bürgerrecht noch erwerben können und im darauffolgenden Jahr die Klingentalmühle gekauft. ${ }^{2252}$ Mit der Heirat der Witwe Peters erhoffte sich Niclaus Ruckh höchstwahrscheinlich, dessen Erbe anzutreten und Papier in einem eigenen Betrieb herzustellen. Um sich und sein Unternehmen gut in der Stadt zu positionieren, bedurfte es allerdings des Bürgerrechts, welches ihm aufgrund seiner

2248 StABS, Urk. Spital 894 (01.08.1517): Hannsen Ytelheinrich der ein Bappyrer gwesen und im land zu brussen mit tod abgangen.

2249 Zeugen waren die Schiffer Hans und Marty Gernler, der Schindler Hans Nussbaum sowie die Müller Hans Contz und Josen Eberly, StABS, Urk. Spital 894 (01.08.1517). Sie wohnten, ebenso wie Hans Ytelheinrichs Bruder Bernhart, nach Ausweis der St. Alban-Registratur von 1502/05 in der St. Albanvorstadt, vgl. StABS, Klosterarchiv, St. Alban H, 2, 3, 10, 11, 17, 18.

2250 Vgl. Kälin 1974, 205. Den Hinweis auf diesen Papiermacher entdeckte Kälin in Ptasnik 1953, 69 mit Anm. 32.

2251 StABS, Protokolle, Öffnungsbücher 8, 65r; Zunftarchive, Zunft zu Safran 25, 146; Ratsbücher D 2, 43r.

2252 StABS, Protokolle, Öffnungsbuch 7, 21r; Gerichtsarchiv B 24, 201v-202r. 
Herkunft verwehrt blieb. ${ }^{2253}$ Daher verkauften Verena Dölin und er am 21. Mai 1550 die Klingentalmühle, ${ }^{2254}$ erwirkten am 9. Juni den ehrlichen Abschied und verließen Basel. ${ }^{2255}$ Wohin sie gingen, konnte nicht eruiert werden.

Weitere Papiermacher, die Basel verließen und sich anderen Orten zuwandten, waren Roland von Caselle, Bartholome Blum und Sebastian Franz. Über Sebastian Franz ist lediglich bekannt, dass er 1476/77 Basel verließ. ${ }^{2256}$ Seiner Steuerpflicht konnte er sich dadurch jedoch nicht entziehen: Sein Schwager Friedrich Lemli wurde verpflichtet, die Steuer für ihn zu entrichten. ${ }^{2257}$ Der aus dem nicht identifizierten Rottenburg stammende Bartholome Blum, der im Jahr 1525 das Basler Bürgerrecht erworben hatte, verlegte seinen Arbeitsplatz vor 1537 in das nahe Lörrach. ${ }^{2258}$

Roland von Caselle erwarb 1489 das Bürgerrecht und 1490 die Safranzunft, gab aber bereits 1492 sein Bürgerrecht wieder auf. ${ }^{2259}$ Wohin er ging, ist nicht bekannt, es sei denn, man setzt ihn mit dem Papiermacher Roland, der im selben Jahr Bürger von Offenburg genannt wurde, gleich. Problematisch erscheint hierbei auf den ersten Blick, dass Roland von Caselle am 4. April 1492 sein Bürgerrecht aufgab, der zweite Roland jedoch schon zwei Tage zuvor, am 2. April, als Bürger von Offenburg bezeichnet wurde. ${ }^{2260}$ Betrachtet man allerdings den Kontext der Erwähnung, so wird deutlich, dass der Offenburger Roland in Basel nicht nur bekannt war, sondern auch als vertrauenswürdig galt. ${ }^{2261}$ In einem auf dem 31. März 1492 datierten Eintrag in das Vergichtbuch des Großbasler Schultheißengerichts übergab der Kaufmann Hans Gallician, Sohn des Papiermachers Anton Gallician, seine leibliche - wohl aber nicht eheliche - Tochter Anna dem Papiermacher Roland zu Offenburg, und dessen Frau Margreth, auf dass sie sie wie ihr eigenes Kind aufziehen. ${ }^{2262}$ Mit dem einmaligen Ein-

2253 Vgl. Kapitel 3.3.3.1, S. 382 f.

2254 StABS, Gerichtsarchiv B 30, 225v-226r.

2255 StABS, Ratsbücher D 2, 137v.

2256 Dies gilt, wenn man in dem Papiermacher Bastian und in Sebastian Franz dieselbe Person erblickt. Vgl. die Erwähnung von Sebastian Franz anlässlich einer Schuldverschreibung im Jahr 1472, StABS, Gerichtsarchiv C 12, 31, und von Bastian dem Papiermacher als Hausbesitzer im Jahr 1476, StABS, Gerichtsarchiv B 10, 92.

2257 Vgl. Kapitel 3.3.5.1, S. 431.

2258 Vgl. Kälin 1990, 173.

2259 Bürgerrechtserwerb: StABS, Ratsbücher P 1, 240r; Kauf der Safranzunft: StABS, Zunftarchive, Zunft zu Safran 24, 208; Bürgerrechtaufgabe: StABS, Protokolle, Öffnungsbuch 7, $13 \mathrm{v}$.

2260 StABS, Gerichtsarchiv A 39, 143v: Da ist Ennelin Hanns Galitzians tochter vervogtet worden mit Rolland dem Barppirmacher (sic!), burger zu Offenburg. Vgl. Piccard 1967, 128; Kälin 1974, 200.

2261 Gerhard Piccard und Hans Kälin geben lediglich den Eintrag in das Urteilsbuch des Schultheißengerichts wider, der deutlich knapper ausfällt als der Eintrag in das Vergichtbuch und der zudem nicht erahnen lässt, was in diesem Falle tatsächlich hinter der Vogtei stand, vgl. daher StABS, Gerichtsarchiv C 15, 55r.

2262 StABS, Gerichtsarchiv C 15, 55r: Da hatt Hanns Galtzian der kouffman Ennelin sin naturlich tochter Rolanden dem Bappirmacher zu Offenburg und Margrethen siner eefrowen als für ir eigen kind ubergeben, also und mit solichen wortten daz dieselben eeliche gemechtt dasselb kind biß es zu sinen tagen 
kleiden des Kinds und der Zahlung von 28 Gulden hatte Hans Gallician II alle elterlichen Rechte und Pflichten an Roland und dessen Frau abgetreten. Auch die Rechte Annas auf das Erbe des leiblichen Vaters waren damit erloschen. Aufgrund dieser besonderen Situation lässt sich die Vermutung anstellen, dass Hans Gallician II den Papiermacher Roland bereits längere Zeit vor der Sorgerechtsübertragung kannte. Offenbar sah der Kaufmann die Chance, dem hinwegziehenden Papiermacher seine uneheliche Tochter mitzugeben und sie somit aus Basel zu „entfernen“. So bot die Migration eines Papiermachers auch Möglichkeiten über das Berufliche hinaus. ${ }^{2263}$

\subsubsection{Augsburg, Bern, Ettlingen, Gengenbach, Kempten, Memmingen, Nürnberg, Ravensburg, Söflingen, Straßburg, Urach, Vieux-Thann und Zürich}

Die große Strahlkraft der piemontesischen Papiermacherei zeigt sich auch an anderen Papiermühlenstandorten im deutschen Südwesten. Die Gründung der Papiermühle $\mathrm{zu}$ Thal bei Bern ging vermutlich von ihrem ersten fassbaren Besitzer, dem Geldwechsler Antonio von Novara, aus. Dem Namen nach stammte er aus Novara, das in der heutigen italienischen Region Piemont ungefähr 100 Kilometer nordöstlich von Turin und 50 Kilometer westlich von Mailand liegt. War er selbst kein Papiermacher, sondern lediglich der Financier des Werks, so kann wahrscheinlich der Inhaber der zweiten Berner Papiermühle, Tschan Jacki, sicher aber sein Sohn und Mitinhaber Anton Jacki als Papiermacher angesprochen werden. Die Jacki kamen aus dem Val di Gressoney, einem nördlichen Ausläufer des Aostatals südlich des Monte Rosa. ${ }^{2264}$ Auch die Heimat der Papiermacher Michel Pol und Constanz zu Worwe, die seit 1491 im Besitz der Papiermühle zu Thal waren, lag im Piemont. ${ }^{2265}$

Von dem Piemontesen, der 1445 die erste Straßburger Papiermühle baute, ist sogar mehr als eine Station seiner Wanderschaft bekannt. Wilhelm de Altomonte, auch Wilhelm de Medicis genannt, stammte nach Ausweis einer Straßburger Urkunde aus dem Bistum Asti, das ungefähr 50 Kilometer östlich von Turin liegt. ${ }^{2266}$ Von dort wanderte er um die 1.000 Kilometer in den Maasraum nach Huy, wo er möglicherweise um 1437 die Papiermacherei einführte. Im Jahr 1442 wurde er selbst Inhaber der Papiermühle. ${ }^{2267}$ Aber offenbar war Wilhelm de Altomonte wie in Straßburg auch in Huy kein wirtschaftlicher Erfolg beschieden, da er 1454 wegen Schulden aus der

kommen getruwlichen in iren costen erziechen und das als ir eigen kind halten sollen. Und soll ouch der vermelt Hanns Galtzian das kind yetzmals zimlichen bekleiden unnd im xxviii gulden unnd im die zu vier zylen bezaln.

2263 Da in Offenburg eventuell bereits seit 1483 eine eigene Papierproduktion bestand, könnte die Wahl des neuen Wohnorts mit beruflichen Zielen verbunden gewesen sein, vgl. Kapitel 3.2.1.14.

2264 Vgl. Fluri sen. 1896, 193; J. Lindt 1964, 77; Fluri jun. 1975, 7.

2265 Vgl. Fluri sen. 1896, 200; J. Lindt 1964, 78; Fluri jun. 1975, 9.

2266 AVES, CH 239, Nr. 4918 (02.08.1445): magistro Wilhelmo de Altomonte Astensis diocesis. Vgl. Fuchs 1962b, 103.

2267 Vgl. Arnould 1976, 289 f.; Irsigler 1999, 264. 
Stadt verbannt wurde und seine Güter eingezogen wurden. ${ }^{2268}$ Deutlich treten hier die Parallelen zur Entwicklung in Straßburg zutage. Wenn es sich tatsächlich um dieselbe Person handelte, was angesichts des Namens wahrscheinlich ist, dann betrieb Wilhelm zeitgleich zwei Papiermühlen, eine in Huy und eine in Straßburg. Die Verleihung einer Allmende im Jahr 1445 ermöglichte ihm den Bau einer Papiermühle in der elsässischen Stadt, die er jedoch nur durch den Verkauf einer Rente unterhalten konnte. Auch in Straßburg machte Wilhelm de Altomonte schließlich Schulden und verließ die Stadt 1450 anlässlich des Jubeljahres gen Rom. ${ }^{2269}$ Er kehrte nicht mehr nach Straßburg zurück. Ob er Huy noch einmal aufsuchte, ist ungewiss. Die Verbannung und die Konfiszierung seines Guts können auch in seiner Abwesenheit angeordnet worden sein. Festzuhalten bleibt, dass der Piemontese zwei Städten nördlich der Alpen, die mehrere hundert Kilometer voneinander entfernt liegen, die Papierherstellung brachte und dabei eine bemerkenswerte Mobilität bewies.

Auffällig ist der große Anteil an Papiermachern, die aus dem Ort Caselle kamen. In Bern verpachteten Tschan und Anton Jacki die Mühle zu Thal 1469 an den Papiermacher Jehan Pastor von Caselle. ${ }^{2270}$ Auch im Augsburg der 1480er-Jahre arbeitete mit Lorenzo Goffasotis ein Papierer aus dem piemontesischen Ort bei Turin. ${ }^{2271}$ Einer der ersten Papierermeister in Kempten, der 1501 erstmals fassbare Bernhard Baschgott, stammte ebenfalls aus Caselle. ${ }^{2272}$ Ob die Heimat seines Kemptener Kollegen Marx Baruttel auch im Piemont zu suchen ist, wie anhand des romanisch klingenden Namens vermutet werden könnte, ist nicht bekannt. ${ }^{2273}$

Erst kürzlich wurden der Reihe an Papiermachern aus Caselle zwei weitere Personen hinzugefügt, die in einer südwestdeutschen Papiermühle tätig waren. Erwin Frauenknecht konnte überzeugend darlegen, dass Anton Turwel, der den Anstoß für die Einrichtung eines Papierwerks in Söflingen gab, von Caselle in das Kloster bei Ulm kam. Diese Interpretation basiert auf der Annahme, dass sich der Kopist des Ulmer Registraturbuchs von 1692, in dem ein Anthoni Dasell aufgeführt ist, verschrieb. Er notierte Dasell statt Casell(e) und machte die Herkunftsbezeichnung zudem zum Familiennamen. ${ }^{2274}$ Der Begründer der Papierherstellung in Urach stammte ebenfalls aus dem durch seine Fachkräfte bekannten Ort im Piemont. Hier macht Frauenknecht die These stark, dass bereits der Schreiber, der den Vertrag zwischen Eberhard im Bart und Anton Terriere aufsetzte, den Herkunftsort des Papiermachers entstellt wiedergab. ${ }^{2275}$ Erhalten ist dieser Text heute lediglich in verschiedenen Repertorien

2268 Vgl. Arnould 1976, 290.

2269 AVES, CH 254, Nr. 5228 (22.11.1452). Vgl. Fuchs 1962b, 105.

2270 Vgl. Fluri sen. 1896, 195; J. Lindt 1964, 78; Fluri jun. 1975, 27.

2271 Vgl. Künast 1997, 115; Amelung 2000/2017; Frauenknecht 2014, 88.

2272 Vgl. Petz 2006, 260, 295; Kata 2015, 297.

2273 Vgl. Petz 2006, 291.

2274 Vgl. Frauenknecht 2014, 89; Frauenknecht 2015, 103 f.

2275 Vgl. Frauenknecht 2014, 88. 
aus dem 17. und 18. Jahrhundert. Dort wird der Ort einmal als Chahilice und einmal als Chasiliae wiedergegeben. Friedrich von Hößle ließ Anton Terriere anhand dieser Angaben aus Kastilien kommen. ${ }^{2276}$ Wahrscheinlicher ist jedoch eine Herkunft aus dem piemontesischen Caselle. ${ }^{2277}$

Von elf Basler Papiermachern und fünf Papiermachern, die in anderen südwestdeutschen Papiermühlen arbeiteten, ist folglich bekannt, dass sie aus Caselle Torinese kamen. Dort wurde vermutlich seit den 1330er-Jahren Papier hergestellt. ${ }^{2278}$ Möglicherweise wurden Papiermacher in Caselle regelrecht für den Arbeitsmarkt nördlich der Alpen ausgebildet. Erstaunlich ist, dass keine Papierer aus anderen bedeutenden Papierproduktionszentren wie beispielsweise Fabriano oder Camerino/Pioraco in den Marken in südwestdeutschen Papiermühlen zu finden sind. Insgesamt brachten im Untersuchungszeitraum mindestens 26 Papiermacher aus dem westlichen Oberitalien ihr Know-how über die Alpen in den oberdeutschen Raum. ${ }^{2279}$

Auch an andere Papiermühlenstandorte des 15. und 16. Jahrhunderts erfolgte der Technologietransfer durch Papierer aus dem Piemont. So ist in Belfaux seit 1445 der Piemontese Ulrich Nicolau aus dem Bistum Turin greifbar. ${ }^{2280}$ Die Konzession für einen Papiermühlenbau im burgundischen Froideconche bei Luxeuil erhielt im Jahr 1466 Martin Coustel von Caselle. ${ }^{2281}$ Pierre de Caselle führte 1477 die Papierherstellung in Serrières bei Neuenburg ein und im selben Jahr wurde die erste Papiermühle in Bains-les-Bains durch den Piemontesen Régnier Marquette von Pignerol eingerichtet. ${ }^{2282}$ Aus Caselle Torinese stammten auch der Papiermacher Jaicome Gavaille, der 1488/89 eine Werkstatt in Metz betrieb, sowie Jacquot de Caselle, der 1505 Besitzer der drei Papiermühlen in Champigneulles bei Nancy war. ${ }^{2283}$ Damit war die Migrationsrichtung der Papiermacher gegenläufig zu derjenigen anderer Handwerker: In einigen Studien zur Handwerkermigration wurde festgestellt, dass zwar deutschsprachige Gesellen nach Italien und Frankreich migrierten, dass aber im Gegenzug kaum fremdsprachige Gesellen in deutschsprachige Gebiete kamen. ${ }^{2284}$ Für die Papiermacherei galt dies offensichtlich nicht.

2276 Vgl. Hößle 1926a, 66 f. Wieder aufgenommen in Zaar-Görgens 2004, 70.

2277 Vgl. Frauenknecht 2014, 86-89; Frauenknecht 2015, 98, 103 f.

2278 Vgl. Donna d'Oldenico 1962, 9-12.

2279 Davon sind 16 Personen in Basel und zehn Papierer in weiteren südwestdeutschen Papiermühlenstandorten fassbar. Der Kemptener Papiermacher Marx Baruttel ist aus dieser Zählung ausgenommen, da nicht sicher ist, ob er auch aus Norditalien stammte. Peter Tschudin vermutet, dass die aus Caselle in die Oberrheinregion eingewanderten Papiermacher den Ochsenkopf als ihr Wasserzeichen mitbrachten, vgl. P. Tschudin 2012c, 1-7.

2280 Vgl. Gerardy 1980a, 52 f., 63 f.; Zaar-Görgens 2004, 71.

2281 Vgl. Hößle 1925, 231; Zaar-Görgens 2004, 72.

2282 Vgl. P. Tschudin 1991, 33; Zaar-Görgens 2004, 72.

2283 Vgl. Zaar-Görgens 2004, 60, 72.

2284 Vgl. Reininghaus 1982, 31 mit Anm. 31; Schulz 2008, 338 f.; Sieber-Lehmann 1995, 283. 
In das Bild von einer Vorrangstellung piemontesischer Papiermacher bei der Vermittlung der Papiermacherei fügen sich die vermeintlich von Ulman Stromer in der Nürnberger Gleismühle angestellten Brüder Franciscus de Marchia und Marcus sowie ihr Knecht Bartholome nahtlos ein. Sie bilden für die Forschung gewissermaßen den Präzedenzfall für alle nachfolgenden Papiermühlengründungen: Ein Kaufmann engagiert fremde Fachkräfte aus einer Innovationsregion für die Einführung eines neuen Gewerbes. ${ }^{2285}$ Auf der Edition des Püchel von mein geslecht und von abentewr von Karl Hegel basierend ${ }^{2286}$ wurde die Geschichte von den welschen Papiermachern, die in Streit mit Ulman Stromer gerieten und von ihm gefangen genommen wurden, bereits in der Anfangszeit der Papierforschung immer wieder aufgegriffen. ${ }^{2287}$ Irritierend ist jedoch, dass auch ein Großteil der neueren Studien die Beteiligung von Italienern an der ersten Papiermühle auf deutschem Gebiet hervorhebt, ${ }^{2288}$ obwohl Lore Sporhan-Krempel bereits 1954 plausibel darlegen konnte, dass die Italiener im Autograph des Püchel nicht erwähnt werden, und diese Entdeckung auch in späteren Publikationen betonte. 2289

Die Version von Stromers Buchs, in der die Geschichte von den Welschen erstmals erzählt wird, wurde offenbar in den Jahren 1550/60 verfasst und ist damit 150 Jahre jünger als das Autograph. ${ }^{2290}$ Lore Sporhan-Krempel geht davon aus, dass der Bericht über die italienischen Papiermacher durch den Kopisten dieser Handschrift hinzuge-

2285 Die Durchschlagkraft dieses Konzepts spiegelt sich auch in dem seit dem Beginn der Papiergeschichtsforschung kursierenden Bericht wieder, Karl IV. habe zwei italienische Papierer nach Böhmen geholt, um dort eine Papiermühle bei Eger (tschech. Cheb) zu errichten. Bislang konnte diese Geschichte nicht durch Quellenbelege bestätigt werden, vgl. V. Thiel 1932, 113; Zaar-Görgens 2004, 71. 2286 Die Edition findet sich in den Chroniken der deutschen Städte, vgl. [Ulman Stromer] 1862, 1-106. $\mathrm{Zu}$ den aktuellen Signaturen der von Hegel verwendeten Handschriften und den Problemen dieser Edition vgl. C. Meyer 2010, 1-29.

2287 Vgl. Marabini 1894, 18-21; Blanchet 1900, 74 f.; Hößle 1924, 535 f.; Bockwitz 1941a, 23; V. Thiel 1941, 31.

2288 Vgl. Preger 1979, 3; Halstrick 1990, 14, 18 f.; Calegari 1990, 25; Sandermann 1992, 118; P. Tschudin 1994, 52; Irsigler 1999, 260; Stahlberg 2004, 173; Zaar-Görgens 2004, 23 f.; Irsigler 2006, 315 f.; Iannuccelli 2010, 100 mit Anm. 16; Bartels 2011, 44; P. Tschudin 2012a, 109. Jüngst auch Anne-Grethe Rischel im Vorwort der Zeitschrift IPH Paper History 19, Rischel 2015, 4.

2289 Vgl. Sporhan-Krempel 1954a, 89-103; Sporhan-Krempel/Stromer 1960, 95; Sporhan-Krempel/ Stromer 1963, 198, 202; Sporhan-Krempel 1990a, 39 f.; Sporhan-Krempel 1990b, 181 f. Nur wenige Autoren gründen ihre Ausführungen auf das seit 1990 im Faksimile zugängliche Autograph Ulman Stromers und die Veröffentlichungen von Sporhan-Krempel, vgl. Bayerl/Pichol 1986, 48 f.; Bayerl 1987, 69; Schlieder 1966, 86-91. Wolfgang von Stromer, der in dem Kommentarband zur Faksimileausgabe des Püchel von 1990 auch den Text der Hegelschen Edition und damit die Geschichte über die italienischen Papiermacher aufnimmt, verweist darauf, dass der Text widersprüchlich ist und erwähnt Sporhan-Krempels kritische Bemerkungen, vgl. Stromer 1990c, 149. Zu Faksimile-Edition vgl. Ulman Stromer 1990a; Ulman Stromer 1990b.

2290 Karl Hegel führte in seiner Edition des Püchel in den Chroniken der deutschen Städte mehrere Handschriften zu einem Text zusammen, darunter auch die Handschrift, die erstmals von den italie- 
fügt wurde. Einen Beweis hierfür sieht sie beispielsweise in den abrupten Wechseln zwischen der ersten und der dritten Person Singular. Während der Nürnberger Kaufmann im Autograph von sich immer nur in der ersten Person Singular spricht, springt der später zugefügte Text zwischen „ich“ und „Ulman Stromer“ als handlungstragender Person hin und her. ${ }^{2291}$ Sporhan-Krempel argumentiert weiter, dass Stromer die Begebenheit mit den fremden Papiermachern, sollte sie sich tatsächlich zugetragen haben, sicherlich in sein Püchel aufgenommen hätte. Daher hält sie den Zusatz für eine Legende. Eventuell existierte zu der Zeit im 16. Jahrhundert bereits eine mündliche Erzähltradition über die Anfänge der Stromerschen Papiermühle. Möglich wäre es aber auch, so Sporhan-Krempel, dass es sich bei der Geschichte über die Welschen um eine Rekonstruktion der Vergangenheit aus humanistischer Sicht handelte. ${ }^{2292}$

Wie für Nürnberg können auch für die beinahe zeitgleich begründete Papiermacherei in Ravensburg keine fremdsprachigen Namen von Papiermachern in den Quellen ausgemacht werden, sodass auch hier ein Techniktransfer durch italienisch- oder französischsprachige Berufsleute nicht belegt werden kann. Die ersten zu Beginn des 15. Jahrhunderts im Ravensburger Bürgerbuch namentlich fassbaren Papierer trugen die Familiennamen Staengly, Wolfartshofer und Krieger. ${ }^{2293}$ Auch die ersten in Gengenbach und Cernay (Sennheim) greifbarer Papierernamen lassen eher einen deutschsprachigen Ursprung vermuten. ${ }^{2294}$

Im Allgemeinen verliefen die Migrationsbewegungen nicht nur von Süd nach Nord. Auch innerhalb des untersuchten Raums wanderten Papiermacher in andere Städte, um dort zu arbeiten. Häufig war dabei der Ausgangsort ebenfalls ein Papiermühlenstandort. Von Reutlingen brachen beispielsweise die Papierer Jerg Moser und Caspar Tochtermann auf. Während ersterer um 1522 in das rund 100 Kilometer entfernte Ettlingen ging, fand letzter im nahen Urach eine Beschäftigung. ${ }^{2295} \mathrm{Nach}$ Urach zog es 1550 auch Caspar Hitzlenberger aus dem 135 Kilometer entfernten Kempten, vermutlich, weil er in seiner Heimat keine Möglichkeit sah, einen eigenen Betrieb zu führen. ${ }^{2296}$ Ettlingen wiederum war ebenfalls Ziel des Papiermachers Jörg Schöpper aus Augsburg, der die markgräfliche Papiermühle 1526 pachtete. ${ }^{2297}$ Der aus Tettnang stammende Gallus Beck wanderte seinerseits um 1500 nach Ettlingen ein. Eventuell hatte er das Papiererhandwerk in Ravensburg erlernt, das nur 15 Kilometer von seiner

nischen Papiermachern berichtet und die er als A4 bezeichnet, vgl. [Ulman Stromer] 1862, 12-20, bes. 17 mit Anm. 1, die Einfügung auf 78-80.

2291 Vgl. Sporhan-Krempel 1954a, 95 f., 99.

2292 Vgl. Sporhan-Krempel 1954a, 102.

2293 Vgl. Kapitel 3.3.3.2 mit Tab. 21.

2294 Zu Gengenbach vgl. Kapitel 3.2.1.13, zu Cernay Kapitel 3.2.1.16.

2295 Vgl. Piccard 1951, 60; Stenzel 1985, 101; Hößle 1939, 560.

2296 Vgl. Petz 2006, 290 f.

2297 Vgl. Piccard 1951, 60; Stenzel 1985, 101; F. Schmidt 1992, 118. 
Heimatstadt entfernt liegt. ${ }^{2298}$ Von Offenburg in das 30 Kilometer entfernte Straßburg migrierte der Papiermacher Wolff Stierlin vor 1510. ${ }^{2299}$ Nach Straßburg brach vor 1517 auch Hans Volpis auf. Er stammte nach Ausweis des Straßburger Bürgerbuchs aus Speyer. ${ }^{2300}$ Für kurze Zeit betrieb er die Papiermühle im 40 Kilometer entfernten Gengenbach, wo er 1531 erwähnt wurde. Volpis kehrte jedoch um diese Zeit nach Straßburg zurück und starb dort im Jahr 1533. ${ }^{2301}$ Von Augsburg ging der Papierer Bernhard Walch vor 1519 nach Kempten. ${ }^{2302}$ Ob der erste Ettlinger Papiermacher Wilhelm von Paris tatsächlich aus der 550 Kilometer entfernten Hauptstadt Frankreichs stammte oder doch aus dem kleinen, nur 170 Kilometer entfernten elsässischen Ort Pairis, lässt sich nicht feststellen. ${ }^{2303}$ Plausibel wäre seine Herkunft aus Paris durchaus, denn in der näheren Umgebung der Stadt wurde bereits seit den 1350er-Jahren Papier hergestellt. ${ }^{2304}$

Der Begründer der Züricher Papierproduktion, Heinrich Walchwiler, der 1471 die Mühle auf dem Werd erwarb, stammte aus dem circa 35 Kilometer entfernten Zug, für das keine eigene Papiermühle zu dieser Zeit bekannt ist. ${ }^{2305}$ Sein Knecht Peter von Genf kam seinem Namen nach hingegen aus einer Stadt, in deren nächster Umgebung bereits seit 1427 Papier produziert wurde. ${ }^{2306}$ In Vieux-Thann ist im Jahr 1463 ebenfalls ein Peter von Genf greifbar, der die dortige Papiermühle einrichtete. ${ }^{2307}$ Sollten diese beiden Personen identisch sein, dann hatte Peter von Genf die Papiermühle in Thann und damit seinen Status als Meister aufgegeben und arbeitete wieder als Geselle. ${ }^{2308}$ Ebenfalls aus Genf stammte der Papierer Peter Fort, der 1482 die von der Stadt erbaute zweite Papiermühle in Memmingen pachtete und vermutlich bereits am Aufbau der ersten Memminger Papiermühle beteiligt war. ${ }^{2309}$ Auch er könnte identisch mit Peter von Genf sein, sodass mindestens ein, maximal drei Papiermacher im Untersuchungszeitraum aus Genf stammten. In Bern betrieb um das Jahr 1529 Franz Bergier die Papiermühle zu Thal. Er kam offenbar aus Freiburg im Üchtland, wo bereits um 1400 eine Papiermühle gearbeitet haben muss und eine Papiermühle sicher für das

2298 Vgl. Piccard 1951, 60; Stenzel 1985, 100; F. Schmidt 1992, 118

2299 Vgl. Le livre de bourgeoisie de la ville de Strasbourg 1954, Bd. 2, 588, Nr. 6006.

2300 Vgl. Le livre de bourgeoisie de la ville de Strasbourg 1954, Bd. 2, 640, Nr. 6682.

2301 Vgl. Piccard 1963, 1004.

2302 Vgl. Künast 1997, 112; Petz 2006, 257, 295.

2303 Vgl. Stenzel 1985, 99.

2304 Vgl. Berthier 2010, bes. 118.

2305 Vgl. Schnyder 1937, 729, Nr. 1248. Zur Papierherstellung in Zug vgl. P. Tschudin 1991, 62.

2306 Peter von Genf wurde vor dem Basler Schultheißengericht als Zeuge in einer Streitsache zwischen seinem Meister Heinrich Walchwiler und Niclaus Boner von Solothurn befragt, StABS, Gerichtsarchiv D 10, 65r. Vgl. Schnyder 1937, 719, Nr. 1236d; Zürcher 1963a, 85. Zur Papierproduktion in Genf vgl. P. Tschudin 1991, 21.

2307 Vgl. P. Schmitt 1960, 79.

2308 Vgl. Kälin 1974, 94 f.

2309 Vgl. Piccard 1960, 597. 
Jahr 1432 im nahen Belfaux belegt ist. ${ }^{2310}$ Aus der Stadt Metz, in der spätestens seit der Mitte des 15. Jahrhunderts Papier produziert wurde, kam Johannes Hettag, der 1451 in der ersten Straßburger Papiermühle arbeitete. ${ }^{2311}$

Für die Einführung der Papiermacherei im deutschen Südwesten zeichneten folglich nicht nur nordwestitalienische Handwerker, sondern auch Papierer aus dem Genfer sowie aus dem südwestdeutschen Raum verantwortlich. Auch nach der Aufnahme der Produktion wanderten fremdsprachige Papiermacher ein.

Betrachtet man die bei der Wanderung zurückgelegten Distanzen, so ergibt sich ein ähnliches Bild wie zuvor für Basel. ${ }^{2312}$ Knapp 39 Prozent der Migrationsbewegungen (10 von 26) umfassten eine Strecke von mehr als 300 Kilometern. Distanzen zwischen 151 und 300 Kilometern wurden in 27 Prozent der Fälle (7 von 26) überwunden. Eine Entfernung von 76 bis 150 Kilometern wurden in 15 Prozent der Wanderungen zurücklegten (4 von 26), während knapp ein Fünftel der Herkunftsorte (5 von 26) in der näheren Umgebung des Zielorts lagen und nur 20 bis 40 Kilometer entfernt von ihm waren. Damit ist der Anteil an weiten Strecken vergleichsweise hoch, was vor allem auf die Einwanderung aus Oberitalien zurückzuführen ist, die man zweifelsohne als Spezialistenmigration bezeichnen kann. ${ }^{2313}$ Neben der großen Zahl an Handwerkern aus Oberitalien und hier vor allem aus dem Piemont, ist zudem auffällig, dass ein Großteil der zwischen 1450 und 1550 im deutschen Südwesten mit einer Herkunftsangabe fassbaren Papiermacher sich innerhalb dieses Raums bewegte. Einige Handwerker kamen aus der heutigen französischsprachigen Schweiz. Ob es sich bei diesen Wanderungen um langfristige Auswanderung oder um kurzfristige Wanderschaft von Gesellen handelte, kann anhand des jetzigen Forschungsstands nicht ermittelt werden.

Dass fremde Papierergesellen aber eine alltägliche Erscheinung innerhalb des Handwerks und innerhalb der Stadt waren, zeigen die Reutlinger Papiermacherord-

2310 Vgl. P. Tschudin 1991, 19.

2311 AVES, CH 251, Nr. 5164 (26.08.1451). Vgl. Fuchs 1962b, 104 f. Zur Papiermacherei in Metz vgl. Zaar-Görgens 2004, $33 \mathrm{f}$.

2312 Von den zuvor erwähnten Personen wurden in diese Betrachtung 24 aufgenommen: Tschan Jacki, Anton Jacki, Michel Pol, Constanz zu Worwe, Wilhelm Medicis de Altomonte, Jehan Pastor von Caselle, Bernhard Baschgott, Lorenzo Goffasotis, Anton Turwel, Anton Terriere, Jerg Moser, Caspar Tochtermann, Caspar Hitzlenberger, Jörg Schöpper, Gallus Beck, Wolff Stierlin, Hans Volpis, Heinrich Walchwiler, Franz Bergier, Johannes Hettag, Bernhard Walch. Die Personen aus Genf mit Namen Peter wurden als drei verschiedene Personen behandelt, so dass der Ausgangspunkt der Wanderung immer Genf darstellt. Die Werte verschieben sich leicht zugunsten kürzerer Entfernungen von 140 bis 200 Kilometern, wenn man in diesen Personen nur zwei Individuen sieht oder sie gar alle in eins setzt. Insgesamt wurden 26 Migrationsbewegungen in die Rechnung einbezogen, da sowohl Wilhelm Medicis de Altomonte als auch Hans Volpis zweimal ihren Arbeitsort wechselten. Nicht mit in die Betrachtung einbezogen wurde Wilhelm von Paris, da nicht sicher ist, ob die französische Hauptstadt oder ein kleiner elsässischer Ort gemeint ist.

2313 Vgl. Koch 2002, 414-416. Vgl. auch Kapitel 3.3.2.1, S. 359. 
nung von 1527 sowie die Züricher Hintersässenordnung von 1545. In der Ordnung der Reutlinger Papierergemeinschaft wird explizit auf wandernde Gesellen Bezug genommen und angeordnet, wie man sich ihnen gegenüber $\mathrm{zu}$ verhalten habe. ${ }^{2314}$ Mit einem starken, unerwünschten Zuzug von fremden Papierer- und Druckergesellen hatte offenbar Zürich in den 1540er-Jahren zu kämpfen. In der Hintersässenordnung aus dem Jahr 1545 regelte die Stadt daher das Aufenthalts- und Niederlassungsrecht für eingewanderte Gesellen. ${ }^{2315}$ Denjenigen Papiermachern oder Druckern, die bereits als Bürger oder Hintersässen aufgenommen seien, war es weiterhin uneingeschränkt gestattet, in der Stadt zu wohnen. Gesellen, die neu in Zürich eintrafen, mussten jedoch einen umfänglichen Ausweis ihrer Rechtschaffenheit erbringen. Dazu gehörten neben dem ehrlichen Abschied, der ein vom vorherigen Aufenthaltsort ausgestelltes Leumundszeugnis darstellte, das Mannrecht sowie der Erbschein. Während das Mannrecht die Ehefähigkeit und die Eignung für den Kriegsdienst nachwies, bestätigte der Erbschein, dass der Herkunftsort im Fall, dass der Zugezogene nach seinem Tod minderjährige Kinder hinterließ, den Unterhalt dieser Kinder gewährleistete. ${ }^{2316}$

\subsubsection{Bürgerrecht}

Die Integration der Papiermacher als Vertreter eines neuen Gewerbes in die städtischen Strukturen spiegelt sich unter anderem in der Aufnahme ins Bürgerrecht wider. Allgemeingültig festzuhalten, wer unter welchen Voraussetzungen und Bedingungen Bürger werden konnte und welche Rechte und Pflichten mit der Aufnahme in das Bürgerrecht einhergingen, ist aufgrund der zahlreichen lokalen Unterschiede nur holzschnittartig möglich. Als kleinster gemeinsamer Nenner kann zunächst gelten, dass derjenige Bürger war, der den Bürgereid geleistet hatte und eventuell in ein Bürgerbuch eingetragen wurde. ${ }^{2317}$ Die Rechte und Pflichten, die mit dem Schwören dieses Eids verbunden waren, basierten vornehmlich auf der Idee „der städtischen Friedens- und Rechtsgemeinschaft sowie der bürgerlichen Schutz- und Solidargemeinschaft.“2318 Auf dieser Grundlage kamen Bürger in den Genuss eines passiven sowie aktiven Wahlrechts und konnten von bestimmten bürgerlichen Nutzungsrechten Gebrauch machen. Zudem stand ihnen ein umfänglicher Rechtsschutz innerhalb wie außerhalb der Stadt zu. Dieser umfasste beispielsweise auch das Freikaufen im Fall der Kriegsgefangenschaft. Die Pflichten eines Bürgers reflektieren zum Teil diese Rechte: Hierzu zählen die Pflicht, Frieden zu halten und alle Rechtsstreitig-

2314 Vgl. Sporhan-Krempel 1972b, 1573. Vgl. Kapitel 3.3.1.2, S. 344 f.

2315 Vgl. Zürcher 1963a, 88.

2316 Vgl. Zürcher 1963a, 88.

2317 Vgl. Isenmann 2002, 208. Zum Bürgereid vgl. Dilcher 2002.

2318 Isenmann 2002, 225. 
keiten vor den städtischen und nicht vor fremden Gerichten zu verhandeln. Außerdem mussten die Bürger sich an den städtischen Kriegszügen beteiligen und Wachdienste zur Verteidigung der Stadt absolvieren. Hinzu kamen die Steuerpflicht sowie allgemein Treue und Gehorsam gegenüber Rat und Stadt. Während die Rechte eines Bürgers nur dem tatsächlich Eingebürgerten zustanden, hatten die bloßen Einwohner oder Beisassen der Stadt meist auch alle oder einen Teil der Pflichten zu erfüllen. ${ }^{2319}$

Unter die Aufnahmebedingungen fiel eine ganze Reihe an Voraussetzungen, die von Stadt zu Stadt, von Zeit zu Zeit und sogar von Fall zu Fall variieren konnten. ${ }^{2320}$ Zunächst ist hier die Zahlung einer Aufnahmegebühr zu nennen, die, je nach Interesse des Rats, viele oder wenige Personen ins Bürgerrecht aufzunehmen, unterschiedlich hoch ausfallen konnte. Einhergehend mit dieser Gebühr war häufig der Nachweis eines Mindestvermögens oder das Stellen eines Bürgen gewünscht. Des Weiteren waren oftmals Hausbesitz oder zumindest der Besitz einer eigenen Feuerstelle Voraussetzung für den Erwerb des Bürgerrechts. In manchen Städten zählten die personenrechtliche Freiheit, die freie und eheliche Geburt sowie ein guter Leumund zu den Aufnahmekriterien. ${ }^{2321}$

Als Quelle für die Einbürgerung einer Person sind die Bürgerbücher heranzuziehen, die in manchen Städten des Reichs bereits in der zweiten Hälfte des 13. Jahrhunderts geführt wurden. In ihrer Ausformung und Ausführlichkeit unterscheiden sich diese Bürgerbücher zwar teilweise sehr stark voneinander, ${ }^{2322}$ gemein ist ihnen jedoch, dass sie sich nach der Definition von Rainer Schwinges als eigener Typ eines Stadtbuchs fassen lassen, der dazu angelegt wurde, separat von anderen Stadtbuchkategorien die Aufnahme von Neubürgern über längere Zeit rechtsverbindlich zu erfassen. ${ }^{2323}$ Des Weiteren lässt sich der Bürgerstatus der hier betrachteten Papiermacher auch durch weitere Quellen erschließen, in denen die betreffenden Personen als Bürger der Stadt bezeichnet werden. Auch ist zu bedenken, dass die Kinder von Bürgern nicht immer in den Bürgerbüchern verzeichnet sind, auch dann nicht, wenn sie das Bürgerrecht nicht qua Geburt erbten, sondern es - eventuell zu einer verminderten Aufnahmegebühr - neu kaufen mussten. ${ }^{2324}$ Diese Personen konnten daher Bürger sein, ohne dass sie im Bürgerbuch fassbar sind.

2319 Vgl. Isenmann 2002, 222 f., 225-227. Vgl. für Frankfurt am Main Dilcher 1980, 84 f., 91 f. 2320 Vgl. Schwinges 2002a, 18; Isenmann 2002, 214. Zur pragmatischen Vergabe des Bürgerrechts vgl. ebd., 207.

2321 Vgl. Isenmann 2002, 217-219, 230-236.

2322 Vgl. Schwinges 2002a, 38-50.

2323 Vgl. Schwinges 2002a, 22. Der von Schwinges 2002 angekündigte Band in der Typologie des sources du Moyen-Âge occidental ist leider bis heute nicht erschienen, vgl. ebd., 22 mit Anm. 10.

2324 Vgl. Schwinges 2002a, 46. Vgl. für Frankfurt am Main Dilcher 1980, 77. 


\subsubsection{Basel}

Die Gebühr für den Erwerb des Basler Bürgerrechts betrug in der ersten Hälfte des 15. Jahrhunderts noch 10 Gulden. Im Jahr 1441 senkte der Rat die Taxe auf 4 Gulden für die Stadt und 3 Schilling für den Schreiber. ${ }^{2325}$ Erst in der Mitte des 16. Jahrhunderts, im Jahr 1552, erhöhte die Stadt die Gebühr wieder auf 10 Gulden. ${ }^{2326}$ Wie auch in anderen Städten waren die Basler Bürger dazu verpflichtet, dem Bürgermeister und dem Rat gehorsam zu sein, das Ungeld zu zahlen, Wachdienst zu leisten und die Stadt auf Feldzügen zu begleiten. ${ }^{2327}$ Seit 1534 verlangte die Stadt Basel als Voraussetzung für die Verleihung des Bürgerrechts den Nachweis des ehrlichen Abschieds. Der Petent musste folglich personenrechtlich frei sein und durfte keinen ihn verfolgenden Herrn haben. ${ }^{2328}$ Per Ratsbeschluss wurde zudem im Jahr 1541 verfügt, dass jeder Neubürger einen Vermögensnachweis zu erbringen habe, der sich auf mindestens 40 bis 50 Gulden belaufen sollte. ${ }^{2329}$ Ein weiterer Punkt dieser Ordnung legte außerdem fest, dass fortan keine Welschen mehr ins Bürgerrecht aufgenommen werden sollten. ${ }^{2330}$

Zur Ermittlung der Neubürger, die zwischen 1450 und 1550 ins Bürgerrecht aufgenommen wurden, kann in Basel kein geschlossen geführtes Bürgerbuch herangezogen werden. Vielmehr wurden die neuen Bürger im betrachteten Zeitraum in drei verschiedene Stadtbücher - und hier vermischt mit anderen Nachrichten - eingetragen. Das älteste Stadtbuch, das neben Ratsverordnungen und -erlassen auch Bürgeraufnahmen verzeichnete, ist das nach seiner Einbandfarbe benannte Rote Buch (RB), das 1358 nach dem großen Erbeben angelegt wurde. In ihm finden sich bis in das Jahr 1488 Einträge zu Neubürgern. ${ }^{2331}$ Als Nachfolger des Roten Buchs können die sogenannten Öffnungsbücher (ÖB) gelten. Auch sie enthalten neben Aufzeichnungen mündlicher Verhandlungen und Beschlüsse Notizen über Bürgeraufnahmen und decken die Periode von 1438 bis 1610 ab. ${ }^{2332}$ Für diese Untersuchung kommen die Bände 4 bis 8 in Betracht. Parallel zu den Öffnungsbüchern wurde von 1486 bis 1520 ein Protokoll über die Entrichtung der Bürgerrechtsgebühren (PB) geführt. ${ }^{233}$ Auch dieses Protokoll stellt kein in sich geschlossenes und vollständiges Neubürger-

2325 Vgl. Heusler 1860, 265; Wackernagel 1911, Bd. 2.1, 355; Portmann 1979, 54; Isenmann 2002, $234 \mathrm{f.}, 242$.

2326 Vgl. Portmann 1979, 54, 56. Nicht nach elf Jahren, wie Portmann aufgrund eines Schreibfehlers angibt (S. 54), sondern nach 111 Jahren wurde die Gebühr wieder erhöht.

2327 Vgl. Heusler 1860, 250.

2328 Vgl. Portmann 1979, 61; Isenmann 2002, 232.

2329 Vgl. Portmann 1979, 61.

2330 Diese Bestimmung wurde in den Jahren 1546, 1553 und 1555 wiederholt, vgl. Portmann 1979, 63; Schulz 1985b, 231; Isenmann 2002, 248. Zum Bild von „den Welschen“, vor allem während der Burgunderkriege in den 1470er-Jahren, vgl. Sieber-Lehmann 1995, 281-300.

2331 StABS, Ratsbücher A 1. Vgl. Portmann 1979, 14.

2332 StABS, Protokolle, Öffnungsbücher 1-9. Vgl. Portmann 1979, 14 f.

2333 StABS, Ratsbücher P 1. Vgl. Portmann 1979, 15. 
verzeichnis dar, sondern führt lediglich diejenigen Neubürger auf, die die Gebühr in Raten zahlten.

Anhand dieser drei Ratsbücher konnte für den untersuchten Zeitraum von hundert Jahren die Aufnahme von 27 Papiermachern festgestellt werden (vgl. Tab. 19). ${ }^{2334}$ Hiervon wurden 22 Namen mit der Berufsbezeichnung Papierer versehen. Die weiteren fünf Personen konnten durch andere Quellen als Papiermacher identifiziert werden. Ob eventuell noch andere in eines der drei Bücher eingetragene Neubürger den Beruf des Papiermachers ausübten, ist nicht auszuschließen. ${ }^{2335}$

Die ersten sechs neu in das Bürgerrecht aufgenommenen Papierer wurden in das Rote Buch eingetragen, wobei drei davon parallel auch in den Öffnungsbüchern zu finden sind. Zwischen 1488 und 1492 konnten bis auf einen Eintrag in den Öffnungsbüchern die meisten Notizen zu Papiermachern, acht an der Zahl, in dem Protokoll über die Bürgerrechtsgebühren ausgemacht werden. Auch hier sind zwei Parallelüberlieferungen in den Öffnungsbüchern zu verzeichnen. Die letzten zwölf Angaben über Papiermacher ab 1499 sind in den Öffnungsbüchern zu finden.

Bei den Einträgen im Roten Buch und in den Öffnungsbüchern findet sich lediglich die Erwähnung, dass die jeweilige Person das Bürgerrecht zu einem bestimmten Datum erworben habe. ${ }^{2336}$ Lediglich aus dem Protokoll über die Bürgerrechtsgebühren lassen sich - dem Zweck dieser Verzeichnisse gemäß - weitere Informationen gewinnen. Dieses Protokoll verschriftlicht die Zahlung der Aufnahmegebühr, wenn diese in Raten erfolgte. Neben den Zahlungsmodalitäten verzeichnet es daher manchmal auch den vom Neubürger gestellten Bürgen.

Für die hier besprochenen Papiermacher konnten in vier Fällen Bürgen ausgemacht werden. So bürgte der Papiermacher und Mühlenbesitzer Hans Züricher im Jahr 1490 für den Papiermacher Wilhelm Frone (W. Varner) aus dem Piemont. Dieser hatte bereits einen Ort, das heißt einen Viertel Gulden, in bar bezahlt und musste nun $\mathrm{zu}$ jeden Fronfasten einen halben Gulden bezahlen, bis er die Bürgerrechtsgebühr

2334 Für die Bürgerrechtsaufnahmen bis 1500 vgl. Kälin 1974, 193-195.

2335 Es ist möglich, dass der einzige Beleg für einen Papiermacher die Notiz über die Aufnahme ins Bürgerrecht war. So lässt sich beispielsweise der Papiermacher Heinrich in Eda nur im Protokoll über die Bürgerrechtsgebühren nachweisen, vgl. StABS, Ratsbücher P 1, 240r. Würde bei dieser Person die Nennung des Berufs fehlen, könnte sie nicht als Papiermacher identifiziert werden. Rolf Portmann gibt an, dass für den Zeitraum von 1451 bis 1500 bei 68 Prozent der Neubürger der Beruf angegeben wurde, vgl. Portmann 1979, 90, Tab. 18. Diese Quote liefert eine gute Übersicht über die verschiedenen Berufszweige und ist im Vergleich mit anderen Städten als hoch anzusehen, vgl. hierzu den durchschnittlichen Anteil an Einträgen mit Berufsbezeichnung von 40 Prozent, den Bruno Koch für Bürgerbücher im reichsweiten Vergleich ermittelte, vgl. Koch 2002, 411.

2336 Im Roten Buch und in den Öffnungsbüchern ist diese Formel noch zum Teil in Latein gehalten, vgl. beispielsweise StABS, Ratsbücher A 1, 219: Item mercurry ante michaelis Lvii ${ }^{\text {to }}$ emerunt civilegium Anteny Galsian und Michel Galsian gebrudere et jurarunt. Das deutsche Pendant dazu lautet: Uff Zinstag nach Andree hatt Hanns Külhamer von Schaffhusen der bapirer burggrecht erkoufft und geschworen, StABS, Protokolle, Öffnungsbuch 6, 112r. 
von 4 Gulden vollständig entrichtet hatte. ${ }^{2337}$ Zwei Jahre zuvor, 1488, hatte sich Hans Züricher auch für den Papiermacher Hug Pastor als Bürge zur Verfügung gestellt. ${ }^{2338}$

Tab. 19: Bürgerrechtsaufnahmen von Papiermachern in Basel 1457 bis $1550 .^{2339}$

\begin{tabular}{|c|c|c|c|c|c|}
\hline & Person & Jahr & RB & ÖB & PB \\
\hline 1. & Anton Gallician, Papiereri & 1457 & A 1,219 & & \\
\hline 2. & Michel Gallician, Papiererii & 1457 & A 1, 219 & & \\
\hline 3. & Hans Gallician I, Papierer & 1461 & A 1,227 & & \\
\hline 4. & Bartholome de Conmola, Papierer & 1464 & A 1,222 & ÖB $4,10 v$ & \\
\hline 5. & Ulrich Züricher, Papiereriii & 1469 & A 1,226 & ÖB 5, 29r & \\
\hline 6. & Peter Höfflin, Papierer & 1472 & A 1,231 & ÖB $5,88 \mathrm{r}$ & \\
\hline 7. & Hans Züricher, Papiereriv & 1488 & & & $P 1,285 r$ \\
\hline 8. & Hug Pastor, Papierer & 1488 & & ÖB $6,108 \mathrm{r}$ & P 1, 290r \\
\hline 9. & Hans Kielhammer, Papierer & 1488 & & ÖB $6,112 r$ & \\
\hline 10. & Roland von Caselle, Papierer & 1489 & & & P 1, 240r \\
\hline 11. & Heinrich in Eda, Papierer & 1489 & & & P 1, 240r \\
\hline 12. & Diebolt Hanman, Papierer & 1489 & & & P 1, 240r \\
\hline 13. & Wilhelm Frone (W. Varner), Papierer & 1489 & & & P 1, 300r \\
\hline 14. & Anton Pastor IIV & 1491 & & & $P 1,311 v$ \\
\hline 15. & Bartholome Pastor, Papierer & 1492 & & ÖB 7, 17r & P 1, 320r \\
\hline 16. & Jacob von Reinach, Papierer & 1499 & & ÖB 7, 67r & \\
\hline 17. & Jörg Dürr d. Ä., Papierer & 1511 & & ÖB 7, 139v & \\
\hline 18. & Mundyn von Caselle, Papierer & 1515 & & ÖB $7,160 v$ & \\
\hline
\end{tabular}

i StABS, Zunftarchive, Gerbern Urk. 14 (21.03.1453).

ii StABS, Zunftarchive, Zunft zu Safran 24, 73.

iii StABS, Teichkorporationen, St. Alban, Urk. 12 (16.07.1473); auch Urkundenbuch der Stadt Basel 1901, Bd. 8, 345, Nr. 439.

iv StABS, Gerichtsarchiv B 12, 125v.

v Dass Anton Pastor II tatsächlich Papiermacher war, ist nicht schriftlich belegt. Dass bei seiner Aufnahme ins Bürgerrecht ein Papiermacher für ihn bürgte und dass er aus dem Papiermacherort Caselle im Piemont stammte, spricht jedoch dafür.

2337 StABS, Ratsbücher P 1, 300r.

2338 StABS, Ratsbücher P 1, 290r.

2339 Die Belege stammen aus: StABS, Ratsbücher A 1; Ratsbücher P 1; Protokolle, Öffnungsbücher. 


\begin{tabular}{|c|c|c|c|c|c|}
\hline & Person & Jahr & RB & ÖB & PB \\
\hline 19. & Hans Wetzel, Papierer & 1515 & & ÖB $7,173 v$ & \\
\hline 20. & Bartholome Blum, Papierer & 1525 & & ÖB 7, 205v & \\
\hline 21. & Peter Sontach, Papierer & 1527 & & ÖB 7, 221r & \\
\hline 22. & Claus Dürr, Papierer & 1527 & & Öв 7, 221r & \\
\hline 23. & Joseph Velek, Papierer & 1539 & & ÖB $8,61 \mathrm{r}$ & \\
\hline 24. & Heinrich Rytz, Papierer & 1539 & & ÖB $8,65 r$ & \\
\hline 25. & Joachim Degenhart, Papierer & 1540 & & ÖB $8,73 v$ & \\
\hline 26. & Hans Bussi, Papierer & 1548 & & Öв $8,127 v$ & \\
\hline 27. & Hans Düring, Papierer & 1550 & & ÖB $8,135 r$ & \\
\hline
\end{tabular}

Der dritte Fall einer Bürgschaft betraf Anton Pastor II, der im Jahr 1491 mit dem Papiermacher Růll als Bürgen in das Bürgerrecht aufgenommen wurde und die Gebühr ratenweise entrichtete. ${ }^{2340} \mathrm{Im}$ Jahr 1492 wurde der Papiermacher Bartholome Pastor Bürger der Stadt Basel. ${ }^{2341}$ Im Protokoll über die Bürgerrechtsgebühren ist er mit seinem Bürgen, dem Drucker Michel Furter, aufgeführt, der einen Teil der Gebühr für ihn entrichtete. ${ }^{2342}$ Durchgestrichen sind die Wörter und ist sin bürg Frantz Galician. Der Papiermacher Franz Gallician war anscheinend zunächst als Bürge für Bartholome Pastor vorgesehen. Seine Aufgabe übernahm dann aber Michel Furter, der noch im Jahr 1496 Raten für Bartholome Pastor abbezahlte. ${ }^{2343}$ Als Bürgen für Papiermacher fungierten in drei von vier Fällen demnach Berufsgenossen. Nur in einem Fall nahm der zunächst eingetragene Papierer Franz Gallician seine Verantwortung nicht wahr. Hier übernahm ein Drucker die Bürgschaft. In welchem Verhältnis die beiden Männer zueinander standen, konnte nicht eruiert werden.

Neben der Entrichtung der vollen Aufnahmegebühr war ein anderer, vor allem im 14. und auch noch im 15. Jahrhundert oft beschrittener Weg, das Bürgerrecht zu erhalten, die aus eigener Tasche finanzierte Teilnahme an Kriegszügen, die die Stadt Basel mit der Verleihung des Bürgerrechts oder einer verminderten Aufnahmegebühr belohnte. ${ }^{2344}$ Auch einige Papiermacher wurden auf diese Weise Basler Bürger. So

2340 StABS, Ratsbücher P 1, 311v. Kälin vermutet - ohne seine Vermutung zu belegen - hinter Růll den Papiermacher Roland von Caselle, vgl. Kälin 1974, 200. Vgl. auch Kapitel 3.3.1.1, S. 329.

2341 StABS, Protokolle, Öffnungsbuch 7, 17r.

2342 StABS, Ratsbücher P 1, 320.

2343 StABS, Ratsbücher P 1, 320. Zunächst gab Bartholome Pastor selbst einen halben Gulden in bar. Franz Gallician scheint überhaupt nicht für ihn eingesprungen zu sein, denn die nächste Rate von einem halben Gulden zahlte eine Person, die stempffer genannt wurde. Anschließend entrichtete Michel Furter ratenweise die übrigen 3 Gulden, zwei davon erst im Jahr 1496. Vgl. auch Kälin 1974, 203. 2344 Vgl. Portmann 1979, 49-51. 
nahm beispielsweise der Papiermacher Hans Gallician I im Jahr 1461 an der Ortenberger Fehde teil und erhielt dafür - ebenso wie 92 weitere Neubürger - die Hälfte der Einbürgerungsgebühr erlassen. ${ }^{2345}$ Gleich drei Papiermacher wurden im Rahmen des Zugs nach Heitersheim im Jahr 1489 zusammen mit weiteren 153 Personen Bürger der Stadt Basel, nämlich Diebolt Hanman, Heinrich in Eda und Roland van pemund. Der Zug nach Heitersheim war die letzte Gelegenheit, zu der eine massenhafte Aufnahme in das Bürgerrecht vollzogen wurde..$^{2346}$

Auf der Basis der statistischen Erhebung von Rolf Portmann zur den Berufen der Basler Neubürger ist es möglich, den Anteil der Papiermacher an allen Einbürgerungen mit Berufsbezeichnung näherungsweise zu ermitteln. ${ }^{2347}$ Da die Berechnungen von Portmann nur bis in das Jahr 1527 reichen, müssen von den 27 Papiermachern die fünf Personen herausgenommen werden, die nach diesem Jahr in das Bürgerrecht aufgenommen wurden. Portmann gibt zudem für den betreffenden Zeitraum lediglich 17 Papiermacher an, da er nur Neubürger mit beistehender Berufsbezeichnung aufgenommen und auf dieser Grundlage seine Statistik berechnet hat. Es fallen somit für diese Betrachtung fünf weitere Papiermacher heraus. ${ }^{2348}$ Unter den 293 Neubürgern mit Berufsangaben, die in der Periode von 1451 bis 1475 Basler Bürger werden, finden sich drei Papierer mit Berufsangabe. Dies entspricht einem Anteil von einem Prozent. Im folgenden Zeitabschnitt von 1476 bis 1500 wurde 735 Personen mit Berufsbezeichnung das Bürgerrecht verliehen, darunter acht Papiermachern. Folglich waren in diesem Zeitraum ebenfalls ein Prozent der Neubürger, bei denen ein Beruf fassbar ist, in der Papierherstellung tätig. Zwischen 1501 und 1527 betrug der Anteil der Papiermacher wieder gut ein Prozent: Von 566 Neubürgern waren sechs Personen Papierer. ${ }^{2349}$

Der Vergleich mit anderen Berufen zeigt, dass die Papiermacher damit zwar nicht zu den häufig vertretenen Professionen gehörten, aber an numerischer Stärke durchaus mit Vertretern anderer kleiner Berufszweige mithalten konnten. ${ }^{2350}$ Durch die starke Ausdifferenzierung beispielsweise der metallverarbeitenden Berufe gab es in

2345 Die Teilnehmer an der Ortenberger Fehde zahlten statt 4 nur 2 Gulden für die Aufnahme ins Bürgerrecht, vgl. StABS, Ratsbücher A 1, 227. Vgl. auch Portmann 1979, 50; Kälin 1974, 157. Paul Koelner und Gerhard Piccard gehen fälschlicherweise davon aus, dass Hans Gallician I das Bürgerrecht gebührenfrei erhalten habe, vgl. Koelner 1935, 531; Piccard 1967, 86. Vgl. hierzu auch Kälin 1974, 268 mit Anm. 83.

2346 Vgl. Portmann 1979, 50.

2347 Zwar ist die historische Statistik gerade bei mittelalterlichen Quellen nur bedingt tragfähig, dennoch kann sie richtungsweisende Tendenzen aufzeigen, vgl. hierzu H. Ammann 1950, 28.

2348 Vgl. Portmann 1979, 134. Ohne Berufsbezeichnung in den Bürgerbüchern, aber durch andere Quellen sicher als Papiermacher identifizierbar sind: Anton Gallician, Michel Gallician, Ulrich Züricher und Hans Züricher. Anton Pastor II wird hingegen in den Quellen nicht als Papiermacher bezeichnet, es soll aber an dieser Stelle dennoch davon ausgegangen werden, dass er diesen Beruf ausübte, vgl. Kapitel 3.3.1.1, S. 329; Kapitel 3.3.2.1, Tab. 17; Kapitel 3.3.3.1, Tab. 19.

2349 Vgl. Portmann 1979, 86, Tab. 14.

2350 Vgl. Portmann 1979, 130-140. 
der spätmittelalterlichen Stadt eine Vielzahl von Berufen, die nur sehr wenige Personen ausübten. ${ }^{2351}$ Nach Portmann erhielten von 1451 bis 1527 zum Beispiel nur acht Nadler das Bürgerrecht. Stark vertreten waren hingegen Berufsgruppen, die im Bekleidungs- oder Nahrungsmittelgewerbe tätig waren. So wurden in dem Zeitabschnitt von 1451 bis 1527 als Neubürger insgesamt etwa 110 Schuhmacher, 73 Schneider sowie circa 70 Metzger aufgenommen. ${ }^{2352}$ Vergleicht man die Anzahl der aufgenommenen Papiermacher mit den anderen Beschreibstoffherstellern, den Pergamentern, so fällt gleich die sehr geringe Zahl an Pergamentmachern auf. Nur ein Neubürger konnte für dieses Handwerk im betrachteten Zeitraum ermittelt werden. ${ }^{2353}$ Dem neuen Gewerbe der Buchdruckerei hingegen gingen fast ebenso viele Personen nach wie der Papiermacherei: 21 Neubürger wurden als Drucker bezeichnet, wobei ein Großteil, nämlich 14 Personen, zwischen 1476 und 1500 aufgenommen wurde..$^{2354}$

Die im Untersuchungszeitraum der vorliegenden Arbeit eingebürgerten 27 Papiermacher repräsentieren nicht alle Papierer, die Basler Bürger waren. Von 1450 bis 1550 konnten aus anderen Quellen zwölf weitere Papiermacher ermittelt werden, die als Bürger zu Basel bezeichnet wurden (vgl. Tab. 20). Unter ihnen befinden sich sechs Papiermacher, die vermutlich nach dem Bürgerrechtskauf ihrer Väter geboren wurden und damit gewissermaßen qua Geburt Basler Bürger waren. ${ }^{2355}$ Hierunter fallen Franz Gallician, dessen Vater Anton Gallician 1457 ins Bürgerrecht aufgenommen worden war, Claus und Jacob Gallician, deren Vater Michel Gallician ebenfalls 1457 das Bürgerrecht erworben hatte, des Weiteren Anton Kielhammer, dessen Vater Hans Kielhammer im Jahr 1488 Basler Bürger geworden war, sowie schließlich Gregorius und Jörg Dürr d. J., deren Vater Jörg Dürr d. Ä. 1511 ins Bürgerrecht eingetreten war. ${ }^{2356}$

In welcher Form diese Söhne ihr Bürgerrecht „aktivierten“, das heißt, ob sie erneut eine Aufnahmegebühr entrichten oder ob sie lediglich den Bürgereid leisten mussten, ist nicht zu eruieren, da ihre Namen in den meisten Fällen nicht erneut im Bürgerbuch dokumentiert wurden. ${ }^{2357}$ Lediglich bei einem Papiermacher, der in der

2351 Vgl. beispielsweise Brandt 2008, 300.

2352 Vgl. Portmann 1979, $133 \mathrm{f}$.

2353 Vgl. Portmann 1979, 134. Auch wenn der traditionelle Beschreibstoff Pergament in vielen Bereichen durch das Papier verdrängt wurde, so erscheint die Aufnahme von nur einem Pergamenter für mehr als 75 Jahre doch wenig. Vermutlich stellten auch andere Handwerker Pergament her, so zum Beispiel Gerber. Möglich ist auch, dass dieser Beschreibstoff noch in größeren Mengen in Klöstern hergestellt wurde oder dass der Bedarf durch Exporte gedeckt wurde, wie beispielsweise im Jahr 1470/71, in dem die Schreibstube des Basler Münsters Häute von der Zurzacher Messe und einem Kaufmann aus Rottweil bezog, vgl. Geering 1886, 235.

2354 Vgl. Portmann 1979, $134 \mathrm{f}$.

2355 Vgl. Portmann 1979, 58, 60.

$2356 \mathrm{Zu}$ den Bürgerrechtseintritten der Väter vgl. Tab. 19. Zur Abstammung der fraglichen Papiermacher vgl. Piccard 1967, 126, 129, 135, 137 f., 140, 143-146; Kälin 1974, 162 f. u. Tafel 6 u. 7; Kälin 1972a, 12, $14 \mathrm{f}$.

2357 Vgl. hierzu Schwinges 2002a, 46. 
Zählung unter denen erscheint, die als Neubürger eingetragen wurden, wird ersichtlich, dass bereits sein Vater Bürger der Stadt Basel war: Nach dem Protokoll über die Bürgerrechtsgebühren wurde Hans Züricher die entsprechende Gebühr wegen seines Vaters erlassen. ${ }^{2358}$ Allerdings war er vermutlich vor dem Bürgerrechtserwerb seines Vaters geboren und mit ihm gemeinsam nach Basel gekommen.

Tab. 20: Weitere als Bürger zu Basel bezeichnete Papiermacher 1459 bis 1547 (Belege StABS).

\begin{tabular}{lll}
\hline & Papiermacher & Belege \\
\hline 1. & Anton Pastor I & 1459: Urk. Spital 566 (06.03.1459) \\
2. & (Peter) Hans Strub & 1487: Gerichtsarchiv B 12, 13r \\
3. & Franz Gallician & 1490: Gerichtsarchiv A 38, 90v \\
4. & Claus Gallician & 1509: Lehenarchiv 0, Urk. 58 (05.02.1509) \\
5. & Jacob Gallician & 1518: Gerichtsarchiv A 53, 217v \\
6. & Fridlin Hüsler d. Ä. & 1519: Gerichtsarchiv B 22, 69r \\
7. & Hans Lufft & 1519: Gerichtsarchiv B 22, 69r \\
8. & Anton Kielhammer & 1520: Gerichtsarchiv C 23, 125r \\
9. & Conrad Grebel & 1523: Gerichtsarchiv B 22, 333r \\
10. & Oswald Banwart & 1524: St. Urk. 2840 (14.05.1524) \\
11. & Gregorius Dürr & 1530: Gerichtsarchiv B 25, 146v \\
12. & Jörg Dürr d. J. & 1547: Privatarchive 22, Urk. 2 (28.02.1547) \\
\hline
\end{tabular}

Die sechs Papiermacher, die als Bürger bezeichnet wurden, aber für die nicht nachweisbar ist, dass bereits ihre Vorfahren das Basler Bürgerrecht besaßen, waren Anton Pastor I, (Peter) Hans Strub, Fridlin Hüsler d. Ä., Hans Lufft von Ettlingen, Conrad Grebel und Oswald Banwart. ${ }^{2359}$ Hans Lufft von Ettlingen beispielsweise war eventuell kurz vor dem Kauf der Rychmühle im Jahr 1494 noch in Lörrach ansässig. ${ }^{2360}$ Einen Hinweis darauf, dass er Basler Bürger war, findet sich erst für das Jahr 1519, als er die Papiermühle wieder veräußerte. Wann er das Bürgerrecht erwarb, bleibt unklar.

2358 StABS, Ratsbücher P 1, 285r: Item Hannsen Züricher ist sin Burgrecht in sins vatter nach gelaßn. 2359 Möglicherweise besaß der Vater von Fridlin Hüsler d. Ä., ein städtischer Waffenknecht gleichen Namens, das Basler Bürgerrecht, vgl. Kälin 1972a, 12.

2360 StABS, Gerichtsarchiv B 13, 167v. Der Zusatz seßhafft zu Lörach ist allerdings durchgestrichen. 
Addiert man die durch andere Zeugnisse klar als Bürger identifizierten Papiermacher zu denjenigen, die als Neubürger in die Ratsbücher eingetragen wurden, so erhält man eine Anzahl von 39 Papiermachern für einen Zeitraum von circa hundert Jahren. Von diesen 39 Papiermachern besaßen nachweislich 18 Personen im Untersuchungszeitraum eine Papiermühle in Basel und waren somit Meister. ${ }^{2361}$ Drei weitere Papierer mit Bürgerrecht - Claus und Jacob Gallician sowie Jörg Dürr d. J. - waren Söhne von Papiermühlenbesitzern, allerdings ohne nachweisbare eigene Basler Werkstatt im Untersuchungszeitraum. Die weiteren 18 Papiermacher, die das Bürgerrecht besaßen, arbeiteten in Basel nicht in ihrer eigenen Werkstatt, sondern waren Pächter oder Angestellte. Zwei Drittel von ihnen waren, wie noch zu zeigen ist, Mitglied der Safranzunft, sodass zwölf Papierer, die keine Papiermühlenbesitzer waren, das Bürgerrecht besaßen und einer Zunft angehörten. ${ }^{2362}$ Bei einem Großteil der Papierer, die nicht ihren eigenen Betrieb leiteten, muss jedoch davon ausgegangen werden, dass keine Einbürgerung vorlag. Von den Papierergesellen sowie Lohnarbeitern und Lohnarbeiterinnen, die namentlich in Basler Quellen fassbar sind, werden rund zwei Drittel nicht als Bürger bezeichnet. ${ }^{2363}$ Die Zahl der nicht in schriftlichen Zeugnissen erfassten Personen, die in der Papierherstellung tätig waren, ist mindestens doppelt, wenn nicht dreifach so hoch anzusetzen wie die der namentlich genannten. ${ }^{2364}$ Eingebürgert wurden folglich vor allem Papiermacher, die eine gehobene Stellung innerhalb ihres Gewerbes einnahmen, sei es als Papiermühlenbesitzer oder als fachlicher Leiter eines fremden Betriebs. Diese Personen konnten sich die Verpflichtungen leisten, die das Bürgerrecht mit sich brachte, und waren an einer weitgehenden Integration in die Stadt interessiert.

Wie lange die Papiermacher bereits in Basel lebten und arbeiteten, bevor sie Bürger der Stadt wurden, variierte von Fall zu Fall. Allerdings ist davon auszugehen, dass es sich meist um mehrere Jahre handelte. So lagen zwischen der Einwanderung Anton und Michel Gallicians Ende der 1440er-Jahre und ihrem gemeinsamen Bürgerrechtserwerb im Jahr 1457 circa acht Jahre. ${ }^{2365}$ Der Papiermacher Diebolt Hanman von Thann war bereits 1478 in Basel ansässig: Er wurde beim Kauf seines Hauses im

2361 Vgl. Tab. 13. Lediglich zwei Papierermeister konnten nicht als Bürger identifiziert werden: Meister Andres und Michel Gernler. Da jedoch bereits Michel Gernlers Vater, der Seiler Heinrich Gernler, in Basel lebte, besteht die Möglichkeit, das Michel Gernler qua Geburt Basler Bürger war, vgl. Kälin 1974, 196.

2362 Vgl. Tab. 19 und Tab. 23.

2363 Vgl. Tab. 16 mit Tab. 19 und Tab. 20. Folgende 17 von 53 Papierern, die nicht Papiermühlenbesitzer waren, werden als Bürger bezeichnet: Anton Pastor I, Anton Pastor II, Bartholome de Conmola, Bartholome Pastor, Diebolt Hanman, Hans Bussi, Hans Wetzel, Heinrich in Eda, Heinrich Rytz, Hug Pastor, Jacob von Reinach, Joachim Degenhart, Joseph Velek, Mundyn von Caselle, Oswald Banwart, Roland von Caselle, Wilhelm Frone (W. Varner).

2364 Vgl. Kapitel 3.3.1.1.

2365 Vgl. Kapitel 3.3.2.1, S. 349; StABS, Ratsbücher A 1, 219. 
St. Albantal als Hintersasse bezeichnet. ${ }^{2366}$ Das Bürgerrecht erwarb Diebolt Hanman jedoch erst elf Jahre später, 1489, anlässlich des Zugs nach Heitersheim. ${ }^{2367}$ Der Papiermacher Hans Kielhammer von Schaffhausen ist schon 1475 im St. Albantal greifbar. Basler Bürger wurde er 13 Jahre später. ${ }^{2368}$ Relativ lang lebte der Papierer Joachim Degenhart ohne Bürgerrecht in Basel: Ganze 20 Jahre verstrichen zwischen dem ersten fassbaren Beleg in dem Eintrittsrodel der Safranzunft 1520 und der Aufnahme als Bürger 1540. ${ }^{2369}$

Auf welche Weise die städtische Einbürgerungspolitik Einfluss auf das Papiergewerbe hatte, zeigt sich am eindrücklichsten an der Aufnahme von Welschen ins Bürgerrecht. Noch im Jahr 1548 wurde der Papiermacher Hans Bussi Bürger zu Basel, obwohl er aus Savoyen stammte und damit durchaus als ein Welscher gelten konnte. ${ }^{2370}$ Im Jahr 1550 aber bat der Papierer Niclaus Ruckh von Épinal, der mit Verena Dölin, der Witwe seines Berufsgenossen Peter Sontach, eine Basler Bürgerin geheiratet hatte, um die Aufnahme ins Bürgerrecht. Der Rat wies sein Gesuch mit der Begründung ab, dass ein Welscher kraft der neuen Stadtordnung weder als Hintersasse noch als Bürger aufgenommen werden solle. ${ }^{2371}$ Niclaus Ruckh entschloss sich daher, Basel zu verlassen und andernorts sein Glück zu suchen. Für dieses Vorhaben konnte er immerhin einen ehrlichen Abschied erwirken, der ihm im Juni 1550 ausgestellt wurde. ${ }^{2372}$ Bemerkenswert ist, dass vor dem Erlass von 1541 - und offensichtlich in Ausnahmefällen auch noch danach - die Stadt Basel mindestens zehn welsche Papiermacher zu ihren Bürgern machte. ${ }^{2373}$ Dies entspricht gut einem Drittel aller in die Bürgerbücher eingetragenen Papiermacher im Untersuchungszeitraum und verweist auf die große Bedeutung italienischer und französischer Fachkräfte für das Basler Papiergewerbe. ${ }^{2374}$ Dass diese oft gut ausgebildeten Handwerker nach 1541

2366 StABS, Gerichtarchiv B 10, 266. Vgl. Anm. 2026. Zum Begriff Hintersasse vgl. Holenstein 2007, $367 \mathrm{f}$.

2367 StABS, Ratsbücher P 1, 240r.

2368 StABS, Steuern B 19, Markzahlsteuer 1475/76, 22v; Protokolle, Öffnungsbuch 6, 112r.

2369 StABS, Zunftarchive, Zunft zu Safran 25, 67; Protokolle, Öffnungsbuch 8, 73v.

2370 StABS, Protokolle, Öffnungsbuch 8, 127v.

2371 StABS, Ratsbücher D 2, 137v: Wir Bernhartt Meyer Bürgermeister und der Rhatt der Statt Basel thunt khunt und bekgennent mit disem brieff als dan Niclous Ruckh von Spynall der Bapirer sich mit unser Bürgerin Verena Dolinnenn wittwen eelichenn verheirathett ich by unss zu setzenn willens gewesen unnd unss umb den ynsitz und Bürgerrecht gepetten des wir aber ime von weg das er ein welscher und sollichs unser nüw angesechnen Statt Ordnung zuwider nitt gestatten noch zulassen können.

2372 StABS, Ratsbücher D 2, 138r: [...] dass gesagt Verenen Dolinen, die zytt sy unser burgerinnen gewesenn, sich fromeklich, ehrlich und woll gehalltenn. So hatt ouch er Niclaus in unser Statt, anderst wir nie gehörtt, ehrlich unnd woll gedientt.

2373 Dies waren Anton Gallician, Michel Gallician, Hans Gallician I, Roland von Caselle, Heinrich in Eda, Anton Pastor I, Bartholome Pastor, Mundyn von Caselle, Peter Sontach und Hans Bussi, vgl. hierzu auch Kapitel 3.3.2.1, S. 349-352.

2374 Vgl. Kapitel 3.3.2.1. 
keine Chance auf eine vollständige Integration in die städtischen Strukturen hatten, dort vielmehr höchstens geduldet wurden, muss einen weitreichenden Einfluss auf das Papiergewerbe gehabt haben. ${ }^{2375}$

\subsubsection{Ettlingen, Kempten, Memmingen, Ravensburg, Reutlingen, Straßburg und Zürich}

Um einen Eindruck davon zu erhalten, wie repräsentativ die Basler Fallstudie in Bezug auf die Bürgeraufnahmen ist, werden als Vergleichsbeispiele die Bürgerbücher der Städte Ravensburg und Straßburg herangezogen. Im Fall von Ravensburg decken zwei vollständig erhaltene sogenannte Bürgerlisten, beide auf Papier ${ }^{2376}$ geschrieben, den Untersuchungszeitraum vom Ende des 14. Jahrhunderts bis 1550 ab. ${ }^{2377}$ Das Büschel 26 des Ravensburger Stadtarchivs stellt das älteste erhaltene Bürgerbuch Ravensburgs dar. Es wurde für die Jahre 1324 bis 1436 geführt und umfasst 275 Seiten. Bis 1405 sind die Einträge in lateinischer Sprache gehalten, danach wurde der deutsche Dialekt der Region verwendet. Das zweite Bürgerbuch - im Ravensburger Stadtarchiv unter der Signatur Bü 27 - zu finden, enthält auf 300 Seiten die Bürgerrechtsaufnahmen von 1436 bis 1549 und verwendet durchgängig die deutsche Sprache. ${ }^{2378}$

Die Aufnahme in das Ravensburger Bürgerrecht, über die der städtische Rat entschied, setzte voraus, dass der Petent personenrechtlich frei war und seinen Wohnsitz in der Stadt hatte. ${ }^{2379}$ Zudem verpflichtete sich jeder Neubürger unter Hinterlegung eines Pfands von 5 Pfund Pfennigen, das Bürgerrecht mindestens fünf Jahre zu halten. ${ }^{2380}$ Dieser Betrag fiel an den Rat, wenn der Neubürger ungehorsam war, das

2375 Für die knapp zehn Jahre ab dem Erlass bis zum Ende des Untersuchungszeitraums ist eine detaillierte Untersuchung dieser Veränderungen leider nicht möglich. Auffällig ist jedoch, dass die großen Basler Papiererfamilien des 16. und 17. Jahrhunderts - die Dürr, die Hüsler, die Düring und die Thurneysen - keine welschen Wurzeln hatten, vgl. P. Tschudin 1991, 35-38.

2376 Das älteste Bürgerbuch vereint unterschiedliche Papiere in sich, unter anderen auch Bogen mit dem Wappenzeichen der Stadt Ravensburg, dem Doppelturm. Diese Tatsache veranlasste Konrad Dieterich Haßler, den Beginn der Ravensburger Papierproduktion vor das Jahr 1324 zu datieren. Haßler ging davon aus, dass der Codex vor der Beschriftung zusammengebunden wurde und dass daher alle Blätter gleich alt seien, vgl. K. D. Haßler 1844, 38 f. Gerhard Piccard konnte hingegen die Papiere mit dem Doppelturm als später - Ende des 14. oder Anfang des 15. Jahrhunderts - hinzugefügt nachweisen, vgl. Piccard 1962, 91. Die Wasserzeichen der anderen Bogen verweisen nicht auf Ravensburg. 2377 StR, Bü 26, Bürgerbuch 1 (1324-1436); Bü 27, Bürgerbuch 2 (1436-1549). Ediert in Bürgerlisten der Reichsstadt Ravensburg 1959; Bürgerlisten der Reichsstadt Ravensburg 1966a. Eine nach dem Alphabet sortierte Auflistung der Neubürger des 15. Jahrhunderts bietet Merk 1911. Vgl. auch Hengstler 1950, 29-32; Schwinges 2002a, $43 \mathrm{f}$.

2378 Vgl. Bürgerlisten der Reichsstadt Ravensburg 1959, 1; Schwinges 2002a, 43 f.

2379 Vgl. K. O. Müller 1916, 167, 173; Dreher 1972, Bd. 2, 463.

2380 Vgl. Merk 1911, 2; K. O. Müller 1916, 173; Dreher 1972, Bd. 2, 464; Isenmann 2002, 237. Hengstler fasst diese Zeitangabe als Beschränkung des Bürgerrechts durch Befristung auf. Die Festlegung dieses Zeitraums war jedoch vermutlich nicht als Befristung gedacht, sondern vielmehr als Verpflichtung 
Bürgerrecht vor der Frist aufgab oder es einen durch ihn verursachten Schaden auszugleichen galt. ${ }^{2381}$ Zur Sicherheit musste jeder Anwärter zusätzlich zwei oder mehr Bürgen stellen. Unabhängig von diesem Geldpfand betrug die Gebühr für den Kauf des Bürgerrechts seit 13963 Pfund Heller, seit 14305 Pfund Heller, im letzteren Fall also ungefähr die Hälfte der Pfandsumme. ${ }^{2382}$ Wie in anderen Städten wurde auch in Ravensburg der Erwerb des Bürgerrechts eng mit dem Eintritt in eine Zunft verknüpft; umgekehrt wurde niemand in eine Zunft aufgenommen, der nicht Bürger war. ${ }^{2383}$ Die bürgerlichen Pflichten bestanden auch wie andernorts darin, die Steuern zu zahlen, mit der Stadt zu wachen und zu reisen. ${ }^{2384}$ Für die Wach- und Kriegsdienste musste ein Neubürger in der Lage sein, einen Harnisch oder eine anderweitige Ausrüstung zu stellen. ${ }^{2385}$

Die Einträge in die Ravensburger Bürgerbücher sind alle nach demselben Muster vorgenommen worden. Nach der Datumsnennung folgen der Name des Neubürgers, eventuell mit Berufs- und/oder Ortsangaben, ${ }^{2386}$ die Information, dass dieser das Bürgerrecht erworben hat, die Angabe der Pfandsumme sowie die Nennung der Bürgen, auch diese eventuell mit Berufsangaben: Uff an Mittwochen nach Johannis Baptiste Peter Bappirer ist burger worden uff 5 jaur, verburget $5 \mathrm{lb}$. dn. burgen Uli Fries und Hans Krieger bappirer. ${ }^{2387}$

Für den Untersuchungszeitraum vom vermutlichen Beginn der Ravensburger Papiermacherei 1392 bis zum Jahr 1550 konnte die Bürgerrechtsaufnahme von elf eindeutig als Papiermacher identifizierten Personen festgestellt werden (vgl. Tab. 21). Den Anfang machte im Jahr 1402 der Papierer Staengly. ${ }^{2388}$ Der Eintrag, der seinen Eintritt ins Bürgerrecht festhält, ist zugleich der erste schriftliche Beleg für die Existenz

des Neubürgers, sich an die Stadt zu binden, und sollte einer starken Fluktuation innerhalb der Bürgerschaft entgegenwirken. Vgl. hierzu Bürgerlisten der Reichsstadt Ravensburg 1959, 4.

2381 Vgl. K. O. Müller 1916, 173; Isenmann 2002, 236.

2382 Vgl. K. O. Müller 1916, 173.

2383 Vgl. Merk 1911, 1; K. O. Müller 1916, 175. Vgl. allgemein Isenmann 2002, 237 f.

2384 Vgl. Bürgerlisten der Reichsstadt Ravensburg 1959, 4.

2385 Vgl. K. O. Müller 1916, 176; Dreher 1972, Bd. 2, 464.

2386 Mit Berufsangaben waren die Ravensburger Stadtschreiber jedoch vergleichsweise sparsam. Nur circa 20 Prozent der Einträge verzeichnen den Beruf des Neubürgers, anders als in Basel, wo im Zeitraum von 1451 bis 1500 - wie bereits erwähnt - 68 Prozent der Neubürger eine Berufsbezeichnung beigefügt wurde, vgl. die in einem Schaubild aufbereiteten Daten in Koch 2002, 412. Betrachtet man ausschließlich das zweite Bürgerbuch, so lässt sich nach den Angaben von Albert Hengstler hingegen ein Anteil von knapp 40 Prozent (706 von 1770 Bürgern) ermitteln, vgl. Bürgerlisten der Reichsstadt Ravensburg 1966b, 159. Vgl. zu Basel Portmann 1979, 90, Tab. 18. Vgl. Anm. 2335.

2387 StR, Bü 26, Bürgerbuch 1 (1324-1436), 243. Die Jahresangabe erfolgte jeweils am Anfang des Jahres und ist daher nicht bei jedem Eintrag wieder aufgeführt. In diesem Falle handelt es sich um das Jahr 1420. Leider ist bei diesem Beispiel nicht festzustellen, ob nur der letztgenannte Bürge den Beruf des Papiermachers ausübte oder ob sich die Berufsbezeichnung auf beide Bürgen bezieht.

2388 StR, Bü 26, Bürgerbuch 1 (1324-1436), 205. Vgl. auch Sporhan-Krempel 1953, 18; Alfred Schulte 1953, 15; Eitel 1990, 47. 
der Papierherstellung in Ravensburg. Im Jahr 1410 wurden die Papiermacher Hans Krieger und Haintz Wolfartshofer Bürger der Stadt Ravensburg. ${ }^{2389}$ Zehn Jahre später, im Juni 1420, bürgte Hans Krieger für Peter Bappirer. ${ }^{2390}$ Dieser erbaute in den 1430erJahren die zwei Papierhäuser in Schornreute mit seinen beiden Berufsgenossen Hans Stengeli und Cuntz Wolfartshofer, die zu diesem Zeitpunkt ebenfalls Ravensburger Bürger waren. ${ }^{2391}$ Ob es sich bei Hans Stengeli um den 1402 ins Bürgerrecht eingetretenen Staengly oder aber um seinen Sohn handelte, ist nicht zu sagen. Nach einer Pause von über 50 Jahren folgte 1477 als nächster Papiermacher Conrat Schuchmacher. ${ }^{2392}$ Gemeinsam ins Bürgerrecht aufgenommen wurden im Jahr 1482 die Papierer Hans Spen und Hans Wäch. ${ }^{2393}$ Zusammen mit seinem Schwiegersohn, dem Papiermacher Hans Schmid, für den er im Jahr 1500 anlässlich seines Bürgerrechtserwerbs bürgte, kaufte Hans Wäch 1498 die drei Papierhäuser des Felix Humpis. ${ }^{2394}$ Im Jahr 1505 wurde der Papiermacher Hans Härb Ravensburger Bürger, zwanzig Jahre darauf sein Kollege Martin Brigel. ${ }^{2395}$ Während über Hans Härb bekannt ist, dass er vor 1513 zusammen mit Jörg Wolfartshofer die untere Papiermühle im Ölschwang kaufte, taucht Martin

2389 StR, Bü 26, Bürgerbuch 1 (1324-1436), 221. Vgl. auch Sporhan-Krempel 1953, 18; Alfred Schulte 1953, 15. Da der erste erwähnte Papierer mit Familiennamen Wolfartshofer - Dietrich Wolfartshofer - nicht im Bürgerbuch zu finden ist, kann davon ausgegangen werden, dass Haintz Wolfartshofer als erster aus seiner Familie das Ravensburger Bürgerrecht erlangte. Kein weiteres Mitglied dieser Familie wurde im Untersuchungszeitraum als Neubürger in das Bürgerbuch eingetragen, allerdings werden einige Familienmitglieder in anderen Quellen als Bürger zu Ravensburg bezeichnet, sodass es sich wahrscheinlich um Bürgerssöhne handelte. Ob sie alle von Haintz Wolfartshofer abstammten, ist nicht festzustellen.

2390 StR, Bü 26, Bürgerbuch 1 (1324-1436), 243. Vgl. Alfred Schulte 1953, 15. Ob es sich bei dem Namenszusatz Bappirer nur um eine Berufsbezeichnung oder um einen Familiennamen handelt, ist nicht gewiss. Peter Bappirer taucht im Folgenden in den Jahren 1420, 1422, 1432, 1435, 1436 und 1446 unter diesem Namen auf, vgl. StR, Bü 26, Bürgerbuch 1 (1324-1436), 243, 274, 271; Bü 27, Bürgerbuch 2 (1436-1549), 30; Urk. 1216 (11.01.1432); Urk. 723 (03.02.1436). Lore Sporhan-Krempel vermutet, dass sich hinter Peter Bappirer Peter Wolfartshofer I verbirgt, vgl. Sporhan-Krempel 1953, 23. Tatsächlich wird um die gleiche Zeit im Jahr 1435 ein Peter Wolfartshofer genannt, vgl. StR, Bü 26, Bürgerbuch 1 (1324-1436), 270.

2391 StR, Urk. 1216 (11.01.1432); Urk. 723 (03.02.1436). Vgl. Alfred Schulte 1953, 20 f.; Sporhan-Krempel 1953, 23.

2392 StR, Bü 27, Bürgerbuch 2 (1436-1549), 101b. Vgl. Alfred Schulte 1953, 15.

2393 StR, Bü 27, Bürgerbuch 2 (1436-1549), 118. Vgl. Alfred Schulte 1953, 15.

2394 StR, Bü 27, Bürgerbuch 2 (1436-1549), 160. Vgl. Alfred Schulte 1953, 15. In der betreffenden Urkunde wurde Hans Schmid, der die Stieftochter des Hans Wäch geheiratet hatte, allerdings bereits als Bürger zu Ravensburg bezeichnet, vgl. StR, Urk. 670 (24.07.1498): den erbern Hannsenn Wähen und Hannsen Schmidt seinem Stieffdochterman, beyd bürger alhie.

2395 StR, Bü 27, Bürgerbuch 2 (1436-1549), 215. Vgl. Alfred Schulte 1953, 22. 
Brigel lediglich in den Steuerbüchern auf. ${ }^{2396}$ Der letzte im zweiten Bürgerbuch fassbare Papiermacher ist Mang Frey, der im Juli 1530 das Bürgerrecht erwarb. ${ }^{2397}$

Tab. 21: Ins Ravensburger Bürgerrecht aufgenommene Papiermacher 1400 bis 1550.

\begin{tabular}{|c|c|c|c|c|}
\hline & Datum & Neubürger & Bürge & Beleg \\
\hline 1. & 1402 & Staengly, Papierer & $\begin{array}{l}\text { Muller junior } \\
\text { Johannes Walk }\end{array}$ & Bü 26, 205 \\
\hline 2. & 24.02 .1410 & Hans Krieger, Papierer & $\begin{array}{l}\text { Claus Paggus } \\
\text { Oschwalt Huber }\end{array}$ & Bü 26, 221 \\
\hline 3. & 24.02 .1410 & Haintz Wolfartshofer, Papierer & $\begin{array}{l}\text { Haintz Wagner } \\
\text { Cuntz Mesner }\end{array}$ & Bü 26, 221 \\
\hline 4. & 26.06 .1420 & Peter Bappirer & $\begin{array}{l}\text { Uli Fries } \\
\text { Hans Krieger, Papierer }\end{array}$ & Bü 26, 243 \\
\hline 5. & 28.07.1477 & Conrat Schuchmacher, Papierer & $\begin{array}{l}\text { Jos Wintzürn d. Ä. } \\
\text { Hanns Wagner, Bäcker }\end{array}$ & Bü 27, 101b \\
\hline 6. & 15.04 .1482 & Hans Spen, Papierer & $\begin{array}{l}\text { Hainrich Humpis } \\
\text { Jos Wintzürn d. Ä. }\end{array}$ & Bü 27, 118 \\
\hline 7. & 15.04 .1482 & Hans Wäch, Papierer & $\begin{array}{l}\text { Hainrich Humpis } \\
\text { Jos Wintzürn d. Ä. }\end{array}$ & Bü 27, 118 \\
\hline 8. & 30.10 .1500 & Hans Schmid, Papierer & $\begin{array}{l}\text { Hans Wäch } \\
\text { Albrecht Doman }\end{array}$ & Bü 27, 160 \\
\hline 9. & 03.10 .1505 & Hans Härb, Papierer & $\begin{array}{l}\text { Heini Wolfartshofer } \\
\text { Krötlin }\end{array}$ & Bü 27, 169 \\
\hline 10. & 20.03 .1525 & Martin Brigel, Papierer & $\begin{array}{l}\text { Paul Wolfartshofer } \\
\text { Hans Thoman }\end{array}$ & Bü 27, 215 \\
\hline 11. & 27.07 .1530 & Mang Frey, Papierer & $\begin{array}{l}\text { Burgkhart Faber } \\
\text { Jörg Stürtzel }\end{array}$ & Bü 27, 228 \\
\hline
\end{tabular}

Unter den insgesamt 22 Bürgen dieser elf Papiermacher befinden sich nur vier Berufsgenossen. Zwei davon wurden zuvor als Neubürger angenommen: Wie bereits erwähnt, bürgte der Papierer Hans Krieger im Jahr 1420 für Peter Bappirer, Hans Wäch stellte sich 1500 als Garant für seinen Schwiegersohn Hans Schmid zur Verfügung. Sowohl für Hans Härb 1505 als auch für Martin Brigel 1525 stellte die Familie Wolfartshofer einen Gewährsmann: Heini beziehungsweise Paul Wolfartshofer. Ob diese beiden Familienmitglieder Papiermacher waren, ist nicht sicher nachzuweisen. Ein

2396 Zu Hans Härb, vgl. StR, Urk. 690 (13.05.1513). Vgl. Alfred Schulte 1953, 23. Zu Martin Brigel vgl. StR, Bü 49, Steuerbuch 1521-1524, 6v; Bü 50, Steuerbuch 1545, 3v.

2397 StR, Bü 27, Bürgerbuch 2 (1436-1549), 228. Vgl. Alfred Schulte 1953, 22. 
Henni Bappirer bürgte ebenfalls 1505 für einen Jacob Keller von Wangen. ${ }^{2398}$ Möglicherweise handelte es sich hierbei um Heini Wolfartshofer, dem somit der Beruf des Papiermachers zuzuschreiben wäre. Paul Wolfartshofer hingegen ist außerhalb des Bürgerbuchs in einem Ravensburger Steuerbuch fassbar und wohnte nach dessen Ausweis in Schornreute, sodass es durchaus wahrscheinlich ist, dass auch er als Papiermacher tätig war. ${ }^{2399}$

Der Großteil der Bürgen steht in keinem erkennbaren Zusammenhang mit der Papierherstellung. Bis auf die Berufsbezeichnung Bäcker bei Hanns Wagner, der 1477 für Conrat Schuchmacher einstand, ${ }^{2400}$ gibt es zudem keine textimmanenten Angaben über den Beruf der Gewährsmänner, sodass für die Bürgen dasselbe zu gelten scheint wie für die Neubürger: Nur bei einem verhältnismäßig geringen Anteil wurde der Beruf angegeben. In welcher Beziehung der ins Bürgerrecht aufgenommene Papiermacher und seine Garanten zueinander standen, kann in den meisten Fällen noch nicht einmal vermutet werden. Handelte es sich bei einem Bürgen um einen Papiermacher, so möchte man hinter der Bürgschaft eine berufliche oder auch verwandtschaftliche Beziehung vermuten. ${ }^{2401}$

Auch in den Fällen, in denen sich Papiermacher als Bürgen zur Verfügung stellten, waren die Neubürger nur zu einem geringen Anteil, nämlich die bereits erwähnten vier Mal, Berufsgenossen. Die Berufe der anderen Neubürger, für die Papiermacher einstanden, sind wiederum zum großen Teil nicht zu identifizieren. Bei den Personen, bei denen ein Beruf festzustellen ist, sind die der Papiermacherei verwandten Berufe, bei denen plausibel eine Verbindung auf professioneller Ebene zu vermuten ist, in der Minderheit. Drei Mal bürgte ein Papiermacher für einen Kartenmacher: Hans Wolfartshofer I im Jahr 1467 für den Kartenmacher Melchior Wernher, Heini Wolfartshofer 1495 für Jacob Schraitz und Paul Wolfartshofer 1533 für den Kartenmacher Hans Rösch. ${ }^{2402}$ Unter den anderen Berufen sind folgende Handwerke vertreten: ein Seiler, ein Weber, ein Schneider oder Tuchscherer, ein Schlosser sowie ein Hutmacher. ${ }^{2403}$ Zudem bürgten Cuntz Wolfartshofer für den Landschreiber Hans Haider und Lienhart Wolfartshofer offenbar für einen Pfarrer. ${ }^{2404}$ Des Weiteren fungierten Papiermacher als Gewährsmänner für Frauen, die in Ravensburg vergleichsweise häufig selbstständig das Bürgerrecht erwarben. ${ }^{2405}$ Während bei Hans Härb, der 1517

2398 StR, Bü 27, Bürgerbuch 2 (1436-1549), 170. Vgl. Alfred Schulte 1953, 22.

2399 StR, Bü 48, Steuerbuch 1512-1514, 3v; Bü 49, Steuerbuch 1521-1524, 3v.

2400 StR, Bü 27, Bürgerbuch 2 (1436-1549), 101b.

2401 So war der 1505 ins Bürgerrecht aufgenommene Hans Härb mit einer Tochter des verstorbenen Peter Wolfartshofer II verheiratet. Als sein Bürge fungierte mit Heini Wolfartshofer ein weiteres Mitglied der Familie seiner Frau, StR, Bü 27, Bürgerbuch 2 (1436-1549), 169. Vgl. Alfred Schulte 1953, 22.

2402 StR, Bü 27, Bürgerbuch 2 (1436-1549), 72, 149, 231.

2403 StR, Bü 26, Bürgerbuch 1 (1324-1436), 243; Bü 27, Bürgerbuch 2 (1436-1549), 5, 183, 222, 261.

2404 StR, Bü 26, Bürgerbuch 1 (1324-1436), 246; Bü 27, Bürgerbuch 2 (1436-1549), 223.

2405 Vgl. Schwinges 2002a, 44; Studer 2002, 170, Tab. 1, 194 f. 
für seine Schwester Anna haftete, ${ }^{2406}$ die Beziehung klar zutage tritt, ist das Verhältnis der anderen drei Frauen zu ihren Bürgen nicht eindeutig zu bestimmen. Im Jahr 1446 stand Peter Bappirer für Elzbeth Wolfartshofer ein. ${ }^{2407}$ Gesetzt den Fall, dass sich hinter Peter Bappirer Peter Wolfartshofer I verbirgt, so ist auch hier von einer verwandtschaftlichen Beziehung auszugehen. Peter Bappirer bürgte aber 1432 auch für Ann Bruodercuentzin und ihre Kinder. ${ }^{2408}$ In diesem Fall ist die Art der Verbindung nicht ersichtlich. Dasselbe gilt für die Bürgschaft Hans Stengelis für die Witwe von Hans Ruef im Jahr 1428. ${ }^{2409}$

Der Anteil der zwischen 1436 und 1549 als Bürger aufgenommenen Papiermacher an allen mit einer Berufsangabe bedachten Neubürgern kann - wie im Fallbeispiel Basel - mit einem Prozent als relativ niedrig beschrieben werden: Von 704 Neubürgern übten sieben den Beruf des Papierers aus. ${ }^{2410}$ Auch im Fall Ravensburgs gilt, dass es dieses Gewerbe damit rein numerisch durchaus mit anderen „kleinen“ Handwerken wie den Nestlern oder den Spenglern aufnehmen konnte, ${ }^{2411}$ wobei jedoch $\mathrm{zu}$ beachten ist, dass eine Abbildung der tatsächlichen Anteile der unterschiedlichen Berufe aufgrund der vergleichsweise niedrigen Nennungsrate von Berufen in den Bürgerbüchern nicht möglich ist. Einen relativ hohen Anteil an den Neubürgern hatten Vertreter aus den klassischen Bekleidungsgewerben: Im zweiten Bürgerbuch sind 52 Schneider und 72 Schuhmacher mit einem Anteil von rund sieben beziehungsweise zehn Prozent verzeichnet. ${ }^{2412}$ An weiteren Beschreibstoffherstellern wurden drei Pergamentmacher in das zweite Bürgerbuch eingetragen, also ungefähr halb so viele wie Papiermacher. ${ }^{2413}$ Dieses Verhältnis von sieben zu drei bietet im Vergleich mit Basel, wo für den Zeitraum von 1451 bis 1527 auf 22 Papiermacher ein Pergamenter kam, ein deutlich ausgeglicheneres Bild. ${ }^{2414}$

Wie bereits anhand der bürgenden Papiermacher deutlich wird, waren mehr als die elf explizit als Neubürger verzeichneten Papierer Ravensburger Bürger. Zum einen ist davon auszugehen, dass alle Gewährsmänner zum Zeitpunkt der Bürgschaft selbst bereits das Bürgerrecht erworben haben mussten. Zum anderen werden Papiermacher auch in anderen Dokumenten als Bürger zu Ravensburg bezeichnet.

2406 StR, Bü 27, Bürgerbuch 2 (1436-1549), 198.

2407 StR, Bü 27, Bürgerbuch 2 (1436-1549), 30. Vgl. Alfred Schulte 1953, 15.

2408 StR, Bü 26, Bürgerbuch 1 (1324-1436), 262. Vgl. Alfred Schulte 1953, 15.

2409 StR, Bü 26, Bürgerbuch 1 (1324-1436), 258.

2410 Vgl. Bürgerlisten der Reichsstadt Ravensburg 1966b, 159. Albert Hengstler gibt an, dass neun Papiermacher in das zweite Bürgerbuch als Neubürger eingetragen wurden. Überprüft man seine Angaben, so wird klar, dass er zwei Papierer, die lediglich als Bürgen fungieren, fälschlicherweise zu den Neubürgern zählt.

2411 Vgl. Bürgerlisten der Reichsstadt Ravensburg 1966b, 159.

2412 Vgl. Bürgerlisten der Reichsstadt Ravensburg 1966b, 159.

2413 Vgl. Bürgerlisten der Reichsstadt Ravensburg 1966b, 159.

2414 Vgl. Kapitel 3.3.3.1, S. 379. 
Auf der Basis dieser Quellen lassen sich noch weitere Papierer als Bürger fassen. In den Jahren 1421, 1435 und 1436 erscheint der Papiermacher Cuntz Wolfartshofer als Bürger zu Ravensburg, ${ }^{2415}$ ein weiterer Conrat Wolfartshofer im Jahr $1492 .{ }^{2416}$ Mehrmals - 1461, 1466, 1467 - bürgte Hans Wolfartshofer I für Neubürger, im Jahr 1487 wird er zudem in einer Urkunde als Bürger bezeichnet. ${ }^{2417}$ Auch im Jahr 1509 ist ein Hans Wolfartshofer d. Ä. als Ravensburger Bürger belegt, wobei nicht sicher ist, ob es sich hierbei um dieselbe oder eine andere Person handelte. ${ }^{2418} \mathrm{Im}$ Jahr 1512 ist des Weiteren ein Michel Wolfartshofer, genannt Bappyrer, als Bürger erwähnt. ${ }^{2419}$ Der Besitzer der unteren Papiermühle im Ölschwang, Jörg Wolfartshofer, war ebenfalls Bürger der Stadt Ravensburg. ${ }^{2420}$ Auch Heini und Paul Wolfartshofer, die 1495 und 1505 beziehungsweise 1525 und 1533 für Neubürger einstanden, hatten das Bürgerrecht inne. ${ }^{2421}$ Überhaupt ist davon auszugehen, dass alle in Ravensburg lebenden Mitglieder der Familie Wolfartshofer nach der ersten eingebürgerten Generation qua Geburt Bürger waren. Nicht sicher ist hingegen, ob sie auch alle im Papiergewerbe tätig waren, sodass eine konkrete Anzahl an eingebürgerten Papiermachern aus dieser Familie nicht zu nennen ist. Die in Schornreute wohnenden Nachfahren des ersten Papiermachers mit Namen Stengeli waren ebenfalls Bürger der Stadt Ravensburg und arbeiteten vermutlich als Papierer. ${ }^{2422}$ Neben den Wolfartshofer und den Stengeli konnten noch die Papiermacher Thoman Grübler und Albrecht Silber als Ravensburger Bürger identifiziert werden. ${ }^{2423}$ Ein Papiermacher namens Jacob Rälles wird zudem als Ausbürger bezeichnet. ${ }^{2424}$ Sein Wohnsitz ist ebenso wenig bekannt wie sein Arbeitsort.

2415 StR, Bü 26, Bürgerbuch 1 (1324-1436), 246, 270 f.; Bü 27, Bürgerbuch 2 (1436-1549), 5; Urk. 723 (03.02.1436).

2416 StR, Urk. 665 (29.03.1492). Vgl. Alfred Schulte 1953, 22.

2417 StR, Urk. 585 (20.06.1487). Vgl. Alfred Schulte 1953, 22.

2418 StR, Urk. 919 (02.07.1509).

2419 StR, Urk. 687 (31.03.1512). Eventuell weist der Zusatz genannt Bappyrer darauf hin, dass Michel Wolfartshofer bereits einen anderen Beruf ausübte. Im Jahr 1515 wird er als Metzger bezeichnet, StR, Urk. 4698 (16.02.1515). Von 1497 bis 1524 wohnte er laut Ausweis der Steuerbücher innerhalb der Stadtmauern am Obertor, das heißt, er wohnte nicht bei den Papierhäusern, vgl. StR, Bü 45, Steuerbuch 1497-1499, 24r; Bü 46, Steuerbuch 1504-1506, 23v; Bü 48, Steuerbuch 1512-1514, 24v; Bü 49, Steuerbuch 1521-1524, 21v.

2420 StR, Urk. 690 (13.05.1513).

2421 StR, Bü 27, Bürgerbuch 2 (1436-1549), 149, 170, 228, 231. Vgl. Alfred Schulte 1953, 15, 22.

2422 Belegt in den Steuerbüchern, StR, Bü 42, Steuerbuch 1473-1476, 1r; Bü 43, Steuerbuch 14821485, 2r; Bü 45, Steuerbuch 1497-1499, 1r; Bü 46, Steuerbuch 1504-1506, 1r; Bü 47, Steuerbuch 15061508, 1r; Bü 48, Steuerbuch 1512-1514, 3r; Bü 49, Steuerbuch 1521-1524, 3r; Bü 50, Steuerbuch 1545, 3r; Bü 51, Steuerbuch 1553-1555, 3r.

2423 Zu Thoman Grübler vgl. StR, Urk. 1091 (02.09.1467): Thoman Grübler den papperer, Lienhahrten Grübler sinen sun ... alle och burger ze Ravenspurg. Vgl. auch Alfred Schulte 1953, 21. Zu Albrecht Silber vgl. StR, Bü 50, Steuerbuch 1545, 3r; Bü 51, Steuerbuch 1553-1555, 3v.

2424 StR, Bü 47, Steuerbuch 1506-1508, 136r. Die Ausbürger hatten eine Sonderstellung innerhalb des städtischen Rechts, da sie zwar in Rechten und Pflichten den Bürgern gleichstellt waren, aber 
Zusammengefasst kann festgehalten werden, dass fast alle Papiermacher, die in Ravensburger Quellen greifbar sind, das Bürgerrecht besaßen. Betrachtet man die Art der Zeugnisse, aus denen diese Informationen gewonnen wurden, so ist dieser Befund nicht verwunderlich. In den Bürgerbüchern finden sich per definitionem nur Bürger, ob als Petenten oder als Gewährsmänner. Auch die Steuerbücher lassen nur einen Einblick in die städtische Bürgerschaft, nicht in die Einwohnerschaft zu, da in Ravensburg lediglich die Bürger - und die Ausbürger - Steuern zu entrichten hatten. Die Papiermacher, die Bürger waren und daher überhaupt in den Ravensburger Quellen greifbar sind, waren zum großen Teil Papiermühlenbesitzer oder Werkleiter oder gehörten der Familie des Besitzers an. Im Gegensatz zu Basel tauchen in der Ravensburger Überlieferung einfache Gesellen oder Lohnarbeiter kaum auf, sodass nicht einmal annähernd festzustellen ist, welcher Anteil der in der Ravensburger Papiermacherei tätigen Personen ins Bürgerrecht aufgenommen wurde.

Für Straßburg konnte das älteste erhaltene Bürgerbuch, das in einer Edition von Charles Wittmer und J. Charles Meyer vorliegt, für eine Ermittlung des Bürgerrechtsstatus der Papiermacher herangezogen werden. ${ }^{2425}$ Es listet alle Neubürger von 1440 bis 1530 auf und ordnet sie zugleich einer Zunft zu. Von den sieben vorhergehenden Bürgerlisten, die im Vorwort zu dem Codex von 1440 bis 1530 aufgeführt werden, ist keine einzige erhalten. ${ }^{2426}$ Für die Jahre von 1530 bis 1542 ist ebenfalls kein Neubürgerverzeichnis überliefert, von 1543 bis 1559 existiert lediglich eine Aufzeichnung der Personen, die das Bürgerrecht durch Heirat erwarben. ${ }^{2427}$ Damit stellt das edierte Bürgerbuch von 1440 bis 1530 die einzige relevante Quelle für den Untersuchungszeitraum dar.

Auch in Straßburg musste eine Person, die das Bürgerrecht erwerben wollte, personenrechtlich frei und in der Stadt ansässig sein. ${ }^{2428}$ Neben dem feierlich vor dem Rat abgelegten Eid war seitens des Neubürgers zur Aufnahme ins Bürgerrecht die Entrichtung einer Gebühr notwendig. In der einschlägigen Literatur finden sich hinsicht-

nicht innerhalb des städtischen Rechtsbezirks lebten. Ob Ausbürger und Pfahlbürger dasselbe meinen, darüber besteht in der Forschung kein Konsens. Während beide Begriffe häufig in eins gesetzt werden, plädiert Guy P. Marchal für eine Differenzierung, indem er unter Ausbürger „Adlige, auf Eigengut sitzende Freie und Kleriker oder kirchliche Gemeinschaften“ versteht, unter Pfahlbürger jedoch „eine Person, die in irgendeiner Weise einer Herrschaft untertan ist, die das Bürgerrecht einer bestimmten Stadt angenommen hat ohne aber den bisherigen Wohnsitz aufzugeben“, Marchal 2002, 334. In diesem Sinne auch Dilcher 1980, 96-98. Keine Unterscheidung treffen K. O. Müller 1916, 180183; Ennen 1980, 1246 f.; Dreher 1972, Bd. 2, 464.

2425 Le livre de bourgeoisie de la ville de Strasbourg 1948-1961.

2426 Vgl. Le livre de bourgeoisie de la ville de Strasbourg 1948, Bd. 1, 1-3; Fuchs 1962a, 19.

2427 Vgl. Mariotte 2000, 121.

2428 Vgl. Le livre de bourgeoisie de la ville de Strasbourg 1961, Bd. 3, XXIX; Fuchs 1962a, 21; Dollinger 1981, 105. 
lich der Höhe dieser Gebühr zwei unterschiedliche Angaben: Sie betrug entweder ein Pfund und 5 Schilling ${ }^{2429}$ oder ein Pfund und 7 Schilling Straßburger Pfennige. ${ }^{2430}$

Die Durchsicht des Straßburger Bürgerbuchs führte zu einem bemerkenswerten Ergebnis: In dem Zeitraum von 90 Jahren erwarben nur zwei Papiermacher das Bürgerrecht. Im Jahr 1510 war dies Wolff Stierlin von Offenburg, im Jahr 1517 Cleinhans Wolpus von Spir. ${ }^{2431}$ Es ist zwar durchaus möglich, dass weitere Personen, die in der Papierherstellung arbeiteten, aber nicht die Berufsbezeichnung Papierer erhielten und die nicht durch eine Parallelüberlieferung als Papiermacher bekannt sind, im Straßburger Bürgerbuch verzeichnet sind. Dies gilt jedoch ebenso für die Fallbeispiele Basel und Ravensburg. Des Weiteren könnte man spekulieren, dass Papiermacher in Straßburg generell nicht ins Bürgerrecht aufgenommen wurden. Diese Vermutung traf auf einen Teil der Papierer sicherlich zu. Aber auch dies gilt ebenso für Basel und für Ravensburg. Als mögliche Erklärung für die im Vergleich zu Basel und Ravensburg sehr geringe Anzahl an Bürgeraufnahmen lässt sich lediglich die Diskontinuität der Straßburger Papierherstellung anführen. Die erste Papiermühle, gelegen am Rosengarten, arbeitete nur neun Jahre, bevor sie abgerissen wurde. Ihr erster Besitzer und Betreiber war Wilhelm de Altomonte, der in den Urkunden, die die Vergabe der Papiermühle verhandeln, nicht als Bürger bezeichnet wurde. ${ }^{2432}$ Offenbar war Wilhelm, der aus dem Bistum Asti stammte und 1450 Straßburg bereits wieder gen Rom verließ, zu dieser Zeit Bürger der Stadt Huy bei Lüttich, in der er noch eine weitere Papiermühle besaß. ${ }^{2433}$ Der nächste Besitzer Nicolas Heilmann war Straßburger Bürger. Er war jedoch kein Papiermacher. Als Werksleiter waren die Papierer Johannes de Altomonte und Johannes Hettag tätig, von denen ebenfalls nicht bekannt ist, ob sie das Bürgerrecht innehatten. In der Urkunde, in denen ihre Namen erscheinen, werden sie jedenfalls nicht als Bürger bezeichnet. ${ }^{2434}$

Auf den Abbruch der Papiermühle beim Rosengarten im Jahr 1454 folgte knapp ein halbes Jahrhundert, in dem Straßburg nicht als Papierproduktionsstandort gelten kann. Die erste Nachricht über eine erneute Aufnahme der Papiermacherei betrifft das Jahr 1503: Zu diesem Zeitpunkt ist der Kartenmaler Gabriel Schwartz als Pächter der städtischen Papiermühle vor dem Weißturmtor fassbar. Ob er das Papiererhandwerk erlernte und ausübte, ist ungewiss, auch wenn er teilweise auch Papiermacher genannt wird. ${ }^{2435}$ Als er das Bürgerrecht im April 1490 erwarb, ist seinem Namen die

2429 Vgl. Le livre de bourgeoisie de la ville de Strasbourg 1961, Bd. 3, XXXIII; Wittmer 1961, 241; Dollinger 1981, 105.

2430 Vgl. Fuchs 1962a, 21. Nach Fuchs auch Isenmann 2002, 235.

2431 Vgl. Le livre de bourgeoisie de la ville de Strasbourg 1954, Bd. 2, 588, Nr. 6006; 640, Nr. 6682.

2432 AVES, CH 239, Nr. 4918 (02.08.1445); CH 239, Nr. 4923 (20.08.1445); CH 251, Nr. 5164 (26.08.1451).

2433 Vgl. Arnould 1976, 289 f. Vgl. Kapitel 3.3.2.2, S. 365 f.

2434 AVES, CH 251, Nr. 5164 (26.08.1451).

2435 Vgl. Ch. Schmidt 1882, 38; P. Schmitt 1960, 78. 
Berufsbezeichnung Maler beigefügt. ${ }^{2436}$ Der nächste Betreiber der Papiermühle war bis 1525 Hans Volpis - und hier ist nun endlich ein Papiermühlenpächter greifbar, der sowohl Papiermacher als auch Bürger war, denn es handelt sich aller Wahrscheinlichkeit nach um den 1517 ins Bürgerrecht aufgenommenen Papierer Cleinhans Wolpus. Aber bereits die darauffolgenden Pächter Wolf Koepfel und Wendelin Rihel waren keine Papiermacher, sondern Buchdrucker, und fallen somit aus der Betrachtung heraus. ${ }^{2437}$

Es sind folglich lediglich vier Pächter oder Betriebsleiter bekannt, die selbst Papiermacher waren: Wilhelm de Altomonte, Johannes de Altomonte, Johannes Hettag und Hans Volpis. Davon besaß offensichtlich nur Hans Volpis das Straßburger Bürgerrecht. Ein weiterer Papierer, Wolff Stierlin, war ebenfalls Bürger der Stadt Straßburg, betrieb die städtische Papiermühle anscheinend jedoch nicht auf eigene Rechnung, sondern war vermutlich bei einem der Pächter angestellt oder dessen Unterpächter. Die geringe Anzahl von Papierern als Neubürger kann nach den vorhergehenden Ausführungen also teilweise auf die knapp 50-jährige Abwesenheit einer Papierproduktion in Straßburg zurückgeführt werden. Für die Betreiber der ersten Papiermühle - Wilhelm und Johannes de Altomonte sowie Johannes Hettag, die offenbar nicht aus Straßburg stammten, sondern Welsche waren - ist denkbar, dass sie nicht planten, sich dauerhaft in Straßburg niederzulassen, und deshalb das Bürgerrecht nicht erwarben. Die beiden fassbaren Bürgerrechtseintritte von Papiermachern fallen in die Anfangsjahrzehnte der zweiten Papiermühle. Mit Hans Volpis und eventuell Gabriel Schwartz hatten alle Papiermacher, die Pächter der städtischen Mühle waren, auch das Bürgerrecht inne. Die Werksleiter, die die fachfremden Beständer der Papiermühle einstellen mussten, erwarben bis auf einen - Wolff Stierlin - offensichtlich nicht das Bürgerrecht oder waren bereits Straßburger Bürger, bevor sie den Beruf erlernten.

Auch in den anderen Papiermühlenstandorten im südwestdeutschen Raum ist zu beobachten, dass die Papiermacher, die zugleich Papiermühlenbesitzer waren, häufig Bürger der jeweiligen Stadt waren oder wurden. ${ }^{2438}$ Dies gilt beispielsweise für Peter Fort und Gregory Schütz, die nacheinander die Memminger Papiermühle im Ried innehatte. ${ }^{2439}$ Auch Wilhelm von Paris, der erste Pächter des Ettlinger Werks wurde vom dortigen Schultheißen unser burger genannt. ${ }^{240} \mathrm{Zu}$ Reutlingen hatten 1519 die Papiermacher Paul Ruep, Jacob Ziser, Jacob Hirten, Conrad Gretzinger und Peter Ziser das Bürgerrecht inne: Bis auf Conrad Gretzinger besaß jeder einen eigenen

2436 Vgl. Le livre de bourgeoisie de la ville de Strasbourg 1954, Bd. 2, 443, Nr. 4097.

2437 Vgl. Ch. Schmidt 1882, 38; P. Schmitt 1960, 78. Vgl. Amelung 1995, 275.

2438 Leider kann anhand der Fachliteratur nicht für alle Orte überprüft werden, ob die betreffenden Papiermacher ins Bürgerrecht aufgenommen wurden, da je nach Erkenntnisinteresse des Autors die dafür notwendigen Informationen nicht erhoben oder nicht angegeben wurden.

2439 Vgl. Piccard 1960, 596, 598.

2440 Vgl. Piccard 1951, 59. 
Betrieb. ${ }^{241}$ Heinrich Walchwiler, der Begründer der Züricher Papierherstellung und erster Besitzer der Papiermühle auf dem Werd, wurde 1471 als Bürger bezeichnet. ${ }^{242}$ Die ersten privaten Inhaber der beiden Papiermühlen zu Kottern bei Kempten - die Papiermacher Moritz Staiger und Peter Stähelin - waren ebenfalls städtische Bürger. ${ }^{2443}$ Moritz Staiger bürgte nachweislich auch für Berufsgenossen anlässlich ihrer Aufnahme ins Bürgerrecht, so beispielsweise 1541 für Balthasar Kleinhainz und 1547 für Martin Mayr. ${ }^{2444}$ Dem Rat von Kempten war es zudem besonders wichtig, dass die Papiermühlen von Kemptener Bürgern geführt wurde: Bei der Übernahme der Kotterner Werke im Jahr 1528 verpflichteten sich Moritz Staiger und Peter Stähelin, die Mühle nur an einen einheimischen Bürger zu veräußern. ${ }^{2445}$

Spricht eine Aufnahme ins Bürgerrecht für eine gute Integration in die städtischen Strukturen, so waren die meisten Papiermacher, die im deutschen Südwesten im Untersuchungszeitraum ein Mühlwerk ihr Eigen nannten, fester Bestandteil der Stadt, in der sie lebten, da sie Bürger waren oder im Laufe der Zeit wurden. Besonders für Basel lassen sich aber auch Papiermacher als Bürger fassen, die keine eigene Mühle besaßen. Das neue Gewerbe der Papiermacherei wurde dabei offenbar nicht anders behandelt als die alteingesessenen Berufe. In ihrer numerischen Stärke konnten sich die ins Bürgerrecht aufgenommenen Papiermacher durchaus mit den Mitgliedern kleinerer Gewerbezweige messen wie die Beispiele Basel und Ravensburg zeigen.

\subsubsection{Zunftzugehörigkeit}

Das neue Gewerbe der Papiermacherei wurde in die bereits bestehende Zunftstruktur von Stadt zu Stadt, von Standort zu Standort anders integriert. Im Allgemeinen wurde von der Papiergeschichtsforschung bereits herausgearbeitet, dass die Papiermacher in keiner Stadt eine eigene Zunft bildeten. ${ }^{2446}$ Die Gründe hierfür sehen einige Papierhistoriker plausibel darin, dass die Ausbildung der Zünfte und der ihnen zugehörigen Handwerke und Gewerbe bereits abgeschlossen war, als die Papiermacherei sich zu etablieren begann. ${ }^{2447}$ Als eine weitere Ursache für das Fehlen einer eigenen Zunft machen andere Papierforscher ebenfalls überzeugend die im Vergleich mit anderen Berufsgruppen geringe Anzahl der Papiermacher und ihre räumliche Streuung

2441 Vgl. Sporhan-Krempel 1972b, 1521.

2442 Vgl. Schnyder 1937, 729, Nr. 1248.

2443 Vgl. Das Bürgerbuch der Reichsstadt Kempten 1940, 1; Petz 2006, 296 f.

2444 Vgl. Das Bürgerbuch der Reichsstadt Kempten 1940, 12, 15; Petz 2006, 269.

2445 Vgl. Petz 2006, 296. Vgl. Kapitel 3.2.1.4.

2446 Vgl. beispielsweise V. Thiel 1932, 137; Hoyer 1941, 43; Schlieder 1966, 131; Bayerl 1987, 568; ZaarGörgens 2004, 104.

2447 Vgl. T. Schulte 1952, 36; Sporhan-Krempel 1953, 70. Vgl. auch Zaar-Görgens 2004, 104. 
aus. ${ }^{2448}$ Siedelten sich die ersten Papiermühlen im südwestdeutschen Raum noch in oder bei großen Städten an, so konstatiert Wolfgang Schlieder, kam es bereits Ende des 15. Jahrhunderts, vermehrt jedoch ab dem 16. Jahrhundert zu landesherrlichen Gründungen an Orten ohne Zunftstruktur. ${ }^{2449}$ Maria Zaar-Görgens vermutet zudem einen Zusammenhang mit einer geringen Sesshaftigkeit, die durch die (Gesellen-) Wanderung bedingt war. ${ }^{2450}$

Wenn Zaar-Görgens dabei von einer „fehlenden Zunftverfassung“2451 spricht, so muss dieser ins Absolute gesetzte Begriff relativiert werden. Betrachtet man die zum Teil äußerst unterschiedlichen Ausprägungen der Zünfte in den verschiedenen Städten des Reichs, dann wird schnell deutlich, dass im Spätmittelalter für kein Handwerk eine städteübergreifende „Zunftverfassung“ existierte. Zünftische Strukturen müssen in ihrem jeweiligen spezifischen Entstehungs- und Wirkungsraum, nämlich der Stadt, in der sie bestehen, untersucht werden. Daher ist auch die Zunftzugehörigkeit der Papiermacher für jeden Standort gesondert zu betrachten.

Die meisten Papierhistoriker, die die fehlende Zünftigkeit der Papierer behandeln, schreiben diese dem Selbstverständnis der Papiermacher als „freie Künstler“ $\mathrm{zu}^{2452}$ Leider wird diese zum Allgemeinplatz gewordene These für das Mittelalter und die Frühe Neuzeit nicht durch zeitgenössische Quellen belegt. Auch für diese Studie lässt sie sich für die Zeit bis 1550 nicht bestätigen. ${ }^{2453}$ Es wird vielmehr zu untersuchen sein, ob sich die Papiermacher der mittelalterlichen Papiermühlenstandorte im deutschen Südwesten - wie es vielerorts nachgewiesen ist ${ }^{2454}$ - einer bereits bestehenden Zunft anschlossen und sich auf diese Weise in existierende städtische Gruppen integrierten.

Für viele Papierhistoriker scheint die Frage nach der Zunftzugehörigkeit der Papierer im Zusammenhang mit gewerberechtlichen Aspekten wie der Existenz von

2448 Vgl. Briquet 1955d, 254; Renker 1950, 125; Schlieder 1966, 132 f.; Bayerl 1987, 568; P. Tschudin 1991, 42; Radermecker 1994, 77. Vgl. auch Zaar-Görgens 2004, 104.

2449 Vgl. Schlieder 1966, $132 \mathrm{f}$.

2450 Vgl. Zaar-Görgens 2004, 105.

2451 Vgl. Zaar-Görgens 2004, 105.

2452 Vgl. u. a. Geering 1886, 53, 334; Hoyer 1941, 43; Renker 1950, 12 f.; Bockwitz 1956, 72 f.; Schlieder 1966, 133; Halstrick 1990, 17; Zaar-Görgens 2004, 104; P. Tschudin 2012a, 129, 145. Kritisch zu der Charakterisierung der Papiermacherei als Kunst äußert sich Sporhan-Krempel 1953, 70.

2453 Vgl. hier auch Piccard 1967, 157, der für Basel ebenfalls keinen Beleg dafür findet, dass es sich um bei der Papiermacherei um eine freie Kunst gehandelt habe. Für spätere Jahrhunderte - vor allem für das 18. Jahrhundert - mag dieses Verständnis von der Papiermacherei als Kunst hingegen zutreffend sein, vgl. die Zitate bei Renker 1950, 13. Vgl. auch Keferstein 1766/1936, 17.

2454 Auch der Anschluss der Papiermacher an andere Zünfte kann als Allgemeinplatz der Papierforschung gelten, vgl. u. a. V. Thiel 1932, 137; Schlieder 1966, 134; Halstrick 1990, 48; P. Tschudin 2012a, 129. 
Handwerksordnungen oder -gebräuchen interessant zu sein. ${ }^{2455}$ Wie Sabine von Heusinger in ihrer Habilitationsschrift Die Zunft im Mittelalter überzeugend darlegt, umfasste der Begriff Zunft jedoch noch weitere Bereiche des sozialen Lebens. ${ }^{2456}$ In Städten, in denen die Zünfte politisches Mitspracherecht hatten und Ratsherren stellten, existierte neben der gewerblichen auch eine politische Zunft. ${ }^{2457}$ Diese konnten in der Zusammensetzung ihrer Mitglieder deckungsgleich sein, mussten es aber nicht und waren es häufig nur zu einem mehr oder minder großen Teil. Zur gewerblichen Zunft gehörte zudem meistens eine Bruderschaft, zu deren Hauptaufgabe das Totengedenken für verstorbene Zunftmitglieder und damit einhergehend das Begehen von Gottesdiensten, Beerdigungen und Seelenmessen zählten. ${ }^{2458}$ Des Weiteren war die Zunft eine militärische Einheit, der die Stellung eines eigenen Kontingents wehrpflichtiger Männer zur Verteidigung der Stadt oblag. Die Zünfte in ihren vier Teilbereichen reichten somit in viele Gebiete des städtischen Lebens hinein und bildeten die größte städtische Gruppe. Aus diesem Grund ist die Zunftzugehörigkeit von Papiermachern nicht nur für gewerbliche Belange von Interesse, sondern in einem umfassenden Sinne für die Eingliederung dieser neuen Handwerker in die bestehenden städtischen Strukturen.

Die in der Zunftforschung Ende des 19. und Anfang des 20. Jahrhunderts geführte Debatte um den Ursprung und damit auch um die Definition von Zunft, die vor allem ökonomische und verfassungsrechtliche Aspekte berücksichtigte, wurde in den 1980er-Jahren von Otto Gerhard Oexle wieder aufgegriffen und um eine rechts- und sozialgeschichtliche Perspektive erweitert. ${ }^{2459}$ Auch Sabine von Heusinger bricht in ihrer Arbeit mit dem starren, abgeschlossenen Zunftmodell, das durch die klassische Zunftforschung auf Grundlage der normativen Quellen wie den Zunftordnungen entwickelt wurde und sich durch Zunftzwang, Kartellbildung sowie das Ausschalten von Konkurrenz beschreiben lässt. ${ }^{2460}$ Sie charakterisiert Zünfte stattdessen als flexible soziale Gruppen, die unter bestimmten Voraussetzungen sowohl eine vertikale als auch eine horizontale Mobilität erlaubten. ${ }^{2461}$ Die eindeutige Zuordnung mancher

2455 Vgl. T. Schulte 1952, 36 f.; Schlieder 1966, 131-138; Zaar-Görgens 2004, 104-111; P. Tschudin 2012a, 129-132.

2456 Heusinger 2009.

2457 Vgl. Heusinger 2009, 90-102, 339-341; Heusinger 2010, 39, 48-52. Vgl. auch Irsigler 1985, 68-70. 2458 Vgl. Heusinger 2009, 85-90, 339; Heusinger 2010, 39, 44-48.

2459 Vgl. Oexle 1982. Für einen Forschungsüberblick vgl. auch Heusinger 2009, 18-29. Eine konzise Einführung in das Thema Zunft gibt Schulz 2010, 39-60.

2460 Vgl. Heusinger 2010, 40 f. Zu den Quellen der Zunftgeschichte vgl. Klötzer 1982. Klötzer betont, dass die bloße Betrachtung von Zunftordnungen das Bild, das sich die Forschung von der Zunft machte, verfälschte und es erst unter Einbeziehungen weiterer Dokumente offensichtlich wurde, dass die Zunftstatuten eher ,ideelle Absichtserklärung als das Abbild der tatsächlichen wirtschaftlichen Verhältnisse“ (Klötzer 1982, 47) waren.

2461 Von Heusinger definiert Zünfte als ,geschworene Einigungen..., die selbst Recht setzten, Sanktionen erließen und Gerichtsbarkeit ausübten“, vgl. Heusinger 2010, 63. Für eine ausführlichere De- 
Handwerke $\mathrm{zu}$ einer bestimmten Zunft war nicht immer möglich, ebenso wenig die Durchsetzung eines Zunftzwangs für alle Handwerker und Gewerbetreibenden, sodass manche unter ihnen auf legalem Wege ihrer Arbeit nachgingen, ohne einer Zunft anzugehören. ${ }^{2462}$ Diese Flexibilität in der Zunftzugehörigkeit relativiert die „Zunftlosigkeit“ der Papiermacher. Sie scheint nun weniger ein Sonderfall, wie es in vielen Beiträgen zur Papiergeschichte anklingt, ${ }^{2463}$ sondern vielmehr ein Fall unter vielen zu sein, für den schließlich von Stadt zu Stadt eine flexible Lösung zur Einordnung in die soziale Gruppe der Zünfte gefunden wurde.

\subsubsection{Basel}

In Basel befanden sich alle Papiermacher, die in eine Zunft eintraten, in der Safranzunft, die ursprünglich die Korporation der Krämer war. ${ }^{2464}$ Seit dem 14. Jahrhundert versammelte die Zunft jedoch eine Vielzahl unterschiedlicher Handwerke und Gewerbe, bei denen eine Zusammengehörigkeit aufgrund ähnlicher handwerkstechnischer Voraussetzungen kaum gegeben war. ${ }^{2465}$ Paul Koelner vertritt die Vermutung, dass ein Großteil der safranzünftigen Handwerke solche waren, die auf den Absatz ihrer Waren durch Krämer angewiesen waren und denen es durch dieses Abhängigkeitsverhältnis nicht gelungen war, eine eigenständige Zunft zu bilden. ${ }^{2466}$ Die Nähe der safranzünftigen Handwerker zu den Krämern manifestierte sich jedoch auch darin, dass viele ihrer Produkte Importgüter waren und daher aus anderen Städten durch Fernhändler und Krämer auf den Basler Markt gebracht wurden. ${ }^{2467}$ Es ist

finition mit Begriffsdiskussion und weiterführender Literatur vgl. Heusinger 2009, 47-51. Für einen Überblick über die Zunftforschung und die darin geführten Debatten vgl. Oexle 1982. Vgl. auch Irsigler 1985. Die Flexibilität dieser Gruppen drückt sich unter anderem in Zunftwechseln aufgrund von Berufswechsel aus. Auch trat beispielsweise der Sohn nur in zwei Dritteln der Fälle in dieselbe Zunft wie der Vater ein, vgl. Heusinger 2009, 342-344. Zur Abkehr von einem starren Zunftmodell auch in den Forschungen zur Frühen Neuzeit vgl. Haupt 2002.

2462 Vgl. Heusinger 2009, 341; Heusinger 2010, $41 \mathrm{f}$.

2463 So erachtet Traugott Geering Papiermacher wie auch Buchdrucker als ,ausserhalb und über dem Zunftwesen stehend“, Geering 1886, 336. Dagegen schreibt schon Gerhard Piccard an, vgl. Piccard 1967, 156. Vgl. auch Schlieder 1966, 131.

2464 Die Annahme von Christoph Halstrick, dass die Papiermacher innerhalb der Safranzunft nicht den Status eines Vollmitglieds besaßen, konnte durch das Quellenstudium nicht bestätigt werden, vgl. Halstrick 1990, 51. Halstrick stützt seine Argumentation auf eine Aussage Geerings, die er jedoch missversteht: Nicht den Papiermachern wurde seitens des Rats untersagt, einen Buchdrucker zum Zunftbeitritt zu zwingen, sondern der Safranzunft selbst, vgl. Geering 1886, 334. Aber auch wenn den Papiermachern verboten worden wäre, einen Drucker zum Zunftkauf zu drängen, so erscheint Halstricks Argumentation nicht plausibel: Eine direkte Relation zwischen Vollmitgliedschaft und Recht zum Ausüben des Zunftzwangs war nicht gegeben.

2465 Vgl. Geering 1886, 227-231; Koelner 1935, 91-95.

2466 Vgl. Koelner 1935, 91.

2467 Vgl. Geering 1886, 231. 
daher denkbar, dass der Beitritt zur Safranzunft es den heimischen Produzenten ermöglichte, Einfluss auf die Einfuhr von fremden Waren zu nehmen und sich als Erzeuger eines bestimmten Produkts zu positionieren.

Trotz ihrer Vielzahl lassen sich die in der Safranzunft vertretenen Berufe teilweise zu Gruppen zusammenfassen. ${ }^{2468}$ So waren beispielsweise einige Handwerke dem Bekleidungsgewerbe zuzuordnen, nämlich die Barettleinmacher, die Hutmacher, die Nestler, die Säckler, die Taschenmacher und die Weißgerber. Aus dem Bereich der Nahrungsmittelherstellung lassen sich die Lebkucher und die Oflater in den Zunftakten finden. Eine weitere Gruppe bildeten metallverarbeitende Handwerke, die vor allem kleine, filigrane Gebrauchsgegenstände herstellten wie die Nadler, die Ringler, die Rotgießer, die Spengler und die Gürtler. Daneben waren mit den Armbrustern, den Scheidenmachern und den Pfeilmachern auch einige Waffenhandwerke vertreten. Des Weiteren versammelte die Safranzunft Lauten- und Saitenmacher, Würfler, Bürstenmacher und Apotheker unter ihrem Dach. Die letzte größere Gruppe, der auch die Papiermacher zuzurechnen sind, sind die Berufe des Buchgewerbes und der Beschreibstoffhersteller. Hierzu können die Buchbinder, die Buchdrucker sowie die Buchführer, die Pergamenter und Papierer, aber auch die Heiligenmaler und Kartenmacher gezählt werden.

Die Safranzunft gehörte als eine der 15 politischen Zünfte Basels zu den vier sogenannten Herrenzünften und folgte in der offiziellen Rangordnung der Zunft der Kaufleute zum Schlüssel, der Zunft der Hausgenossen und der Zunft der Weinleute. ${ }^{2469}$ Unter den elf Handwerkszünften stellten die Rebleute die erste Zunft dar, gefolgt von den Brotbecken. Das Schlusslicht bildete die Zunft der Fischer und Schiffleute. ${ }^{2470}$ Die vier Herrenzünfte - und damit auch die Zunft zu Safran - genossen ein deutlich höheres Ansehen als die Handwerkszünfte und verfügten zudem über ein größeres Vermögen. ${ }^{2471}$

Die Basler Zünfte waren vor allem politische Zünfte, wie am Zusammenschluss häufig sehr unterschiedlicher Handwerke zu erkennen ist. Zwar vereinte keine Zunft so viele verschiedene Handwerke und Gewerbe wie die Safranzunft, dennoch weisen auch die anderen Zünfte eine heterogene Zusammensetzung auf. So umfasste beispielsweise die Spinnwetterzunft nicht nur die Bauhandwerke, sondern auch viele Handwerker, die Holz handelten oder verarbeiteten. Hier könnte die Ähnlichkeit des Materials Ausschlag für die Zuordnung gegeben haben. Die Zunftzugehörigkeit der

2468 Vgl. die Auflistung der safranzünftigen Handwerke bei Koelner 1935, $91 \mathrm{f}$.

2469 Vgl. Wackernagel 1911, Bd. 2.1, 389; Simon-Muscheid 1988, 5-7. Zur Zunftentwicklung in Basel vgl. allgemein Heusler 1860, 114-119; Geering 1886, 1-53; Wackernagel 1911, Bd. 2.1, 387-401, 412-416; Schulz 1985c; Berner/Sieber-Lehmann/Wichers 2008, 38 f. Zu den repräsentativen Zunfthäusern vgl. Schulz 2008, 326-332.

2470 Vgl. Wackernagel 1911, Bd. 2.1, 413-415; Füglister 1981, 2; Simon-Muscheid 1988, 6-10; Egger 2005, 17, 29 f.; Schulz 2010, 76 f.

2471 Vgl. Simon-Muscheid 1988, 5. 
Müller zu den Schmieden hingegen erklärt sich weniger aus dem bearbeiteten Material und auch nicht aus dem Zweck des hergestellten Produkts, sondern wahrscheinlich einzig aus der Tatsache, dass sowohl Müller als auch Schmiede die Wasserkraft für ihr Gewerbe nutzten. ${ }^{242}$ Die Hausgenossen, deren Mitglieder ursprünglich vor allem im Kreditgeschäft tätig waren, nahmen in ihre Zunft spezialisierte metallverarbeitende Handwerke - Goldschmiede, Hafengießer, Kannengießer - auf. ${ }^{2473}$ Auch die Zunft der Gartner war eine Komposition aus Nahrungsmittelgewerben wie den Habermelwern, Pastetenmachern und Köchen, aus Gebrauchsgüterhandwerken wie den Korbmachern und Seilern und aus Kleinsthandel (Gremper). Neben der Spinnwetterzunft, den Rebleuten, den Schmieden, den Gerbern und Schuhmachern sowie den Gartnern gehörte die Safranzunft zu den mitgliedsstärksten Zünften. ${ }^{2474}$

Anteil an der städtischen Regierung hatten seit 1382 alle 15 Zunftmeister sowie 15 durch bischöfliche Wahlmänner gewählte Zunftratsherren. Sie bildeten zusammen mit vier Rittern und acht patrizischen Burgern den kleinen Rat. ${ }^{2475}$ Im Laufe des 15. Jahrhunderts verloren die Patrizier immer mehr an Einfluss. ${ }^{2476}$ Dies äußerte sich zu Beginn des 16. Jahrhunderts in der Gleichstellung aller Zunftmitglieder mit den Genossen der Hohen Stube ${ }^{2477}$ hinsichtlich der Wählbarkeit in alle städtischen Ämter und in der darauffolgenden Wahl eines Bürgermeisters, der einer der Zünfte entstammte. In der ersten Hälfte des 16. Jahrhunderts verbreiterten zudem die Handwerkszünfte ihre Machtbasis gegenüber den Herrenzünften, sodass von einem Handwerksregiment gesprochen werden kann. ${ }^{2478}$

Die Vertretung der Zünfte im Rat waren die jeweiligen Zunftmeister, die zugleich als Vorstand ihrer Zunft fungierten. An der Spitze der Safranzunft stand der jedes Jahr am Sonntag vor dem Johannistag gewählte Vorstand, der aus einem Ratsherrn, dem Zunftmeister und den Sechs bestand. Während der Ratsherr nicht zunftintern, sondern bis 1521 durch bischöfliche Wahlmänner und danach vom Stadtrat erwählt wurde, lag die Wahl des Zunftmeisters in den Händen der Zunft selbst. Diesen zwei Häuptern der Zunft wurde ein Kollegium bestehend aus sechs Personen beigeordnet, das sich nach der Anzahl der beteiligten Männer Sechser nannte. Seit dem 15. Jahr-

2472 Vgl. Simon-Muscheid 1988, 78-84; Schulz 2008, 329.

2473 Vgl. Schulz 2010, 75.

2474 Vgl. Simon-Muscheid 1988, 61; Schulz 2010, 76 f.

2475 Vgl. Heusler 1860, 373; Wackernagel 1911, Bd. 2.1, 222 f.; Koelner 1935, 14.

2476 Vgl. Schulz 2010, 61.

2477 Das städtische Patriziat bestehend aus Rittern und Burgern - ein geschlossener Kreis an Großkaufleuten - war in der sogenannten Hohen Stube vereinigt, die in ihrer gesellschaftlichen Funktion denZünften glich.IhrepolitischeFunktion büßtedieHoheStubemit der Verfassungsänderung von 1515 nach und nach ein, sodass ihr um 1540 nur noch gesellschaftliche Aufgaben zufielen, vgl. Geering 1886, 44; Wackernagel 1911, Bd. 2.1, 380-383; Heusler 1860, 423-425; Füglister 1981, 1 f., $257-$ 261.

2478 Vgl. Füglister 1981, 257-271. 
hundert blieb ein Großteil der Zunftgenossen von den Wahlen ausgeschlossen, da der alte Vorstand den neuen wählte. ${ }^{2479}$ Aus den Sechsern rekrutierten sich der Seckelmeister, der für die Überwachung der zünftischen Einnahmen und Ausgaben zuständig war, sowie der Zunftschreiber. ${ }^{2480} \mathrm{Zu}$ den Kompetenzen des Vorstands zählte unter anderem auch die Zunftgerichtsbarkeit, die dieser zum einen bei gewerblichen Streitfällen, zum anderen bei geringeren Straftaten ausübte. Als Strafe verhängte die Zunft vor allem Geldbußen, ordnete aber je nach verhandeltem Fall auch die Konfiszierung minderwertiger Ware an. ${ }^{2481}$ Mit den täglich anfallenden Aufgaben waren ein Stubenknecht sowie ein Oberknecht betraut, wobei ersterer als eine Art Hauswart für das Zunfthaus, dessen Beheizung, Instandhaltung und die Versorgung mit Speis und Trank verantwortlich war, während in den Verantwortungsbereich des Oberknechts zahlreiche auswärtige Tätigkeiten fielen. ${ }^{2482}$

Neben und mit der Zunft existierte die Stubengesellschaft zum Safran. Ihr konnte nur beitreten, wer bereits safranzünftig war und zudem laut der Stubenordnung von 1372 eine Beitrittstaxe von 4 Gulden entrichtete. Die Stubengesellschaft nahm eine gesellschaftliche Funktion wahr: Sie diente dem Austausch und dem gemeinsamen Essen und Spielen der Zunftgenossen in einer exklusiven Gesellschaft. ${ }^{2483}$

Den Aufgaben religiöser und karitativer Natur kam die Safranzunft in Form einer Laienbruderschaft, der St. Andreas-Bruderschaft, nach. ${ }^{2484}$ Benannt ist diese Bruderschaft nach der Kapelle St. Andreas, die ursprünglich zum Stift St. Peter gehörte. Seit dem 15. Jahrhundert galt die Safranzunft als eigentlicher Schirmherr der Kapelle. ${ }^{2485}$ $\mathrm{Zu}$ den Pflichten der Bruderschaft gehörten Leichenfolge und Grablege beim Tod eines Zunftgenossen, Fürsorge bei armen oder kranken Zunftmitgliedern sowie das Ausrichten von Gottesdiensten. ${ }^{2486}$

Zusätzlich zu ihrer politischen, gesellschaftlichen und religiösen Funktion besaß die Safranzunft ebenfalls einen militärischen Auftrag. So mussten ihre Mitglieder an einem bestimmten Abschnitt der Stadtmauer Wachdienste leisten. Allerdings absolvierten nur die in der Basler Kernstadt ansässigen Zunftgenossen diesen Wachdienst

2479 Vgl. Heusler 1860, 377; Geering 1886, 102-110; Koelner 1935, 14; Gilomen 1980, 1511; SimonMuscheid 1988, 2.

2480 Vgl. Koelner 1935, $17 \mathrm{f}$.

2481 Vgl. Koelner 1935, $20 \mathrm{f}$.

2482 Vgl. Koelner 1935, 23-29. Zu den Aufgaben des Oberknechts gehörten unter anderem: die Einteilung der Zunftgenossen zum Wachdienst, Kontrolle und Eichung aller bei Krämern und Kaufleuten in Gebrauch befindlichen Waagen und Gewichte, Organisation von Trauerfeiern für verstorbene Zunftbrüder, Versorgung der St. Andreas-Kapelle.

2483 Vgl. Koelner 1935, 29-34. Allgemein zu Basler Zunft-Trinkstuben als „soziale Orte“ vgl. SimonMuscheid 2003.

$2484 \mathrm{Zu}$ Bruderschaften im mittelalterlichen Basel vgl. Wackernagel 1883; Geering 1886, 95-101.

2485 Vgl. Wackernagel 1916, Bd. 2.2, 673 f.; Koelner 1935, 85; Marchal 1971, 39-53.

2486 Vgl. Koelner 1935, 12, 80; Marchal 1971, 39. 
innerhalb ihrer Zunft. Die in den Vorstädten und in Kleinbasel wohnenden Zunftbrüder versahen ihren Dienst im Rahmen ihrer jeweiligen Vorstadtgesellschaft. ${ }^{2487}$ Auch bei Feuersbrunst und Überschwemmungen musste die Safranzunft Mitglieder als Hilfskontingente entsenden. ${ }^{2488}$ Sie hatte zudem im Kriegsfall eine Einheit zu stellen, die sie aus ihren wehrpflichtigen Zunftgenossen formierte und die unter der Fahne der Zunft marschierte. Seit 1503 dokumentierte die Safranzunft in einem Reisbüchlein alle Safranzünftigen, die mit der Stadt reisten, das heißt für sie ins Feld zogen. ${ }^{2489}$

In diesem Reisbüchlein sind auch Papiermacher verzeichnet. So beteiligte sich Jacob Gallician als einer von neun safranzünftigen Büchsenschützen 1503 am sechswöchigen Bellenzer Zug. ${ }^{2490}$ Der Papiermacher Hans Lufft, Besitzer der Rychmühle, stellte für den Pavierzug im Jahr 1512 einen Söldner und entzog sich somit der Verpflichtung, selbst auszurücken. ${ }^{2491}$ Dieses Vorgehen war auch bei den anderen safranzünftigen Personen, die zum Kriegsdienst verpflichtet waren, gang und gäbe: Zehn von 17 Zunftgenossen schickten eine Vertretung ins Feld. ${ }^{2492}$ Im selben Jahr zog der Papiermacher Franz Gallician, Inhaber der Stegreifmühle, in eigener Person aus. ${ }^{2493}$ Bei der Schlacht von Marignano ${ }^{2494}$ im Jahr 1515 schickten drei Papiermacher eine Stellvertretung ins Feld: Jörg Dürr d. Ä. engagierte einen Büchsenschützen namens Hans Nunni, ${ }^{2495}$ Hans Kielhammer von Schaffhausen sandte seinen zu diesem Zeitpunkt noch nicht in die Safranzunft eingetretenen Sohn Anton Kielhammer mit einem Spieß in die Schlacht ${ }^{2496}$ und Jacob Gallician schickte dieses Mal ebenfalls einen mit einem Spieß bewaffneten Knecht an seiner statt. ${ }^{2497}$ Auch hier bildeten die Papiermacher keine Ausnahme: Von den 62 aufgelisteten Zunftbrüdern stellten 48 einen Söldner oder Knecht, der an ihrer statt in den Krieg zog. Nur 14 Zünftler beteiligten sich in eigener Person an der Reise. ${ }^{2498}$ Nach seinem Zunfteintritt im Jahr 1518 nahm der Papiermacher Anton Kielhammer ein weiteres Mal in eigener Person an einem

2487 Vgl. Koelner 1935, 8.

2488 Vgl. Koelner 1935, 9 f.

2489 Vgl. Koelner 1935, 11.

2490 StABS, Zunftarchive, Zunft zu Safran 55a, 2r. Zum Bellenzer Zug - Bellenz ist der deutsche Name der Stadt Bellinzona - vgl. Wackernagel 1924, Bd. 3, 9; Koelner 1935, 11.

2491 StABS, Zunftarchive, Zunft zu Safran 55a, 4r: Item Hans Lufft hatt ein soldner. Zum Pavierzug, vgl. Wackernagel 1924, Bd. 3, 22.

2492 StABS, Zunftarchive, Zunft zu Safran 55a, 4r.

2493 StABS, Zunftarchive, Zunft zu Safran 55a, 4v.

2494 Zur Schlacht von Marignano vgl. Wackernagel 1924, Bd. 3, 35-37; Koelner 1935, 12.

2495 StABS, Zunftarchive, Zunft zu Safran 55a, 6v: Jerg Dürr bapirer ein soldner wz Hanns Nunni trug ein buchssen.

2496 StABS, Zunftarchive, Zunft zu Safran 55a, 7r: Hans Kyelhamer von Schafhusen ein bapirer ein soldner sin sun Anthenge Kyelhamer ein spieß.

2497 StABS, Zunftarchive, Zunft zu Safran 55a, 8r: Jacob Galician ein knächt Balthassar Männlin von Basel mit eim spieß.

2498 StABS, Zunftarchive, Zunft zu Safran 55a, 6v-9r. 
Feldzug teil. Im ersten Kappeler Krieg 1529 marschierte er, ausgerüstet mit einer Hellebarde, zusammen mit seinem Berufskollegen Joachim Degenhart, der eine Büchse mit sich führte. ${ }^{2499}$ Am zweiten Kappeler Krieg im Jahr 1531 beteiligten sich ebenfalls zwei Papiermacher: Fridlin Hüsler d. Ä. und Peter Sontach. ${ }^{2500}$

Was die hier angeführten Papiermacher motivierte, selbst ins Feld zu ziehen oder lieber einen Söldner zu stellen, kann kaum beantwortet werden. Neben der Abkömmlichkeit im Betrieb können auch finanzielle, politische oder moralische Erwägungen eine Rolle gespielt haben. Interessant ist, dass der Besitz oder die Leitung einer Papiermühle nicht den Ausschlag dafür gegeben haben, sich im Feld vertreten zu lassen. Franz Gallician, Fridlin Hüsler d. Ä. und Peter Sontach besaßen zum Zeitpunkt ihres Ausrückens selbst eine Papiermühle, Joachim Degenhart war vermutlich in einer der Papiermühlen als Werkmeister angestellt. ${ }^{2501}$

Die soeben in Bezug auf ihre militärischen Pflichten genannten Personen sind nur einige der safranzünftigen Papierer. Insgesamt konnten 45 Papiermacher ermitteln werden, die zwischen 1451 und 1550 in die Safranzunft eintraten. Ihr Anteil an allen in dieser Periode aufgenommenen Zunftmitgliedern beträgt 5,3 Prozent. ${ }^{2502}$ Splittet man den Zeitraum wie Paul Koelner in seiner Darstellung in zwei Abschnitte, so ergibt sich für die zweite Hälfte des 15. Jahrhunderts für die Papiermacher mit 26 Beitritten ein Anteil von 6,6 Prozent an allen Neuaufnahmen, während ihr Anteil in der ersten Hälfte des 16. Jahrhunderts mit 19 Beitritten nur 4,2 Prozent beträgt. ${ }^{2503}$

2499 StABS, Zunftarchive, Zunft zu Safran 55a, 9v. Vgl. Kälin 1972a, 15.

2500 StABS, Zunftarchive, Zunft zu Safran 55a, 10v. Vgl. Kälin 1972a, 13. Höchstwahrscheinlich handelt es sich bei dem im Reisbüchlein aufgeführten Petter bapirrer von Baden, der im Jahr 1524 safranzünftig geworden war, um Peter Sontach von Baden, der 1527 das Basler Bürgerrecht und ein Jahr später die Stegreifmühle erwarb, vgl. StABS, Protokolle, Öffnungsbuch 7, 221; Gerichtsarchiv B 24, 201v. Zu den Kappelerkriegen vgl. Heusler 1918, 102-104; H. Meyer 2008, 93.

2501 Franz Gallician besaß 1512 die Stegreifmühle, Fridlin Hüsler d. Ä. hatte 1531 die Rychmühle inne und Peter Sontach war im selben Jahr Besitzer der Klingentalmühle. Bis zur Flucht Hans Gallicians II nach Solothurn 1521 war Joachim Degenhart Pächter der Klingentalmühle, vgl. StABS, Gerichtarchiv A 54, 332v. Wo er danach arbeitete, ist ungewiss. Da er im Jahr 1542 jedoch Eigentümer der Rychmühle wurde, ist davon auszugehen, dass er weiterhin als Pächter oder zumindest als Werkmeister in einer der Papiermühlen arbeitete. Vgl. Kapitel 3.3.1.1, S. 329, 333.

2502 Diese Rechnung erfolgte auf der Grundlage der bei Koelner in einer Tabelle numerisch für die verschiedenen Berufe zusammengeführten Zunftaufnahmen zwischen 1451 und 1550. Ausgenommen sind die Berufsgruppe der Beamten, Kleriker, Gelehrten und Offiziere sowie die Gruppe, die Paul Koelner unter „nicht safranzünftige Berufe“ fasst. Bei der ersten Kategorie handelt es sich weder um Handwerker noch um Gewerbetreibende, bei der zweiten Gruppe ist eine Differenzierung zwischen verschiedenen Berufen nicht möglich und beide fungieren zudem als Sammelkategorien, die vergleichsweise viele Neumitglieder aufweisen und auf diese Weise die Statistik verfälschen. Mit dieser Einschränkung sind für diesen Zeitraum 840 Aufnahmen zu verzeichnen, vgl. Koelner 1935, $94 \mathrm{f}$.

2503 Vgl. die Tabelle in Koelner 1935, 94 f. Koelner gibt für den Zeitraum von 1451 bis 1500 die Aufnahme von 29 Papiermachern an. Die Differenz zu den in dieser Untersuchung eruierten 26 Papiermachern ergibt sich daraus, dass Koelner auch Hans Gallician I, Hans Gallician II und Martin Gallician 
Auf den ersten Blick mögen sich diese Zahlen zwar bescheiden ausnehmen, vergleicht man sie jedoch mit den Zunftbeitritten anderer Gewerbe, so fällt auf, dass die Papiermacher in der Safranzunft relativ stark vertreten waren. ${ }^{2504}$ Für den Zeitraum von 1451 bis 1500 wiesen lediglich drei andere klar definierte Berufsgruppen mehr Neumitglieder auf. Dies waren in den Handwerksberufen mit 31 respektive 37 Beitritten die Säckler und die Hutmacher. Unangefochten an der Spitze stand mit 92 Neumitgliedschaften die eigentliche Zielgruppe der Zunft, die Krämer. ${ }^{2505}$ Die 24 weiteren Gewerbe hatten weniger Vertreter in der Safranzunft als die Papiermacher, davon waren 53 Prozent mit nicht mehr als jeweils bis zu zehn Personen repräsentiert. ${ }^{2506}$ Acht Gewerbezweige, das heißt 29 Prozent, stellten jeweils zwischen 11 und 20 Personen. ${ }^{2507}$ Nur eine weitere Berufsgruppe lag mit ihren Neumitgliedern wie die Papiermacher im Bereich von 21 bis 30 Zunftaufnahmen: die Tuchleute mit 23 Personen. Damit entfielen auf diesen Zahlenbereich nur 7 Prozent aller Berufsgruppen.

Für die Periode zwischen 1501 und 1550 verschiebt sich das Bild leicht, auch wenn die Papiermacher immer noch im oberen Drittel der am stärksten repräsentierten Berufe lagen. Nun sind aber sechs andere Professionen stärker vertreten als die Papiermacher, darunter mit jeweils 23 Zunfteintritten die Barettmacher und die Nestler sowie mit 28 neuen Mitgliedern die Buchdrucker. Die Säckler stellten mit 44 neuen Zunftmitgliedern immer noch einen bedeutenden Anteil, mehr Berufsgenossen wiesen nur die Tuchleute und die Krämer mit jeweils 67 Personen auf. ${ }^{2508}$ Diese sechs Gewerbe stellten rund 18 Prozent der zu dieser Zeit safranzünftig gewordenen Berufsgruppen. Wiederum 54 Prozent der Berufe, 17 an der Zahl, waren lediglich mit bis zu zehn Personen in der Safranzunft vertreten. ${ }^{2509}$ Neun Professionen,

als safranzünftige Papierer auflistet. Da Hans Gallician II und Martin Gallician nicht als Papiermacher bezeichnet werden und Hans Gallician I nicht im Eintrittsrodel der Safranzunft verzeichnet ist, bleiben sie bei der Analyse außen vor. Für den Zeitraum von 1501 bis 1550 führt Koelner eine Aufnahme von 20 Papierern an. Auch hier wurde für die vorliegende Untersuchung eine Zunftaufnahme abgezogen, da nicht belegt ist, dass Michel Höfflin Papiermacher war, vgl. Koelner 1935, 531-533. Nimmt man die Berufsgruppe der Beamten, Kleriker, Gelehrten und Offiziere sowie die Gruppe „nicht safranzünftiger Berufe“ mit in die Berechnung hinein, so ergibt sich für den Zeitraum von 1451 bis 1500 ein Anteil von 5,5 Prozent, für den Zeitraum von 1501 bis 1550 ein Anteil an 3,7 Prozent und für die gesamten 100 Jahre ein Anteil von 4,6 Prozent.

2504 Vgl. Anm. 2502.

2505 Vgl. Koelner 1935, 94.

2506 In absoluten Zahlen: 15 Handwerke. Hierzu zählten in aufsteigender Reihenfolge die Eisenkrämer, Pergamenter, Scheidenmacher, Gewürzkrämer, Spiegler, Würfler, Lautenmacher, Silberkrämer, Buchbinder, Apotheker, Armbrustmacher, Buchführer, Spengler, Taschenmacher und Weißgerber vgl. Koelner 1935, $94 \mathrm{f}$.

2507 Dies waren die Rot- und Zapfengießer, Nadler, Ringler, Lebkucher, Nestler, Buchdrucker, Gürtler sowie die Kartenmacher und Heiligenmaler vgl. Koelner 1935, 94 f.

2508 Vgl. Koelner 1935, 94 f.

2509 Dies sind in aufsteigender Ordnung die Lautenmacher, Pergamenter, Seiden-/Zeugkrämer, Taschenmacher, Bürstenbinder, Handelsleute, Lebkücher, Lederbereiter, Silberkrämer, Armbrustma- 
das heißt gut 28 Prozent, darunter auch die Papiermacher mit ihren 19 Vertretern im oberen Bereich liegend, stellten jeweils zwischen 11 und 20 Neumitglieder. ${ }^{2510}$

Tab. 22: Anzahl der Neumitglieder der Safranzunft pro Berufsgruppe von 1451 bis 1550, berechnet nach Koelner 1935, $94 \mathrm{f}$.

\begin{tabular}{|c|c|c|c|c|c|c|c|}
\hline $\begin{array}{l}\text { Anzahl Neumitglieder pro } \\
\text { Berufsgruppe }\end{array}$ & $1-10$ & $11-20$ & $21-30$ & $31-40$ & $41-50$ & ab 51 & gesamt \\
\hline \multicolumn{8}{|c|}{$1451-1500$} \\
\hline $\begin{array}{l}\text { Berufsgruppen } \\
\text { Total }\end{array}$ & 15 & 8 & 2 & 2 & --- & 1 & 28 \\
\hline $\begin{array}{l}\text { Berufsgruppen } \\
\text { Prozent }\end{array}$ & $53 \%$ & $29 \%$ & $7 \%$ & $7 \%$ & $\cdots$ & $4 \%$ & $100 \%$ \\
\hline \multicolumn{8}{|c|}{$1501-1550$} \\
\hline $\begin{array}{l}\text { Berufsgruppen } \\
\text { Total }\end{array}$ & 17 & 9 & 3 & --- & 1 & 2 & 32 \\
\hline $\begin{array}{l}\text { Berufsgruppen } \\
\text { Prozent }\end{array}$ & $54 \%$ & $28 \%$ & $9 \%$ & --- & $3 \%$ & $6 \%$ & $100 \%$ \\
\hline
\end{tabular}

Der direkte Vergleich mit den anderen Beschreibstoffherstellern dieser Zeit, den Pergamentern, zeigt ein weiteres Mal, dass - wie es bereits bei den Bürgeraufnahmen deutlich wurde - diese Berufsgruppe nur in einem sehr geringen Maße vertreten war. Über den gesamten Untersuchungszeitraum von hundert Jahren, in dem 45 Papiermacher in die Safranzunft eintraten, wurde lediglich zwei Pergamentmachern die Zunft verliehen. ${ }^{2511} \mathrm{Ob}$ dies tatsächlich an einer Verdrängung des traditionellen Handwerks durch das neue Gewerbe der Papierherstellung lag, wie es Paul Koelner vermutet, kann letztlich nicht beantwortet werden. ${ }^{2512}$ Festzuhalten ist allerdings, dass die Safranzunft in den hundert Jahren davor, von 1351 bis 1450, elf Pergamenter aufnahm, und in den hundert Jahren danach, von 1551 bis 1650, die Anzahl der Pergamentmacher wieder auf sieben Personen anstieg. ${ }^{2513}$ Das ebenfalls noch junge Gewerbe des Buchdrucks ist über den gesamten Untersuchungszeitraum mit ungefähr ebenso vielen neu aufgenommenen Zunftmitgliedern vertreten wie die Papiermacher,

cher, Rot- und Zapfengießer, Eisenkrämer, Seifensieder, Ringler, Buchführer, Nadler und Weißgerber, vgl. Koelner 1935, $94 \mathrm{f}$.

2510 Hierzu sind zu rechnen die Strelmacher, Gewürzkrämer, Spengler, Apotheker, Buchbinder, Gürtler, Hutmacher, Kartenmacher/Heiligenmaler sowie die Papierer, vgl. Koelner 1935, 94 f.

2511 Vgl. Koelner 1935, 94, 161-166, 543 f.

2512 Vgl. Koelner 1935, 163.

2513 Vgl. Koelner 1935, 94. 
nämlich 44 Personen, wobei das Verhältnis bezogen auf die beiden Zeitabschnitte umgekehrt ist: Zwischen 1451 und 1500 nahm die Safranzunft 16 und zwischen 1501 und 155028 Drucker auf. ${ }^{2514}$

Eine Zusammenstellung aller im Untersuchungszeitraum safranzünftig gewordenen Papiermacher bietet Tabelle 23. ${ }^{2515}$ Die in dieser Darstellung verarbeiteten Daten stammen aus den jeweiligen Eintrittsrodeln der Safranzunft, in die jedes neue Mitglied chronologisch nach Aufnahmedatum eingetragen wurde. ${ }^{2516}$ Dabei wurden bis auf sechs begründete Ausnahmen in die Tabelle nur Personen aufgenommen, die direkt in den Eintrittsrodeln oder in einer anderen Quelle als Papiermacher bezeichnet werden. In letzterem Fall ist der Zusatz Papiermacher durch eine Anmerkung ergänzt. Neben der Signatur und der Seitenangabe wird auch der Bürge namentlich aufgeführt, sofern einer gestellt wurde.

Von den in die Tabelle als Papiermacher aufgenommenen 45 Personen werden 28 direkt in den Eintrittsrodeln mit dem Berufszusatz Papiermacher versehen. Bei elf weiteren Personen ist durch andere Quellen belegt, dass es sich um Papierer handelte. Für insgesamt sechs Namen konnte dieser Beleg nicht sicher erbracht werden. In drei dieser Fälle ist aufgrund ihres Herkunftsorts, Caselle im Piemont, und der Tat-

2514 Vgl. Koelner 1935, 94.

2515 In der tabellarischen Zusammenstellung der safranzünftigen Papiermacher hat diese Untersuchung bereits Vorgänger. So bietet die Arbeit Paul Koelners neben einer Einführung in die Geschichte der Safranzunft auch eine nach Berufsgruppen geordnete Aufstellung der Zunftaufnahmen und damit auch eine Liste der aufgenommenen Papierer. Dort sind nicht nur die Namen und das Beitrittsjahr vermerkt, sondern ebenfalls zusätzliche Angaben zu den betreffenden Personen aufgeführt wie beispielsweise die Aufnahme ins Bürgerrecht, Ämter und der Besitz von Papiermühlen, vgl. Koelner 1935, 531-535. Diese Informationen stammen aus anderen Quellen, die Koelner jedoch nur teilweise angibt. Auch für die Ermittlung der Berufsbezeichnung Papierer bediente Koelner sich anderer Archivalien. Daher finden sich in seiner Aufstellung Berufsbezeichnungen, die nicht im Eintrittsrodel der Safranzunft verzeichnet sind, sondern vom Autor in der frühneuhochdeutschen Schreibweise bapirer oder papirmacher hinzugefügt wurden. Eine Überprüfung ergab, dass Koelner einige Personen als Papiermacher nennt, die in den Quellen nicht als solche bezeichnet werden. Durch die scheinbare Verwendung von Quellenbegriffen entsteht das trügerische Bild, er beziehe diese Angaben direkt aus den von ihm ausgewerteten Archivalien, wie bereits Gerhard Piccard feststellte, vgl. Piccard 1967, $141 \mathrm{f}$. Die von Piccard vorgenommene Korrektur der in den Eintrittsrodeln nicht anzutreffenden Berufsbezeichnungen ist vor diesem Hintergrund berechtigt. Allerdings unterliefen ihm dabei dieselben Fehler, die er bei Koelner beanstandet. In seiner Aufzählung der safranzünftigen Papiermacher werden Hug Pastor, der 1491 aufgenommene Anton Pastor II und Roland von Caselle mit der Bezeichnung Papiermacher versehen, ohne dass diese Angaben im Zunftrodel verzeichnet sind, vgl. hierzu auch Kälin 1974, 283 mit Anm. 222. Anhand der frühneuhochdeutschen Schreibweise der Berufsangaben - und der identischen Kommasetzung - tritt klar zutage, dass Piccard in diesen Fällen die Angaben ohne Überprüfung von Koelner übernahm, vgl. Koelner 1935, 532, und Piccard 1967, 150 f.

2516 StABS, Zunftarchive, Zunft zu Safran 24 u. 25. 
sache, dass Papiermacher für sie beim Zunft- oder Bürgerrechtskauf bürgen, zu vermuten, dass diese Personen in der Papiermacherei tätig waren. ${ }^{2517}$

Zwei weitere Personen, die bei Hans Kälin als Papiermacher aufgeführt werden, sind nur schwer zu identifizieren, da es aufgrund von Namensgleichheit Schwierigkeiten mit der Zuordnung gibt. Ungewiss ist zum einen die Zuordnung des 1486 safranzünftig gewordenen Peter von Lothringen. ${ }^{2518}$ In dieser Namenskombination konnte diese Person nur einmal aufgefunden werden. Dass es sich bei ihr um den in Steuerlisten von 1454, 1453/54 bis 1456/57 und 1457/58 bis 1460/61 ohne Familiennamen aufgeführten Papierergesellen Peter handelt, erscheint aufgrund der Zeitstellung unwahrscheinlich. ${ }^{2519}$ Ebenfalls unwahrscheinlich ist die Gleichsetzung von Peter von Lothringen mit dem Papiererknecht Peter Fester, der bereits vor 1476 bei Anton Gallician angestellt war und 1477 vermutlich aus Basel fortzog. ${ }^{2520}$ Ob in dem Papiermacher Peter Schlegel, der im Jahr 1489 erwähnt wird, Peter von Lothringen zu erblicken ist, muss auch offen bleiben. ${ }^{2521}$ Sollte Peter von Lothringen mit keiner dieser Personen identisch sein, so kann ausschließlich anhand seines Bürgen Franz Gallician darauf geschlossen werden, dass er Papiermacher war.

Problematisch ist zum anderen die Zunftaufnahme von Meister Hans Strub im Jahr 1486. Während Koelner ihn als Papiermacher angibt, sieht Gerhard Piccard in ihm den Gerbermeister Hans Strub. ${ }^{2522}$ Kälin wiederum gelingt es, drei Personen mit dem Namen Hans Strub zu differenzieren: den besagten Gerbermeister, einen Weinmann, der zusammen mit seiner Frau Anna Plattner im Oktober 1486 die Zunzigermühle besaß, ${ }^{2523}$ und den zumeist Peter Hans Strub genannten Papierer, der mit einer Elsin Wesslin verheiratet war und die Zunzigermühle direkt nach dem Weinmann Hans Strub innehatte. ${ }^{2524}$ Die Person, die im Jahr 1486 safranzünftig wurde, setzt Kälin mit dem letztgenannten Peter Hans Strub gleich. Da dieser in dem einzigen Zeugnis, in dem er 1487 als Inhaber der Zunzigermühle genannt wird, als Bappirer bezeichnet wird, ist er in die Tabelle 23 aufgenommen. ${ }^{2525}$

2517 Dies sind Bartholome Pass, Marx Trappo, Anton Pastor II. Sowohl Gerhard Piccard als auch Hans Kälin führen diese Personen als Papiermacher auf, vgl. Piccard 1967, 150 f.; Kälin 1974, 190 f.

2518 StABS, Zunftarchive, Zunft zu Safran 24, 189.

2519 StABS, Steuern B 12, Markzahlsteuer 1453/54-1456/57, ohne Blattzählung, unter der Ortsbezeichnung mülinen; Markzahlsteuer 1457/58-1460/61, ohne Blattzählung, unter der Ortsbezeichnung in den mulenen zu Sant Alban; Steuern B 15, 6v.

2520 Vgl. Kapitel 3.3.1.1, S. 336 f.

2521 StABS, St. Peter Urk. 1159 (20.07.1489). Vgl. Kälin 1974, 203.

2522 Vgl. Koelner 1935, 532; Piccard 1967, 150, 153 f.

2523 StABS, Gerichtsarchiv B 11, 263r-264r.

2524 Vgl. Kälin 1974, 197, 281 mit Anm. 199 f.

2525 StABS, Gerichtsarchiv B 12, 13r. Vgl. Kapitel 3.2.1.1, S. 215. 
Schließlich konnte auch für den 1538 aufgenommenen Hieronymus Dürr, den Paul Koelner als Papierer bezeichnet und der vermutlich der Papiererfamilie Dürr angehörte, nicht sicher belegt werden, dass er tatsächlich Papiermacher war. ${ }^{2526}$

Nicht in die Tabelle aufgenommen wurde der Papiermacher Hans Gallician I, Bruder von Anton und Michel Gallician, da sich für ihn kein Eintrag im Eintrittsrodel der Safranzunft findet. Allerdings wird er im Roten Buch anlässlich seines Bürgerrechtserwerbs durch Teilnahme an der Ortenberger Fehde unter den Krämern aufgeführt. ${ }^{2527}$ Entweder ist er daher vor 1461 der Safranzunft beigetreten oder er wurde lediglich von einem anderen Safranzünftigen an dessen Stelle ins Feld geschickt und firmiert aus diesem Grund unter den Krämern. Da sie nachweislich keine Papiermacher waren, wurden des Weiteren weder Hans Gallician II, Sohn von Anton Gallician, noch Martin Gallician, Sohn von Michel Gallician, in die Liste aufgenommen. ${ }^{2528}$

Der Eintritt in die Safranzunft kostete seit 14234 Gulden, wenn man die Zunft als Sohn eines Safranzünftigen nicht für einen deutlich geringeren Preis erneuerte, wie es insgesamt neun Papiermacher taten. ${ }^{2529} \mathrm{Zu}$ diesem Betrag kamen des Weiteren ein Schilling für den Zunftmeister und ein Schilling für den Oberknecht. ${ }^{2530}$ Jedoch

2526 Vgl. Koelner 1935, 533. Einen Hieronymus Dürr findet man im Ämterbuch der Safranzunft im Jahr 1546 als Sechser und im Jahr 1551 als Zunftschreiber, allerdings ohne die Bezeichnung Papierer, StABS, Zunftarchive, Zunft zu Safran 57, 43, 61. Im Gegensatz dazu steht Jörg Dürr d. J., der im Jahr 1546 ebenfalls zum Sechser gewählt wurde und Papierer genannt wird. Hieronymus Dürr ist von 1538 bis 1552 ebenfalls im Heizrodel der Safranzunft fassbar, allerdings wieder ohne die Bezeichnung Papierer, StABS, Zunftarchive, Zunft zu Safran 28, 48 f., 60 f. Er war offenbar der Sohn des Papiermachers Claus Dürr, der wiederum ein Neffe Jörg Dürrs d. Ä. war. Diese Tatsache mag für eine Tätigkeit als Papiermacher sprechen, vgl. Geering 1886, 529; Piccard 1967, 140.

2527 Vgl. StABS, Ratsbücher A 1, 227. Vgl. auch Piccard 1967, 148 f.; Kälin 1974, 157 f.

2528 Hans Gallician II war Kaufmann, Martin Gallician seit 1484, ein Jahr vor seinem Zunfteintritt, Baccalaureus artium, vgl. Kälin 1974, 162 f.

2529 Dies war möglich, wenn der Vater bereits zum Zeitpunkt der Geburt des Petenten safranzünftig war, das heißt, wenn letzterer nach dem väterlichen Zunftkauf geboren war. Derjenige, der die Zunft erneuerte, kam in den Genuss einer stark reduzierten Beitrittstaxe von lediglich 10 Schilling, einem Viertel Wein, einem Schilling für den Zunftmeister und einem Schilling für den Oberknecht beziehungsweise insgesamt 13 Schilling 4 Pfennig, vgl. Koelner 1935, 6. Ab der Zunfterneuerung von Jacob Gallician im Jahr 1499 zahlten die Papiermacher, die die Zunft erneuerten, 13 Schilling 4 Pfennig. Im Untersuchungszeitraum erneuerten neun Papiermacher die Zunft. Acht davon führten den Beruf ihres Vaters weiter. Hug Pastor war der Sohn des Papiermachers Anton Pastor I, Franz Gallician war Sohn von Anton Gallician. Der Vater der beiden 1489 beziehungsweise 1499 aufgenommenen Brüder Claus und Jacob Gallician war der Papierer Michel Gallician. Im Jahr 1518 erneuerte Anton Kielhammer, Sohn des Papiermachers Hans Kielhammer von Schaffhausen, die Zunft. Die Brüder Gregorius und Jörg Dürr d. J., die 1527 respektive 1543 die Zunft erwarben, waren die Nachkommen des Papierers Jörg Dürr d. Ä. Vater des 1545 eingetretenen Fridlin Hüsler d. J. war der gleichnamige Papierer, der 1520 safranzünftig geworden war. Einzig der Vater von Christian Schmidt, Jerg Schmidt, übte nicht den Beruf des Papiermachers aus, sondern war ein safranzünftiger Pulverkrämer. Für die Belege vgl. Tab. 23 und Koelner 1935, 531-533.

2530 Vgl. Koelner 1935, 3. 
zahlten weniger als ein Drittel, nämlich elf, der safranzünftig gewordenen Papiermacher diese Beitrittsgebühr direkt beim Zunfteintritt. ${ }^{2531} \mathrm{Mehr}$ als zwei Drittel der Berufsgenossen entrichteten den Betrag ratenweise. Wer sich für die Zahlung auf Raten entschied, der musste einen Bürgen stellen. ${ }^{2532}$ Von den 25 Papiermachern, die diese Zahlungsmodalitäten wählten, wird bei 22 Personen ein Bürge genannt. Lediglich bei Odere Nicolau, der die Zunft 1453 kaufte, bei Anton Gallician, der im Jahr danach Zunftmitglied wurde, sowie bei Bartholome de Conmola im Jahr 1464 fehlt die Nominierung eines Garanten. Allerdings wurde Nicolau dazu aufgefordert, einen Bürgen zu stellen, wie der Eintrag im Eintrittsrodel verrät. ${ }^{2533}$ Die vierteljährlichen Raten von einem Gulden waren die in der Safranzunft übliche Stundung, die auch ein Großteil der Neumitglieder aus anderen Gewerben nutzte. ${ }^{2534}$ Zwei Papiermacher, Bartholome Pass und Marx Trappo aus Caselle, wählten die kleinere Rate von einem halben Gulden zu jeden Fronfasten. ${ }^{2535}$

Konnte kein Bürge gestellt werden, so war es auch möglich, ein Pfand zu hinterlassen. ${ }^{2536}$ Diese Variante nutzte 1464 der Papiermacher Bartholome de Conmola: Er zahlte einen Gulden sofort und hinterlegte vier Ries Papier als Pfand für die ausstehenden 3 Gulden, die er, wie gewöhnlich, vierteljährlich zu einer Rate von einem Gulden abbezahlen sollte. ${ }^{2537}$ Interessanteweise löste Bartholome die vier Ries nicht selbst aus, sondern verabredete anscheinend mit dem Heiligenmaler ${ }^{2538}$ Adam von Spir, dass dieser die restlichen 3 Gulden für ihn begleichen und dafür das Papier nehmen solle. ${ }^{2539}$ Damit ist Adam von Spir eigentlich nicht als Bürge zu bezeichnen, da er das Papier, das er wahrscheinlich für seine Arbeit benötigte, durch die 3 Gulden einfach kaufte, wenn auch nur indirekt von Bartholome de Conmola.

2531 Dazu gehörten 1488 Hans Kielhammer, 1494 Michel Gernler, 1520 Joachim Degenhart, 1522 Bartholome von Caselle, 1527 Claus Dürr und Bartholome Blum, 1540 Heinrich Rytz von Montabaur, 1548 Hans Bussi und 1550 Hans Düring. Abgesehen von der Stundung einer geringfügigen Summe bezahlten auch Peter Höfflin 1472 und Hieronymus Dürr 1538 die Beitrittstaxe direkt.

2532 Vgl. Koelner 1935, $3 \mathrm{f}$.

2533 StABS, Zunftarchive, Zunft zu Safran 24, 67: Item uff mittwůch in der osterwoche anno liii hat Odere Nicolau der bappir macher von bemund die zunfft empfangen und her Hans Gurly der dez jor $\beta$ meister wass umb iiii gulden und gab di zů mol $i$ gulden bar und sol hinenthin alle fronfasten $i$ gulden geben untz er bezalt und sol ein burge geben.

2534 Vgl. Koelner 1935, $3 \mathrm{f}$.

2535 StABS, Zunftarchive, Zunft zu Safran 24, $180 \mathrm{f}$.

2536 Vgl. Koelner 1935, 4. Die Angabe Koelners, dass Hans Gallician II 1461 vier Ries Papier als Pfand hinterlegt hatte, findet sich in den Eintrittsrodeln nicht wieder.

2537 StABS, Zunftarchive, Zunft zu Safran 24, 116: Item an sant Katherine obent anno lxiii hat Bartholome de Conmola der bappir macher die zunfft empfangen und meister Peter Danhuser der dez jor $\beta$ meister wasß umb iiii gulden und gab do zu mol ein gulden bar für das überig hat er zu pfant geben fier risen bappir und sol hinnethin alle fronfasten i gulden geben. Vgl. auch Piccard 1967, 149.

2538 Vgl. Koelner 1935, 297-300.

2539 StABS, Zunftarchive, Zunft zu Safran 24, 116: iii gulden gab Adam von Spir und nam daz pappir. 
Tab. 23: Safranzünftige Papiermacher in Basel 1450 bis $1550 .^{2540}$

\begin{tabular}{|c|c|c|c|c|}
\hline & Jahr & Neumitglied & Bürge & Beleg \\
\hline 1. & 1453 & Odere Nicolau, Papierer & --.--.-.-. & Sfz 24,67 \\
\hline 2. & 1454 & Anton Gallician, Papierer & --.---.--. & Sfz 24,73 \\
\hline 3. & 1455 & Michel Gallician, Papierer & Anton Gallician & Sfz 24,80 \\
\hline 4. & 1455 & Anton Pastor I, Papierer & Walter Tschan/Heinrich Halbysen d. J. & Sfz 24, 81 \\
\hline 5. & 1464 & $\begin{array}{l}\text { Bartholome de Conmola, } \\
\text { Papierer }\end{array}$ & Pfandauslösung: Adam von Spir & Sfz 24,116 \\
\hline 6. & 1469 & Ulrich Züricher, Papiereri & Heinrich Jungermann & Sfz 24,127 \\
\hline 7. & 1472 & Peter Höfflin, Papierer & --.----.-- & Sfz 24,138 \\
\hline 8. & 1477 & Hans Züricher, Papiererii & Andres Bischoff & Sfz 24,153 \\
\hline 9. & 1479 & Michel Gerbera, Papierer & Anton Gallician, Papierer & Sfz 24,164 \\
\hline 10. & 1480 & Michel Gallician II, Papiereriii & Anton Gallician, Papierer & Sfz 24,166 \\
\hline 11. & 1480 & Hug Pastor, Papiereriv & --.----.-- & Sfz 24,168 \\
\hline 12. & 1483 & Bartholome Pass von Caselle ${ }^{v}$ & Anton Gallician, Papierer & Sfz 24,180 \\
\hline 13. & 1483 & Marx Trappo von Caselle ${ }^{v i}$ & Anton Gallician, Papierer & Sfz 24,181 \\
\hline 14. & 1485 & Franz Gallician, Papierer & -..---.-- & Sfz 24, 187 \\
\hline
\end{tabular}

i StABS, Teichkorporationen, St. Alban, Urk. 12 (16.07.1473); auch Urkundenbuch der Stadt Basel 1901, Bd. 8, 345, Nr. 439.

ii StABS, Gerichtsarchiv B 12, 125v.

iii StABS, Steuern B 19, Markzahlsteuer 1477/78, 21v: der Langmichel Galician Michel Galician papirknecht. Michel Gallician II wird im Eintrittsrodel der Safranzunft als Vetter Anton Gallicians bezeichnet. Walter Friedrich Tschudin vermutete in ihm den Vater von Hans Gallician II und Franz Gallician, die jedoch durch die Arbeiten von Gerhard Piccard und Hans Kälin als Söhne von Anton Gallician identifiziert werden konnten, vgl. W. Fr. Tschudin 1958, 114; Piccard 1967, 143-146; Kälin 1974, Tafel 6 u. 7.

iv StABS, Protokolle, Öffnungsbuch 6, 108r.

v Bartholome Pass und Marx Trappo werden lediglich im Eintrittsrodel und im Heizgeldrodel (vgl. StABS, Zunftarchive, Zunft zu Safran 28, 18) der Safranzunft erwähnt und sind dort nicht mit der Berufsbezeichnung Papierer versehen. Dass der Papierer Anton Gallician für sie bürgte und dass sie, wie viele Basler Papiermacher, aus Caselle im Piemont stammten, lässt vermuten, dass es sich um Papiermacher handelte.

vi Vgl. Tab. 23, Anm. v.

2540 Alle Belege stammen aus: StABS, Zunftarchive, Zunft zu Safran. 


\begin{tabular}{|c|c|c|c|c|}
\hline & Jahr & Neumitglied & Bürge & Beleg \\
\hline 15. & 1486 & Peter von Lothringen vii & Franz Gallician, Papierer & Sfz 24, 189 \\
\hline 16. & 1486 & (Peter) Hans Strub & Meister Hans Breitschwert & Sfz 24, 192 \\
\hline 17. & 1486 & Caspar Helg, Papierer & Meister Hans von Basel, Schneider & Sfz 24, 192 \\
\hline 18. & 1488 & $\begin{array}{l}\text { Hans Kielhammer von Schaffhau- } \\
\text { sen, Papierer }\end{array}$ & ------- & Sfz 24, 202 \\
\hline 19. & 1489 & $\begin{array}{l}\text { Wilhelm Frone (W. Varner), } \\
\text { Papierer }\end{array}$ & Hans Züricher, Papierer & Sfz 24, 204 \\
\hline 20. & 1489 & Claus Gallician, Papiererviii & -..--..--. & Sfz 24, 206 \\
\hline 21. & 1490 & Roland von Caselle, Papierer ${ }^{\mathrm{ix}}$ & Franz Gallician, Papierer & Sfz 24, 208 \\
\hline 22. & 1491 & $\begin{array}{l}\text { Anton Pastor II von Caselle im } \\
\text { Piemont }^{x}\end{array}$ & Heinrich David & Sfz 24, 215 \\
\hline 23. & 1492 & Bartholome Pastor, Papierer & Franz Gallician, Papierer & Sfz 24, 223 \\
\hline 24. & 1494 & Michel Gernler, Papierer xi & -.---.-- & Sfz 24, 228 \\
\hline 25. & 1494 & Hans Lufft von Ettlingen, Papierer & Michel Gallician, Papierer & Sfz 24,230 \\
\hline 26. & 1499 & Jacob Gallician, Papierer & -..--..--. & Sfz 24,250 \\
\hline 27. & 1508 & Jörg Dürr d. Ä., Papierer & Hans Gallician II & Sfz 25, 27 \\
\hline 28. & 1518 & Anton Kielhammer, Papierer & --.---.-- & Sfz 25, 58 \\
\hline 29. & 1518 & $\begin{array}{l}\text { Hans Wetzel von Blaubeuren, } \\
\text { Papiererxii }\end{array}$ & Jörg Dürr d. Ä., Papierer & Sfz 25, 61 \\
\hline 30. & 1520 & Fridlin Hüsler d. Ä., Papiereriii & Heinrich Warner & Sfz 25, 66 \\
\hline 31. & 1520 & Joachim Degenhart, Papierer & --.---.-- & Sfz 25, 67 \\
\hline 32. & 1521 & Conrad Grebel, Papierer & Hans Lufft & Sfz 25,73 \\
\hline 33. & 1522 & Bartholome von Caselle, Papierer & -.---.--- & Sfz 25, 76 \\
\hline 34. & 1524 & $\begin{array}{l}\text { Peter (Sontach) von Baden, } \\
\text { Papierer }\end{array}$ & Jörg Dürr d. Ä., Papierer & Sfz 25, 91 \\
\hline
\end{tabular}

vii Hier deutet nur der Bürge Franz Gallician darauf hin, dass es sich um einen Papiermacher handelte.

viii StABS, Gerichtsarchiv C 20, 28v.

ix StABS, Ratsbücher P 1, 240r.

x Anton Pastor II wird in den eingesehenen Archivalien nicht als Papiermacher bezeichnet. Auch hier können allein sein Herkunftsort, ein weiteres Mal Caselle im Piemont, und sein Bürge beim Erwerb des Bürgerrechts 1491, ein Papiermacher namens Růll, ebenfalls aus dem Piemont, ein Hinweis auf eine Tätigkeit als Papiermacher sein, StABS, Ratsbücher P 1, 311v.

xi StABS, Gerichtsarchiv C 18, 53.

xii StABS, Protokolle, Öffnungsbuch 7, $173 \mathrm{v}$.

xiii StABS, Gerichtsarchiv B 22, 69r. 


\begin{tabular}{|c|c|c|c|c|}
\hline & Jahr & Neumitglied & Bürge & Beleg \\
\hline 35. & 1525 & Andres Tröly, Papierer & Heinrich Warner, der alte Stampfer & Sfz 25, 97 \\
\hline 36. & 1527 & $\begin{array}{l}\text { Claus Dürr von Reutlingen, } \\
\text { Papierer }\end{array}$ & -..-...-.- & $\begin{array}{l}\text { Sfz } 25,104 \\
\text { u. } 105\end{array}$ \\
\hline 37. & 1527 & Gregorius Dürr, Papierer & -.--..-..-- & Sfz 25, 104 \\
\hline 38. & 1527 & $\begin{array}{l}\text { Bartholome Blum von Rotenburg, } \\
\text { Papierer }\end{array}$ & 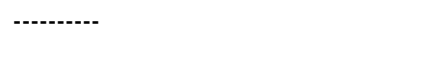 & Sfz 25, 105 \\
\hline 39. & 1538 & Hieronymus Dürrxiv & --.--.-.-. & Sfz 25,140 \\
\hline 40. & 1540 & $\begin{array}{l}\text { Heinrich Rytz von Montabaur, } \\
\text { Papierer }^{\mathrm{xv}}\end{array}$ & -.--.-.-.- & Sfz 25, 146 \\
\hline 41. & 1543 & Jörg Dürr d. J., Papierer & -..-..-..-- & Sfz 25, 157 \\
\hline 42. & 1545 & Fridlin Hüsler d. J., Papierer & 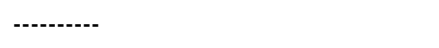 & Sfz 25, 166 \\
\hline 43. & 1547 & Christian Schmidt, Papierer & -.----.- & Sfz 25, 176 \\
\hline 44. & 1548 & Hans Bussi, Papierervi & (Peter Sontach) & Sfz 25, 182 \\
\hline 45. & 1550 & $\begin{array}{l}\text { Hans Düring von Ettingen, } \\
\text { Papierer }\end{array}$ & --.--.---. & Sfz 25, 187 \\
\hline
\end{tabular}

Wie bereits erwähnt, stellten die meisten in Raten zahlenden Neumitglieder einen Bürgen, der im Notfall die ausstehende Summe für sie entrichtete. Außer den drei genannten bürgenlosen Personen konnte jeder der übrigen 22 Papiermacher, die ratenweise zahlten, einen Gewährsmann vorweisen. In 13 Fällen war dieser Garant ein anderer Papiermacher. Besonders häufig übernahm Anton Gallician diese Verantwortung. Er bürgte 1455 für seinen Bruder Michel Gallician, 1479 für Michel Gerbera, 1480 für den zweiten Michel Gallician sowie 1483 für Bartholome Pass und Marx Trappo aus Caselle. ${ }^{2541}$ Auch sein Sohn Franz Gallician stellte sich mehrmals als Bürge zur Verfügung: 1486 für Peter von Lothringen, 1490 für Roland von Caselle und 1492 für Bartholome Pastor. ${ }^{2542}$ Im Unterschied zu seinem Vater besaß Franz Gallician zum jeweiligen Zeitpunkt der drei Bürgschaften vermutlich noch keine Papier-

xiv Für diese Person konnte innerhalb des Untersuchungszeitraums kein Beleg für die Berufsbezeichnung Papierer erbracht werden. Vgl. Anm. 2526.

xv StABS, Ratsbücher D 2, 43r.

xvi StABS, Protokolle, Öffnungsbuch 8, 127v.

2541 StABS, Zunftarchive, Zunft zu Safran 24, 80, 164, 166, 180 f.

2542 StABS, Zunftarchive, Zunft zu Safran 24, 189, 208, 223. 
mühle, da die Stegreifmühle erst nach dem Tod Anton Gallicians um das Jahr 1497 in seinen Besitz überging. Der Papiermacher Hans Lufft hatte seine Papiermühle, die Rychmühle, 1519 und damit vor seiner Bürgschaft für Conrad Grebel im Jahr 1521 verkauft. $^{2543}$

In neun der 13 Fälle waren die Papiermacher, die als Gewährsmänner fungierten, jedoch auch Papiermühlenbesitzer. Davon entfallen fünf Bürgschaften, wie bereits aufgeführt, auf Anton Gallician. Des Weiteren bürgte der Besitzer der Zunzigermühle, Hans Züricher, im Jahr 1489 für den Papiermacher Wilhelm Frone (W. Varner), ${ }^{2544}$ und Michel Gallician, Inhaber der Rychmühle, im Jahr 1494 für Hans Lufft von Ettlingen. ${ }^{2545}$ Jörg Dürr d. Ä. haftete im Jahr 1518 als Eigentümer der hinteren Spiegelmühle für Hans Wetzel von Blaubeuren ${ }^{2546}$ und 1524 als Eigentümer der hinteren Spiegelmühle sowie der Stegreifmühle für Peter Sontach. ${ }^{2547} \mathrm{Zu}$ den neun Bürgschaften, die von Papiermühlenbesitzern übernommen wurden, die gleichzeitig Papiermacher waren, gesellten sich der Kaufmann Heinrich Halbysen d. J., der ebenfalls Inhaber zweier Papiermühlen im St. Albantal - Zunzigermühle und Rychmühle - war und der im Jahr 1455 für Anton Pastor I bürgte, ${ }^{2548}$ sowie Hans Gallician II, der die Klingentalmühle 1497 von seinem Vater Anton Gallician übernahm und im Jahr 1508 für den Papiermacher Jörg Dürr d. Ä. bürgte. ${ }^{2549}$ Folglich war bei insgesamt 15 von 22 Bürgschaften der Gewährsmann ein Papiermacher und/oder Papiermühlenbesitzer. 2550 Dies spricht für eine direkte geschäftliche Beziehung zwischen neuem Zunftmitglied und Garant, die sich in den meisten Fällen vermutlich in einem Arbeitnehmer-Arbeitgeber-Verhältnis ausdrückte.

Als Beispiel sei der Zunfteintritt des Hans Lufft von Ettlingen genannt. Hier stand Michel Gallician am 23. Oktober 1494 als Bürge ein. ${ }^{2551}$ Keine zwei Wochen später, am 4. November, veräußerte er seine Papiermühle, die Rychmühle, an Hans Lufft. ${ }^{2552}$ Die Bürgschaft bei der Zunftaufnahme deutet darauf hin, dass Michel Gallician und Hans Lufft sich bereits längere Zeit vor der Übertragung der Papiermühle kannten. Eventu-

2543 StABS, Zunftarchive, Zunft zu Safran 25, 73. Vgl. Kapitel 3.2.1.1, S. 214.

2544 StABS, Zunftarchive, Zunft zu Safran 24, 204.

2545 StABS, Zunftarchive, Zunft zu Safran 24, 230.

2546 StABS, Zunftarchive, Zunft zu Safran 25, 61.

2547 StABS, Zunftarchive, Zunft zu Safran 25, 91.

2548 StABS, Zunftarchive, Zunft zu Safran 24, 81. Bevor Heinrich Halbysen d. J. die Bürgerschaft übernahm, hatte sich Anton Pastors I Schwiegervater Walter Tschan, der vermutlich Schindler war, zur Verfügung gestellt. Vgl. Kälin 1974, 195, 202.

2549 StABS, Zunftarchive, Zunft zu Safran 25, 27.

2550 Eine Art Bürgschaft leistete der Papierer Peter Sontach im Jahr 1548 beim Zunfteintritt seines Schwiegersohns Hans Bussi: Er bat den Zunftvorstand um Aufnahme seines Schwiegersohns. Da die volle Beitrittsgebühr jedoch sofort erlegt wurde, handelt es sich nicht um eine Bürgschaft im engen Sinne, vgl. StABS, Zunftarchive, Zunft zu Safran 25, 182.

2551 StABS, Zunftarchive, Zunft zu Safran 24, 230.

2552 StABS, Gerichtsarchiv B 13, 167v. 
ell arbeitete Hans Lufft als Werkmeister oder Pächter in der Rychmühle. ${ }^{2553}$ Kurz vor der Abwicklung der Transaktion, mit der er selbstständiger Meister und Mühlenbesitzer wurde, erwarb Hans Lufft mit Hilfe seines ehemaligen Arbeitgebers oder Verpächters die Safranzunft und wurde somit in jeder Hinsicht zum selbstständigen Meister.

Weitere sieben Bürgschaften für Papiermacher übernahmen Personen unterschiedlicher Berufe. Dreimal bürgten Kaufleute: im Jahr 1469 zunächst der Kaufmann Heinrich Jungermann für Ulrich Züricher. ${ }^{2554}$ In diesem Fall lässt sich eine Verbindung zu Heinrich Halbysen d. J. herstellen, da Heinrich Jungermann d. J. durch die Heirat mit Margreth Halbysen dessen Schwiegersohn war. ${ }^{2555}$ Heinrich Halbysen d. J. aber verkaufte im darauffolgenden Jahr 1470 die Zunzigermühle an Ulrich Züricher. Vielleicht war die Übernahme der Bürgschaft durch seinen Schwiegersohn auf seinen Wunsch hin zustande gekommen. Auch der Papiermacher Hans Züricher, Sohn von Ulrich Züricher, stellte mit Andres Bischoff im Jahr 1477 einen Kaufmann als Bürgen. ${ }^{2556}$ Eventuell stand sein Vater im Rahmen seiner Beziehungen zur MeltingerZscheckapürlin-Gesellschaft mit Bischoff in geschäftlichem Kontakt. ${ }^{2557}$ Mit Andres' Frau Barbara Bischoff bestand eine nachweisbare geschäftliche Beziehung. Sie hatte von Ulrich Zürichers Papiermühle, der Zunzigermühle, eine Rente von 25 Gulden jährlich gekauft. ${ }^{2558}$ Für Anton Pastor II von Caselle leistet 1491 der Kaufmann Heinrich David Gewähr. Dieser war zu diesem Zeitpunkt im Handel mit gedruckten Büchern aktiv, wie zwei Einträge aus den Basler Gerichtsbüchern belegen, und lieferte Druckern offenbar auch Papier. ${ }^{2559}$ Gerhard Piccard vermutet, dass Heinrich David ein Gläubiger des 1494 bankrottgegangenen Hans Züricher war und diesem einen Papiermacher als Werkmeister schickte. ${ }^{2560}$

Die Bürgen der Papiermacher (Peter) Hans Strub und Caspar Helg waren im Jahr 1486 der Kürschnermeister Hans Breitschwert ${ }^{2561}$ beziehungsweise der Schneider-

2553 Vgl. hierzu auch Kälin 1974, 197.

2554 StABS, Zunftarchive, Zunft zu Safran 24, 127.

2555 Vgl. Kälin 1974, 153, 198. Auf S. 198 spricht Kälin von Schwager, nicht von Schwiegersohn, meint aber wohl letzteres.

2556 StABS, Zunftarchive, Zunft zu Safran 24, 153.

2557 Vgl. Kälin 1974, 186, 198 f. Vgl. Kapitel 3.3.6.1, S. 454-457.

2558 StABS, Gerichtsarchiv E 6, 112.

2559 Im Jahr 1490 legte Heinrich David Beschlag auf mehrere Bücher, die Jacob Allgouwer gehörten, da dieser ihm noch 200 Gulden für eine Papierlieferung schuldete, vgl. StABS, Gerichtsarchiv A 38, 126r; Stehlin 1888, 107 f., Nr. 688. Im Jahr 1492 schuldete der Papiermacher Franz Gallician Heinrich David 100 Gulden, vgl. StABS, Gerichtsarchiv C 15, 67r; Stehlin 1888, 142, Nr. 867. Vgl. auch Piccard 1967, 154.

2560 Vgl. Piccard 1967, 154. Auch Kälin nimmt an, dass Anton Pastor II in einer der beiden Mühlen Zürichers, nämlich in der Spisselismühle, arbeitete, vgl. Kälin 1974, 177.

2561 StABS, Zunftarchive, Zunft zu Safran 24, 192. Hans Breitschwert war der Vater von Barbara Breitschwert, der Frau Franz Gallicians, vgl. Piccard 1967, 129; Kälin 1974, 162. 
meister Hans von Basel. ${ }^{2562}$ In welcher Beziehung (Peter) Hans Strub zu Hans Breitschwert stand, ist nicht zu sagen. Hans von Basel hingegen ist aus einem anderen Dokument als Vogt der Witwe und der Kinder von Hermann Helg, dem Müller, bekannt, der wahrscheinlich der Vater von Caspar Helg war. ${ }^{2563}$ Zweimal bürgte Heinrich Warner für Papiermacher: Im Jahr 1520 übernahm er die Bürgschaft für Fridlin Hüsler d. Ä., ${ }^{2564}$ fünf Jahre später verantwortete er sich für Andres Tröly. ${ }^{2565} \mathrm{Nach}$ Koelner war Heinrich Warner Kartenmaler und ebenfalls Papiermacher, allerdings sind diese Angaben nicht belegt. ${ }^{2566}$ Sicher ist hingegen, dass Heinrich Warner, wie der Eintrag zu Andres Tröly zeigt, Stampfer in der Gewürzmühle der Safranzunft war, die ebenfalls im St. Albantal lag. ${ }^{2567}$ Sein Nachfolger wurde anscheinend der als Papiermacher bezeichnete Andres Tröly, der im Jahr seines Zunftkaufs 1525 von der Safranzunft als Stampfer angenommen wurde. ${ }^{2568}$

Vergleicht man die Papiermacher, die die Beitrittsgebühr in Raten zahlten, mit denen, die die gesamte Summe direkt beglichen, so lässt sich kein substantieller Unterschied in der Position der einzelnen Personen entdecken. Die These, dass beispielsweise Papiermühlenbesitzer die Summe immer bar zahlten, weil sie die nötigen Rücklagen hatten, trifft nicht zu. Zwar kaufte Michel Gernler, seit 1487 Eigentümer der hinteren Spiegelmühle, im Jahr 1494 die Zunft direkt und in bar, Anton Gallician, der seit 1453 die Klingentalmühle im St. Albantal besaß, vereinbarte jedoch 1455 eine ratenweise Zahlung mit der Safranzunft. Auch könnte man vermuten, dass Gesellen, besonders solche, die gerade nach Basel gezogen waren, die volle Summe nicht in bar aufbringen konnten. Tatsächlich zahlten viele safranzünftige Papierergesellen ihre Eintrittsgebühr ratenweise, vor allem in der zweiten Hälfte des 15. Jahrhunderts. Für die erste Hälfte des 16. Jahrhunderts finden sich jedoch auch Belege für eine Barzahlung. So entrichtete der Papierer Bartholome von Caselle, der dem Namen nach nicht aus Basel stammte und in den Quellen nicht weiter genannt wird, die Taxe sofort in voller Höhe. ${ }^{2569}$ Auch die ortsfremden Papiermacher Claus Dürr aus Reutlingen und Heinrich Rytz aus Montabaur verzichteten auf die Ratenzahlung. 2570

Diese wenigen Beispiele sollen genügen, um zu zeigen, dass zum einen die individuelle finanzielle Lage nicht an äußeren Merkmalen wie dem Besitz einer Papiermühle oder dem Gesellendasein festgemacht werden kann. Ein Papiermühlenbesitzer konnte vermögend sein, da er einen eigenen gut laufenden Betrieb unterhielt,

2562 StABS, Zunftarchive, Zunft zu Safran 24, 192.

2563 StABS, Gerichtsarchiv A 38, 138r. Vgl. Piccard 1967, 176 f.

2564 StABS, Zunftarchive, Zunft zu Safran 25, 66.

2565 StABS, Zunftarchive, Zunft zu Safran 25, 97.

2566 Vgl. Koelner 1935, 533.

2567 Vgl. Schweizer 1923, 61; Koelner 1935, 103-106.

2568 StABS, Zunftarchive, Zunft zu Safran 25, 97. Vgl. auch Zunftarchive, Zunft zu Safran 28, 26.

2569 StABS, Zunftarchive, Zunft zu Safran 25, 76.

2570 StABS, Zunftarchive, Zunft zu Safran 25, 104, 105, 146. 
er konnte jedoch auch in finanziellen Schwierigkeiten stecken, da der Kauf und der Unterhalt einer Mühle sehr kostspielig waren, wie die hohe Rentenbelastung der Gebäude zeigt. ${ }^{2571}$ Der Geldbeutel eines Gesellen konnte durch Wanderschaft und geringen Lohn leer sein, es bestand aber auch die Möglichkeit, dass er Rücklagen gebildet hatte und es bevorzugte, den Betrag direkt zu bezahlen, um nicht auf die Bürgschaft seines Meisters angewiesen zu sein. Zum anderen ist auch ein direkter Zusammenhang zwischen finanzieller Situation und Ratenzahlung nicht gegeben. Es scheint vor allem im 15. Jahrhundert Usus gewesen zu sein, die Zunftgebühr ratenweise zu zahlen, gleich, ob man sich die Zahlung der vollen Summe eigentlich leisten konnte oder nicht. ${ }^{2572}$

Im 15. Jahrhundert war der Besitz des Bürgerrechts keine unbedingte Voraussetzung für den Zunfterwerb. ${ }^{2573}$ Allerdings hatte der Basler Rat die Zünfte in den Jahren 1484 und 1487 angewiesen, keinen mehr aufzunehmen, der nicht auch das Bürgerrecht besaß. Dies wurde allerdings vergleichsweise locker gehandhabt, sodass der Rat 1525 und 1528 erneut bestimmte, dass alle Zünftigen das Bürgerrecht erwerben sollen. 1541 wurde der Zwang zum Bürgerrechtskauf dann strikt durchgesetzt. ${ }^{2574}$

Von den 45 safranzünftigen Papiermachern wurden 21 Personen - folglich knapp 47 Prozent - anlässlich ihres Bürgerrechtserwerbs in die Ratsbücher eingetragen. Ein Großteil von ihnen erwarb die Safranzunft vor oder zeitgleich mit dem Bürgerrecht. So wurden zehn Papiermachern die Zunft und das Bürgerrecht im selben Jahr verliehen. ${ }^{2575}$ Sieben weitere Papierer traten zunächst der Safranzunft bei und kauften später das Bürgerrecht. Der Zeitraum zwischen Zunftkauf und Bürgerrechtserwerb war dabei unterschiedlich groß. Während Anton Gallician, Michel Gallician, Jörg Dürr d. Ä. und Peter Sontach zwei bis drei Jahre nach dem Eintritt in die Safranzunft Basler Bürger wurden, ${ }^{2576}$ verstrichen bei Hug Pastor acht, bei Hans Züricher elf und bei Joachim Degenhart sogar 20 Jahre. ${ }^{2577}$ Zunächst Bürger und dann Zunftmitglied wurden vier Papiermacher, wobei in diesen Fällen nicht mehr als vier Jahre vergingen, bis beide Status erworben waren. Roland von Caselle, der im Oktober 1489 das

2571 Vgl. Kapitel 3.2.4.1.

2572 Vgl. Koelner 1935, 3. Hier mag der Vergleich mit heutigen Praktiken der Ratenzahlung beispielsweise beim Kauf eines Fernsehers oder eines Autos erhellend sein.

2573 Vgl. Geering 1886, 54-56; Koelner 1935, 4.

2574 Vgl. Geering 1886, 56; Portmann 1979, 67 f; Isenmann 2002, 238.

2575 Bartholome de Conmola 1464, Ulrich Züricher 1469, Peter Höfflin 1472, Hans Kielhammer 1488, Wilhelm Frone (W. Varner) 1489, Anton Pastor II 1491, Bartholome Pastor 1492, Claus Dürr 1527, Hans Bussi 1548 und Hans Düring 1550, vgl. Tab. 19 und Tab. 23.

2576 Anton Gallician: Safranzunft 1454, Bürgerrecht 1457; Michel Gallician: Safranzunft 1455, Bürgerrecht 1457; Jörg Dürr d. Ä.: Safranzunft 1508, Bürgerrecht 1511; Peter Sontach: Safranzunft 1524, Bürgerrecht 1527, vgl. Tab. 19 und Tab. 23.

2577 Hug Pastor: Safranzunft 1480, Bürgerrecht 1488; Hans Züricher: Safranzunft 1477, Bürgerrecht 1488; Joachim Degenhart: Safranzunft 1520, Bürgerrecht 1540, vgl. Tab. 19 und Tab. 23. 
Bürgerrecht kaufte und anschließend im März 1490 in die Safranzunft eintrat, ließ nur ein halbes Jahr verstreichen. In einer ähnlich geringen Zeitspanne erwarb Heinrich Rytz von Montabaur Bürgerrecht - im Jahr 1539 - und Zunft - im Jahr 1540. Zwei Jahre Abstand lagen bei dem Papiermacher Bartholome Blum zwischen Bürgerrechtserwerb und Zunfteintritt und Hans Wetzel von Blaubeuren wurde knapp vier Jahre nach Bürgerrechtskauf Mitglied der Safranzunft. ${ }^{2578}$

Unter den restlichen 24 safranzünftigen Papiermachern befinden sich elf Personen, die in anderen Dokumenten als Bürger bezeichnet werden. ${ }^{2579}$ Bei einem weiteren Papiermacher kann vermutet werden, dass er das Bürgerrecht besaß, da bereits sein Vater Basler Bürger war. ${ }^{250}$ Zwölf Papiermacher, die safranzünftig wurden, konnten somit nicht als Bürger identifiziert werden. Damit waren gut 73 Prozent (33 von 45 Personen) der safranzünftigen Papiermacher gleichzeitig Basler Bürger. Umgekehrt waren knapp 78 Prozent (21 von 27 Personen) der ins Bürgerbuch eingetragenen Papiermacher und 85 Prozent (33 von 39 Personen) aller als Bürger identifizierten Papiermacher safranzünftig. ${ }^{2581}$

Alle Papiermühlenbesitzer, die zugleich als Papierer bezeichnet werden, wurden safranzünftig, ein Großteil bereits mehr oder weniger lange Zeit vor dem Kauf der Papiermühle. Lediglich drei Papiermacher traten der Zunft bereits als Inhaber einer Papiermühle bei. So kaufte Anton Gallician im Jahr 1453 die Klingentalmühle und erst im Jahr darauf die Safranzunft. Er ist zudem der einzige Papiermacher, von dem bekannt ist, dass er auch noch einer anderen Zunft angehörte. Er kaufte im Jahr 1464 ebenfalls die Schlüsselzunft, die hauptsächlich die Zunft der Tuchhändler war, vermutlich, um sich am Tuchhandel und am Tuchschnitt beteiligen zu können. ${ }^{2582}$

2578 Hans Wetzel erwarb am 27.01.1515 das Bürgerrecht und trat am 19.12.1518 in die Safranzunft ein, vgl. StABS, Protokolle, Öffnungsbuch 7, 173v; Zunftarchive, Zunft zu Safran 25, 61.

2579 Dies sind Anton Pastor I, Franz Gallician, (Peter) Hans Strub, Claus Gallician, Hans Lufft von Ettlingen, Jacob Gallician, Anton Kielhammer, Fridlin Hüsler d. Ä., Conrad Grebel, Gregorius Dürr, Jörg Dürr d. J., vgl. Tab. 20.

2580 Es handelt sich hierbei um Fridlin Hüsler d. J., Sohn von Fridlin Hüsler d. Ä.

2581 Mit Anton Gallician, Michel Gallician, Bartholome de Conmola, Ulrich Züricher, Peter Höfflin, Hans Züricher, Hug Pastor, Hans Kielhammer, Roland von Caselle, Wilhelm Frone (W. Varner), Anton Pastor II, Bartholome Pastor, Jörg Dürr d. Ä., Hans Wetzel, Bartholome Blum, Claus Dürr, Peter Sontach, Heinrich Rytz, Joachim Degenhart, Hans Bussi und Hans Düring waren 21 Papiermacher sowohl im Bürgerbuch als auch im Eintrittsrodel der Safranzunft verzeichnet. Die sechs Papierer Hans Gallician I, Heinrich in Eda, Diebolt Hanman, Jacob von Reinach, Mundyn von Caselle und Joseph Velek wurden zwar ins Bürgerrecht aufgenommen, lassen sich jedoch nicht im Eintrittsrodel der Safranzunft fassen. Vgl. Tab. 19 und Tab. 23.

2582 StABS, Zunftarchive, Zunft zum Schlüssel 11, 39v. Vgl. Koelner 1953, 251; Piccard 1967, 89; Kälin 1974, 193; Halstrick 1990, 54. Auch der Gründer der ersten Basler Papiermühle, Heinrich Halbysen d. Ä., und sein Sohn, Heinrich Halbysen d. J., ebenfalls Papiermühlenbesitzer, waren sowohl in der Safran- als auch in der Schlüsselzunft Mitglieder, ebenso wie der Sohn Anton Gallicians, der Kaufmann und Papiermühleninhaber Hans Gallician II, vgl. StABS, Zunftarchive, Zunft zum Schlüssel 10, 
Michel Gernler übernahm im Jahr 1487 die hintere Spiegelmühle von seinem Stiefvater Peter Höfflin, erwarb jedoch erst 1494 die Zunft. Im Dezember 1519, keine drei Monate vor seinem Zunftkauf im März 1520, wurde Fridlin Hüsler d. Ä. Besitzer der Rychmühle. Die anderen 15 Papiermühlenbesitzer wurden erst Zunftmitglieder und später Inhaber eines eigenen Betriebs, wobei diese Ereignisse bei manchen Personen eng aufeinander folgten. Der Fall von Hans Lufft, der im Jahr 1494 zwei Wochen nach seinem Zunftkauf die Rychmühle erwarb, wurde schon erläutert. Auch der Zunfterwerb und der Mühlenkauf von Ulrich Züricher 1469 beziehungsweise 1470 liegen sehr nah beieinander.

Bei den Papiermachern, die keine eigene Mühle besaßen, als sie Mitglied der Safranzunft wurden, erscheint die Vermutung Gerhard Piccards äußerst plausibel, dass es sich um Pächter oder um die Werkmeister einer Papiermühle handelte. ${ }^{2583} \mathrm{Zwar}$ kann diese Hypothese nicht für alle diese Papiermacher durch Quellenbelege bestätigt werden, einige Fälle weisen jedoch in diese Richtung. So wurde der Papiermacher Jörg Dürr d. Ä. im Jahr 1508 safranzünftig und stellte als Bürgen den Krämer Hans Gallician II, der seit dem Tod seines Vaters, des Papiermachers Anton Gallician, die Klingentalmühle besaß. Aufgrund dieser Verbindung ist anzunehmen, dass Jörg Dürr d. Ä. als Werkmeister den Betrieb von Hans Gallician II, der selbst kein Papiermacher war, leitete. Jörg Dürr kaufte 1513 die hintere Spiegelmühle und erwarb im Jahr 1523 mit der Stegreifmühle einen zweiten Betrieb. Im darauffolgenden Jahr bürgte er für den Papiermacher und späteren Mühlenbesitzer Peter Sontach bei dessen Zunftkauf. Hier überzeugt die Vermutung, dass Peter Sontach als Werkmeister für einen der beiden Betriebe Dürrs eingesetzt wurde, als dieser sein Unternehmen durch eine zweite Mühle erweiterte. Als letztes Beispiel soll der Fall Joachim Degenhart dienen, der bereits 1520 safranzünftig wurde, aber erst 1542 mit dem Kauf der Rychmühle Papiermühlenbesitzer wurde. Bei seinem Zunftkauf stellte er keinen Gewährsmann, da er die erforderliche Summe bar entrichtete. Aus den Urteilsbüchern erfahren wir aber, dass er zu dieser Zeit Pächter von Hans Gallicians II Papiermühle, wahrscheinlich der Klingentalmühle, war. ${ }^{2584}$

Während die soeben aufgeführten Papiermacher später doch noch eine eigene Papiermühle besaßen und damit zu den insgesamt 19 Papiermachern gehörten, die bei oder nach Zunfteintritt Mühlenbesitzer waren beziehungsweise wurden, arbeiteten 26 andere in den Eintrittsrodeln der Safranzunft verzeichneten Papiermacher während des Untersuchungszeitraums nicht in ihrer eigenen Papiermühle. Aber auch hier liegt die Vermutung nahe, dass es sich um Pächter oder Betriebsleiter von Papiermühlen handelte. Anhand der Bürgen, so vorhanden, lässt sich eine hypothetische

30v; Zunft zum Schlüssel 11, 20v; Zunft zum Schlüssel 12, 119r; Koelner 1953, 205, 243, 279. Zur Doppelzünftigkeit vgl. Geering 1886, 49-52; Füglister 1981, 152-156.

2583 Vgl. Piccard 1967, 153-156.

2584 StABS, Gerichtsarchiv A 54, 332v. Vgl. Piccard 1967, 171, 178. 
Zuordnung der Papiermacher zu den Papiermühlen, zumindest aber zu ihren Besitzern vornehmen. ${ }^{2585}$

Inwiefern die anderen safranzünftigen Papiermacher, für die sich kein Bürge fassen lässt und die nicht Söhne von Papiermühlenbesitzern waren, eine leitende Stellung innerhalb einer der Papiermühlen innehatten, kann leider nicht nachvollzogen werden. Es ist aber davon auszugehen, dass vorwiegend Werkmeister und altgediente Gesellen in die Zunft aufgenommen wurden. Aus diesem Grund waren, wie dies bei anderen Handwerken auch der Fall war, nicht alle Personen, die den betreffenden Beruf ausübten, in einer Zunft vertreten. Gerhard Piccard geht davon aus, dass ein Viertel der in der Papierherstellung tätigen Personen der Safranzunft beitrat. ${ }^{2586}$ Drei Viertel der Papiermacher - hiervon sei der überwiegende Teil als Gesellen oder als Lohnarbeiter zu bezeichnen - seien ihrem Beruf ohne Zunftmitgliedschaft nachgegangen, da sie in Abhängigkeit von einem Meister und/oder Betriebsleiter standen. Auf der Basis der 45 Zunftaufnahmen von 1450 bis 1550 würde dies bedeuten, dass in diesem Zeitraum in Basel ungefähr 180 Personen in der Papierherstellung tätig waren. Diese These - einschließlich der vermuteten Anzahl der beschäftigten Personen - deckt sich mit dem Befund, dass in der gesamten Basler Überlieferung lediglich ungefähr ein Drittel der in der Papiermacherei tätigen Personen fassbar ist. ${ }^{2587}$

Auf die Frage nach dem „Wer“ folgt gewissermaßen zwangsläufig die Frage nach dem „Warum“: Aus welchem Grund wurden die Papiermacher, denen erst 1601 vorgeschrieben wurde, dass sie die Safranzunft für die Ausübung ihres Gewerbes kaufen mussten, safranzünftig? ${ }^{2588}$ Gerhard Piccard vertritt die Ansicht, dass nur diejenigen Papierer der Safranzunft beitraten, die für den Verkauf des Papiers verantwortlich waren, da sie ansonsten ihre Produkte nicht auf dem städtischen Markt hätten verkaufen dürfen. ${ }^{2589}$ Hierunter zählt Piccard vor allem die Mühlenbesitzer sowie die Werkmeister. ${ }^{2590}$ Diese These überzeugt indes nicht. Wie Christoph Halstrick bemerkt, hatte jedes Handwerk das Verkaufsrecht für die vom ihm hergestellte Ware. ${ }^{2591}$ Es ist davon auszugehen, dass dieses Verkaufsrecht auch für die Papiermacherei galt. Daher ist es unwahrscheinlich, dass ein Papiermacher das von ihm produzierte Papier nur verkaufen durfte, wenn er Mitglied der Krämerzunft wurde.

Plausibler erscheinen hier neben ökonomischen vor allem soziale Gründe. Die Zugehörigkeit zu einer Zunft - und damit in den meisten Fällen auch zu ihrer Bru-

2585 Vgl. Kapitel 3.3.1.1, S. 328 f. und Tab. 16. Vgl. auch Piccard 1967, 152-154; Kälin 1974, 176-180, 182. 2586 Vgl. Piccard 1967, $154 \mathrm{f}$.

2587 Vgl. hier die auf Basis der Schillingsteuerbücher und der namentlich genannten Papiermacher errechnete Differenz zwischen in der Papierherstellung tätigen Personen und den davon in den Quellen namentlich fassbaren, Kapitel 3.3.1.1.

2588 Vgl. Koelner 1935, 92; Piccard 1967, 157.

2589 Vgl. Piccard 1967, 148.

2590 Vgl. Piccard 1967, 147 f., 155 f.

2591 Vgl. Halstrick 1990, 52 f. 
derschaft und zu ihrer Trinkstube - förderte die Integration des Einzelnen in die städtische Gesellschaft. Da die Zünfte, wie bereits erwähnt, die größten Gruppen innerhalb einer Kommune waren, bedeutete die Mitgliedschaft in einer solchen die Partizipation am gesellschaftlichen und politischen Leben einer Stadt. Die Zunft und vor allem die Trinkstube fungierten als „soziale Orte“: Sie erleichterten die Kommunikation in einem exklusiven Raum und waren damit Katalysatoren für den Aufbau von Netzwerken und Handelsbeziehungen. ${ }^{2592}$ Warum die Papiermacher der Safranzunft und nicht eine der anderen Basler Zünfte beitraten, kann indes nur vermutet werden. Neben dem Charakter der Safranzunft als ein Sammelbecken für unterschiedliche Gewerbe war möglicherweise auch die Zugehörigkeit der ersten Papiermühlenbesitzer Heinrich Halbysen d. Ä. und Heinrich Halbysen d. J. ausschlaggebend.

\subsubsection{Bern, Kempten, Ravensburg, Reutlingen, Straßburg und Zürich}

Für die anderen südwestdeutschen Papiermühlenstandorte kann für den Untersuchungszeitraum die Zugehörigkeit zu einer Zunft leider nicht im Detail untersucht werden. Im Fall der Stadt Ravensburg, für die eigene Archivrecherchen unternommen wurden, liegt dies an den verfügbaren Quellen. Für die anderen Orte, die im 15. Jahrhundert eine Papierproduktion aufwiesen, wird die Zunftzugehörigkeit in der einschlägigen Literatur kaum behandelt. Ob dieses Phänomen auf Desinteresse gegenüber dieser Fragestellung oder ebenfalls auf einen Mangel an aussagekräftigen Quellen zurückzuführen ist, lässt sich auf der Basis des aktuellen Forschungsstands nicht beantworten.

Für Ravensburg konstatierte bereits Lore Sporhan-Krempel, dass aus dem 15. Jahrhundert keinerlei Informationen über den Anschluss der Papiermacher an eine Zunft überliefert sind. ${ }^{2593}$ Erst das 17. Jahrhundert erlaubt tiefere Einblicke in die zünftische Organisation der Ravensburger Papierer, die sich der Schneiderzunft angliederten. ${ }^{2594}$ Ein erster Zusammenhang zwischen Papiermachern und Schneiderzunft lässt sich jedoch schon für das erste Viertel des 16. Jahrhunderts feststellen. Eine auf das Jahr 1519 datierte Auflistung der von den Mitgliedern der Schneiderzunft gestellten Waffen nennt Namen von Papiermachern, nämlich Peter, Paul und Jörg Wolfartshofer. ${ }^{2595}$ Diese Namen sind nicht separat aufgeführt, sondern befinden sich zwischen den

2592 Vgl. zu den Bruderschaften und Trinkstuben Simon-Muscheid 2003, 161 f. Christoph Halstrick vermutet ebenfalls eher „weiche“ Beweggründe für den Kauf der Safranzunft, vgl. Halstrick 1990, 53 f. 2593 Vgl. Sporhan-Krempel 1953, 70. Für die Zeit bis 1550 sind leider keine aussagekräftigen Zunftakten wie beispielsweise Eintrittsverzeichnisse erhalten. Für die Zeit bis 1520 sind überhaupt nur allgemeine Dokumente über die Zünfte erhalten, die Schneiderzunft betreffende Zeugnisse finden sich erst nach 1520, allerdings auch nur vereinzelt, vgl. hierzu die handschriftlichen Repertorien 1 und 3 im Stadtarchiv Ravensburg. Vgl. auch Hengstler 1950, 7 f.

2594 Vgl. Sporhan-Krempel 1953, 70-72.

2595 StR, Bü 488c/2/1. 
Namen anderen Schneiderzünftiger. Das Gleiche ist für eine Waffenliste von 1523/25 zu beobachten: Unter die anderen Zunftmitglieder mischen sich einige Papiermacher aus der Familie der Wolfartshofer. So stellten Hans Wolfartshofer II genannt Meck, ein weiterer Hans Wolfartshofer, Peter Wolfartshofer III, Paul Wolfartshofer und Jörg Wolfartshofer jeweils einen Spieß. ${ }^{2596}$ Zudem lässt sich in der Aufstellung ein Hans Wäch finden, der mit einer Büchse ausgestattet war. ${ }^{2597} \mathrm{Ob}$ es sich um den gleichnamigen Papiermacher handelt, der 1482 ins Bürgerrecht aufgenommen wurde, ist jedoch nicht zu überprüfen. ${ }^{2598}$

Die ersten Hinweise auf eine Angliederung der Ravensburger Papiermacher an die Schneiderzunft gehen folglich aus Dokumenten hervor, die die Verteidigung der Stadt und den Einsatz in kriegerischen Auseinandersetzungen organisieren. Christoph Halstrick hat aus dieser Tatsache geschlussfolgert, dass es sich bei der Mitgliedschaft in der Schneiderzunft lediglich um eine verwaltungstechnische Zuordnung gehandelt habe und dass die Papiermacher keine vollwertigen und komplett integrierten Zunftgenossen gewesen seien. ${ }^{2599}$ Er führt als Begründung für seine These an, dass die Papiermacher in Dokumenten und Akten gesondert als Anhang nach den anderen Mitgliedern der Schneiderzunft aufgeführt werden. Dies mag zwar für die von Lore Sporhan-Krempel erwähnten Quellen - eine Aufstellung der Bürgerschaft von 1647 und die Steuerbücher ab 1719 - gelten, ${ }^{2600}$ gerade für die frühen Hinweise auf den Anschluss der Papiermacher an die Schneider von 1519 und 1525 ist eine solche Separierung jedoch nicht $\mathrm{zu}$ beobachten. Ob dies nun tatsächlich etwas über die Integration dieses Gewerbes in die betreffende Zunft aussagt, sei dahingestellt. Aber ebenso wenig kann man anhand der Anordnung in den verschiedenen Listen eine fehlende Einbindung der Papierer ausmachen.

Das Problem, dass neue Handwerke und Gewerbe in ein bestehendes Zunftsystem eingegliedert werden mussten, stellte sich nicht nur für das Papiergewerbe. Daher nahmen viele der acht spätestens seit der Mitte des 15. Jahrhunderts existierenden Ravensburger Zünfte - Bäckerzunft, Metzgerzunft, Rebleutezunft, Schmiedezunft, Schneiderzunft, Schuhmacherzunft, Weberzunft und Zimmerleutezunft - neben dem namensgebenden Handwerk auch mehr oder weniger verwandte Berufe auf. ${ }^{2601}$ So führte die immer stärkere Spezialisierung auch in Ravensburg dazu, dass sich innerhalb der Zünfte Untergruppen bildeten. Nach dem Dreißigjährigen Krieg fungierte gerade die Schneiderzunft, ähnlich wie die Safranzunft zu Basel, als ein Sammelbecken unterschiedlicher Handwerke. ${ }^{2602}$ Bereits in der ersten Hälfte des 16. Jahrhun-

2596 StR, Bü 488c/1/1, [3v, 4v, 5r].

2597 StR, Bü 488c/1/1, [3r].

2598 Vgl. Kapitel 3.3.3.2, S. 385.

2599 Vgl. Halstrick 1990, 49.

2600 Vgl. Sporhan-Krempel 1953, 70 f.; Halstrick 1990, 49.

2601 Vgl. Dreher 1972, Bd. 2, 471.

2602 Vgl. Dreher 1972, Bd. 2, 507-510. 
derts traten vermutlich Kleinhändler und Krämer den Schneidern bei. ${ }^{2603}$ In Bern ist ein Papiermacher, Michel Warmund, 1478 in der Schneider- und Tuchschererzunft zum Mohren fassbar. ${ }^{2604}$

Im Straßburger Fall ist bemerkenswert, dass sich die Papiermacher der ersten Papiermühle beim Rosengarten offenbar keiner der $\mathrm{zu}$ dieser Zeit bestehenden 28 Zünften anschlossen. ${ }^{2605}$ Weder eigene Recherchen noch die für das Straßburger Zunftwesen im Mittelalter äußerst instruktive Studie von Sabine von Heusinger ergaben Indizien für eine Zunftzugehörigkeit der Papiermacher in der Mitte des 15. Jahrhunderts. ${ }^{2606}$ Für das beginnende 16. Jahrhundert lassen sich anhand der Bürgerbücher zwei Papiermacher greifen, die sich parallel zu ihrer Aufnahme ins Bürgerrecht einer Zunft anschlossen - allerdings wählten die beiden nicht dieselbe Korporation. Im Jahr 1510 trat der Papiermacher Wolff Stierlin der Zunft zum Spiegel bei, der Vereinigung der Krämer und Kaufleute. ${ }^{2607}$ Diese bildeten zusammen mit den Gürtlern, Hutmachern, Säcklern und Täschnern eine politische Sammelzunft, allerdings unterhielten die Kaufleute eine separate Trinkstube Zum großen Spiegel, während die Handwerksberufe sich im Kleinen Spiegel trafen. ${ }^{2608}$

Es ist nicht bekannt, wie Wolff Stierlin sich in die Zunft integrierte, welche Rechte und Pflichten er wahrnehmen durfte beziehungsweise musste und aus welchen Gründen er die Zunft zum Spiegel wählte. Sein Berufsgenosse Hans Volpis entschied sich nämlich sieben Jahre später, im Oktober 1517, für die Zunft zur Stelz, ${ }^{2609}$ in der sich seit dem Aufkommen des Buchdrucks neben Goldschmieden, Malern und Schiltern auch Drucker, Buchbinder, Kartenmacher und Formenschneider befanden. ${ }^{2610}$ In Hinblick auf die Verwandtschaft der Berufe erscheint diese Wahl plausibler. Offensichtlich hatten die Papiermacher zu Beginn des 16. Jahrhunderts keine „Stammzunft“. Da nur diese beiden Papiermacher als Straßburger Bürger bekannt sind, gab es bis ins Jahr 1550 vermutlich, wenn überhaupt, nur sehr wenige andere Berufskollegen, die in eine Zunft eintraten.

Der erste Betreiber der städtischen Papiermühle auf dem Werd in Zürich, Eustach Froschauer, Bruder des Pächters und Buchdruckers Christoph Froschauer, war bei den Krämern zum Safran zünftig. Wahrscheinlich konnten die Papierer - wie auch

2603 Vgl. Dreher 1972, Bd. 2, 507.

2604 Vgl. J. Lindt 1964, 78. Zur Zunft zum Mohren vgl. Gerster 1870.

$2605 \mathrm{Zu}$ der Anzahl der Straßburger Zünften im Jahr 1444 vgl. Schulz 1985b, 39; Alioth 1988, Bd. 1, 321; Mariotte 2000, 122; Heusinger 2009, 206.

2606 So führt von Heusinger die Papiermacher überhaupt nicht in der Zusammenstellung der Berufe und ihrer Zuordnung zu einer Zunft auf, vgl. Heusinger 2009, 349-355.

2607 Vgl. Le livre de bourgeoisie de la ville de Strasbourg 1954, Bd. 2, 588, Nr. 6006.

2608 Vgl. Heusinger 2009, 351.

2609 Vgl. Le livre de bourgeoisie de la ville de Strasbourg 1954, Bd. 2, 640, Nr. 6682.

2610 Vgl. Ch. Schmidt 1882, 78 f.; Mariotte 2000, 122; Heusinger 2009, 350. 
die Buchdrucker - ihre Zunft mehr oder minder frei wählen. ${ }^{2611}$ Über eine Zunftzugehörigkeit der beiden Papiermacher Heinrich Walchwiler und Hans Conrad Grebel, die die Mühle Ende des 15. Jahrhunderts in Privatbesitz hatten, ist nichts bekannt. Auch in Kempten waren Papiermacher in der örtlichen Krämerzunft zu finden. ${ }^{2612}$ Ebenfalls der Zunft der Krämer schlossen sich die Reutlinger Papiermacher an. ${ }^{2613}$ Dieser Zuordnung spricht Christoph Halstrick ebenfalls eine bloße verwaltungstechnische Bedeutung zu. ${ }^{2614}$ Im Fall Reutlingen begründet er diese These damit, dass die Papiermacher mit der Papiermacherordnung von 1527 eine eigene Zunft gebildet hätten, die vom Rat anerkannt wurde und somit der Anschluss an eine andere Zunft eigentlich obsolet war. Lediglich aus der verwaltungsökonomischen Praxis heraus habe man die Papiermacher, die sich als Korporation noch nicht behauptet hätten, auch weiterhin zu den Krämern gezählt. Diese Ansicht basiert auf der Annahme, dass die Zunft lediglich ein gewerblicher Verband war und dementsprechend nur gewerberegelnde Funktionen erfüllte. Mit der Gründung einer eigenen gewerblichen Organisation sei - diesem Ansatz zufolge - dann jede Angliederung an eine andere Zunft hinfällig geworden.

Eine andere Sichtweise eröffnet sich hingegen, wenn man die Zunft als Korporation mit vielfältigen Aufgaben und Funktionen sieht. Besonders die für die spätmittelalterliche Stadt so wichtige politische Funktion setzt eine relativ hohe Beständigkeit und Stabilität in der Anzahl der Zünfte voraus. Neue Handwerke und Gewerbe mussten sich in Hinblick auf diese politische Funktion oftmals in eine bereits bestehende Zunft eingliedern. Hier waren sie ebenso wie die anderen Zünftigen ordentliche Mitglieder, die sich zudem noch in die jeweilige Trinkstube einkauften und an den karitativen Aufgaben der Bruderschaft partizipierten. All dies schloss nicht aus, dass neue Berufe, die nicht von den bisherigen gewerblichen Regelungen ,ihrer“ Zunft erfasst wurden, sich eine eigene Gewerbeordnung gaben. So waren die Reutlinger Papiermacher vermutlich vollwertige Mitglieder der Krämerzunft. Die von Halstrick als Ausdruck einer Zunftbildung verstandene Papiermacherordnung von 1527 ist in dieser Perspektive eine Handwerksordnung, der politische und militärische Elemente völlig fehlen. Wenn ein Papiermacher in Reutlingen wie andernorts eine Integration in die Stadt anstrebte, musste er sich einer der bestehenden Zünfte anschließen.

2611 Vgl. Zürcher 1963a, 83 f.

2612 Vgl. Petz 2006, 277.

2613 Vgl. Sporhan-Krempel 1972b, 1521.

2614 Vgl. Halstrick 1990, 49. 


\subsubsection{Vermögensverhältnisse}

Der häufig praktizierte Verkauf von Renten, der entweder direkt zur Finanzierung eines Papiermühlenkaufs oder aber zur Aufrechterhaltung des laufenden Betriebs getätigt wurde, macht deutlich, dass die Papiermacher einen erhöhten Geldbedarf hatten, den sie nicht alleine $\mathrm{zu}$ decken vermochten. ${ }^{2615}$ Um eine Papiermühle $\mathrm{zu}$ kaufen, sie anschließend instand zu halten und die benötigten Rohstoffe zu besorgen, war der Papiermacher häufig auf die Unterstützung von finanzkräftigen Kaufleuten oder anderen Kapitalgebern angewiesen. ${ }^{2616}$ Vor diesem Hintergrund stellt sich die Frage nach der persönlichen finanziellen Situation der Papiermacher. Sind sie aufgrund des hohen Kreditbedarfs als arm zu bezeichnen? Konnte man mit der Papiermacherei zu Vermögen kommen? Und wie gestalteten sich die Vermögensverhältnisse innerhalb dieses Berufs?

Um die finanzielle Situation von Papierern zu ermitteln, ist neben der Untersuchung von Rentenverkäufen die Analyse von städtischen Steuerbüchern von großem Wert. In diesem Kapitel sollen die aus dem Untersuchungszeitraum erhaltenen Steuerbücher von Basel und Ravensburg ausgewertet werden. Unter Steuerbüchern werden dabei die Verwaltungsschriften verstanden, die die Entrichtung einer Vermögenssteuer nach Personen verzeichnen. ${ }^{2617}$ Wenn es nicht bereits explizit angegeben ist, lässt sich das Vermögen des betreffenden Steuerzahlers anhand der dort notierten Steuersumme und des Steuersatzes errechnen. Die spätmittelalterliche Vermögenssteuer, die oft mit einer Personalsteuer verknüpft war, war eine direkte Besteuerung des persönlichen Vermögens und umfasste sowohl Liegenschaften als auch bewegliche Güter. Der Zeitraum der Erhebung sowie der Steuersatz waren von Stadt zu Stadt verschieden. Während beispielsweise in Ravensburg seit dem 14. Jahrhundert eine jährliche Vermögenssteuer erhoben wurde, beschloss der Basler Rat im 14. und 15. Jahrhundert nur im Bedarfsfall - vorwiegend zur Finanzierung kriegerischer Auseinandersetzungen - und für einen begrenzten Zeitraum eine direkte Steuer.

\subsubsection{Basel}

Die finanziellen Verhältnisse, in denen die Basler Papiermacher lebten, sind nur für einen kleinen Teil der in der Papierherstellung tätigen Personen zu eruieren, da die Basler Steuerbücher des 15. Jahrhunderts lediglich die Papiermacher namentlich aufführen, die entweder ein Haus oder zumindest einen eigenen Hausstand besaßen. ${ }^{2618}$

2615 Vgl. Kapitel 3.2.4.

2616 Vgl. Bockwitz 1939, 14, 16; Schlieder 1966, 110 f., 131 f.; Zaar-Görgens 2004, 81.

2617 Zur Vermögenssteuer vgl. Heidenhain 1906; Erler 1939, 15-89. Zu Steuerbüchern als Stadtbuchtyp vgl. Vogeler 2003 u. Vogeler 2004.

2618 Die maßgebliche Arbeit zu den außerordentlichen Steuererhebungen sowie den Basler Steuerbüchern legte Gustav Schönberg 1879 vor, vgl. Schönberg 1879. Die folgenden allgemeinen Ausführungen zu den Basler Steuern basieren daher auf seinem Werk. 
Handelt es sich bei der erhobenen Steuer um eine Vermögenssteuer, kann anhand der Steuersumme auf das versteuerte Vermögen der betreffenden Person geschlossen werden. Häufig wurde der Vermögenswert auch direkt angegeben. Als Ergänzung zu den Steuerbüchern wird zudem der Liegenschaftsbesitz von Papiermachern betrachtet.

Die Betrachtung der Vermögensverhältnisse der Basler Papiermacher anhand der Steuerverzeichnisse kann bedauerlicherweise nur für die erste Hälfte des Untersuchungszeitraums erfolgen, da von 1497 bis 1798 - mit einer Ausnahme während des Dreißigjährigen Kriegs - keine direkten Steuern erhoben wurden. ${ }^{2619}$ Im 15. Jahrhundert wurden in Basel sechs Mal für einen begrenzten Zeitraum außerordentliche Steuern erhoben, die jeweils auch eine Vermögenssteuer enthielten. ${ }^{2620}$ Für die vorliegende Untersuchung sind fünf dieser außerordentlichen Steuern von Interesse.

Die erste Steuer, die nach der Einführung der Papiermacherei in Basel erhoben wurde, wurde im Jahr 1446 als eine kombinierte Abgabe aus einer Vermögenssteuer und einer Personalsteuer beschlossen. ${ }^{2621}$ Die Steuerbücher wurden 1446 für fünf Steuerbezirke geführt: Kleinbasel, St. Leonhard, St. Martin, St. Peter sowie St. Alban und St. Ulrich. Für Kleinbasel, dem Standort der zu dieser Zeit einzigen Papiermühle Basels, der Allenwindenmühle, fehlen Erwähnungen von Papiermachern völlig. ${ }^{2622}$ Einzig der Besitzer der Mühle lässt sich in dem Steuerbuch für St. Martin fassen. Der Eintrag zu Heinrich Halbysen d. Ä. ist in einem aus zwei Teilen zusammengefügten und nur fragmentarisch auf uns gekommenen Codex enthalten. ${ }^{2623}$ Mit Heinrich Halbysen d. Ä. steuerten sein Sohn Heinrich Halbysen d. J. mit seiner Familie, sein Sohn Jacob mit seiner Frau sowie ein Knecht und drei Dienstmägde. ${ }^{2624}$ Nach der Steuerverordnung muss sich das Vermögen der Familie Halbysen auf ungefähr 12.000

2619 Vgl. Staehelin 1982, 19.

2620 Vgl. Schönberg 1879, 4.

2621 Vgl. Schönberg 1879, 189, 207-210.

2622 StABS, Steuern B 7 (1446).

2623 StABS, Steuern B 3 (1446). Während die ersten und die letzten fünf Blätter mit lediglich 112 verzeichneten Namen nur einen Bruchteil des Steuerbuchs von St. Martin darstellen, waren die dazwischen eingebundenen 30 Folia vermutlich für Aufzeichnungen zum Steuerbezirk St. Peter gedacht, wie der Titel des Steuerbuchs vermuten lässt. Sie blieben bis auf einzelne Überschriften unbeschrieben. Vgl. Schönberg 1879, 238-240. Sichtbar wird dies auch an dem verwendeten Papier. Die ersten und die letzten fünf Blätter bestehen aus anderem Papier als die mittleren Lagen. Während die einen einen Ochsenkopf als Wasserzeichen aufweisen, sind die anderen mit einem halben Hufeisen versehen, wobei zudem das Papier mit dem Hufeisen dicker ist. Das halbe Hufeisen war das Wasserzeichen der Familie Halbysen und stellt ein sprechendes Motiv dar, das auf den Familiennamen verweist, vgl. W. Fr. Tschudin 1955, 2 f.; W. Fr. Tschudin 1958, 104 f.; Kälin 1974, 206. Die Verbindung des Namens Halbysen mit einem halben Hufeisen findet sich in der Beschreibung des Grabmals von Heinrich Halbysen d. Ä. wieder. Auf dessen Grabplatte im Basler Münster war ein halb rosysen in den Stein gehauen, vgl. Kälin 1974, 149.

2624 StABS, Steuern B 3, [9 von hinten]. Vgl. Kapitel 3.3.1.1., Anm. 2066. 
Gulden belaufen haben. ${ }^{2625}$ Wer davon welchen Anteil besaß, kann nicht eruiert werden. ${ }^{2626}$

Das erste Mal explizit Erwähnung finden Papiermacher in den Steuerbüchern des Jahres 1451. Im Herbst des betreffenden Jahres wurde eine neue außerordentliche Steuer angeordnet, die für zwei Jahre erhoben werden sollte. Sie war ebenfalls eine kombinierte Steuer bestehend aus einer Vermögenssteuer, einer partiellen Personalsteuer und einer partiellen Einkommenssteuer. Dazu kamen noch drei weitere außerordentliche Steuern, nämlich eine Weinsteuer, eine Fleischsteuer und ein sogenannter neuer Pfundzoll. ${ }^{2627}$ Für die Ermittlung des Vermögens interessiert an dieser Stelle vor allem die kombinierte sogenannte Markzahlsteuer. ${ }^{2628}$ Sie musste von allen weltlichen, in der Stadt Basel oder ihren Ämtern ansässigen und dem Stadtrecht unterworfenen Personen geleistet werden, die ein eigenes Vermögen besaßen. ${ }^{2629}$ Hiervon ausgenommen waren Dienstleute, die weder Bürger der Stadt noch dort geboren waren und sich erst seit kurzem in Basel aufhielten. Sie mussten nicht ihr gesamtes Vermögen versteuern, sondern nur den Teil, den sie in Basel bei sich hatten.

Alle Einwohner, die eigentlich vermögenssteuerpflichtig waren, aber kein Vermögen versteuern konnten, mussten stattdessen eine Kopfsteuer von einmalig 4 Schilling zahlen. ${ }^{2630}$ Zudem mussten Gesellen, Knechte und Dienstmägde, die entweder Basler Bürger oder Hintersassen, gebürtige Basler oder schon lange in Basel ansässig waren, aber kein besteuerbares Vermögen besaßen, wie auch fremde Dienstleute im Rahmen einer „Einkommenssteuer“ einmalig eine Summe in der Höhe ihres Wochenlohns entrichten. ${ }^{2631}$ Die Zahlung der Vermögenssteuer erfolgte in Vermögensklassen. ${ }^{2632}$

Von der Markzahlsteuer des Jahres 1451 sind nur aus zwei von fünf Bezirken die Steuerbücher erhalten, nämlich aus St. Leonhard sowie - glücklicherweise - aus St. Alban und St. Ulrich. ${ }^{2633}$ Für die Suche nach Papiermachern ist vor allem das letzte Steuerbuch relevant, da zu dieser Zeit bereits zwei Papiermühlen, die Rychmühle und die Zunzigermühle, im St. Albantal arbeiteten. Die Gliederung des Steuerbuchs erfolgte nach der klassischen Reihenfolge der Zünfte. Nach der Niederschrift der Steuerordnung wurden zunächst die Mitglieder der vier Herrenzünfte aufgelistet,

2625 StABS, Steuern B 3, 7. Vgl. auch Schönberg 1879, 205.

2626 Vgl. hierzu auch Piccard 1967, 43.

2627 Vgl. Schönberg 1879, 257.

2628 Der Begriff Markzahl verweist auf eine proportionale, anteilsmäßige Besteuerung, vgl. Deutsches Rechtswörterbuch 1992-1996, Bd. 9, 299-301; Erler 1939, 31.

2629 Vgl. Schönberg 1879, $272 \mathrm{f}$.

2630 Vgl. Schönberg 1879, $287 \mathrm{f}$.

2631 Vgl. Schönberg 1879, 288.

2632 StABS, Steuern B 8, 2r. Vgl. auch Schönberg 1879, 260 f., 284-287.

2633 StABS, Steuern B 8 (1451, St. Alban und St. Ulrich), B 9 (1451, St. Leonhard). Vgl. Schönberg 1879, 257. 
danach die Handwerkszünfte mit den Schiffleuten und Fischern als Schlusslicht. Darauf folgen als eine eigene Kategorie die Dienstknechte und die Dienstjungfrauen. Anschließend werden diejenige Steuerpflichtigen aufgeführt die nit zunffte hand, das heißt, die in keiner Zunft Mitglied waren, aber auch nicht dienten. ${ }^{2634}$ Neben der Markzahlsteuer, die zusammen mit dem Namen des Steuerzahlenden auf den VersoSeiten vermerkt ist, wurde dieses Steuerbuch auch für die Weinsteuer verwendet, für die die Recto-Seiten reserviert waren.

Unter die Personen, die keiner Zunft angehörten, fiel auch ein namentlich nicht genannter Papiermacher mit seinen zwei Knechten. ${ }^{2635}$ Sie besaßen kein besteuerbares Vermögen, wie der Vermerk hant nut hinter den Namen beweist, und zählten damit zu den „Habenichtsen“, denn in das besteuerbare Vermögen fielen nicht nur liquide Geldbeträge, sondern alles fahrende und liegende Gut, das sich im Besitz der steuerpflichtigen Person befand, darunter auch kleyder, silbergeschirr und hußrate nutzit ußgenommen. ${ }^{2636}$ Ihre Steuerleistung lag insgesamt bei einem Gulden. Wie sich dieser Gulden genau auf die einzelnen Personen und die Steuerarten - Personalsteuer und „Einkommenssteuer“ - verteilte, ist nicht bekannt.

Bei den nächsten von der Stadt Basel erhobenen außerordentlichen Steuern können in den Steuerbüchern bereits deutlich mehr Papiermacher - auch namentlich - festgemacht werden. Sie sind in dem Markzahlsteuerbuch von St. Martin, St. Alban und St. Ulrich zu finden. ${ }^{2637}$ Die Markzahlsteuer wurde im Jahr 1453/54 als eine kombinierte Vermögens- und Personalsteuer für vier Jahre beschlossen und anschließend weitere vier Jahre - bis 1460/61 - verlängert, jedoch mit einem um die Hälfte reduzierten Steuersatz. ${ }^{2638}$ Steuerpflichtig waren alle weltlichen Personen, die ein Haus besaßen oder einen eigenen Haushalt führten. Dies galt auch für Knechte und Mägde, insofern sie einem eigenen Haushalt vorstanden. ${ }^{2639}$ Wer kein Vermögen besaß, aber steuerpflichtig war, der musste eine Personalsteuer von einem Schilling jährlich in den ersten vier Steuerjahren und von 6 Pfennig jährlich in den nächsten vier Steuerjahren entrichten. Die Vermögenswerte wurden auch bei dieser Steuer in Klassen

2634 StABS, Steuern B 8 (1451). Das Steuerbuch ist ungefähr 100 Blatt stark und trägt keine Foliooder Seitenzählung.

2635 StABS, Steuern B 8 (1451): Item der papiren macher und sin knecht sind dryg - hant nut - sollent i gulden. Eine leichte Unsicherheit besteht in der Frage, ob alle Personen zusammen oder nur die Knechte drei an der Zahl sind. Plausibler erscheint jedoch, dass mit der Nennung der Zahl 3 alle Personen einschließlich des Papiermachers gemeint sind, da auf dieser Grundlage die Steuer berechnet wurde.

2636 StABS, Steuern B 8, 1r.

2637 StABS, Steuern B 12, Markzahlsteuer 1453/54-1456/57, ohne Blattzählung; Markzahlsteuer 1457/58-1460/61, ohne Blattzählung. Diese Bezirke bildeten diesmal einen der lediglich zwei Großbasler Steuerbezirke, vgl. Schönberg 1879, $348 \mathrm{f}$.

2638 Vgl. Schönberg 1879, 348.

2639 Vgl. Schönberg 1879, 352, 357 f. 
eingeteilt, wobei allerdings der in den Steuerordnungen angegebene Steuersatz der Vermögenswerte zwischen 10 und 100 Gulden nach Gustav Schönberg nicht dem tatsächlich erhobenen Steuersatz entspricht. ${ }^{2640}$

Für Vermögenswerte über 100 Gulden sind, so Schönberg, die Angaben der Steuerverordnung von 1453 verlässlich. ${ }^{2641}$ Diese besagt, dass von den ersten 100 Gulden vorab ein Ort und als eigentliche Markzahl noch einmal ein Ort zu geben sei, dementsprechend für 100 Gulden 2 Ort (gleich einem halben Gulden), für 200 Gulden 3 Ort, für 300 Gulden 4 Ort (gleich ein Gulden) und so weiter. ${ }^{2642}$ Anhand dieser Angaben soll im Folgenden das Vermögen der im St. Albantal steuernden Papiermacher in seiner ungefähren Höhe ermittelt werden.

Die Vermögensverhältnisse der steuernden Papiermacher gestalteten sich äußerst unterschiedlich, wobei auch diachrone Veränderungen der individuellen finanziellen Lage auftraten. Da in den Markzahlsteuerbüchern von 1453/54 bis 1460/61 lediglich die entrichtete Steuersumme und nicht das besteuerte Vermögen angegeben wird, muss dieses anhand der Steuerbeträge errechnet werden. Aufgrund der unklaren Angaben in der betreffenden Steuerordnung handelt es sich bei den ermittelten Vermögenswerten um Näherungswerte (vgl. Tab. 24 und 25).

Unter den sieben Papiermachern, die zwischen 1453 und 1461 steuerten, besaßen drei Personen entweder keinen besteuerbaren Besitz oder nur ein sehr geringes Vermögen unter 10 Gulden. ${ }^{2643}$ Es ist dies zum einen der Papiermachergeselle Peter, der zwar einen eigenen Haushalt führte und verheiratet war, aber in jedem der acht Steuerjahre nur einen Schilling in den ersten beziehungsweise 6 Pfennig in den letzten vier Jahren zahlte. Der Wert seines Besitzes lag daher unter 10 Gulden. Zum anderen ist dies Hans bapirer, der vermutlich mit Hans Gallician I, dem jüngsten der drei Gallicianbrüder, zu identifizieren ist. Er steuerte in den Jahren 1459/60 und 1460/61 ebenfalls in der niedrigsten Steuerklasse. Der dritte Papiermacher, Passion (Bastian), entrichtete 1459/60 noch den Grundsteuersatz von 6 Pfennig. Im darauffolgenden Jahr wurde neben seinem Namen das Wort nichel vermerkt: Zu diesem Zeitpunkt konnte er offenbar noch nicht einmal die für die Personalsteuer erforderlichen 6 Pfennig aufbringen.

2640 Vgl. Schönberg 1879, 359-380. Für den von Schönberg anhand der tatsächlich gezahlten Steuern errechneten Steuersatz vgl. ebd., $373 \mathrm{f}$.

2641 Vgl. Schönberg 1879, 360.

2642 StABS, Steuern B 12, Markzahlsteuer 1453/54-1456/57, Vorwort; Markzahlsteuer 1457/58-1460/61, Vorwort. Vgl. Schönberg 1879, $354 \mathrm{f}$.

2643 Während die Personen ohne Vermögen eine Personalsteuer von einem Schilling respektive 6 Pfennig zu entrichten hatten, zahlten die Steuerpflichtigen mit einem Vermögen unter 10 Gulden den gleichen Betrag als Vermögenssteuer, vgl. Schönberg 1879, 353. 

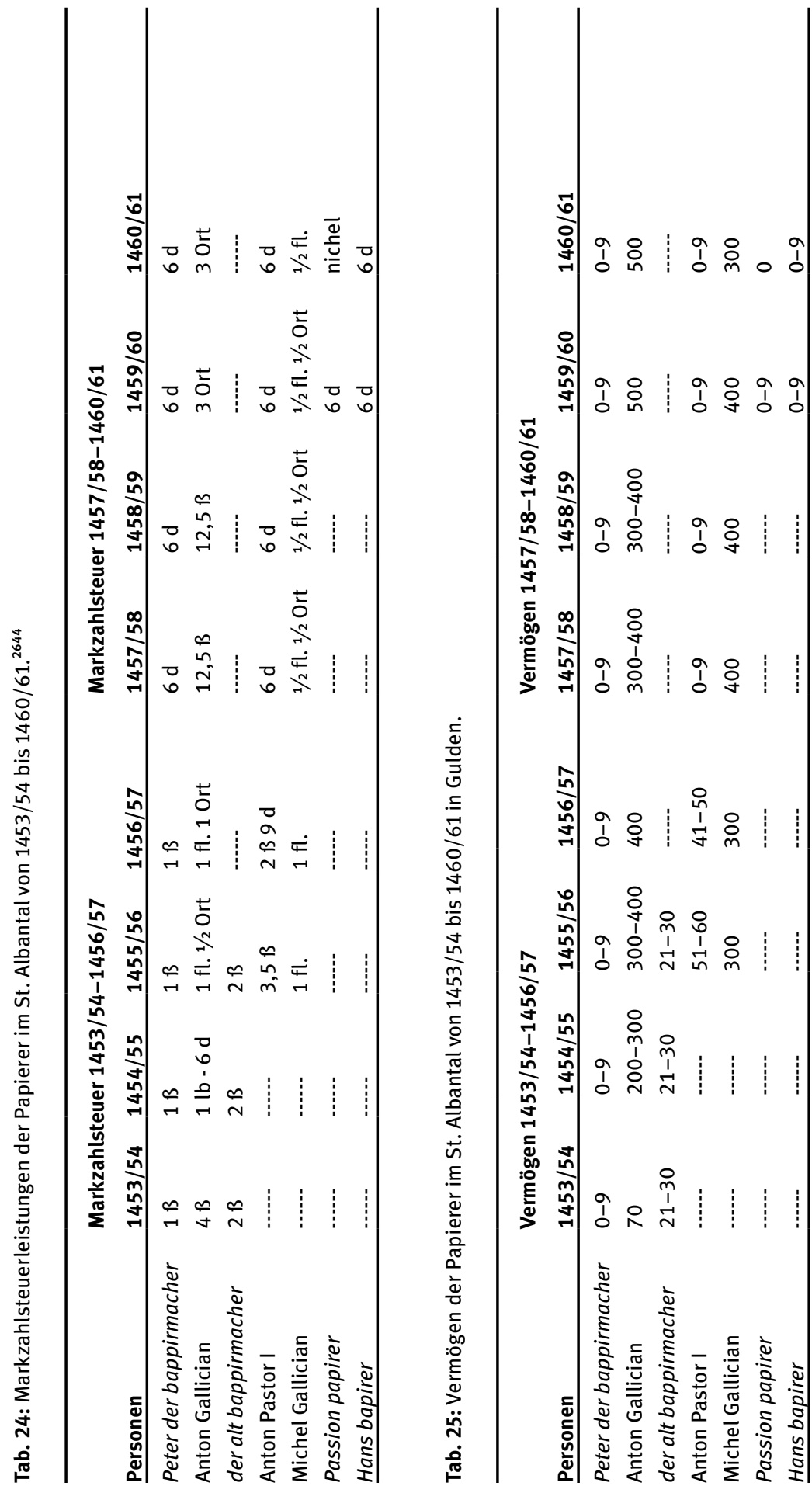

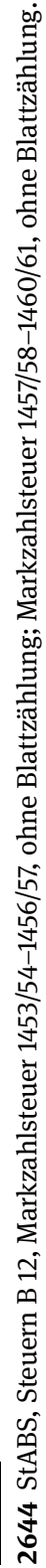


Die finanziellen Verhältnisse von Anton Pastor I, der im Jahr 1454 möglicherweise noch als Geselle im Haushalt von Meister Andres lebte und sich erst danach mit einer eigenen Haushaltung selbstständig machte, scheinen sich über den Steuerzeitraum hinweg verschlechtert zu haben. ${ }^{2645}$ Versteuerte er 1455/56 und 1456/57 noch ein Vermögen zwischen 41 und 60 Gulden, ${ }^{2646}$ wobei hier schon eine Abnahme der besteuerten Summe zu verzeichnen ist, so zahlte er in den letzten vier Jahren der Steuer nur den Grundsteuersatz von 6 Pfennig. Folglich muss sich der Wert seines Besitzes auf unter 10 Gulden verringert haben. Der alt bappirmacher, der vermutlich identisch mit dem im Schillingsteuerverzeichnis von 1454 erwähnten Meister Andres ist, entrichtete in den ersten drei Steuerjahren bis 1455/56 jährlich 2 Schilling. ${ }^{2647}$ Das nach der Steuerordnung berechnete Vermögen beliefe sich auf 21 bis 30 Gulden, während der nach Schönberg berechnete Vermögenswert lediglich zwischen 11 und 20 Gulden läge. In jedem Fall man wird seine finanziellen Verhältnisse als bescheiden bezeichnen können.

Damit versteuerten fünf von sieben Papiermachern ein eher geringes Vermögen, das unter 60 Gulden lag. Die Brüder Anton und Michel Gallician hingegen besaßen jeweils ein Vermögen von mehreren 100 Gulden. Im ersten Steuerjahr zahlte Anton Gallician lediglich 4 Schilling. Dies entsprach nach der Steuerordnung einem Vermögenswert zwischen 61 und 70 Gulden, nach der Neuberechnung der Vermögensklassen durch Schönberg jedoch nur einem Vermögenswert von 31 bis 40 Gulden. Für das nächste Steuerjahr 1454/55 ist dann ein sprunghafter Anstieg zu verzeichnen: Die Steuerzahlung von einem Pfund minus 6 Pfennig muss einem Vermögen zwischen 200 und 300 Gulden entsprochen haben. ${ }^{2648}$ Auch in den beiden Folgejahren lässt sich ein weiterer Anstieg beobachten. Liegt Anton Gallicians Vermögen 1455/56 bereits zwischen 300 und 400 Gulden, so bedeutet die 1456/57 gezahlte Steuersumme von einem Gulden und einem Ort ein Vermögenswert von 400 Gulden. In den nächsten zwei

2645 Das Jahr 1455 ist zugleich das Jahr, in dem Anton Pastor I die Safranzunft kaufte. Zu diesem Zeitpunkt war er bereits, vermutlich relativ frisch, mit Margret Tschan verheiratet. Dies lässt sich daran erkennen, dass sein Bürge beim Zunftkauf zunächst sein swecher Walter Tschan war. Die Vermutung, dass Anton Pastor bei Meister Andres in einer der Papiermühlen von Heinrich Halbysen d. J. tätig war, ergibt sich daraus, dass Heinrich Halbysen d. J. die ausstehenden Raten der Zunftgebühr für Anton Pastor bezahlte. Anton Pastor hatte folglich vor 1454 als Geselle in einer der Papiermühlen von Heinrich Halbysen d. J. unter Meister Andres angefangen zu arbeiten, hatte dort bis zu seiner Heirat auch gewohnt und gründete danach einen eigenen Hausstand.

2646 Nach den von Schönberg berechneten Steuersätzen besaß Anton Pastor I lediglich ein Vermögen von 21 bis 30 Gulden.

2647 StABS, Steuern B 15, 7r; Steuern B 12, Markzahlsteuer 1453/54-1456/57, ohne Blattzählung. Vgl. Anm. 1985.

2648 Der Steuerbetrag von einem Pfund minus 6 Pfennig, id est 19,5 Schilling, ist nicht in der Steuerordnung enthalten, liegt aber zwischen den drei Ort (gleich 17 Schilling 3 Pfennig), die für 200 Gulden entrichtet werden mussten, und dem einen Gulden (gleich ein Pfund 3 Schilling), der für ein Vermögen von 300 Gulden gezahlt werden musste. 
Steuerjahren stagniert der Vermögenswert zwischen 300 und 400 Gulden, ${ }^{2649}$ um sich in den Steuerjahren 1459/60 und 1460/61 auf 500 Gulden zu erhöhen. Damit kann Anton Gallician - noch vor seinem Bruder Michel Gallician, der ab 1455/56 zwischen 300 und 400 Gulden versteuerte - als der wohlhabendste unter den Papiermachern bezeichnet werden.

Die letzte für diese Untersuchung relevante außerordentliche Steuererhebung wurde im September 1475 für einen Zeitraum von sechs Jahren beschlossen. Anlass für diese Steuer waren die immensen Ausgaben während der sogenannten Burgunderkriege, in denen Basel an der Seite der Eidgenossen gegen den Herzog von Burgund, Karl den Kühnen, kämpfte. ${ }^{2650}$ Neben einer Fleischsteuer wurde eine Personalsteuer in Form der Schillingsteuer und eine Vermögenssteuer erlassen. ${ }^{2651}$

Die Markzahlsteuer von 1475 war, wie die vorangegangenen Markzahlsteuern, eine kombinierte Steuer aus einer Vermögens- und einer Personalsteuer. Letztere Steuerform griff bei den Personen, die zwar steuerpflichtig waren, jedoch kein besteuerbares Vermögen besaßen. Sie mussten in den ersten vier Steuerjahren jährlich 5 Schilling, in den letzten zwei 2,5 Schilling entrichtet. ${ }^{2652}$ Steuerpflichtig waren zum einen alle in Basel ansässigen Personen mit einem eigenen Vermögen, so auch Dienstleute, zum anderen alle Personen, die einen eigenen Haushalt führten, auch wenn sie kein Vermögen nachweisen konnten. ${ }^{2653}$ Der Steuersatz belief sich für Vermögen unter 100 Gulden auf ein Prozent. Für einen Vermögenswert von 100 Gulden war ein Gulden zu entrichten, für Vermögen über 100 Gulden wurde für die ersten 100 Gulden ein Gulden, für die weiteren jeweils 5 Schilling veranschlagt. ${ }^{2654}$

Von den fünf bereits bekannten Steuerbezirken sind lediglich die Steuerbücher von drei Bezirken erhalten, darunter auch das Steuerbuch des St. Alban-Ulrichkirchspiels. ${ }^{2655}$ Für die Markzahlsteuer wurde jedes Jahr eine neue Liste angelegt, in der die Namen der steuerpflichtigen Personen, der besteuerte Vermögenswert sowie der entrichtete Betrag aufgeführt wurden. Jeweils zwei Listen wurden zu einem Buch zusammengebunden, sodass insgesamt drei Steuerbücher für die Jahre 1475/76 bis 1480/81 existieren. ${ }^{2656}$ In der gleichen Weise wurde bei der Schillingsteuer verfahren: Auch

2649 Der Steuersumme von 12,5 Schilling entspricht leider keine Angabe in der Steuerordnung. Da die 12,5 Schilling zwischen dem halben Gulden (gleich 2 Ort, gleich 11,5 Schilling) für 300 Gulden Vermögen und dem zweieinhalb Ort (ungefähr 14 Schilling 4 Pfennig) für 400 Gulden Vermögenswert liegen, lässt sich auf ein Vermögen zwischen 300 und 400 Gulden schließen.

2650 StABS, Steuern B 19, Markzahlsteuer 1475/76-1476/77, 1v. Vgl. auch Schönberg 1879, 448 f., $493-$ 501. Zu den Burgunderkriegen vgl. Sieber-Lehmann 1995, bes. 45-161.

2651 Zur Auswertung der Schillingsteuerbücher vgl. Kapitel 3.3.1.1.

2652 Vgl. Schönberg 1879, 460.

2653 Vgl. Schönberg 1879, $459 \mathrm{f}$.

2654 StABS, Steuern B 19, Markzahlsteuer 1475/76-1476/77, 1v. Vgl. Schönberg 1879, 450, 461.

2655 StABS, Steuern B 19. Vgl. auch Schönberg 1879, 457.

2656 Vgl. Schönberg 1879, 457 f. 
hier wurde für jedes Steuerjahr eine neue Liste begonnen und die sechs so entstandenen Hefte zu drei Büchern vereint. Die interne Gliederung orientiert sich nach den im Steuerrundgang absolvierten Straßen.

Im Vergleich zu der Markzahlsteuer von 1453/54 bis 1460/61 lassen sich die Namen zweier Papiermacher nicht mehr in den Steuerbüchern finden: Es ist dies zum einen Anton Pastor I und zum anderen Hans bapirer, der wahrscheinlich mit Hans Gallician I zu identifizieren ist. ${ }^{2657} \mathrm{Zu}$ den bereits bekannten Papiermachern treten jedoch noch weitere Namen hinzu, sodass für die sechsjährige Steuerperiode insgesamt 13 steuerpflichtige Papierer ausgemacht werden konnten. Fünf davon konnten kein besteuerbares Vermögen aufweisen und mussten daher lediglich die Personalsteuer entrichten. Darunter zählten in den beiden ersten Steuerjahren der Papierergeselle Peter Fester und Jacob Parella, die vermutlich bei Ulrich Züricher respektive Anton Gallician angestellt waren, ${ }^{2658}$ sowie der Langmichel Gallician genannte Papierer, der offenbar auch zur Familie Gallician gehörte und Knecht von Michel Gallician war. Er steuerte auch noch im darauffolgenden Rechnungsjahr die 5 Schilling Personalsteuer. ${ }^{2659}$ Auch der Papiermacher Michel Reri, ${ }^{2660}$ der zum ersten Mal 1477/78 steuerte, gab nur die Personalsteuer, da er kein Vermögen besaß. ${ }^{2661}$ Ob es sich bei dem Papiererknecht Michel, der in den Markzahlsteuerbüchern der Jahre 1479/80 und 1480/81 verzeichnet ist, um Michel Reri, um (Lang-)Michel Gallician oder um eine dritte Person handelte, kann nicht entschieden werden. ${ }^{2662}$ Jedenfalls zahlte auch dieser Michel nur die Personalsteuer. Für das letzte Jahr der Steuerperiode ist sogar nur sein Name vermerkt, Angaben über seine Steuerleistung fehlen. In den letzten

2657 Hans Gallician I ist zuletzt anlässlich seines Bürgerrechtserwerbs 1461 belegt. Vermutlich verließ er Basel in den darauffolgenden Jahren, wie es Hans Kälin annimmt, oder er verstarb, wofür sich Gerhard Piccard ausspricht, vgl. Piccard 1967, 86 f.; Kälin 1974, 157 f.

2658 StABS, Steuern B 19, Markzahlsteuer 1475/76, 26v; Markzahlsteuer 1476/77, 48v, 49r. Vgl. Kapitel 3.3.1.1, S. $336 \mathrm{f}$.

2659 StABS, Steuern B 19, Markzahlsteuer 1475/76, 25v; Markzahlsteuer 1476/77, 46v; Markzahlsteuer 1477/78, 21v.

2660 Vgl. Anm. 2021-2023. Vgl. auch Kälin 1974, 203.

2661 StABS, Steuern B 19, Markzahlsteuer 1477/78, 21r; Markzahlsteuer 1478/79, 21r. Bemerkenswert ist, dass Michel Reri zu diesem Zeitpunkt vermutlich eine Liegenschaft im St. Albantal besaß. Im Januar 1479 verkaufte er nämlich sein Haus, das zwischen dem Haus von Alban Leimer und dem Haus von Lienhardt Spinner lag, an Michel Gallician, StABS, Gerichtsarchiv B 10, 273. Die Kaufsumme betrug 15 Gulden. Auf den ersten Blick erscheint erstaunlich, dass der Besitzer eines Hauses, das ja auch einen Vermögenswert darstellte, kein besteuerbares Vermögen aufweisen konnte. Dieses Missverhältnis klärt sich jedoch, wenn man bedenkt, dass der Steuersatz von einem Prozent, angewendet auf den Hauswert von 15 Gulden, weniger als die Grundsteuer von 5 Schilling ergab. Die Steuerordnung sah jedoch vor, dass für keinen Vermögenswert weniger als die Personalsteuer, folglich 5 Schilling, entrichtet werden sollte, vgl. Schönberg 1879, 461.

2662 StABS, Steuern B 19, Markzahlsteuer 1478/79, 21r; Markzahlsteuer 1479/80, 19v; Markzahlsteuer 1480/81, 20r. Vgl. Anm. 2025. 
beiden Steuerjahren kam als ein weiterer vermögensloser Papierergeselle Anton der bappirerknecht hinzu. ${ }^{2663}$

Der Papierergeselle Bastian, der durchaus plausibel sowohl mit Passion bapirer als auch mit Sebastian Franz ${ }^{2664}$ identifiziert werden kann, versteuerte im Jahr 1475/76 ein Vermögen von 35 Gulden und zahlte dafür 8 Schilling Abgaben. ${ }^{2665}$ Im nächsten Steuerjahr hatte er jedoch Basel verlassen. Sein Schwager, der Weber Friedrich Lemli, wurde dazu verpflichtet, die Steuerschuld von Bastian für die restlichen fünf Jahre zu erlegen. ${ }^{2666}$ Als Vermögenswert wurden 40 Pfund angegeben. Dies entspricht in etwa dem im Vorjahr angegebenem Betrag von 32 Gulden, wenn man davon ausgeht, dass in diesem Jahr ein Gulden einem Pfund und 5 Schilling gleichkam. ${ }^{2667}$ Damit hatte der Papierergeselle Bastian ein bescheidenes Vermögen zu versteuern. In derselben finanziellen Situation befand sich im letzten Steuerjahr der Papiermacher Diebolt Hanman, dessen Steuerzahlung von 4 Schilling ebenfalls ein Vermögen von 40 Pfund zugrunde lag. ${ }^{2668}$ Sowohl Bastian als auch Diebolt Hanman waren im Zeitraum der Steuererhebung Hausbesitzer im St. Albantal. ${ }^{2669}$ Daher ist davon auszugehen, dass der Liegenschaftswert einen Großteil ihres Vermögens ausmachte. Nachweisbar ist dies zumindest für Diebolt Hanman, der im Jahr 1478 ein Haus mit Hofstatt, gelegen zwischen der Pulverstampfe und der hinteren Schleife, für 34 Pfund kaufte. ${ }^{2670}$

Mit einem versteuerten Vermögen von 70 Gulden wurde Hans Züricher, der zuvor vermutlich noch im Haushalt seines Vaters Ulrich Züricher gelebt hatte und sich nun parallel zum Zunftkauf selbstständig machte, im Rechnungsjahr 1477/78 das erste Mal in die Steuerbücher eingetragen. In den darauffolgenden Jahren konnte er sein Vermögen auf 100 Pfund, das heißt ungefähr 87 Gulden, steigern. ${ }^{2671}$ Sein Vater Ulrich Züricher, seit 1470 Besitzer der Zunzigermühle, musste hingegen während der sechsjährigen Steuerperiode einen Verlust von mehr als der Hälfte seines Vermögens hinnehmen. Versteuerte er in den ersten zwei Jahren noch 200 Gulden, so blieb ihm in den letzten beiden nur mehr ein Guthaben von ungefähr 87 Gulden beziehungsweise

2663 StABS, Steuern B 19, Markzahlsteuer 1479/80, 19v; Markzahlsteuer 1480/81, 20r.

2664 Vgl. Anm. 2012, 2230.

2665 StABS, Steuern B 19, Markzahlsteuer 1475/76, 26r.

2666 StABS, Steuern B 19, Markzahlsteuer 1475/76-1476/77, 2v: Anno xxvi an zinstag nach Invocavit als Bastian der bappir macher hinweg ziehen wolt da gelopt und versprach Fridrich Lemli der Weber sin swager für den genanten Bastian für die stur und fronvasten gelt gnůg zetůnd was er schuldig wurde die funff kunfftigen jar. Auch StABS, Steuern B 19, Markzahlsteuer 1476/77, 49r. Vgl. Schönberg 1879, 460.

2667 Vgl. Rosen 1989, 145.

2668 StABS, Steuern B 19, Markzahlsteuer 1480/81, 20v.

2669 StABS, Gerichtsarchiv B 10, 92, 266. Vgl. Kälin 1974, 201.

2670 StABS, Gerichtarchiv B 10, 266. Vgl. Anm. 2026.

2671 StABS, Steuern B 19, Markzahlsteuer 1477/78, 21v; Markzahlsteuer 1478/79, 21r; Markzahlsteuer 1479/80, 20r; Markzahlsteuer 1480/81, 20v. 
100 Pfund. ${ }^{2672}$ Diese Abnahme des Vermögens mag bereits auf seinen sechs Jahre später erfolgten Konkurs hindeuten. Einen über die gesamte Steuerperiode konstant bei 100 Pfund liegenden Vermögenswert versteuerte der Papiermacher Hans Kielhammer von Schaffhausen. ${ }^{2673}$

Deutlichen und stetigen Gewinn machte Peter Höfflin, der zum Zeitpunkt der Steuereinziehung wahrscheinlich bereits als selbstständiger Meister in der hinteren Spiegelmühle arbeitete. Während er im ersten Rechnungsjahr 1475/76 bereits 200 Gulden Vermögen angab, erhöhte sich diese Summe im Folgejahr um 50 Gulden, im dritten Jahr um 100 weitere Gulden. Gegen Ende der Steuerperiode veranschlagte er den Wert seiner Habe mit 400 Gulden. ${ }^{2674}$ Damit verfügte er über ein ähnliches Vermögen wie Anton und Michel Gallician in der vorangegangenen Steuerperiode von $1453 / 54$ bis 1460/61. In der der zweiten Hälfte der 1470er-Jahre muss den beiden Brüdern dieser Vermögensbetrag jedoch nahezu lächerlich erschienen sein. Michel Gallician, der bereits im Jahr 1475/76 ein Vermögen von 1.000 Gulden versteuerte, steigerte sein Vermögen von 1.200 im darauffolgenden Jahr über $1.500 \mathrm{im}$ Jahr 1477/78 bis zu 1.700 Gulden in den letzten drei Steuerjahren. ${ }^{2675}$ Übertroffen wurde er nur von seinem älteren Bruder Anton Gallician. Dieser besaß in den ersten Jahren der Steuererhebung bereits 4.000 Gulden und konnte sein Vermögen bis auf 4.200 Gulden in den Jahren 1479/80 und 1480/81 mehren. ${ }^{2676}$

Anhand einer Zählung der steuernden Personen und ihrer Zuordnung zu Vermögensklassen, die Gustav Schönberg für das Rechnungsjahr 1475/76 vorgenommen hat, können die Vermögenswerte der Papiermacher in Relation zu denen der anderen steuerpflichtigen Einwohner Basels gesetzt werden. ${ }^{2677}$ Da nur für drei der fünf Steuer-

2672 StABS, Steuern B 19, Markzahlsteuer 1475/76, 25v; Markzahlsteuer 1476/77, 47v; Markzahlsteuer 1477/78, 21v; Markzahlsteuer 1478/79, 21r; Markzahlsteuer 1479/80, 20r; Markzahlsteuer 1480/81, 20v. Nicht ganz klar ist, ob der Schreiber Vater und Sohn Züricher als getrennt steuernde Personen listete. In den letzten beiden Steuerjahren versteuerten beiden ein Vermögen von 100 Pfund beziehungsweise 100 Gulden. Bei ihren Namen steht der Zusatz diß hand durcheinander bezalt. Ob einer der beiden für den anderen zahlte oder ob beide zusammen ein Vermögen von 100 Pfund respektive 100 Gulden versteuerten, wird nicht deutlich. Auch besteht die Möglichkeit, dass der Schreiber Vater und Sohn verwechselte. Im Jahr 1478/79 führte er bei Hans Züricher 240 Gulden auf, während Ulrich Züricher nur 50 Gulden versteuerte.

2673 StABS, Steuern B 19, Markzahlsteuer 1475/76, 22v; Markzahlsteuer 1476/77, 45r; Markzahlsteuer 1477/78, 19r; Markzahlsteuer 1478/79, 19r; Markzahlsteuer 1479/80, 17v; Markzahlsteuer 1480/81, 18v.

2674 StABS, Steuern B 19, Markzahlsteuer 1475/76, 25v; Markzahlsteuer 1476/77, 47v; Markzahlsteuer 1477/78, 21v; Markzahlsteuer 1478/79, 21r; Markzahlsteuer 1479/80, 19v; Markzahlsteuer 1480/81, 20v.

2675 StABS, Steuern B 19, Markzahlsteuer 1475/76, 27r; Markzahlsteuer 1476/77, 49r; Markzahlsteuer 1477/78, 20v; Markzahlsteuer 1478/79, 19v; Markzahlsteuer 1479/80, 18r; Markzahlsteuer 1480/81, 19r. 2676 StABS, Steuern B 19, Markzahlsteuer 1475/76, 26r; Markzahlsteuer 1476/77, 48r; Markzahlsteuer 1477/78, 21v; Markzahlsteuer 1478/79, 21r; Markzahlsteuer 1479/80, 19v; Markzahlsteuer 1480/81, 20v. 2677 Vgl. Schönberg 1879, 476. 
bezirke die Steuerbücher erhalten sind, beschränkt sich die Auswertung auf St. Alban und St. Ulrich, St. Martin sowie Kleinbasel.

In den drei Steuerbezirken konnten 30 Prozent der 1.047 steuerpflichtigen Personen kein besteuerbares Vermögen aufweisen. Die drei Papiermacher, die zu dieser Zeit lediglich die Personalsteuer entrichteten, gehörten damit einer breiten Masse vermögensloser Personen an. Ein größerer Anteil, gut 36 Prozent, verfügten über einen Besitz im Wert von unter 100 Gulden. In diese Vermögensklasse können die beiden Papiermacher Bastian und Hans Kielhammer von Schaffhausen eingeordnet werden, die 35 Gulden respektive 80 Gulden Vermögenswert ihr Eigen nannten. ${ }^{2678}$ Peter Höfflin und Ulrich Züricher, die zu dieser Zeit beide noch 200 Gulden angaben, können zu den 26 Prozent gerechnet werden, die zwischen 100 und 1.000 Gulden Vermögen besaßen. Zur Kategorie der Vermögenden ab 1.000 Gulden, die einen Anteil von gut 7 Prozent der steuerpflichtigen Bevölkerung ausmachte, zählten Anton und Michel Gallician, wobei Anton Gallician mit einem Vermögen von 4.000 Gulden zu den 1,5 Prozent der reichsten steuernden Basler gehörte.

Mit der Markzahlsteuer von 1475/76 bis 1480/81 endete die Zeit der Vermögensbesteuerung für das Basler St. Albantal. Daher ist es für die Zeit von 1481 bis 1550 nicht möglich, zu ähnlich verlässlichen und vollständigen Informationen bezüglich der finanziellen Situation der Papiermacher zu gelangen.

Im Allgemeinen wird man die Basler Papiermacher bis zur Mitte des 16. Jahrhunderts im Durchschnitt jedoch nicht als arm bezeichnen können, auch wenn wie dies auch bei anderen Handwerken der Fall war - lediglich die Meister wohlhabend waren. Immerhin besaßen auch einige angestellte Papierer, die keinen eigenen Betrieb führten, ein Haus. So gehörte Anton Pastor I eine Liegenschaft im St. Albantal, von der er im Jahr 1459 eine jährliche Rente von einem halben Gulden für 12 Gulden Hauptgut verkaufte. ${ }^{2679}$ Der 1476 flüchtig gewordene Bartholome de Conmola besaß ebenfalls ein Haus in den mülinen, das neben dem Grundstück des Papiermachers Sebastian Franz lag. ${ }^{2680}$ Der Papierer Michel Reri verkaufte sein Haus mit Hofstatt im Jahr 1479 an Michel Gallician. ${ }^{2681}$ In der St. Alban-Registratur von 1502/05 finden sich gleich zwei Papiermacher, die Hausbesitzer sind. Dies ist zum einen Diebolt

2678 Im Rechnungsjahr 1475/76 entsprachen nach Josef Rosen 100 Gulden 125 Pfund, das heißt ein Gulden entsprach einem Pfund 5 Pfennig, vgl. Rosen 1989, 145. 100 Pfund entsprachen daher 80 Gulden.

2679 StABS, Urk. Spital 566 (06.03.1459).

2680 StABS, Gerichtsarchiv B 10, 92: Item do koufft zem dritten und letsten kouff für xxx lb schuld Margret Bülerin daß huß und hoffstatt mit aller zugehörung zu Basel in Sant Albans mülinen gelegen zwischen Bastion des bappyrmachers ze einer und Berbelin Nußbomyn hüsern zer andern siten. Besunder alle die recht forderungen und ansprach so Bartholme der bappyrmacher als ein flüchtiger daran gehept hett und haben mocht.

2681 StABS, Gerichtsarchiv B 10, 273. Vgl. Kälin 1974, 203. 
Junkher, der außer einem Rebacker noch ein Eckhaus im St. Albantal besaß. ${ }^{2682}$ Zum anderen ist dies sein Berufskollege und Namensvetter Diebolt Hanman, dem seit 1478 ein bei der hinteren Schleife gelegenes Gebäude, Brestenberg genannt, gehörte, das sich 1502/1505 noch immer in seinem Besitz befand. ${ }^{2683}$ Zudem war er Inhaber eines Hauses namens Erenberg, das auf dem St. Albanberg lag, sodass er zu Beginn des 16. Jahrhunderts sogar zwei Liegenschaften besaß. ${ }^{2684}$

Neben ihrem vergleichsweise kostspieligen Mühlwerk konnten sich auch viele Papiermühlenbesitzer noch weitere Liegenschaften leisten. So war Peter Höfflin 1472 im Besitz eines Hauses mit Hofstatt, dass zwischen Henßlins von Altkirch und Weydlingers Haus lag. ${ }^{2685} \mathrm{Zu}$ der Zunzigermühle gehörte seit Heinrich Halbysen d. J. auch das Losers huß genannte Gebäude auf der gegenüberliegenden Straßenseite, das an den Klostergarten grenzte. ${ }^{2686}$ Nachdem Fridlin Hüsler d. Ä. 1532 die Zunzigermühle samt dem Haus erworben hatte, kaufte er 1537 den Klostergarten dazu und vergrößerte damit das Grundstück auf den heutigen Umfang. ${ }^{2687}$ Ulrich Züricher, ein vormaliger Besitzer der Liegenschaft, hatte 1481 hingegen zusätzlich zu der Mühle und Losers Haus ein weiteres Grundstück erworben, bei dem es sich um einen Teil von St. Albantal 27 handeln könnte. ${ }^{2688}$ Diese Liegenschaft im St. Albantal gehörte bis 1494 seinem Sohn Hans Züricher. ${ }^{2689} 1515$ lässt sich der Papiermacher Jörg Dürr d. Ä. als Besitzer fassen. ${ }^{2690}$

Abgesehen von seinen beiden Papierwerken, der Klingentalmühle seit 1453 und der Stegreifmühle seit 1480/81, war Anton Gallician im Jahr 1477 auch noch Inhaber zweier Liegenschaften in der Basler Kernstadt, nämlich dem Ryppen huß in der Neuen Gasse bei dem Haus zur Meerkatze (heute Spiegelgasse) und einem Hof in der Spiegelgasse zwischen Rudolf Meders und Diebolts des Söldners Haus. ${ }^{2691}$ In diesem Jahr verkaufte er von den beiden Grundstücken eine jährliche Rente von 8 Gulden für ein Hauptgut von 160 Gulden. Anton Gallician bezog im Gegenzug offenbar eine Rente von der Spittelmüllersmühle (St. Albantal 2), die er 1476 um versessenen Zins frönte und an sich zog. Sie verblieb bis 1486 in seinem Besitz. ${ }^{2692}$

2682 StABS, Klosterarchiv, St. Alban H, 9, 33; St. Alban DD 1, Corpus 1502, 10v; Corpus 1505, $15 \mathrm{v}$. 2683 StABS, Gerichtsarchiv B 10, 266; Klosterarchiv, St. Alban H, 13; St. Alban DD 1, Corpus 1505, 16v. Vgl. Anm. 2026.

2684 StABS, Klosterarchiv, St. Alban H, 23; St. Alban DD 1, Corpus 1505, 16v.

2685 StABS, Gerichtsarchiv B 9, 293.

2686 StABS, Klosterarchiv, St. Alban H, 13. Vgl. Baur/Nagel 2009, 45 f.

2687 StABS, Klosterarchiv, St. Alban, Urk. 594 (22.02.1537). Vgl. Baur/Nagel 2009, 45 f.

2688 StABS, Gerichtsarchiv B 11, 36v.

2689 StABS, Klosterarchiv, St. Alban, Urk. 485 (04.11.1494). Vgl. Kapitel 3.2.1.1, S. 222.

2690 StABS, Gerichtsarchiv B 20, 146v.

2691 StABS, Gerichtsarchiv B 10, 174. Vgl. Piccard 1967, 92; Kälin 1974, 165.

2692 Vgl. W. Fr. Tschudin 1958, 27; Kälin 1974, 165, 182. 
Auch Michel Gallician nannte außer der Rychmühle noch weitere Liegenschaften sein Eigen. Seit 1471 gehörte ihm ein Haus auf dem St. Albanberg, das er von Heinrich Halbysen d. J. erworben hatte. ${ }^{2693} 1479$ kaufte er dem Papiermacher Michel Reri dessen Haus in den mülinen zwischen Alban Leimers und Lienhardt Spinners Haus ab. ${ }^{2694}$ In den Jahren 1470 und 1487 erwarb der Papiermacher außerdem noch jeweils einen Rebgarten, ${ }^{2695}$ beide wurden im Jahr 1501 gepfändet. ${ }^{2696}$ Durch seine vor 1464 geschlossene Ehe mit Adelheid Phunser, Tochter des Gerichtsschreibers Magnus Phunser, kam Michel Gallician in den Besitz eines Lehens zu Habsheim, das der Graf von Thierstein bereits seinem Schwiegervater verliehen hatte und nun ihm, seiner Frau und deren Bruder Hans Phunser übertrug. ${ }^{2697}$ Michel Gallician hatte dieses Lehen - seit 1489 als einziger Lehensträger - bis 1509 inne. ${ }^{2698}$ In diesem Jahr ging es an seine Kinder Claus, Georg, Margaretha und Veronica Gallician. ${ }^{2699}$ Tatsächlich verblieb das Lehen zu Habsheim auch über den Wechsel in den Besitz der Stadt Basel im Jahr 1534 hinweg noch bis 1535 in der Hand von Papiermachern: Nach dem Papierer Jörg Dürr d. Ä., der durch die Ehe mit Veronica, einer Tochter Michel Gallicians, Leheninhaber wurde, hatte der aus dieser Ehe hervorgegangene Sohn Gregorius Dürr, ebenfalls Papiermacher, und seine zu diesem Zeitpunkt noch unmündigen Brüder Jörg und Jacob Dürr das Lehen inne. Im Juni 1535 traten sie schließlich ihre Ansprüche am Lehen zu Habsheim an das Basler Spital ab. ${ }^{2700}$

Gerhard Piccard schätzt die finanzielle Situation Michel Gallicians zu Recht als unsicher ein. Zwar gehörte er in den 1470er-Jahren mit einem versteuerten Vermögen von 1.000 Gulden zu den wohlhabenden Basler Bürgern, aber er besaß gegen Ende des 15. Jahrhunderts wohl kein flüssiges Kapital, sodass er 1494 seine Papiermühle verkaufen musste und es 1501 schließlich zur Pfändung und Einziehung der zwei Rebgärten kam. ${ }^{2701}$ Deutlich wird Michel Gallicians finanzielle Situation in der Streitsache mit seinem ehemaligen Gesellen Anton Loub. Michel Gallician war nicht in der Lage, die ausstehenden Forderungen um Lidlohn abzugelten, auch nicht in Form von Pfändern, da seine Söhne seinen gesamten Besitz an sich genommen hatten. ${ }^{2702}$ Wodurch es zu diesem augenscheinlichen Bruch mit seinen Söhnen gekommen war, in Folge

2693 StABS, Gerichtsarchiv B 9, 222.

2694 StABS, Gerichtsarchiv B 10, 273. Vgl. Kälin 1974, 203.

2695 StABS, Gerichtsarchiv B 9, 146; B 12, 53r. Vgl. Piccard 1967, 100.

2696 StABS, Gerichtsarchiv B 15, 56r. Vgl. Piccard 1967, 101, 178.

2697 StABS, Lehenarchiv O, Urk. 23 (20.07.1464); Urk. 24 (28.07.1464); Urk. 26 (10.12.1464). Vgl. Piccard 1967, 88 f.; Kälin 1974, 158.

2698 StABS, Lehenarchiv O, Urk. 41 (20.07.1489); Urk. 42 (20.07.1489). Vgl. Piccard 1967, 99.

2699 StABS, Lehenarchiv O, Urk. 58 (05.02.1509). Vgl. Piccard 1967, 99.

2700 StABS, Lehenarchiv O, Urk. 91 (22.08.1534); Urk. 92 (22.08.1534); Urk. 93 (07.06.1535). Vgl. Piccard 1967, $99 \mathrm{f}$.

2701 Vgl. Piccard 1967, $100 \mathrm{f}$.

2702 StABS, Gerichtarchiv A 40, 247v-248r; A 43, 70r. Vgl. Kapitel 3.3.1.1, S. 339 f. 
dessen Michel Gallician noch nicht einmal seine Schulden begleichen konnte, lässt sich nicht ermitteln. Vielleicht war es über den Verkauf der Rychmühle zu Streitigkeiten gekommen, denn auffällig ist, dass zwei Söhne Michels, Claus und Jacob, in den 1490er-Jahren nicht in Basel lebten. Zwar ist nicht zu sagen, ob Claus Gallician sich erst nach dem Verkauf der Rychmühle entschloss, in einer anderen Stadt einen Betrieb zu übernehmen, sicher ist aber, dass er 1495 der neue Leheninhaber der Papiermühle zu Ettlingen war und sie auf zehn Jahre pachtete. Er kehrte bereits nach fünf Jahren wieder nach Basel zurück. ${ }^{2703}$ Sein Bruder Jacob hingegen war schon seit 1489 im Besitz einer Papiermühle in Reutlingen. ${ }^{2704}$ Seinen Lebensabend beschloss Michel Gallician im Haus seiner Tochter Veronica und seines Schwiegersohns Jörg Dürr d. Ä. ${ }^{2705}$

Bemerkenswert ist, dass auch Anton Gallician, obgleich Ende der 1470er-Jahre mit 4.000 Gulden Vermögen ausgestattet, im Jahr 1477 Zinsen von seinen Liegenschaften in der Basler Kernstadt verkaufte. ${ }^{2706}$ Offenbar verfügte er nicht über das für ein Geschäft benötigte Bargeld. Zinssäumig wurde er offenbar auch, denn 1496 wurde die Stegreifmühle gepfändet, eine Zwangsvollstreckung konnte jedoch - vermutlich durch eine Nachzahlung der Zinsen - verhindert werden. ${ }^{2707}$ Ob diese finanziellen Schwierigkeiten von Anton und Michel Gallician allerdings der Papiermacherei oder nicht vielmehr anderweitigen Handelsunternehmungen zuzuschreiben sind, bleibt ungewiss. Aufschlussreich wäre ein Vergleich mit anderen Handwerksmeistern und Kaufleuten dieser Zeit. Betrachtet man beispielsweise die Finanzsituation des erfolgreichen Kaufmanns Heinrich Halbysen d. Ä., der offensichtlich allenthalben Schulden hatte, da seine Güter nach seinem Tod von mehreren Personen gepfändet wurden, dann mag die wechselhafte Lage der Gallician wie eine für risikobereite Unternehmer übliche Vermögenskonjunktur erscheinen. ${ }^{2708}$ Anton Gallician war zudem in der Lage, seinen beiden Söhnen die beiden Werke, die Klingentalmühle und die Stegreifmühle, zu hinterlassen. In einer wirklich prekären finanziellen Lage befand er sich vermutlich nicht.

Dass Papiermacher Konkurs gehen konnten, zeigt das Beispiel von Ulrich Züricher. Wodurch er bankrott ging, ist nicht zu festzustellen. Vermutlich lag auch hier die Ursache weniger in der Papierherstellung begründet als vielmehr in Zürichers anderweitigen Handelsgeschäften, die zum Teil im Verkauf von Tuch bestanden, wie eine

2703 Vgl. Piccard 1951, 59; Piccard 1967, 118 f.; Kälin 1974, 166; Stenzel 1985, 100; F. Schmidt 1992, 116. 2704 Vgl. Sporhan-Krempel 1972b, 1515 mit Anm. 3, 1518. In den Basler Gerichtsbüchern wird Jacob Gallician zu dieser Zeit als Bürger von Reutlingen genannt, StABS, Gerichtsarchiv A 41, 5v. Vgl. Anm. 2237.

2705 StABS, Lehenarchiv O, Urk. 59 (12.10.1513). Vgl. Piccard 1967, 99; Kälin 1972a, 13.

2706 Vgl. Anm. 2691.

2707 StABS, Gerichtsarchiv E 7, 35 v.

2708 StABS, Gerichtsarchiv E 3, 143v, 144r, 144v, 145r, 145v, 152r, 153v, 173v. Vgl. Piccard 1967, 62-66. 
Verwarnung der Schlüsselzunft aus dem Jahr 1482 nahelegt. ${ }^{2709}$ Jedenfalls konnte er 1486 seine Schulden nicht mehr begleichen und entzog sich seinen Gläubigern durch Flucht. Diese meldeten daraufhin ihre Ansprüche dem Basler Schultheißengericht. Die Zunzigermühle wurde im August 1486 an Barbara Bischoff vergeben, die ein Kapital von 500 Gulden eingelegt hatte. ${ }^{2710}$ Das restliche Gut Zürichers wurde offenbar im Oktober 1486 verrechnet: Es verblieben lediglich 28 Pfund 17 Schilling 8 Pfennig, die unter den übrigen Gläubigern anteilig aufgeteilt wurden. ${ }^{2711}$ Dass Ulrich Züricher nicht nur in Basel Schulden hatte, macht die Klage des Straßburger Bürgers Ludwig Rink deutlich, der im September 1486 vor dem Hofgericht in Rottweil seine Ansprüche auf die Papiermühle und weitere Güter Zürichers gegenüber der Stadt Basel vertrat. Der Basler Rat beschied sein Gesuch jedoch abschlägig, da er das Hab und Gut des Schuldners bereits nach Basler Gesetz ausgegeben habe. ${ }^{2712}$

Langfristiger Erfolg war auch Ulrichs Sohn Hans Züricher nicht beschieden. Er erlitt Konkurs wie sein Vater, ohne dass die Gründe dafür fassbar sind. Im Frühjahr 1494 ergriff der Papiermacher und Mühlenbesitzer die Flucht vor seinen Gläubigern, die im Mai desselben Jahres Beschlag auf seine Güter legten. ${ }^{2713} \mathrm{Im}$ Rahmen des Konkursverfahrens meldeten mindestens 30 Personen ihre Forderungen im Wert zwischen 9 Schilling und 21 Pfund 17 Schilling dem Gerichtsschreiber, wie ein mehrere Seiten umfassender Eintrag in die Frönungen und Verbote des Schultheißengerichts bezeugt (vgl. Anhang V). ${ }^{2714}$ Dieser Eintrag fasst in kondensierter Form zusammen, mit wem Hans Züricher in geschäftlichen Beziehungen stand. So finden sich unter seinen Gläubigern die Papiermacher Michel Gallician und Hans Kielhammer von Schaffhausen sowie der Drucker Johann Amerbach, aber auch Angestellte aus seinen Papiermühlen, deren Forderung auf ihrem mit Hans Züricher vereinbarten, noch

2709 StABS, Zunftarchive, Zunft zum Schlüssel 11, 84v. Ulrich Züricher bezog 1484 beispielsweise 40 Ellen Tischtuch vom Kaufmann Ulrich Meltinger, StABS, Privatarchive 62, 165r. Vgl. Kälin 1974, 199. 2710 StABS, Gerichtsarchiv E 6, 112; B 11, 260. Vgl. Kapitel 3.2.4.1, S. 285.

2711 StABS, Gerichtsarchiv G 2, 82v. Vgl. Kälin 1974, 199.

2712 StABS, St. Urk. 2258 (26.09.1486); Urkundenbuch der Stadt Basel 1905, Bd. 9, 25 f., Nr. 41: So were sin anwalt gen Basel kommen unnd hette an sy ervordert, in in Ulrich Zürichers gütere zusetzen als ains offen vorschriben achters gütere unnd inbesonnder bestimpt die bappir mulin. Were im antwort worden, das die gemelt mulin unnd ander des Zürichers gütere vor unnd eemals er gen Basel komen unnd sy der erlangten recht erinndert, den schuldneren nach ir statt recht vergantet worden. Vgl. Piccard 1967, 168.

2713 Üblicherweise mussten die Gläubiger bei einer Frönung oder einem Verbot dreimal eine vierzehntägige Frist verstreichen lassen und ihre Ansprüche vor dem Gericht nach Ablauf jeder Frist wiederholen. Wenn diese Zeitspanne verstrichen war und der Schuldner die Forderungen nicht befriedigt hatte, wurde sein fahrendes Gut dem Stadtkäufler zum Verkauf auf dem Markt überantwortet. Die Liegenschaften wurden, wenn es sich nicht um versessene Zinsen handelte, an drei Gerichtstagen zum Kauf durch den Meistbietenden angeboten. Die aus diesen Verkäufen erlöste Summe bildete die Basis für die Ausbezahlung der Gläubiger, die in Relation zu der von ihnen geforderten Summe befriedigt wurden. Vgl. Hagemann 1987, 134-137.

2714 StABS, Gerichtsarchiv E 7, 15v-17r. 
ausstehenden Lohn, dem sogenannten Lidlohn, basierte. ${ }^{2715}$ Neben den versessenen Zinsen von seinen beiden Papiermühlen beliefen sich Züricher Schulden auf gut 150 Pfund.

\subsubsection{Bern, Ravensburg, Reutlingen, Straßburg und Zürich}

Die finanzielle Situation der Papiermacher in den anderen südwestdeutschen Papiermühlenstandorten kann mit Ausnahme von Ravensburg nur punktuell dargestellt werden, da diese Frage in der Forschung bislang nicht systematisch untersucht wurde. Für Ravensburg befindet sich der Historiker in der glücklichen Lage, ebenfalls Steuerbücher auswerten zu können. Bei den Personen, die man sicher als Papierer identifizieren kann, bietet sich zum einen ein Vergleich ihrer Vermögenslage mit dem durchschnittlichen Reichtum der Ravensburger Bürger an. Auf diese Weise kann der sozioökonomische Stand dieses Berufszweigs innerhalb der städtischen Gesellschaft beleuchtet werden. Zum anderen gibt die über die verschiedenen Steuerjahre hinweg betrachtete Vermögensentwicklung einzelner Papierer Aufschluss über ihren wirtschaftlichen Erfolg. Trotz lückenhafter Überlieferung stellen die erhaltenen Steuerbücher daher eine wertvolle Quelle für die Erforschung der Ravensburger Papiermacherei dar. $^{2716}$

Bereits im ältesten erhaltenen Ravensburger Stadtrecht, das auf um 1330 datiert wird, wurde - anders als in Basel, wo nur außerordentliche direkte Steuern erhoben wurden - die Erhebung einer jährlichen Steuer festgesetzt. ${ }^{2717}$ Diese setzte sich aus einer Kopf- und einer Vermögenssteuer zusammen, wobei der Kopfsteuersatz seit 1381 bei 18 Pfennig lag. ${ }^{2718}$ Die Kopfsteuer musste jeder Ravensburger Bürger unabhängig von seinem Vermögen entrichten. Wer selbst diese 18 Pfennig nicht aufbringen konnte, wurde von der Besteuerung ausgenommen. Die Bürger mit Besitz mussten ihre Vermögenswerte unter Eid angeben; hierbei wurde, wie es auch in den Steuerbüchern ersichtlich ist, zwischen liegender und fahrender Habe unterschieden. Während unter ersterer alle Liegenschaften, also Immobilien, verstanden wurden, zählten zur fahrenden Habe alle beweglichen Wertgegenstände, darunter Bargeld, kostbares Geschirr und Schmuck, aber auch Vorräte wie Schmalz und gepökeltes Fleisch sowie Vieh und Werkzeug. ${ }^{2719}$ Diese sogenannten mobilia wurden doppelt so

2715 StABS, Gerichtsarchiv E 7, 15v, 16v. Vgl. Kapitel 3.3.1.1, S. 339.

2716 Vgl. Schultz/Follmer 2015, 20-24.

2717 Vgl. Stadtrecht A, Art. 53, in: K. O. Müller 1924, 76. Vgl. auch Dreher 1966, 176 f.; Dreher 1972, Bd. 2, 688 .

2718 Vgl. Stadtrecht B, Art. 230, in: K. O. Müller 1924, 191 f. Vgl. auch Hafner 1889, 117; Dreher 1966, 176; Eitel 1970, 111; Dreher 1972, Bd. 2, 687.

2719 StR, Bü 43, Steuerbuch 1482-1485, 1r: barschafft an gold und müntz, allen klainaten, guldin und silbrin geschier, win, korn, mel, roß, vech wölherlay das wer, how, stro, schmaltz, saltz, flaisch im saltz, holtz, väßer, werchzug, kromery, unzerschniten tuch wullis und linis, garn, hanfwerch, visch und geltschulden. Vgl. allgemein Heidenhain 1906, 40. 
hoch besteuert wie die immobilia, nämlich ein Pfennig zu einem Heller je Vermögenswert von einer Mark Silber. ${ }^{2720}$ Der Steuereinzug fand im Herbst statt und dauerte zwei bis drei Wochen, meist in der Zeit zwischen St. Gallus (16. Oktober) und St. Martin (11. November). Am 11. November musste jeder seine Steuern entrichtet haben. ${ }^{2721}$ Wer bis zum Nikolaustag säumig war, zahlte ein Drittel des Steuerbetrags mehr. Wer sie uf Sant thomas tag vor wihennechte aber nit hat geben der sol umb zunfft und burckrecht komen $\sin ,{ }^{2722}$ das heißt wer bis zum 21. Dezember keine Steuern gezahlt hatte, der wurde mit dem Verlust des Bürgerrechts und der Zunftzugehörigkeit bestraft. ${ }^{2723}$ Zuständig für die Erhebung der Steuern war eine Kommission, die sich aus dem Steuermeister, dem Bürgermeister, dem alten Bürgermeister, dem obersten Zunftmeister und dem Stadtschreiber zusammensetzte. ${ }^{2724}$ Das Amt des Steuermeisters, der die Zahlungen entgegennahm, wurde Anfang der 1380er-Jahre zur Entlastung des Stadtrechners eingeführt, dem bis dahin der Steuereinzug oblag. Seit dieser Zeit führten der Steuermeister und der Stadtschreiber jeweils ein Buch, sodass es ursprünglich eine zweifache Ausführung der Steuerbücher gab. ${ }^{2725}$

Wie auch in anderen Städten üblich ${ }^{2726}$ orientierte sich die Gliederung der Ravensburger Steuerbücher an den Bezirken der Stadt, sodass in der Anlage des Buchs der Rundgang des Steuermeisters nachzuvollziehen ist. Er begann seinen Weg außerhalb der Stadtmauer in den östlichen Vorstädten und beendete ihn in der Unterstadt. Auf diese Weise eröffnet die Vorstadt Schornreute, ein Standort von Papiermühlen, die Aufzeichnungen. ${ }^{2727}$ Dass die Steuerbücher für mehrere Jahre angelegt wurden, lässt sich an Strichen, die an den Namen der Steuerzahler angebracht wurden, erkennen. Pro Jahr, in dem die betreffende Person Steuern entrichtete, wurde ein Strich gesetzt. $^{2728}$

2720 StR, Bü 42, Steuerbuch 1473-1476, 1r. Ein Heller entspricht 0,5 Pfennig. Vgl. Hafner 1889, 117; Dreher 1966, 179; Eitel 1970, 111; Dreher 1972, Bd. 2, 690.

2721 StR, Bü 42, Steuerbuch 1473-1476, 1r. Vgl. Dreher 1972, Bd. 2, 689.

2722 StR, Bü 43, Steuerbuch 1482-1485, 1r.

2723 Vgl. Dreher 1972, Bd. 2, 689.

2724 StR, Bü 42, Steuerbuch 1473-1476, 1r. Vgl. Dreher 1966, 176; Dreher 1972, Bd. 2, 687 f.

2725 Anhand der Steuerbücher Bü 43 und Bü 44 bestärkt sich die Vermutung Alfons Drehers, dass die Schreibarbeit für beide Ausfertigungen von der Stadtkanzlei übernommen wurde, vgl. Dreher 1972, Bd. 2, 688. Die beiden Exemplare eines Steuerjahrgangs enthalten das gleiche Wasserzeichenpaar. Es ist daher plausibel, dass das Papier aus einer Produktion stammte, als Ries gekauft und an ein und demselben Ort beschrieben wurde, vgl. Schultz/Follmer 2015, 20 f., 24 f. mit Tab. 1.

2726 Für den Steuerrundgang in Marburg vgl. Verscharen 1987, 21; für Augsburg vgl. Kraus 1993; für Konstanz vgl. Die Steuerbücher der Stadt Konstanz 1958-1966; für Göttingen vgl. Denecke 1987, 200 mit Anm. 4.

2727 Am deutlichsten erkennt man diese Struktur bei Steuerbuch Bü 45. Hier gibt es auf der ersten Seite ein Stadtteilverzeichnis mit Folioangaben, StR, Bü 45, Steuerbuch 1497-1499, 1r.

2728 Verwirrend ist hierbei allerdings die Datierung, die das Ravensburger Stadtarchiv etabliert hat. Die Steuerbücher Bü 43 und Bü 44 sind auf den Zeitraum von 1482 bis 1485 datiert, weisen jedoch 
Für den Untersuchungszeitraum existieren zehn Steuerbücher, wobei ein Steuerbuch meist drei oder vier Steuerjahre umfasst (vgl. Tab. 26). Geht man davon aus, dass ursprünglich jedes Jahr erfasst wurde, dann fehlen zwischen dem ersten hier genannten Steuerbuch Bü 42 und dem letzten Steuerbuch Bü 51 rund 20 Bücher. Das Ausmaß des Verlusts, vermutlich durch Kassation verursacht, ${ }^{2729}$ wird noch deutlicher, wenn man bedenkt, dass es ursprünglich eine doppelte Ausfertigung von jedem Jahrgang gab. Dass der Stadtschreiber und der Steuermeister jeweils ein Buch führten, ist noch für die Steuerjahre 1482 bis $1485 \mathrm{zu}$ erkennen. Hinter der Signatur Bü 43 verbirgt sich das Steuerbuch des Stadtschreibers, während die Signatur Bü 44 das Steuerbuch des Steuermeisters darstellt. ${ }^{2730}$ Diese beiden Steuerbücher sind die einzigen bis zum Beginn des 17. Jahrhunderts, die noch in ihrer zweifachen Ausführung erhalten sind. ${ }^{2731}$ Für alle anderen Steuerjahre wurde mindestens das „doppelte“ Exemplar vernichtet.

Tab. 26: Ravensburger Steuerbücher von 1473 bis 1555 im Stadtarchiv Ravensburg.

\begin{tabular}{llll}
\hline & Signatur & Steuerjahre & Ausfertigung vom \\
\hline 1. & Steuerbuch Bü 42 & $1473-1476$ & $-\cdots---$ \\
2. & Steuerbuch Bü 43 & $1482-1485$ & Stadtschreiber \\
3. & Steuerbuch Bü 44 & $1482-1485$ & Steuermeister \\
4. & Steuerbuch Bü 45 & $1497-1499$ & Stadtschreiber \\
5. & Steuerbuch Bü 46 & $1504-1506$ & Steuermeister \\
6. & Steuerbuch Bü 47 & $1506-1508$ & Steuermeister \\
7. & Steuerbuch Bü 48 & $1512-1514$ & Steuermeister \\
8. & Steuerbuch Bü 49 & $1521-1523$ & Steuermeister \\
9. & Steuerbuch Bü 50 & $1546-1548$ & Stadtschreiber \\
10. & Steuerbuch Bü 51 & $1553-1555$ & Stadtschreiber \\
\hline
\end{tabular}

nur maximal drei Striche an einem Namen auf. Dies spricht eher dafür, dass die Bücher nur für drei Jahre geführt wurden, nämlich für die Jahre 1482, 1483 und 1484. Den umgekehrten Fall treffen wir bei Steuerbuch Bü 45 an: Der angegebene Zeitraum von 1497 bis 1499 legt eine Verwendung von drei Jahren nahe. Es finden sich hingegen in den meisten Fällen vier Striche an den Namen, sodass eine vierjährige Buchführung wahrscheinlicher ist.

2729 Vgl. Hengstler 1950, 14.

2730 Vgl. Schultz/Follmer 2015, 25, Abb. 4 u. 5.

2731 Vgl. Dreher 1966, 177 mit Anm. 193. 
Auf den ersten Blick scheint das Vorhandensein einer zweifachen Ausführung für die Untersuchung der Ravensburger Papiermacherei nicht von zentraler Bedeutung. ${ }^{2732}$ Doch bei der Betrachtung der auf uns gekommenen zwei Versionen für die Jahre 1482 bis 1485 fällt auf, dass der Ravensburger Bürger Hans Spen in dem Buch des Steuermeisters mit der Berufsbezeichnung papirer versehen ist, während dieser Zusatz in dem Buch des Stadtschreibers fehlt. ${ }^{2733}$ Im Allgemeinen muss leider festgestellt werden, dass die Namen der steuernden Personen nur selten durch eine Berufsbezeichnung ergänzt wurden. Daher werden in die Betrachtung die Personen aufgenommen, von denen aufgrund einer Parallelüberlieferung vermutet werden darf, dass es sich um Papiermacher handelte, und die zusätzlich im Ölschwang oder in Schornreute steuerten. Auf diese Weise ist zumindest ein direkter Zusammenhang mit den Papiermühlen gegeben. Unsicher ist nämlich beispielsweise, welche Mitglieder der Familie Wolfartshofer zu Beginn des 16. Jahrhunderts tatsächlich das Papiererhandwerk ausübten. Somit fallen aus der Untersuchung diejenigen Papiermacher heraus, die nicht bei den Papiermühlen wohnten und für einen anderen Bezirk ihre Steuern entrichteten. In der Langzeitbetrachtung ergibt sich zudem aufgrund der großen Lücken in der Überlieferung die Schwierigkeit, Personen gleichen Namens voneinander zu unterscheiden oder auch miteinander zu identifizieren, was die Untersuchung der individuellen Vermögensentwicklung erschwert.

Die Einträge in die Steuerbücher erfolgten, wie bereits erwähnt, nach Stadtteilen, wobei der Name des betreffenden Bezirks als Überschrift fungiert, unter der sich die Namen der steuernden Personen aufgelistet finden. Hinter dem Namen des Steuerzahlers wurde der Vermögenswert getrennt nach immobilia und mobilia angegeben. Am rechten Rand einer Seite wurde schließlich der Steuerbetrag notiert, der sich aus der Vermögenssteuer und der Kopfsteuer zusammensetzte. Die Steuersumme wurde in Pfund, Schilling und Pfennig angegeben, während die Vermögenswerte für Liegenschaften und fahrendes Gut in Mark Silber aufgeführt wurden. Für diese Untersuchung wurden die betreffenden Vermögenswerte in Pfund Pfennige umgerechnet, wobei eine Mark Silber 3 Pfund Pfennige entspricht. ${ }^{2734}$

2732 Wichtig wäre ein Vergleich der beiden Versionen für die Untersuchung der Organisation einer städtischen Schreibstube. Da es sich um handschriftliche Abschriften und daher nicht um identische Kopien im heutigen Verständnis handelt, können bei einem Vergleich inhaltliche Unterschiede zutage treten. Vgl. hierzu allgemein, allerdings mit Schwerpunkt auf literarische Text(re)produktion Gertz/Schultz/Šimek 2015. Eine Studie der verschiedenen Schreiberhände könnte zudem Aufschluss über die personelle Besetzung und die Arbeitsteilung in einer Kanzlei geben, vgl. hierzu auch Bange 2015, 118.

2733 StR, Bü 43, Steuerbuch 1482-1485, 7r; Bü 44, Steuerbuch 1482-1485, 7r.

2734 Vgl. Dreher 1966, 179. Lore Sporhan-Krempel beachtete nicht, dass die Vermögenswerte in Mark Silber angegeben wurden und kommt somit zu falschen Ergebnissen, da sie den Markbetrag für den Pfundbetrag hält, vgl. Sporhan-Krempel 1953, 28. 
Im Folgenden werden die Vermögenswerte der steuernden Papiermacher zunächst nach Steuerbüchern und damit für einen bestimmten Zeitpunkt betrachtet. Dabei ermöglicht es eine statistische Auswertung, die Peter Eitel 1970 anfertigte, ${ }^{2735}$ die Angaben der Papiermacher mit den versteuerten Vermögenswerten aller Steuerzahlenden Ravensburgs in Beziehung zu setzen. Auf diese Weise lässt sich die finanzielle Positionierung der Papierer im städtischen Raum besser fassen. Da Peter Eitel die Daten lediglich für sechs Steuerbücher des Untersuchungszeitraums erhoben hat, sollen an dieser Stelle auch nur diese in die Betrachtung einfließen. ${ }^{2736}$ Um die Ergebnisse systematisch $\mathrm{zu}$ veranschaulichen, werden sowohl die steuernden Papiermacher als auch die Gesamtheit der Steuerzahler in Anlehnung an Peter Eitel in acht Vermögensklassen eingeteilt (vgl. Tab. 27). ${ }^{2737}$ Diese Einteilung dient als Analyseinstrument, bei dem Vorteil und Nachteil gleichermaßen in der Schematisierung der gegebenen Daten liegen. ${ }^{2738}$

Tab. 27: Vermögensklassen der Ravensburger Bürger nach Peter Eitel. ${ }^{2739}$

\begin{tabular}{ll}
\hline Vermögensklasse 1 & kein Vermögen \\
Vermögensklasse 2 & $\leq 50 \mathrm{lb}$ \\
Vermögensklasse 3 & $51-100 \mathrm{lb}$ \\
Vermögensklasse 4 & $101-500 \mathrm{lb}$ \\
Vermögensklasse 5 & $501-1.000 \mathrm{lb}$ \\
Vermögensklasse 6 & $1.001-2.000 \mathrm{lb}$ \\
Vermögensklasse 7 & $2.001-5.000 \mathrm{lb}$ \\
Vermögensklasse 8 & $>5.000 \mathrm{lb}$ \\
\hline
\end{tabular}

Einen Überblick über die in den Steuerbüchern ermittelten Papiermacher und ihre Vermögenswerte in Relation zu den Vermögensklassen und den Anteilen aller steuernden Bürger bietet Tabelle 28. In der Periode von 1473 bis 1476 steuerten in Schornreute und im Ölschwang fünf Papiermacher vergleichsweise unterschiedliche Ver-

2735 Vgl. Eitel 1970, 119.

2736 Es handelt sich um das Steuerbuch 1473-1476 (Bü 42), das Steuerbuch 1482-1485 (Bü 44), das Steuerbuch 1497-1499 (Bü 45), das Steuerbuch 1506-1508 (Bü 47), das Steuerbuch 1521-1524 (Bü 49) und das Steuerbuch 1553-1555 (Bü 51). Vgl. Eitel 1970, 120 mit Anm. 50a, der statt Bü 42 Bü 43 anführt, obwohl er in der Tabelle auf S. 119 die Steuerperiode von 1473 bis 1476 angibt.

2737 Peter Eitel operierte mit neun Vermögensklassen, für diese Untersuchung wurden die beiden höchsten Klassen zu einer zusammengefasst, da keine der betrachteten Personen über 5.000 Pfund besaß.

2738 Vgl. Eitel 1970, 118.

2739 Vgl. Eitel 1970, 119. 
mögenswerte. Hans Wolfartshofer I gab einen Vermögenswert von 300 Mark an, was 900 Pfund entsprach. Damit gehörte er zu den 8,5 Prozent der reichsten Ravensburger Bürger. Hans Stengeli, der einen Besitz von 315 Pfund Wert versteuerte, und Conrat Wolfartshofer I, der 240 Pfund Vermögen besaß, waren in einer Vermögensklasse mit 18,5 Prozent der Steuernden. Der Papierer Conrat Schuchmacher entrichtete 12 Pfund und lag damit in derselben Vermögenskategorie wie 25 Prozent der Bürger. Peter Wolfartshofer zahlte, wie rund 38 Prozent aller Steuerpflichtigen, lediglich die Kopfsteuer von 18 Pfennig. ${ }^{270}$

In den Jahren zwischen 1482 bis 1485 sind sieben Papiermacher greifbar. Hans Wolfartshofer I gehörte mit einem Vermögenswert von 1.212 Pfund zu den 5 Prozent der wohlhabendsten Bürger der Stadt. Hans Wolfartshofer II versteuerte Hab und Gut im Wert von 294 Pfund und lag dadurch mit 19 Prozent der Steuernden in einer Vermögensklasse zwischen über 100 Pfund und 500 Pfund. Hans Stengelis finanzielle Lage hatte sich in den letzten Jahren verschlechtert: Er entrichtete nun Steuern für ein Vermögen von 69 Pfund, dies entsprach weniger als einem Viertel seines vorherigen Vermögens. In die Vermögenskategorie der Steuerzahler, die bis zu 50 Pfund besaßen und 27 Prozent aller Steuerpflichtigen ausmachten, fielen vier Papiermacher, Peter Wolfartshofer II mit 45 Pfund, Conrat Schuchmacher mit 24 Pfund sowie Hans Wäch und Hans Spen mit jeweils 21 Pfund. ${ }^{2741}$

Bis zur Steuerperiode von 1497 bis 1499, in der sechs Papierer erfasst sind, konnte Hans Wolfartshofer I sein Vermögen noch vermehren. Er versteuerte zu diesem Zeitpunkt Güter im Wert von 1.560 Pfund und gehörte damit zu den 6,5 Prozent der reichsten Ravensburger Bürger. Ebenso wie insgesamt 19 Prozent der Steuerzahler können Hans Wäch mit 420 Pfund, Hans Wolfartshofer II mit 288 Pfund und Claus Stengeli mit 126 Pfund in die vierte Vermögensklasse eingeordnet werden, da sie ein Vermögen von über 100 bis 500 Pfund ihr Eigen nannten. Hans Spen besaß mit 54 Pfund wie gut 10 Prozent der Bürger Ravensburgs ein Vermögen zwischen 51 und 100 Pfund. Conrat Schuchmacher verblieb mit einem Hab und Gut von 24 Pfund in seiner bisherigen Vermögenskategorie und gehörte damit zu 24,5 Prozent der Steuernden. ${ }^{2742}$

Auch in den Jahren 1506 bis 1508, für die ebenfalls sechs Papiermacher und eine Papiererwitwe $\mathrm{zu}$ greifen sind, war Hans Wolfartshofer I mit einem Vermögen von 2.160 Pfund der wohlhabendste Papiermacher und befand sich unter den 3,5 Prozent der reichsten Ravensburger Bürger. Ihm folgten in der vierten Vermögenskategorie, der ein Fünftel der Steuerzahlenden zuzurechnen sind, Hans Wäch mit 420 Pfund,

2740 StR, Bü 42, Steuerbuch 1473-1476, 1r-1v, 5v, 19v. Es handelt sich hier um den jungen Peter Wolfartshofer, im Folgenden als Peter Wolfartshofer II bezeichnet. Er war vermutlich der Sohn des 1435 erwähnten Peter Wolfartshofer I, der im Jahr 1473 laut Ausweis des Steuerbuchs verstorben war. Vgl. Anm. 2390.

2741 StR, Bü 44, Steuerbuch 1482-1485, 1r-2r, 6r, 7r.

2742 StR, Bü 45, Steuerbuch 1497-1499, 1r, 6v, 8r. 
dessen Schwiegersohn Hans Schmid mit 360 Pfund sowie Hans Wolfartshofer Meck mit 324 Pfund. Hans Spen versteuerte hingegen einen bescheidenen Vermögenswert von 33 Pfund, die Witwe von Conrat Schuchmacher gab 24 Pfund an. Sie lagen damit, wie 25,5 Prozent aller Steuernden, in einer Vermögensklasse bis 50 Pfund. Der Papierer Hans Härb besaß überhaupt kein besteuerbares Vermögen und entrichtete daher lediglich die Kopfsteuer. ${ }^{2743}$

Im Steuerbuch von 1521 bis 1524, in dem fünf Papiermacher dokumentiert sind, ist mit 420 Pfund Vermögen Paul Wolfartshofer der reichste Papiermacher. Zu seiner Vermögensklasse gehörten 21,5 Prozent der Ravensburger Bürger. Auch Hans Wolfartshofer mit 270 Pfund, Mathias (Tyas) Stengeli mit 210 Pfund und Hans Wolfartshofer der Jung ${ }^{2744}$ mit 148 Pfund reihen sich in diese Kategorie ein. Conrat Wolfartshofer II versteuerte mit 24 Pfund das geringste Vermögen und befand sich damit mit einem Viertel der Steuerzahler in einer Vermögenskategorie. ${ }^{2745}$

In der letzten hier untersuchten Steuerperiode von 1553 bis 1555, für die vier Papiermacher und zwei Papiermühlenbesitzer fassbar sind, bezifferten die Mühlenbesitzer Jörg Sauter d. Ä. und sein gleichnamiger Sohn ihr Hab und Gut auf einen Wert von 1.788 beziehungsweise 1.008 Pfund. Sie gehörten damit zu den 8,5 Prozent der reichsten Ravensburger. Die Personen, die zu dieser Zeit vermutlich als Papiermacher arbeiteten, waren weniger vermögend. Hans Wolfartshofer mit 84 Pfund und Heinrich Im Thurn mit 98 Pfund zählten zu den 14,5 Prozent der Steuerzahler, die ein Vermögen zwischen 51 und 100 Pfund aufwiesen. Conrat Wolfartshofer II versteuerte mit 36 Pfund einen Betrag unter 50 Pfund wie 23,5 Prozent der Steuernden. Gänzlich unvermögend war Martin Brigel, der lediglich die Kopfsteuer bezahlte. ${ }^{2746}$

Zusammengefasst spiegelt die Verteilung der Papiermacher auf die Vermögensklassen im Groben die Verteilung aller Steuerzahler wider. In der Tendenz gab es mehr Papiermacher, die zwischen 101 und 500 Pfund versteuerten, als solche, die einen Vermögenswert von unter 50 Pfund angaben. Somit können viele der untersuchten Papiermacher als relativ gut situiert beschrieben werden. Personen, die ein Vermögen von über 1.000 Pfund besaßen, machen zwischen 5 und 8 Prozent aller Steuerzahler aus und sind auch unter den Papiermachern vereinzelt festzustellen. Der einzige frappante Unterschied liegt in der ersten Vermögenskategorie der Besitzlosen, die bis in die 1520er-Jahre mit 29,5 bis 38 Prozent den größten Anteil an Steuernden aufweist. Dieser Vermögensklasse lassen sich jedoch nur drei Papiermacher

2743 StR, Bü 47, Steuerbuch 1506-1508, 1r-1v, 5v, 6v, 7v.

$2744 \mathrm{Ob}$ es sich bei einer dieser beiden Personen mit Namen Hans Wolfartshofer um einen der Hans Wolfartshofer aus der Steuerperiode 1506-1508 handelt, ist nicht zu sagen.

2745 StR, Bü 49, Steuerbuch 1521-1524, 3r-3v.

2746 StR, Bü 51, Steuerbuch 1553-1555, 3r-3v, 36r, 66r. 
zuordnen. Dies legt den Schluss nahe, dass nur wenige Papierer, die Ravensburger Bürger waren, überhaupt kein Vermögen besaßen. ${ }^{2747}$

Fassbar sind in der Ravensburger Überlieferung tatsächlich fast nur die Papiermacher, die Bürger der Stadt waren, da das Quellencorpus zum Großteil aus den Bürgerbüchern und den Steuerbüchern besteht. ${ }^{2748}$ Über die Gesellen und Hilfsarbeiter und deren finanzielle Lage ist daher für den Untersuchungszeitraum keine Aussage zu treffen. ${ }^{2749}$ Erfasst wurden in den Steuerbüchern folglich hauptsächlich Papiermühlenbesitzer und Betriebsleiter, die einen gewissen Grad an Selbstständigkeit besaßen. Unter ihnen gab es mehr oder weniger wohlhabende Papiermacher, wobei sich diese Situation vermutlich kaum von der Situation in anderen Handwerken unterschied, die meist auch heterogen zusammengesetzt waren und arme und reiche Meister kannten. ${ }^{2750}$

Betrachtet man die Vermögenslage einzelner Papiermacher, so entdeckt man ebenfalls unterschiedliche Entwicklungen: Während die einen ihr Vermögen vermehrten, verschlechterte sich die finanzielle Situation anderer Berufsgenossen erheblich; bei dritten wiederum stagnierte sie in den unteren Bereichen der Vermögensskala (vgl. Abb. 16 u. Tab. 29). ${ }^{2751}$ Als ausgesprochen wohlhabend lässt sich Hans Wolfartshofer I bezeichnen: Er besaß nach Auskunft des ersten erhaltenen Steuerbuchs in den Jahren 1473 bis 1476900 Pfund und verdoppelte sein Vermögen bis zur Steuerperiode von 1512 bis 1514 mit einer Spitze von 2.160 Pfund in den Jahren 1506 bis $1508 .{ }^{2752}$ Auch Conrat Schuchmacher verdoppelte seinen Vermögenswert, allerdings gehörte er mit 12 bis 24 Pfund zu denjenigen mit bescheidenem Vermögen. ${ }^{2753}$ Die stattliche Summe von 525 Pfund versteuerte der Papierer Albrecht Silber im Jahr 1545. Da er im nächsten Steuerbuch als fortgezogen eingetragen wurde, kann die Entwicklung seines Vermögens nicht beobachtet werden. ${ }^{2754}$

2747 Aloys Schulte behauptet hingegen, dass die meisten Papierer „wenig wohlhabend“ waren. Leider unterstützt er diese Vermutung nicht mit Quellenbefunden, vgl. Aloys Schulte 1923, Bd. 1, 15.

2748 Anders als in Basel steuerten in Ravensburg nur die Bürger, da bei Säumigkeit mit dem Verlust des Bürgerrechts gedroht wurde, vgl. Dreher 1972, Bd. 2, 689.

2749 Für das Ende des 18. Jahrhunderts ist in Ravensburg eine zunehmende Verarmung der Papiermachergesellen zu beobachten, vgl. Sporhan-Krempel 1954b, $976 \mathrm{f}$.

2750 Vgl. allgemein Brandt 2008, 296 f. Für die Basler Metzger vgl. Simon-Muscheid 1988, 103 f.

2751 In diese Betrachtung wurden alle zehn Steuerbücher des Untersuchungszeitraums einbezogen. 2752 StR, Bü 42, Steuerbuch 1473-1476, 1r; Bü 44, Steuerbuch 1482-1485, 1r; Bü 45, Steuerbuch 1497-1499, 1r; Bü 46, Steuerbuch 1504-1506, 1r; Bü 47, Steuerbuch 1506-1508, 1r; Bü 48, Steuerbuch 1512-1514, 3v.

2753 StR, Bü 42, Steuerbuch 1473-1476, 5v; Bü 44, Steuerbuch 1482-1485, 6r; Bü 45, Steuerbuch 14971499, 6v; Bü 46, Steuerbuch 1504-1506, 6r; Bü 47, Steuerbuch 1506-1508, 6v.

2754 StR, Bü 50, Steuerbuch 1545, 3r; Bü 51, Steuerbuch 1553-1555, 3v. 


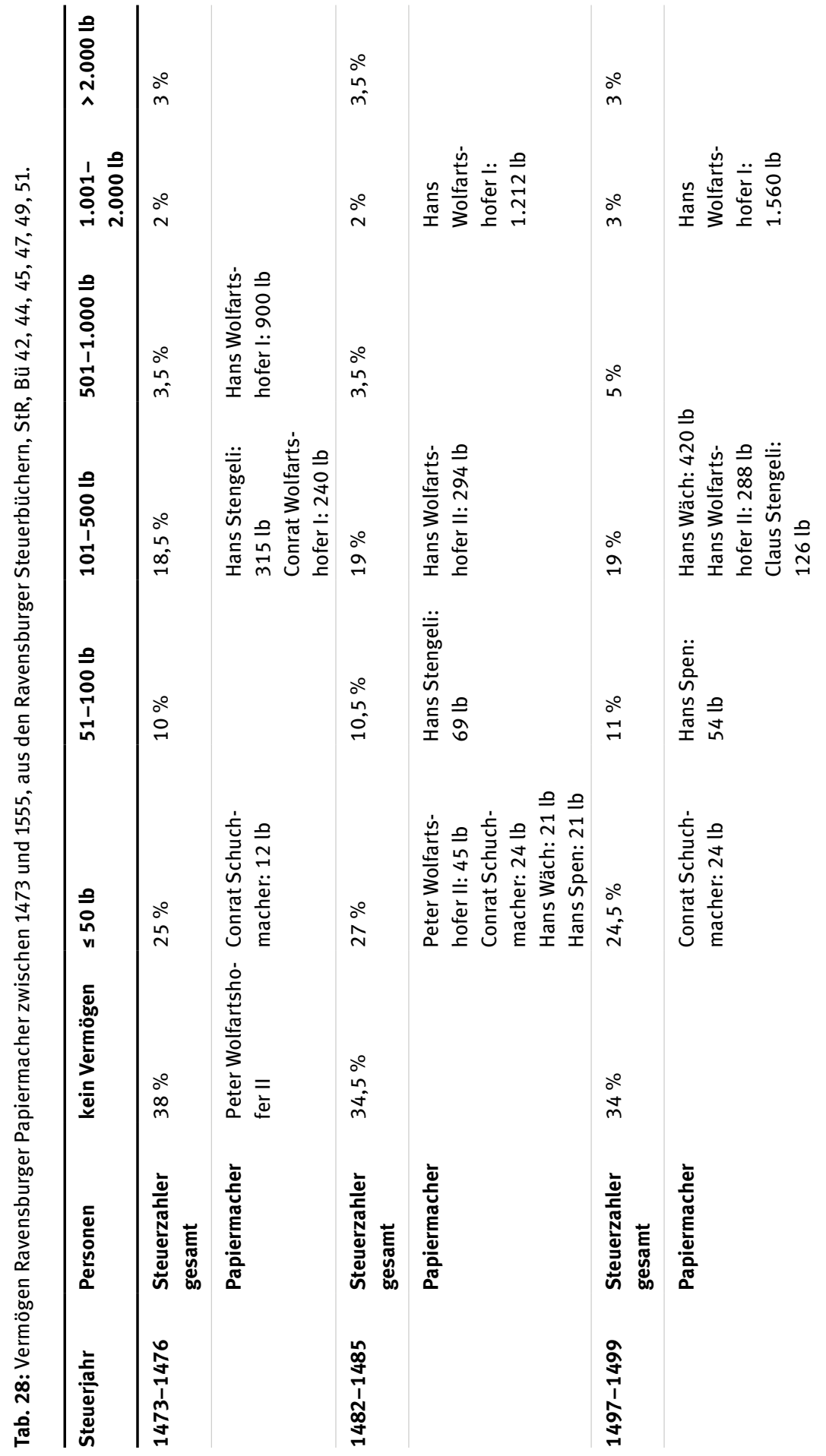




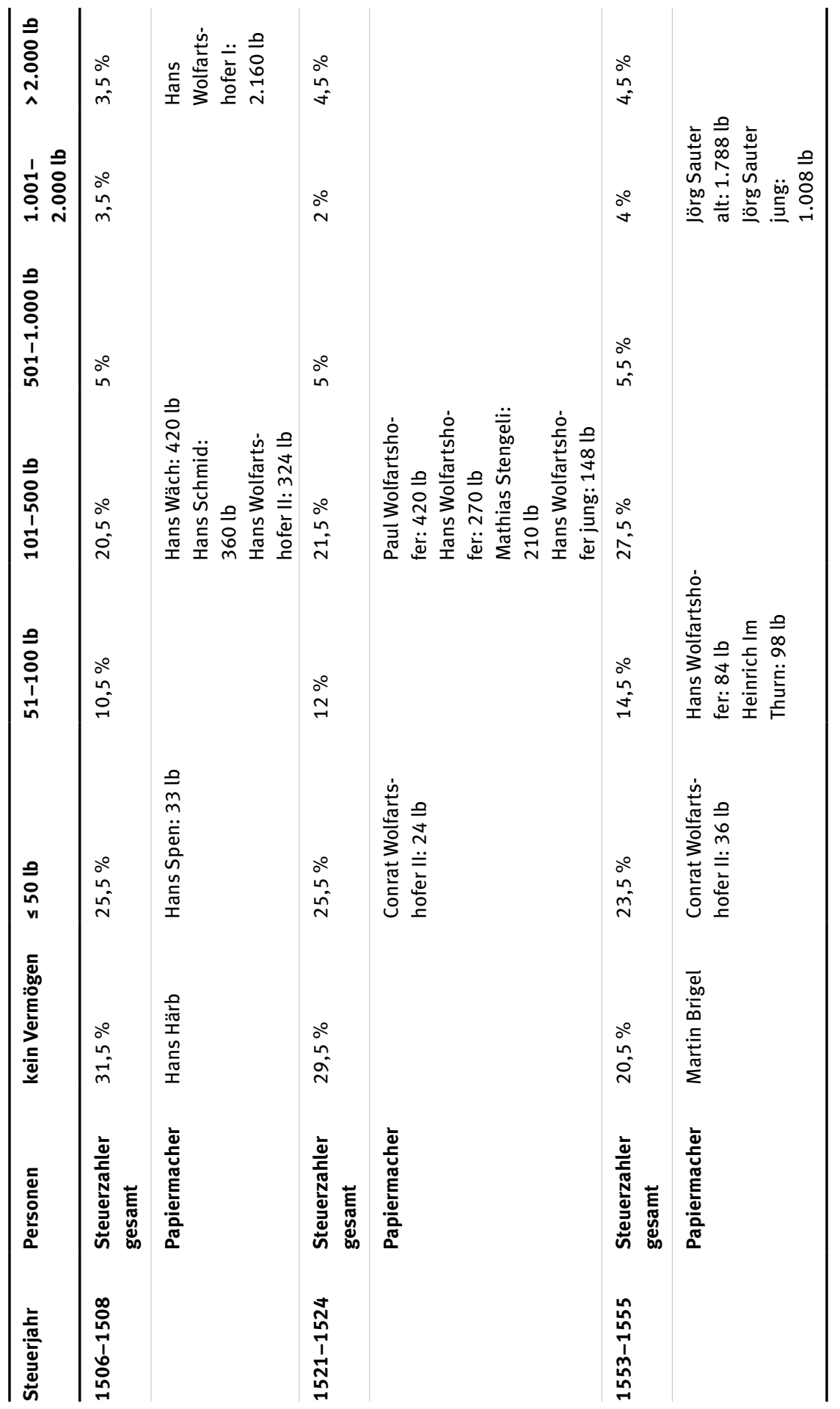



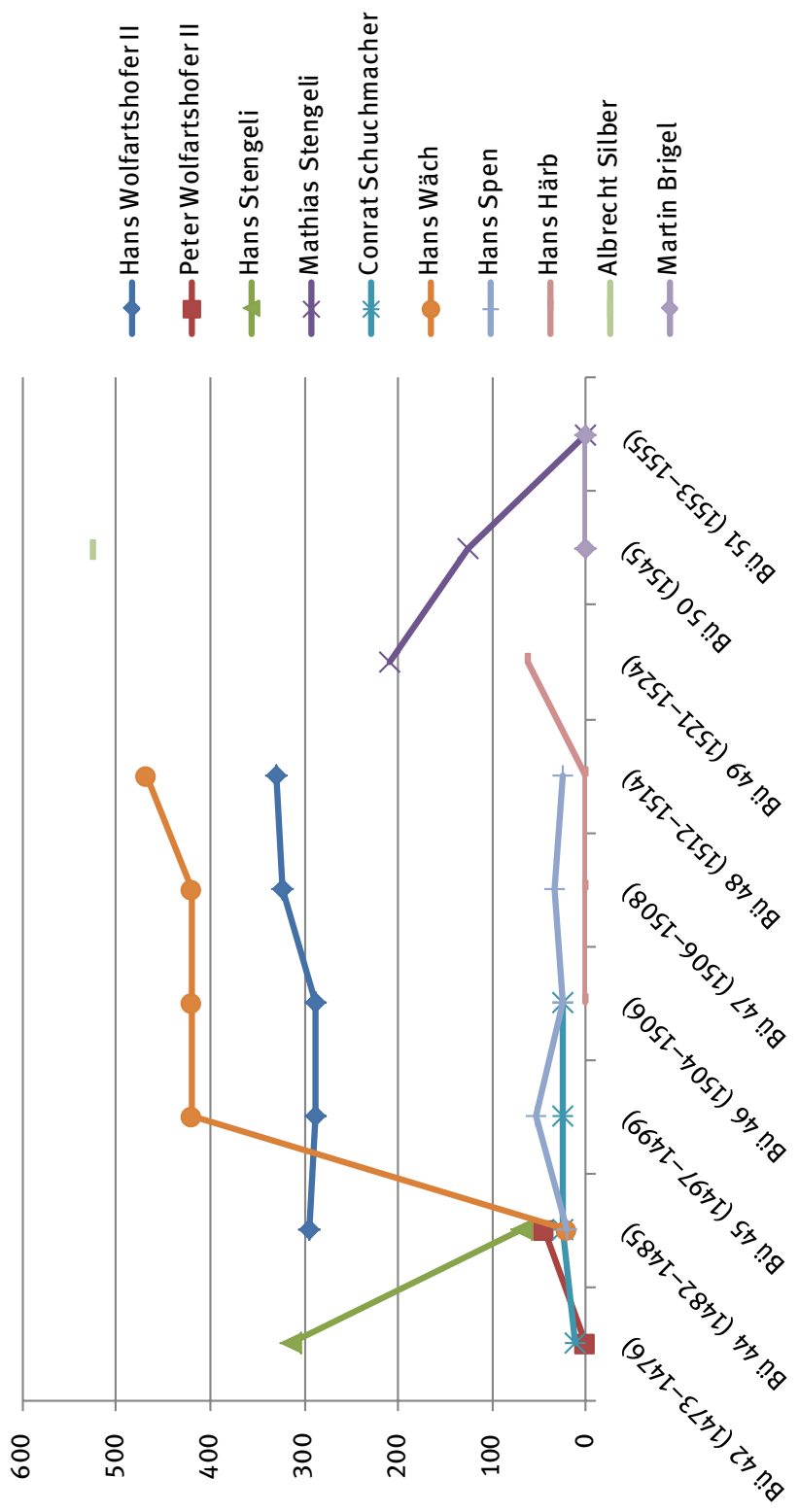

Abb. 16: Liniendiagramm zur Vermögensentwicklung bei Ravensburger Papiermachern von 1473 bis 1555.

Die Vermögenssummen von Hans Wolfartshofer I sind deutlich höher als die seiner Kollegen und können daher im Liniendiagramm nicht zusammen mit deren Vermögenskurven abgebildet werden, da ansonsten der Ausschnitt für die kleineren Summen zu undifferenziert erscheint. 


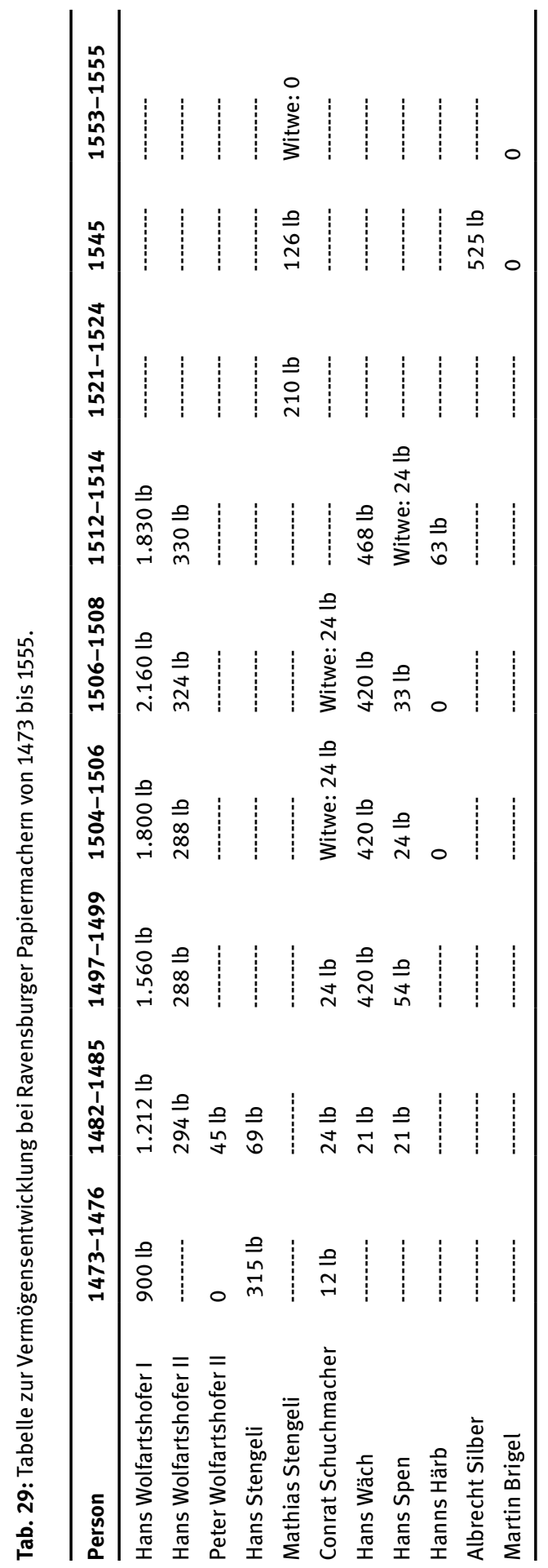


Der Wert des von Hans Wolfartshofer II $^{2755}$ versteuerten Besitzes bewegte sich im Zeitraum von 1482 bis 1514 in einer respektablen Höhe um 300 Pfund, wobei dieser Papiermacher einen kleinen Anstieg von circa zehn Prozent verzeichnen konnte. ${ }^{2756}$ Eine Besserung ihrer finanziellen Lage ist für Peter Wolfartshofer II und Hans Härb festzustellen. Konnte Peter Wolfartshofer noch in der Steuerperiode 1473 bis 1476 kein besteuerbares Vermögen aufweisen, so gab er im Steuerbuch für die Jahre 1483 bis 1485 immerhin 45 Pfund an. ${ }^{2757}$ Hans Härb war von 1504 bis 1508 besitzlos, versteuerte im Jahr 1512 dann jedoch 63 Pfund. ${ }^{2758}$ Im Gegensatz dazu blieb ihr Kollege Martin Brigel, der bereits 1525 das Bürgerrecht erworben hatte, nach Ausweis der Steuerbücher aus der Mitte des 16. Jahrhunderts im Untersuchungszeitraum vermögenslos. ${ }^{2759}$ Eine Verminderung des Vermögens ist für die Papiermacher Hans und Mathias Stengeli zu verzeichnen. Während Hans Stengeli im Jahr 1473 noch 315 Pfund angab, versteuerte er 1482 nur noch 69 Pfund und musste somit einen Vermögensverlust von knapp 80 Prozent hinnehmen. ${ }^{2760}$ Auch Mathias Stengelis Vermögen sank von 210 Pfund im Jahr 1521 auf 126 Pfund im Jahr 1545. Seine Witwe konnte im Jahr 1553 gar kein versteuerbares Vermögen mehr vorweisen. ${ }^{2761}$

Wie unterschiedlich die persönliche Erfolgsgeschichte verlaufen konnte, zeigt sich am Beispiel der Papierer Hans Wäch und Hans Spen, die vermutlich anfangs zusammen in einer Papiermühle arbeiteten. ${ }^{2762}$ In den ersten Jahren ihres Auftretens in Ravensburg verlief ihr Lebensweg erstaunlich parallel. Sie erwarben im Jahr 1482 gemeinsam das Bürgerrecht und siedelten sich, nach ihrer Auflistung in den Steuerbüchern zu urteilen, im Ölschwang an. ${ }^{2763}$ Beide steuerten im selben Jahr das erste Mal in Ravensburg und zahlten neben der Kopfsteuer von 18 Pfennig jeweils 7 Pfennig für einen Vermögenswert von 21 Pfund. ${ }^{2764}$ Die beiden Papiermacher waren zu dieser Zeit folglich gleich vermögend. Fünfzehn Jahre später, 1497, zahlte Hans Spen 10 Pfennig

2755 Hierbei wurde Hans Wolfartshofer jung aus den Steuerbüchern 1482-1485 und 1497-1499 mit Hans Wolfartshofer Meck aus den Steuerbüchern 1504-1506, 1506-1508 und 1512-1514 identifiziert.

2756 StR, Bü 44, Steuerbuch 1482-1485, 1r; Bü 45, Steuerbuch 1497-1499, 1r; Bü 46, Steuerbuch 15041506, 1v; Bü 47, Steuerbuch 1506-1508, 1v; Bü 48, Steuerbuch 1512-1514, 3r.

2757 StR, Bü 42, Steuerbuch 1473-1476, 1v; Bü 44, Steuerbuch 1482-1485, 1v.

2758 StR, Bü 46, Steuerbuch 1504-1506, 5v; Bü 47, Steuerbuch 1506-1508, 5v; Bü 48, Steuerbuch 1512-1514, 8v.

2759 StR, Bü 50, Steuerbuch 1545, 3v; Bü 51, Steuerbuch 1553-1555, 3v.

2760 StR, Bü 42, Steuerbuch 1473-1476, 1r; Bü 44, Steuerbuch 1482-1485, 2r.

2761 StR, Bü 49, Steuerbuch 1521-1524, 3r; Bü 50, Steuerbuch 1545, 3r; Bü 51, Steuerbuch 1553-1555, $3 r$.

2762 Anders als Wolfgang Schlieder vermutet, wurden diese beiden Männer durchaus als Papiermacher bezeichnet, vgl. StR, Bü 44, Steuerbuch 1482-1485, 7r. Vgl. dagegen Schlieder 1966, 95.

2763 StR, Bü 27, Bürgerbuch 2 (1436-1549), 118; Bü 43, Steuerbuch 1482-1485, 7r; Bü 44, Steuerbuch 1482-1485, 7r; Büschel 45, Steuerbuch 1497-1499, 6v, 8r.

2764 StR, Bü 43, Steuerbuch 1482-1485, 7r; Bü 44, Steuerbuch 1482-1485, 7r. 
für 54 Pfund, ${ }^{2765}$ während Hans Wäch ein Vermögen von insgesamt 420 Pfund angab. ${ }^{2766}$ Zwar konnten beide Papiermacher ihr Vermögen vermehren, aber während Hans Spens Zuwachs etwas mehr als das Anderthalbfache betrug, konnte Hans Wäch einen Anstieg auf das Zwanzigfache verbuchen. Bleiben die Ursachen für Gewinn und Verlust in den meisten Fällen verborgen, so lässt sich Hans Wächs wirtschaftlicher Erfolg größtenteils auf die Heirat mit Lena Schnitzer, der wohlhabenden Witwe des ehemaligen Ravensburger Bürgermeisters Peter Schnitzer, zurückführen, die 1491 einiges an Besitz in die Ehe einbrachte. ${ }^{2767}$ Der Kauf der drei Papierhäuser im Ölschwang im Jahr 1498 betonte den Gegensatz zu seinem weniger erfolgreichen Kollegen Hans Spen. ${ }^{2768}$ Während Hans Wäch im Jahr 1512 nunmehr 468 Pfund versteuerte, waren Hans Spens Witwe nur noch 24 Pfund Vermögen verblieben. ${ }^{2769}$ Im wirtschaftlichen, aber vor allem auch im sozialen Aufstieg durch Heirat ähnelt dieser Fall der Eheschließung des Basler Papiermachers Michel Gallician mit Adelheid Phunser, der Tochter des Basler Gerichtsschreibers Magnus Phunser. ${ }^{2770}$

Die Abhängigkeit von Kapitalgebern in der Papiermacherei macht das Beispiel des Papierers Heinrich Im Thurn deutlich, der seit 1547 die Papiermühle von Jörg Sauter in Schornreute gepachtet hatte. Während die Papiermühlenbesitzer Jörg Sauter d. Ä. und sein gleichnamiger Sohn im Jahr 15452.937 Pfund beziehungsweise 420 Pfund und im Jahr 15531.788 beziehungsweise 1.008 Pfund versteuerten, gab ihr Pächter Heinrich Im Thurn für das Jahr 1553 knapp unter 100 Pfund Vermögenswert an, der sich im Vergleich zu dem seiner Verpächter äußerst bescheiden ausnimmt. ${ }^{271}$ Dass Heinrich Im Thurn zumindest seiner Ansicht nach kaum in der Lage war, den Betrieb aufrecht zu erhalten, weil ihm das notwendige und von Jörg Sauter eigentlich zugesagte Kapital fehlte, macht die prekäre finanzielle Situation, in der sich der Papiermacher befand, deutlich. Anhand des Steuerbuchs für die Jahre von 1553 bis 1555 lässt sich zudem erkennen, dass sich Im Thurns Vermögen aus Liegenschaften zusammensetzte und er keinerlei fahrende Habe von Wert besaß. 1549 hatte er bereits einen Rock seiner Frau verkauft, um an Bargeld zu gelangen. ${ }^{2772}$

In einer finanziell instabilen Lage befanden sich offenbar auch Papiermacher in anderen südwestdeutschen Papiermühlenstandorten, wenngleich auch Nach-

2765 StR, Bü 45, Steuerbuch 1497-1499, 6v.

2766 StR, Bü 45, Steuerbuch 1497-1499, 8r.

2767 StR, Urk. 842 (26.05.1491). Vgl. Sporhan-Krempel 1953, 28; Alfred Schulte 1953, 22; Schlieder 1966, 95. Lena Schnitzers erster Mann Peter Schnitzer, ein angesehener Ravensburger Bürger und von 1473 bis 1483 Bürgermeister, verstarb um 1490, vgl. Dreher 1966, 269.

2768 StR, Urk. 670 (24.07.1498). Vgl. Kapitel 3.2.1.2, S. 225 f., 229 f.

2769 StR, Bü 48, Steuerbuch 1512-1514, 6v, 8r.

2770 Vgl. Kapitel 3.3.5.1, S. 435. Auch andere Handwerker legten den Grundstein ihres Vermögens durch die Heirat mit einer gut situierten Frau, vgl. Brandt 2008, 297.

2771 Vgl. Sporhan-Krempel 1953, 31 f. Vgl. auch Kapitel 3.2.3.2, S. 273.

2772 Vgl. Sporhan-Krempel 1953, 31 f. 
richten von vergleichsweise großen Vermögen existieren. So besaßen die Reutlinger Papiermacher Jacob Ziser und Paul Hirter, nach ihrem Beitrag zur Türkensteuer zu schließen, im Jahr 15455.000 Gulden beziehungsweise 1.200 Gulden Vermögen. ${ }^{2773}$ Der Papierer Wilhelm de Altomonte in Straßburg hingegen verkaufte 1447, zwei Jahre nachdem ihm der Bau einer Papiermühle bewilligt wurde, eine jährliche Rente von 8 Gulden an die Frau des Nicolas Heilmann und bezeugt auf diese Weise seinen Kapitalbedarf, den er womöglich nur durch einen Rentenverkauf decken konnte. Er war bereits mit der Zahlung mehrerer Jahreszinsen im Rückstand, als er 1450 zum Jubeljahr nach Rom aufbrach, von dem er nie zurückkehrte. ${ }^{2774}$ Die Vermutung liegt zwar nahe, dass er während seiner Reise starb. Denkbar wäre jedoch auch, dass Wilhelm de Altomonte unter dem Vorwand, einen vollkommenen Ablass zu erwerben, ${ }^{2775}$ aus Straßburg floh, um seinen Schulden zu entkommen. Auch die Papiermacher, die zwischenzeitlich seine Papiermühle betrieben, waren verschuldet: Georg de Altomonte, wohl ein Verwandter Wilhelms, hatte Schulden bei Nicolas Heilmann, war aber im Jahr 1451 verstorben, sodass sich der Gläubiger mit seiner Forderung an Johannes de Altomonte und Johannes Hettag wandte, die für Georg gebürgt hatten. ${ }^{2776}$ Letztlich zog Nicolas Heilmann die Papiermühle an sich. ${ }^{2777}$

Ebenfalls den - zumindest vorübergehenden - Verlust der Papiermühle hatte der Papiermacher Hans Conrad Grebel zu beklagen. Sein Mühlwerk auf dem Werd in Zürich wurde 1491 um versessenen Zins gepfändet und eingezogen. Spätestens im Jahr 1513 war Grebel jedoch wieder im Besitz der Papiermühle, denn auch aus diesem Jahr sind Zinsforderungen gegen ihn bekannt. ${ }^{2778}$ Sein Vorgänger Heinrich Walchwiler lebte vermutlich ebenso wenig in gesicherten finanziellen Verhältnissen. Bereits beim Kauf der Papiermühle 1471 nahm er mit einer Hauskaufrente ein Hauptgut von 400 Gulden auf die Liegenschaft auf. ${ }^{2779}$ Zudem schuldete er dem Verkäufer Otto im Werd im Jahr 1474 noch 2 Gulden 12 Schilling für einen großen und einen kleinen Wellbaum. ${ }^{2780}$ Weitere Schuldverschreibungen Walchwilers über 4,5 Gulden sowie 23 Gulden 36 Schilling 6 Pfennig lassen sich für die Jahre 1473 und 1477 greifen. ${ }^{2781}$ Sein Berner Berufsgenosse, der Papiermühlenbesitzer Tschan Jacki, blieb in den 1460er-Jahren mehrmals die Bezahlung seiner Schulden säumig, sodass er 1467 schließlich sogar gefangen genommen wurde. Seit 1459 hatte Jacki, der in Solothurn mit Wein handelte, offenbar die fällige Weinsteuer nicht in vollem Umfang bezahlt.

2773 Vgl. Sporhan-Krempel 1972b, 1537.

2774 AVES, CH 251, Nr. 5164 (26.08.1451); CH 254, Nr. 5228 (22.11.1452). Vgl. Fuchs 1962b, 105.

2775 Vgl. Schimmelpfennig 1989, $2024 \mathrm{f}$.

2776 AVES, CH 251, Nr. 5164 (26.08.1451). Vgl. Fuchs 1962b, 104 f.

2777 Vgl. Kapitel 3.2.4.2, S. 297.

2778 Vgl. Zürcher 1963b, $121 \mathrm{f}$.

2779 Vgl. Schnyder 1937, 729, Nr. 1248.

2780 Vgl. Schnyder 1937, 717, Nr. 1233.

2781 Vgl. Schnyder 1937, 739, Nr. 1268; 746, Nr. 1289. 
Der Solothurner Rat richtete sich deshalb an die Stadt Bern, die versprach, sich für die Bezahlung der Schulden zu verwenden. Letztlich verrechnete die Stadt Bern beim Kauf der Mühle zu Worblaufen 1470 die geschuldeten 120 Gulden mit der Kaufsumme von 150 Gulden. ${ }^{2782}$ Tschan Jackis Schulden resultierten folglich zwar aus dem Weinhandel und nicht aus der Papierherstellung, dennoch hatte die prekäre finanzielle Lage Einfluss auf die Papiermacherei, wenn man davon ausgeht, dass er die Papiermühle zu Worblaufen schuldenhalber an die Stadt Bern veräußerte.

Die Befunde aus Ravensburg und den anderen südwestedeutschen Papiermühlenstandorten bestätigen das Bild, dass sich anhand der Basler Steuerbücher zeichnen lässt: Die Vermögensverhältnisse der Papiermacher waren äußerst heterogen. So gelang es einigen Papiermühlenbesitzern, ein beachtliches Vermögen aufzubauen und es auch zu verstetigen, während andere der finanziellen Belastung, die eine Papiermühle darstellte, nicht gewachsen waren und Konkurs anmelden mussten. Zwischen diesen beiden Extremen gab es Meister, die mit der Papiermacherei ein solides Auskommen erwirtschaften konnten. Auch einige der nicht selbstständig arbeitenden Gesellen konnten sich einen eigenen Hausstand und sogar ein Haus leisten. Andere wiederum besaßen keine Vermögenswerte, konnten im Vergleich zu ihren Berufsgenossen im 18. Jahrhundert aber offenbar von ihrer Arbeit leben.

\subsubsection{Beziehungen zu Rohstofflieferanten und Kunden}

Bislang noch nicht beleuchtet wurden die geschäftlichen Kontakte der Papiermacher zum einen zu ihren Zulieferern und zum anderen zu ihren Kunden. Von wem bezogen sie ihre Rohstoffe, vor allem Leim und Lumpen, und wem verkauften sie ihr Papier? Hatten sie direkten Kontakt zum Verbraucher oder wurde ihre Ware ausschließlich von Kaufleuten vertrieben? Welche Art von Verbindung ist überhaupt in den Quellen fassbar?

\subsubsection{Basel}

Für die Basler Papiermacherei ist der Historiker in der glücklichen Lage, in dem Kaufmann Ulrich Meltinger einen Lieferanten von Rohstoffen fassen zu können, die zur Papierherstellung benötigt wurden. Den Verkauf von Lumpen und Leim an Basler sowie an auswärtige Papiermacher verzeichnete Ulrich Meltinger in seinem Geschäftsbuch, das heute in den Privatarchiven des Staatsarchivs Basel-Stadt aufbewahrt wird. ${ }^{2783}$ Dass dieses Geschäftsbuch auf uns gekommen ist, verdanken wir

2782 Vgl. Morgenthaler 1917, 66-69; Fluri jun. 1967, 46; Fluri jun. 1975, 7 f.

2783 StABS, Privatarchive 62. 
den Anschuldigungen, die der Basler Rat im Jahr 1493 gegen Meltinger vorbrachte. Dieser sah sich dem Verdacht gegenüber, als Pfleger des Siechenhauses St. Jakob an der Birs Gelder veruntreut und Urkunden gefälscht zu haben. ${ }^{2784}$ Im Zuge des Prozesses wurden sowohl die Rechnungsbücher des Siechenhauses als auch Meltingers privates Geschäftsbuch eingezogen. Auch nach seinem Schuldeingeständnis, das es ihm in der Folgezeit unmöglich machte, politische Ämter wahrzunehmen, verblieb das Geschäftsbuch im Rathaus - und wurde auf diese Weise bis heute erhalten. ${ }^{2785}$

In sein Geschäftsbuch trug Ulrich Meltinger, nach Personen geordnet, seine Handelsgeschäfte - sowohl Einkäufe wie auch Verkäufe - ein und notierte, ob die Bezahlung bereits erfolgt war beziehungsweise welche Summe noch ausstand. Zudem hielt er darin auch Kredit- und Immobiliengeschäfte sowie Verlagsverträge und Bergwerksbeteiligungen fest. ${ }^{2786}$ Meltinger, der Mitglied der Schlüsselzunft und Teilhaber der Großen Handelsgesellschaft war, ${ }^{2787}$ handelte vor allem mit Wolle und Tuch sowie mit Eisen und Eisenwaren, aber auch mit Papier, das er teilweise von Papiermachern aus dem St. Albantal bezog.

Den Handel mit den beiden zur Papierherstellung benötigten Rohstoffen Lumpen und Leim betrieb Ulrich Meltinger nach Ausweis seines Geschäftsbuchs vor allem zu Beginn der 1470er-Jahre. So verkaufte er Anton Gallician im Juli 1473 9,5 Zentner Lumpen, die er zuvor von seinem Bruder Martin Meltinger bezogen hatte. ${ }^{2788}$ Der neue Besitzer der Zunzigermühle, Ulrich Züricher, erhielt in den Jahren 1471, 1472 und 1473 mehrere Lumpenkontingente von Ulrich Meltinger geschickt, insgesamt wohl über 120 Zentner. ${ }^{2789}$ Auch der Papiermacher Peter Höfflin zählte zu Meltingers Kunden. Er erwarb im Jahr 1473 um die 85 Zentner Lumpen. ${ }^{2790}$ Schließlich kaufte auch Michel Gallician 1472 zusammen mit Andres Bischoff, der wie Meltinger der Großen Handelsgesellschaft angehörte, 44 Zentner und 54 Pfund Lumpen. Allerdings verwendete er diesen Rohstoff nicht für seine eigene Papiermühle im St. Albantal, sondern schickte

2784 Vgl. Steinbrink 2007, 199-203; Steinbrink 2010b, 318 f.

2785 Vgl. Steinbrink 2007, 61; Steinbrink 2010a, 194. Eine Gesamtedition des Geschäftsbuchs bietet Steinbrink 2007, 213-529.

2786 Zur Anlage des Geschäftsbuchs und Meltingers Rechnungsführung vgl. Steinbrink 2007, 51-61; Steinbrink 2010a, 194 f.; Steinbrink 2010b, 318-323.

2787 Zur Großen Handelsgesellschaft, die auch Meltinger-Zscheckapürlin-Gesellschaft genannt wurde, vgl. Apelbaum 1915, 43-47; Hagemann 1983, 564 f.; Steinbrink 2007, 184-191.

2788 StABS, Privatarchive 62, 310v. Vgl. Kälin 1974, 328; Steinbrink 2007, 498.

2789 StABS, Privatarchive 62, 35r, 77r, 305r, 308r, 310r. Vgl. Kälin 1974, 316, 319, 326-328; Steinbrink 2007, 168, 267, 306, 492, 495, 497. Bei der Berechnung der erstandenen Lumpenmenge ist zu beachten, dass Meltingers Buchführung doppelte Einträge hervorgebracht hat, auf die er meistens Querverweise gibt.

2790 StABS, Privatarchive 62, 76v, 83v, 310r. Vgl. Kälin 1974, 318, 321, 328; Steinbrink 2007, 305 f., 312, 497. 
ihn nach Lörrach. ${ }^{2791}$ Der dortige Papiermacher empfing 1472 zudem eine weitere, durch Andres Bischoff finanzierte Lumpenlieferung von 31 Zentnern und 30 Pfund direkt von Ulrich Meltinger. ${ }^{2792}$

Der Preis, den die genannten Papiermacher für einen Zentner Lumpen bezahlten, belief sich meist auf 20 Schilling; dies entspricht einem Pfund Pfennige. ${ }^{2793}$ Eine Preisreduktion musste Ulrich Meltinger offensichtlich anbieten, wenn die Hadern durchfeuchtet waren. So erließ er Peter Höfflin auf dessen Beschwerde hin, dass die Lumpen nass seien, einen kleinen Teil der Kaufsumme. ${ }^{2794}$ Ob die feuchten Lumpen tatsächlich qualitativ weniger wert waren oder ob es bei einer solchen Preisminderung vielmehr darum ging, dass die Hadern nass gewogen wurden und somit schwerer als im trockenen Zustand waren, ist nicht zu sagen. Bei einer Lieferung für Ulrich Züricher wurden die nass gewordenen Lumpen offenbar erst gewogen, nachdem sie getrocknet waren. ${ }^{2795}$ Ulrich Meltinger bezog die Hadern zum Großteil von seinem Bruder Martin Meltinger, der ihm von 1471 bis 1473 insgesamt circa 246 Zentner lieferte. ${ }^{2796}$ Eine weitere Bezugsquelle für Lumpen war offenbar eine Mömpelgarder Krämerin namens Berbelina, von der er im September 1471 Hadern erwerben wollte. ${ }^{2797}$ $\mathrm{Zu}$ Beginn der 1490er-Jahre wird außerdem ein Ludwig Kanstetter, der lonpenman, in Meltingers Rechnungsbuch genannt. Er war vermutlich Lumpensammler, wurde jedoch nicht im Zusammenhang mit einer Hadernlieferung erwähnt. ${ }^{2798}$

Die vier Basler Papiermacher, die sich über Ulrich Meltinger mit Lumpen versorgten, bezogen auch Leim von ihm. Ulrich Züricher erwarb 1471 beispielsweise zwei Fuhren Leim: Die eine wog 6 Zentner 13 Pfund und kostete 28 Schilling pro Zentner, die andere wog 16,5 Zentner und lag preislich bei 30 Schilling pro Zentner. ${ }^{2799}$ Teurer war der Zentnerpreis, den Peter Höfflin für 10 Zentner und 25 Pfund Leim entrichteten musste: Er lag bei 32 Schilling. ${ }^{2800}$ Michel Gallician hingegen bezahlte für 105 Pfund Leim 2 Pfund und damit sogar 38 Schilling je Zentner. ${ }^{2801}$ Von Anton Gallician ist bekannt, dass er im Januar 1472260 Pfund Leim für 3 Pfund und 12,5 Schilling

2791 StABS, Privatarchive 62, 50r, 51r. Vgl. Kälin 1974, 317; Steinbrink 2007, 281 f. Zur Papierproduktion in Lörrach vgl. Kapitel 3.2.1.12.

2792 StABS, Privatarchive 62, 51r. Vgl. Kälin 1974, 161, 317; Steinbrink 2007, 282.

2793 StABS, Privatarchive 62, 35r, 51r, 76v. Vgl. Kälin 1974, 316-318; Steinbrink 2007, 168, 267, $282,305$. 2794 StABS, Privatarchive 62, 76v. Vgl. Kälin 1974, 318; Steinbrink 2007, 306.

2795 StABS, Privatarchive 62, 35r: Item er sol mir i karen mit lonpen, waß naß, das man in im koufhuß nit wag, was der wigt, scrib ich harnoch. Vgl. Kälin 1974, 316; Steinbrink 2007, 267.

2796 StABS, Privatarchive 62, 305r, 307v, 308r, 308v, 310r, 310v, 316r. Vgl. Kälin 1974, 326-329; Steinbrink 2007, 492, 494 f., 497, 503 f. Vgl. auch Steinbrink 2007, 168.

2797 StABS, Privatarchive 62, 25v. Vgl. Kälin 1974, 315; Steinbrink 2007, 256.

2798 StABS, Privatarchive 62, 202r. Vgl. Kälin 1974, 324; Steinbrink 2007, 415.

2799 StABS, Privatarchive 62, 77r, 305r. Vgl. Kälin 1974, 319, 326; Steinbrink 2007, 167, 306, 492.

2800 StABS, Privatarchive 62, 76v. Vgl. Kälin 1974, 318; Steinbrink 2007, 167, 305.

2801 StABS, Privatarchive 62, 107r. Steinbrink 2007, 336. Vgl. auch die nicht völlig korrekte Transkription in Kälin 1974, 322. Interessant ist der Hinweis, dass das Gewicht des Sacks, in dem der Leim 
kaufte. ${ }^{2802}$ Er zahlte folglich nur um die 28 Schilling für einen Zentner Leim. Im Jahr darauf bestellte er zunächst 19,5 Zentner Leim, ließ diese aber wieder an Meltinger zurückschicken. ${ }^{2803}$

Ulrich Meltinger bezog den Leim für einen Einkaufspreis von 20 bis 26 Schilling von zwei Basler Weißgerbern, Haßmann und Peter Hennentaler. ${ }^{2804}$ An einem Eintrag im Geschäftsbuch wird die Verbindungslinie von den Weißgerbern über den Kaufmann zum Papiermacher explizit dargelegt. ${ }^{2805}$ Der Kauf von Leim deutet darauf hin, dass die Basler Papiermacher den zum Leimen benötigten Rohstoff zumindest teilweise nicht selbst herstellten, sondern auf ein fertiges Produkt zurückgriffen. Für wieviel Ries der eingekaufte Leim ausreichte, ist nicht zu sagen, da es zudem schwerfällt, das Verhältnis von getrocknetem Leim zu flüssigem Leim zu bestimmen. Ähnliches gilt für die gekauften Lumpenmengen. Im ersten Hauptteil dieser Arbeit wurde versucht, den Jahresbedarf an Hadern einer Papiermühle mit einer Bütte zu berechnen. ${ }^{2806}$ Nach der Regensburger Mühlenordnung aus der zweiten Hälfte des 16. Jahrhunderts benötigte man für die erwartete Jahresleistung von 1.800 Ries rund 450 Zentner Lumpen. Die durch Ulrich Züricher bezogenen 120 Zentner Hadern stellten folglich nur gut ein Viertel der im Jahr benötigten Lumpenmenge dar, sodass davon auszugehen ist, dass die Basler Papiermacher neben Ulrich Meltinger andere Bezugsquellen für den Kauf von Hadern hatten.

Die vier Basler Papiermacher, die zu Beginn der 1470er-Jahren Lumpen und Leim von Ulrich Meltinger erwarben, haben gemeinsam, dass es sich bei ihnen um die Besitzer der vier Papiermühlen im St. Albantal handelte. ${ }^{2807}$ Während dieser drei bis vier Jahre zwischen 1471 und 1474 kauften demnach alle Papiermühlenbesitzer Rohstoffkontingente bei Ulrich Meltinger. Woher sie Lumpen und Leim vor und nach dieser kurzen Periode bezogen, konnte nicht festgestellt werden. Einen kleinen Hinweis auf den Bezug dieser Rohstoffe gibt das Ordnungenbuch der Safranzunft. Hier wird angegeben, dass die Papiermacher nach der Basler Kaufhausordnung ein Vorkaufsrecht

transportiert wurde und der 5 Pfund wog, vom Gesamtgewicht abgezogen wurde. Der Transport des Leims in Säcken lässt zudem darauf schließen, dass es sich um getrockneten Leim handelte.

2802 StABS, Privatarchive 62, 29v. Vgl. Kälin 1974, 315; Steinbrink 2007, 261.

2803 Vgl. Kapitel 3.3.6.2, S. 472.

2804 StABS, Privatarchive 62, 35r, 36v, 45v, 77r. Vgl. Kälin 1974, 316 f., 319; Steinbrink 2007, 167,267 f., 277, 306. Vgl. Kapitel 2.3.7, S. 146.

2805 StABS, Privatarchive 62, 77r: Item Ulrich Zuricher stott folio 35 und sol mir aber vi zenter und xiii lb lim, den zenter fur ein lb viii $\beta$, was Haßmans und Hennetallers, tůt an gelt viii lb xij $\beta$.

2806 Vgl. Kapitel 2.3.1.2, S. 64-66.

2807 Anton Gallician besaß die Klingentalmühle, sein Bruder Michel Gallician war Inhaber der Rychmühle, Ulrich Züricher gehörte die gegenüberliegende Zunzigermühle und Peter Höfflin war vermutlich Pächter der hinteren Spiegelmühle. Vgl. Kapitel 3.2.1.1, S. 214, 215, 216, 218 f. 
auf Lumpen und Leim hatten. Zudem war es ihnen erlaubt, die Hadern ohne Umweg über das Kaufhaus direkt in ihre Mühlen transportieren zu lassen. ${ }^{2808}$

Dieses Privileg stieß jedoch 1541 bei zwei Papiermühlenbesitzern auf Missfallen. Die Papiermacher Peter Sontach, Inhaber der Klingentalmühle, und Joachim Degenhart, der zu dieser Zeit vermutlich noch als Pächter in einer der Papiermühlen arbeitete und im darauffolgenden Jahr die Rychmühle erwarb, brachten dem Basler Rat ein Gesuch des lumpenkoufs halp vor. ${ }^{2809}$ Sie beschwerten sich zum einen, dass deutsche und welsche Lumpensammler keine Lumpen mehr nach Basel lieferten und die städtischen Lumpenverkäufer durch den daraus entstehenden Mangel den Preis diktieren konnten. Zum anderen forderten die beiden Papiermacher, dass die Lumpenkäufe ihrer Basler Kollegen nicht mehr wie bisher direkt in die Papiermühlen geführt, sondern ins Kaufhaus gebracht werden sollten, damit ein jeder Papiermacher davon kaufen könne, was er benötigte. Der Rat ging offenbar auf die Bitte der beiden Papiermacher ein. ${ }^{2810}$

Kehren wir noch einmal in die 1470er-Jahre zurück. Der Kaufmann Ulrich Meltinger erwarb im Gegenzug zu seinen Geschäften mit Lumpen und Leim Papier aus den Basler Papiermühlen, allerdings nur in kleinen Mengen, die häufig mit anderen Gütern verrechnet wurden. ${ }^{2811}$ Aber die Einträge in Meltingers Buch geben für die Wasserzeichenforschung wichtige Hinweise, da bei Papierlieferungen von Anton Gallician und Ulrich Züricher die Papiere näher beschrieben wurden. So gab Anton Gallician Ulrich Meltinger im Oktober 1472 ein risen pappir mit sant Anthonius crutz. ${ }^{2812}$ Ulrich Züricher schickte Meltinger 1484 ein riß bappir myt dem berg. ${ }^{2813}$ Dieser Zusatz, der das Wasserzeichen beschreibt, ermöglicht eine Zuordnung der Wasserzeichen Antoniuskreuz und Berg zu den jeweiligen Papiermachern - für die mittelalterliche Papiermacherei im deutschen Raum eine Seltenheit. Hans Kälin hat darauf hingewiesen, dass die Papiermarke, die zuvor in der Literatur als Schlächterbeil, lateinischer Buchstabe T oder griechischer Buchstabe Tau bezeichnet wurde, mit diesem Beleg sicher als Antoniuskreuz identifiziert werden kann. ${ }^{2814}$ Das Anthoniuskreuz

2808 StABS, Zunftarchive, Zunft zu Safran 2, 70r, 93r. Vgl. Geering 1886, 525 f.; Koelner 1935, 303; Kälin 1972a, 20.

2809 StABS, Handel und Gewerbe, LLL 1, 4.

2810 StABS, Handel und Gewerbe, LLL 1, 4. Vgl. Geering 1886, 527; Koelner 1935, 303 mit Anm. 2; Kälin 1972a, 20.

2811 Vgl. Steinbrink 2007, 166.

2812 StABS, Privatarchive 62, 29v, 82r. Vgl. Kälin 1974, 315, 320; Steinbrink 2007, $261,311$.

2813 StABS, Privatarchive 62, 165r. Vgl. Kälin 1974, 323; Steinbrink 2007, 389.

2814 Vgl. Kälin 1974, 159, 208, s. auch 413, Wasserzeichenabbildungen Nr. 99-104. Charles-Moïse Briquet hielt von den Möglichkeiten lateinischer Buchstabe T, griechischer Buchstabe Tau oder Anthoniuskreuz die Verwendung eines einfachen $\mathrm{T}$ in Analogie $\mathrm{zu}$ anderen Buchstabenwasserzeichen wie dem $\mathrm{P}$ am wahrscheinlichsten, vgl. Briquet 1968, Bd. 2, 751. Traugott Geering hingegen brachte die Interpretation als Schlächterbeil auf und dachte dabei an einen Vorfahren Heinrich Halbysens d. Ä., den Metzger Rudman Halbysen, vgl. Geering 1886, 321. Walter Friedrich Tschudin bezeichnete das 
existierte sowohl als eigenständiges Zeichen wie auch als Beizeichen, beispielsweise über einem Ochsenkopf. ${ }^{2815}$

Weitere explizite Beziehungen von Basler Papiermachern zu Händlern, die den Absatz ihrer Produkte übernahmen, konnten bislang nicht ermittelt werden. Betrachtet man die Reichweite, die der Handel mit Basler Papier erlangte, so dürfte jedoch gewiss sein, dass die Papiermacher ihr Papier durch Kaufleute vertreiben ließen. ${ }^{2816}$ Viele Papiermacher standen aber auch in unmittelbarem Kontakt zu ihren Endkunden, besonders zu solchen, die in der näheren Umgebung ansässig waren. Diese Geschäftsbeziehungen von Papierern lassen sich vornehmlich aus den Gerichtsbüchern des Schultheißengerichts gewinnen. Da diese Quellengattung jedoch nur die Geschäfte verzeichnet, bei denen es zu Problemen kam und die daher vor einem Gericht verhandelt wurden, erhalten wir vor allem Einblicke in strittige Geschäftsangelegenheiten.

Für einen direkten Vertrieb des Papiers bot der aufkommende Buchdruck einen großen Absatzmarkt. ${ }^{2817}$ Anhand dreier Fallbeispiele sollen daher die Beziehungen zwischen Papiermachern und Druckern dargelegt werden. Zunächst rücken die Papiermacher, Papiermühlenbesitzer und Kaufleute Anton und Michel Gallician in den Fokus. Die beiden Brüder standen mit mehreren Druckern aus Basel und anderen Druckorten in direktem geschäftlichem Kontakt. Einer von ihnen war der Drucker Heinrich Eggestein, der vermutlich seit 1464 eine eigene Offizin führte und mit Johannes Mentelin als einer der frühsten Straßburger Drucker gilt. ${ }^{2818}$ Im Mai 1478 versprach er, Anton Gallician die ausstehende Summe von 112 Gulden zu zwei Terminen, nemlich lvi guldin uff die Frankfurter herbstmess und die übrigen uff $d z$ löblich hochziit wyhennechten, zu zahlen. ${ }^{2819}$ Welche Leistung seitens Anton Gallicians hinter dem geschuldeten Betrag stand, wurde nicht notiert. Kaum zwei Jahre später, im April 1480, lesen wir von einer neuen Geldschuld Eggesteins: Diesmal war er mit 200 Gulden im Rückstand und auch diesmal ist unbekannt, wofür. Anton Gallician gab an, dass er nach dem Vertrag, den sie geschlossen hatten und der anscheinend in schriftlicher

fragliche Wasserzeichen provisorisch als Tau oder als $\mathrm{T}$ und verwies bereits auf das Antoniuskreuz, enthielt sich jedoch einer endgültigen Namenszuschreibung, vgl. W. Fr. Tschudin 1958, 111 f., 247 mit Anm. 114, 251 mit Anm. 148. Gerhard Piccard jedoch legte sich fest und meinte, in diesem Zeichen ein Tau als magisches Heilszeichen zu sehen, vgl. Piccard 1967, 293 f., 303.

2815 Vgl. Kälin 1974, 208, 416. Zu den Basler Wasserzeichen des 15. und 16. Jahrhunderts vgl. auch Gerardy 1986.

2816 Vgl. Ehrensperger 1972, 40, 58, 77, 210, 229, 253; Kälin 1973, 18-27; Kälin 1974, 210-213; Bayerl 1987, 84 f.; Irsigler 2006, 315.

2817 Im Jahr 1939 zeigte Hans Heinrich Bockwitz die Desiderate für eine gemeinsame Geschichte von Papiermachern und Buchdruckern auf, vgl. Bockwitz 1939. Einen instruktiven Einblick in diese vielfältigen Beziehungen bietet Zaar-Görgens 2004, 163-188. Eine erste Auswertung für Basel nahm Peter Tschudin vor, vgl. P. Tschudin 1997.

2818 Zu Heinrich Eggestein vgl. Geldner 1959, 336; Geldner 1968b, 60-62; Amelung 1989, 420 f.

2819 StABS, Gerichtsarchiv C 12, 283. Vgl. Stehlin 1888, 21, Nr. 87. 
Form existierte, die Rückzahlung der Summe bis Ostern erwartet habe. ${ }^{2820}$ Das Schultheißengericht hingegen sah noch keine Notwendigkeit, einzugreifen, und wies den Kläger sowie den Beklagten daher an, die Möglichkeit eines Vergleichs wahrzunehmen. Erst wenn mithilfe von dritten, unbeteiligten Personen keine Einigung erzielt werde könne, solle sich Anton Gallician wieder an das Gericht wenden und dafür seine Vertragsausfertigung, sinen houptbrieff, mitbringen. ${ }^{2821}$ Es ist möglich, dass die geschäftlichen Beziehungen zwischen Anton Gallician und Heinrich Eggestein bereits seit den 1460er-Jahren bestanden. Der Straßburger Drucker verwendete nach Gerhard Piccard schon vor 1468 Großregalpapier aus den Mühlen der Gallician für den Druck einer lateinischen Bibel und griff auch für spätere großformatige Drucke in den Jahren 1472 und 1474 auf dieses Papier zurück. ${ }^{2822}$ Natürlich deutet dies nicht zwingend auf einen direkten Kontakt hin, da das Papier auch durch einen Zwischenhändler zu Eggestein nach Straßburg gekommen sein konnte. Sicher ist jedoch, dass der Drucker Anton Gallician und seine Produkte bereits vor 1478 kannte und schätzte.

Ein weiterer Kontakt zu einem Straßburger Drucker bietet mehr Details und macht deutlich, dass Anton Gallician auch als Verleger von Druckwerken tätig wurde. Im Juni 1480 klagten sein Sohn Hans Gallician II und sein Schwiegersohn Jacob Meyer, der Mann seiner Tochter Anna, ${ }^{2823}$ gegen Ulrich von Löwingen. ${ }^{2824}$ Dieser befand sich zur betreffenden Zeit in Basel und hatte in einer Herberge Quartier bezogen. Dorthin brachten ihm die Kläger ein Buch zur Ansicht, das er nun nicht mehr herausgeben wollte. Der Beklagte sah sich jedoch im Recht, da Anton Gallician ihn zuvor gefragt habe, ob er eben dieses Buch für ihn drucken wolle, und ihm dazu den Exklusivauftrag erteilt und die Lieferung des benötigten Papiers versprochen habe. Ulrich von Löwingen hatte diesen Auftrag nach eigener Aussage angenommen und bereits damit begonnen, seine Werkstatt für den Druck des Buchs vorzubereiten. Daher forderte er, dass die Kläger ihm das Buch zum Drucken überlassen und ihm das notwendige Papier dazu schicken sollten. Anderenfalls würde er eine Entschädigung für die bereits entstandenen Kosten verlangen. Das Basler Gericht sah diese mit Anton Galli-

2820 StABS, Gerichtsarchiv A 33, 366. Vgl. Stehlin 1888, 30, Nr. 139.

2821 StABS, Gerichtsarchiv A 33, 366. Vgl. Stehlin 1888, 30, Nr. 139.

2822 Vgl. Piccard 1967, 308. Leider gibt Piccard keine Maße für das Großregalformat an. In einer anderen Publikation setzt er es, wieder ohne Maßangaben, mit dem Imperialformat gleich, vgl. Piccard 1956, 80. Karl Theodor Weiss bezeichnet - ohne Zeitangaben - einen Bogen von 52,9 Zentimetern auf 73,6 Zentimetern als Großregal, Peter Tschudin führt für das 19. Jahrhundert die Maße 50 Zentimeter mal 65 Zentimeter an, vgl. K. Th. Weiss 1962, 57; P. Tschudin 2012a, 269. Zur Verwendung von Papier mit den Wasserzeichen der Gallician durch Eggestein vgl. auch W. Fr. Tschudin 1955, Tab. 8a; W. Fr. Tschudin 1958, 110. Nach Charles-Moïse Briquet maßen die in Straßburger und Basler Drucken verwendeten großformatigen Papiere mit Ochsenkopf und Buchstabe T circa 48 Zentimeter auf 70 Zentimeter, vgl. Briquet 1968, Bd. 2, 751.

2823 StABS, Gerichtsarchiv B 11, 109r. Vgl. Kälin 1974, 161.

2824 StABS, Gerichtsarchiv A 33, 392. Vgl. Stehlin 1888, 31, Nr. 146. Vgl. P. Tschudin 1997, 26. 
cian getroffene Verabredung offenbar nicht als legitimen Grund, das Buch gegen den Willen der Kläger zu behalten, und ordnete daher die Rückgabe des Werks an. Ulrich von Löwingen erhielt jedoch die Möglichkeit, innerhalb von drei Wochen gerichtlich gegen Anton Gallician vorzugehen. Während dieses Zeitraums durfte letzterer keiner dritten Person einen Druckauftrag für das betreffende Buch erteilen. Nach Verstreichen der Frist sollte allerdings Ulrichs Exklusivrecht auf das Buch und damit der zwischen Papiermacher und Drucker geschlossene Vertrag erlöschen. Dieses Beispiel zeigt deutlich, dass der Drucker Ulrich von Löwingen zwar Papier von Anton Gallician erhalten sollte, aber kein regulärer Kunde war, sondern dass vielmehr Anton Gallician sein Auftraggeber war.

Auch zu Basler Druckern unterhielten Anton und Michel Gallician geschäftliche Beziehungen. Sowohl im Streitfall mit Michel Wenssler ${ }^{2825}$ im Jahr 1484 als auch mit Niclaus Kessler ${ }^{2826}$ im Jahr 1486 gab Anton seinem Schwiegersohn Adam Kridwyß, Doktor der Rechte an der Universität Basel, die Vollmacht, für ihn vor Gericht zu prozessieren. ${ }^{2827}$ Der Hintergrund der Streitigkeiten ist unbekannt. Michel Gallician stand zwischen 1489 und 1497 ebenfalls in geschäftlichem Kontakt mit Michel Wenssler und Niclaus Kessler sowie mit Erhard Oeglin. ${ }^{2828}$ Einen tieferen Einblick erhalten wir in die Beziehung Antons zu Berthold Ruppel, allerdings erst nach dem Tod des Druckers im Jahr $1495 .^{2829}$ Ebenso wie bei Ulrich von Löwingen engagierte sich Anton Gallician bei Berthold Ruppel als Verleger. Dies geht aus einem Eintrag im Kundschaftenbuch des Schultheißengerichts hervor. Martin Flach, ebenfalls Drucker und Mitglied des Basler Rats, sagte aus, dass ihm ein nicht näher benannter Welsche in Besançon ${ }^{2830}$ ein Buch mit dem Titel Summa Predicancium zum Druck angeboten habe. Das Buch habe der Mann jedoch nur herausgeben wollen, wenn Meister Anton Gallician dafür Bürgschaft leistete. Dies tat er offenbar, denn als Martin Flach, nach Basel zurückge-

2825 Michel Wenssler wirkte zwischen 1473 und 1491 als Drucker in Basel. Er gilt als einer der bedeutendsten Basler Frühdrucker und beschäftigte zeitweise knapp 30 Angestellte. 1491 erlebte er seinen Bankrott und flüchtete aus Basel. Er ist anschließend als Drucker in Cluny, Mâcon und Lyon greifbar, vgl. Hagemann 1960, 262-264; Geldner 1968b, 113. Zum Konkursverfahren gegen Wenssler vgl. Hagemann 1987, 134.

2826 Niclaus Kessler war von 1483 bis 1510 in Basel als Drucker tätig und mit der Tochter des Druckers Bernhart Richel verheiratet, dessen Offizin Zum Blumen er nach dessen Tod 1482 übernahm, vgl. Reske 2015, 66 f.

2827 StABS, Gerichtsarchiv A 35, 1r, 112v. Vgl. Stehlin 1888, 59, Nr. 367; 69, Nr. 451.

2828 StABS, Gerichtsarchiv C 14, 83v; A 40, 247r; C 16, 41v; A 41, 228r, 230r-230v; C 16, 47v. Vgl. Stehlin 1888, 91 f., Nr. 609; 154, Nr. 965; 162, Nr. 1025; 163, Nr. 1030; 164, Nr. 1033 u. 1036.

2829 Berthold Ruppel arbeitete vermutlich seit 1468 als Drucker in Basel. Er verstarb 1495. Ob es sich bei ihm um den Berthold von Hanau genannten Gesellen Gutenbergs handelt, ist zwar nicht bewiesen, wird jedoch vermutet, vgl. Geldner 1968b, 111 f.; Reske 2005, 280 f.

2830 Nach Besançon bestanden noch weitere wichtige Verbindungen zu Papiermachern und Kaufleuten, vgl. Kälin 1974, 91 f. 
kehrt, sich anderen Geschäften zuwandte und das Buch nicht mehr drucken wollte, beauftragte Anton Gallician Berthold Ruppel mit dem Druck. ${ }^{2831}$

Dass der Papiermacher und der Drucker auch außerhalb dieses einen Auftrags in enger geschäftlicher Verbindung zueinander standen, belegt die Aussage von Bertholds Witwe, gegen die Anton Gallician vermutlich wegen noch ausstehenden Schulden Klage erhoben hatte. ${ }^{2832}$ Sie gab zu Protokoll, dass Anton Gallician während der Krankheit ihres Manns zu ihm gekommen sei. Bei dieser Gelegenheit habe sie die beiden, die viele Geschäfte miteinander abgewickelt hätten, angesprochen, eine letzte Abrechnung zu machen. Daraufhin habe Anton Gallician gesagt, Berthold schulde ihm nichts. ${ }^{2833}$

Die Bekanntheit Anton Gallicians über Basel hinaus bestätigt ein undatierter Brief Adolf Ruschs an Johann Amerbach. ${ }^{2834}$ Hierin schrieb der Straßburger Drucker seinem Basler Kollegen, dass Meister Anton und dessen Bruder ihn, wenn sie Geld bräuchten, um Abnahme ihrer Ware ersuchen könnten. ${ }^{2835}$ Wenn es sich bei diesem Meister Anton und seinem Bruder tatsächlich um Anton und Michel Gallician handelte, und nicht, wie Oscar von Hase annimmt, um zwei Papiermacher aus Épinal, dann hat bereits Alfred Hartmann zu Recht angemerkt, dass die Gallician-Brüder in den 1480er-Jahren wohl kaum auf den Kauf ihres Papiers durch Adolf Rusch angewiesen waren. ${ }^{2836}$ Beide versteuerten bereits Ende der 1470er-Jahre ein Vermögen von über 1.000 Gulden. ${ }^{2837}$

Mit seinem Schwiegersohn Michel Warmund besaß Anton Gallician ebenfalls Verbindungen nach Bern. ${ }^{2838}$ Diese nutzte er, um seinen Geschäften mit Basler Druckern auch in dieser Stadt nachzugehen. So verpflichtete er im Jahr 1482 seinen

2831 StABS, Gerichtsarchiv D 16, 135v; Stehlin 1888, 157, Nr. 982.

2832 Vgl. auch Piccard 1967, 203 f. Piccard gibt zudem an, dass die Verbindung zu Anton Gallician bis auf eine weitere die einzige in den Gerichtsprotokollen verzeichnete Geschäftsbeziehung Berthold Ruppels war.

2833 StABS, Gerichtsarchiv A 40, 245v-246r: [...] daz meister Anthoni zu meister Berchtold uff einen tag in siner kranckheitt kommen unnd sy zu im geredt hab es were eben recht sy zwen hetten eben vil mitteinander gehandelt sy sollten sagen wer dem anderen schuldig were, daruff meister Anthoni gesprochen hett er vorderte meister Berchtold nützit, vgl. Stehlin 1888, 154, Nr. 964.

2834 Alfred Hartmann vermutet, dass der Brief um das Jahr 1483 verfasst wurde, vgl. Die Amerbachkorrespondenz 1942, 8, Nr. 7. Zu Adolf Rusch vgl. Geldner 1968b, 62 f.

2835 Die Amerbachkorrespondenz 1942, 8 f., Nr. 7.

2836 Vgl. Die Amerbachkorrespondenz 1942, 9 mit Anm. 6, Nr. 7.

2837 Vgl. Kapitel 3.3.5.1, S. 433.

2838 Vgl. Kapitel 3.2.1.7. 
Schwiegersohn, für die beiden Basler Drucker Meister Jacob und Hans Wurster, ${ }^{2839}$ die geschäftlich in Bern zu tun hatten, als Bürge zu fungieren. ${ }^{2840}$

Wie das zweite Fallbeispiel zeigt, konnte sich umgekehrt auch Michel Warmund auf seine Basler Verwandtschaft verlassen. Als er in den Jahren 1479 bis 1483 in einem Rechtsstreit mit dem Basler Drucker Johannes Meister lag, beauftragte er Hans Gallician, den Sohn Antons, ihn vor Gericht zu vertreten. ${ }^{2841}$ Johannes Meister forderte von dem Berner Papiermacher Schadensersatz, weil dieser versprochen habe, ihm umgehend Papier zu liefern, mit der Lieferung jedoch säumig wurde, wodurch ihm kosten und schaden entstanden seien. Diesen Verlust, so Johannes Meister, müsse Michel Warmund ausgleichen. Zudem verlangte der Drucker, dass Warmund das Geld, das er von einem Priester eingezogen habe, zurückerstatte. ${ }^{2842}$ Hans Gallician II antwortete im Namen seines Schwagers mit einer Gegenklage. Johannes Meister war dem Papiermacher nach dessen Aussage noch 100 Gulden schuldig, die er eigentlich bereits zur Frankfurter Messe hätte bezahlen müssen. ${ }^{2843}$ Durch diese Säumigkeit seien Michel Warmund Kosten entstanden, die er durch das Einziehen von 8,5 Gulden und 18 Schilling von besagtem Priester wenigstens zu einem Bruchteil hatte ausgleichen wollen. Johannes Meister selbst habe ihn dazu ermächtigt. Das Gericht erkannte

2839 Es handelte sich wahrscheinlich um die Drucker Jacob Wolf von Pforzheim und Johannes Wurster, die Geschäftspartner waren, vgl. Steiff 1898, 345 f. Zu Jacob von Pforzheim vgl. Reske 2015, 67.

2840 StABS, Gerichtsarchiv A 34, 108; Stehlin 1888, 43, Nr. 233. Bei diesem Eintrag ist bemerkenswert, wie oft der Schreiber zunächst Michel anstatt Anton Gallician schrieb oder schreiben wollte, seinen Irrtum bemerkte und - meistens - ausbesserte. Dies zeigt, dass die beiden Brüder dem Gericht gleich gut bekannt waren. Zudem ist zu vermuten, dass diese Art von Fehler des Öfteren vorkam. Als Beispiel sei hier die Vollmacht an Jacob Gallician genannt, die einmal Michel Gallician seinem Sohn, das andere Mal aber möglicherweise Anton Gallician seinem Brudersohn gab. Beide Male wird jedoch nur Michel Gallician genannt, vgl. StABS, Gerichtsarchiv A 40, 247r; A 41, 5v. Vgl. Stehlin 1888, 154 f., Nr. 965 u. 966. Vgl. Anm. 2237.

2841 StABS, Gerichtsarchiv A 33, 131; A 34, 188, 312. Vgl. Stehlin 1888, 27, Nr. 118; 46, Nr. 264; 54, Nr. 314. Dass eine solche Vollmacht es tatsächlich ermöglichte, den eigentlichen Kläger in allen Belangen die Streitsache betreffend zu vertreten, macht ein weiterer Eintrag in die Gerichtsprotokolle deutlich. Im Dezember 1482, folglich nach der Übertragung der Vollmacht auf Hans Gallician II im September desselben Jahres, wurde der Drucker Johannes Meister vom Gericht aufgefordert, in seinem Streitfall gegen Antoni Gallicienß sun seine Zeugenaussagen vorzulegen. Der Name des eigentlichen Klägers, Michel Warmund aus Bern, wurde hier nicht genannt. Erstaunlich hierbei ist, dass auch Hans Gallician II nicht mit Namen erwähnt wurde, sondern dass seines Vaters Name für ihn stand. StABS, Gerichtsarchiv A 34, 205. Karl Stehlin gibt in seinem Regest zu diesem Eintrag fälschlicherweise Anton Gallician als Kläger an. Vgl. Stehlin 1888, 49, Nr. 277.

2842 StABS, Gerichtsarchiv A 34, 312. Vgl. Stehlin 1888, 54, Nr. 314.

2843 Da der Eintrag in das Urteilsbuch auf den 2. August 1483 datiert ist, handelte es sich vermutlich um die Frankfurter Fastenmessen, die jährlich vom Sonntag Oculi bis zum Sonntag Judica, also zwischen dem vierten und dem zweiten Sonntag vor Ostern stattfand. Die Frankfurter Herbstmesse begann erst an Mariä Himmelfahrt (15. August) und endete an Mariä Geburt (8. September), vgl. Schneidmüller 1991, 73; Rothmann 1998, 102. 
daraufhin, dass Hans Gallician II die besseren Beweise hatte vorbringen können. ${ }^{2844}$ Das Interessante an diesem Fall ist - neben der Abhängigkeit der Drucker von pünktlichen Papierlieferungen - die Tatsache, dass Papier auch bei der Existenz mehrerer lokaler Papiermühlen mit qualitativ hochwertigen Produkten aus anderen Städten importiert wurde.

Das dritte Beispiel behandelt die geschäftlichen Beziehungen Hans Sigmunds von Aug, Besitzer der Papiermühlen zu Kluben vor den Toren Basels. ${ }^{2845}$ Ebenfalls eine Papierlieferung betraf der Rechtsstreit mit dem Basler Drucker Johann Froben. ${ }^{2846}$ Dank mehrerer Einträge in die Gerichtsprotokolle lässt sich die Verhandlung dieses Falls sehr gut nachvollziehen. Im August 1518 hatte Hans Sigmund von Aug Klage gegen Johann Froben erhoben. Er habe dem Drucker insgesamt 15 Ballen Papier geliefert, davon habe Froben jedoch nur zehn Ballen bezahlt. Daher sei er ihm noch die Bezahlung der letzten fünf Ballen Papier schuldig, die er ihm zwischen dem 17. Januar und Fastnacht geschickt habe. Froben wollte von dieser Sache jedoch nichts wissen. Das Gericht bat daraufhin die Prozessparteien, sich gütlich zu einigen und erst dann mit Beweisen vor Gericht zu treten, wenn eine solche Einigung gescheitert sei. ${ }^{2847}$ Offensichtlich kamen Hans Sigmund von Aug und Johann Froben nicht überein, denn im Dezember 1518 wurde der Papierer Oswald Banwart, der angab, vor einem Jahr bei Meister Sigmund gearbeitet zu haben, als Zeuge vorgeladen. Er sagte aus, dass er in der Papiermühle zu Kluben Papier gemacht habe, wovon einiges an Johann Froben ausgeliefert worden sei. Was die beiden Meister untereinander vereinbart hatten und wieviel Papier tatsächlich an den Drucker geschickt wurde, wusste er anscheinend nicht. $^{2848}$

2844 StABS, Gerichtsarchiv A 34, 312. Vgl. Stehlin 1888, 54, Nr. 314. Vgl. auch P. Tschudin 1997, 25 f. In einem auf den 11. August (Lune post Laurentii) datierten Eintrag wird dieselbe Streitsache verhandelt. Hier wird allerdings der Berner Papiermacher Michel mit dem Familiennamen Gallician bedacht, obwohl er lediglich angeheiratet war und sonst Michel Warmund, Wermund, Warung, Warnung oder Verdon genannt wurde. Das Urteil des Gerichts lautete hier, dass Hans Gallician II die Beweise für seine Aussage innerhalb der gerichtlichen Frist erbringen solle, STABS, Gerichtsarchiv A 34, 315; Stehlin 1888, 54, Nr. 314. In diesem Zusammenhang stellt sich auch die Frage, ob eine im November 1479 eingetragene Streitsache zwischen Michel Gallician und Johannes Meister, die ebenfalls 100 Gulden zum Gegenstand hatte, nicht eigentlich denselben Fall zwischen Michel Warmund und dem Drucker betraf und der Gerichtsschreiber sich verschrieben hatte, vgl. StABS, Gerichtsarchiv A 33, 142; Stehlin 1888, 27, Nr. 120. Vgl. hierzu auch Piccard 1967, 219. Zu den Namensvarianten von Warmund, vgl. ebd., 134; Kälin 1974, 272 mit Anm. 105.

2845 Vgl. Kapitel 3.2.1.1, S. 223.

2846 Johann Froben hatte bei Anton Koberger in Nürnberg gelernt und war seit Anfang der 1490erJahre in Basel als Drucker tätig, wo er nach 1512 zum Mittelpunkt des deutschen Humanismus wurde, vgl. Reske 2015, $67 \mathrm{f}$.

2847 StABS, Gerichtsarchiv A 53, 200v; Stehlin 1891, 73, Nr. 2039. Vgl. Kälin 1982, 32; P. Tschudin $1997,26$.

2848 StABS, Gerichtsarchiv D 23, 26r: Oswald Banwart der bapirer hatt gesworn unnd sagt das er vor einem jar by meister Sigmund zu Klůben gedient unnd bapir gemacht von welhem bapir meister Sigmund 
Unterstützte bereits die Zeugenaussage des eigenen Gesellen nicht die Rechtmäßigkeit von Meister Sigmunds Forderung, so taten es die am 16. Januar 1519 aufgenommenen Vernehmungen noch weniger. Ein Druckergeselle von Johann Froben, Alexander Pfefferkorn, berichtete, dass er seit November 1517 nicht mehr als zehn Ballen Papier aus Kluben bezogen habe. Das wisse er genau, denn er schreibe solche Dinge auf. ${ }^{2849}$ Die letzten fünf Ballen hatte die Offizin Froben nach dieser Aussage nie bezogen und war daher auch nicht verpflichtet, zu zahlen.

Eine weitere Zeugenaussage in derselben Streitsache tätigte der Druckergeselle Jörg Fuß. Sie wurde von einem weiteren Druckergesellen, Hans Swartz, bestätigt. Die beiden Gesellen arbeiteten vermutlich ebenfalls in der Werkstatt Johann Frobens und wurden von dessen Schwiegervater, dem im Januar 1518 verstorbenen Buchhändler Wolfgang Lachner, der sich in der Offizin seines Schwiegersohns als Verleger betätigte, vor dem 25. November 1517 zu Meister Sigmund nach Kluben geschickt. ${ }^{2850}$ Dort sollten sie um die Auslieferung von Papier ersuchen, damit ein bereits begonnenes Werk fertiggestellt werden konnte. Sigmund von Aug hatte jedoch gerade einen Produktionsengpass, denn er konnte den beiden Gesellen nicht mehr als fünf Ries zur sofortigen Mitnahme anbieten. Eine größere Sendung sei ihm erst möglich, wenn er bei besserer Witterung wieder leimen könne. ${ }^{2851}$ Dann wolle er die vier Ballen Papier, die er Wolfgang Lachner noch schuldete, liefern. Jörg Fuß und Hans Swartz begnügten sich damit, vier Ries Papier mitzunehmen. Diese wurden offensichtlich direkt weiterverarbeitet: Die Gesellen sollten die Bogen auf Geheiß Lachners anfeuchten und bald darauf sei das Buch fertig gedruckt gewesen. Ob Sigmund von Aug danach das versprochene Papier noch geschickt habe, konnte keiner der beiden sagen. ${ }^{2852}$

Damit fielen diese Zeugen auf der einen Seite für eine Bestätigung der Version einer der beiden Parteien eigentlich aus, da sie über den Gesamtumfang der Papierlieferungen keinen Überblick hatten. Auf der anderen Seite bewies diese Vernehmung jedoch, dass Sigmund von Aug Lieferschwierigkeiten hatte und bei Wolfgang Lachner noch mit vier Ballen Papier im Rückstand war. In welchem Umfang er das Papier nachlieferte, blieb umstritten. Letztlich konnte Sigmund von Aug nicht beweisen,

meister Hannsen zum Sessel etlichs geschickt aber wievil oder was sy mit einandern gehandelt habenn darvon sye im nutzit zewissenn. Vgl. Stehlin 1891, 75 f., Nr. 2048.

2849 StABS, Gerichtsarchiv D 23, 29r: Alexander Pfefferkorn der trucker gessell hatt gesworn unnd sagt, als er meister Hannsen Froben diener gwesen und noch sye das er von meister Sigmunden Steinschnider von Katherine im xvii jar verschinen bis uff den huttigen tag nit mer dann zehen ballen bappirs empfangen dann er sollichs eygentlich ufgeschriben hab. Vgl. Stehlin 1891, 76, Nr. 2050.

2850 StABS, Gerichtsarchiv D 23, 29r-29v. Vgl. Stehlin 1891, 76, Nr. 2050. Zu Wolfgang Lachner vgl. Hieronymus 1982, $377 \mathrm{f}$.

2851 StABS, Gerichtsarchiv D 23, 29v: So bald er dann gewitters halp lymen köndi wolt er sollichs thun unnd im alßdann mer schicken. In dieser Passage scheint ein technisches Detail des Produktionsprozesses durch, vgl. Kapitel 2.3.7, S. 37, 156.

2852 StABS, Gerichtsarchiv D 23, 29v. Vgl. Stehlin 1891, 76, Nr. 2050. 
dass er 15 statt nur zehn Ballen an Froben geschickt hatte. Dieser schwor, nur zehn Ballen Papier erhalten zu haben, und war damit der Anklage ledig. ${ }^{2853}$

Eindeutig und berechtigt scheinen hingegen die Forderungen Sigmunds von Aug an die Drucker Adam Petri und Niclaus Lamparter gewesen zu sein. Adam Petri und seine Frau bekannten sich im Oktober 1519 dazu, Meister Sigmund 126 Gulden 10 Schilling schuldig zu sein und versprachen, diesen Betrag innerhalb von 14 Tagen $\mathrm{zu}$ bezahlen. Als Pfand stellten sie Liegenschaften in Basel. ${ }^{2854}$ Wofür sie diesen relativ hohen Betrag schuldeten, wird nicht angegeben. Dass es sich, wie eventuell auch im nächsten Fall, um die Bezahlung einer Papierlieferung handelte, ist jedoch wahrscheinlich. Niclaus Lamparter hatte ebenfalls Schulden bei Sigmund von Aug und verpflichtete sich im Oktober 1519 gerichtlich, ihm die 76 Gulden in Raten zu entrichten. ${ }^{2855}$

Neben Buchdruckern benötigten auch andere Gewerbe Papier zur Produktion ihrer Waren. Daher gehörten zu den Kunden der Papierer auch Kartenmaler, Buchbinder und andere mit dem Buchdruck in Verbindung stehende Handwerke. Bereits im Jahr 1462 belegte Michel Gallician das Gut des Kartenmachers Jacob wegen einer ausstehenden Schuldsumme mit Arrest. ${ }^{2856}$ Ende der 1470er-Jahre war er gemeinsam mit weiteren Personen, darunter sein Bruder Anton Gallician sowie Ulrich Meltinger, Gläubiger des einmal als Buchstabenschneider, einmal als Buchdrucker bezeichneten Hans Frank von Straßburg. ${ }^{2857}$ Ob Hans Franks horrende Schulden durch eine erfolglose Tätigkeit als Drucker entstanden waren, lässt sich nicht mit Sicherheit sagen. ${ }^{2858}$ Gewiss ist hingegen, dass seine Gläubiger auf das falsche Pferd gesetzt hatten. Hans Frank ging 1478 bankrott und flüchtete aus Basel. Seinen Kreditgebern blieb nichts anderes übrig, als ihre Forderungen beim Schultheißengericht anzumelden, das anschließend das Konkursverfahren einleitete. Die Vermögensliquidierung des von Hans Frank in Basel zurückgelassenen Besitzes erlaubte jedoch keine vollständige Ausbezahlung der Geldgeber. Die erlösten 27 Pfund 14 Schilling 11 Pfennig ermöglichten in den meisten Fällen lediglich die Zahlung von einem Schilling je Pfund, also fünf Prozent der Schuldsumme. So bekam Michel Gallician, der für eine Forderung von 110 Gulden Francks Gut mit Arrest belegt hatte, ${ }^{2859}$ nur 5,5 Pfund ein Schilling 6 Pfennig erstattet. ${ }^{2860}$ Anton Gallician wurden 7 Pfund 9 Schilling 6 Pfennig

2853 StABS, Gerichtsarchiv A 53, 259r. Vgl. Stehlin 1891, 76 f., Nr. 2052. Vgl. P. Tschudin 1997, 26.

2854 StABS, Gerichtsarchiv C 23, 95v. Vgl. Kälin 1982, 32, 36.

2855 StABS, Gerichtsarchiv C 23, 97v. Vgl. Kälin 1982, 36.

2856 StABS, Gerichtsarchiv E 4, 143r. Vgl. auch Piccard 1967, 87 f.

2857 Vgl. Piccard 1967, 217 f., 242 f.

2858 Vgl. Piccard 1967, 217 f., 242 f.

2859 StABS, Gerichtsarchiv E 6, 25v. Vgl. Stehlin 1888, 20, Nr. 82.

2860 StABS, Gerichtsarchiv G 2, 41v. Vgl. Stehlin 1888, 22 f., Nr. 98. 
ausbezahlt. Dies entsprach rechnerisch einem ursprünglichen Kapitaleinsatz von 149,5 Pfund, sodass Anton Gallician Verluste im Wert von gut 142 Pfund machte. ${ }^{2861}$

So risikoreich waren aber bei weitem nicht alle Geschäfte, auch wenn die Gefahr, dass ein Schuldner sich durch Flucht seiner Verantwortung entzog, häufig gegeben war. Der Kartenmaler Heini Wolleben schuldete Hans Lufft von Ettlingen, dem die Rychmühle im St. Albantal gehörte, einen nicht genannten Geldbetrag, vermutlich aufgrund von Papierlieferungen, und hatte seine Schuld am vereinbarten Termin nicht beglichen. Daher wandte sich Hans Lufft im März 1501 an das Großbasler Schultheißengericht und forderte, dass die Frau Heini Wollebens den ausstehenden Betrag für ihren Mann entrichten solle. Die Beklagte lehnte diese Forderung mit der Begründung ab, dass ihr Mann die Stadt verlassen habe und sie noch nicht einmal wisse, ob er tod oder lebend sye. ${ }^{2862}$ Die 4 Pfund, die sie selbst Hans Lufft schuldete, wolle sie ihm aber geben. ${ }^{2863}$ Hinsichtlich der anderen Schuldsumme versprach sie, bis zum nächsten Gerichtstag nach Ostern nach ihrem Mann zu suchen und solange nichts von ihrem Hausrat zu veräußern. Diese Auflage sollte verhindern, dass die Frau ihr Hab und Gut zu Geld machte und sich ebenfalls absetzte. In diesem Fall wäre die Befriedigung des Gläubigers durch Liquidation der vorhandenen Vermögenswerte erschwert worden, wie es auch beim flüchtigen Hans Frank der Fall war.

Im September 1501 war Heini Wolleben offenbar immer noch nicht nach Basel zurückgekehrt, denn es wurde seitens des Gerichts die Möglichkeit erwogen, ihn für flüchtig zu erklären. Ausgelöst hatte dies der Antrag des Papiermachers Hans von Schaffhausen, der Zugriff auf Wollebens Gut verlangte, bis die Schulden, die der Kartenmaler anscheinend bei ihm hatte, beglichen seien. Das Gericht gab diesem Antrag statt und verlangte lediglich, dass Hans von Schaffhausen seinem Schuldner den dinglichen Arrest ankündigte - wenn er ihn nicht gleich für flüchtig erklären ließ.2864

Weitere Verbindungen zwischen Papiermachern und ihren Kunden lassen sich zum einen zwischen Hans Kielhammer von Schaffhausen und dem Buchbinder Jacob

2861 StABS, Gerichtsarchiv G 2, 41v. Vgl. Stehlin 1888, 22 f., Nr. 98. 149,5 Pfund entsprachen im Rechnungsjahr 1478/79 ungefähr einem Guldenwert von 130 Gulden, 142,025 Pfund einem Guldenwert von 123,5 Gulden, vgl. den Kurs von 115 Pfund zu 100 Gulden in Rosen 1989, 145. Ein Verlust von 119,6 Gulden ergibt sich, wenn man den Guldenwert mit dem im Jahr davor und im Jahr danach gültigen Verhältnis von 125 Pfund zu 100 Gulden berechnet. Auf diesem letzteren Wert basiert wahrscheinlich, aufgerundet, Gerhard Piccards Angabe, Anton Gallician habe 120 Gulden Verlust gemacht, vgl. Piccard 1967, 243.

2862 StABS, Gerichtsarchiv A 43, 144v. Vgl. Stehlin 1891, 11, Nr. 1636.

2863 Vgl. auch einen dahingehend lautenden Eintrag im Vergichtbuch, der auf denselben Tag datiert ist, StABS, Gerichtsarchiv C 17, 15v. Vgl. Stehlin 1891, 11 f., Nr. 1637.

2864 StABS, Gerichtsarchiv A 43, 189v. Vgl. Stehlin 1891, 13, Nr. 1648. Zwar ist es durchaus möglich, dass auch Hans Kielhammer von Schaffhausen Gläubiger Heini Wollebens war, ein leiser Zweifel bleibt jedoch hinsichtlich der Frage, ob hier nicht vielleicht der Name verwechselt wurde und es eigentlich Hans (Lufft) von Ettlingen heißen müsste. 
Spidler, der ihm im Jahr 15022 Pfund schuldete, ${ }^{2865}$ zum anderen 1508 zwischen Franz Gallician und dem Züricher Kartenmaler Rudolf Schelti nachweisen. ${ }^{2866}$ In einem dritten Fall schuldete Thoman Kartenmaler dem Papiermacher und Besitzer der hinteren Spiegelmühle Michel Gernler im Jahr 1504 eine Summe von 3 Pfund 3 Schilling. ${ }^{2867}$ Eine deutlich größere Menge an Papier scheinen der Kartenmaler Thoman Swartz, der eventuell identisch mit Thoman Kartenmaler war, und seine Frau Magdalena von Jörg Dürr d. Ä. bezogen zu haben. Sie schuldeten ihm nämlich im Jahr 1511 umb bappyr 40 Pfund Basler Stebler, die sie im Zeitraum von einem Jahr abzubezahlen versprachen. Als Sicherheit gaben sie ihr Haus Zum kleinen roten Löwen an der Freien Straße als Pfand. ${ }^{2868}$

Jörg Dürr d. Ä. lieferte auch Papier an den Buchführer Hans Haselberg. Im Jahr 1519 war dieser dem Papiermacher eine nicht genannte Summe Geld für Papier schuldig und verpfändete ihm dafür mehrere Bücher. Diese Bücher wollte Jörg Dürr nun verkaufen, um auf diese Weise zu seinem Geld zu kommen. Hans Haselberg hatte ihm den Verkauf in einem Brief zwar schriftlich gestattet, aber Jörg Dürr wollte sichergehen, dass er mit der Veräußerung der Bücher auch rechtlich korrekt handelte. Das Gericht erklärte sein geplantes Vorgehen für rechtens, unter der Bedingung, dass er im Streitfall eine ordentliche Abrechnung über den Verkauf vorlegen könne. ${ }^{2869}$ Somit wurde der Papiermacher Jörg Dürr - zumindest temporär - auch zum Buchführer.

In geschäftlichem Kontakt mit Basler Kartenmalern, darunter auch der bereits genannte Thoman Swartz, stand auch Fridlin Mennli, der vermutlich die Lörracher Papiermühle leitete. ${ }^{2870}$ Er hatte 1508 versucht, den Kartenmaler Diebolt Müg zur Begleichung seiner Schuld zu bringen, indem er sein Werkzeug beschlagnahmte. Anscheinend funktionierte diese Vorgehensweise, denn Diebolt versprach, innerhalb von 14 Tagen eine Anzahlung von 2 Gulden zu leisten. Im Gegenzug sollte Fridlin Mennli ihm sin werkzüg wider zu handen geben. ${ }^{2871}$ Den restlichen Betrag zahlte Diebolt Müg in wöchentlichen Raten von je 5 Schilling. Die Witwe des Kartenmalers Thoman Swartz hatte ebenfalls noch offene Rechnungen bei Fridlin Mennli zu begleichen. Sie schuldete ihm 15183 Pfund und 6 Pfennig, vermutlich auch für die Lie-

2865 StABS, Gerichtsarchiv C 17, 89r. Vgl. Stehlin 1891, 16, Nr. 1677.

2866 StABS, Gerichtsarchiv A 49, 31r. Vgl. Stehlin 1891, 34, Nr. 1802.

2867 StABS, Gerichtsarchiv C 18, 53r. Vgl. Stehlin 1891, 19, Nr. 1699.

2868 StABS, Gerichtsarchiv C 20, 167r. Vgl. Stehlin 1891, 46 f., Nr. 1883.

2869 StABS, Gerichtsarchiv A 54, 50v. Vgl. Stehlin 1891, 81, Nr. 2076.

2870 Vgl. Kapitel 3.2.1.12.

2871 StABS, Gerichtsarchiv C 20, 34v. Vgl. Stehlin 1891, 35, Nr. 1820. Das Einbehalten von Werkzeug als Pfand stellte ein probates Mittel dar, um sich der Rückzahlung einer geliehenen Summe zu versichern. Ein ähnliches Beispiel ist aus Speyer bekannt. Dort lieh der Drucker Peter Drach 1500 einem Geltschlager von Mainz einen halben Gulden und behielt dafür dessen Schlagstein als Pfand ein, vgl. Geldner 1962/64, 132; Mäkeler 2005, 50. 
ferung von Papier, und versprach ihm, die ausstehende Summe in vierzehntägigen Raten zu 5 Pfennig abzubezahlen. ${ }^{2872}$

Aber auch die potentiellen Kunden in Basel selbst - Drucker, Kartenmacher, Buchbinder - bezogen Papier von auswärtigen Papiermühlen, da Papier keine Ware war, die man ausschließlich vor Ort kaufte, sondern ein Exportgut, bei dem Verfügbarkeit, Preis, Qualität und die Beziehung zum Verkäufer den Bezugsort bestimmten. ${ }^{2873}$ Ein Beispiel hierfür ist der Drucker Johann Amerbach, dessen reiche Korrespondenz einen kleinen Einblick in den spätmittelalterlichen Papierhandel und die Bezugsquellen von Bedruckstoffen gibt. In der Mitte der 1480er-Jahre schrieb der Straßburger Drucker Adolf Rusch in einem Brief an Johann Amerbach, dass dieser elf Ballen Papier aus Bern erhalten werden. Dieses Papier stammte aller Wahrscheinlichkeit nach aus der Papiermühle zu Thal, die Michel Warmund seit 1474 betrieb. ${ }^{2874}$ Zusätzlich sollte Amerbach sechs bis acht Ballen bei dem Papiermacher Ulrich Züricher in Basel kaufen und diese in Leinen eingeschlagen an Rusch schicken. ${ }^{2875}$

Der rege Briefwechsel zwischen dem Nürnberger Druckherrn Anton Koberger und Johann Amerbach offenbart die enge Zusammenarbeit der beiden Geschäftspartner, die zusammen mehrere Werke verlegten und druckten. In den meisten Fällen war der Nürnberger Drucker der Verleger, während Johann Amerbach die Bücher in Basel druckte. Das hierfür benötigte Papier organisierte und bezahlte Anton Koberger und ließ es an Amerbach liefern. Die Briefe berichten häufig von den Schwierigkeiten, die bei solchen Papierlieferungen auftraten. So beschwerte sich Johann Amerbach im Mai 1497 bei Anton Koberger über das Papier, das ihm auf dessen Geheiß ein Conrad Meyer geschickt hatte: Es sei zu klein, zu kurz und zu schmal und zudem von minderer Qualität. ${ }^{2876}$ Um seinen Worten Nachdruck zu verleihen, hatte er dem Brief offenbar einen Bogen dieses Papiers beigelegt. Anton Koberger wies ihn an, dieses Papier auf keinen Fall zum Druck zu verwenden und die bereits erhaltenen 25 Ballen an Conrad Meyer zurückzugeben. Er versprach zudem, sich mit dem Lieferanten in Verbindung zu setzen, damit dieser gemäß ihrer vorhergehenden Vereinbarung Papier von richtiger Größe und guter Qualität sende. Um sicherzugehen, dass Amerbach nicht erneut von Conrad Meyer betrogen wurde, fügte Koberger seinem Brief eine Papierprobe hinzu. ${ }^{2877}$

2872 StABS, Gerichtsarchiv C 22, 244v, 256v. Vgl. Stehlin 1891, 71, Nr. 2030 u. 2032.

2873 Im Jahr 1506 erleichterte der Basler Rat den städtischen Druckern den Kauf von auswärtig produziertem Papier, indem er gestattete, das Papier, welches sie außerhalb der Stadt kauften, direkt in ihre Offizinen zu führen, ohne den Umweg über das Kaufhaus gehen und ohne den Kaufhauszoll zahlen zu müssen, vgl. StABS, Ratsbücher B 2, 22r. Vgl. Stehlin 1891, 27, Nr. 1748. Zum Papierhandel vgl. Irsigler 2006.

2874 Vgl. Kapitel 3.2.1.7.

2875 Die Amerbachkorrespondenz 1942, 17, Nr. 12.

2876 Das Briefbuch der Koberger 1885, IX f., Nr. 7 u. 8. Vgl. auch Hase 1885, 66.

2877 Das Briefbuch der Koberger 1885, X, Nr. 8. 
Zwei Jahre später, 1499, bat Anton Koberger seinen Basler Geschäftspartner, das für den Druck der Biblia cum postillis Hugonis de Santo Charo benötigte Papier vom Straßburger Kaufmann Friedrich Prechter zu beziehen. ${ }^{2878}$ Dieser handelte vorwiegend mit lothringischem Papier, das er in Épinal kaufte. ${ }^{2879}$ Auch hier kam es zu Unstimmigkeiten ob der Qualität des Papiers. Im März 1502 hatte Anton Koberger vernommen, dass Johann Amerbach mit der Güte des Papiers, das ihm Friedrich Prechter geschickt hatte, nicht zufrieden war. Er bot ihm daher an, Prechter um die Sendung von gutem Papier und um die Rücknahme des schlechten Papiers zu ersuchen. ${ }^{2880}$ Doch entweder kam Friedrich Prechter dieser Bitte nicht nach oder die erneute Papierlieferung traf bei Amerbach ebenfalls auf Missfallen, denn im August desselben Jahres empfahl der Nürnberger Drucker seinem Basler Kollegen in zwei Briefen, Papier nicht mehr von Prechter, sondern direkt aus Basel zu beziehen. ${ }^{2881}$ Es ist äußerst interessant zu sehen, dass die Möglichkeit, Papier vor Ort - und damit wahrscheinlich auch aus den lokalen Papiermühlen - zu kaufen, erst nach wiederholten Schwierigkeiten mit dem eigentlichen Lieferanten in Betracht gezogen wurde.

Der Kauf von Basler Papier für die Unternehmungen der Koberger-AmerbachVerlagsgemeinschaft blieb jedoch ein Einzelfall. Bereits im April 1503 erhielt Johann Amerbach wieder Papier von Prechter - und war auch diesmal mit dem Papier nicht zufrieden. ${ }^{2882}$ War Anton Koberger hier noch ganz der Meinung Amerbachs und riet zur Rücksendung der Ware, so änderte sich dies im März 1504, als der Basler Drucker erneut eine Lieferung Prechters beanstandete. Anton Koberger konnte anhand der beigelegten Proben keinen Qualitätsunterschied zwischen dem angeblich schlechten Papier Prechters und dem Papier, das Amerbach selbst eingekauft hatte und für den Druck verwenden wollte, erkennen und ersuchte daher Amerbach, das bereits bezahlte Papier Prechters zu behalten und zu benutzen. ${ }^{2883}$ Anscheinend fand Johann

2878 Das Briefbuch der Koberger 1885, XXVI f., Nr. 24 u. 25. Vgl. auch Hase 1885, 67. Zur Straßburger Familie Prechter und ihren Handelbeziehungen vgl. Fuchs 1956; Westermann/Westermann 2011. Friedrich Prechter war seit 1499 der hauptsächliche Papierlieferant Kobergers, vgl. Fuchs 1956, 166168; Zaar-Görgens 2004, 173. Neben dem bedeutenden Druckherrn hatte Prechter nach Ausweis der Nürnberger Libri conservatorii noch weitere Kunden in der Stadt, wie beispielsweise die Kartenmaler Endres Gogel und Michel Schrag, vgl. Westermann/Westermann 2011, 256. Auch mit Hans Gallician II, Sohn von Anton und Bruder von Franz Gallician, unterhielt Friedrich Prechter offenbar Handelsbeziehungen. Nach dem politischen Sturz Hans Gallicians II während des Pensionensturms 1521 und der anschließenden Flucht nach Solothurn musste sein Bruder Franz für seine Schulden bei Prechter einstehen, vgl. StABS, Gerichtsarchiv A 56, 21v-22v, 132v, 133r, 147r, 155v. Zu Hans Gallician II vgl. Piccard 1967, 102-117; Kälin 1972a, 7-9.

2879 Vgl. Westermann/Westermann 2011, 257.

2880 Die Amerbachkorrespondenz 1942, 136, Nr. 150.

2881 Das Briefbuch der Koberger 1885, LXVII, Nr. 55, ähnlich LXVIII, Nr. 56. Vgl. auch Hase 1885, 68; Zaar-Görgens 2004, 174.

2882 Das Briefbuch der Koberger 1885, LXXXIV, Nr. 68.

2883 Die Amerbachkorrespondenz 1942, 208, Nr. 219. 
Amerbach jedoch größeren Gefallen an dem Papier, das er selbst gekauft hatte, zumindest hatte er das von Prechter gelieferte Papier nicht für den gemeinsam geplanten Druck verwendet. In einem Brief vom Juni 1504 zeigte Koberger sein Unverständnis darüber. Er bat Amerbach eindringlich, das Papier zum Druck zu gebrauchen, da es gutes Papier sei und er dafür ansonsten keine Verwendung habe. ${ }^{2884}$

Woher Johann Amerbach das Papier bezog, dass er stattdessen bedrucken lassen wollte, ist nicht bekannt. Neben der Vermutung, dass es sich um Basler Papier gehandelt haben könnte, steht die Möglichkeit, dass er es von einem elsässischen Papiermacher liefern ließ. Belegt sind geschäftliche Verbindungen Amerbachs zu dem Papiermacher Lorentz Jörg in Cernay (Sennheim). ${ }^{2855}$ Dieser hatte ihm im Jahr 1497 Papier nach Basel geschickt und ihn bei dieser Gelegenheit gebeten, für ihn die 15 Gulden Schulden, die er bei dem Stadtschreiber von Cernay hatte, auszulegen. Zudem hatte Lorentz Jörg sich weitere 4 Gulden direkt von Amerbach geliehen. Er versprach, ihm beide Beträge zu vergüten, vermutlich in Form von Papierlieferungen. Dass es nicht dazu kam, beweist ein Eintrag in das Urteilsbuch des Großbasler Schultheißengerichts: Im Februar 1500 gab Johann Amerbach dem Papiermacher Burckart von Thann ${ }^{2886}$ die Vollmacht, die ausstehenden Schuldsummen von Lorentz Jörg, der allerdings inzwischen verstorben war, einzuziehen. ${ }^{2887}$

Einen Großauftrag erteilte Johann Amerbach im Jahr 1509 dem Papiermacher Albius, der wohl im elsässischen Erstein, südlich von Straßburg, eine Papiermühle betrieb. ${ }^{2888}$ In seinem Brief vom 25. Mai an den Basler Drucker schrieb Albius von insgesamt 400 Ballen Papier, die er zu liefern zugesagt hatte. Ein erstes, von Amerbach im Voraus bezahltes Kontingent von 100 Ballen sollte er wahrscheinlich im Frühjahr 1509 an den Drucker senden. Bis dato hatte er bereits 68 Ballen geschickt und versprach, weitere 23 Ballen zu schicken, sobald sein Karren wieder aus Basel zurückgekehrt sei. ${ }^{2889}$ Die fehlenden neun Ballen wollte er sobald wie möglich nachliefern.

2884 Das Briefbuch der Koberger 1885, XCVI, Nr. 79.

2885 Die Amerbachkorrespondenz 1942, 63, Nr. 54. Vgl. auch P. Tschudin 2009, 6 f., dort auch der Abdruck des Originalbriefs. Dieser Brief gilt zugleich als Beleg für die erste Papiermühle in Cernay, dt. Sennheim, vgl. P. Schmitt 1960, 68 f.

2886 Ob dieser Papiermacher in der Papiermühle in Vieux-Thann arbeitete oder ob sein Beiname lediglich darauf verweist, dass er ursprünglich aus Thann kam, ist nicht zu sagen. Er könnte sowohl in Thann als auch in Cernay oder in Basel tätig gewesen sein.

2887 StABS, Gerichtsarchiv A 43, 20r: Meister Hanns von Amerbach hatt gwalt geben Burckarten Bappirmacher von Tann die schuld nemlich $x v$ gulden so er by dem stattschriber von Sennhen geschicht unnd iii gulden so er im selbs geben hatt meister Lorentzen Bappirmacher zu Sennhen seligen guttlich oder rechtlich inzeziechen. Vgl. Stehlin 1888, 171, Nr. 1088.

2888 Die Amerbachkorrespondenz 1942, 379 f., Nr. 417; 382, Nr. 419. Vgl. auch P. Tschudin 2009, 8-10, dort auch der Abdruck der beiden Originalbriefe. Diese zwei Dokumente sind der einzige Beleg für eine Papiermühle in Erstein, vgl. P. Schmitt 1960, 71.

2889 Hieraus kann man schließen, dass Albius' Wagen ein Ladevolumen von 23 Ballen Papier hatte, vgl. P. Tschudin 2009, 9. 
Allerdings befand sich Albius in finanziellen Schwierigkeiten, da der Vorschuss nicht ausreichte, um die Kosten zu decken und sich und seine Familie zu ernähren. Aus diesem Grund bat er seinen Auftraggeber, den Lohn für den Fuhrmann zu übernehmen.

Aus seinem zweiten Brief vom 20. Juni 1509 erfahren wir, dass Johann Amerbach sich zum einen bereit erklärt hatte, das Zehrgeld von 12 Schilling für den Fuhrmann zu zahlen. Zum anderen hatte er seine aktuelle Lieferungsforderung auf 40 bis 50 Ballen beschränkt und Albius hierfür ein Muster mitgeschickt, nach dessen Vorlage er das Papier anfertigen sollte. ${ }^{2890}$ Diese Ballen sollten in der gewünschten Qualität bis zum 29. September ausgeliefert sein. Albius sah sich offenbar durchaus in der Lage, diesen Auftrag termingerecht auszuführen. Dies bedeutet, dass er innerhalb von gut drei Monaten 40 bis 50 Ballen Papier, das heißt 400 bis 500 Ries, herstellen musste. Diese Anzahl lag sicherlich im Rahmen des Möglichen. Wenn man bei einer Papiermühle mit einer Bütte von einer Mindesttagesleistung von sechs Ries ausgeht, wie es beispielsweise sowohl die Reutlinger Papiermacherordnung als auch die Regensburger Mühlenordnung angeben, ${ }^{2891}$ dann musste der Ersteiner Papiermacher für die Fertigstellung von 50 Ballen 83 Tage arbeiten. Rechnet man diese 50 Ballen auf das Jahr hoch, so ergibt sich eine Jahresproduktion von 200 Ballen oder 2.000 Ries. Auch dies entspricht den anhand von anderen Zeugnissen ermittelten Zahlen. ${ }^{2892}$ Albius schrieb jedoch, dass er an zwei Bütten arbeite. Daher war es ihm vermutlich sogar möglich, täglich einen Ballen oder mehr zu produzieren. ${ }^{2893}$

\subsubsection{Augsburg, Bern, Ettlingen, Gengenbach, Kempten, Ravensburg, Straßburg, Urach und Zürich}

Auch für einige südwestdeutsche Papiermühlenstandorte können Verbindungen von Papiermachern und Papiermühlenbesitzern zu Zulieferern, Kunden und anderen Geschäftspartnern nachgezeichnet werden, die teilweise weit über die Stadtgrenzen hinaus reichten.

Die Versorgung mit Lumpen, aber auch mit Leim war für die Papiermacher von zentraler Bedeutung. Dennoch lassen sich nur wenige Lieferanten von Lumpen oder Leim namentlich fassen. Darunter fällt für Zürich - wie auch bereits für Basel - der Basler Kaufmann Ulrich Meltinger, der zu Beginn der 1470er-Jahre nicht nur die Papiermacher im St. Albantal, sondern auch den Züricher Papiermacher Heinrich Walchwiler, Inhaber der Papiermühle auf dem Werd, belieferte. Im September 1473 bezog Walchwiler knapp 20 Zentner Lumpen von Meltinger für einen Preis von

2890 Die Amerbachkorrespondenz 1942, 382, Nr. 419. Vgl. P. Tschudin 2009, 9.

2891 Vgl. Sporhan-Krempel 1972b, 1574; Regensburger Mühlenordnung, in: Blanchet 1900, 98.

2892 Vgl. Kapitel 2.3.1.2 u. Anhang II.

2893 Vgl. P. Tschudin 2009, 9. 
2 Gulden pro Zentner. ${ }^{2894} 5$ Gulden zahlte der Züricher Papiermacher offenbar beim Erhalt der Ware, die restlichen 35 Gulden entrichtete er vor Weihnachten 1473 und am Fastnachtssonntag 1474. Mit einem Zentnerpreis von 2 Gulden verkaufte Meltinger dem Züricher Papiermacher die Hadern deutlich teurer als seinen Basler Kollegen, die im Durchschnitt lediglich ein Pfund Pfennige zahlten. ${ }^{2895}$ Das galt auch für den Bezug von Leim. Im Jahr 1473 nahm Walchwiler vermutlich eine Fuhre Leim von 19,5 Zentner ab, die Anton Gallician aus unbekannten Gründen an Ulrich Meltinger zurückgeschickt hatte. Ein Verkaufspreis ist hier nicht erwähnt. ${ }^{2896}$ Walchwiler kaufte auch im Jahr 1474 Leim von Ulrich Meltinger und musste mit 44 Schilling pro Zentner einen deutlich höheren Preis entrichten als die Basler Papiermacher. ${ }^{2897}$ Dieser Preis galt zwar nicht für den Zentner minderwertigen Leim, der sich unter den knapp 9 nach Zürich gelieferten Zentnern befand und für den Heinrich Walchwiler lediglich rund 40 Schilling zahlen musste. ${ }^{2898}$ Im Vergleich mit den Summen zwischen 20 und 26 Schilling, die die Basler Papiermacher für den Leim zahlten, war dies jedoch immer noch ein stolzer Preis. ${ }^{2899}$

Für einen Gulden pro Zentner, folglich für die Hälfte des Preises, den Walchwiler in Zürich zahlte, bezog der Berner Papiermacher Michel Warmund 1474 seine Lumpen. Dieser Preis war in einem Exklusivvertrag mit dem Lumpenlieferanten Wilhelm Abert festgelegt worden. Von ihm erhielt Warmund auch Leim. ${ }^{2900}$ Offenbar konnte der Berner Papierer seinen Lumpenbedarf über diesen Vertrag nicht decken oder suchte nach preiswerteren Bezugsquellen, denn 1478 kaufte er in Zürich Hadern, die jedoch beschlagnahmt wurden. Vermutlich hatte sein Züricher Berufsgenosse Walchwiler ein Vorrecht auf den Lumpenkauf angemeldet. Erst als der Berner Rat auf Bitten Warmunds an die Stadt Zürich schrieb und die Herausgabe der Hadern verlangte, wurde die Ware freigegeben. ${ }^{2901}$ Ende der 1540er-Jahre sind Verbindungen des Berner Papiermachers Anton Bergier zu den zwei Lumpensammlern Peter Käch und Marti bekannt. ${ }^{2902}$

Die Berner Papiermacher besaßen seit 1467 ein Monopol auf den Lumpenhandel im gesamten Berner Gebiet. Dieses Privileg wurde nach dem Verkauf der Mühle zu Worblaufen an die Stadt 1470 für die Papiermühle zu Thal bestätigt. ${ }^{2903}$ Im Dezember

2894 StABS, Privatarchive 62, 82v. Vgl. Kälin 1974, 321; Steinbrink 2007, 312.

2895 StABS, Privatarchive 62, 35r, 51r, 76v. Vgl. Kälin 1974, 316-318; Steinbrink 2007, 168, 267, $282,305$.

2896 StABS, Privatarchive 62, 82r. Vgl. Kälin 1974, 159, 320; Steinbrink 2007, 311.

2897 StABS, Privatarchive 62, 95v. Vgl. Kälin 1974, 159, 321; Steinbrink 2007, 167 f., 326.

2898 StABS, Privatarchive 62, 95v: ...und was dar under ein boser zenter gab ich im fur ii fl minder ein ort...

2899 Vgl. Steinbrink 2007, 167.

2900 Vgl. Fluri sen. 1896, 198; Fluri jun. 1954, 48; Fluri jun. 1975, 9.

2901 Vgl. Fluri sen. 1896, 199; Fluri jun. 1954, 48; Fluri jun. 1975, 9.

2902 Vgl. Fluri sen. 1896, 206 f.; Fluri jun. 1954, 48; Fluri jun. 1975, 11.

2903 Vgl. J. Lindt 1964, 77; Fluri sen. 1896, 193, 195; Fluri jun. 1954, 47, 79; Fluri jun. 1975, 7, 27. 
1503 wurde den Berner Papiermachern zudem - gegen den Willen der Händler und Krämer - gestattet, mit Krämerwaren Handel zu treiben, wenn sie diese zum Tausch mit Lumpen einsetzten. Auf die Klage der Papierer, dass durch einen akuten Rohstoffmangel die Stampfwerke teilweise stillstehen würden, reagierte der Berner Rat 1519 mit einer Erneuerung des Lumpenausfuhrverbots. Er untersagte den Export von Hadern und sicherte gleichzeitig den Lumpensammlern Zollfreiheit auf den begehrten Rohstoff zu. ${ }^{2904}$

Den Rohstoffbezug betrifft auch die erste Nachricht von der Papiermühle zu Ettlingen überhaupt. Im Jahr 1461 war es offenbar zwischen dem Ettlinger Papierermeister Wilhelm von Paris und dem Straßburger Lumpensammler Dietrich von Dielsperg zu Streitigkeiten über eine Schuldsumme gekommen. ${ }^{2905}$ Das Gericht zu Ettlingen verfügte, dass die beiden Parteien ihre Sache einem Viererausschuss vortragen und dessen Urteil annehmen sollten. Der Lumpensammler nahm diesen Termin jedoch nicht wahr und erwirkte das Verbot für Wilhelm von Paris, die Stadt Straßburg zu betreten, sodass diesem damit die Handelsmöglichkeiten mit der oberrheinischen Großstadt genommen waren. Wer wem welche Summe schuldete, geht aus dem betreffenden Zeugnis nicht hervor.

Der Gengenbacher Papierer Georg Dietz, der unter Hinterlassung einer hohen Schuldsumme im Jahr 1544 verstarb, bezog noch kurz vor seinem Tod 64 Zentner Lumpen von Anton Langenbach. ${ }^{2906}$ Offensichtlich war diese Lieferung jedoch noch nicht bezahlt worden, denn Anton Langenbach meldete eine Forderung von 25 Pfund Pfennige an, die er selbst für die Lumpen bezahlt habe. Warum er lediglich den Einkaufspreis erstattet haben wollte und keinerlei Gewinnspanne miteinbezog, ist nicht nachzuvollziehen. ${ }^{2907}$ Zudem erscheint der Zentnerpreis mit knapp 8 Schilling vergleichsweise niedrig.

$\mathrm{Zu}$ den direkten Kunden der südwestdeutschen Papiermacher gehörten - ebenso wie in Basel - Kaufleute, Drucker, Kartenmaler, aber auch städtische Einrichtungen. Für Zürich ist beispielsweise eine weitere, wenn auch indirekte Verbindung zu Ulrich Meltinger nachweisbar. Er bezog um das Jahr 148432 Ballen gutes Züricher Papier von Ulrich von Augsburg. ${ }^{2908}$ Dieser hatte die Ware vermutlich von Christoph Grebel erstanden, einem Verwandten des Papiermühlenbesitzers Hans Conrad Grebel. Im August 1485 klagte Christoph Grebel gegen Ulrich von Augsburg, weil dieser ihm noch die Bezahlung von 56 Ballen Papier schuldig sei. Insgesamt habe er 251 Ballen an

2904 Vgl. Fluri sen. 1896, 200-202; Fluri jun. 1954, 48; J. Lindt 1964, 120; Fluri jun. 1975, 10; ZaarGörgens 2004, 91.

2905 Vgl. Piccard 1951, 59; Stenzel 1985, 99; F. Schmidt 1992, 118.

2906 Vgl. K. Th. Weiss 1951, 25, 27.

2907 Auch die Gewinnmarge des Basler Kaufmanns Meltinger war mit fünf Prozent eher gering, vgl. Steinbrink 2007, 168.

2908 StABS, Privatarchive 62, 188v. Vgl. Kälin 1974, 324; Steinbrink 2007, 166 f., 405. 
Ulrich geschickt. ${ }^{2909}$ Dieser antwortete darauf, dass er nie mehr als 192 Ballen erhalten und die Rechnung dafür bereits vollständig beglichen habe. ${ }^{2910}$ Da zwischen dem Kauf des Papiers durch Ulrich von Augsburg und der Klage sicherlich mehrere Monate lagen, ist es gut möglich, dass die 32 an Meltinger verkauften Ballen aus dem von Christoph Grebel gelieferten Kontingent stammten.

In Augsburg besaß der Papiermacher Hans Widmann d. Ä., seit 1487 Besitzer der unteren Papiermühle an der Sinkel, mehrere geschäftliche Verbindungen zu Buchdruckern, die sich alle durch Einträge in die städtischen Gerichtsbücher fassen lassen. So schuldete ihm Christoph Schnaitter, der sich in den Jahren 1493 und 1494 finanziell erfolglos als Drucker versuchte, 5 Gulden, die Widmann mehrmals einfordern musste. ${ }^{2911}$ Der Drucker Johann Schönsperger d. J. hatte 1508 über 100 Gulden Schulden bei dem Papiermacher. ${ }^{2912}$ Ob dieser Betrag durch Papierlieferungen zustande kam, lässt sich auf dem Stand der aktuellen Forschung nur vermuten. Allerdings scheint Hans Widmann auch noch als Buchführer tätig gewesen zu sein. Im Jahr 1494 hatte er dem Buchbinder Hans Müller offenbar 300 Exemplare einer DonatusAusgabe zum Binden gegeben. Bei einer Hausuntersuchung nach Müllers Flucht aus Augsburg fand er jedoch nur noch 19 Bücher vor, sodass er eine nicht geringe finanzielle Einbuße hinnehmen musste. ${ }^{2913}$ In geschäftlichem Kontakt mit Druckern - vornehmlich mit Johann Bämler, aber auch mit Anton Sorg - standen die Papiermacher Markus Nider und Lorenzo Goffasotis in den Jahren 1484 und 1485. Bämlers Bevollmächtigter, sein Stiefsohn Johann Schönsperger d. Ä., verlangte im Frühjahr 1485 von den beiden Papiermachern die Zusicherung vor Gericht, dass sie ab Pfingsten sechs Wochen lang nur weißes Schreibpapier für Bämler herstellten. ${ }^{2914}$ Interessanterweise ist 1485 auch das Jahr, in dem die Drucker Johann Bämler und Anton Sorg erstmals als Besitzer einer Papiermühle genannt wurden. ${ }^{2915}$ Möglicherweise gab der Streit mit den Papiermachern den Ausschlag für den Erwerb der Papiermühlen.

Nicht nur heimische Papierer unterhielten Beziehungen zu Augsburger Druckern. Für das Jahr 1501 ist eine gerichtliche Auseinandersetzung zwischen Johann Schönsperger d. Ä. und dem Kemptener Papiermacher Bernhard Baschgott bekannt. Baschgott forderte von Schönsperger, seine Schuld von einem Gulden zu begleichen. ${ }^{2916}$ Gegen die Summe, die der Augsburger Drucker Heinrich Steiner dem Uracher Papiermacher Caspar Tochtermann im Jahr 1545 schuldete, nimmt sich dieser Betrag aus-

2909 Schnyder 1937, 811, Nr. 1416q. Vgl. Zürcher 1963a, 93.

2910 Schnyder 1937, 812, Nr. 1416u. Vgl. Züricher; Zürcher, 1963a, 93.

2911 Vgl. Künast 1997, 62, 115.

2912 Vgl. Künast 1997, 63.

2913 Vgl. Künast 1997, 116.

2914 Vgl. Amelung 2000/2017. Vgl. auch die davon abweichende Darstellung in Künast 1997, 115.

2915 Während Bämler die untere Papiermühle an der Sinkel besaß, gehörte Anton Sorg die obere Papiermühle an der Sinkel, vgl. Kapitel 3.2.1.3.

2916 Vgl. Petz 2006, 256 f. 
gesprochen bescheiden aus. Tochtermann hatte dem Drucker Papier im Wert von 427 Gulden geliefert und forderte diese Summe nun ein. ${ }^{2917}$

Dadurch, dass sich in den 1480er- und 1490er-Jahren Augsburger Papiermühlen im Besitz von Druckern befanden, hatten die Papiermacher eine gewissermaßen institutionalisierte Beziehung zu den Buchdruckern. Ähnliches gilt für die Papiermacher, die im Auftrag des Frankfurter Druckers Christian Egenolff in Gengenbach arbeiteten, ${ }^{2918}$ sowie für den Werkmeister der Züricher Papiermühle auf dem Werd, die Christoph Froschauer gepachtet hatte. Froschauer verwendete Papier, das in seiner Papiermühle gefertigt wurde, offenbar nicht nur in der eigenen Offizin, sondern versandte es auch. Im Jahr 1536 schickte er dem Humanisten Joachim Vadian ein Ries seines Schreibpapiers nach St. Gallen. ${ }^{2919}$ Im April 1540 lieferte er Vadian ein Ries von besonders dünnem Papier, das er mit dessen Namen gekennzeichnet hatte, sowie sechs Ries Papier mit dem roten Löwen und ein Ries mit einem Bärenwasserzeichen. ${ }^{2920}$ Joachim Vadian war offensichtlich mit dem von Froschauer gelieferten Schreibpapier zufrieden und bestellte im Januar 1545 ein weiteres Mal gutes Papier aus der Mühle Froschauers. Dieser hatte zu dieser Zeit jedoch Lieferschwierigkeiten, da er die gesamte Produktionskapazität der Papiermühle für seine mit stattlichen vier Pressen ausgestattete Druckerei benötigte. Um diese Pressen beschicken zu können, hatte er bereits Papier für 200 Gulden aus Basel dazukaufen müssen. ${ }^{2921}$

Neben den Druckern bezogen auch Kartenmaler und städtische Einrichtungen Papier direkt aus den Papiermühlen. So hatte sich im Jahr 1490 der Züricher Kartenmaler Hans Schätti an Hans Conrad Grebel gewandt und ihn um Papier gebeten, das er bezahlen wolle, wenn er die daraus gefertigten Spielkarten verkauft habe. Zunächst weigerte sich Grebel, ihm Papier zu liefern, vermutlich aus der Sorge heraus, dass Schätti seine Schulden nicht begleichen würde. Nachdem dieser jedoch einen Bürgen gestellt hatte, schickte der Papiermacher ihm genügend Papier, damit der Kartenmaler seine Arbeit wieder aufnehmen konnte. ${ }^{2922}$ Verbindungen zu Kartenmachern sind auch für die Kemptener Papierer fassbar. ${ }^{2923}$

2917 Vgl. Künast 1997, 70 f., 115 f.

2918 Vgl. Piccard 1963, 1007-1012.

2919 Vgl. Leemann-van Elck 1940, 195.

2920 Vgl. Leemann-van Elck 1940, 195. Während der Riesumschlag mit dem roten Löwen Papier aus der Züricher Papiermühle bezeichnete, stammte das Bärenpapier vermutlich aus Bern - oder war eines der Imitate, gegen die sich Bern zu wehren versuchte, vgl. Zürcher 1963a, 96 f., 103 f.; Fluri sen. 1896, 203-205; Fluri jun. 1954, 48; Fluri jun. 1975, 11.

2921 Vgl. Leemann-van Elck 1940, 196. Bemerkenswert ist die klare Unterscheidung zwischen Schreib- und Druckpapier. Vadian bestellte explizit Schreibpapier, Froschauer wies darauf hin, dass er noch nicht einmal genügend Druckpapier herstellen konnte und daher mit der Fertigung von Schreibpapier, das für ihn vermutlich von untergeordneter Priorität war, im Rückstand war.

2922 Schnyder 1937, 864, Nr. 1486. Vgl. Zürcher 1963a, 93 f.

2923 Vgl. Petz 2006, 254. 
Dem Züricher Spital verkaufte der Papierergeselle Ludi, der wahrscheinlich identisch mit dem bei Hans Conrad Grebel arbeitenden Ludwig Nußbäumer war, im Jahr 1497 Papier für 11 Pfund Pfennige. ${ }^{2924}$ In den Jahren 1504 und 1507 bezog das Säckelamt Papier von Hans Conrad Grebel. ${ }^{2925}$ Papierlieferungen aus der städtischen Papiermühle an die Ämter der Stadt sind erst ab 1544 nachweisbar, obwohl das Werk bereits 1535 die Produktion aufgenommen hatte. ${ }^{2926}$

Auch die Kanzlei der Stadt Ravensburg bezog Papier aus den heimischen Mühlen. ${ }^{2927}$ Zwischen 1459 bis 1525 wurde im städtischen Rechnungsbuch fünfzehn Mal der Einkauf von Papier vermerkt, wobei als Lieferanten in elf Fällen lediglich die Papierer genannt sind (vgl. Tab. 30). ${ }^{2928}$ Diese unbestimmte Formulierung macht es zwar schwierig, einen konkreten Papiermacher zu greifen, sie spricht jedoch auch deutlich dafür, dass es sich um die örtlichen Papierer handelte, die wohl nach Ermessen des Rechnungsführers auch mit einer allgemeinen Bezeichnung klar identifizierbar waren.

Aus einem Eintrag von 1470 geht hervor, dass drei Ries Papier von den Papiermachern gekauft wurden, die in der oberen Papiermühle zu Schornreute arbeiteten. In zwei Posten wird der Lieferant namentlich genannt. 1468 zahlte die Stadt 8 Schilling 9 Pfennig für Firnis und Papier an den Ravensburger Bürger Wilhelm Humpis und 1525 versorgte ein nicht näher bestimmtes Mitglied der Familie Wolfartshofer die Stadt mit sechs Ries Papier. Nur ein Mal wurde überhaupt keine Bezugsquelle genannt. Der Riespreis lag von 1469 bis 1491 bis auf eine Ausnahme konstant bei 16 Schilling und stieg ab 1513 auf 17 Schilling 6 Pfennig an. ${ }^{2929}$ Dies entspricht dem Riespreis, den Hans Kälin für das preiswertere von der Basler Kanzlei im 15. Jahrhundert bezogene Papier ermitteln konnte. ${ }^{2930}$ Dieser Befund korreliert zudem mit den Ergebnissen der materialanalytischen Untersuchung der Ravensburger Steuerbücher aus dem 15. Jahrhundert. Das in der städtischen Schreibstube verwendete Papier war ein gutes Schreibpapier, das jedoch kleine Makel aufwies und daher nicht der höchsten Preisklasse zuzuordnen ist. ${ }^{2931}$

2924 Schnyder 1937, 970, Nr. 1598. Vgl. Zürcher 1963a, 94.

2925 Vgl. Zürcher 1963a, 94.

2926 Vgl. Zürcher 1963a, 95.

2927 Vgl. Schultz/Follmer 2015, 20.

2928 StR, Bü 38, Rechnungsbuch; Bü 39, Rechnungsbuch.

2929 Zu Papierpreisen vgl. Piccard 1962, 96 f.; Piccard 1967, 277-281; Kälin 1974, 60-66; Corsten 1976. 2930 Vgl. Kälin 1974, 60, 65.

2931 Vgl. Schultz/Follmer 2015, $41 \mathrm{f}$. 
Tab. 30: Papierbezug der Stadt Ravensburg von 1459 bis 1525 (Quelle: StR, Bü38; Bü39).

\begin{tabular}{|c|c|c|c|c|c|}
\hline & Jahr & Posten & Betrag & Riespreis & Beleg \\
\hline 1. & 1459 & Item den pappirern umb pappir & $3 \mathrm{lb} 12 \mathrm{~B}$ & $-\cdots$ & Bü 38, 201v \\
\hline 2. & 1468 & Item Wilhalm Hunpiß umb firnieß und pappir & $8 B 9 d$ & $-\cdots-\cdot$ & Bü 38, 57v \\
\hline 3. & 1469 & Item den pappirern von iiii risen bappir & $3 \mathrm{lb} 4$ ß & $16 ß$ & Bü 38, 77v \\
\hline \multirow[t]{2}{*}{4.} & 1470 & $\begin{array}{l}\text { Item den obern pappirern zu Schornrutin umb iii } \\
\text { risen }\end{array}$ & $3 \mathrm{fl}$. & $1 \mathrm{fl}$. & Bü 38, 104v \\
\hline & & me umb ii risen & $2 \mathrm{fl}$. & & \\
\hline 5. & 1471 & Item den pappirern umb bappir & $1 \mathrm{lb} 12$ ß & $-\cdots-\cdot$ & Bü 38, 148v \\
\hline 6. & 1472 & Item den pappirern umb iii risen & $2 \mathrm{lb} 8 \mathrm{~B}$ & $16 ß$ & Bü 38, 173r \\
\hline 7. & 1478 & Item den pappirern für iii risen pappir & $2 \mathrm{lb} 8$ ß & $16 ß$ & Bü 38, 8v \\
\hline 8. & 1484 & Item den pappirern umb pappir & $4 \mathrm{lb}$ & $-\cdots--\cdot$ & Bü 38, 224v \\
\hline 9. & 1488 & Item den pappirern von iii risen bappir & $2 \mathrm{lb} 8 \mathrm{~B}$ & $16 ß$ & Bü 38, $274 v$ \\
\hline 10. & 1489 & Item den bappirern umb iiii risen bappir & $3 \mathrm{lb} 4$ ß & $16 ß$ & Bü 38, 322v \\
\hline 11. & 1491 & Item den bappirern umb v risen bappir zu $16 \beta$ & $4 \mathrm{lb}$ & $16 ß$ & Bü 38, 348r \\
\hline 12. & 1513 & Item den bappirern umb 5 ryß bappir & $4 \mathrm{lb} 7 \mathrm{~B} 6 \mathrm{~d}$ & $17 ß 6 \mathrm{~d}$ & Bü 39, 10r \\
\hline 13. & 1514 & Item den bappirern v ryß bappir & $4 \mathrm{lb} 7$ B $6 \mathrm{~d}$ & $17 ß 6 \mathrm{~d}$ & Bü 39, 56v \\
\hline 14. & 1522 & Item umb vi risen bappyr & $5 \mathrm{lb} 5$ ß & $17 ß 6 \mathrm{~d}$ & Bü 39, 103v \\
\hline 15. & 1525 & Item Wolfatzhofer umb vi risen bappyr & $5 \mathrm{lb} 5 \mathrm{~B}$ & $17 ß 6 \mathrm{~d}$ & Bü $39,232 v$ \\
\hline
\end{tabular}

Wie Gerhard Piccard und Lore Sporhan-Krempel herausgearbeitet haben, wurde Ravensburger Papier von mehreren süddeutschen Kanzleien bezogen und ist im 15. und 16. Jahrhundert im gesamten deutschsprachigen Raum beschrieben worden. ${ }^{2932}$ Wer für den Vertrieb der Ware verantwortlich zeichnete und ob womöglich die Ravensburger Papiermacher in direktem Kontakt zur Verwaltung anderer Städte standen, ist in den meisten Fällen jedoch nicht nachzuvollziehen. Eine Ausnahme bildet hier ein Brief des Ravensburger Stadtschreibers an seinen Ulmer Kollegen, der heute im Stadtarchiv Ulm liegt. In diesem Schreiben vom Dezember 1427 bittet Oswald Gülch den Stadtschreiber Ambrosius Nithart darum, die ausstehende Summe zu begleichen, die dieser dem Ravensburger Papiermühlenbesitzer Heinrich Gelderich für eine Fuhre Papier schulde. ${ }^{2933}$ Der Transport und die Rechnungsabwicklung lief über den Ravensburger Stadtschreiber selbst, der allerdings nur 50 Pfund Haller anstelle des vollen Verkaufspreises erhalten und diese Heinrich Gelderich

2932 Vgl. Piccard 1962, 96 f.; Sporhan-Krempel 1984, 36-42.

2933 StU, A-Urk. Ve 129 (14.12.1427). Vgl. K. D. Haßler 1844, 36 f. 
nach Abzug der Kosten für Seile zum Binden der Ballen ausgehändigt hatte. ${ }^{2934} \mathrm{Nach}$ einem weiterem Brief von Oswald Gülch an Ambrosius Nithart aus dem Jahr $1428 \mathrm{zu}$ urteilen, der leider nur bei Konrad Dieterich Haßler transkribiert ist, sich jedoch im Stadtarchiv Ulm nicht mehr auffinden ließ, hatte der Ulmer Stadtschreiber den ausstehenden Betrag entrichtet und - vermittelt durch den Ravensburger Stadtschreiber - bereits neues Papier bei Gelderich bestellt. ${ }^{2935}$

Weniger zufrieden als der Ulmer Stadtschreiber war offensichtlich der Bürgermeister der Stadt Überlingen, der sich 1548 bei Jörg Sauter d. Ä., dem Besitzer der äußeren Papiermühle in Schornreute, ${ }^{2936}$ über die schlechte Qualität des Papiers beschwerte, das dieser ihm geliefert hatte: Es sei zerrissen und fleckig. ${ }^{2937}$ Auch eine Lieferung an Eytelhans Ebinger, dem Landschreiber der Grafschaft Heiligenberg, entsprach nicht dessen Anforderungen an gutes Papier. ${ }^{2938}$ Hieran wird deutlich, dass der Papiermühlenbesitzer Sauter sein Produkt zumindest in Teilen selbst vertrieb.

Diese Befunde zu Zulieferern und Kunden der südwestdeutschen Papiermacher zeigen, wie sehr die Beantwortung einer Frage von den verfügbaren Quellen abhängt. Da aus dem 15. und aus der ersten Hälfte des 16. Jahrhunderts keine Geschäftsbücher von Papiermachern erhalten sind, werfen lediglich Zufallsfunde vereinzelte Schlaglichter auf ihre Geschäftsbeziehungen und damit auf die Vertriebswege von Rohstoffen und Papier. Besonders der Bezug von Lumpen und Leim konnte nur punktuell für wenige Fälle beschrieben werden. $\mathrm{Zu}$ welchen Anteilen Papiermacher ihre Ware selbst vertrieben und zu welchem Anteil Kaufleuten das Produkt an den Endkunden brachten, ist ebenfalls nicht zu ermitteln. Der Verkauf des Papiers an Buchdrucker, Kartenmaler und städtische Kanzleien erfolgte - wie gezeigt werden konnte - in Teilen über die Papiermacher selbst. Fassbar sind in den Quellen zudem besonders die Geschäftsbeziehungen, die zu Streit führten, weil der Käufer nicht zahlte oder der Verkäufer nicht lieferte. Sie fanden den Weg in die Akten und beleuchten auf diese Weise vor allem die problematische Seite der Handelsbeziehungen von Papiermachern.

2934 StU, A-Urk. Ve 129 (14.12.1427): und han daz übrig geben umb dz übrig daz daruff gangen waz mit binden umb sail und anderes. Anscheinend hatte Gülch das Einbinden der Ballen selbst in Auftrag gegeben und bezahlt.

2935 Vgl. K. D. Haßler 1844, 37.

2936 Vgl. Sporhan-Krempel 1953, 30.

2937 Vgl. Sporhan-Krempel 1984, 40.

2938 Vgl. Sporhan-Krempel 1984, 40. 